UNIVERSIDADE DE SÃO PAULO

FACULDADE DE FILOSOFIA, LETRAS E CIÊNCIAS HUMANAS

DEPARTAMENTO DE LETRAS MODERNAS

PROGRAMA DE PÓS-GRADUAÇÃO EM ESTUDOS DA TRADUÇÃO

GABRIELA PEREIRA DOS SANTOS

Glossário bilíngue Português-Inglês de colocações especializadas de Harmonia Musical, baseado em corpus

Versão corrigida

São Paulo 
GABRIELA PEREIRA DOS SANTOS

\title{
Glossário bilíngue Português-Inglês de colocações especializadas de Harmonia Musical, baseado em corpus
}

\author{
Versão corrigida
}

Dissertação apresentada ao Programa de PósGraduação em Estudos da Tradução do Departamento de Letras Modernas da Faculdade de Filosofia, Letras e Ciências Humanas da Universidade de São Paulo, para a obtenção do título de Mestre em Letras.

Orientadora: Prof ${ }^{a}$ Dr $^{a}$ Ângela Maria Tenório Zucchi

De acordo.

São Paulo 
Autorizo a reprodução e divulgação total ou parcial deste trabalho, por qualquer meio convencional ou eletrônico, para fins de estudo e pesquisa, desde que citada a fonte.

Catalogação na Publicação

Serviço de Biblioteca e Documentação

Faculdade de Filosofia, Letras e Ciências Humanas da Universidade de São Paulo

Glossário bilíngue Português-Inglês de colocações especializadas de Harmonia Musical, baseado em corpus / Gabriela Pereira dos Santos ; orientador Ângela Maria Tenório Zucchi. - São Paulo, 2017. $390 \mathrm{f}$.

Dissertação (Mestrado) - Faculdade de Filosofia, Letras e Ciências Humanas da Universidade de São Paulo. Departamento de Letras Modernas. Área de concentração: Estudos da Tradução.

1. Colocações especializadas. 2. Harmonia (Música). 3. Linguística de corpus. 4. Terminologia. 5. Tradução. I. Zucchi, Ângela Maria Tenório, orient. II. Título. 


\section{FOLHA DE APROVAÇÃO}

SANTOS, G. P. Glossário bilíngue Português-Inglês de colocações especializadas de Harmonia Musical, baseado em corpus. Dissertação apresentada à Faculdade de Filosofia, Letras e Ciências Humanas da Universidade de São Paulo para obtenção do título de Mestre em Letras.

Aprovado em:

\section{Banca Examinadora}

Prof. Dr. : Instituição:

Julgamento: Assinatura:

Prof. Dr. Instituição:

Julgamento: Assinatura:

Prof. Dr. : Instituição:

Julgamento: Assinatura: 
Dedico este trabalho a minha amada família: aos meus pais, Daniel e Mercês, aos meus irmãos, Gilberto e Genilson e à minha sobrinha, Thamires. 


\section{AGRADECIMENTOS}

Aos meus pais, por sempre desejarem o melhor para a minha vida profissional e pessoal.

Aos meus irmãos, por compreenderem meus momentos de isolamento devido ao processo de pesquisa, leitura, reflexão e redação deste trabalho.

A minha orientadora Ângela M. T. Zucchi, pelas valiosas dicas, pela amizade, pela confiança depositada em mim e por sempre incentivar o desenvolvimento desta pesquisa.

Aos professores Stella E. O Tagnin e João Azenha Junior, cujas disciplinas forneceram conhecimentos relevantes para minha pesquisa e pelas contribuições no exame de qualificação.

Aos professores Tinka Reichmann, Stéfano Paschoal e Monica Isabel Lucas pelas disciplinas ministradas, as quais ampliaram o horizonte da pesquisa, fornecendo informações e referências bibliográficas indispensáveis ao projeto.

Aos amigos, pela torcida e incentivo. 
"Dentro da língua da música, a Harmonia é um dialeto à parte, a ser conquistado. Os vocábulos são os acordes e, uma vez descobertos, são adotados na linguagem (...)

O enriquecimento do vocabulário se desenvolve através da prática contínua de harmonizar músicas por ouvido(...)

A percepção da harmonia está interligada com a riqueza do vocabulário de cada um, pois só entendemos o que fazemos."

Ian Guest 


\section{RESUMO}

SANTOS, G. P. Glossário bilíngue Português-Inglês de colocações especializadas de Harmonia Musical, baseado em corpus. Dissertação (Mestrado). Faculdade de Filosofia, Letras e Ciências Humanas, Universidade de São Paulo, 2017.

Esta pesquisa tem o objetivo de propor a construção de um glossário bilíngue (inglêsportuguês) de colocações especializadas com a palavra "acorde", relacionadas à área de Harmonia Musical. Ela se justifica pela falta de estudos terminológicos relacionados às colocações especializadas do campo da Teoria Musical. Os alicerces teóricos que sustentam a pesquisa são: os Estudos da Tradução Baseados em corpus, que vincula a metodologia da Linguística de Corpus (LC) aos Estudos Descritivos da Tradução; a Teoria Comunicativa da Terminologia (TCT) que orienta a análise terminológica e a elaboração de glossários especializados; e a Fraseologia, que fornece respaldo à análise das colocações. Para este estudo foi construído um corpus comparável de textos escritos em Inglês (EUA) e Português (BR), com publicações ou reedições a partir de 1990, abrangendo os seguintes gêneros: instrucionais (livros-textos, apostilas) e acadêmico-científicos (artigos científicos, dissertações e teses). Os materiais, coletados de meio eletrônico e impresso, provém de sites de revistas especializadas, periódicos, congressos, conservatórios e faculdades de Música. A análise descritiva do corpus de estudo conta com a ajuda do software Wordsmith Tools (Scott, 2016) que gera listas de palavras-chave, colocados, clusters e concordâncias. A partir da análise das listas e comparação entre contextos nas duas línguas, foi elaborado um glossário, cujos verbetes estão organizados em ordem alfabética, com exemplos de uso retirados do corpus. $\mathrm{O}$ produto final tem, como público alvo, tradutores e músicos.

PALAVRAS-CHAVE Colocações especializadas, Harmonia (Música), Linguística de Corpus, Terminologia, Tradução. 


\begin{abstract}
SANTOS, G. P. Corpus-based bilingual English-Portuguese glossary of specialized collocations related to Musical Harmony. Dissertação (Mestrado). Faculdade de Filosofia, Letras e Ciências Humanas, Universidade de São Paulo, 2017.

This research aims to propose the construction of a bilingual English-Portuguese glossary of specialized collocations related to the term "chord" from the area of Musical Harmony. The reason for this study is the lack of terminological researches about specialized collocations from Musical Theory. This research is based on the following theoretical foundations: Corpus-based Translation Studies that links the methodology of Corpus Linguistics (CL) to Descriptive Translation Studies; The Communicative Theory of Terminology (TCT) which guides the terminological analysis and the elaboration of specialized glossaries; and Phraseology, which gives support to the analysis of collocations. A comparable corpus of texts written in English (USA) and Portuguese (BR) was compiled for this study. The texts published from 1990 are subdivided into two text genres: instructional texts (textbooks, study manuals) and scientific research (scientific articles, dissertations and theses). These materials, collected from electronic and print media, were obtained from the websites of specialized magazines, periodicals, conferences, conservatories and music colleges. The descriptive analysis of the study corpus was accomplished from the data provided by the software Wordsmith Tools (SCOTT, 2016) that generates wordlists, keywords, clusters and concordances. From the analysis of the lists and the comparison between contexts in both languages, we elaborated a glossary, whose entries are organized alphabetically, with examples of usage extracted from the corpus. The final product is intended to assist translators and musicians.
\end{abstract}

KEYWORDS: Specialized collocations, Musical Harmony, Corpus Linguistics, Terminology, Translation. 


\section{ÍNDICE DE FIGURAS}

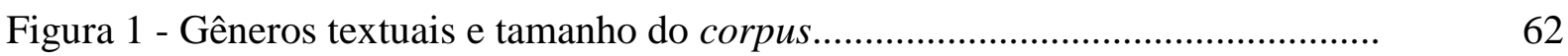

Figura 2 - Lista de palavras (parcial) do subcorpus de português................................ 70

Figura 3 - Lista de palavras (parcial) do subcorpus de inglês...................................... 70

Figura 4 - Lista de palavras-chave (parcial) do subcorpus de português...................... 72

Figura 5 - Lista de palavras-chave (parcial) do subcorpus de inglês............................. 72

Figura 6 - Linhas de concordâncias (parciais) da palavra de busca "acorde"............. 73

Figura 7 - Linhas de concordâncias (parciais) da palavra de busca "chord".............. 74

Figura 8 - Lista de colocados (parcial) para a palavra de busca “chord"'.................. 75

Figura 9 - Lista de clusters (parcial) para a palavra de busca "chord"..................... 75

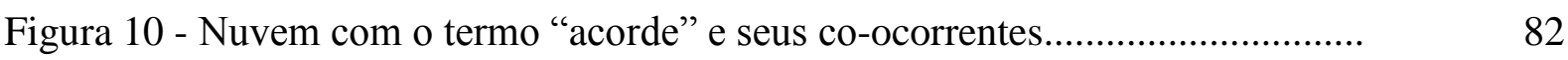

Figura 11 - Linhas de concordância de "acorde consonante"................................... 87

Figura 12 - Linhas de concordância de "consonant chord" no singular e plural........ 87

Figura 13 - Linhas de concordância de "acorde dissonante"..................................... 89

Figura 14 - Linhas de concordância de "dissonante chord" (singular e plural)........... 90

Figura 15 - Linhas de concordâncias (parciais) de "tríade"........................................ 92

Figura 16 - Linhas de concordâncias (parciais) de "acorde perfeito"........................... 92

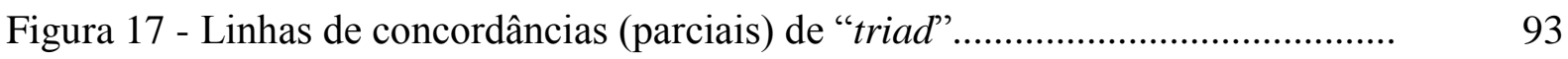

Figura 18 - Linhas de concordância (parciais) de "acorde maior" .............................. 95

Figura 19 - Linhas de concordância (parciais) de "acorde perfeito maior" ............... 95

Figura 20 - Linhas de concordância (parciais) de "acorde maior" .............................. 95

Figura 21 - Linhas de concordância de "major chord" ............................................... 97

Figura 22 - Linhas de concordância (parciais) de "major triad" ................................ 97

Figura 23 - Linhas de concordância ( parciais) de "acorde menor"............................. 99

Figura 24 - Linhas de concordância (parciais) de "acorde perfeito menor" ............... 99

Figura 25 - Linhas de concordância (parciais) de "tríade menor" ............................. 100

Figura 26 - Linhas de concordância (parciais) de "minor chord" ............................... 101

Figura 27 - Linhas de concordância (parciais) de "minor triad".................................... 101

Figura 28 - Linhas de concordância (parciais) de "acordes aumentados"................ 103

Figura 29 - Linhas de concordância (parciais) de "acorde de quinta aumentada"...... 103 
Figura 30 - Linhas de concordância (parciais) de "tríade aumentada".

Figura 31 - Linhas de concordância parciais de "augmented chord"

Figura 32 - Linhas de concordância parciais de "augmented triad"

Figura 33 - Linhas de concordância (parciais) de "acorde diminuto"

Figura 34 - Linhas de concordância de "acorde de quinta diminuta"

Figura 35 - Linhas de concordância (parciais) de "tríade diminuta"

Figura 36 - Linhas de concordância (parciais) de "diminished chord"

Figura 37 - Linhas de concordância de "diminished triad"

Figura 38 - Linhas de concordância (parciais) de "acorde de sétima".

Figura 39 - Linhas de concordância (parciais) de "tétrade"

Figura 40 - Linhas de concordância (parciais) de "seventh chords"

Figura 41 - Linhas de concordância (parciais) de "acorde meio-diminuto"

Figura 42 - Linhas de concordância (parciais) de "half-diminished chords" (singular e plural)

Figura 43 - Linhas de concordância (parciais) de "acorde de sétima diminuta".

Figura 44 - Linhas de concordância (parciais) de "tétrade diminuta".

Figura 45 - Linhas de concordância (parciais) de "diminished-seventh chords".

Figura 46 - Linhas de concordância (parciais) de "fully diminished seventh chords"

Figura 47- Linhas de concordância (parciais) de "acorde suspenso".....

Figura 48 - Linhas de concordância parciais de "acorde sus".

Figura 49 - Linhas de concordância parciais de "acorde sus4".

Figura 50 - Linhas de concordância parciais de "suspended fourth chord".

Figura 51 - Linhas de concordância (parciais) de "sus chord".

Figura 52 - Linhas de concordância de "suspended chord".

Figura 53 - Linhas de concordância (parciais) de "acorde invertido"

Figura 54 - Linhas de concordância (parciais) de "inverted chords"

Figura 55 - Linhas de concordância (parciais) de "acordes de sexta"

Figura 56 - Linhas de concordância (parciais) de "sixth chords".

Figura 57 - Linhas de concordância de "acorde de quarta-e-sexta"

Figura 58 - Linhas de concordância (parciais) de "six-four chord"

Figura 59 - Linhas de concordância (parciais) de "acorde diatônico". 
Figura 60 - Linhas de concordância (parciais) de "diatonic chord".............................. 136

Figura 61 - Linhas de concordância (parciais) de "acordes não-diatônicos"............... 136

Figura 62 - Linhas de concordância (parciais) de "non-diatonic chord" (singular e

plural).

Figura 63 - Linhas de concordância (parciais) de "notas do acorde / notas de acorde"

Figura 64 - Linhas de concordância (parciais) de "chord tone"

Figura 65 - Linhas de concordância (parciais) de "chord tones"

Figura 66 - Linhas de concordância (parciais) de "nota estranha ao acorde".

Figura 67 - Linhas de concordância (parciais) de "notas estranhas ao acordes".

Figura 68 - Linhas de concordância (parciais) de "non-chord tones"

Figura 69 - Linhas de concordância (parciais) de "acorde alterado".

Figura 70 - Linhas de concordância (parciais) de "acordes alterados".

Figura 71 - Linhas de concordância ( parciais) de “altered chord" no singular e no plural

Figura 72 - Linhas de concordância ( parciais) de "acordes cromáticos"

Figura 73 - Linhas de concordância (parciais) de "chromatic chord" no singular e plural"

Figura 74 - Linhas de concordância parciais de "acorde bordadura".....

Figura 75 - Linhas de concordância de "acorde de bordadura".

Figura 76 - Linhas de concordância (parciais) de "neighbor chord".

Figura 77 - Linhas de concordância parciais de "embellishing chords".

Figura 78 - Linhas de concordância (parciais) de "acorde de passagem"

Figura 79 - Linhas de concordância (parciais) de "passing chord".

Figura 80 - Linhas de concordância de "acorde pedal"...

Figura 81 - Linhas de concordância de "pedal chord".....

Figura 82 - Linhas de concordância (parciais) de "acorde vagante".

Figura 83 - Linhas de concordância (parciais) para "vagrant chord $(s)$ ".

Figura 84 - Linhas de concordância (parciais) de "acordes de empréstimo modal"..

Figura 85 - Linhas de concordância de "borrowed chords".....

Figura 86 - Linhas de concordância (parciais) de "acorde de Tristão". 
Figura 88 - Linhas de concordância (parciais) de "acordes quebrados".

Figura 89 - Linhas de concordância (parciais) de "arpejo".

Figura 90 - Linhas de concordância (parciais) de "acorde arpejado".

Figura 91 - Linhas de concordância (parciais) de "arpeggiated chords".

Figura 92 - Linhas de concordância (parciais) de "broken chords".

Figura 93 - Linhas de concordância (parciais) de "arpeggio"

Figura 94 - Linhas de concordância (parciais) de "block chords".

Figura 95 - Linhas de concordância (parciais) de "acorde de sexta napolitana".

Figura 96 - Linhas de concordância (parciais) de "acorde napolitano".

Figura 97 - Linhas de concordância de "Neapolitan chord".

Figura 98 - Linhas de concordância de "Neapolitan sixth"

Figura 99 - Linhas de concordância (parciais) de "acorde de sexta aumentada"

Figura 100 - Linhas de concordância (parciais) de "augmented sixth chord".

Figura 101 - Linhas de concordâncias das variantes "acorde de sexta alemã " e

"sexta alemã"

Figura 102 - Linhas de concordâncias de "acorde de sexta alemã"

Figura 103 - Linhas de concordâncias (parciais) de "acorde de sexta germânica".....

Figura 104 - Linhas de concordâncias (parciais) de "German augmented-sixth chord"

Figura 105 - Linhas de concordâncias (parciais) de "German sixth (chord)".

Figura 106 - Linhas de concordância de "acorde de sexta aumentada francesa".....

Figura 107 - Linhas de concordância (parciais) de "acorde de sexta francesa"

Figura 108 - Linhas de concordância (parciais) de "sexta francesa"

Figura 109 - Linhas de concordância de "French augmented sixth chord"e "French sixth chord"

Figura 110 - Linhas de concordância de "French sixth".

Figura 111 - Linhas de concordâncias de "acorde de sexta aumentada italiana".....

Figura 112 - Linhas de concordância (parciais) de "acorde de sexta italiana".

Figura 113 - Linhas de concordância parciais de "acorde de sexta acrescentada".

Figura 114 - Linhas de concordância de "acorde de Rameau"

Figura 115 - Linhas de concordância de "added-sixth chord"

Figura 116 - Linhas de concordância de "acorde de nona" 
Figura 117 - Linhas de concordância de "ninth chord" (singular e plural).................. 201

Figura 118 - Linhas de concordância (parciais) de "acorde de décima primeira"....... 202

Figura 119 - Linhas de concordância (parciais) de "eleventh chord" (sing/plural)...... 203

Figura 120 - Linhas de concordância de "acorde de décima terceira"......................... 204

Figura 121 - Linhas de concordância (parciais) de "thirteenth chord" (singular e plural)

Figura 122 - Linhas de concordância (parciais) de “acorde primário”(singular e plural)

Figura 123 - Linhas de concordância (parciais) de "acordes principais"....

Figura 124 - Linhas de concordância (parciais) de "tríades principais".

Figura 125 - Linhas de concordância parciais de "primary chord"(singular e plural)

Figura 126 - Clusters relacionados a "acordes de função" e suas ocorrências no subcorpus Português

Figura 127 - Linhas de concordância (parciais) de "acorde de tônica".

Figura 128 - Linhas de concordância de "tonic chord".

Figura 129 - Linhas de concordância de "acorde de dominante".

Figura 130 - Linhas de concordância parciais de "acorde dominante"

Figura 131 - Linhas de concordância (parciais) de "dominant chord".

Figura 132- Linhas de concordância de "acorde de subdominante"

Figura 133 - Linhas de concordância de "subdominant chord"

Figura 134 - Linhas de concordância de "acorde de sétima da dominante"

Figura 135 - Linhas de concordância de "dominant seventh chord".....

Figura 136 - Linhas de concordância de "acorde de sétima da sensível".

Figura 137 - Linhas de concordância de "leading-tone seventh chord"

Figura 138 - Linhas de concordância parciais de "acorde de nona da dominante".

Figura 139 - Linhas de concordância de "dominant-ninth chord".

Figura 140 - Linhas de concordância parciais de "acorde secundário".

Figura 141 - Linhas de concordância parciais de "secondary chord"

Figura 142 - Linhas de concordância parciais de "acorde relativo".

Figura 143 - Linhas de concordância parciais de "relative chord". 
Figura 145 - Linhas de concordância de "dominante secundária".

Figura 146 - Linhas de concordância de "acorde dominante secundário / dominante secundário"

Figura 147 - Linhas de concordância de "secondary dominant"

Figura 148- Linhas de concordância de "acorde de dominante substituta"

Figura 149 - Linhas de concordância de "acorde subV7"....

Figura 150 - Linhas de concordância de "acordes substitutos".....

Figura 151 - Linhas de concordância de "tritone substitution chord / tritone

substitute chord"

Figura 152 - Linhas de concordância de "tritone substitute"

Figura 153 - Linhas de concordância de "tritone substitutes"

Figura 154 - Linhas de concordância de "dominant substitute / dominant substitute

chord"

Figura 155 - Linhas de concordância do predicativo "tonicalizado".

Figura 156 - Linhas de concordância do predicativo "tonicizado".

Figura 157 - Linhas de concordância parciais de "tonicized chord"

Figura 158 - Linhas de concordância parciais de "voicing".

Figura 159 - Linhas de concordância parciais de "chord voicing"

Figura 160 - Linhas de concordância parciais de "encadeamento de acordes"

Figura 161 - Linhas de concordância parciais de "voice-leading"

Figura 162 - Linhas de concordância parciais de "progressão harmônica",

Figura 163 - Linhas de concordância parciais de "chord progressions".....

Figura 164 - Linhas de concordância parciais de "harmonic progression"

Figura 165 - Linhas de concordância de "acorde interpolado".

Figura 166 - Linhas de concordância de "interpolated chords".

Figura 167 - Linhas de concordância de "acorde de preparação".

Figura 168 - Linhas de concordância (parciais) de "dominant preparation chord" e

Figura 169 - Linhas de concordância de "pre-dominant chord"

Figura 170 - Linhas de concordância parciais de "acorde de resolução".

Figura 171 - Linhas de concordância de "resolution chord". 
Figura 173 - Linhas de concordância (parciais) de "acorde cadencial"......................... 266

Figura 174 - Linhas de concordância (parciais) de "cadential chord"'........................ 267

Figura 175 - Linhas de concordância de "acorde de quarta e sexta cadencial”............. 267

Figura 176 - Linhas de concordância de "cadential six-four chord"............................ 269

Figura 177 - Linhas de concordância (parciais) de "sucessão de acordes"................... 271

Figura 178 - Linhas de concordância (parciais) de "chord succession”........................ 271

Figura 179 - Linhas de concordância (parciais) de "sequência de acordes"................. 272

Figura 180 - Linhas de concordância (parciais) de "chord sequence"......................... 273

Figura 181 - Linhas de concordância (parciais) de "sequence of chords".................... 273

Figura 182 - Linhas de concordância parciais de "acorde comum"............................ 275

Figura 183 - Linhas de concordância parciais de "acorde pivô"................................... 276

Figura 184 - Linhas de concordância parciais de "common chords"........................... 278

Figura 185 - Linhas de concordância parciais de "pivot chord" .................................. 278

Figura 186 - Linhas de concordância parciais de "modulação através de acorde comum/acordes comuns"

Figura 187 - Linhas de concordância parciais de common chord modulation"............. 280

Figura 188 - Linhas de concordância (parciais) do termo 'cifra"............................... 281

Figura 189 - Linhas de concordância (parciais) de "chord symbol".............................. 282 


\section{LISTA DE QUADROS}

Quadro 1 - Definições para os termos “chord" e "acorde” em dicionários especializados.

Quadro 2 - Quantidade de colocações especializadas em dicionários especializados.. $\quad 34$

Quadro 3 - Gêneros com predominância de um tipo textual - Travaglia (2007).......... 47

Quadro 4 - Tipos textuais encontrados nos gêneros textuais do corpus de estudo...... $\quad 50$

Quadro 5 - A intertextualidade analisada pelo número de frequência no corpus de estudo

Quadro 6 - Tipologia do corpus de estudo sobre Harmonia....................................... 63

Quadro 7 - Subcorpus de estudo - Inglês................................................................... 66

Quadro 8 - Subcorpus de estudo - Português............................................................. 69

Quadro 9 - Modelo de Ficha Terminográfica.......................................................... 77

Quadro 10 - Exemplo de Ficha Preenchida - Acorde de Dominante......................... 79

Quadro 11 - Exemplo de Ficha Preenchida - Dominant Chord …............................. $\quad 80$

Quadro 12 - Número de ocorrências dos termos na forma singular e plural............... 81

Quadro 13 - Ordem numérica das colocações para discussão de dados...................... $\quad 85$

Quadro 14 - Tipos de notas ornamentais e seus correspondentes em inglês................ 147

Quadro 15 - Colocações Adjetivas e Nominais em português.................................... 284

Quadro 16 - Colocações Adjetivas e Nominais em inglês.......................................... 285

Quadro 17 - Colocações especializadas estendidas do subcorpus de português......... 287

Quadro 18 - Colocações especializadas estendidas do subcorpus de inglês............... 288

Quadro 19 - Variantes terminológicas linguísticas lexicais em português................. 289

Quadro 20 - Variantes terminológicas linguísticas lexicais em inglês......................... 290 


\section{LISTA DE ABREVIATURAS}

\begin{tabular}{|c|l|}
\hline LC & Linguística de Corpus \\
\hline TGT & Teoria Geral da Terminologia \\
\hline TCT & Teoria Comunicativa da Terminologia \\
\hline WST & Wordsmith Tools \\
\hline UFs & Unidades fraseológicas \\
\hline
\end{tabular}

\section{HARMONIA}

\begin{tabular}{|c|c|c|}
\hline \multirow{7}{*}{$\begin{array}{l}\text { Notas Musicais e } \\
\text { Cifras de Acordes }\end{array}$} & $\mathrm{A}$ & Lá \\
\hline & B & Sí \\
\hline & $\mathrm{C}$ & Dó \\
\hline & $\mathrm{D}$ & Ré \\
\hline & $\mathrm{E}$ & $\mathrm{Mi}$ \\
\hline & $\mathrm{F}$ & Fá \\
\hline & $\mathrm{G}$ & Sol \\
\hline Graus & $\begin{array}{l}\text { I, II, III, IV, } \\
\text { V, VI e VII }\end{array}$ & $\begin{array}{l}\text { Os algarismos romanos se referem à cada grau da } \\
\text { escala e aos acordes formados a partir desses graus. }\end{array}$ \\
\hline \multirow[t]{4}{*}{ Acidentes } & $\mathrm{b}$ & Bemol \\
\hline & $\#$ & Sustenido \\
\hline & $\mathrm{bb}$ & Dobrado bemol \\
\hline & \#\# & Dobrado sustenido \\
\hline \multirow{4}{*}{$\begin{array}{l}\text { Qualidade dos } \\
\text { acordes }\end{array}$} & M & Maior \\
\hline & $\mathrm{m}$ & menor \\
\hline & $\operatorname{dim}$ & Diminuto \\
\hline & aum & Aumentado \\
\hline
\end{tabular}




\section{SUMÁRIO}

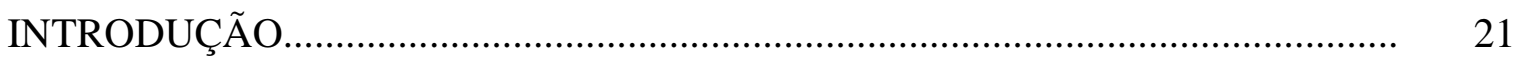

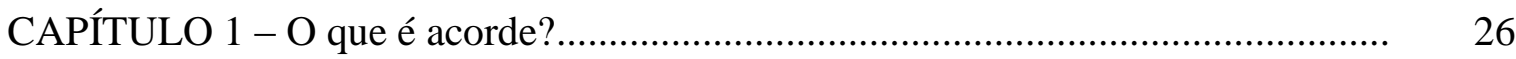

CAPÍTULO 2 - Colocações especializadas em dicionários de termos musicais monolíngues, em Inglês e Português, a partir dos termos correspondentes "acorde" e "chord"

CAPÍTULO 3 - Fundamentação téorica............................................................. 37

3.1 Estudos descritivos da tradução baseados em corpora ......................................... 37

3.2 Linguística de Corpus................................................................................... 38

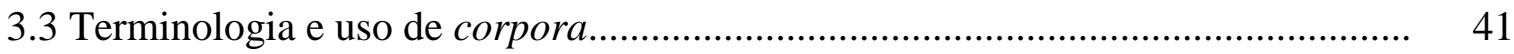

3.4 A Teoria Comunicativa da Terminologia........................................................ 43

3.5 A linguagem e o texto no contexto de especialidade............................................ 45

3.5.1 A linguagem de especialidade..................................................................... 45

3.5.2 Marcas culturais do texto de especialidade: tipos e gêneros textuais, intertextualidade e convencionalidade ..................................................................... 46

3.6 Colocações especializadas e estendidas........................................................... 53

3.7 Glossário bilíngue de especialidade com contextos.......................................... 58

CAPÍTULO 4 - Materiais e Métodos................................................................... 60

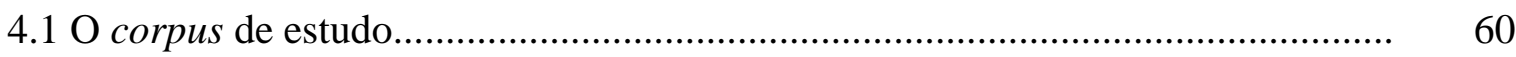

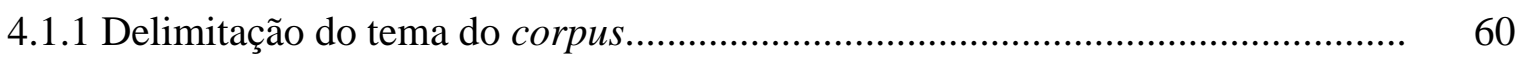

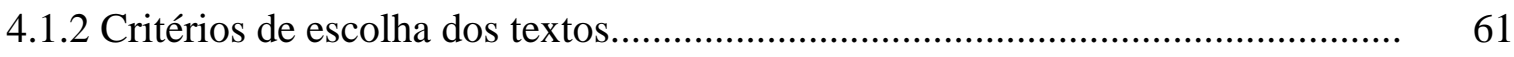

4.1.3 Composição do subcorpus de inglês.................................................................... 64

4.1.4 Composição do subcorpus de português............................................................ 66

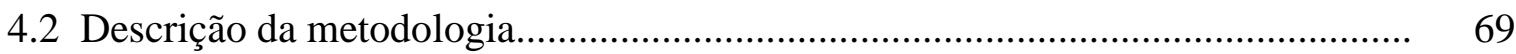

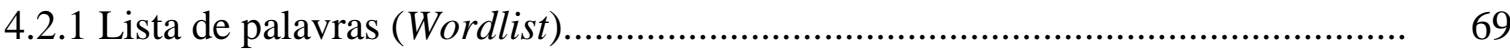


4.2.2 Listas de palavras-chave (Keywords) ….................................................. 71

4.2.3 Listagem de concordâncias (Concord) …......................................................... 73

4.2.4 Listas de clusters e de colocados (Collocates) ................................................. 74

4.2.5 Procedimentos adotados para a identificação das colocações e seus correspondentes na língua de chegada.................................................................... $\quad 76$

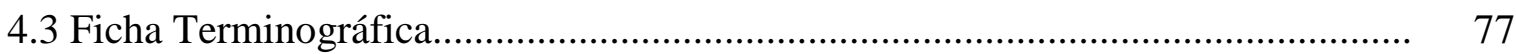

CAPÍTULO 5 - Análise e discussão dos dados.......................................................... 81

5.1 Colocações especializadas do termo "acorde" e seus correspondentes em Inglês. 82

5.2 Análise da composição das colocações especializadas........................................ 283

5.2.1 Tipologia das colocações especializadas do corpus de estudo........................... 283

5.2.1.1 Colocações especializadas: adjetivas, nominais e com

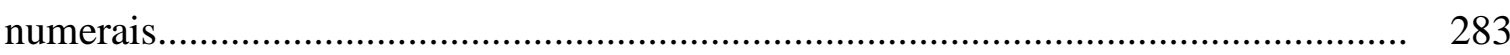

5.2.1.2 Colocações especializadas estendidas....................................................... 286

5.3 Análise das relações semânticas entre colocações................................................ 288

5.3.1 Alguns problemas causados pelas variantes terminológicas lexicais em textos

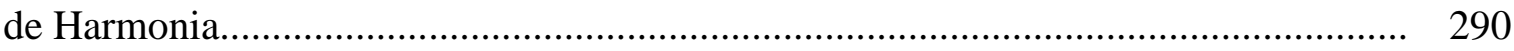

CAPÍTULO 6 - Modelo de verbete........................................................................ 292

Inglês - Português........................................................................................ 293

Português - Inglês..................................................................................... 327

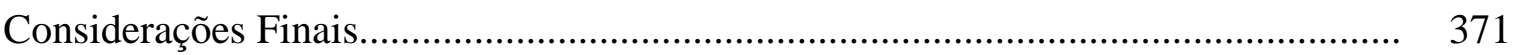

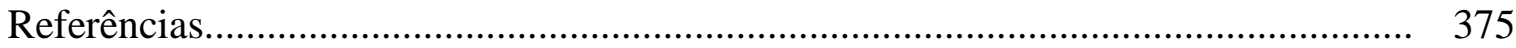




\section{INTRODUÇÃO}

Os glossários bilíngues constituem um dos recursos de pesquisa no ofício do tradutor, principalmente quando a tradução é voltada para uma área específica do conhecimento, em que a terminologia é própria. Nesse caso, um glossário pode ser um ótimo aliado se ele oferecer, além da tradução do termo, exemplos de uso retirados de contextos reais. Exemplos de glossários assim são aqueles construídos a partir de corpora (conjuntos de textos em formato eletrônico), considerados como uma fonte rica de informações sobre o uso convencional de um termo na comunicação entre especialistas.

$\mathrm{Na}$ área da Música, por exemplo, constatamos que não há glossários bilíngues que venham com tais contextos. Foi a partir dessa constatação que nasceu a ideia de criar um glossário bilíngue de termos musicais para uso de tradutores.

Verificamos também que durante o processo de tradução de textos sobre teoria musical, mais especificamente sobre Harmonia, o tradutor pode enfrentar algumas dificuldades, principalmente se ele não for um especialista, já que é uma área com um vasto material bibliográfico, em que há divergências entre alguns textos.

No mundo da Música Ocidental, a Harmonia constitui um dos principais parâmetros de estudo no campo musical. Do Tratado de Rameau (1722), que consagrou a Harmonia como ciência, até os nossos dias, inúmeras obras teóricas foram publicadas. Da Europa para outros continentes, muitas dessas obras influenciaram a formação de músicos de diversas nacionalidades. No decorrer desse tempo, foram observadas inúmeras mudanças conceituais apresentadas por tratadistas (ou teóricos musicais) de várias épocas acerca das "melhores" práticas de harmonização musical. Influenciadas por um conjunto de convenções estéticoculturais, tais obras teóricas muitas vezes se apresentavam como "leis" que ditavam o uso "correto" dessas práticas musicais. Grande parte dos tratados musicais tem até hoje um caráter normativo, que orienta o que os músicos, em processo de formação, devem fazer ou evitar, de acordo com a abordagem teórica adotada.

Nesse contexto, em que coexistem pontos de vistas diferentes, protagonizados por sujeitos de culturas distintas, é de se esperar que a terminologia utilizada na área musical 
carregue consigo a influência histórica dos vários idiomas que contribuíram para a formação dos termos. Se a influência cultural dita os padrões predominantes nas práticas de harmonia no campo da Música, isso se reflete diretamente na forma como o conhecimento é transmitido, ou seja, por meio do uso da linguagem. O contexto linguístico, sociocultural e tecnológico no qual a área de especialidade musical se insere favorece a criação e uso de combinações lexicais específicas na comunicação entre especialistas. A terminologia não é criada arbitrariamente. Ela, assim como a Música, também é resultante de consensos conceituais compartilhados por integrantes da área de especialidade. Dessa forma, se aquilo que é convenção sofre alteração, por conta da criação de novas teorias e práticas musicais, refletirá diretamente na linguagem especializada.

Por conta dessa diversidade no material, tivemos de estabelecer critérios na seleção do corpus de estudo. Por esta ser uma pesquisa sincrônica, optamos por publicações realizadas nos últimos trinta anos que abrangessem os gêneros textuais: apostila, livro-texto, artigo científico, tese e dissertação. Reunimos materiais sobre Harmonia Tradicional, Funcional e Aplicada ao contexto popular, escritos originalmente em Português do Brasil e em Inglês dos Estados Unidos. Não foram incluídas obras traduzidas, mesmo as mais consagradas, porque pretendemos observar o uso de expressões cristalizadas contidas em textos escritos diretamente em um dos idiomas. Os materiais foram coletados de meio eletrônico e impresso, extraídos de sites de revistas especializadas, periódicos, conservatórios e faculdades de Música.

Optamos por estudar colocações especializadas, ou seja, combinações lexicais convencionais de uma área do conhecimento, utilizadas na comunicação entre um grupo de especialistas (L'HOMME; BERTRAND, 2000). Tais colocações contém o termo "acorde" (ou "chord" em Inglês), que é uma palavra recorrente nos dois subcorpora e de grande importância no estudo da Harmonia.

Este é um estudo descritivo-comparativo sob o respaldo teórico dos Estudos Descritivos da Tradução Baseados em corpus e da Linguística de Corpus, que se ocupa da identificação de padrões lexicais a partir da observação de textos armazenados em um corpus eletrônico. Esta pesquisa também é norteada pela Teoria Comunicativa da Terminologia, que defende o estudo do termo em seu contexto de uso, e pela Fraseologia, que estuda a formação das colocações da língua geral e da linguagem de especialidade. 
Em relação à metodologia, para o levantamento de dados e seleção de candidatos a termos, escolhemos o programa de análise lexical Wordsmith Tools 6.0, doravante WST (SCOTT, 2008). De tal software, utilizaremos as seguintes funções: lista de palavras (Wordlist), lista de palavras-chave (Keyword), listagem de concordâncias (Concord), listas de clusters e de colocados (Collocates). A análise será quantitativa (apoiada na observação da frequência dos termos no corpus) e qualitativa (seguindo o critério da convencionalidade proposto por Tagnin (2013)).

\section{Objetivos principais e secundários:}

O objetivo principal deste projeto é o de propor um modelo de glossário bilíngue de colocações da área de Harmonia Musical. As colocações escolhidas para compor o glossário são derivadas da palavra "acorde" (chord, em Inglês), que ora aparece como base, ora como colocado. Base é o elemento conhecido da colocação e colocado é o elemento que co-ocorre de forma significativa com uma palavra de busca (TAGNIN, 2015).

Como objetivos específicos, são propostos: a partir da compilação do corpus comparável português-inglês de Harmonia Musical, a realização de um levantamento das colocações derivadas de "acorde" com base na frequência de uso e na convencionalidade; identificação no subcorpus em inglês das colocações mais frequentes para o termo correspondente "chord"; análise comparativa dos resultados, relacionando os termos correspondentes nos dois idiomas; análise de aspectos comunicativos e culturais relacionados à terminologia e à linguagem de especialidade; preenchimento das fichas terminológicas e elaboração de verbetes.

Essa escolha foi motivada pela análise prévia da frequência nas listas de palavras. Tanto em inglês como em português, são palavras que apresentam uma das maiores ocorrências. Outra razão da escolha é que os acordes são um dos objetos principais de estudo da Harmonia, como dito anteriormente, o que pode evidenciar a riqueza de conteúdo em torno de tais termos. 


\section{Justificativa}

A partir da observação de dicionários bilíngues de termos musicais, verificamos a falta de uma obra bilíngue no par linguístico Inglês Estadunidense e Português Brasileiro, baseada em corpora, que auxiliasse tradutores.

O que há à disposição do tradutor são dicionários de termos musicais monolíngues, que incluem na lista de verbetes termos estrangeiros já incorporados à terminologia musical daquela cultura, com definições, porém, em nenhum deles encontram-se exemplos de como são utilizados os termos. E os escassos glossários bilíngues encontrados na Internet apresentam poucas entradas, com termos descontextualizados.

Verificamos também que, embora sejam utilizadas como apoio ao processo de tradução, tais obras não são específicas para um trabalho bilíngue, já que o objetivo maior é atender o público da área musical (estudantes, pesquisadores e músicos). Também observamos que elas trazem um número parcial de colocações especializadas, o que constitui uma oportunidade interessante de estudo para pesquisas com ferramentas de análise lexical, já que a partir da compilação de textos especializados é possível observar a recorrência de outras colocações, constatar o caráter convencional com que tais expressões são utilizadas na linguagem de especialidade musical e apontá-las como candidatas a verbetes de futuros dicionários.

Por tais razões, acreditamos que a compilação de um glossário bilíngue de colocações especializadas que auxilie o tradutor a encontrar correspondentes e soluções de tradução, com base na frequência, no uso convencional e contexto de uso dos termos poderá ser útil no processo tradutório.

Em relação às partes que compõem essa dissertação, subdividimos os capítulos da seguinte forma:

- Introdução: Apresentação do tema, dos objetivos gerais e específicos, e da justificativa da pesquisa;

- Capítulo 1: Uma breve explicação sobre o termo "acorde" e sua importância para a área de Harmonia; 
- Capítulo 2: Apresentação de uma consulta a alguns dicionários de termos musicais em Inglês e em Português para verificar a quantidade de entradas em que os termos "acorde" e "chord" aparecem como integrantes de colocações;

- Capítulo 3: Apresentação das abordagens teóricas utilizadas para o desenvolvimento desta pesquisa;

- Capítulo 4: Apresentação do corpus de estudo, da metodologia utilizada e dos critérios para a extração de termos e compilação do glossário;

- Capítulo 5: Análise e discussão dos resultados da pesquisa;

- Capítulo 6: Apresentação do modelo de verbete e do glossário de colocações especializadas a partir dos termos "acorde" e "chord"; e

- Considerações finais: Comentários sobre os resultados obtidos e os pontos relevantes da pesquisa. 


\section{CAPÍTULO 1}

\section{O QUE É ACORDE?}

O termo "acorde", definido pelo Dicionário Etimológico de Língua Portuguesa (CUNHA, 2015) como complexo sonoro de três ou mais sons de frequência diferente, data de 1871 e vem do termo francês "accord". Definição quase similar foi encontrada no dicionário etimológico online de Língua Inglesa (HARPER, 2017) para o termo chord: "originally two notes; of three or more from 18c". Dentro da área musical, a disciplina que se aprofunda no estudo e pesquisa sobre os acordes é a Harmonia. (CAMARA, 2008).

No mundo da Música Ocidental, a Harmonia constitui um dos principais parâmetros de estudo no campo musical e possui uma extensa bibliografia. Do Tratado de Harmonia de Rameau (1722), obra que dá à Harmonia o estatuto de ciência, até os nossos dias, inúmeros trabalhos teóricos foram publicados. Da Europa para outros continentes, muitas dessas obras influenciaram a formação de músicos de diversas nacionalidades. No decorrer desse tempo, observaram-se diversas mudanças conceituais em função dos vários pontos de vista apresentados por tratadistas (ou teóricos musicais) de várias épocas acerca das "melhores" práticas de harmonização musical e de como utilizar os acordes. Essas variações conceituais foram se cristalizando na linguagem de especialidade musical e exercem influência em bibliografias mais recentes sobre o tema. Assim, é de se esperar que o termo "acorde" varie conceitualmente de acordo com a abordagem teórica utilizada.

Um grande número de publicações descreve "acorde" como três ou mais notas tocadas simultaneamente, formado a partir da sobreposição de duas ou mais terças. Essa é uma concepção utilizada de forma tradicional, relacionada ao que se chama de Tonalismo, sistema harmônico praticado desde a Idade Média e que foi herdado da cultura musical europeia. Em linhas gerais, no sistema tonal, a música apresenta uma tonalidade definida, em que as notas respeitam uma hierarquia em torno de uma nota principal, chamada de tônica (PY, 2006).

Obras teóricas que tratam das práticas musicais de compositores do século $\mathrm{XX}$, fase pós-tonal, mencionam acordes de formações distintas, baseadas em práticas não-tonais, tais como: acordes em segunda (formados a partir da superposição de intervalos de segunda), 
acordes em quarta (a partir da superposição de intervalos de quarta), policordes (a partir da sobreposição de uma ou mais tríades ou tétrades), clusters (formados por notas consecutivas de uma escala), mistos (formados a partir da superposição de intervalos mistos) etc (PERSICHETTI, 1961).

No nosso levantamento de termos, acordes relacionados às práticas atonais quase não aparecem, já que as publicações da nossa amostra referem-se predominantemente a contextos tonais.

No corpus selecionado para esta pesquisa, com publicações realizadas nos últimos trinta anos, como será detalhado no item "4.1 - Corpus de estudo", verificamos que o uso dos acordes é analisado seguindo duas correntes tonais: Harmonia Tradicional e Harmonia Funcional.

De forma bem resumida, pode-se dizer que a Harmonia Tradicional, ancorada no baixo cifrado e na teoria dos graus (baseada nas escalas maior e menor, que formam os acordes), apresenta regras de estilo para práticas harmônicas que orientam a condução das vozes e encadeamento dos acordes, orientando sobre o que é permitido e o que deve ser evitado na composição tonal. Tais obras têm um caráter prescritivo e descrevem práticas comuns do Ocidente Europeu (do Barroco ao Romantismo), consagradas pelo repertório erudito. Nessa vertente, autores que constam em referências de textos do corpus de estudo são: SCHOENBERG (2001, 2004), HINDEMINTH (1988), MOTTE (1988), PISTON (1987), KOSTKA; PAYNE (1989) etc.

A Harmonia Funcional, embora utilize fundamentos da Harmonia Tradicional, segue a teoria das funções, em que os acordes assumem funções específicas no universo harmônico, determinadas pelo nível de "atração" entre eles. Os acordes principais são denominados de acordo com sua função no sistema: tônica, subdominante e dominante (CAMINHA, 2000). Nas obras teóricas relacionadas ao tema, os acordes são analisados sob cinco leis tonais. Nessa vertente, os principais autores mencionados em referências de textos do corpus de estudo são: RIEMANN (1903), REGER (1903), KOELLREUTER (1980), BRISOLLA (2006) etc.

No corpus também há textos que citam obras voltadas para a análise harmônica da música popular, tais como as de: CHEDIAK (1987), FARIA (1991), NETTLES (1987) etc. Na Harmonia aplicada à música popular, verificamos um hibridismo de abordagens analíticas 
que tentam explicar o fenômeno das práticas harmônicas populares relacionadas ao Jazz, MPB, Pop, Rock, Bossa Nova etc.

Aqui o nosso foco de estudo é analisar a terminologia em volta dos acordes sob uma ótica linguística e descritiva. Portanto, não temos como objetivo a análise crítica a respeito das abordagens da teoria harmônica, já que isso pertence ao âmbito da Música. No nosso estudo, realizamos um levantamento de expressões usadas para denominar os tipos de acorde e como eles são utilizados na comunicação especializada nos dois idiomas e a partir daí comparar os contextos em busca dos correspondentes das colocações nos dois idiomas. 


\section{CAPÍTULO 2}

\section{COLOCAÇÕES ESPECIALIZADAS EM DICIONÁRIOS DE TERMOS MUSICAIS MONOLÍNGUES, EM INGLÊS E PORTUGUÊS, A PARTIR DOS TERMOS CORRESPONDENTES “ACORDE" E "CHORD”}

Como veremos no subitem 3.6 (sobre colocações especializadas e estendidas), o termo "colocação" se refere a uma combinação de palavras que aparecem frequentemente juntas (TAGNIN, 2013). As colocações especializadas são aquelas utilizadas na linguagem de especialidade e aparecem em textos especializados. Algumas combinações aparecem em dicionários, contudo nem sempre tais obras contemplam tais estruturas. De uma forma geral, autores e editoras não atualizam dicionários na mesma velocidade em que são criadas novas expressões na língua. Além disso, sem a utilização de corpora, uma colocação pode não ser percebida ou conhecida pelo autor do dicionário e não ser incluída na obra. Em nossa pesquisa, a repetição da colocação - utilizada por diferentes falantes no discurso especializado - é constatada por meio de análise lexical de textos escritos, os quais compõem o corpus de estudo.

Neste capítulo, apresentaremos um levantamento realizado em cinco dicionários de termos musicais. O objetivo aqui é verificar a quantidade de colocações registrada nas entradas de dicionários de termos musicais publicados no Brasil e nos Estados Unidos. Como é uma análise sincrônica, utilizamos o mesmo critério que foi adotado na seleção do corpus de estudo, publicações realizadas nos últimos vinte anos. Compararemos esse resultado com o obtido a partir da análise do corpus de estudo.

Encontramos apenas dois dicionários de termos musicais em Língua Portuguesa. Em Língua Inglesa, a quantidade de publicações de obras referenciais do gênero é maior. Optamos por três obras.

No decorrer deste estudo, utilizaremos códigos para nos referir a essas obras. Os de Língua Portuguesa serão especificados como DP-DOURADO e DP-GALTER; os de Língua Inglesa, como DI-OXFORD, DI-HARVARD e DI-ON MUSIC, descritos a seguir. 
- DP-DOURADO: (DOURADO, Henrique Autran. Dicionário de termos e expressões da música. São Paulo: Editora 34, 2004).

É um dicionário impresso, escrito em português brasileiro e possui 382 páginas. Conta com mais de dez mil entradas. Uma grande parte dos termos contemplados no dicionário é oriunda de outros idiomas (alemão, inglês, italiano e francês, por exemplo) e foi incorporada à terminologia musical utilizada no Brasil. Tais termos estrangeiros nem sempre apresentam as definições. Nesse caso, no lugar da definição, há o correspondente em português ou uma remissiva. É uma obra pluritemática, com a terminologia utilizada na música erudita e popular de diversos países e culturas. Não contém biografias nem títulos de composições. Na nota introdutória da obra, o autor modestamente comenta que o projeto inicial era voltado para um público leigo. Entretanto, além de ser um dos poucos dicionários de termos musicais redigidos em Português Brasileiro, a obra é uma referência bibliográfica para estudantes, músicos e pesquisadores. Por apresentar a tradução de alguns termos estrangeiros, também pode servir de apoio ao tradutor.

- DP-GalTer: (GAlTER, Vidal. Dicionário da Música. Teoria Musical, Danças, Festas, Ritmos, Definições e Conceitos Gerais, Folclore e Ilustrações. Brasília: Vidal Galter, 2013).

É um dicionário em formato digital, com 315 páginas. A obra não especifica quantos verbetes, estimamos um número de seis a sete mil verbetes, em ordem alfabética. Assim como no dicionário DP-DOURADO, há vários termos oriundos de idiomas estrangeiros (alemão, inglês, italiano, francês etc). É uma obra pluritemática, abordando Teoria Musical, Folclore e apresenta ilustrações. As definições são escritas em português brasileiro. A obra tem como público alvo iniciantes em Música.

- DI-OXFORD: (LATHAM, Alison. The Oxford Dictionary of Musical Terms. USA, New York: Oxford University Press Inc., 2004)

É um dicionário impresso e possui 208 páginas. Conta com mais de 2500 entradas, em ordem alfabética. Assim como observado nos dicionários em Língua Portuguesa, há termos oriundos de outros idiomas (alemão, italiano, francês, latim etc), que foram incorporados à terminologia musical usada nos Estados Unidos. É uma obra concisa, destinada a consultas rápidas. Alison Latham é responsável pela edição. As definições são escritas em inglês. Os temas abordados estão relacionados com a Música Ocidental: ritmo, métrica, forma, gêneros 
musicais, escalas, acordes, harmonia, contraponto, análise e composição, performance, estética, tempo, períodos históricos e movimentos artísticos, acústica etc. A obra é destinada a: músicos, estudantes, professores e apreciadores.

- DI-HARVARD: (RANDEL, Don Michael. The Harvard Dictionary of Music. 4th ed. USA: The Belknap Press of Harvard University Press, 2003)

É um dicionário impresso e possui 1008 páginas. Conta com mais de 6000 entradas, em ordem alfabética, na Língua Inglesa e em outras línguas (alemão, italiano, francês etc). As definições são redigidas em inglês. Como apoio, há mais de 450 figuras ilustrativas de trechos musicais (em pentagramas), instrumentos musicais etc. As entradas incluem estilos e formas da Música Ocidental, artigos sobre música africana, asiática, latino-americana e do Oriente Próximo, informações sobre obras musicais etc. Também aborda termos relacionados à música popular, ao Jazz e ao Rock. A obra é destinada a músicos, estudantes e apreciadores.

- DI-ON MUSIC: On Music Dictionary. USA, Virginia: Connect For Education Inc, 2015. (Disponível em: < https://dictionary.onmusic.org/>)

É um dicionário online, sucessor do Virginia Tech Multimedia Music Dictionary, e conta com recursos multimídia. Possui 4392 entradas, em ordem alfabética, na Língua Inglesa e em outras línguas (alemão, italiano, francês etc). Para cada entrada, há um ícone de áudio que reproduz a pronúncia do termo. As definições são escritas em inglês e algumas contam com apoio de figuras e de trechos musicais com áudio. O dicionário também oferece um menu com os itens: instrumentos musicais, compositor, símbolos musicais e apêndice temático (dividido em performance prática e teoria musical). Os temas abordados estão relacionados com a Música Ocidental: ritmo, métrica, forma, gêneros musicais, escalas, acordes, harmonia e contraponto, análise e composição, performance, título de peças musicais, instrumentos etc. Também apresenta termos utilizados na música popular. O dicionário é destinado principalmente a estudantes de faculdades de Música.

Nos dicionários especificados acima, os termos acorde e chord são definidos da seguinte forma: 


\begin{tabular}{|c|c|}
\hline Dicionário & Definição \\
\hline $\begin{array}{l}\text { DP- } \\
\text { DOURADO }\end{array}$ & $\begin{array}{l}\text { Grupo de três ou mais notas (e poucas vezes somente duas, a depender do } \\
\text { contexto harmônico) executadas de forma simultânea. }\end{array}$ \\
\hline $\begin{array}{l}\text { DP- } \\
\text { GALTER }\end{array}$ & $\begin{array}{l}\text { Conjunto de notas musicais, que normalmente são tocadas simultaneamente } \\
\text { ou ainda de forma sucessiva, quando são arpejadas. Normalmente, os } \\
\text { acordes são constituídos de tríades ou tétrades. }\end{array}$ \\
\hline $\begin{array}{l}\text { DI- } \\
\text { OXFORD }\end{array}$ & $\begin{array}{l}\text { Two or more notes sounded together. The different types are named } \\
\text { according to the intervals they span: the triad, for example - the fundamental } \\
\text { chord in Western Harmony - is built from a root note with two superposed } \\
\text { thirds, the dominant seventh consists of a triad on the dominant of the } \\
\text { diatonic major scale with the addition of the note a seventh above the } \\
\text { dominant. }\end{array}$ \\
\hline $\begin{array}{l}\text { DI- } \\
\text { HARVARD }\end{array}$ & $\begin{array}{l}\text { Three or more pitches sounded simultaneously or functioning as if sounded } \\
\text { simultaneously; two such pitches normally referred to as an interval. The } \\
\text { most basic chords in the system of the tonic-dominant or triadic tonality are } \\
\text { the major and minor triads and their inversions (the sixth or six-three chord } \\
\text { and the six-four chord). Other chords that play an important though } \\
\text { subordinate role are the seventh chord (especially the dominant seventh), the } \\
\text { augmented sixth chord, the ninth chord, and the diminished triad, each of } \\
\text { which is regarded in this context as dissonant (...) In the analysis of tonal } \\
\text { music, all chords may be regarded as consisting of or deriving from to or } \\
\text { more thirds (whether major or minor; see interval) arranged one above } \\
\text { another (e.g., G-B-D-F). When a chord is arranged in this most compact form } \\
\text { containing only thirds, the lowest pitch is the root. A chord in which the root } \\
\text { is the lowest pitch is said to be in root position regardless of the spacing of } \\
\text { the pitches that lie above the root. The superposition of thirds may be } \\
\text { extended to include ninth, eleventh, and thirteenth chords, each of which its } \\
\text { name from the interval that separates the lowest and highest pitches when the } \\
\text { chord is the most compact form of root position. All such chords can be } \\
\text { inverted, and, in some circumstances, one or more pitches other than the }\end{array}$ \\
\hline
\end{tabular}




\begin{tabular}{|l|l|}
\hline highest may be omitted. In works of the $20^{\text {th }}$ century not based on the tonal \\
system, chords of numerous types are used, the concepts of consonance and \\
dissonance being often irrelevant (see also fourth chord, tone cluster, \\
atonality, twelve-tone music). Discussions of such theory often prefers the \\
term simultaneity to chord, though the latter may appear in such compounds \\
as trichord, tetrachord, pentachord and hexachord for collections of three, \\
four, five, and six pitches, respectively, that may or not be sounded \\
simultaneously. Two pitches may be referred to as dyad. \\
DI -ON & $\begin{array}{l}\text { The sounding of two or more notes (usually at least three) simultaneously. } \\
\text { Most chords are based on triads or three notes with the interval of } \\
\text { a major or minor third between each of the three notes. The two most } \\
\text { common chords are the major and minor chords. A major chord is composed } \\
\text { of a major third above the tonic note, and a perfect fifth above the tonic, } \\
\text { a minor chord is composed of a minor third and a perfect fifth. }\end{array}$ \\
\hline
\end{tabular}

Quadro 1 - Definições para os termos “chord" e "acorde” em dicionários especializados

Verifica-se que os dicionários em Língua Inglesa tendem a ser mais descritivos e utilizam mais informações na definição do que os em Língua Portuguesa. Como verificaremos na análise dos resultados (Capítulo 5), apresentar conteúdos com um volume maior de informações é uma das marcas culturais presentes em textos americanos. Na comparação entre todos os dicionários, o DI-HARVARD é o que mais apresenta conteúdos informativos na definição e contrasta abordagens teóricas distintas: acorde construído por sobreposição de terças, baseado no sistema tonal e outras construções de acordes que não são baseadas nesse sistema.

Em relação à quantidade de colocações e colocados (palavras que acompanham o termo "acorde"), encontramos os seguintes resultados:

\begin{tabular}{|l|l|l|}
\hline Dicionário & Quantidade & \multicolumn{1}{c|}{ Colocações e Colocados } \\
\hline $\begin{array}{l}\text { DP - } \\
\text { DOURADO }\end{array}$ & 26 & $\begin{array}{l}\text { Acorde alterado, acorde consonante, acorde de diminuta, acorde de } \\
\text { meia diminuta ou meio diminuto, acorde de sétima da diminuta, } \\
\text { acorde de quarta e sexta, acorde de sexta e quarta, acorde diminuto, } \\
\text { acorde dissonante, acorde pivô, acorde quebrado, acordes }\end{array}$ \\
\hline
\end{tabular}




\begin{tabular}{|c|c|c|}
\hline & & $\begin{array}{l}\text { primários, dominante, dominante secundária, nona, nona da } \\
\text { dominante, sétima, sétima da diminuta, sétima da dominante, sexta } \\
\text { alemã, sexta francesa, sexta italiana, sexta napolitana, } \\
\text { subdominante, submediante e tônica. }\end{array}$ \\
\hline $\begin{array}{l}\text { DP - } \\
\text { GALTER }\end{array}$ & 8 & $\begin{array}{l}\text { acorde de sétima, acorde de sétima da dominante, acorde de sétima } \\
\text { diminuta, acorde interpolado, acorde invertido, acorde maior, } \\
\text { acorde menor, acorde quebrado. }\end{array}$ \\
\hline $\begin{array}{l}\text { DI - } \\
\text { OXFORD }\end{array}$ & 17 & $\begin{array}{l}\text { added sixth chord, altered chord, augmented sixth chord, broken } \\
\text { chord, common chord, diminished seventh chord, dominant seventh } \\
\text { chord, French sixth chord, half-diminished seventh chord, Italian } \\
\text { sixth chord, Neapolitan sixth chord, pivot chord, secondary } \\
\text { dominant chord, seventh chord, six-four chord, six-three chord, } \\
\text { Tristan chord. }\end{array}$ \\
\hline $\begin{array}{l}\text { DI - } \\
\text { HARVARD }\end{array}$ & 26 & $\begin{array}{l}\text { added sixth chord, broken chord, common chord, diminished seventh } \\
\text { chord, dominant seventh chord, eleventh chord, five-three chord, } \\
\text { French sixth chord, German sixth chord, half-diminished seventh } \\
\text { chord, Italian sixth chord, Major chord, minor chord, Neapolitan } \\
\text { sixth, Ninth chord, parallel chords, passing chord, pivot chord, } \\
\text { primary chords, seventh chord, six-four chord, sixth chord, sixth } \\
\text { chord style, substitution chord, thirteenth chord, Tristan chord. }\end{array}$ \\
\hline $\begin{array}{l}\text { DI - ON } \\
\text { MUSIC }\end{array}$ & 21 & $\begin{array}{l}\text { augmented chords, barbershop seventh chord, broken chord, chord } \\
\text { progression, chord symbol, common chord, diminished chord, } \\
\text { dominant chord, eleventh chord, half-diminished seventh chord, } \\
\text { Neapolitan sixth, ninth chord, no chord, parallel chord, ringing } \\
\text { chord, seventh chord, sixth chord, six-four chord, subdominant } \\
\text { chord, thirteenth chord, tonic chord, Tristan chord. }\end{array}$ \\
\hline
\end{tabular}

Quadro 2 - Quantidade de colocações especializadas em dicionários especializados

Comparando os dicionários em Língua Portuguesa, há mais colocações/colocados relacionados ao termo acorde no dicionário DP- DOURADO: vinte e seis. Observa-se que a colocação comum entre as duas obras é: "acorde quebrado". Contudo, ao analisar as definições de "sétima da diminuta" (DP -DOURADO) e "acorde de sétima diminuta" (DP- 
GALTER), verificamos que são variantes e explicam, com palavras diferentes, o mesmo tipo de acorde (uma tétrade diminuta):

- Sétima da Diminuta: Acorde construído sobre uma tríade diminuta acrescida de uma sétima menor alterada descendentemente, contada a partir da tônica (do-mi bemol - sol bemol - si dobrado bemol) (DP-DOURADO)

- Acorde de sétima diminuta: são os acordes constituídos pela terça menor, quinta diminuta e a sétima diminuta. (DP-GALTER).

Em "sétima da diminuta" observa-se a omissão do termo "acorde" e uso de preposição + artigo (da) entre sétima e diminuta. O tipo de variante linguística que omite o termo "acorde" é um dos mais comuns, observados na nossa análise. Por exemplo: dominante, dominante secundária, nona, nona da dominante, sétima da diminuta, sétima da dominante, sexta alemã, sexta francesa, sexta italiana, sexta napolitana, subdominante, submediante e tônica.

Também observamos o uso das duas variantes em obras distintas: "acorde de sétima da dominante" (DP-GALTER) e "sétima da dominante" (DP-DOURADO), cujas definições comprovam ser o mesmo acorde:

- Acorde de sétima da dominante: Acorde de sétima que tem como primeira nota, ou fundamental, a dominante (V grau) da escala. (DP-GALTER)

- Sétima da dominante: acorde que consiste em uma tríade construída sobre o quinto grau de uma escala, acrescida de uma sétima contada a partir de sua fundamental (sol-si-ré-fá, na tonalidade de dó maior). (DP-DOURADO)

Verificamos que no dicionário DP-DOURADO, a colocação "acorde de diminuta" tem uma remissiva para "acorde diminuto", indicando serem variantes do mesmo conceito. No mesmo dicionário, há remissivas entre colocações que alternam a ordem de seus componentes, porém se referem ao mesmo significado, como "acorde de sexta e quarta" e “acorde de quarta e sexta" (esta é remissiva daquela).

Em Inglês, o dicionário DI-HARVARD é o que apresenta mais colocações, vinte e seis. As colocações comuns às três obras são: broken chord, common chord, half-diminished seventh chord, seventh chord, six-four chord e Tristan Chord. 
As colocações comuns aos dicionários DI-OXFORD e DI-HARVARD são: added sixth chord, diminished seventh chord, dominant seventh chord, French sixth chord, Neapolitan sixth (chord), pivot chord.

E colocações comuns aos dicionários DI-HARVARD e DI-ON MUSIC são: eleventh chord, ninth chord, parallel chords, sixth chord e thirteenth chord.

Também encontramos variantes para a colocação "Neapolitan sixth chord". Tal variação é semelhante à que acontece em Português, com omissão do termo "acorde". Mas comparando os dicionários, percebe-se que, em Inglês, a maioria das colocações encontradas não omite o "chord”. Já em Português, há vários casos desse tipo de redução.

Dois dicionários omitem o termo:

- Neapolitan sixth chord (DI-OXFORD): Name given to one of the chromatic chords - the first inversion (i.e. the $6^{\text {th }}$ chord) of the triad built on the flattened supertonic.Ex.1 shows an example in the key of $C$. It is often used to replace the subdominant chord in cadential progression IV-V-I. Although it was already an established feature in Music (not only Italian) of the second half of the $17^{\text {th }}$ Century, it appears to take its name from its use by composers of the $18^{\text {th }}$ century (Neapolitan School', e.g Alessandro Scarlatti and Pergolesi).

- Neapolitan sixth (DI-HARVARD): see sixth chord.

- Neapolitan sixth (DI-ON MUSIC): A chord composed of a minor third and a minor sixth, based on the subdominant, in the key of $C$, the Neapolitan sixth would be F, A-flat, D-flat.

Embora haja um número considerável de colocações especializadas para o termo "acorde" e chord nos dicionários analisados, ele ainda é pequeno em comparação com o resultado que se pode alcançar utilizando ferramentas de análise lexical, como veremos posteriormente.

O objetivo deste capítulo foi o de, inicialmente, apontar quais colocações já estão registradas em dicionários especializados e a quantidade. Esses dados serão comparados com os resultados obtidos a partir da extração e análise de colocações do nosso corpus de estudo, que será assunto do capítulo 5 - Análise e discussão de dados. 


\section{CAPÍTULO 3}

\section{FUNDAMENTAÇÃO TEÓRICA}

Este capítulo tem como objetivo realizar um breve panorama do arcabouço teórico utilizado neste trabalho e que fundamenta a nossa pesquisa.

Serão apresentados a seguir os seguintes tópicos: Estudos Descritivos da Tradução Baseados em Corpora, Linguística de Corpus (LC), Teoria Comunicativa da Terminologia (TCT), Estudos da Fraseologia e Colocações especializadas.

\subsection{Estudos Descritivos da Tradução Baseados em Corpora}

Os Estudos Descritivos da Tradução foram uma das correntes de pensamento utilizadas por Baker (1995) para a criação de uma metodologia de análise linguística baseada em corpus. Baker define corpus (ou corpora, no plural) como um conjunto de textos naturais, armazenados em computador, passíveis de serem analisados de forma automática ou semiautomática, criado com o propósito específico de observar fenômenos linguísticos. De acordo com a finalidade da pesquisa, o corpus pode abranger linguagem escrita e/ou falada, com a possibilidade de inclusão de textos das mais diversas áreas do conhecimento (DAYRELL, 2005).

Influenciada por Gideon Toury, que defendia a importância de um estudo descritivocomparativo das normas em torno dos textos traduzidos e daqueles não traduzidos, Baker considera a tradução um registro autêntico de eventos comunicativos que sofre influências da cultura-alvo e possui características típicas quando da comparação com o texto de partida. Aliando essa abordagem à corrente de pensamento de John Sinclair, cuja metodologia permitia a investigação linguística de corpora eletrônicos com base na frequência das palavras e em dados probabilísticos, Baker viu a oportunidade de criar uma disciplina que tivesse a tradução como objeto principal de pesquisa e a Linguística de corpus como metodologia (CAMARGO e HASMANN, 2013).

A metodologia baseada em corpora possibilitou à disciplina Estudos da Tradução um valioso recurso pedagógico na prática tradutória e capacitação de tradutores profissionais. Isso porque os corpora eletrônicos têm grande utilidade no processo de extração de terminologia, 
podendo ser uma excelente fonte para analisar aspectos discursivo-comunicativos, decisões tomadas por tradutores, uso convencional de certas expressões, bem como identificar características peculiares relacionadas ao estilo do autor (OLOHAN, 2004; DAYRELL, 2005).

A busca de universais da tradução proposta por Baker é um marco na investigação de textos traduzidos. O uso de ferramentas de análise lexical facilita a identificação desses universais, ou categorias típicas de traduções, como simplificação (linguagem mais simples do que no texto original), explicitação (tendência a explicar informações que no original estavam implícitas), normalização (tendência a traduzir expressões mais marcadas da línguafonte de uma forma menos marcada na língua-alvo) e estabilização (aspectos linguísticos semelhantes verificados nos textos traduzidos). (BERBER-SARDINHA, 2002)

Tal abordagem influencia o desenvolvimento de uma nova perspectiva dentro dos Estudos da Tradução, trazendo questionamentos em relação à supremacia do texto fonte sobre o texto de chegada, à noção de equivalência relacionada aos aspectos semânticos ou formais, e às abordagens anteriores que defendiam um tipo ideal de tradução. Dessa forma, o objetivo principal dos Estudos Descritivos da Tradução passa a ser o de descrever textos traduzidos, observando a influência dos contextos literários, culturais e históricos sobre tais textos (DAYRELL, 2005).

Dessa forma, os Estudos da Tradução Baseados em Corpora têm como papel analisar a tradução como um evento comunicativo genuíno, explorando e explicando características típicas dos textos traduzidos. Embora sejam disciplinas distintas e com focos de estudos diferentes, a Linguística de Corpus e os Estudos Descritivos da Tradução têm pontos em comum em relação ao caráter descritivo de seus objetos de estudo, à autenticidade dos resultados obtidos a partir da análise quantitativa e qualitativa dos dados, com base em textos que comprovam o uso da linguagem em contexto real e não de fontes oriundas da intuição (DAYRELL, 2005).

\subsection{Linguística de Corpus}

Antes da Era do Computador, já havia a pesquisa a partir de corpus. Mas “corpus” era entendido como conjunto de documentos, que poderiam ser coletados e analisados 
manualmente (BERBER-SARDINHA, 2000). E aqui está a diferença do conceito de corpus utilizado pela Linguística de Corpus. Corpora são coletâneas de textos em formato eletrônico, criteriosamente compilados e organizados, destinados à pesquisa (TAGNIN, 2013, 2015).

O primeiro corpus eletrônico foi lançado em 1964, com o nome de Brown University Standard Corpus of Present-Day American English ou simplesmente Brown Corpus, como é mais conhecido, com textos em Inglês Americano. Ele foi compilado pelos pesquisadores Henry Kučera e W. Nelson Francis da Brown University e possui um milhão de palavras. Na década de 1970, o Lancaster-Oslo/Bergen Corpus, conhecido como LOB Corpus, com um milhão de palavras, foi compilado em colaboração com três universidades (Lancaster, Oslo, Bergen), em Inglês Britânico, para contrastar com o Brown.

Historicamente, o desenvolvimento da Linguística de Corpus está relacionado aos avanços da Tecnologia, uma vez que graças ao surgimento do computador e da Internet, tem sido possível a análise de corpora extensos por meio de ferramentas computacionais, o que seria praticamente inviável numa tarefa manual (TAGNIN e BEVILACQUA, 2013).

De acordo com Leech (1991), a Linguística de Corpus tem as seguintes características que a diferem da visão Chomskyana:

a) foco no desempenho: analisa o comportamento linguístico por meio da observação dos discursos naturais (escritos ou falados), em vez de se centrar na competência;

b) foco na descrição linguística, em vez de considerar universais linguísticos;

c) foco em modelos de língua quantitativos e qualitativos: com base na frequência e na descrição mais detalhada dos fenômenos linguísticos; e

d) visão empírica, em vez da racionalista.

A Linguística de Corpus trabalha com a linguagem autêntica, comprovando que nem todas as construções gramaticais possíveis numa língua ocorrem de fato; dessa forma, a língua é considerada um sistema probabilístico, em que algumas construções têm maior probabilidade de serem utilizadas em contexto real do que outras (HALLIDAY,1961).

Berber-Sardinha (2004) explica que há padrões no uso da língua que são percebidos pela recorrência, ou seja, pela repetição significativa. É o caso das colocações (associação 
entre itens lexicais), coligações (associação entre itens lexicais e gramaticais), prosódia semântica (associação entre itens lexicais e conotação, esta podendo ser negativa, positiva ou neutra) etc. Podemos citar como exemplos: upright piano (colocação adjetiva: adjetivo + substantivo), expert in (coligação: substantivo + preposição), cause problem (a prosódia semântica do verbo "to cause" é negativa por atrair palavras com sentido negativo, como problem, disease, damage, death etc). As colocações serão assunto do item 3.6 desta dissertação.

Em relação à tipologia, um corpus pode ser classificado como monolíngue, bi- ou multilíngue, dependendo da quantidade de línguas a serem estudadas; sincrônico, diacrônico, contemporâneo ou histórico; paralelo e/ou comparável, para fins de estudos tradutológicos e contrastivos. Paralelos são corpora compostos por textos originais em determinada língua e suas respectivas traduções em uma ou mais línguas. Comparáveis, no sentido específico, são os textos originais em duas ou mais línguas que tratam de um determinado tema e podem ser comparados entre si. Podem conter registros de língua falada e/ou escrita, geral ou de especialidade, e ser disponibilizados online ou off-line (TAGNIN, 2015). Em relação à finalidade, Berber Sardinha (2000) explica que o corpus pode ser de: estudo, referência (para contraste com o corpus de estudo) ou teste (para aperfeiçoamento da própria ferramenta de análise lexical). O tamanho do corpus variará de acordo com o objetivo da pesquisa.

Os requisitos para compilação de um corpus são: autenticidade (textos autênticos em linguagem natural), representatividade (em relação a um idioma ou tipo de linguagem), balanceamento (distribuição equivalente entre textos, gêneros, quantidade de palavras, etc), amostragem, diversidade (variedades textuais) e tamanho (SINCLAIR, 2005).

Em relação à abordagem, essa pode ser baseada em corpus (corpus-based) ou direcionada pelo corpus (corpus-driven). Na primeira, o corpus é utilizado para explicitar, testar ou comprovar hipóteses pré-existentes; na segunda, não há hipóteses pré-concebidas, o corpus vai apresentando qual o caminho a ser percorrido na pesquisa (BERBER SARDINHA,2000).

As três etapas para a construção de um corpus de acordo com os pressupostos da LC são: (1) definição da composição do corpus de estudo; (2) seleção dos textos que farão parte do corpus; (3) pré-processamento dos textos: conversão para o formato compatível com o software de análise lexical, limpeza (extração de figuras, gráficos etc), nomeação, geração de 
cabeçalhos e definição de padrões de anotação para os textos compilados, conforme propósito da investigação linguística (ALMEIDA, 2006; DI FELIPPO; ALMEIDA, 2010).

Após esses procedimentos, o corpus estará pronto para o processo de análise e extração de termos.

Programas de análise lexical como Wordsmith Tools (SCOTT, 2015) e Antconc (ANTHONY, 2014) têm sido bem utilizados para o processamento de corpora personalizados. O primeiro software é pago e o segundo disponível para download gratuito na Internet. Há também corpora que podem ser consultados online, sem a necessidade de download, que é o caso do Webcorp (http://www.webcorp.org.uk/live/). Este utiliza páginas da Internet para localizar contextos de uma palavra de busca e conta com ferramentas de análise no próprio site. Em geral os softwares de análise lexical contam com as seguintes ferramentas: lista de palavras, lista de palavras-chave e concordância. Tais ferramentas serão detalhadas no capítulo 4 - Materiais e Métodos.

\subsection{Terminologia e uso de corpora}

Inicialmente, faz-se necessário diferenciar os usos do termo "terminologia". Ao nos referirmos à disciplina que se aprofunda nos estudos sobre os termos técnico-científicos e os conceitos utilizados na linguagem especializada, utilizaremos o termo com a letra inicial maiúscula. Quando nos referirmos ao conjunto de termos utilizados em uma determinada área de conhecimento, ele será escrito com a inicial minúscula (KRIEGER; FINATO, 2004).

A Terminologia como disciplina científica se deu pela contribuição do engenheiro austríaco Eugen Wüster (1898-1977) que a introduziu na Universidade de Viena e estabeleceu as bases para a chamada Escola de Terminologia. O estudioso tinha como um dos principais objetivos a padronização dos termos técnico-científicos, com o fim de contribuir para uma univocidade na comunicação entre especialistas. Com foco no estudo dos termos técnicocientíficos, desenvolveu diversos trabalhos que deram origem à Teoria Geral da Terminologia (TGT). Seu ideal era atingir a padronização terminológica para que ruídos na comunicação técnico-científica fossem evitados, principalmente entre especialistas de nacionalidades diferentes, e a unificação de métodos de trabalho terminológico. Nessa perspectiva, não se admitia que um termo técnico-científico fosse polissêmico ou tivesse variantes, uma vez que 
daria margem a várias interpretações. Os trabalhos desenvolvidos pelo engenheiro tinham um caráter prescritivo. Com o decorrer do tempo, os princípios apresentados nesta teoria começaram a ser questionados, abrindo caminho para novas discussões (KRIEGER; FINATO, 2004).

Cabré et al (1998) apontam as seguintes fragilidades da TGT: logicismo, universalismo, estatismo, reducionismo e idealismo.

Logicismo - ao tentar analisar a realidade sob o prisma científico, organizando os conceitos a partir de um modelo hierárquico e binário, as relações tratadas como exceções deste modelo eram apontadas e não descritas de forma satisfatória.

Universalismo - a metodologia científica descrita em normas internacionais tinha o intuito de padronizar a análise do conhecimento sem levar em conta as diferenças geográficas, linguísticas, socioeconômicas e culturais entre os países envolvidos.

Estatismo - tendência a não levar em conta o caráter dinâmico com que a terminologia evolui, em função da perspectiva de estudo predominantemente sincrônica.

Reducionismo - os estudos específicos da Mecânica e Engenharia serviram de padrão para outras áreas técnicas, sem levar em conta as especificidades entre elas, gerando assim uma redução relevante na capacidade de descrição do modelo.

Idealismo - criação de terminologia com base em consenso no laboratório, privilegiando apenas o conceito, ignorando a integração do termo com os diversos contextos reais de uso.

A utilização de corpora na área da Terminologia, conforme Bevilacqua (2013), se deu com o surgimento de novos paradigmas teóricos, mais flexíveis e que questionavam as insuficiências da teoria de Wüster. De uma abordagem prescritiva, postulada pela TGT, que vai dos anos 1950 até início dos 1990, passa-se então para propostas descritivas (AUGER e ROSSEAU, 1998; BOURIGAULT e SLODIAN, 2004; CABRÉ, 1999; TEMMERMAN, 2000). Ao contrário da TGT, de caráter onomasiológico, normalizador e focado no conceito em detrimento do termo, as novas abordagens assumem uma posição semasiológica, em que o ponto de partida é a análise descritiva do termo. Elas consideram as variáveis pragmáticas que influenciam a formação das terminologias e analisam o termo a partir de seu contexto real de uso. Desta forma, há dois enfoques de estudo: de um lado, a análise descritiva do objeto e o 
desenvolvimento teórico; e do outro, as aplicações terminológicas que geram produtos como glossários, dicionários técnico-científicos, bancos de dados terminológicos e sistemas de reconhecimento automático de terminologias (KRIEGER e FINATTO, 2004).

Tais paradigmas de caráter descritivo, de acordo com Almeida e Vale (2008), foram cruciais para a aceitação de novos procedimentos metodológicos na extração de termos e favoreceram a utilização da metodologia da Linguística de Corpus nas pesquisas terminológicas.

\subsection{A Teoria Comunicativa da Terminologia}

Das várias propostas descritivas relativas ao estudo terminológico, escolhemos para este projeto as orientações da Teoria Comunicativa da Terminologia (TCT) de Maria Teresa Cabré que propõe os seguintes parâmetros (CABRÉ, 2003; KRIEGER e FINATTO, 2004; ALMEIDA, 2006):

- O objeto central da Terminologia são as unidades terminológicas e não os conceitos. Dessa forma, as unidades são analisadas sob uma perspectiva linguística, seguindo uma abordagem semasiológica;

- A priori não há diferença entre termo e palavra, mas somente signos linguísticos que, dependendo do discurso e da situação comunicativa, podem ser identificados ou como termo ou como palavra;

- Os termos devem ser analisados em seu contexto de uso, ou seja, nos discursos especializados;

- A variação conceitual e denominativa deve ser levada em consideração;

- Os níveis lexical, morfológico, sintático e textual podem veicular conhecimento especializado;

- As unidades terminológicas estão subordinadas a um contexto temático, ocupando um lugar preciso num mapa conceitual; e seu significado específico é determinado pelo lugar que ocupam nesse mapa. 
Em outras palavras, os fundamentos da TCT consideram o uso das unidades terminológicas dentro do universo das comunicações especializadas e, de modo sistemático, introduzem a perspectiva linguística aos estudos terminológicos. Tal perspectiva baseia-se na análise da terminologia como um conjunto de unidades denominativo-conceituais, retiradas da linguagem natural, a partir de uma situação real do contexto de especialidade (SALES, 2007; NAVARRO, 2011).

No nosso estudo, observamos ocorrências de variação conceitual e denominativa. Para a análise e descrição das colocações especializadas desta pesquisa, seguiremos a tipologia das variantes terminológicas utilizadas por Faulstich (1999) e Demai (2006). Entretanto, como na nossa pesquisa o corpus é composto de apenas textos escritos (não trabalhamos com o discurso oral) interessa-nos citar apenas as variantes terminológicas linguísticas que são as mais encontradas no nosso estudo.

Como variante terminológica, entende-se a unidade terminológica de concorrência, de natureza linguística ou de registro, que corresponde a uma das opções denominativas de um mesmo referente, em determinado contexto. Ela se diferencia do sinônimo terminológico, que é resultante da escolha do autor por outra unidade terminológica de coocorrência textual, com intuito de fazer variar a denominação, mas que pertence a um mesmo contexto (DEMAI, 2006).

As variantes terminológicas linguísticas são analisadas e classificadas de acordo com o teor semântico do termo e uso em contexto escrito ou oral.

A variante terminológica linguística do tipo lexical, comum entre as colocações levantadas nesta pesquisa, se dá quando um item lexical sofre comutação em uma das partes, fazendo com que a estrutura da colocação se estenda ou se reduza, sem alteração conceitual. É o que acontece, por exemplo, com a colocação "acorde de sexta aumentada francesa” e suas variantes linguísticas lexicais reduzidas: acorde de sexta francesa e sexta francesa.

É a partir do discurso especializado que se pode analisar contextos de uso dos termos. O discurso acontece por meio da linguagem de especialidade, cujos conceitos serão apresentados no próximo subitem. 


\subsection{A Linguagem e o texto no contexto de especialidade}

\subsubsection{A Linguagem de especialidade}

A linguagem de especialidade não surge de forma aleatória, ela se constitui a partir de elementos da língua geral. O léxico da língua geral é o conjunto de palavras conhecidas e dominadas por um indivíduo falante da respectiva língua (idioma), ao passo que o léxico da linguagem de especialidade é o conjunto de termos utilizados por membros de uma determinada área do conhecimento. Nesse sentido, a terminologia não é criada arbitrariamente, ela é resultante de consensos conceituais que são compartilhados por integrantes de um campo científico ou tecnológico. Se os consensos mudam, por conta da criação de novas teorias ou fenômenos, isso reflete diretamente na linguagem de especialidade. Tanto a terminologia quanto a linguagem de especialidade são oriundas da necessidade da comunicação especializada, para adquirir e transferir o conhecimento (SAGER, 1980; GALVÃO, 2004; SALES, 2007).

Assim como a língua geral, as linguagens de especialidade são culturalmente determinadas. Sendo as culturas fenômenos complexos que se refletem na língua, as linguagens de especialidade também herdarão produtos complexos, que não isentam a terminologia das variações linguísticas, ao contrário do que algumas teorias idealistas sonham (DEMAI, 2006).

A linguagem de especialidade é muito mais do que uma simples lista de palavras ou rótulos. Nela estão envolvidos: interlocutores, comunicação, práticas textuais e uma série de conhecimentos sócio-historicamente construídos (KRIEGER; FINATTO, 2004).

Aubert (2001) explica que a linguagem de especialidade é caracterizada por um conjunto de marcas lexicais, sintáticas, estilísticas e discursivas utilizadas por meio de um código linguístico, em ambiente de interação social, e que identifica uma área de atividade humana.

Nesse contexto, o tradutor, que lida com atividades tradutórias e terminológicas, desempenha o papel de mediador entre dois mundos distintos e deve estar atento às particularidades culturais de cada língua, contidas nos textos, e que condicionam a tradução. 
Presentes tanto nos textos de partida quanto nos de chegada, as influências culturais ou condicionantes culturais são fatores externos que influenciam a produção de textos. Embora os textos técnicos sigam certos padrões estilísticos, a terminologia utilizada não se isenta dos traços culturais. Nessa perspectiva, um texto técnico ou de especialidade é visto como uma estrutura historicamente ancorada, formada por diferentes planos portadores de sentido que se inter-relacionam (AZENHA JUNIOR, 1999).

E é a partir do contexto de interação social, seja por meio da língua geral ou da linguagem de especialidade, que são constituídos os tipos e gêneros textuais (cujos conceitos abordaremos no próximo subitem).

\subsubsection{Marcas culturais do texto de especialidade: tipos e gêneros textuais, intertextualidade e convencionalidade}

Há várias abordagens sobre tipologia e gênero textual. Neste trabalho, explicaremos de forma bem sucinta algumas que julgamos relevantes para a análise da tipologia e do gênero de textos teóricos musicais relacionados ao campo de Harmonia, especificamente sobre as formas textuais coletadas para esta pesquisa: livros-texto, apostilas, artigos científicos, dissertações, teses. Tais textos seguem certos padrões próprios do gênero textual de que fazem parte.

Um gênero textual pode conter um ou vários tipos textuais. O tipo textual é definido por Marcuschi (2002) como uma espécie de construção teórica definida de acordo com a natureza linguística de sua composição (aspectos lexicais, sintáticos, tempos verbais, relações lógicas) e abrange as seguintes categorias: narração, argumentação, exposição, descrição e injunção. Já os gêneros textuais são realizações linguísticas, concretas, que apresentam aspectos sócio-comunicativos definidos por conteúdos, propriedades funcionais, estilo e composição características. Os gêneros são formas híbridas, ou seja, podem ser formados por um ou mais de um tipo textual. A característica fundamental do gênero é a sua capacidade de se moldar ao ciclo interminável de construção, reorganização e desconstrução das práticas sociais (MARCUSCHI, 2002).

Uma expressão utilizada por Marcuschi (2002) é o “domínio discursivo". Utilizado para a análise dos gêneros e tipos, a expressão designa uma esfera ou instância de produção 
discursiva ou de atividade humana. Tais domínios não são textos nem discursos, mas favorecem a criação de discursos especializados, como por exemplo, o de teoria musical.

Travaglia (2007) utiliza uma classificação textual em que cita três elementos: tipo, gênero e espécie. O tipo se refere a uma forma de interação, de interlocução, que varia de acordo com perspectivas e critérios. Os tipos citados pelo autor adaptam-se a um contexto jurídico, mas podem ser utilizados em diversos contextos: descrição, narração, dissertação, injunção; texto argumentativo "stricto sensu"; preditivo. Quanto ao gênero, ele exerce uma função sócio-comunicativa específica. E a espécie é caracterizada por aspectos formais de estrutura ou por aspectos de conteúdo. $\mathrm{O}$ autor ressalta que os três elementos estão interligados.

Apresentamos um resumo dos tipos propostos por Travaglia (2007), relacionando-os com suas funções sócio-comunicativas e predominância deles em certos gêneros:

\begin{tabular}{|c|c|c|}
\hline Tipo & Função & $\begin{array}{l}\text { Gêneros textuais em que o tipo } \\
\text { predomina }\end{array}$ \\
\hline Descritivo & caracterizar um objeto & Qualificação, classificados. \\
\hline Dissertativo & $\begin{array}{l}\text { buscar a reflexão, explicação, } \\
\text { avaliação, } \quad \text { conceituação, } \\
\text { exposição de ideias, análise. }\end{array}$ & $\begin{array}{l}\text { Tese, dissertação de mestrado, } \\
\text { acadêmico-científico, editorial de } \\
\text { monografia, conferência. }\end{array}$ \\
\hline Injuntivo & instruir como fazer algo & $\begin{array}{l}\text { Mensagem religiosa-doutrinária, instruções, } \\
\text { manuais de uso e/ou montagem de aparelhos, } \\
\text { receitas culinárias e médicas, preces etc. }\end{array}$ \\
\hline Narrativo & $\begin{array}{l}\text { contar fatos, acontecimentos, } \\
\text { entendidos como episódios ou a } \\
\text { ocorrência de uma ação. }\end{array}$ & $\begin{array}{l}\text { Atas, notícias, peças de teatro, romances, } \\
\text { novelas, contos, fábulas, mitos, lendas etc. }\end{array}$ \\
\hline $\begin{array}{l}\text { Argumentativo } \\
\text { Stricto sensu }\end{array}$ & $\begin{array}{llll}\text { convencer } & \text { e } & \text { persuadir } & 0 \\
\text { alocutário } & & & \\
& & & \\
\end{array}$ & Editorial de jornal, sermão. \\
\hline Preditivo & $\begin{array}{l}\text { antecipar a ocorrência } \mathrm{de} \\
\text { situações por alguma razão. }\end{array}$ & Boletim meteorológico, profecias. \\
\hline
\end{tabular}

Quadro 3 - Gêneros com predominância de um tipo textual - Travaglia (2007) 
No quadro acima, verifica-se que o estudo sobre tipologia e gênero de Travaglia abrange desde textos de conhecimentos gerais até os mais específicos. Para a nossa pesquisa interessam-nos os dos tipos: descritivo, dissertativo, injuntivo, argumentativo stricto sensu. Tais tipos são os mais encontrados em gêneros textuais específicos do nosso corpus de estudo.

Leibruder (2002) apud Costa (2011) aponta que os textos científicos se utilizam de estruturas textuais convencionais empregando, por exemplo: linguagem formal, concisa e objetiva; expressões e termos técnicos da área de domínio científico; impessoalidade, obtida pelo uso de verbos na terceira pessoa do singular seguidos do índice de indeterminação do sujeito (pronome "se").

$\mathrm{Na}$ nossa pesquisa, o foco são textos de conhecimento especializado da área de Harmonia. Os gêneros que fazem parte do corpus são de área técnico-científica e estão subdivididos em: artigos científicos, teses, dissertações de mestrado, livros-texto e apostilas. Optamos por agrupá-los de acordo com a função e o público alvo, que são determinantes para a escolha da linguagem a ser utilizada.

A categoria que engloba as apostilas e livros-texto foi denominada "subcorpus Instrucional". São textos voltados para um público iniciado (estudantes que já possuem conhecimentos básicos em teoria musical), apresentam definições, conceitos e exemplos, utilizando uma linguagem próxima do leitor, apresentando-o à terminologia da área de forma gradativa. Nesses textos, a comunicação é realizada de especialistas para estudantes.

A categoria denominada de "subcorpus acadêmico-científico" é composta por artigos científicos, dissertações de mestrado e teses. São textos em que a comunicação é realizada entre especialistas e utilizam uma linguagem mais técnica, em que não há a preocupação de explicar conceitos básicos relacionados à terminologia, uma vez que é subentendido que os interlocutores já tenham o domínio de expressões convencionais da área (jargões). O foco da função comunicativa, nesses casos, é apresentar e compartilhar os resultados de um estudo científico (PAGANO et al, 2000). São trabalhos que contribuem para a ampliação de conhecimentos e compreensão de certos problemas, da mesma forma como podem servir de modelo para outros trabalhos (VIANA FILHO, 2006).

Seguindo a abordagem de Travaglia, elaboramos um quadro com as características principais dos textos de especialidade da área de Harmonia analisados: 


\begin{tabular}{|c|c|c|c|}
\hline Gênero & $\begin{array}{l}\text { Tipos } \\
\text { encontrados }\end{array}$ & Público-Alvo & Função Comunicativa \\
\hline Apostila & $\begin{array}{l}\text { Descrição } \\
\text { Injunção }\end{array}$ & Estudantes & $\begin{array}{ll}\checkmark & \text { Descrever a simbologia musical } \\
\checkmark & \text { Introduzir e explicar os termos e } \\
& \text { conceitos } \\
\checkmark & \text { Exemplificar } \\
\checkmark & \text { Instruir à prática musical } \\
\checkmark & \text { Prescrever regras } \\
\checkmark & \text { Defender uma ou mais abordagens } \\
& \text { teóricas (Implícito no objetivo da } \\
& \text { obra) }\end{array}$ \\
\hline Livro-texto & $\begin{array}{l}\text { Descrição } \\
\text { Injunção }\end{array}$ & Estudantes & $\begin{array}{ll}\checkmark & \text { Descrever a simbologia musical } \\
\checkmark & \text { Introduzir e explicar os termos e } \\
& \text { conceitos } \\
\checkmark & \text { Exemplificar } \\
\checkmark & \text { Prescrever regras } \\
\checkmark & \text { Instruir à prática musical } \\
\checkmark & \text { Defender uma ou mais abordagens } \\
& \text { teóricas }\end{array}$ \\
\hline $\begin{array}{l}\text { Artigos } \\
\text { científicos }\end{array}$ & $\begin{array}{l}\text { Exposição } \\
\text { Argumentação }\end{array}$ & $\begin{array}{l}\text { Especialistas- } \\
\text { Pesquisadores }\end{array}$ & $\begin{array}{ll}\checkmark & \text { Descrever uma situação problema } \\
\checkmark & \text { Apresentar aspectos e informações } \\
& \text { pertinentes ao tema; } \\
\checkmark & \text { Explicar conceitos relevantes; } \\
\checkmark & \text { Defender ou questionar uma ou } \\
& \text { mais abordagens teóricas de forma } \\
& \text { explícita } \\
\checkmark & \text { Comunicar os resultados parciais } \\
& \text { da pesquisa }\end{array}$ \\
\hline Dissertações & $\begin{array}{l}\text { Exposição } \\
\text { Argumentação }\end{array}$ & $\begin{array}{l}\text { Especialistas- } \\
\text { Pesquisadores }\end{array}$ & $\begin{array}{ll}\checkmark & \text { Descrever uma situação problema } \\
\checkmark & \text { Explicar conceitos e exemplificar } \\
\checkmark & \text { Defender ou questionar uma ou }\end{array}$ \\
\hline
\end{tabular}




\begin{tabular}{|c|c|c|c|}
\hline & & & $\begin{aligned} & \text { mais abordagens teóricas de forma } \\
& \text { explícita } \\
\checkmark & \text { Discutir, interpretar e analisar o } \\
& \text { material de pesquisa. } \\
\checkmark & \text { Propor soluções } \\
\checkmark & \text { Comunicar os resultados da } \\
& \text { pesquisa (metas alcançadas). }\end{aligned}$ \\
\hline Teses & $\begin{array}{l}\text { Exposição } \\
\text { Argumentação }\end{array}$ & $\begin{array}{l}\text { Especialistas- } \\
\text { Pesquisadores }\end{array}$ & $\begin{array}{ll}\checkmark & \text { Descrever uma situação problema } \\
\checkmark & \text { Explicar conceitos e exemplificar } \\
\checkmark & \text { Defender ou questionar uma ou } \\
& \text { mais abordagens teóricas de forma } \\
& \text { explícita } \\
\checkmark & \text { Discutir, interpretar e analisar o } \\
& \text { material de pesquisa. } \\
\checkmark & \text { Propor soluções inéditas ou } \\
& \text { originais } \\
\checkmark & \text { Comunicar os resultados da } \\
\text { pesquisa (metas alcançadas). }\end{array}$ \\
\hline
\end{tabular}

Quadro 4 - Tipos textuais encontrados nos gêneros textuais do corpus de estudo

O Quadro 4 apresenta as características principais verificadas nos gêneros textuais do corpus de estudo. Percebemos uma diferença em relação à denominação para tese e dissertação. No Brasil, a dissertação é um gênero textual escolhido para o trabalho de conclusão de mestrado, enquanto que a tese para o doutorado. Nos EUA, Dissertation é um gênero utilizado para o trabalho de conclusão de doutorado $(\mathrm{PhD})$, enquanto que thesis é para o mestrado.

Um dos aspectos relevantes dos textos especializados é o uso de referências a outros textos, bem como de citações. Esse diálogo entre o texto consultado e o texto reconstruído é chamado de intertextualidade (KRISTEVA, 1974). Os textos de referência ou de apoio são chamados intertextos.

Koch (2000) aponta vários tipos de intertextualidade, sendo os mais comuns: 
a) De conteúdo: textos científicos de uma mesma área ou corrente do conhecimento tendem a reportar-se a conceitos e expressões comuns, mencionados anteriormente em outros textos do mesma área;

b) Explícita ou implícita: A intertextualidade explícita ocorre se há citação da fonte do intertexto, como no discurso relatado, nas citações e referências; nos resumos, resenhas e traduções; nas retomadas do texto do parceiro para encadear sobre ele ou questioná-lo, na conversação. É bem utilizado em textos acadêmicos, como um dos principais recursos utilizados para validar a argumentação. Na intertextualidade implícita, não se revela a fonte, sendo o sentido do texto recuperado pela memória do interlocutor.

c) Semelhanças ou diferenças: Na intertextualidade das semelhanças, o texto concorda com o intertexto; e na intertextualidade das diferenças, o texto discorda do intertexto.

Em outras palavras, é a partir da leitura de outros textos de apoio que se dá o processo de produção dos gêneros textuais técnico-científicos. A intertextualidade, no âmbito técnico científico, é um dos fatores que favorece a cristalização de expressões convencionais da área. As referências e citações, por exemplo, são mecanismos de propagação do uso de certas expressões e blocos de palavras na área de especialidade. A consagração de termos pode ser constatada a partir da frequência do uso e reuso de tais estruturas por diferentes interlocutores.

Em relação aos textos produzidos no campo da Harmonia, especificamente àqueles que fazem parte do nosso corpus de estudo, além da intertextualidade entre textos do mesmo idioma, muitas das referências bibliográficas e citações contidas nos textos dos subcorpora reportam-se a textos estrangeiros (a partir de originais e de traduções).

Nesse sentido, dois procedimentos bilíngues merecem destaque:

1) O texto final faz menção a um intertexto escrito em língua estrangeira: Uma boa parte das citações e referências provém de textos escritos em idiomas estrangeiros, tais como alemão, inglês, espanhol, italiano e francês, por exemplo. Em outras palavras, houve um processo bilíngue de leitura e interpretação dos textos fonte antes da produção do texto final.

2) O texto final faz menção a um intertexto traduzido: Da mesma forma, também são consultadas obras em português, oriundas de traduções do alemão, inglês, 
italiano e francês, por exemplo. Nesse caso, a tradução foi o intertexto utilizado para interpretação dos conceitos, ou seja, de forma intermediária, as escolhas do tradutor do intertexto traduzido têm influência na produção do texto final.

Os dois tipos de procedimentos bilíngues contribuem para a manutenção e recriação de terminologia musical. Isso é fácil de constatar, ao folhearmos um dicionário de termos musicais. Vários termos que constam nas entradas são oriundos de outros idiomas. De certa forma, antes de eles adquirirem o estatuto de termo, eles passam por uma cadeia de uso e reuso, caracterizada pelo processo de intertextualidade, até se tornarem convencionais, ou seja, para fazer parte da terminologia, os termos têm de ser adotados e reutilizados nos discursos de vários membros de uma dada comunidade científica.

Para exemplificar com dados do nosso corpus de estudo, utilizamos o software Wordsmith Tools (que será descrito no capítulo sobre Materiais e Métodos) para sondar a ocorrência da intertextualidade nos textos do corpus. Um forte indício de intertextualidade é a frequência de sobrenomes de autores/compositores na lista de palavras e a quantidade de textos em que eles são citados/referenciados. A partir de dados estatísticos obtidos pelo software mencionado, selecionamos dois autores/compositores, cujos nomes apresentam frequência relevante nos dois subcorpora: Schoenberg e Riemann.

\begin{tabular}{|l|l|c|c|c|c|}
\hline Autor/Compositor & \multirow{2}{*}{ Nacionalidade } & \multicolumn{2}{|l|}{ Subcorpus de inglês } & \multicolumn{2}{|l|}{ Subcorpus de português } \\
\cline { 3 - 6 } & & Frequência & $\mathbf{N}^{\mathbf{0}}$ Textos & Frequência & $\mathbf{N}^{\mathbf{0}}$ Textos \\
\hline SCHOENBERG & $\begin{array}{l}\text { Áustria } \\
(\mathbf{1 8 7 4 - 1 9 5 1 )}\end{array}$ & 263 & 18 & 934 & 28 \\
\hline RIEMANN & $\begin{array}{l}\text { Alemanha (1849- } \\
\text { 1919) }\end{array}$ & 796 & 8 & 372 & 23 \\
\hline
\end{tabular}

Quadro 5 - A intertextualidade analisada pelo número de frequência no corpus de estudo

O levantamento, apresentado no quadro 5, mostra que Schoenberg (Arnold Schoenberg, 1874-1951), autor e compositor austríaco, é citado em 18 textos do corpus de Inglês e 28 textos de Português. Na área de Harmonia, obras teóricas do autor são consagradas. No subcorpus de Língua Portuguesa, as traduções das obras do autor são utilizadas como intertextos, assim como as obras escritas em Alemão e Inglês. No subcorpus Inglês, recorrem-se às obras em alemão e inglês.

Já Riemann (Karl Wilhelm Julius Hugo Riemann, 1849-1919), idealizador da Harmonia Funcional, é citado em 23 textos de Português e 8 em Inglês. 
Em uma análise mais detalhada dos subcorpora de Língua Portuguesa e Língua Inglesa, verificamos que há menção de obras do autor, traduzidas e originais. A tradução mais citada é a do alemão para o inglês.

Também constatamos que o número de textos que citam tais autores é bem maior no subcorpus de estudo de Português do que no de inglês.

A partir desses dados, observamos que, embora o corpus de estudo do nosso projeto seja constituído por textos escritos originalmente nas duas línguas (inglês e português), a influência de intertextos de fontes estrangeiras no corpus revela que há uma produção textual alimentada pela comunicação bilíngue (direta ou indireta) que contribui no processo de criação/adoção de termos utilizados nessa área de especialidade.

Somadas todas as características textuais mencionadas neste subitem, constatamos que as marcas culturais presentes nos textos de especialidade podem ser analisadas a partir dos tipos e gêneros textuais, da intertextualidade que ajuda a difundir novos termos e tornar convencionais outros e da comunicação advinda da interação social entre membros de uma área de especialidade.

\subsection{Colocações Especializadas e Estendidas}

As colocações são um dos objetos de estudo da Fraseologia, área que foca na descrição e análise das combinações fixas que apresentam significados individuais (CUNHA, 2012)

No estudo sobre as colocações, verificamos que não há uma definição que seja de consenso geral entre os teóricos da área de Fraseologia. Entretanto, um ponto de vista compartilhado é que elas são combinações lexicais coesas, recorrentes e arbitrárias, que não são expressões idiomáticas, mas que o significado de uma das partes é contextualmente restrito àquela combinação específica (HEYLEN; MAXWELL, 1994; TAGNIN, 2013; ORENHA-OTTAIANO, 2013, 2012).

O termo "colocação" (collocation, em Inglês) foi usado primeiramente por J. R. Firth em 1957 para se referir aos casos de co-ocorrência léxico-sintática, que são palavras que frequentemente aparecem juntas. Os elementos que compõem uma colocação são 
selecionados de forma idiossincrática, arbitrária e refletem características individuais de uma dada língua, dessa forma, é comum que grande parte das colocações em um idioma não seja construída da mesma forma que uma colocação correspondente em outro idioma (SELISTRE, 2010; CUNHA, 2012; TAGNIN, 2013).

Corpas Pastor (1996) defende que as colocações são criadas a partir de regras da própria fala e são definidas com base na fixação analítica e nas restrições semânticas e sintáticas, estabelecidas pelo uso.

Sinclair (1991) propõe dois princípios para a análise da língua: o princípio da livre escolha e o princípio idiomático. O primeiro segue o modelo de slot-and-filler, em que o texto é observado como uma série de lacunas, que podem ser preenchidas com palavras ou frases; o segundo, que complementa o primeiro, sustenta que o usuário da língua conta com um grande número de expressões pré-fabricadas, que são únicas e ajudam a produzir textos fluentes e naturais. Contudo, vale ressaltar que, em muitos casos, a união de tais blocos de palavras nem sempre pode ser explicada pela gramática, sendo tal união caracterizada pelo aspecto convencional de uso, que lhe confere um dado significado. Assim, o princípio idiomático torna-se claro quando se trata de colocações cuja ordem dos componentes pode alterar totalmente o sentido. Como exemplo, a colocação "grande homem" no contexto: Ele é um grande homem (ou seja, ele tem um bom coração) muda totalmente de significado se a ordem dos componentes for alterada para "homem grande".

Em termos de estrutura, uma colocação pode ser composta de duas partes na colocação: uma base e um colocado. A base é a palavra que determina a escolha do outro elemento coocorrente e o colocado, o constituinte determinado (HAUSMANN,1989; NAVARRO, 2010; COSTA, 2011). Hausmann agrupa as colocações de acordo com as estruturas sintáticas. Exemplos:

- Substantivo + adjetivo. Exemplo: água potável

- Substantivo + verbo. Exemplo: leite ferve

- Verbo + substantivo. Exemplo: sentir calor

- Verbo + advérbio. Exemplo: mentir descaradamente

- Advérbio + adjetivo. Exemplo: bem colocado

- Substantivo + preposição + substantivo. Exemplo: fermento em pó 
Tagnin (2013) também utiliza classes gramaticais, porém, apresenta a seguinte taxonomia:

- Colocação adjetiva: composta por adjetivo e substantivo. Exemplo: Brown sugar (açúcar mascavo);

- Colocação adverbial: composta por verbo e advérbio, ou advérbio e adjetivo. Exemplos: cry loudly (chorar copiosamente); absolutely right (absolutamente certo);

- Colocação nominal: composta por dois substantivos. Exemplo: ink knife (lâmina do tinteiro);

- Colocação verbal: composta por verbo e substantivo. Exemplo: pay attention.

Há algumas características apontadas por Tagnin (1989) que ajudam na identificação e delimitação do escopo das colocações:

1) Recorrência: a combinação tem de ter a frequência superior a 1 ;

2) Não-idiomaticidade: o significado da combinação é composicional, podendo ser deduzido do significado de cada um de seus componentes;

3) Coesão: ligação forte entre seus elementos;

4) Restrição contextual: probabilidade de ocorrência num contexto específico;

5) Coocorrência arbitrária entre seus elementos.

Já as colocações, em textos de especialidade, carregam um conteúdo próprio dentro de determinada área de conhecimento. Para distingui-las das colocações empregadas na língua geral, Orenha-Ottaiano (2004) tem utilizado em seus trabalhos o termo "colocações especializadas". A autora explica que, embora ambas sejam analisadas sob os mesmos critérios descritivos, a diferença entre elas é que a base das colocações da língua geral é uma unidade lexical que pertence à própria língua geral e a base das colocações especializadas é uma unidade terminológica pertencente a um domínio de conhecimento específico.

L'Homme (2000), ao se aprofundar no estudo das semelhanças e diferenças entre as colocações da língua geral e as colocações especializadas, aponta cinco aspectos:

1. natureza convencional das combinações: as relações entre os componentes de uma colocação são resultantes de um consenso na seleção dos elementos que compõem as colocações. Embora ambas compartilhem elementos gramaticais e parte do 
repertório léxico-semântico, as unidades lexicais de uma dada área de especialidade assumem conceitos próprios e que são distintos da língua geral. Por exemplo: a colocação "movimento contrário" adquire um significado próprio em Teoria Musical, referindo-se ao movimento melódico de duas partes (vozes) em direções opostas;

2. a composição das combinações: as da língua geral são constituídas por uma base e um colocado; as especializadas são compostas por uma base que é a unidade terminológica e por um co-ocorrente. Na realidade, o que muda é a terminologia, pois os componentes tem a mesma função. Exemplo: acorde maior $=>$ acorde é a unidade terminológica e maior, co-ocorrente;

3. a composicionalidade ou não-composicionalidade das combinações: nas colocações da língua geral, salvo exceções, o colocado é não-composicional, mas a base é e o seleciona. Nas colocações especializadas, a composicionalidade não demonstra ser um critério relevante para a pesquisa terminológica, mas sim o significado, que é resultante da relação entre a base e seus co-ocorrentes e não pode ser identificado por meio da definição geral da base. Como exemplo, podemos citar a palavra "intervalo". Ela adquire um significado específico para área de Teoria Musical, referindo-se à distância entre duas notas. Ex.: o intervalo de quinta justa.

4. o agrupamento de palavras-chave em diversas unidades lexicais: há uma tendência maior, na linguagem de especialidade, de um dado elemento combinar com várias unidades lexicais semanticamente relacionadas. Por exemplo, o termo "acorde" aparece em várias colocações: acorde maior, acorde menor, acorde diminuto etc; e

5. a generalização das relações semânticas entre os componentes: a autora defende que o número de categorias que descrevem as relações semânticas nas combinações lexicais especializadas geralmente é mais reduzido que o observado nas colocações de língua geral.

Em suma, para L'Homme as colocações da língua geral podem ser descritas em termos de coocorrência restrita e as colocações especializadas em termos de coocorrência lexical livre. Contudo, assim como Orenha-Ottaiano (2012; 2013), verificamos que, de um modo geral, há mais semelhanças do que diferenças na comparação entre tais colocações. A distinção mais significativa entre elas é que uma é utilizada na língua geral e a outra em 
domínio especializado; dessa forma, a unidade lexical de língua geral é a base das colocações de língua geral; enquanto que a unidade terminológica é a base das colocações especializadas.

As unidades terminológicas podem combinar tanto com um grupo pequeno de unidades terminológicas como com um de grande extensão. No corpus de estudo, há também a ocorrência de estruturas formadas pela combinação de várias palavras e, geralmente, são extensões das colocações especializadas. Nesse caso, tais combinações mais extensas serão tratadas como "colocações especializadas estendidas", expressão empregada por OrenhaOttaiano (2009) em seus trabalhos. Para exemplificar com exemplos do corpus de estudo, temos:

Colocação especializada: Common chord (Acorde comum)

Colocação especializada estendida: Common chord modulation (Modulação através de acorde comum)

Com base nas características apontadas para as colocações, utilizaremos os seguintes critérios para identificação:

- número de frequência e ocorrências em mais de um texto: a frequência aponta para o uso convencional na língua analisada, contudo é preciso analisar se as ocorrências estão distribuídas em mais de um texto ou em apenas um. Para que uma colocação seja qualificada como convencional precisa aparecer em mais de um texto. Se ela tem uma frequência alta num único texto, é necessário pesquisar fontes externas ao corpus de estudo para sondar se o uso do termo é convencional na área;

- análise das classes gramaticais que compõem as colocações;

- extensão: será considerado o intervalo de quatro palavras à esquerda do termo e quatro à direita para investigar a quantidade de palavras pertencentes à colocação;

- grau de fixação: nível de variação na composição. Composições fixas e semifixas serão analisadas;

- variantes terminológicas linguísticas lexicais serão analisadas sob o prisma da TCT; e 
- relações semânticas serão analisadas em conjunto com os critérios apontados pela TCT.

A partir dos critérios expostos, definiremos, no próximo subitem, as características que adotaremos para o glossário bilíngue.

\subsection{Glossário bilíngue de especialidade com contextos}

O produto resultante do presente estudo é um glossário bilíngue de colocações especializadas de Harmonia Musical, que vai além do propósito de um glossário que apenas apresenta termos correspondentes.

Verificamos que ainda não há um consenso terminológico que defina os tipos de obras lexicográficas da área de especialidade, tais como glossário, vocabulário e dicionário. Por conta disso, apresentamos o conceito proposto por Faulstich (1995), que é o que mais se aproxima da nossa proposta.

O glossário é descrito pela autora como um repertório que define termos de uma área científica ou técnica. Nele, os termos podem ser dispostos em ordem alfabética ou em ordem sistemática, seguidos de informação gramatical e do contexto de ocorrência. Como a obra trabalha com um repertório bilíngue, nela também devem constar os termos equivalentes na língua de chegada.

Nosso glossário tem como público alvo tradutores. Partindo do princípio de que os tradutores podem ser especialistas, os contextos de uso são mais relevantes do que as definições, principalmente nos casos em que se verificam variantes lexicais. Contudo, serão mencionados os contextos definitórios que foram encontrados no subcorpus, como excertos opcionais.

Em relação à macroestrutura do nosso glossário, as colocações especializadas serão organizadas em ordem alfabética e subdivididas em duas direções: Português-Inglês e InglêsPortuguês. A constituição da microestrutura do verbete é composta de: tradução do verbete, variantes lexicais ou denominativas (se houver), contexto definitório (se houver), contexto de 
uso, remissiva e notas explicativas (quando necessário). O modelo de verbete será apresentado no capítulo 6.

Salientamos que o nosso projeto não tem a pretensão de cobrir de forma exaustiva a terminologia da área, como seria o caso de um dicionário ou vocabulário técnico. Tampouco o de julgar ou estabelecer parâmetros do que é certo ou errado, já que nossa pesquisa é linguística, tem caráter descritivo, baseada na frequência de uso dos termos. Para esse fim, os termos, analisados in vivo, são extraídos de contextos reais de uso. Os materiais e métodos utilizados para esse estudo e compilação do glossário serão apresentados no capítulo seguinte. 


\section{CAPÍTULO 4 MATERIAIS E MÉTODOS}

Neste capítulo apresentaremos o corpus de estudo, a metodologia utilizada para a identificação e extração das colocações especializadas e os critérios adotados para análise de dados. A análise é quantitativa (apoiada na observação da frequência dos termos no corpus) e qualitativa (seguindo o critério da convencionalidade proposto por Tagnin (2013)).

\subsection{O Corpus de Estudo}

\subsubsection{Delimitação do tema do corpus}

O primeiro passo, antes da tarefa de pesquisar e coletar textos, foi definir qual seria a área temática dos corpora de português e inglês.

No início do mestrado, a ideia era compor um corpus de Teoria Musical. Numa pesquisa inicial, percebemos que os textos relacionados ao assunto eram em sua maioria do gênero instrucional (livros-textos e apostilas). De acordo com as recomendações de Almeida (2006), a compilação de um corpus que tenha por objetivo a construção de um glossário deve ser híbrida em relação aos gêneros. A autora aconselha que um corpus de especialidade médio, balanceado e diversificado pode ser muito mais representativo e oferecer uma amostra significativa de possibilidades comunicativas de determinado domínio. Aubert (2001) ressalta que a variação de gêneros textuais é a possibilidade de encontrar as definições dos termos no próprio corpus e compará-las nos dois idiomas, para assim legitimar ou não a relação de equivalência entre o termo da língua $\mathrm{A}$ e o termo da língua B.

Tendo em vista tais recomendações, resolvemos delimitar o tema para Harmonia, que possui uma quantidade maior de publicações nos gêneros instrucionais e acadêmicocientíficos. Entretanto, mesmo com a delimitação temática, verificamos que ainda era necessário redefinir as subáreas de estudo da Harmonia, os gêneros textuais a serem coletados, período de publicação dos textos, e especificar a localização geográfica dos idiomas a serem investigados. Depois de várias pesquisas, optamos por reunir textos sobre Harmonia Tradicional, Harmonia Funcional e Análise Harmônica aplicada às práticas da 
música popular (americana e brasileira). Como gêneros textuais escolhemos: livros-texto, apostilas, artigos científicos, dissertações de mestrado e teses de doutorado. Como a pesquisa é sincrônica, a maior parte dos textos foi publicada no decorrer dos últimos vinte anos, no Brasil e nos Estados Unidos.

De acordo com Câmara (2008), a disciplina Harmonia examina as notas musicais em suas diversas sobreposições, formando os acordes, e se aprofunda na pesquisa sobre a combinação desses acordes e a relação entre eles.

Como campo semântico, a Harmonia está subordinada à Teoria Musical, que, por sua vez, faz parte da área de especialidade da Música. Esta está alocada na grande área de conhecimento "Linguística, Letras e Artes", tendo como área de avaliação "Artes/Música" e subárea "Artes".

\subsubsection{Critérios de escolha dos textos}

Um dos critérios utilizados para a escolha dos textos foi o par linguístico e a área geográfica dos idiomas. Foram então selecionados textos escritos em Inglês Estadunidense e Português Brasileiro. Com exceção de alguns livros-texto de caráter instrucional, a maioria dos textos foi publicada nos últimos vinte anos.

O corpus se divide em dois subcorpora: Inglês e Português. Os textos estão subdivididos nas seguintes categorias: instrucionais (livros-texto, apostilas) e científicoacadêmicos (artigos científicos, dissertações e teses). Os materiais foram coletados de meio eletrônico e impresso, extraídos de sites de revistas especializadas, periódicos, congressos, conservatórios e faculdades de Música.

As escolhas dos gêneros textuais seguiram as recomendações de Almeida (2006) que aconselha o hibridismo de gêneros para localizar contextos definitórios da colocação (geralmente encontrado nos gêneros científicos de divulgação e instrucionais como apostila, livro-texto, manual etc) e contextos de uso dos termos entre especialistas (verificados em materiais do gênero acadêmico-científico como artigos científicos, teses, dissertações etc). Os excertos extraídos do subcorpus acadêmico-científico servem de exemplos para o glossário e são provas de como os termos e colocações são utilizados pela área em contextos reais. 
Optamos por trabalhar com um corpus comparável, escrito originalmente em Inglês e Português. Embora algumas traduções na área de Harmonia sejam consagradas e utilizadas em universidades, faculdades de música e conservatórios, além de contribuírem para a ampliação de termos novos, não incluímos textos traduzidos no corpus, pois o objetivo de nosso estudo é observar o uso convencional das colocações especializadas em textos publicados originalmente em Língua Portuguesa e Língua Inglesa; e assim buscar correspondentes que tenham o uso convencional entre especialistas falantes dos dois idiomas.

A figura 1 mostra como o corpus está organizado e subdividido.

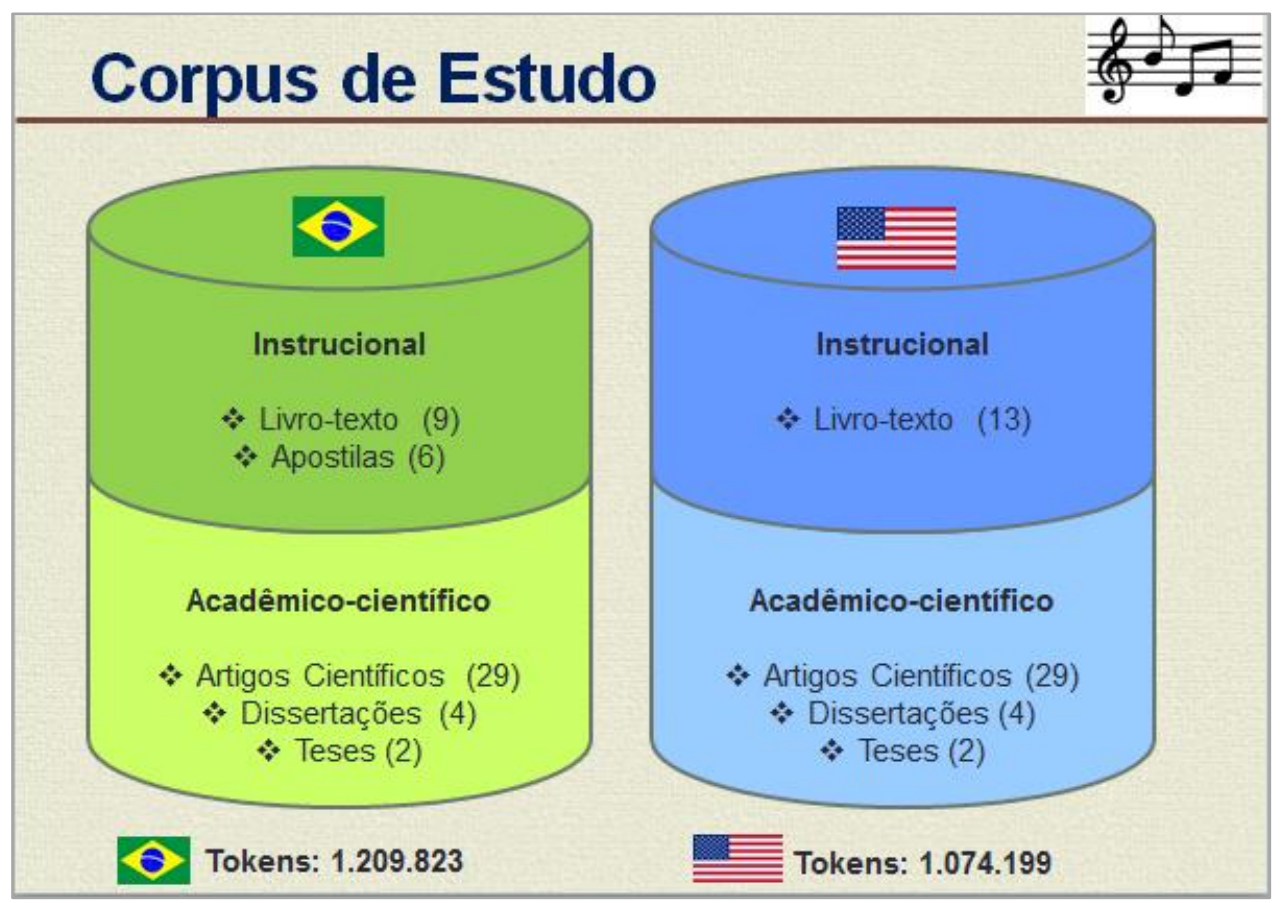

Figura 1 - Gêneros textuais e tamanho do corpus

Procuramos balancear o corpus pela quantidade total de palavras e, na medida do possível, pela quantidade de textos. Na fase de reavaliação de textos dos subcorpora "Instrucionais" havia mais apostilas em português do que em inglês. Em contrapartida, notamos que a quantidade de livros publicados em inglês era superior à quantidade encontrada em português. Então resolvemos tentar balancear a quantidade de tokens dos subcorpora Instrucionais, mas verificamos que em inglês (estadunidense) há uma tendência de os textos serem mais explicativos do que em português. Essa observação já foi realizada por Navarro (2013) que menciona a teoria antropológica de Edward Hall. De acordo com essa teoria, 
culturas que tendem a utilizar um volume maior de informações para que uma comunicação tenha sucesso é chamada low context culture, ao passo que a que utiliza um volume menor de informações é high context culture. O termo context se refere à quantidade de informação armazenada na mente do receptor da mensagem, ou seja, é a expectativa que se tem sobre o público-alvo do texto. Assim, a cultura brasileira seria high context e a estadunidense, low context. Notamos essa diferença ao compararmos as informações disponíveis entre dicionários de termos musicais. Em Inglês, as obras continham mais informações sobre os termos do que as em Português.

Dessa forma, o balanceamento dos corpora foi realizado pela quantidade total de palavras, buscando equilibrar a quantidade de textos do gênero acadêmico-científico, que são as fontes dos contextos de uso para o glossário. O não balanceamento dos textos do gênero instrucional não prejudicou a pesquisa.

No quadro 6, apresentamos os critérios para composição do corpus, de acordo com a tipologia proposta por Berber Sardinha (2004).

\begin{tabular}{|ll|}
\hline Idioma & Inglês - Português \\
Disposição Interna & Comparável \\
Modo & Escrito \\
Conteúdo & Instrucional / Acadêmico-científico \\
Tipo & Especializado \\
Seleção & Sincrônico \\
Uso na Pesquisa & Estática \\
\hline
\end{tabular}

Quadro 6 - Tipologia do corpus de estudo sobre Harmonia

Para serem armazenados em formato txt, os textos passaram por um processo de conversão. Na coleta, deparamos com textos impressos (livros) e textos em pdf. Os textos impressos foram digitalizados e, com a ajuda de um software de OCR, convertidos em txt. Entretanto, todos tiveram de ser revisados por conta de erros tipográficos na conversão. Alguns livros tiveram também de ser digitados. Os textos que compõem o subcorpus acadêmico-científico, coletados da Internet e em formato pdf, foram convertidos em txt. Como a análise é textual, figuras e tabelas foram eliminadas no processo de limpeza do 
corpus. Por questões de direitos autorais, livros-texto (do subcorpus instrucional) não foram digitados em sua totalidade, mantivemos o conteúdo que interessa para a pesquisa, que são as partes que detalham os diversos tipos de acordes.

Em relação ao armazenamento, os textos foram nomeados para facilitar a manipulação na ferramenta de análise lexical, separados por idioma em pastas e organizados por códigos. As siglas utilizadas nos códigos contêm as seguintes informações: identificação do idioma do corpus, gênero e sua numeração. Exemplos:

\section{- PORTMAPO01:}

O texto faz parte do subcorpus "Português" (POR), de Teoria Musical (TM), é uma apostila (APO) e, nessa categoria, tem número de identificação 01.

- INGTMLIV01:

O texto faz parte do subcorpus "Inglês" (INGL), de Teoria Musical (TM), é um livro (LIV) e, nessa categoria, tem número de identificação 01.

- INGTMART01:

O texto faz parte do subcorpus "Inglês" (ING), de Teoria Musical (TM), é uma artigo (ART) e, nessa categoria, tem número de identificação 01.

\section{- PORTMDM01:}

O texto faz parte do subcorpus "Português" (POR), de Teoria Musical (TM), é uma dissertação $(\mathrm{DM})$ e, nesta categoria, tem número de identificação 01 .

\section{- INGTMTE01}

O texto faz parte do subcorpus "Inglês" (ING), de Teoria Musical (TM), é uma tese (TE) e, nessa categoria, tem número de identificação 01.

\subsubsection{Composição do corpus Inglês}

O corpus de Inglês tem o tamanho total de 1.074.119 palavras (tokens). Ele é subdividido por gêneros textuais. O Subcorpus Instrucional contém 13 livros-texto, somando o total de 545.788 palavras. O subcorpus Acadêmico-Científico contém 29 artigos científicos, 4 dissertações de mestrado e 2 teses, somando o total de 528.331 palavras. 


\begin{tabular}{|c|c|c|c|}
\hline Código & Tipo & SUBCORPUS INSTRUCIONAL - INGLÊS & $\begin{array}{l}\text { Tamanho } \\
\text { (tokens) }\end{array}$ \\
\hline INGTMLIV01 & Livro-texto & $\begin{array}{l}\text { SCHMIDT-JONES, C. The Basic Elements of Music. Texas: Rice } \\
\text { University, } 2008 .\end{array}$ & 40.328 \\
\hline INGTMLIV02 & Livro-texto & $\begin{array}{l}\text { BENWARD, B.; SAKER, M. Music in Theory and Practice. USA: Mc } \\
\text { Graw-Hill, 2008. }\end{array}$ & 80.465 \\
\hline INGTMLIV03 & Livro-texto & $\begin{array}{l}\text { SCHMIDT-JONES, C. Understanding Basic Music Theory. Texas: } \\
\text { Rice University, } 2007 .\end{array}$ & 74.154 \\
\hline INGTMLIV04 & Livro-texto & $\begin{array}{l}\text { HEWITT, Michael. Music Theory for Computer Musicians. USA: } \\
\text { Cengage Learning, } 2008 \text {. }\end{array}$ & 62.281 \\
\hline INGTMLIV05 & Livro-texto & $\begin{array}{l}\text { FUENTES, David. Figuring out Melody. USA: Calvin University, } \\
2010 .\end{array}$ & 64.826 \\
\hline INGTMLIV06 & Livro-texto & $\begin{array}{l}\text { TAYLOR, Mary Su ; STOUFFER, Tere. Teach Yourself Visually } \\
\text { Piano. New Jersey: Wiley, } 2006 .\end{array}$ & 30.283 \\
\hline INGTMLIV07 & Livro-texto & SMITH, Stuart. Jazz Theory. USA: UMass Lowell, 2008 & 24.428 \\
\hline INGTMLIV08 & Livro-texto & $\begin{array}{l}\text { FEEZELL, Mark . Music Theory Fundamentals: High-Yield Music } \\
\text { Theory, Vol 01.USA: Mark Feezell } 2011 .\end{array}$ & 9.078 \\
\hline INGTMLIV09 & Livro-texto & $\begin{array}{l}\text { WYATT, Keith; SCHROEDER, Carl . Harmony and Theory. USA: } \\
\text { Hal Leonard Online, } 1998 .\end{array}$ & 6.495 \\
\hline INGTMLIV10 & Livro-texto & $\begin{array}{l}\text { KOPP, David. Chromatic Transformations in Nineteenth-century } \\
\text { music. USA: Cambridge, } 2002 .\end{array}$ & 122.710 \\
\hline INGTMLIV11 & Livro-texto & PISTON, Walter. Harmony. USA: W. W. Norton \& Company, 1987. & 14.317 \\
\hline INGTMLIV12 & Livro-texto & $\begin{array}{l}\text { KOSTKA, S; PAYNE, D.;ALMÉN, B. Tonal Harmony: with an } \\
\text { introduction to twentieth -century music. New York: McGraw Hill, } \\
2013 \text {. }\end{array}$ & 8.061 \\
\hline INGTMLIV13 & Livro-texto & $\begin{array}{l}\text { LAITZ, S. G.The complete musician: An integrated approach to tonal } \\
\text { theory, analysis, and listening. New York: OUP, } 2008 .\end{array}$ & 8.362 \\
\hline Código & Tipo & SUBCORPUS ACADÊMICO-CIENTÍFICO - INGLÊS & $\begin{array}{c}\text { Tamanho } \\
\text { (tokens) }\end{array}$ \\
\hline INGTMART01 & $\begin{array}{c}\text { Artigo } \\
\text { Científico }\end{array}$ & $\begin{array}{l}\text { TAUBE, H; BURNSON. W.A. Software for teaching Music Theory. } \\
\text { USA: University of Illinois at Champaign-Urbana, } 2009 .\end{array}$ & 2.630 \\
\hline INGTMART02 & $\begin{array}{c}\text { Artigo } \\
\text { Científico }\end{array}$ & $\begin{array}{l}\text { TEMPERLEY, David. Composition perception and schenkerian } \\
\text { Theory. Music Theory Spectrum, v.33, n 2, pp. 146-168, } 2011 .\end{array}$ & 18.133 \\
\hline INGTMART03 & $\begin{array}{c}\text { Artigo } \\
\text { Científico }\end{array}$ & $\begin{array}{l}\text { JOHNSTON, B. Modal Idioms and Their Rhetorical Associations in } \\
\text { Rachmaninoff's Works. Music Theory Online, v. 20, n. 4, dezembro } \\
\text { 2014. }\end{array}$ & 13.036 \\
\hline INGTMART04 & $\begin{array}{c}\text { Artigo } \\
\text { Científico }\end{array}$ & $\begin{array}{l}\text { CLEMENT, Brett G. Scale systems and large-scale form in the music } \\
\text { of yes. Music Theory Online, v. 21, n.1, Mar } 2015 .\end{array}$ & 12.122 \\
\hline INGTMART05 & $\begin{array}{c}\text { Artigo } \\
\text { Científico }\end{array}$ & $\begin{array}{l}\text { HORN, K; HURON, D. On the changing use of the major and minor } \\
\text { modes } 1750-1900 . \text { Music Theory Online, V. 21, N. 1, Mar } 2015\end{array}$ & 6.935 \\
\hline INGTMART06 & $\begin{array}{c}\text { Artigo } \\
\text { Científico }\end{array}$ & $\begin{array}{l}\text { STRAUS, J. Total voice leading. Music Theory Online, V. 20, N. 2, } \\
\text { jun } 2014 .\end{array}$ & 7.403 \\
\hline INGTMART07 & $\begin{array}{c}\text { Artigo } \\
\text { Científico }\end{array}$ & $\begin{array}{l}\text { LEHMAN, F. Hollywood cadences - music and the structure of } \\
\text { cinematic expectation. Music Theory Online, V. 19, N. 4, dec, } 2013 .\end{array}$ & 18.827 \\
\hline INGTMART08 & $\begin{array}{c}\text { Artigo } \\
\text { Científico } \\
\end{array}$ & $\begin{array}{l}\text { LOVE, S. C. Possible Paths - Schemata of Phrasing and Melody in } \\
\text { Charlie Parker's Blues. Music Theory Online, v. 18, n. 3, sep, } 2012 .\end{array}$ & 9.338 \\
\hline INGTMART09 & $\begin{array}{c}\text { Artigo } \\
\text { Científico }\end{array}$ & $\begin{array}{l}\text { BAROLSKY, D; MARTENS, P. Rendering the Prosaic Persuasive - } \\
\text { Gould and the Performance of Bach's C-minor Prelude (WTC1). Music } \\
\text { Theory Online, v. 18, n. 1, apr ,2012. }\end{array}$ & 4.524 \\
\hline INGTMART10 & $\begin{array}{c}\text { Artigo } \\
\text { Científico } \\
\end{array}$ & $\begin{array}{l}\text { NOBILE, D. F. Form and Voice Leading in Early Beatles Song. Music } \\
\text { Theory Online, v. } 17, \text { n. 3, oct, } 2011 .\end{array}$ & 7.780 \\
\hline INGTMART11 & $\begin{array}{c}\text { Artigo } \\
\text { Científico } \\
\end{array}$ & $\begin{array}{l}\text { HEETDERKS, D. J. A tonal revolution in Fifhts and Semitones - Aaro } \\
\text { Copland's: Quiet City. Music Theory Online, v. 17, n. 2, july } 2011 .\end{array}$ & 8.748 \\
\hline INGTMART12 & $\begin{array}{c}\text { Artigo } \\
\text { Científico }\end{array}$ & $\begin{array}{l}\text { TEMPERLEY, D. The Cadential IV in Rock. Music Theory Online , v. } \\
\text { 17, n. 1, apr } 2011 .\end{array}$ & 12.941 \\
\hline INGTMART13 & $\begin{array}{l}\text { Artigo } \\
\text { Científico }\end{array}$ & $\begin{array}{l}\text { STOIA, N. Mode, Harmony, and Dissonance Treatment in American } \\
\text { Folk and Popular Music, c. } 1920-1945 . \text { Music Theory Online, v. 16, } \\
\text { n. 3, Agosto } 2010 .\end{array}$ & 7.893 \\
\hline INGTMART14 & $\begin{array}{c}\text { Artigo } \\
\text { Científico }\end{array}$ & $\begin{array}{l}\text { BRASKY, J. T. Extraordinary Function and the Half-Diminished } \\
\text { Seventh in the song of the Wood Dove. Music Theory Online, v. 16, n. } \\
\text { 1, fevereiro } 2010 .\end{array}$ & 14.856 \\
\hline INGTMART15 & $\begin{array}{c}\text { Artigo } \\
\text { Científico }\end{array}$ & $\begin{array}{l}\text { MALAWEY, V. Harmonic Stasis and Oscillation in Björk's Medúlla. } \\
\text { Music Theory Online, v. 16, n. 1, janeiro } 2010 .\end{array}$ & 9.391 \\
\hline INGTMART16 & $\begin{array}{c}\text { Artigo } \\
\text { Científico }\end{array}$ & $\begin{array}{l}\text { BROWN, S. C. Axis tonality and submediant in the music of } \\
\text { Shostakovich. Music Theory Online, v. 15, n. 2, junho } 2009 .\end{array}$ & 6.167 \\
\hline
\end{tabular}




\begin{tabular}{|c|c|c|c|}
\hline INGTMART17 & $\begin{array}{c}\text { Artigo } \\
\text { Científico }\end{array}$ & $\begin{array}{l}\text { SAMAROTTO, F. "Plays of Opposing motion": Contra-structural } \\
\text { melodic impulses in voice-leading analysis. Music Theory Online, v. } \\
\text { 15, n. 2, junho } 2009 .\end{array}$ & 5.121 \\
\hline INGTMART18 & $\begin{array}{c}\text { Artigo } \\
\text { Científico }\end{array}$ & $\begin{array}{l}\text { BIAMONTE, N. Augmented-Sixth Chords vs Tritone Substitutes. } \\
\text { Music Theory Online, v. } 14, \text { n. } 2 \text {, junho } 2008 .\end{array}$ & 4.424 \\
\hline INGTMART19 & $\begin{array}{c}\text { Artigo } \\
\text { Científico }\end{array}$ & $\begin{array}{l}\text { TEREFENKO, D. Jazz Transformations of the ii7-V7-I Progression. } \\
\text { Current Research in Jazz, v. 1, } 2009 .\end{array}$ & 3.682 \\
\hline INGTMART20 & $\begin{array}{c}\text { Artigo } \\
\text { Científico }\end{array}$ & $\begin{array}{l}\text { ROHRMEIER, M. Towards a generative syntax of tonal harmony. } \\
\text { Journal of Mathematics and Music, v. 5, n.1, p. 35-53, março } 2011 .\end{array}$ & 6.476 \\
\hline INGTMART21 & $\begin{array}{c}\text { Artigo } \\
\text { Científico }\end{array}$ & $\begin{array}{l}\text { ROTHGEB, J. Re- Eytan Agmon on Functional Theory. Music Theory } \\
\text { Online, v.2, n. 1, janeiro } 1996 .\end{array}$ & 2.446 \\
\hline INGTMART22 & $\begin{array}{c}\text { Artigo } \\
\text { Científico }\end{array}$ & $\begin{array}{l}\text { YUST, J. Voice-Leading Transformation and Generative Theories of } \\
\text { Tonal Structure. Music Theory Online, v. 21, n. 4, dezembro } 2015 .\end{array}$ & 13.818 \\
\hline INGTMART23 & $\begin{array}{c}\text { Artigo } \\
\text { Científico }\end{array}$ & $\begin{array}{l}\text { HEETDERKS, D. J. Hipster Harmony - The Hybrid Syntax of Seventh } \\
\text { Chords in Post-Millennial Rock. Music Theory Online, v. 21, n. 2, } \\
\text { junho } 2015 .\end{array}$ & 9.144 \\
\hline INGTMART24 & $\begin{array}{l}\text { Artigo } \\
\text { Científico }\end{array}$ & $\begin{array}{l}\text { EVERETT, W. Making Sense of Rock's Tonal Systems. Society for } \\
\text { Music Theory. Volume 10, Number 4, December } 2004 .\end{array}$ & 11.661 \\
\hline INGTMART25 & $\begin{array}{c}\text { Artigo } \\
\text { Científico }\end{array}$ & $\begin{array}{l}\text { DOLL, C. Definitions of 'Chord' in the Teaching of } \\
\text { Tonal Harmony. Dutch Journal of Music Theory, Volume 18, Number } \\
2,2013 \text {. }\end{array}$ & 8.063 \\
\hline INGTMART26 & $\begin{array}{c}\text { Artigo } \\
\text { Científico }\end{array}$ & $\begin{array}{l}\text { DOLL, C. Transformation in Rock Harmony: an explanatory strategy. } \\
\text { USA: GAMUT, } 2009\end{array}$ & 7.851 \\
\hline INGTMART27 & $\begin{array}{c}\text { Artigo } \\
\text { Científico }\end{array}$ & $\begin{array}{l}\text { CRATTY, W. S. The Role of Vagrant Harmonies in Selected Lieder } \\
\text { by Wolf, Strauss and Schoenberg. A Journal of Compositional and } \\
\text { Theorical Research in Music. Vol. IV/2 (1988). }\end{array}$ & 4.092 \\
\hline INGTMART28 & $\begin{array}{l}\text { Artigo } \\
\text { Científico }\end{array}$ & $\begin{array}{l}\text { WILKERSON, D. S. Harmony Explained: Progress Towards A } \\
\text { Scientific Theory of Music. USA: Cornell University: } 2014\end{array}$ & 39.891 \\
\hline INGTMART29 & $\begin{array}{c}\text { Artigo } \\
\text { Científico }\end{array}$ & $\begin{array}{l}\text { PERRY, L. From Modality to Tonality: The Reformulation of } \\
\text { Harmony and Structure in Seventeenth-Century Music. USA: } \\
\text { University of Puget Sound, } 2011 .\end{array}$ & 11.124 \\
\hline INGTMDM01 & Dissertação & $\begin{array}{l}\text { PARTRIDGE, D. J. Harmony Form and voice leading in the mature } \\
\text { works of Antonin Dvorak. Dissertation (PhD in Music). The City } \\
\text { University of New York, New York, } 2012 .\end{array}$ & 89.063 \\
\hline INGTMDM02 & Dissertação & $\begin{array}{l}\text { LOVELL, J. An exploration of melody harmony and improvisation in } \\
\text { the Music of Stevie Wonder. Dissertation (PhD). School of Music and } \\
\text { Dance and Graduate School of the University of Oregon, Oregon, } \\
2012 \text {. }\end{array}$ & 51.772 \\
\hline INGTMDM03 & Dissertação & $\begin{array}{l}\text { KIM, S H. An Analytical study: applying Hindemith's tonal theory to } \\
\text { Niels Viggo Bentzon's third piano sonata, 0. 44. Dissertation (phD). } \\
\text { University of North Texas, Texas, 2009. }\end{array}$ & 10.278 \\
\hline INGTMDM04 & Dissertação & $\begin{array}{l}\text { ROGERS, M. A. Tonality and the extended common practice in the } \\
\text { music of Thad Jones. (phD). University of North Texas. Texas, } 2015 .\end{array}$ & 69.164 \\
\hline INGTMTE01 & Tese & $\begin{array}{l}\text { TACHOVSKY, T. Hugo Riemann's concept of tonality. Thesis } \\
\text { (Master in Arts) Department of Music of the University of North } \\
\text { Carolina at Chapel Hill, Chapel Hill, } 2007 .\end{array}$ & 8.062 \\
\hline INGTMTE02 & Tese & $\begin{array}{l}\text { BILLS, D. C. Harmony and structure in Richard Strauss's Macbeth . } \\
\text { Thesis (Master in Music). Graduate Council of the University of North } \\
\text { Texas, Texas, 1996. }\end{array}$ & 11.925 \\
\hline
\end{tabular}

Quadro 7 - Subcorpus de estudo - Inglês

\subsubsection{Composição do Corpus Português}

O corpus de Português tem o tamanho total de $\mathbf{1 . 2 0 9 . 8 2 3}$ palavras (tokens). Também é subdividido por gêneros textuais. O Subcorpus Instrucional contém 6 apostilas, 9 livros- 
textos, somando o total de 286.861 palavras. O subcorpus acadêmico-científico contém 29 artigos científicos, 4 dissertações de mestrado e 2 teses, somando o total de 922.962 palavras.

\begin{tabular}{|c|c|c|c|}
\hline Código & Tipo & SUBCORPUS INSTRUCIONAL - PORTUGUÊS & $\begin{array}{c}\text { Tamanho } \\
\text { (tokens) }\end{array}$ \\
\hline PORTMAPO01 & Apostila & $\begin{array}{l}\text { DUDEQUE, N. Harmonia Tonal I e II. São Paulo: Norton Dudeque, } \\
2003 .\end{array}$ & 21.315 \\
\hline PORTMAPO02 & Apostila & $\begin{array}{l}\text { LACERDA, H. Fundamentos de harmonia. Apostila para Disciplina } \\
\text { Fundamentos de Harmonia I da Escola de Música da Universidade } \\
\text { Federal de Minas Gerais, 2003. }\end{array}$ & 2.661 \\
\hline PORTMAPO03 & Apostila & ALVES, C.G. Curso Básico de Harmonia. São Paulo: ELAM, 2010. & 5.013 \\
\hline PORTMAPO04 & Apostila & $\begin{array}{l}\text { MELLO, M. Harmonia Avançada. I Festival de Música de Ourinhos. } \\
\text { Ourinhos, 2001. }\end{array}$ & 12.803 \\
\hline PORTMAPO05 & Apostila & GOMES, Alan. Harmonia I e II. Brasíla: Alan Gomes, 2013. & 117.320 \\
\hline PORTMAPO06 & Apostila & $\begin{array}{l}\text { PASCOAL, M.L; PASCOAL, A. Estrutura Tonal: Harmonia. São } \\
\text { Paulo: Instituto de Artes da UNICAMP, } 2000 .\end{array}$ & 17.856 \\
\hline PORTMLIV01 & Livro-texto & $\begin{array}{l}\text { LIMA, M. R. R. Harmonia- uma abordagem prática. São Paulo: Marisa } \\
\text { Ramires Rosa de Lima, } 2008 .\end{array}$ & 13.751 \\
\hline PORTMLIV02 & Livro-texto & MED, B. Teoria da Música. Brasília,DF: Musimed: 1996. & 25.873 \\
\hline PORTMLIV03 & Livro-texto & $\begin{array}{l}\text { PRIOLLI, M.L.M. Harmonia da Concepção Básica a Expressão } \\
\text { Contemporânea. } 10^{\mathrm{a}} \text { ed. Rio de Janeiro: Casa Oliveira de Música, } 2011\end{array}$ & 4.553 \\
\hline PORTMLIV04 & Livro-texto & $\begin{array}{l}\text { ALVES, L. Teoria Musical: Lições essenciais. São Paulo: Irmãos } \\
\text { Vitale, } 2004 .\end{array}$ & 23.177 \\
\hline PORTMLIV05 & Livro-texto & $\begin{array}{l}\text { FAGUNDES, M. D. Teoria da Música Vol } 1 \text { - São Paulo: Keyboard, } \\
2004 .\end{array}$ & 15.879 \\
\hline PORTMLIV06 & Livro-texto & $\begin{array}{l}\text { BRISOLLA, C. Princípios de Harmonia Funcional. 2ª Ed. São Paulo: } \\
\text { Annablume, } 2006 .\end{array}$ & 4.008 \\
\hline PORTMLIV07 & Livro-texto & $\begin{array}{l}\text { CHEDIAK, A. Harmonia e Improvisação. Vol 1. São Paulo: Irmãos } \\
\text { Vitale, } 2009 .\end{array}$ & 7.222 \\
\hline PORTMLIV08 & Livro-texto & SENNA, C. Curso de Harmonia. Rio de Janeiro: Caio Senna, 2002. & 2.285 \\
\hline PORTMLIV09 & Livro-texto & $\begin{array}{l}\text { ALMADA, C. Harmonia Funcional. São Paulo: Editora Unicamo, } \\
2012 .\end{array}$ & 8.259 \\
\hline Código & Tipo & SUBCORPUS ACADÊMICO-CIENTÍFICO - PORTUGUÊS & $\begin{array}{c}\text { Tamanho } \\
\text { (tokens) }\end{array}$ \\
\hline PORTMART01 & $\begin{array}{c}\text { Artigo } \\
\text { Científico }\end{array}$ & $\begin{array}{l}\text { FREITAS, S. P. R. Da harmonia pela harmonia - sobre formalismo e } \\
\text { seus impactos na ideia de harmonia funcional. Revista do } \\
\text { Conservatório de Música da UFPEL, Pelotas, n.5, p.1-35, } 2012 .\end{array}$ & 14.395 \\
\hline PORTMART02 & $\begin{array}{l}\text { Artigo } \\
\text { Científico }\end{array}$ & $\begin{array}{l}\text { REIS, J. T. A abordagem do conceito de harmonia tonal nos processos } \\
\text { de ensino e aprendizagem de acordeon fomentados por dois professores } \\
\text { atuantes na região metropolitana de Porto Alegre. ABEM, Londrina, v. } \\
19, \text { n. } 26 \text {, p. } 145-157,2011 \text {. }\end{array}$ & 6.436 \\
\hline PORTMART03 & $\begin{array}{c}\text { Artigo } \\
\text { Científico }\end{array}$ & $\begin{array}{l}\text { OLIVEIRA, J. Z; OLIVEIRA, M. Noção de tonalidade. In } \\
\text { MEDEIROS, B. R. (Org). Cognição Musical: aspectos } \\
\text { multidisciplinares. São Paulo: Paulistana, 2008. pp 42-45. }\end{array}$ & 1.544 \\
\hline PORTMART04 & $\begin{array}{l}\text { Artigo } \\
\text { Científico }\end{array}$ & $\begin{array}{l}\text { ARAUJO, F.; BOREM; A Harmonia tonal de Schoenberg: uma } \\
\text { proposta para a análise, realização e composição de lead sheets. Per } \\
\text { Musi, Belo Horizonte, n. 28, pp 35-69, 2013. }\end{array}$ & 18.062 \\
\hline PORTMART05 & $\begin{array}{l}\text { Artigo } \\
\text { Científico }\end{array}$ & $\begin{array}{l}\text { FIGUEIREDO, J. C. O acorde de sexta aumentada: interpretações } \\
\text { diferentes para o mesmo fenômeno sonoro. Thesis, São Paulo, ano IV, } \\
\text { n. } 17, \text { p. } 18-19,1^{\circ} \text { semestre } 2012 \text {. }\end{array}$ & 2.655 \\
\hline PORTMART06 & $\begin{array}{c}\text { Artigo } \\
\text { Científico }\end{array}$ & $\begin{array}{l}\text { WILDT, F. K. Condução melódica harmônica das dissonâncias na } \\
\text { Harmonia Prática Comum - Definindo parâmetros para uma análise } \\
\text { musical. I Encontro Internacional de Artes da FAP, pp73-83, } 2009 .\end{array}$ & 4.490 \\
\hline PORTMART07 & $\begin{array}{c}\text { Artigo } \\
\text { Científico }\end{array}$ & $\begin{array}{l}\text { ARAUJO, F; BOREM, F. Variação Progressiva de Schoenberg em } \\
\text { Hermeto Pascoal - análise e realização de duas lead sheets do } \\
\text { Calendário do som. Per Musi, Belo Horizonte, n. 28, p.70-95,julho- } \\
\text { dezembro 2003. }\end{array}$ & 10.098 \\
\hline PORTMART08 & $\begin{array}{c}\text { Artigo } \\
\text { Científico }\end{array}$ & $\begin{array}{l}\text { QUEIROZ, F. J. G. Canto gregoriano, modos eclesiásticos: o que } \\
\text { aprendemos com os nossos livros de teoria musical. Ictus-Periódico do } \\
\text { PPGMUS/UFBA, Vol.7,p. 113-136, 2006. }\end{array}$ & 7.858 \\
\hline PORTMART09 & Artigo & BITTENCOURT, M.A. O arcabouço de uma proposta de metodologia & 9.490 \\
\hline
\end{tabular}




\begin{tabular}{|c|c|c|c|}
\hline & Científico & $\begin{array}{l}\text { analítica para o tonalismo do século XIX - uma revisão taxonômica da } \\
\text { teoria da modulação. Música Hodie, Goiânia, v. 13, n.1, p. 134-154, } \\
2013 \text {. }\end{array}$ & \\
\hline PORTMART10 & $\begin{array}{l}\text { Artigo } \\
\text { Científico }\end{array}$ & $\begin{array}{l}\text { QUEIROZ, A.A. Uma notação musical para representação de } \\
\text { progressões harmônicas utilizando grafos. Música Hodie, v.9, n. 1, } \\
2009 \text {. }\end{array}$ & 5.998 \\
\hline PORTMART11 & $\begin{array}{l}\text { Artigo } \\
\text { Científico }\end{array}$ & $\begin{array}{l}\text { ALMEIDA, S. Um modelo de realização de baixo continuo - 2o } \\
\text { movimento da sonata em si menor BWV } 1030 \text { para flauta e cravo } \\
\text { obbligato de J.S. Bach. Música Hodie, v.6, n. 1, p.23-34, } 2006 .\end{array}$ & 3.287 \\
\hline PORTMART12 & $\begin{array}{c}\text { Artigo } \\
\text { Científico }\end{array}$ & $\begin{array}{l}\text { FAGERLANDE, M. Duas cadências para a sonata em Ré Maior para } \\
\text { flauta e cravo obbligato, WQ.83, de C.Ph.E. Bach. Música Hodie, v. } 8 \text {, } \\
\text { n.1, p. } 27-35,2008 \text {. }\end{array}$ & 1.194 \\
\hline PORTMART13 & $\begin{array}{c}\text { Artigo } \\
\text { Científico }\end{array}$ & $\begin{array}{l}\text { FARIA, A. G. Harmonia Funcional, arranjos e a velha condução de } \\
\text { vozes. Em Pauta, Porto Alegre, v. 18, n. 30, p. 81-94, } 2007 .\end{array}$ & 4.503 \\
\hline PORTMART14 & $\begin{array}{c}\text { Artigo } \\
\text { Científico }\end{array}$ & $\begin{array}{l}\text { WILDT, F. K. Primeira Lei Tonal - Função Harmônica nas óticas } \\
\text { funcional e tradicional - um breve estudo comparativo. InCantare, } \\
\text { Curitiba, v. 5, n. 2,p. 29-48, julho-dezembro } 2015 \text {. }\end{array}$ & 5.749 \\
\hline PORTMART15 & $\begin{array}{c}\text { Artigo } \\
\text { Científico }\end{array}$ & $\begin{array}{l}\text { MACHADO, E. L.; WILDT, F.K. Harmonia na Bossa Nova - Um } \\
\text { mapeamento da produção científica. Anais VI Forum de Pesquisa } \\
\text { Cientifica em Arte da Escola de Musica e Belas Artes do Parana. } \\
\text { Curitiba, 2008-2009. P. 2216-226. }\end{array}$ & 3.379 \\
\hline PORTMART16 & $\begin{array}{c}\text { Artigo } \\
\text { Científico }\end{array}$ & $\begin{array}{l}\text { TADDEI, R. C. A teoria de Hugo Riemann - Além da Harmonia } \\
\text { simplificada ou funções tonais dos acordes. Anais do SIMPOM, Rio de } \\
\text { Janeiro, n. 2, p. 1313-1320, } 2012 \text {. }\end{array}$ & 2.082 \\
\hline PORTMART17 & $\begin{array}{c}\text { Artigo } \\
\text { Científico }\end{array}$ & $\begin{array}{l}\text { COSTA, R.L.M. Apontamentos sobre o estudo da harmonia - por uma } \\
\text { abordagem abrangente. ANPPOM - } 15^{\circ} \text { Congresso, p. } 318-326,2005 .\end{array}$ & 2.722 \\
\hline PORTMART18 & $\begin{array}{c}\text { Artigo } \\
\text { Científico }\end{array}$ & $\begin{array}{l}\text { DUDEQUE, N. Schoenberg e a função tonal. Revista Eletrônica de } \\
\text { Musicologia, v. 2.1/Outubro de } 1997 .\end{array}$ & 9.367 \\
\hline PORTMART19 & $\begin{array}{l}\text { Artigo } \\
\text { Científico }\end{array}$ & $\begin{array}{l}\text { FARIA, L.C.F. Analise da proposta metodológica das disciplinas } \\
\text { Harmonia Musical do Curso Superior de Tecnologia em Produção } \\
\text { Fonográfica. TCC apresentado a Pró-Reitoria de Pesquisa e Pós- } \\
\text { Graduação da UNOESTE, }\end{array}$ & 2.619 \\
\hline PORTMART20 & $\begin{array}{l}\text { Artigo } \\
\text { Científico }\end{array}$ & $\begin{array}{l}\text { RAMIRES, M. A análise harmônica e suas questões recorrentes - o } \\
\text { legado de Rameau. IV Encontro de Pequisa em Música da } \\
\text { Universidade Estadual de Maringá, p. 1-8, Maringá, } 2009 .\end{array}$ & 2.870 \\
\hline PORTMART21 & $\begin{array}{c}\text { Artigo } \\
\text { Científico }\end{array}$ & $\begin{array}{l}\text { CASTELÕES, L.E. Propostas de Teoria Musical Comparada. Revista } \\
\text { Eletrônica de Musicologia, v. XIV, setembro de } 2010 .\end{array}$ & 4.463 \\
\hline PORTMART22 & $\begin{array}{l}\text { Artigo } \\
\text { Científico }\end{array}$ & $\begin{array}{l}\text { FREIRE, R. D; OLIVEIRA; H.M. O uso de acordes de empréstimo } \\
\text { modal (AEM) na música de Tom Jobim. ANPPOM, } 15^{\circ} \text { Congresso, } \\
2005 .\end{array}$ & 2.591 \\
\hline PORTMART23 & $\begin{array}{l}\text { Artigo } \\
\text { Científico }\end{array}$ & $\begin{array}{l}\text { BITTENCOURT, M. A. Apresentação de uma reforma simbológica } \\
\text { para a análise harmônica funcional do repertório tonal. XIX Congresso } \\
\text { da ANPPOM Curitiba, agosto e 2009, Departamento de Artes, UFPR. }\end{array}$ & 5.277 \\
\hline PORTMART24 & $\begin{array}{c}\text { Artigo } \\
\text { Científico } \\
\end{array}$ & $\begin{array}{l}\text { TINÉ, P.J.S. A harmonia no contexto da música popular: um paralelo } \\
\text { com a harmonia tradicional. Videtur, Letras 6, São Paulo, } 2002 .\end{array}$ & 3.578 \\
\hline PORTMART25 & $\begin{array}{c}\text { Artigo } \\
\text { Científico }\end{array}$ & $\begin{array}{l}\text { CHUEKE, Z. Fantasias Opus } 116 \text { de Johannes Brahms: análise para } \\
\text { intérpretes. Rio Grande do Sul: Em Pauta, V. } 20 \text { n. 34/35, } 2012\end{array}$ & 6.198 \\
\hline PORTMART26 & $\begin{array}{c}\text { Artigo } \\
\text { Científico } \\
\end{array}$ & $\begin{array}{l}\text { CORREA, A. F.; KERR, D. M. Função e refuncionalização. Em pausta, v. } \\
15, \text { n. } 25 \text {, julho a dezembro d3 } 2004 .\end{array}$ & 10.312 \\
\hline PORTMART27 & $\begin{array}{c}\text { Artigo } \\
\text { Científico } \\
\end{array}$ & $\begin{array}{l}\text { BATALHA, R.S. Composição e pesquisa de música tonal na } \\
\text { contemporaneidade. Anais do III SIMPOM, n.3, 2014, Rio de Janeiro }\end{array}$ & 3.597 \\
\hline PORTMART28 & $\begin{array}{l}\text { Artigo } \\
\text { Científico }\end{array}$ & $\begin{array}{l}\text { FREITAS, S.P.R. Memórias e histórias do acorde napolitano e de suas } \\
\text { funções em certas canções da música popular no Brasil. Revista do } \\
\text { Instituto de Estudos Brasileiros. N, 59, 2014. São Paulo }\end{array}$ & 8.246 \\
\hline PORTMART29 & $\begin{array}{c}\text { Artigo } \\
\text { Científico }\end{array}$ & $\begin{array}{l}\text { CARVALHO, A. O uso das tétrades na linguagem harmônica de Barry } \\
\text { Galbraith. }\end{array}$ & 2.122 \\
\hline PORTMDM01 & Dissertação & $\begin{array}{l}\text { KOENTOPP, M. Métodos de Ensino de Harmonia nos cursos de } \\
\text { graduação musical. Dissertação (Mestrado em Música), Música, } \\
\text { Universidade Federal do Paraná, Paraná, 2010. }\end{array}$ & 43.952 \\
\hline PORTMDM02 & Dissertação & $\begin{array}{l}\text { CAMINHA, A. O. MHITS - Um Sistema Tutor em Harmonia Musical. } \\
\text { Dissertação (Mestrado em Ciência da Computação), Ciência da } \\
\text { Computação, Universidade Federal da Paraíba, Paraíba, } 2000 .\end{array}$ & 27.102 \\
\hline PORTMDM03 & Dissertação & $\begin{array}{l}\text { BATISTA,A.C. Tétrades: um estudo de Harmonia aplicado à guitarra } \\
\text { elétrica. (Mestrado em Música), UNICAMP, Campinas, } 2006 .\end{array}$ & 24.068 \\
\hline PORTMDM04 & Dissertação & $\begin{array}{l}\text { PY, B. M.A. A Harmonia na música popular brasileira: reflexões sobre } \\
\text { a prática e a teoria da harmonia e seu desenvolvimento através da }\end{array}$ & 24.031 \\
\hline
\end{tabular}




\begin{tabular}{|l|c|l|c|}
\hline & & $\begin{array}{l}\text { canção no século XX. (Mestrado em Música),UNIRIO, Rio de Janeiro, } \\
\text { 2006. }\end{array}$ & \\
\hline PORTMTE01 & Tese & $\begin{array}{l}\text { CAMARA, F. A. Sobre Harmonia : uma proposta de perfil conceitual. } \\
\text { Tese (Doutorado em Educação), Faculdade de Educação de Minas } \\
\text { Gerais, Belo Horizonte, 2008. }\end{array}$ & 181.903 \\
\hline PORTMTE02 & Tese & $\begin{array}{l}\text { FREITAS, S. P.R. Que acorde ponho aqui - Harmonia, práticas teóricas } \\
\text { e o estudo de planos tonais em música popular . Tese (Doutorado em } \\
\text { Música), Música, Insituto de Artes da UNICAMP, Campinas, 2010. }\end{array}$ & 454.974 \\
\hline
\end{tabular}

Quadro 8 - Subcorpus de estudo - Português

Comparado ao subcorpus acadêmico-cientifico de inglês, o número total de tokens em português é bem maior; contudo, vale salientar esse número é influenciado pelos dois textos (do gênero tese) do subcorpus de Português, que são bem extensos. Se analisarmos a quantidade de tokens somando o total de tokens dos artigos científicos, em que há uma quantidade maior de amostras, teremos 288.517 tokens em inglês e 165.182 em português, evidenciando, neste gênero textual, a tendência de os textos em inglês serem mais extensos.

\subsection{Descrição da metodologia}

Para o levantamento de dados e seleção de candidatos a termos, escolhemos o programa de análise lexical Wordsmith Tools 6.0, doravante WST (SCOTT, 2015), do qual utilizaremos as seguintes ferramentas:

\subsubsection{Lista de palavras (Wordlist)}

É usada para investigar o tipo de vocabulário, a frequência total das palavras no corpus, o total de ocorrências de uma dada palavra em um em um conjunto de textos ou entre gêneros textuais etc.

Observa-se que, geralmente, as palavras gramaticais (artigos, preposições, conjunções e pronomes) são as que têm maior frequência num corpus e estão entre as primeiras da lista de palavras (SCOTT, 2015), conforme podemos verificar nas figuras 2 e 3. 


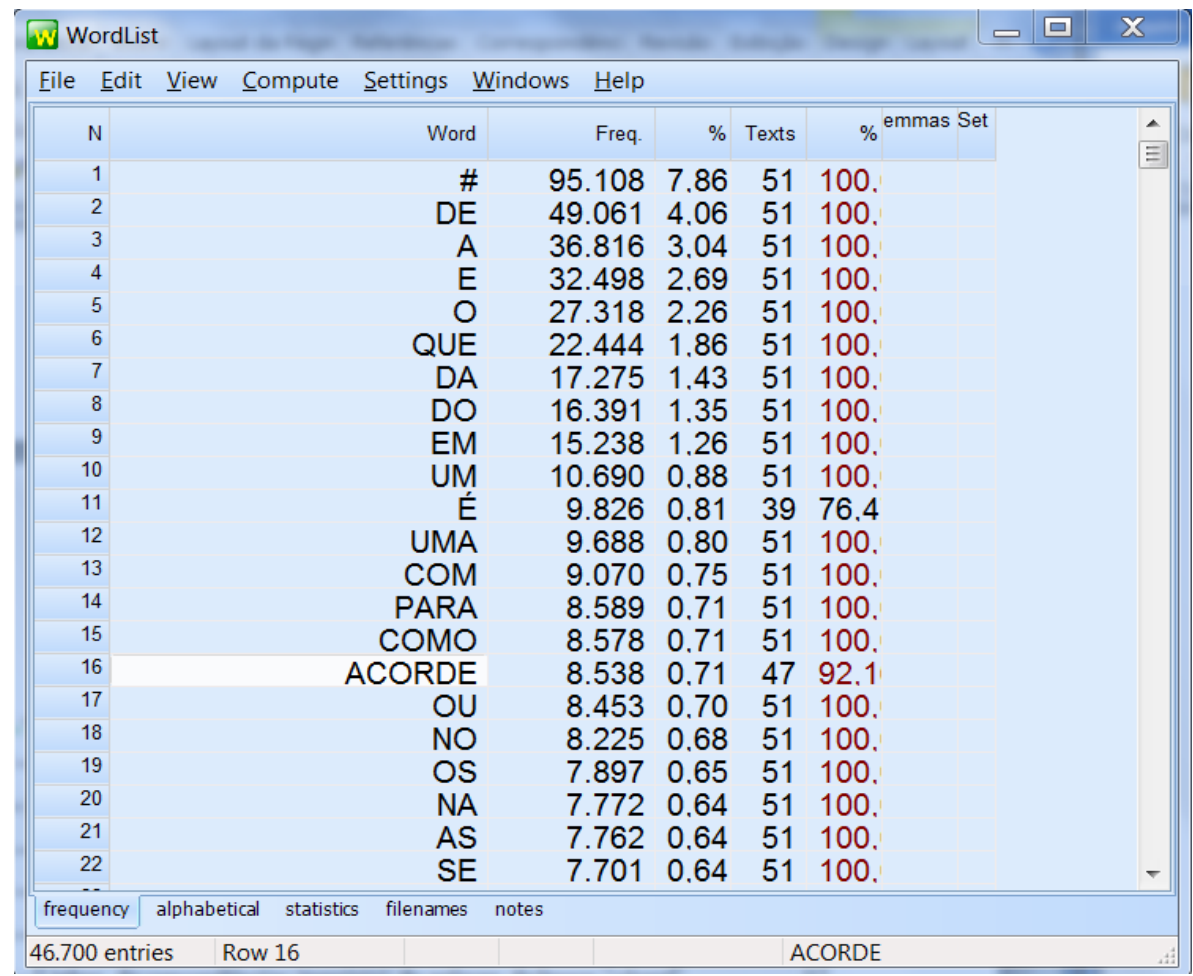

Figura 2 - Lista de palavras (parcial) do subcorpus de português

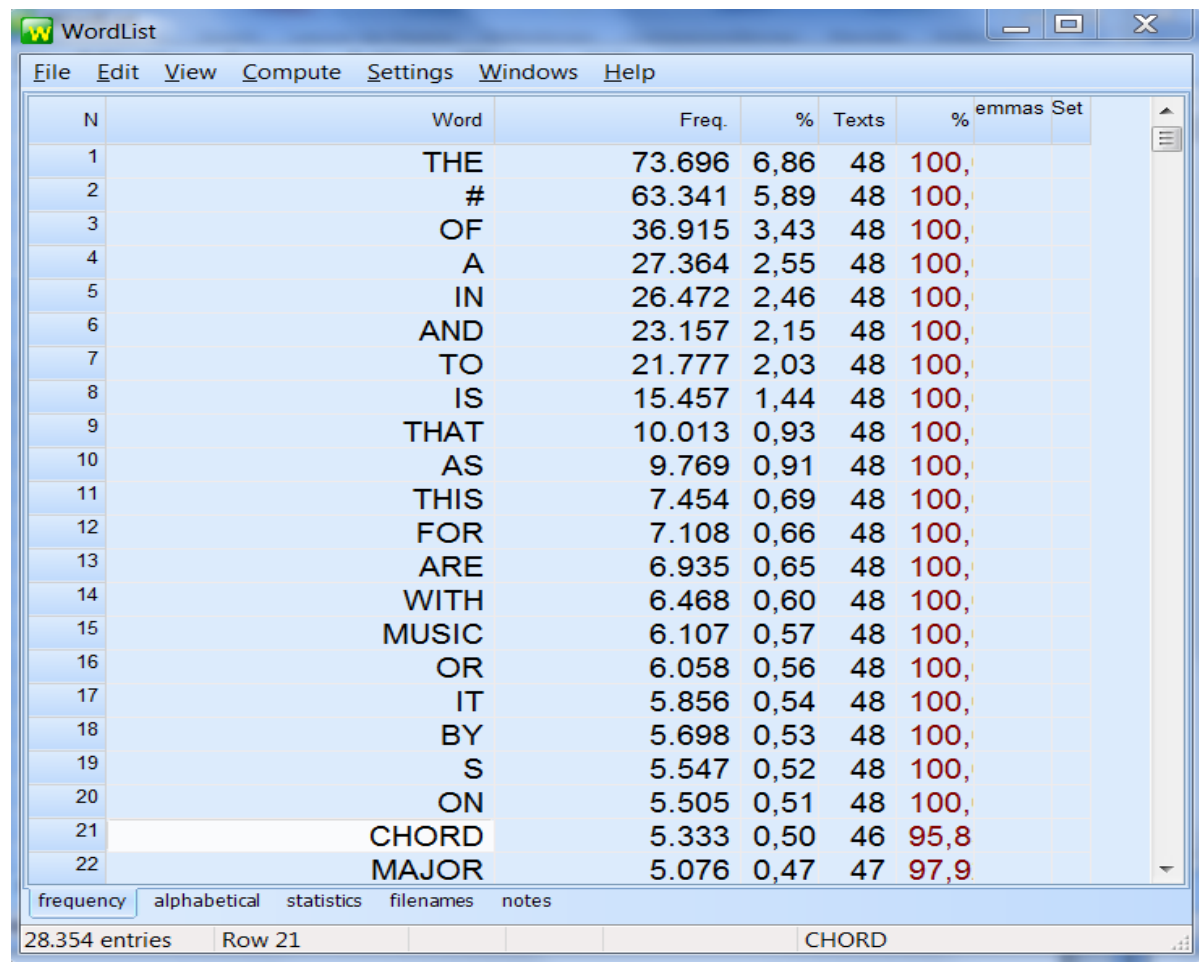

Figura 3 - Lista de palavras (parcial) do subcorpus de inglês 
As palavras de busca na forma singular (sem o processo de lematização) aparecem nas posições 14 (acorde) e 21 (chord). Em Português, o termo tem a frequência de 8.538 ocorrências e o correspondente em Inglês 5.333.

Podemos notar uma diferença entre o número de tipos de palavras (types) entre os dois subcorpora: português apresenta 46.700 e inglês, 28.354. Isso indica que, nos textos do corpus, o uso do repertório de palavras é mais diversificado em português do que em inglês.

\subsubsection{Lista de palavras-chave (Keywords)}

A lista de palavras-chave apresenta palavras cuja frequência é elevada num dado corpus em comparação com outras consideradas comuns num corpus de língua geral. Uma lista de palavras-chave é gerada a partir da comparação entre duas listas de palavras, sendo: uma do corpus de estudo e a outra do corpus de referência.

Corpus de referência é um corpus que serve de comparação ao corpus de estudo. Seguimos a orientação de Berber-Sardinha (2004) que aconselha a escolha de corpora de referência geral, os quais incluem vários gêneros textuais, como é o caso do Lacio-Web em Português e o COCA (Corpus of Contemporary American English) em Inglês, selecionados para esta pesquisa. Nesse processo, uma lista de frequência de palavras do corpus de referência será comparada com a do corpus de estudo, por meio de uma prova estatística selecionada pelo usuário. De acordo com o resultado dessa prova, uma nova lista de palavras, considerada lista de palavras-chave, é revelada, sendo eliminadas as palavras com frequência similar nos dois corpora. Essa lista de palavras-chave indica quais palavras tendem a aparecer com maior frequência em textos similares sobre o mesmo tema.

De acordo com Tagnin (2013), recomenda-se que o corpus de referência tenha de três a cinco vezes o tamanho do corpus de estudo.

Nas figuras 4 e 5, apresentamos uma lista parcial das palavras-chave obtidas a partir da comparação entre os corpora de referência citados e os de estudo. 


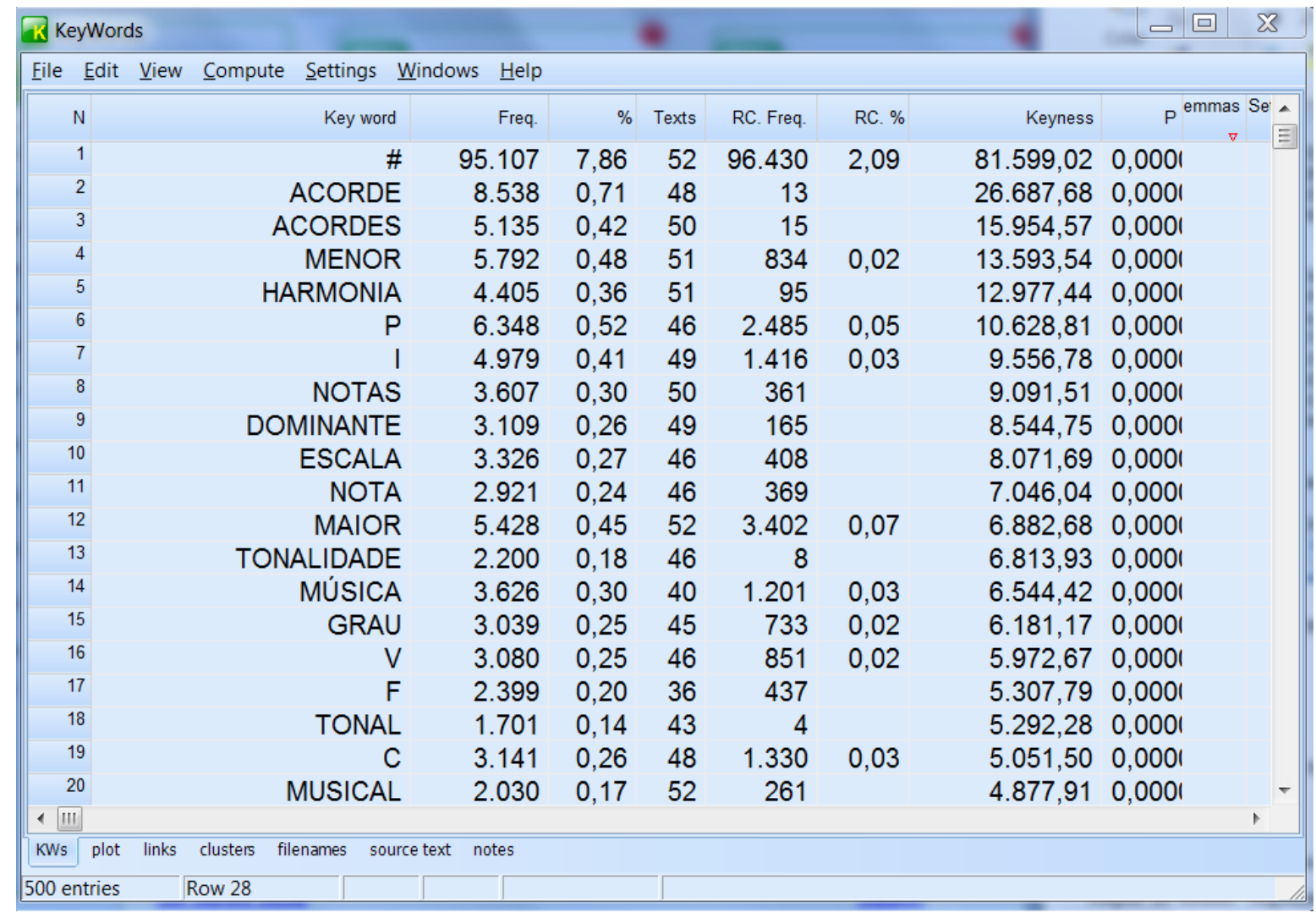

Figura 4- Lista de palavras-chave (parcial) do subcorpus de português

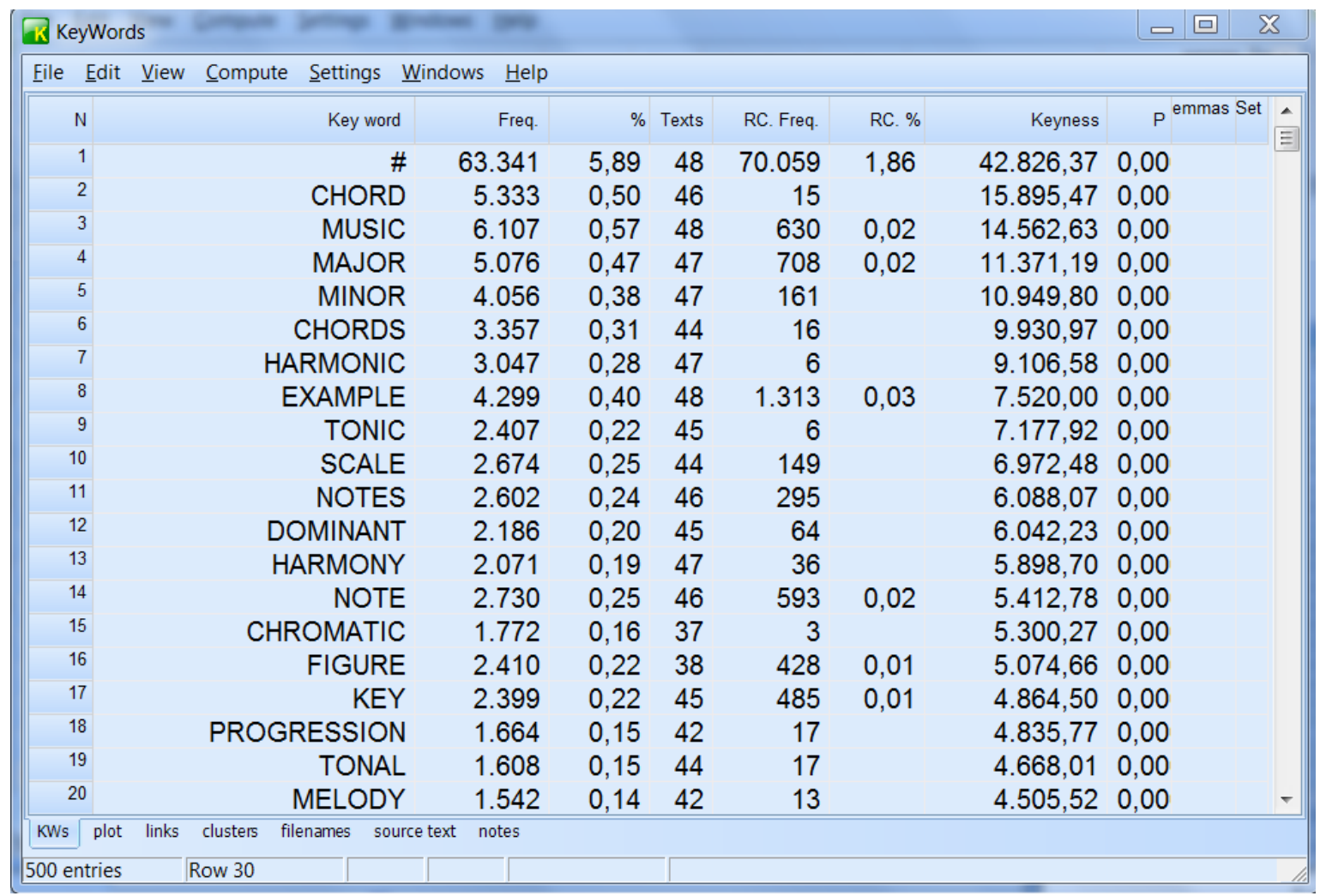

Figura 5 - Lista de palavras-chave (parcial) do subcorpus de inglês 
Observando a lista de palavras-chave, já é possível deduzir o teor temático do corpus de estudo. Algumas palavras que aparecem nas listas da figura 4 e 5, tais como: acorde, menor, maior, dominante, tonalidade, grau, tonal, harmonia, chord(s), major, minor, harmonic, tonic, scale, dominant, harmony, chromatic, key, progression, tonal, são recorrentes em textos sobre Harmonia.

\subsubsection{Listagem de concordâncias (Concord)}

Essa ferramenta, denominada "concord", gera uma listagem de concordâncias com base na lista de palavras-chave (SCOTT, 2015) e apresenta os contextos de ocorrência. É utilizada para identificar agrupamentos recorrentes de palavras, verificar com qual ou quais palavras um item co-ocorre e com que frequência (SCOTT, 2015). A figura 6 mostra linhas de concordância (parciais) da palavra "acorde" e a figura 7, da palavra "chord".

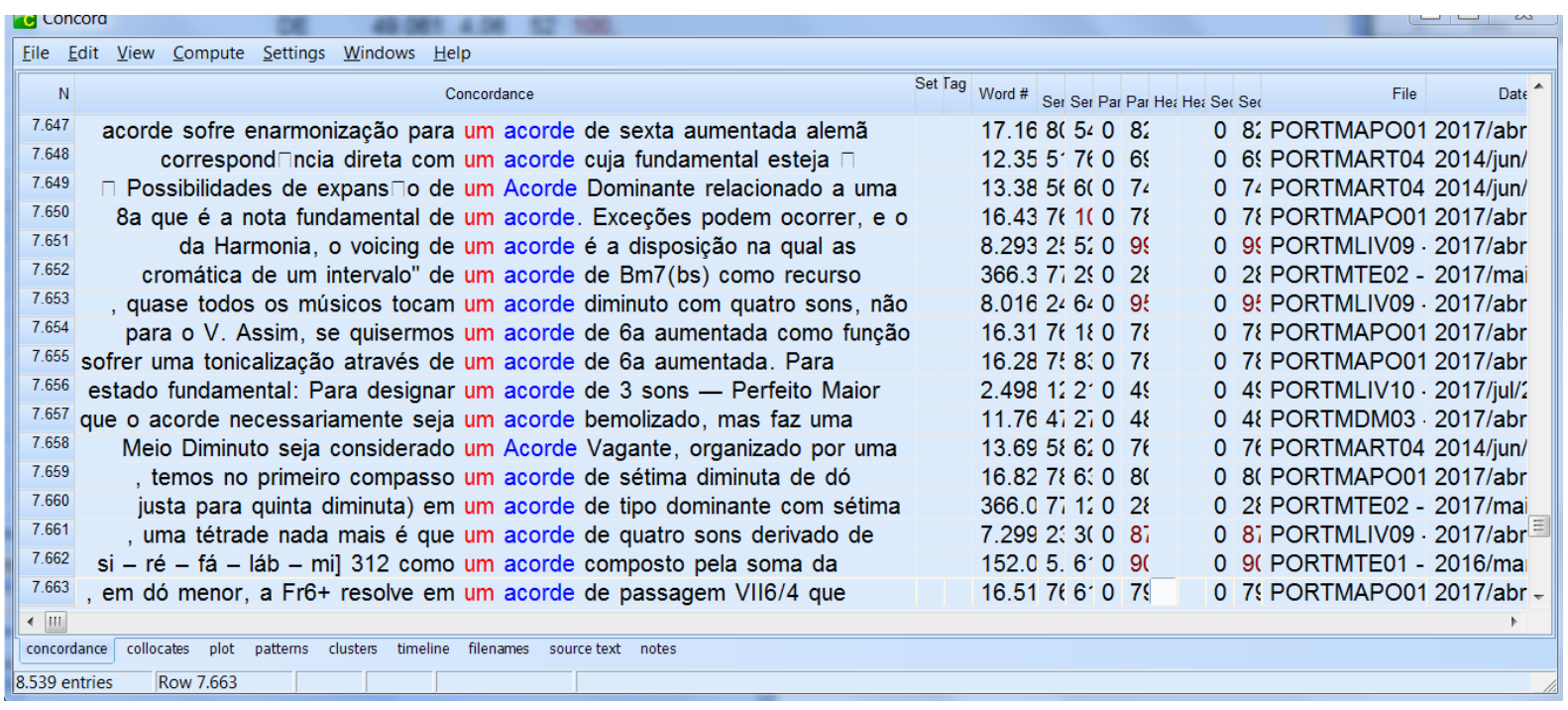

Figura 6 - Linhas de concordâncias (parciais) da palavra de busca "acorde" 


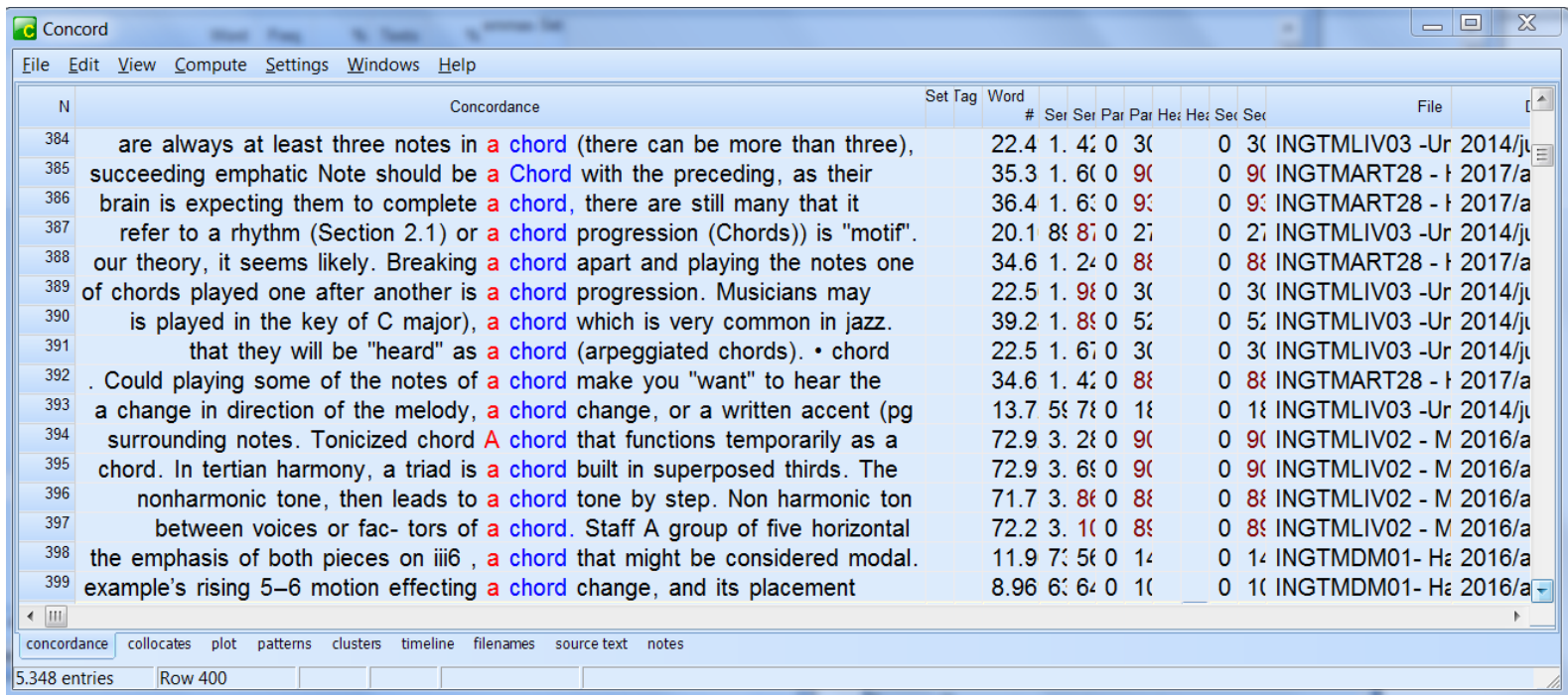

Figura 7 - Linhas de concordâncias (parciais) da palavra de busca "chord"

A partir das linhas de concordâncias, é possível analisar contextos em que as palavras de busca aparecem e os padrões lexicais recorrentes.

\subsubsection{Listas de clusters e de colocados (Collocates)}

A lista de cluster relaciona os agrupamentos de palavras em que aparece a palavra de busca, enquanto que a de "Collocates" traz uma lista de colocados (SCOTT, 2015). Os colocados se referem a item (ou itens) que coocorre $(\mathrm{m})$ significativamente com uma palavra de busca (TAGNIN; BEVILACQUA, 2013). A investigação de clusters e colocados permite que sejam identificadas, no contexto de uso, as colocações especializadas mais frequentes e convencionais utilizadas por especialistas da área.

A figura 8 apresenta alguns colocados que acompanham a palavra "chord", indicando a posição mais comum que ocupam na estrutura da colocação. As colunas que apresentam a letra "L" mostram a frequência do colocado na posição esquerda e as com a letra "R", na direita. Os números que acompanham as letras $\mathrm{L}$ e $\mathrm{R}$ indicam a posição do colocado em relação à palavra de busca, que está na coluna central (“Centre”). 


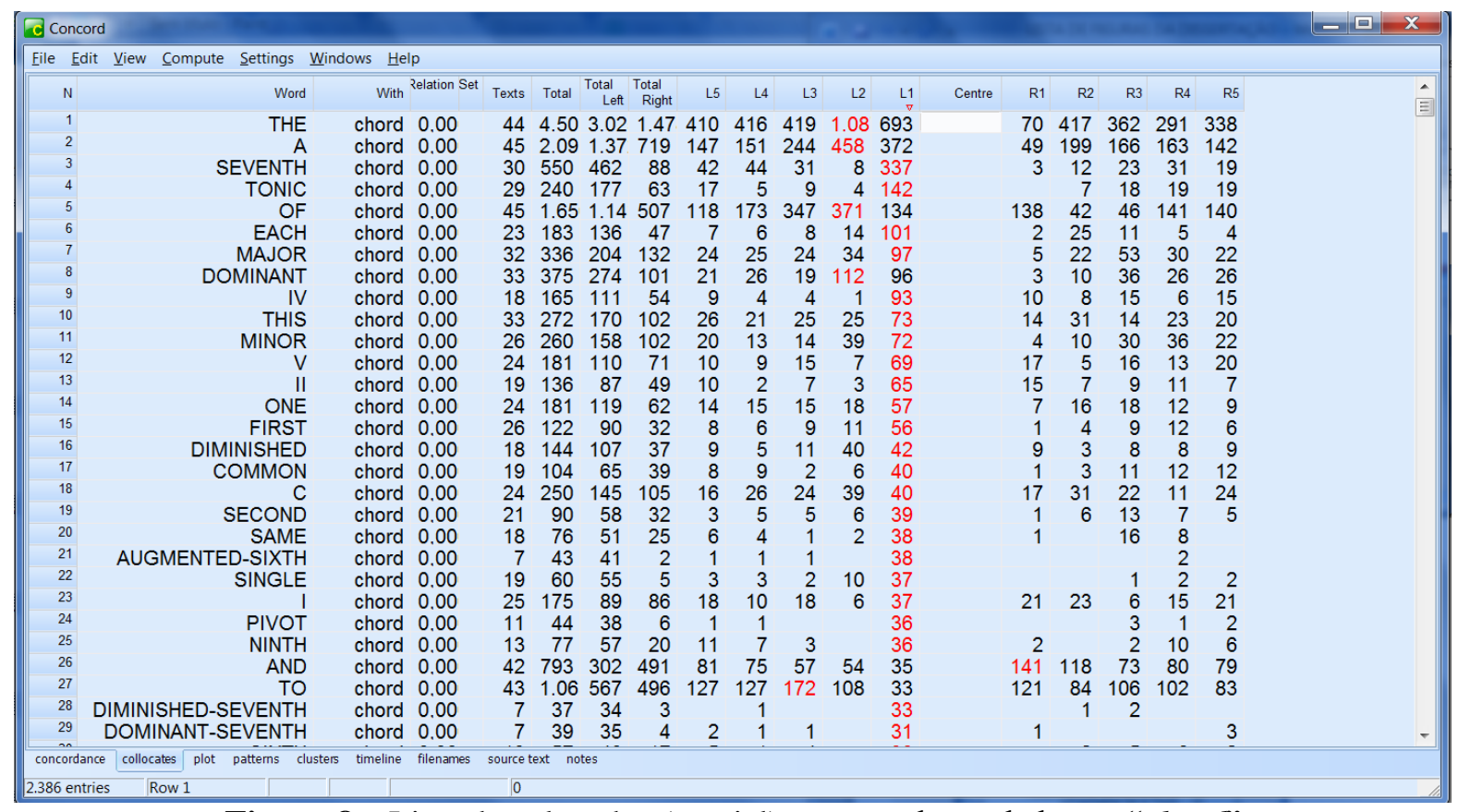

Figura 8 - Lista de colocados (parcial) para a palavra de busca "chord"

Na figura 8, é possível verificar quais são as palavras em torno da palavra de busca. Por exemplo, o colocado seventh aparece do lado esquerdo com 337 ocorrências destacadas em vermelho.

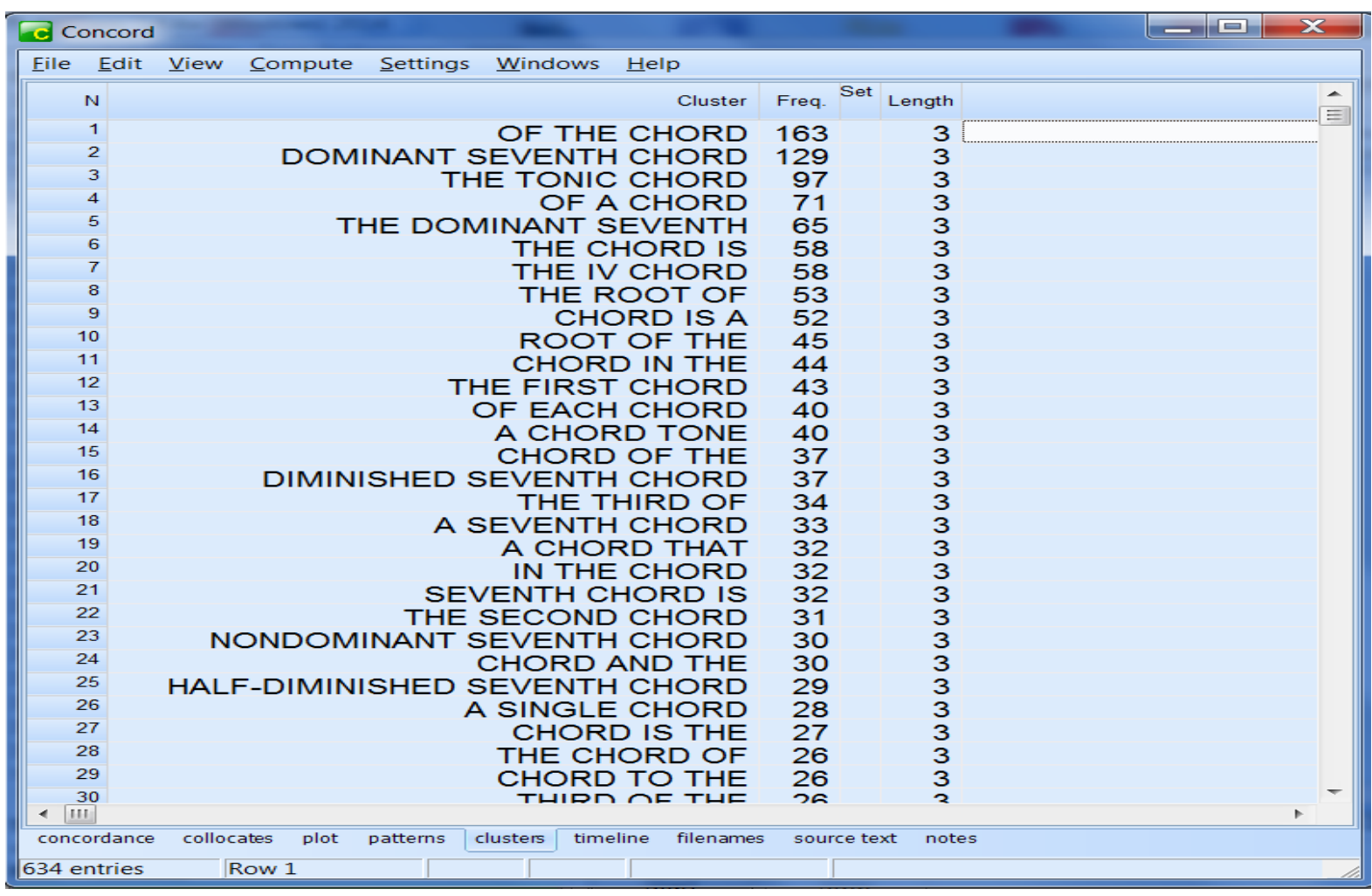

Figura 9 - Lista de clusters (parcial) para a palavra de busca "chord" 
Selecionando a ferramenta cluster (figura 9), podemos analisar com mais detalhes os agrupamentos formados em torno de "chord" e notamos que a colocação seventh chord (acorde de sétima) torna-se mais específica nas posições 2, 16, 23 e 25 da tela: dominant seventh chord (129 ocorrências), diminished seventh chord (37 ocorrências), nondominant seventh chord (30 ocorrências), half-diminished seventh chord (29 ocorrências).

Constata-se que as ferramentas citadas se completam no processo de identificação de possíveis colocações, já que apresentam ângulos diferentes para uma análise mais detalhada.

\subsubsection{Procedimentos adotados para a identificação das colocações e seus correspondentes na língua de chegada}

Os procedimentos para a identificação das colocações especializadas e estendidas em português foram:

- lista de palavras do corpus;

- lista de palavras-chave;

- levantamento das palavras-chave mais recorrentes (com base na frequência);

- lista de colocados que coocorrem com a palavra de busca "Acorde/Acordes";

- lista de clusters para a palavra de busca "Acorde/Acordes";

- seleção das colocações;

- análise das linhas de concordâncias;

- análise dos contextos definitórios (Subcorpus Instrucional) para comparar com os de Inglês;

- análise dos contextos de uso (Subcorpus Acadêmico-Científico) e pesquisa redirecionada quando necessário (busca de conceitos em materiais suplementares: obras referenciais).

Para a identificação de correspondentes das colocações encontradas no subcorpus de Português, adotamos os seguintes procedimentos de busca no subcorpus de inglês:

- lista de palavras do corpus;

- lista de palavras-chave;

- Levantamento das palavras-chave mais recorrentes (com base na frequência) 
- lista de colocados que coocorrem com a palavra de busca "chord/chords";

- lista de clusters para a palavra de busca "chord";

- $\quad$ seleção das colocações;

- análise das linhas de concordâncias;

- análise dos contextos e pesquisa redirecionada quando necessário (busca de conceitos em materiais suplementares);

- análise comparativa de contextos definitórios e de uso entre as colocações em português e inglês.

\subsection{Ficha Terminográfica}

O uso da ficha terminográfica permite o registro e organização de várias informações a respeito dos termos. Seguindo as recomendações de Barros (2004) sobre a elaboração de fichas terminográficas, criamos um modelo de ficha adaptado à nossa pesquisa. As fichas foram armazenadas eletronicamente, organizadas alfabeticamente e separadas pelo idioma. Nelas, há os seguintes campos:

\begin{tabular}{|l|l|l|}
\hline Colocação & & Correspondente \\
\hline Estrutura & & \\
\hline Frequência & \\
\hline Contexto definitório & \\
\hline Contexto de uso & \\
\hline Remissiva & \\
\hline Observação & \\
\hline Data de Registro & \\
\hline $\begin{array}{l}\text { Data da Última } \\
\text { atualização }\end{array}$ & \\
\hline $\begin{array}{l}\text { Consulta em } \\
\text { dicionários }\end{array}$ & \\
\hline
\end{tabular}

Quadro 9 - Modelo de Ficha Terminográfica 
Os campos criados foram preenchidos da seguinte maneira:

1) Colocação: termo encontrado na língua de partida

2) Correspondente: termo correspondente na língua de chegada

3) Estrutura: categorias gramaticais que compõem a colocação

4) Frequência: número de ocorrências no corpus

5) Contexto definitório: apresenta o conceito do termo que foi encontrado no Subcorpus Instrucional. Não é um campo obrigatório tendo em vista que haverá casos em que a definição não constará no corpus.

6) Contexto de uso: transcrição do contexto da colocação, com sua fonte (código do arquivo), conforme encontrado no corpus.

7) Consulta a dicionários: apresenta as definições encontradas em dicionários.

8) Remissiva: significados relacionados

9) Observação: variantes linguísticas encontradas no corpus e informações complementares.

10) Data de registro: data inicial

11) Data da última atualização: dia em que o arquivo foi alterado pela última vez.

Para exemplificar, apresentaremos fichas terminográficas preenchidas com as colocações correspondentes Acorde de dominante e Dominant chord:

\begin{tabular}{|c|c|c|c|}
\hline Colocação & Acorde de dominante & Correspondente & Dominant Chord \\
\hline Estrutura & \multicolumn{3}{|c|}{ Substantivo + preposição + substantivo } \\
\hline Frequência & \multicolumn{3}{|l|}{280} \\
\hline Definição & \multicolumn{3}{|c|}{ Acorde formado pelo V grau no modo Maior e menor. (PORTMLIV02) } \\
\hline Exemplo(s) de Uso & \multicolumn{3}{|c|}{$\begin{array}{l}\text { - Voltando ao assunto das progressões harmônicas em tons menores, } \\
\text { nossa atenção se centrará sobre o acorde de dominante como o fator } \\
\text { harmônico mais poderoso. (PORTMTE02) } \\
\text { - Assim, serão considerados acordes dominantes, somente os acordes } \\
\text { construídos sobre o V grau das escalas menores - harmônica e } \\
\text { melódica. (PORTMDM03) } \\
\text { - Com essa nomenclatura especialmente diferenciada, reafirmando }\end{array}$} \\
\hline
\end{tabular}




\begin{tabular}{|c|c|}
\hline & $\begin{array}{l}\text { novamente o emblema distinguir para unir, Rameau valoriza o fato de } \\
\text { que nos diferentes momentos das progressões por quinta descendentes } \\
\text { as dominantes (i.e., as tétrades) não são mesmo iguais: em termos } \\
\text { ramistas, os ciclos que se observam no interior de uma tonalidade se } \\
\text { compõem de dominantes (acordes maiores e menores com sétimas } \\
\text { maiores e menores) e da dominante tonique (o V7 grau propriamente } \\
\text { diferenciado, acorde maior com sétima menor e em clara preparação } \\
\text { para um acorde com função de I grau).(PORTMTE02) }\end{array}$ \\
\hline Remissiva & $\begin{array}{l}\text { Acorde de sétima da dominante, acorde de nona da dominante, acorde de } \\
\text { dominante substituta, dominante secundária. }\end{array}$ \\
\hline Observação & Acorde dominante, Dominante \\
\hline Data de Registro & $17 / 09 / 2016$ \\
\hline $\begin{array}{l}\text { Data da Última } \\
\text { atualização }\end{array}$ & $15 / 03 / 2017$ \\
\hline $\begin{array}{l}\text { Consulta } \\
\text { dicionários }\end{array}$ & $\begin{array}{l}\text { Acorde que no sistema tonal é construído sobre o quinto grau das escalas } \\
\text { maiores e menores. Constitui o momento de tensão que tende a se resolver } \\
\text { no acorde de tônica ou principal. (ex.: Sol, dominante na tonalidade de Dó } \\
\text { Maior ou Menor). (DP-DOURADO) }\end{array}$ \\
\hline
\end{tabular}

Quadro 10 - Exemplo de Ficha Preenchida - Acorde de Dominante

\begin{tabular}{|c|c|c|c|}
\hline Colocação & Dominant Chord & Correspondentes & $\begin{array}{l}\text { Acorde Dominante } \\
\text { Acorde de Dominante } \\
\text { Dominante }\end{array}$ \\
\hline Estrutura & \multicolumn{3}{|c|}{ Substantivo + Substantivo } \\
\hline Frequência & \multicolumn{3}{|l|}{58} \\
\hline Definição & \multicolumn{3}{|c|}{$\begin{array}{l}\text { The dominant chord always occurs on degree five of the scale. Therefore, in } \\
\text { the scale of C major, the dominant chord is a G major triad. (INGTMLIVO4) }\end{array}$} \\
\hline Exemplo(s) de Uso & \multicolumn{3}{|c|}{$\begin{array}{l}\text { - In this progression it is clear that the IV chord fulfills the function of the } \\
\text { absent dominant chord, occurring after the pre-dominant IIsharp and } \\
\text { leading back to I. (INGTMART10) } \\
\text { - If, for example, Jones had followed Eb diminished whole tone with A }\end{array}$} \\
\hline
\end{tabular}




\begin{tabular}{|c|c|}
\hline & $\begin{array}{l}\text { Lydian dominant, he would have recycled the same pitch collection and } \\
\text { therefore created a potentially static contrapuntal situation in which } \\
\text { both dominant chords are essentially the same save for the bass } \\
\text { note.(INGTMDM04) }\end{array}$ \\
\hline Remissiva & $\begin{array}{l}\text { Dominant seventh chord, Dominant ninth chord, Tritone substitution chord, } \\
\text { Dominant substitute chord }\end{array}$ \\
\hline Observação & $\begin{array}{l}\text { Dominant chords are the most unstable due to the presence of the tritone, } \\
\text { which consist of the fourth and seventh degree of the key. (Beyond functional } \\
\text { Harmony - Wayne) }\end{array}$ \\
\hline Data de Registro & $17 / 09 / 2016$ \\
\hline $\begin{array}{l}\text { Data da Última } \\
\text { atualização }\end{array}$ & $15 / 03 / 2017$ \\
\hline $\begin{array}{l}\text { Consulta } \\
\text { dicionários }\end{array}$ & $\begin{array}{l}\text { - Dominant Chord - The chord or triad that is based on the fifth tone of } \\
\text { the scale. In the key of C, the dominant triad would consist of G, B, } \\
\text { and D. A dominant seventh chord is a dominant chord with } \\
\text { a seventh added; in the key of C, the dominant seventh chord would } \\
\text { consist of G, B, D, and F. (DI-ON MUSIC) } \\
\text { - Dominant-(1) The fifth * scale degree of the major or minor scale. The } \\
\text { *triad and the seventh chord built on this degree as root are the } \\
\text { dominant triad and dominant seventh, respectively. As part of a } \\
\text { *adence, both of these chords are most often resolved to the *tonic } \\
\text { triad because of the presence in both of the leading tone and the } \\
\text { supertonic. The relationship of dominant and tonic expressed in such a } \\
\text { cadence, which is a function of both *Counterpoint and *Harmony, is } \\
\text { the most powerful in *Tonal Music and is fundamental to the sctructure } \\
\text { to tonal melodies and of both small- and large-scale forms [see Binary } \\
\text { and Ternary Form, Sonata Form]. When serving as the root of a chord, } \\
\text { the fifth scale degree is identified in *Harmonic Analysis by the numeral } \\
V \text { or the letter D (for Dominant). Secondary dominants [see also } \\
\text { Tonicization] are the dominants of degrees other than the tonic and are } \\
\text { designated as follows: Vof II (or simply V/II; e.g in the key of C, the fifth } \\
\text { above D, namely A), Vof III (V/III) etc. (DI - HARVARD) }\end{array}$ \\
\hline
\end{tabular}

Quadro 11 - Exemplo de Ficha Preenchida - Dominant Chord 


\section{CAPÍtULO 5}

\section{ANÁLISE E DISCUSSÃO DOS DADOS}

No capítulo 2, apresentamos uma pesquisa realizada em dicionários de termos musicais em Português e Inglês para verificar a quantidade de colocações registradas nas obras para as palavras de busca "acorde" e "chord".

Nos três dicionários pesquisados em Língua Inglesa, foi encontrado o total de 40 colocações diferentes para o termo "chord". Dos três dicionários, o que apresentou maior número foi o DI - HARVARD (RANDEL, Don Michael. The Havard Dictionary of Music. 4th ed. USA: The Belknap Press of Havard University Press, 2003): 26 colocações.

Em Língua Portuguesa, encontramos 32 colocações, somando os dois dicionários de termos musicais, sendo que a maior parte (26) delas constava no dicionário DP - DOURADO (DOURADO, Henrique Autran. Dicionário de termos e expressões da música. São Paulo: Editora 34, 2004).

No nosso corpus de estudo, o termo "acorde", bem como o correspondente "chord" em Inglês, apresenta um número significativo de ocorrências (Quadro 12), que se justifica pela relevância do estudo dele no contexto de Harmonia Musical.

\begin{tabular}{|c|c|}
\hline Acorde: $\mathbf{8 . 5 3 8}$ & Chord: $\mathbf{5 . 3 3 3}$ \\
\hline Acordes: $\mathbf{5 . 1 3 5}$ & Chords: $\mathbf{3 . 3 5 7}$ \\
\hline
\end{tabular}

Quadro 12 - Número de ocorrências dos termos na forma singular e plural

No nosso levantamento, encontramos 96 colocações em Português, incluindo as formas variantes. E em Inglês, foram localizadas 89 colocações, somadas as formas variantes. Todas serão utilizadas como entradas no glossário.

Neste capítulo, apresentaremos a análise das colocações especializadas em que os termos "acorde(s)" estão inseridos e os procedimentos realizados para a busca de correspondentes em inglês, identificação de formas variantes, definições e contextos de uso 
extraídos do corpus e, análise comparativa das definições dos dicionários (no caso daquelas colocações encontradas na pesquisa em dicionários de termos musicais) com as encontradas no corpus. Acrescentamos que para todas as colocações encontramos contextos, entretanto, para um número pequeno delas não foram encontrados contextos definitórios ou contextos de uso. Nesse caso, foi a comparação dos contextos encontrados que indicou os correspondentes. O resultado desta análise contribuirá para uma proposta de glossário de colocações especializadas de Harmonia Musical, na direção inglês-português e português-inglês, para tradutores.

Para aquelas colocações que ainda não constam nos dicionários de termos musicais pesquisados, o critério de convencionalidade, apontado pela análise de frequência no corpus, será relevante para a seleção como candidatos a termos.

O capítulo está subdivido em duas partes: colocações de acorde e seus correspondentes em Inglês, análise da composição das colocações encontradas nas duas línguas e análise das variantes lexicais.

\subsection{Colocações especializadas do termo "acorde" e seus correspondentes em Inglês}

Neste subitem, apresentaremos uma discussão para cada colocação e como foi o processo de localização da colocação correspondente em Inglês. A figura abaixo mostra uma nuvem que relaciona o termo acorde com seus co-ocorrentes (ou colocados), com base no levantamento de ocorrências das colocações encontradas.

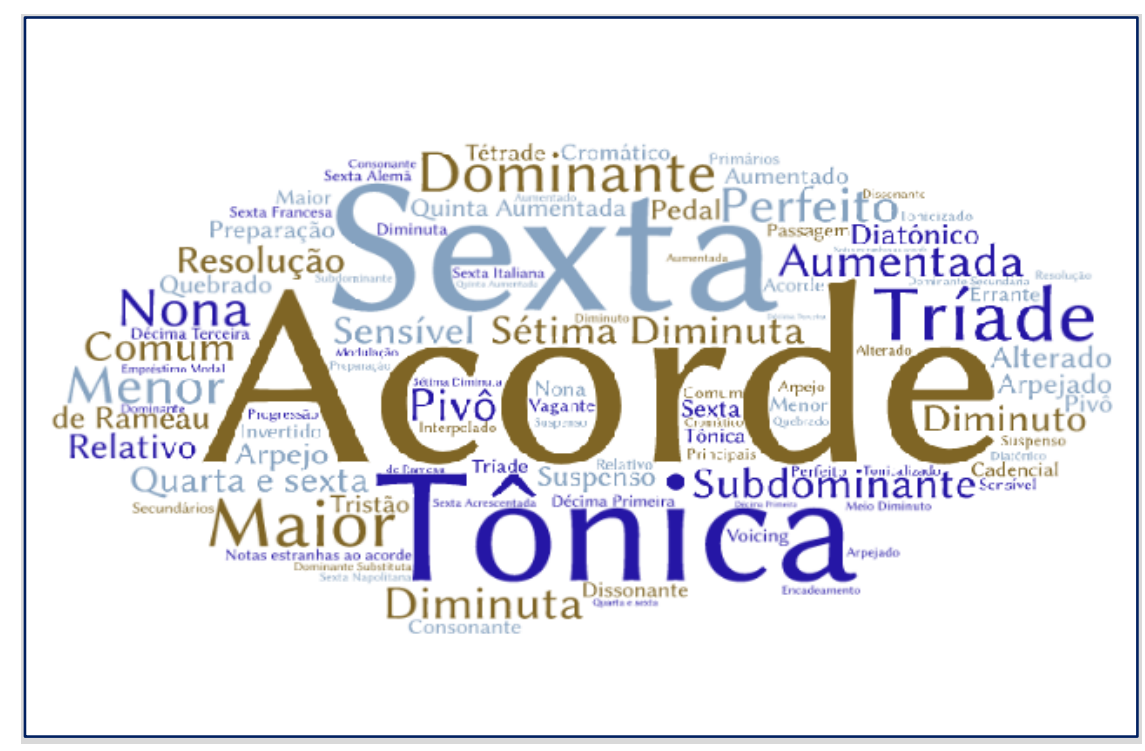

Figura 10 - Nuvem com o termo "acorde" e seus co-ocorrentes 
Organizamos as colocações por subtemas, após observar as relações semânticas entre elas e alguns subtemas da Harmonia. O quadro 13 apresenta como organizamos e agrupamos as colocações neste capítulo. A distribuição das colocações por subtemas tem o intuito de organizar sistematicamente as colocações para efeito de discussão de resultados. Adotaremos a ordem numérica a seguir para discutir cada item e como foi realizada a busca de correspondentes. Lembramos que, na construção do glossário, optamos por organizar as entradas em ordem alfabética.

\begin{tabular}{|c|c|c|}
\hline $\begin{array}{l}\text { SUBTEMAS DA } \\
\text { HARMONIA }\end{array}$ & & COLOCAÇÕES \\
\hline CONSONÂNCIA/DISSONÂNCIA & & $\begin{array}{l}\text { 1) Acorde consonante } \\
\text { 2) Acorde dissonante }\end{array}$ \\
\hline \multirow[t]{3}{*}{ FORMAÇÃO } & $\begin{array}{l}\text { Com três } \\
\text { notas }\end{array}$ & $\begin{array}{l}\text { 3) Acorde perfeito, tríade } \\
\text { 4) Acorde maior, acorde perfeito maior, } \\
\text { tríade maior } \\
\text { 5) Acorde menor, acorde perfeito menor, } \\
\text { tríade menor } \\
\text { 6) Acorde aumentado, acorde de quinta } \\
\text { aumentada, tríade aumentada } \\
\text { 7) Acorde diminuto, acorde de quinta } \\
\text { diminuta, tríade diminuta }\end{array}$ \\
\hline & $\begin{array}{l}\text { Com } \\
\text { quatro } \\
\text { notas }\end{array}$ & $\begin{array}{l}\text { 8) Acorde de sétima, tétrade } \\
\text { 9) Acorde meio-diminuto } \\
\text { 10) Acorde de sétima diminuta, tétrade } \\
\text { diminuta }\end{array}$ \\
\hline & $\begin{array}{l}\text { Com notas } \\
\text { suspensas }\end{array}$ & $\begin{array}{l}\text { 11) Acorde suspenso, acorde sus, acorde } \\
\text { sus4, acorde de quarta suspensa }\end{array}$ \\
\hline INVERSÃO & & $\begin{array}{l}\text { 12) Acorde Invertido } \\
\text { 13) Acorde de sexta } \\
\text { 14) Acorde de quarta e sexta }\end{array}$ \\
\hline DIATÔNICO / NÃO DIATÔNICO & & $\begin{array}{l}\text { 15) Acorde diatônico } \\
\text { 16) Acorde não-diatônico }\end{array}$ \\
\hline NOTAS PERTENCENTES /NOTAS & & 17) Notas do acorde \\
\hline
\end{tabular}




\begin{tabular}{|c|c|}
\hline ESTRANHAS & 18) Notas estranhas ao acorde \\
\hline ALTERAÇÕES & $\begin{array}{l}\text { 19) Acorde alterado } \\
\text { 20) Acorde cromático } \\
\text { 21) Acorde bordadura } \\
\text { 22) Acorde de passagem } \\
\text { 23) Acorde pedal } \\
\text { 24) Acorde errante, acorde vagante } \\
\text { 25) Acorde de empréstimo modal } \\
\text { 26) Acorde de Tristão }\end{array}$ \\
\hline ARPEJO & 27) Acorde arpejado, acorde quebrado \\
\hline $\begin{array}{l}\text { ACORDES DE SEXTA } \\
\text { (INVERTIDOS / COM } \\
\text { ACRÉSCIMO DE SEXTA) }\end{array}$ & $\begin{array}{l}\text { 28) Acorde napolitano, Acorde de sexta } \\
\text { napolitana } \\
\text { 29) Acorde de sexta aumentada } \\
\text { 30) Acorde de sexta aumentada alemã, } \\
\text { acorde de sexta alemã, acorde de sexta } \\
\text { germânica, sexta alemã } \\
\text { 31) Acorde de sexta aumentada francesa, } \\
\text { acorde de sexta francesa, sexta francesa } \\
\text { 32) Acorde de sexta aumentada italiana, } \\
\text { acorde de sexta italiana, sexta italiana } \\
\text { 33) Acorde de sexta acrescentada (de } \\
\text { Rameau), Acorde de Rameau }\end{array}$ \\
\hline TENSÕES ADICIONADAS & $\begin{array}{l}\text { 34) Acorde de nona } \\
\text { 35) Acorde de décima primeira } \\
\text { 36) Acorde de décima terceira }\end{array}$ \\
\hline $\begin{array}{l}\text { FUNÇÔES PRIMÁRIAS E } \\
\text { SECUNDÁRIAS }\end{array}$ & $\begin{array}{l}\text { 37) Acordes principais, acordes primários, } \\
\text { tríades principais } \\
\text { 38) Acorde de tônica } \\
\text { 39) Acorde de dominante, acorde dominante } \\
\text { 40) Acorde de subdominante } \\
\text { 41) Acorde de sétima da dominante, acorde } \\
\text { de dominante com sétima } \\
\text { 42) Acorde de sétima da sensível } \\
\text { 43) Acorde de nona da dominante, acorde de } \\
\text { dominante com nona } \\
\text { 44) Acordes secundários } \\
\text { 45) Acordes relativos e anti-relativos } \\
\text { 46) Acorde de dominante secundária } \\
\text { 47) Acorde de dominante substituta } \\
\text { 48) Acorde acorde tonicizado / Acorde }\end{array}$ \\
\hline
\end{tabular}




\begin{tabular}{|c|c|}
\hline & tonicalizado \\
\hline DISPOSIÇÃO DAS NOTAS & $\begin{array}{l}\text { 49) Voicing (Correspondente em inglês é } \\
\text { uma colocação com } \text { chord) }\end{array}$ \\
\hline ENCADEAMENTO & 50) Encadeamento dos acordes \\
\hline PROGRESSÃO E CADÊNCIA & $\begin{array}{l}\text { 51) Progressão dos acordes } \\
\text { 52) Acorde interpolado } \\
\text { 53) Acorde de preparação, acorde pré- } \\
\text { dominante } \\
\text { 54) Acorde de resolução } \\
\text { 55) Acorde cadencial } \\
\text { 56) Acorde de quarta e sexta cadencial } \\
\text { 57) Acorde de quarta e sexta de passagem } \\
\text { 58) Sucessão de acordes, sequência de } \\
\text { acordes }\end{array}$ \\
\hline MODULAÇÃO & $\begin{array}{l}\text { 59) Acorde comum, Acorde pivô } \\
\text { 60) Modulação através de acorde comum }\end{array}$ \\
\hline CIFRA & $\begin{array}{l}\text { 61) Cifra (correspondente em Inglês é uma } \\
\text { colocação com } \text { chord) }\end{array}$ \\
\hline
\end{tabular}

Quadro 13 - Ordem numérica das colocações para discussão de dados

De acordo com a sequência numérica apresentada na tabela anterior, realizaremos a análise das colocações apontadas.

\section{1) Acorde consonante}

"Acorde consonante" tem a frequência de 7 ocorrências no subcorpus de estudo e foi uma das colocações encontradas em um dicionário de termos musicais de Português. 
$\underline{\text { Acorde consonante }}$ - ver consonância. (Consonância: Vibrações sonoras concordantes; portanto aceitas como mais confortáveis ao ouvido, em oposição às dissonâncias. Em sentido mais amplo, o termo é subjetivo e envolve aspectos culturais e históricos.) (DP - DOURADO)

No Subcorpus Instrucional de Português, encontramos os seguintes contextos definitórios para a colocação:

- Conforme a Teoria Tradicional, os acordes consonantes criam a impressão de estabilidade, relaxamento e tranquilidade. Não exigem Resolução. (PORTMLIV02)

- De acordo com os intervalos que os formam, os acordes podem ser classificados como consonantes ou dissonantes. $\underline{\text { Consonantes }-S a ̃ o ~ a c o r d e s ~ f o r m a d o s ~ s o m e n t e ~}$ por intervalos consonantes. Ex.: - Acorde perfeito maior; Acorde perfeito menor. (PORTMAPO03)

O adjetivo "consonante" deriva do termo "consonância". O conceito de consonância varia de acordo com a vertente teórica adotada e gera calorosas discussões na área. Destacamos do corpus de estudo um trecho que complementa o exposto no dicionário DP DOURADO:

As consonâncias são produzidas pelos harmônicos mais próximos do som fundamental, dentro da série harmônica. A partir do sétimo harmônico, são encontradas as dissonâncias. Os conceitos de consonância e dissonância geram controvérsia e variam de acordo com a época e o estilo musical.

Selecionamos do subcorpus acadêmico-científico, um contexto de uso extraído de um texto em que a análise harmônica é voltada para a música popular e apresenta um posicionamento em relação às regras da abordagem tradicional:

Contando com a intelecção desta transgressão é que este acorde consonante ("Vm") se fez ouvir como "tensão", i.e., um confronto a uma norma habitual que permitiu a consolidação de uma metáfora musical útil para a representação da afronta aos valores impostos como a normalidade. (PORTMTE02) 


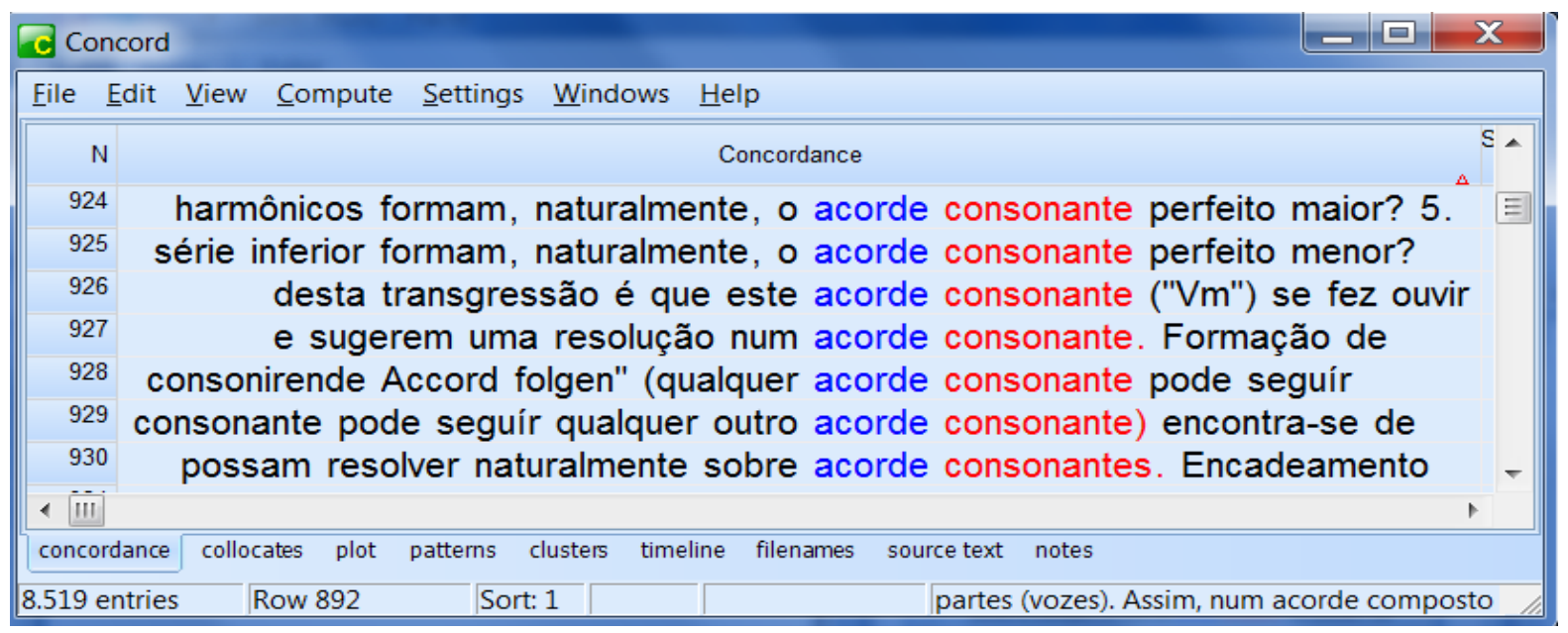

Figura 11 - Linhas de concordância de "acorde consonante"

No subcorpus de Inglês, encontramos a colocação correspondente: consonant chord. Ela aparece apenas 4 vezes no corpus de estudo. Selecionamos dois contextos definitórios. A descrição do primeiro se aproxima à explicação do dicionário mencionado anteriormente, em Português:

- Notes that sound good together when played at the same time are called consonant. Chords built only of consonances sound pleasant and "stable"; you can listen to one for a long time without feeling that the music needs to change to a different chord. (INGTMLIV0)

- Major and minor triads are consonant chords because they contain only consonant intervals. (INGTMLIV11)

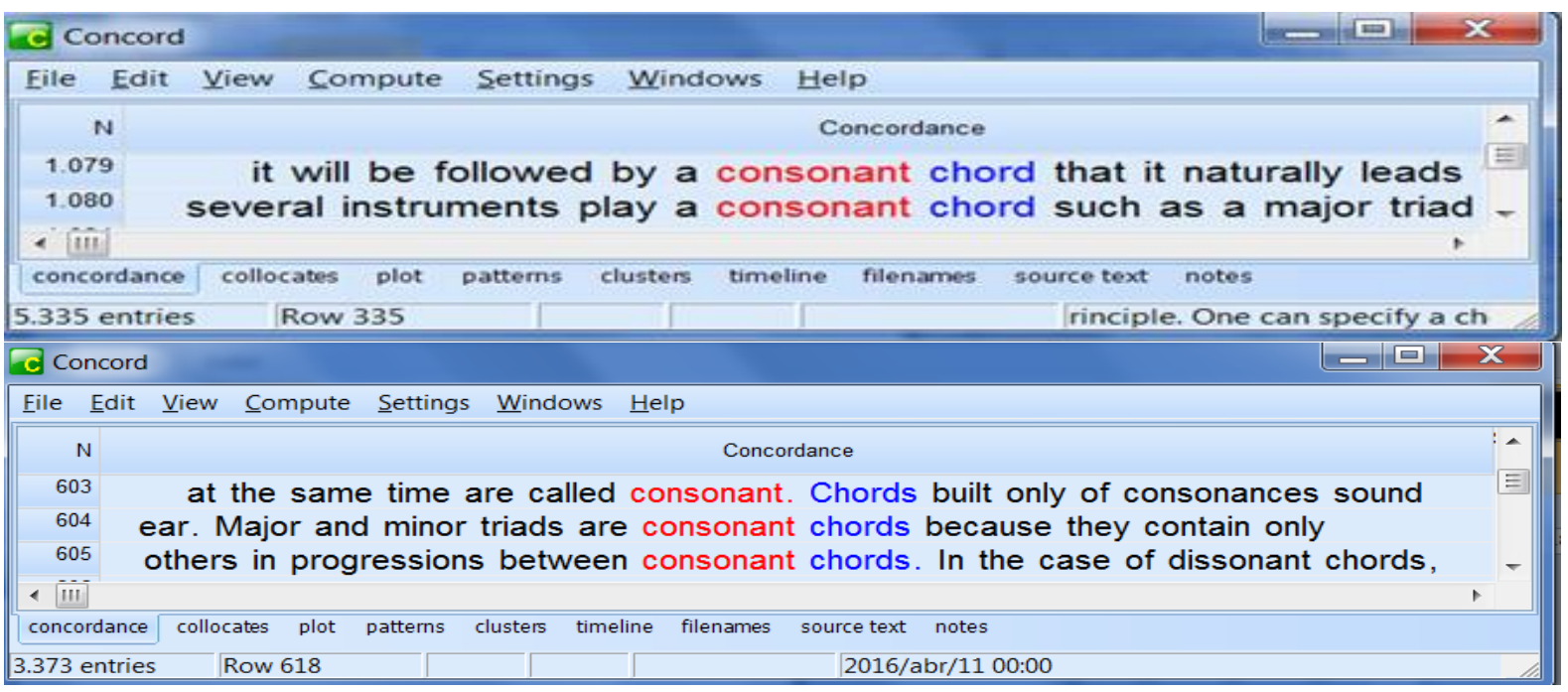

Figura 12 - Linhas de concordância de "consonant chord" no singular e plural

Como exemplo de uso, selecionamos o trecho abaixo do subcorpus acadêmicocientífico: 
Tone scales used in Western music are also based on intervals or frequency ratios of simple integers, such as the octave (2:1), the fifth (3:2), and the major third (5:4).

When several instruments play a consonant chord such as a major triad (do-mi-so), harmonics will match so that no beats will occur. (INGMART28)

Na nossa análise, as colocações especializadas acorde consonante e consonant chord são correspondentes.

\section{2) Acorde dissonante}

A colocação "acorde dissonante" apresenta a frequência de 4 ocorrências no corpus de estudo. Dissonante é um adjetivo derivado do termo Dissonância. Tanto o termo "consonância" como "dissonância" geram muitos debates no meio musical, por conta de pontos de vista distintos verificados em obras teóricas publicadas ao longo da História da Musical Ocidental.

A colocação foi um dos itens que encontramos no dicionário DP-DOURADO, com remissiva para o termo dissonância:

- $\quad$ Acorde dissonante - ver dissonância.

- Dissonância: Na harmonia tradicional, grupo de duas ou mais notas de um acorde que criam forte tensão e se tornam instáveis ao ouvido humano, que por natureza busca predominantemente a sua resolução em acordes consonantes. Com a ruptura dos conceitos rígidos do tonalismo e ao sabor das correntes de composição que seguiram, passou-se a entender que a tensão da dissonância não precisa ser obrigatoriamente resolvida.

No subcorpus instrucional, encontramos o seguinte contexto definitório:

- Os acordes dissonantes criam a impressão de intranquilidade ou tensão. Soam como se fossem incompletos ou inacabados e sugerem uma resolução num acorde consonante. (PORTMLIV02)

- Dê acordo com os intervalos que os formam, os acordes podem ser classificados como consonantes ou dissonantes. (...) b) Dissonantes - São acordes que contêm 
um ou mais intervalos consonantes. Ex.: - Acorde de $5^{a}$ diminuta; Acorde de $5^{a}$ aumentada; Todos os acordes de $7^{a}$; Todos acordes com $9^{a}$. (PORTMAPO03)

No primeiro trecho, a explicação é um pouco subjetiva. No segundo, o texto menciona intervalos considerados, naquela abordagem teórica, como consonantes e dissonantes.

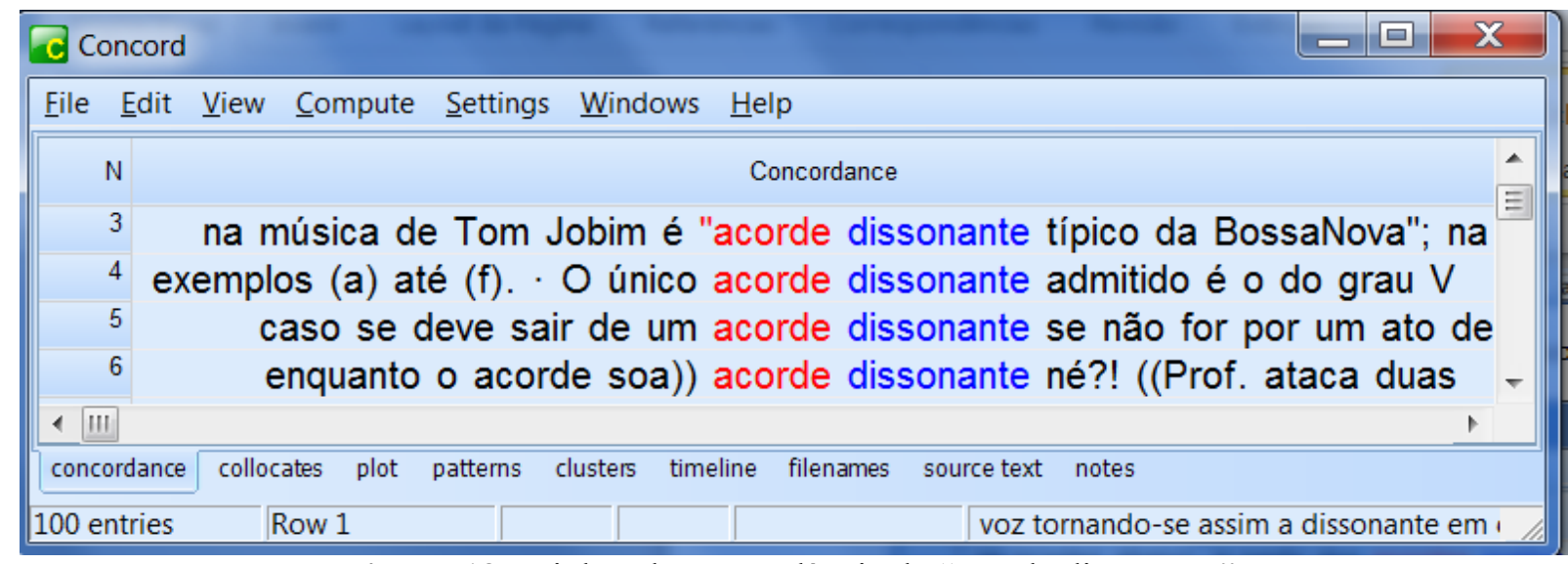

Figura 13 - Linhas de concordância de "acorde dissonante"

Os exemplos retirados do corpus acadêmico-científico apresentam o uso das colocações em textos sobre análise harmônica aplicada à música popular brasileira, cuja abordagem critica a forma tradicional de tratamento das dissonâncias do acorde.

- O próprio emprego de acordes dissonantes torna difícil a observação dos ditames de condução de vozes históricos. (PORTMTE02)

- O emprego sistemático dos acordes dissonantes acabou por demandar, dos autores e professores associados à Zona Popular, todo um novo esforço de teorização. (PORTMTE01)

No subcorpus de Inglês, encontramos a colocação "dissonant chord". Ela apresenta sete ocorrências. 


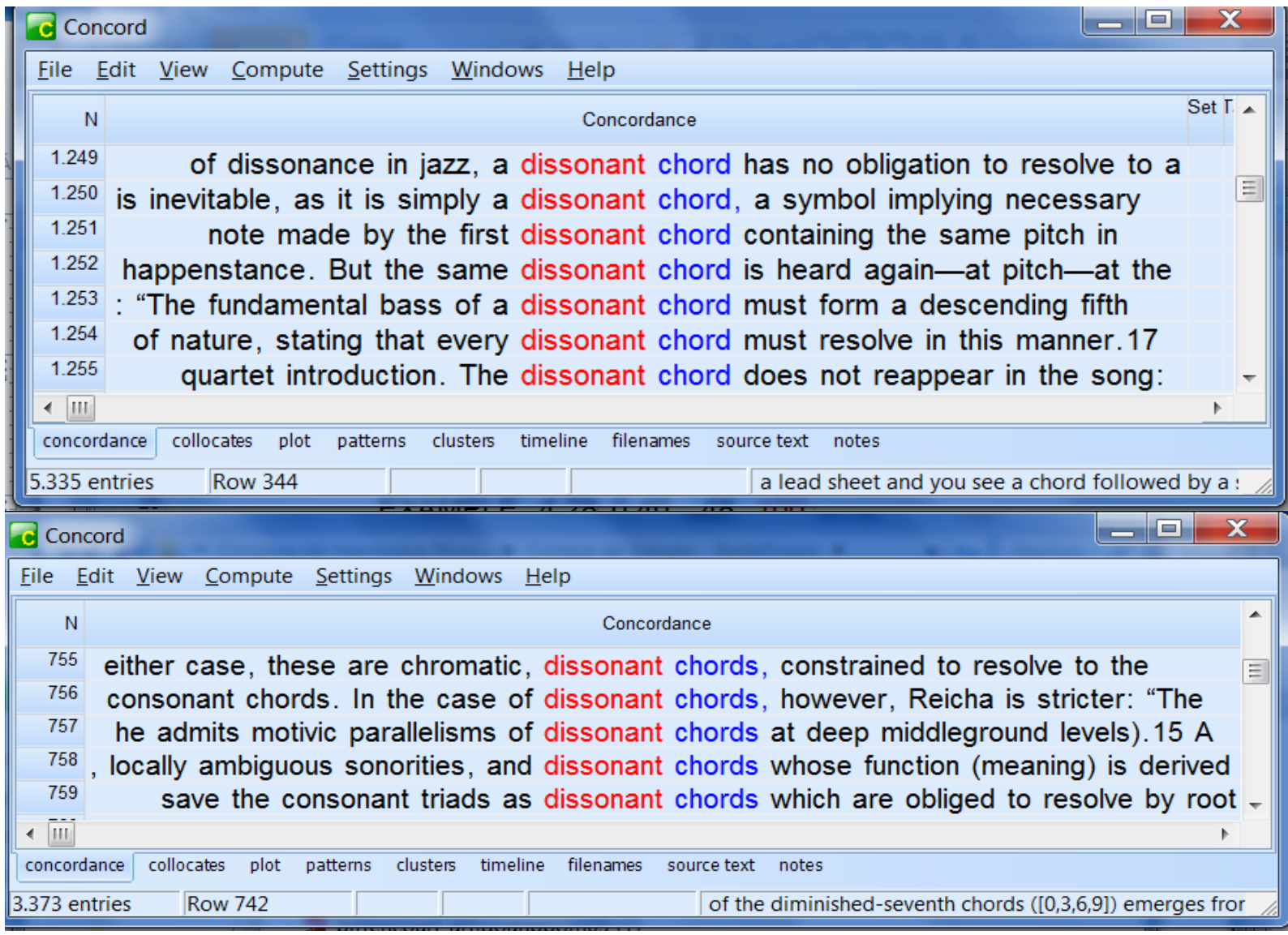

Figura 14 - Linhas de concordância de "dissonante chord" (singular e plural)

No subcorpus instrucional não encontramos um contexto definitório para a colocação. Então buscamos pelo termo "dissonance"(derivador do adjetivo dissonant), e verificamos que ele tem uma frequência alta no corpus: 206 ocorrências. Encontramos a seguinte explicação:

A dissonance is a note, chord, or interval that does not get into the triadic harmonies that we have learned to expect from music. A dissonance may sound surprising, jarring, even unpleasant. (INGTMLIV01)

Na explicação acima também nota-se a presença de elementos subjetivos (adjetivos surprising, jarring e unpleasant") na descrição do termo. Selecionamos dois excertos com comentários sobre visões distintas a respeito da dissonância:

- Because of the looser treatment of dissonance in jazz, a dissonant chord has no obligation to resolve to a chord predicted by the stylistic conventions of classical music.(INGTMLIV07) 
- The idea provided by Straus of dissonant chords resolving to consonant ones is problematic in this music. Schoenberg asserts that consonance/dissonance is not an antithesis, but rather a continuum of degrees. Others have echoed this idea, including Hindemith, who categorizes the degree of dissonance in particular chords based on a graded series of dissonant intervals. And because dissonance is not an either/or proposition, but rather a graded phenomenon, it stands to reason that dissonant perception can be skewed when listening to music saturated with dissonance. Daniel Harrison asserts that "increasing levels of dissonance allow a higher setting of the consonance band. "And in reference specifically to jazz, James McGowan calls for a new conception of consonance and dissonance. He argues that (regardless of the vertical acoustic conditions) consonance refers to stable/passive harmonic entities, while dissonance refers to unstable/active ones, within the musical grammar of a distinct cultural system. (INGTMDM04)

Na nossa análise, as colocações especializadas acorde dissonante e dissonant chord são correspondentes.

\section{3) Acorde perfeito, tríade}

A colocação "acorde perfeito" tem a frequência de 96 ocorrências e apresenta como variante o termo "tríade", com uma quantidade superior de ocorrências: 459. Vejamos os contextos definitórios encontrados para ambos:

- Acorde perfeito é assim denominado em consequência do intervalo de quinta justa (consonância perfeita) entre a nota mais grave $e$ a nota mais aguda. (PORTMLIV02)

- Entende-se por "acorde perfeito" a tríade: Acorde de três sons formado por terças sobrepostas. (PORTMART19)

Embora um "acorde perfeito" seja uma "tríade", uma "tríade" nem sempre é um "acorde perfeito". O "acorde perfeito" pode ser maior ou menor. A "tríade" pode ser maior, menor, aumentada ou diminuta. Nesse caso, o contexto é que determinará o significado:

A tríade é formada pelo agrupamento de três notas separadas por intervalos de terças e pode ser maior, menor, diminuta e ou aumentada. (PORTMLIV07) 
O termo tríade consta no dicionário DP-DOURADO, definido como:

Triade (ing. Triad) Acorde simples formado por duas terças sobrepostas, como dó-misol (tríade maior) ou lá-do-mi (tríade menor).

O autor não menciona os termos diminuto nem aumentado.

As colocações "acorde perfeito maior", "acorde perfeito menor", 'tríade maior", "tríade menor", "tríade aumentada", "tríade diminuta" serão vistas nos próximos subitens.

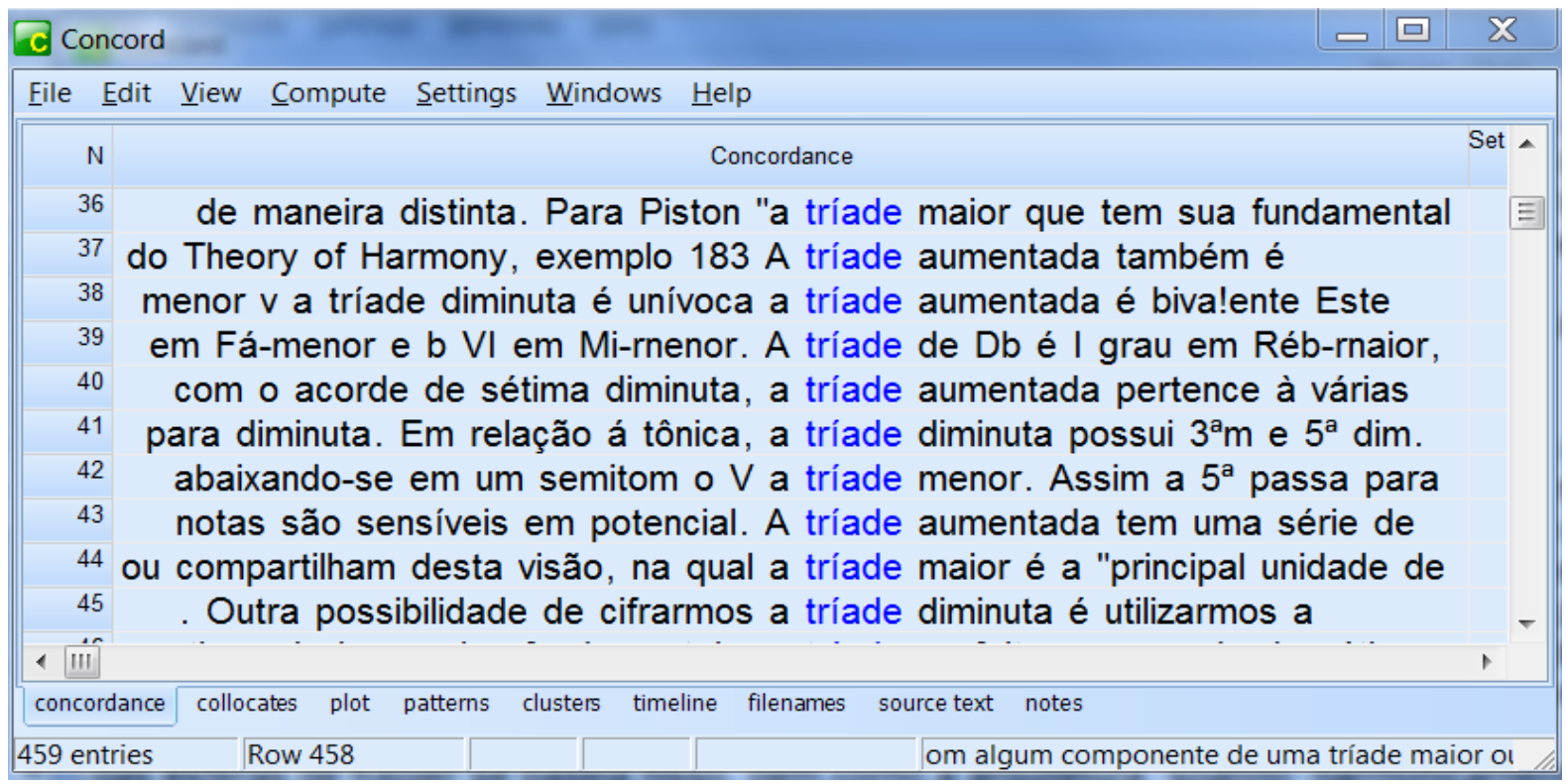

Figura 15 - Linhas de concordâncias (parciais) de "tríade"

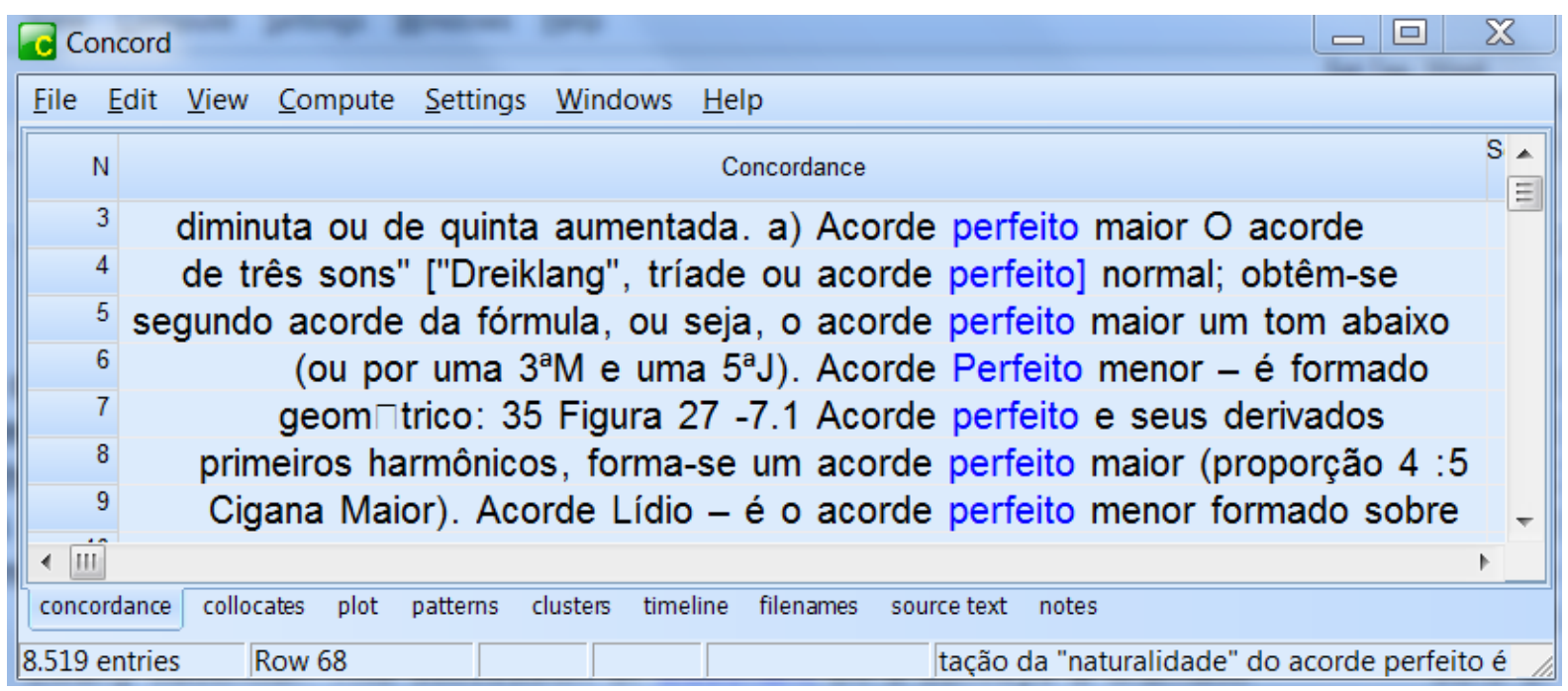

Figura 16 - Linhas de concordâncias (parciais) de "acorde perfeito" 
Encontramos como corresponde de "acorde perfeito" o termo "triad" com 1.477 ocorrências. Entretanto, observamos que nos dicionários especializados em Inglês, as definições encontradas para "common chord" se aproximam do significado de "Acorde perfeito" apresentado em Português:

A triad in which the fifth is perfect, i.e, the major or minor triad. In American usage, only the major triad is so described. (DI-OXFORD)

A chord consisting of the root, third and fifth; a triad. (DI-ON MUSIC)

Common chord - Major triad. (DI-HARVARD).

A colocação "common chord" foi encontrada no corpus apresentando outro significado, como veremos adiante. Ela é usada como um acorde que faz ponte modulatória entre duas tonalidades diferentes. Entretanto encontramos a colocação "common triad" (que apresenta a definição do dicionário, acrescentando também "minor triad" (INGTMLIV04). Detalharemos essa informação no item sobre "Acorde comum, acorde pivô".

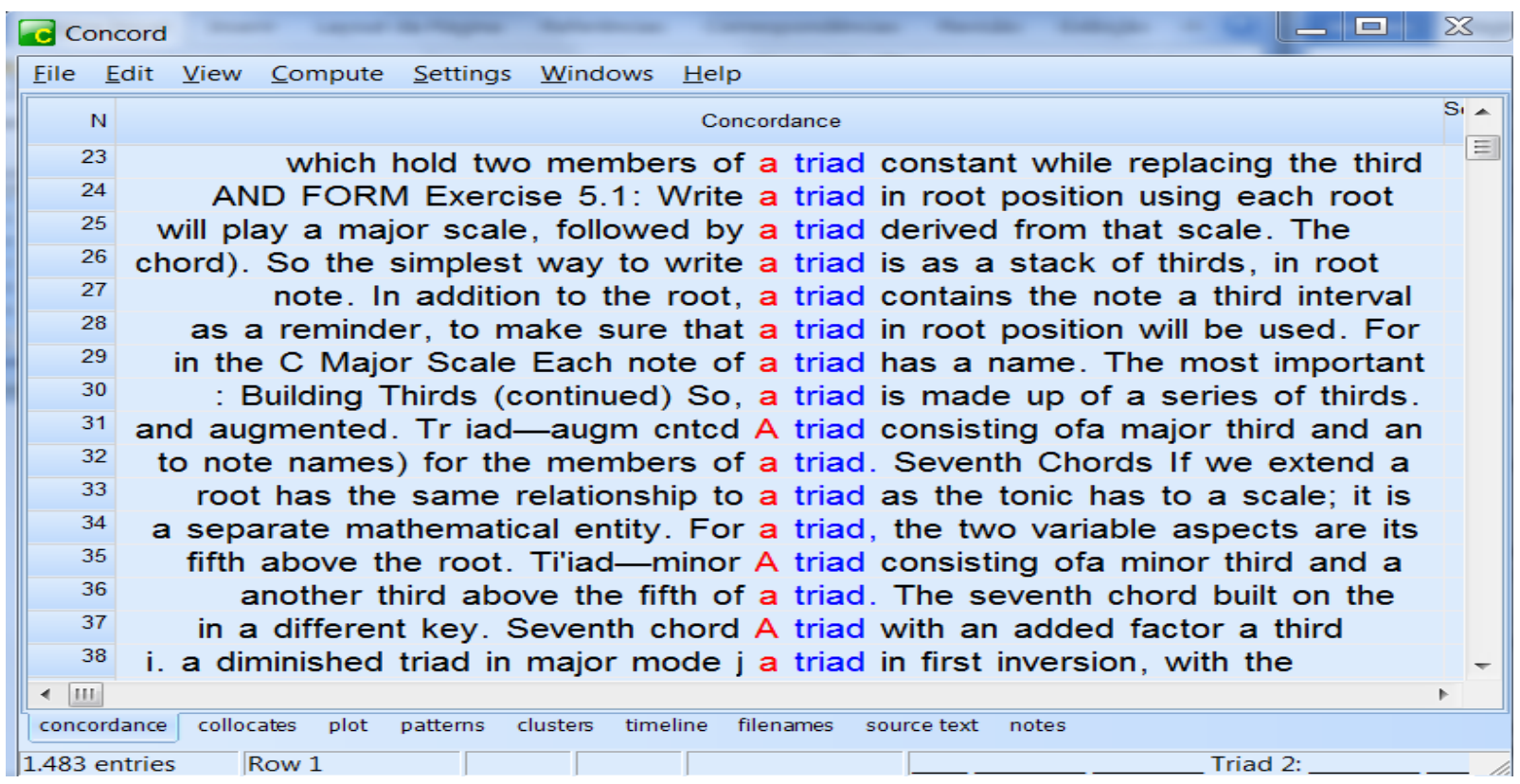

Figura 17 - Linhas de concordâncias (parciais) de "triad"

Selecionamos dois excertos, um com contexto definitório e outro com exemplo de uso: 
Triad: Strictly speaking, a triad is any three-tone chord. In tertian harmony, a triad is a chord built in superposed thirds. The four types of triads are major, minor, diminished, and augmented. (INGTMLIV02)

The pivot modulation uses a triad, as a pivotal point, that is considered functional on both tonal levels. (INGTMTE02)

Da nossa análise, a colocação "acorde perfeito" tem como correspondente triad /common triad.

\section{4) Acorde maior, acorde perfeito maior, tríade maior}

Neste subitem agrupamos três termos que apresentam conceitos semelhantes:

- Acorde Maior é composto pela fundamental, terça maior e quinta justa. (PORTMLIV02)

- Acorde perfeito maior. É formado por uma terça maior e uma terça menor sobrepostas (ou por uma terça maior e uma quinta justa). (PORTMLIV02)

- Tríade Maior. É formada pela fundamental, terça maior e quinta justa e se caracteriza, também, pela superposição de uma terça maior e uma terça menor. (PORTMLIV07)

Das três colocações, encontramos apenas uma delas em um dos dicionários de termos musicais pesquisado:

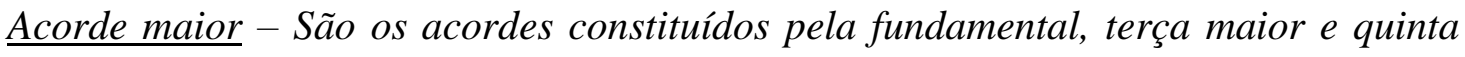
justa. (DP-GALTER)

No subcorpus de Português, essas colocações têm a frequência de 199 ocorrências para "acorde maior", 41 ocorrências de "acorde perfeito maior" e 77 para "tríade maior". 


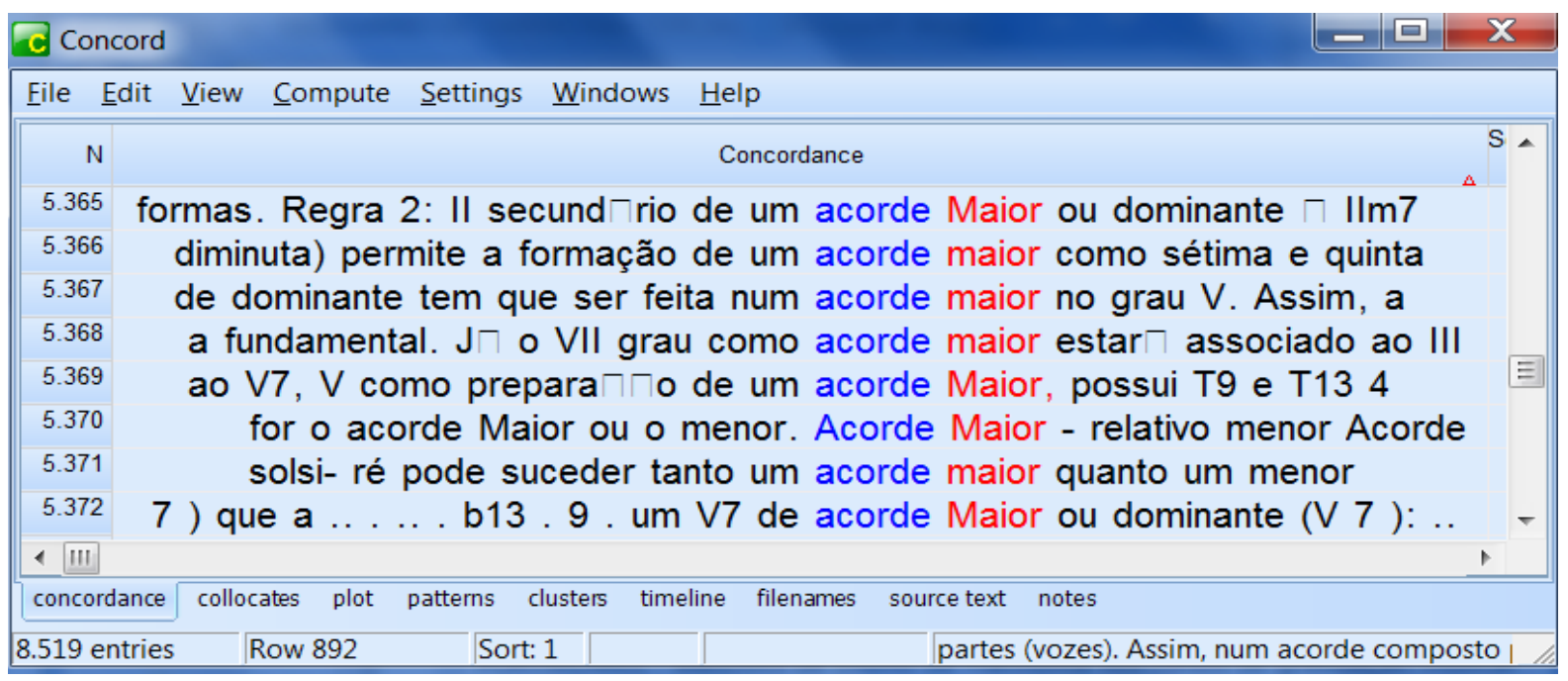

Figura 18 - Linhas de concordância (parciais) de "acorde maior"

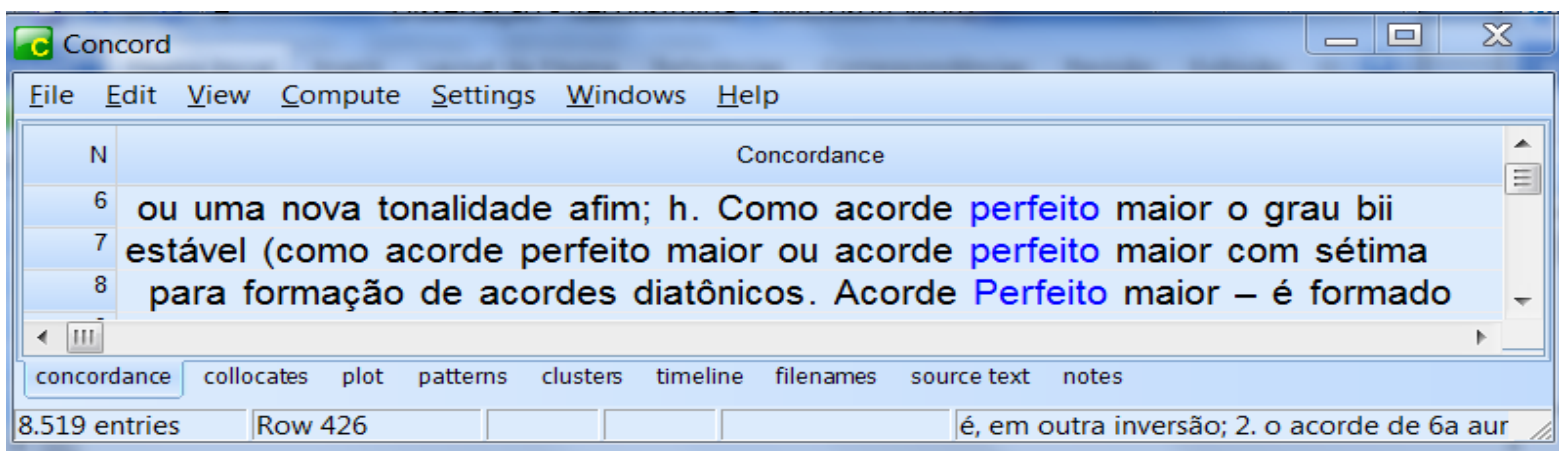

Figura 19 - Linhas de concordância (parciais) de "acorde perfeito maior"

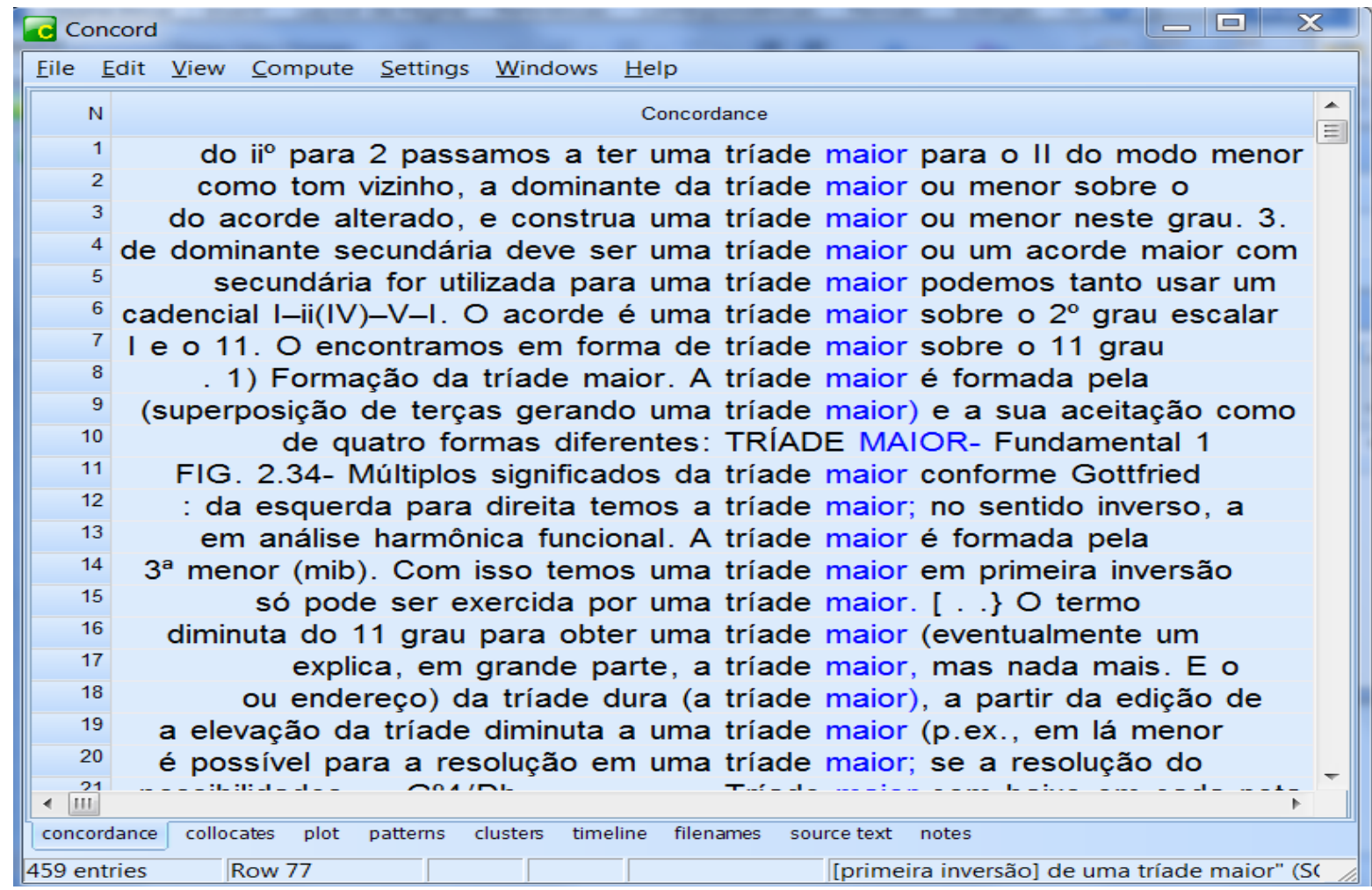

Figura 20 - Linhas de concordância (parciais) de "acorde maior" 
Os trechos abaixo apresentam alguns dos contextos de uso em que as colocações aparecem:

- É importante lembrar que, caso o acorde da resolução seja um acorde maior, a preparação obedece as características do modo maior, ou seja, o II grau se configurará um acorde menor com sétima menor. (PORTMDM03)

- Institui, então, que as funções de Tônica, Subdominante e Dominante são, respectivamente, os I, IV e V graus da escala, onde a Tônica (ou I grau) é o acorde perfeito maior que se localiza no centro dos três únicos acordes perfeitos da escala, separados por intervalos de quinta. (PORTMART19)

- A definição de uma fundamental de um acorde qualquer é devida em grande parte a sua forma assimétrica, por exemplo, em uma tríade maior encontramos uma terça menor acima de uma maior, e reconhecemos uma fundamental em parte por esta forma assimétrica. (PORTMART18)

Da mesma forma que em Português, agrupamos os dois correspondentes encontrados: major chord e major triad, cujos contextos definitórios descrevem, com palavras diferentes, uma tríade maior:

- For the major chord, you count up four semitones to get the third, and then three semitones to get the fifth. (INGTMLIV04)

- A major triad consists of a major third and a perfect fifth. (INGTMLIV02)

As colocações apresentam as seguintes frequências no subcorpus de Inglês: 318 ocorrências para major triad e 97 para major chord. 


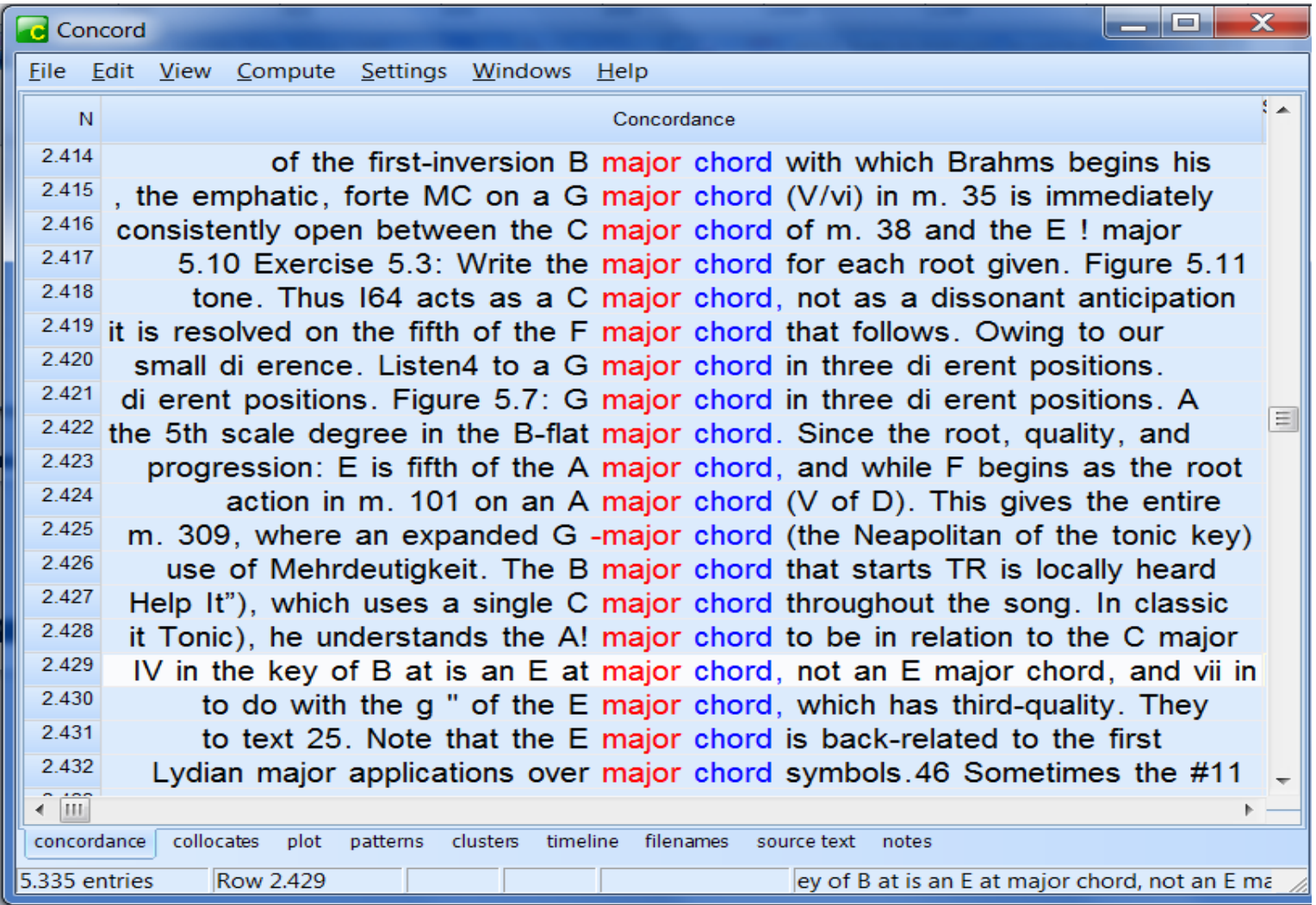

Figura 21 - Linhas de concordância (parciais) de "major chord"

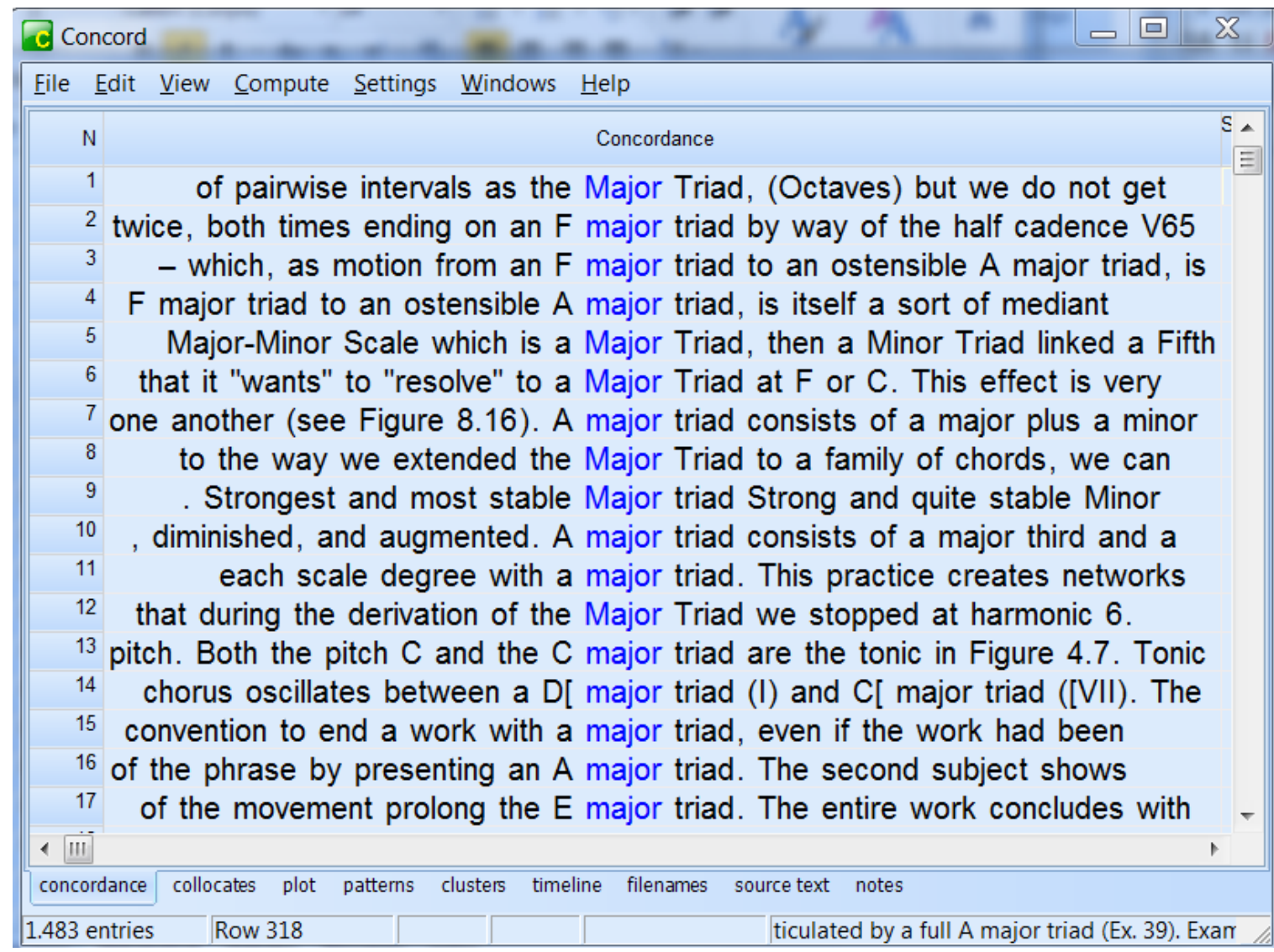

Figura 22 - Linhas de concordância (parciais) de "major triad" 
Selecionamos os seguintes contextos de uso das colocações, extraídas do subcorpus acadêmico-científico:

- The Three Stripped Gears alternate this strain with a contrasting strain using the eight-bar "Spoonful" scheme, represented harmonically as: VI-VI-II-II-V-V-I-I, all major chords. (INGTMART13)

- The minor third in a major triad could only be indirectly derived from the major third. For Zarlino, the bottom interval of the major triad was of greater importance, and the minor third above it was merely the "residue" that filled in the space between the major third and the fifth in a major triad.(INGTMTE01)

De acordo com os contextos acima, optamos pelas seguintes correspondências:

- Acorde perfeito maior $\Leftrightarrow$ major triad (também common chord, de acordo com os dicionários pesquisados, item 3 , e com o corpus de estudo)

- Acorde maior $\Leftrightarrow$ major chord

- Tríade maior $\Leftrightarrow$ major triad

Para todas as entradas acima utilizaremos remissivas.

\section{5) Acorde menor, acorde perfeito menor, tríade menor}

Assim como no subitem anterior, agrupamos três colocações que apresentam conceitos semelhantes: "acorde menor" (201 ocorrências), "acorde perfeito menor" (20 ocorrências) e "tríade menor" (35 ocorrências).

- Acorde menor - formado por fundamental, terça menor e quinta justa (PORTMAPO06);

- Acorde perfeito menor: É formado por uma terça menor e uma terça maior sobrepostas (ou por uma terça menor e uma quinta justa).(PORTMLIV02)

- Tríade menor: É formada pela fundamental, terça menor e quinta justa que se caracteriza, também, pela superposição de uma terça menor e maior. (PORTMLIV07) 
Das três colocações, encontramos "acorde menor" na pesquisa aos dicionários de termos musicais:

$\underline{\text { Acorde menor }-S a ̃ o ~ o s ~ a c o r d e s ~ c o n s t i t u i ́ d o s ~ p e l a ~ f u n d a m e n t a l, ~ t e r c ̧ a ~ m e n o r ~ e ~ q u i n t a ~}$ justa. (DP-GALTER)

\begin{tabular}{|c|c|c|c|}
\hline Conc & cord & - & \\
\hline Eile $\underline{E}$ & Edit View Compute Settings Windows Help & & \\
\hline $\mathrm{N}$ & Concordance & & a \\
\hline 5.696 & tipos de acordes: o acorde maior, o acorde & e menor e o acorde dominante. & \\
\hline 5.697 & como um II na cadência II-V de um acorde & e menor $\mathrm{e}$, neste contexto, tem & \\
\hline 5.698 & o baixo) e permanec $\sqcap$-la como $5 \sqcap \mathrm{J}$ do acorde & e menor. Nas restantes, observe & \\
\hline 5.699 & e $\neg$ muito bem empregado em V7 de acorde & e menor. (d) $\sqcap$ tamb $\neg \mathrm{m} \mathbf{n} \sqcap \mathbf{0} \sqcap$ & \\
\hline 5.700 & Maior e Preparação - Resolução em Acorde & e Menor. 3.1 Rearmonização & \\
\hline 5.701 & subentende Tb13 e vice-versa. . V7 de acorde & e menor $\mathbf{s} \sqcap$ o subentendidas $\mathrm{e}$ & \\
\hline 5.702 & olicada por Rameau em 1731 Acorde & e menor com sétima sobre o & \\
\hline 5.703 & grau bemol pode-se então introduzir o acorde & e menor de tônica (i) em & \\
\hline 5.704 & equival $\square$ ncia do SubV7 com V7 de acorde & e menor ser $\rceil$ vista com mais & \\
\hline 5.705 & que também se configura como um 90 acorde & e menor com sétima menor e & \\
\hline 5.706 & popular. Sempre que se tem um acorde & e menor no tempo forte do & \\
\hline 5.707 & (como o mencionado D C acima) e o acorde & e menor com $6^{a}$ menor. Por & \\
\hline 5.708 & menor $-5^{a}$ aumentada e $7^{a}$ menor. 9. Acorde & e Menor com Sétima Menor e & \\
\hline 5.709 & Desta forma, ao substituir o $\mathrm{V} 7 \mathrm{de}$ um acorde & e menor, a possibilidade de & \\
\hline 5.710 & , 2005, p. 108-110). No caso do acorde & e menor (FIG. 7.10a, b), o & \\
\hline 5.711 & "cientificamente" o fenômeno do "acorde & enor", pois, como se sabe, & \\
\hline 5.712 & rça menor (e logo, do acorde & neno & \\
\hline 5.713 & des dissonantes derivados do acorde & e menor com sétima construído & \\
\hline 5.714 & do II auxiliar ser $\rceil$ geralmente um acorde & e menor, respectivo ao $1 \mathrm{Im} 7 \mathrm{da}$ & \\
\hline 5.715 & om o acordo sonoro oposto de um "acorde & e menor com sétima maior"? & \\
\hline 5.716 & , muito comum antecedendo b13 .. um acorde & e menor. Em V7, T9 subentende & \\
\hline 5.717 & equivocada na formação deste. Acorde & e Menor com Sétima Menor e & \\
\hline 5.718 & . 533 de Mozart, 1788593 FIG. 4.16- Acorde & e menor com sexta & \\
\hline 5.719 & se refere à sétima, e não à terça; c) o acorde & e menor com sétima e quir & \\
\hline 5.720 & como 9 & & \\
\hline 5.721 & um acorc & pincide & \\
\hline 5.722 & ima Menor e Quinta Diminuta Acorde & e Menor com Quinta Diminuta & \\
\hline \& iIII & & & \\
\hline concord: & dance collocates plot patterns clusters timeline filenames sour & urce text notes & \\
\hline
\end{tabular}

Figura 23 - Linhas de concordância (parciais) de "acorde menor"

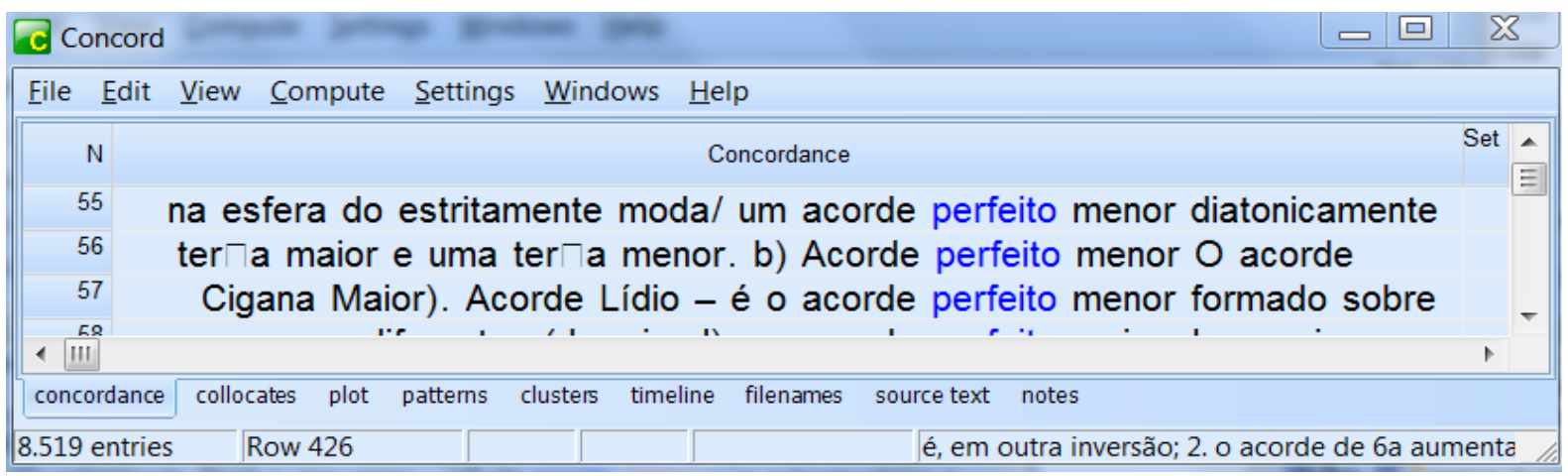

Figura 24 - Linhas de concordância (parciais) de "acorde perfeito menor" 


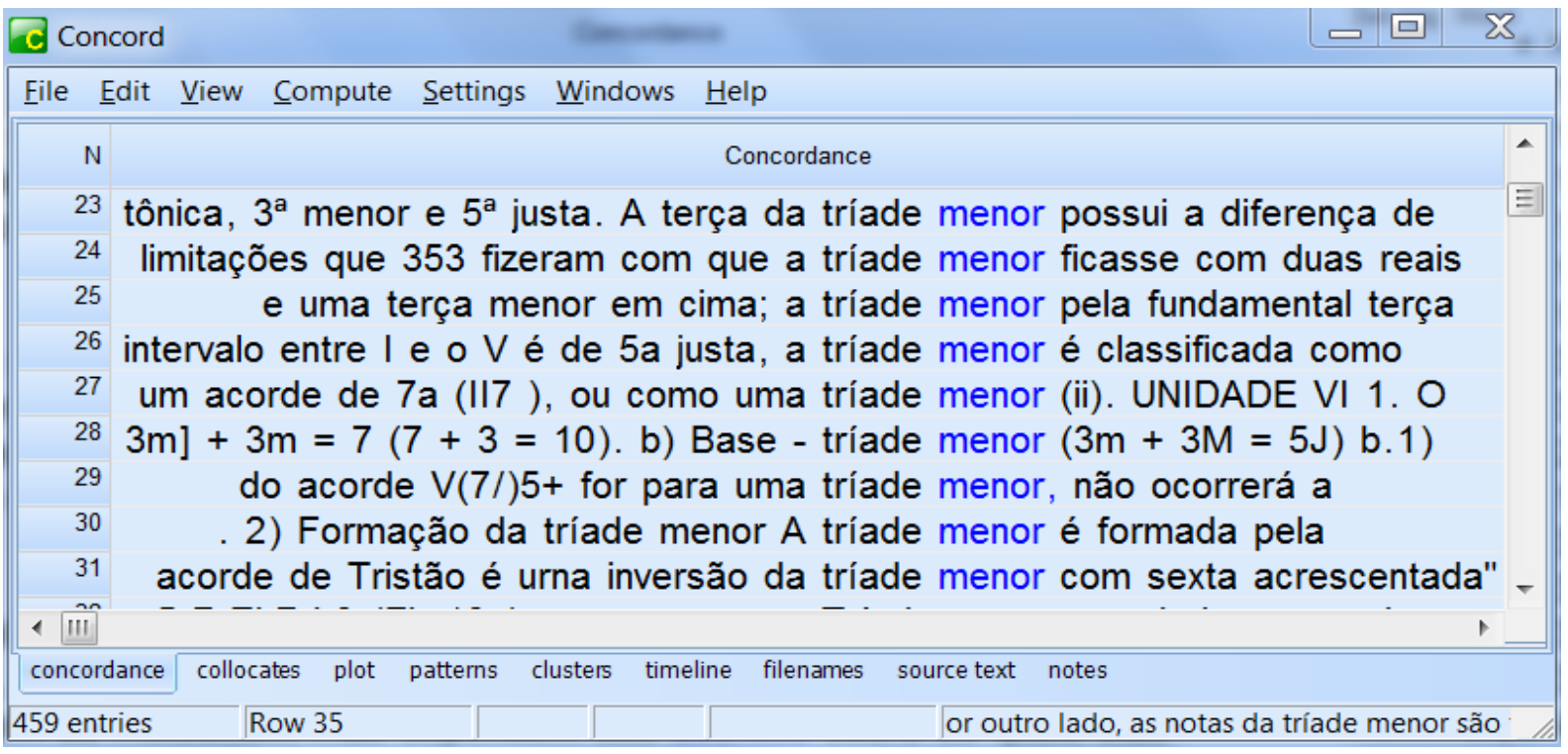

Figura 25 - Linhas de concordância (parciais) de "tríade menor"

Selecionamos os seguintes contextos de uso das colocações, extraídas do subcorpus acadêmico-científico:

- Esse acorde de três sons passava por inferior, fraco e, num sentido hierárquico negativo. Zarlino chama o acorde perfeito menor de affeto tristo-sentimento ruim. (PORTMTE02)

- Outras possibilidades poderiam surgir a partir desse mesmo acorde menor. (PORTMART04)

- Junto a isto há que se nomear a aparição da tríade menor de dominante na cadência, com uma resolução sobre a tônica maior ou menor (PORTMTE02)

Em Inglês, os correspondentes para essas colocações são: minor chord (150 ocorrências) e minor triad (205 ocorrências).

A colocação "acorde menor", no dicionário de termos musicais DP-GALTER, é definida como: acordes constituídos pela fundamental, terça menor e a quinta justa.

No subcorpus instrucional, os contextos definitórios para as colocações são:

- A minor triad consists of a minor and a perfect fifth. (INGTMLIV02) 
- If the interval between the root and the third of the chord is the minor third (and the major third is between the third and fifth of the chord), then the triad is a minor chord. (INGTMLIV03)

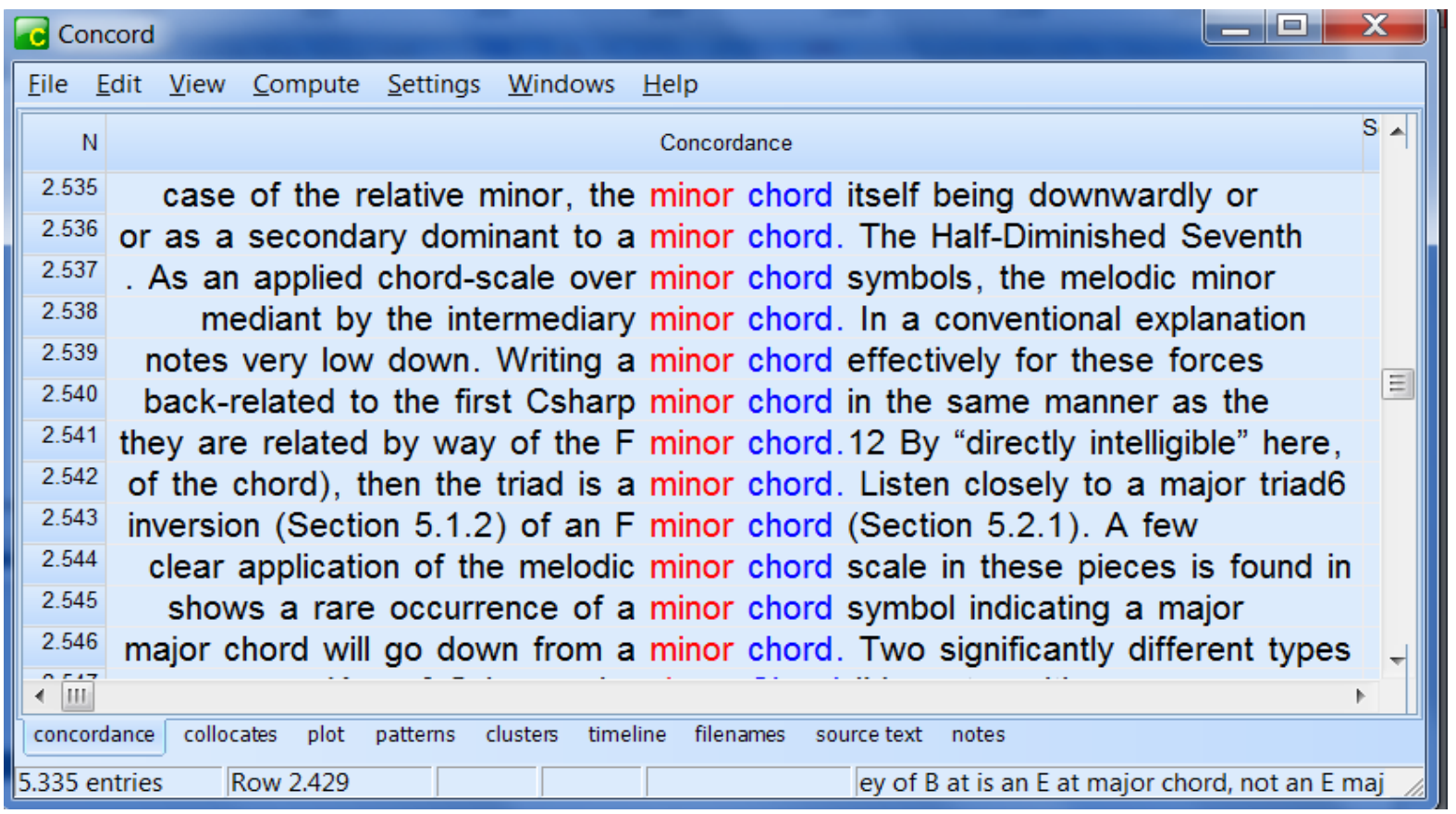

Figura 26 - Linhas de concordância (parciais) de "minor chord"

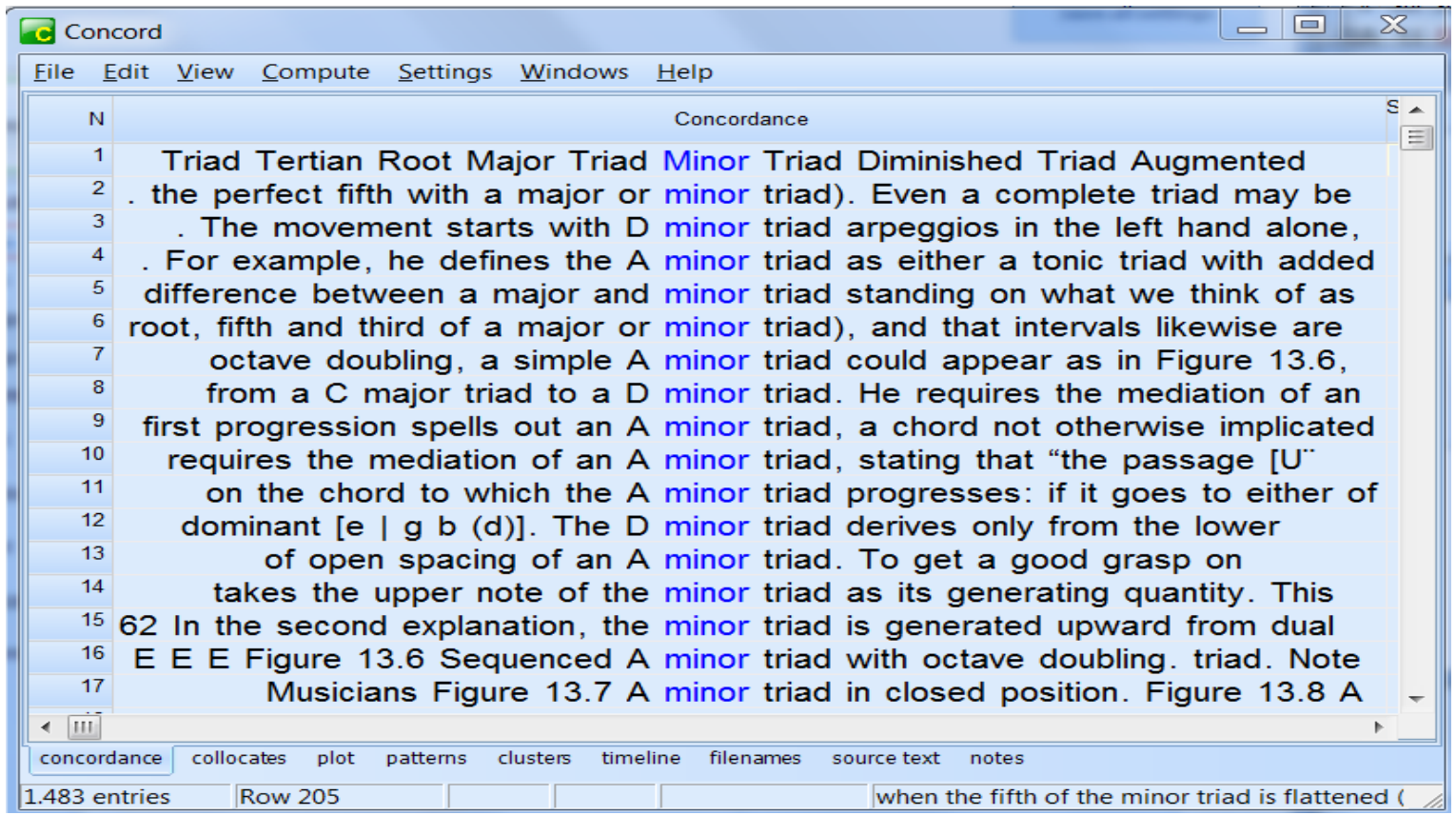

Figura 27 - Linhas de concordância (parciais) de "minor triad" 
A seguir, apresentamos alguns dos contextos de uso em que as colocações aparecem:

- In contrast, the minor third resembled the arithmetic mean, which Zarlino considered to be contrary to nature. He classified the minor triad as less perfect harmony, because unlike in the major triad, the elements are not arranged in their “natural” locations. (INGTMTE01)

- If the ninth of the chord sounds in the second of the two chords, it produces the major third of the previous minor chord. (INGTMDM04)

A partir da análise dos contextos, a escolha mais adequada para as correspondências entre as colocações são:

- Acorde perfeito menor $\Leftrightarrow$ minor triad

- Acorde menor $\Leftrightarrow$ minor chord

- Tríade menor $\Leftrightarrow$ minor triad

Para todas as entradas acima utilizaremos remissivas.

\section{6) Acorde aumentado, acorde de quinta aumentada, tríade aumentada}

Encontramos, no subcorpus instrucional, contextos definitórios semelhantes para as colocações "acorde aumentado", "acorde de quinta aumentada" e "tríade aumentada".

- Acorde Aumentado - É formado por duas terças maiores sobrepostas (ou por uma terça maior e uma quinta aumentada). (PORTMLIV02)

- Acorde de quinta aumentada - É formado pela fundamental (1), terça maior (3M) e quinta aumentada (5aum) e se caracteriza pela superposição de duas terças maiores. (PORTMAPO03)

- $\quad$ Tríade Aumentada - A tríade aumentada é formada pela fundamental (1), terça maior (3M) e quinta aumentada e se caracteriza, também, pela superposição de terças maiores. (PORTMLIV07)

"Acorde aumentado" tem frequência de 24 ocorrências (somadas as formas no singular e plural). "Acorde de quinta aumentada" ocorre 28 vezes e "tríade aumentada" aparece 49 vezes. 


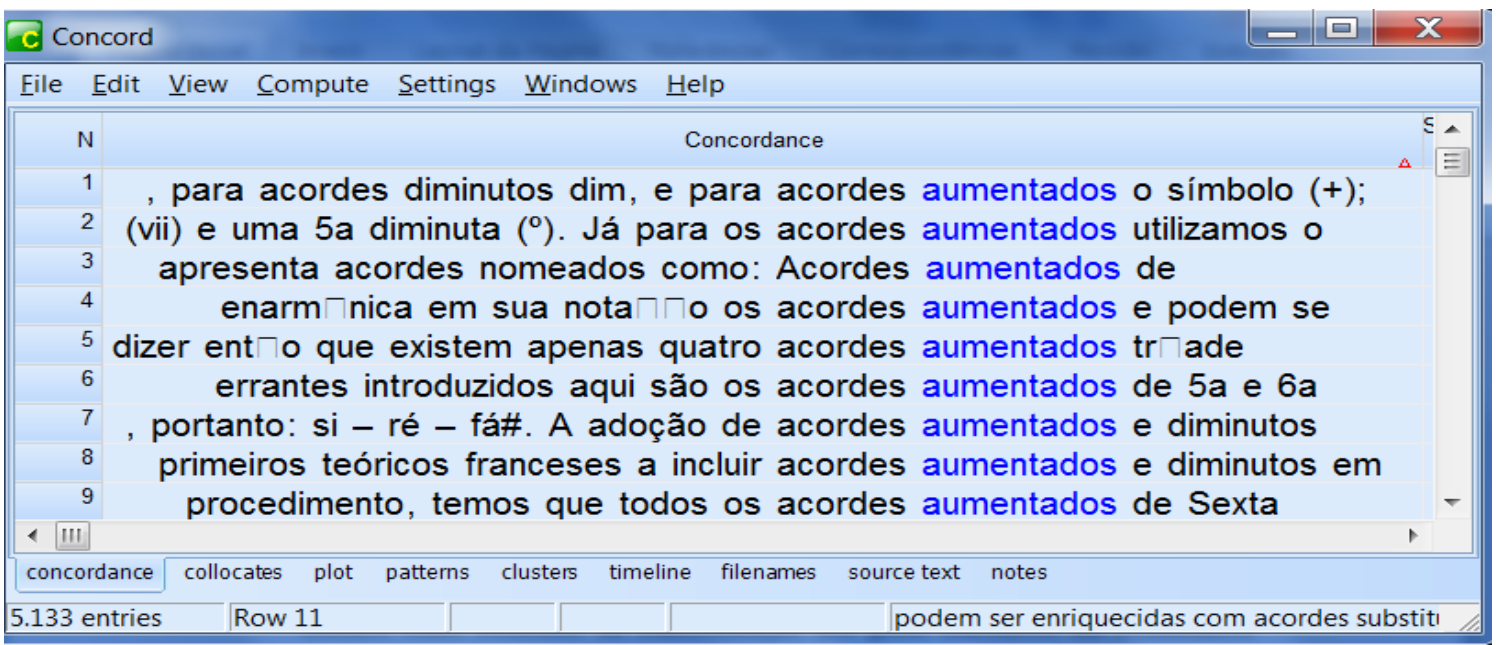

Figura 28 - Linhas de concordância (parciais) de "Acordes aumentados"

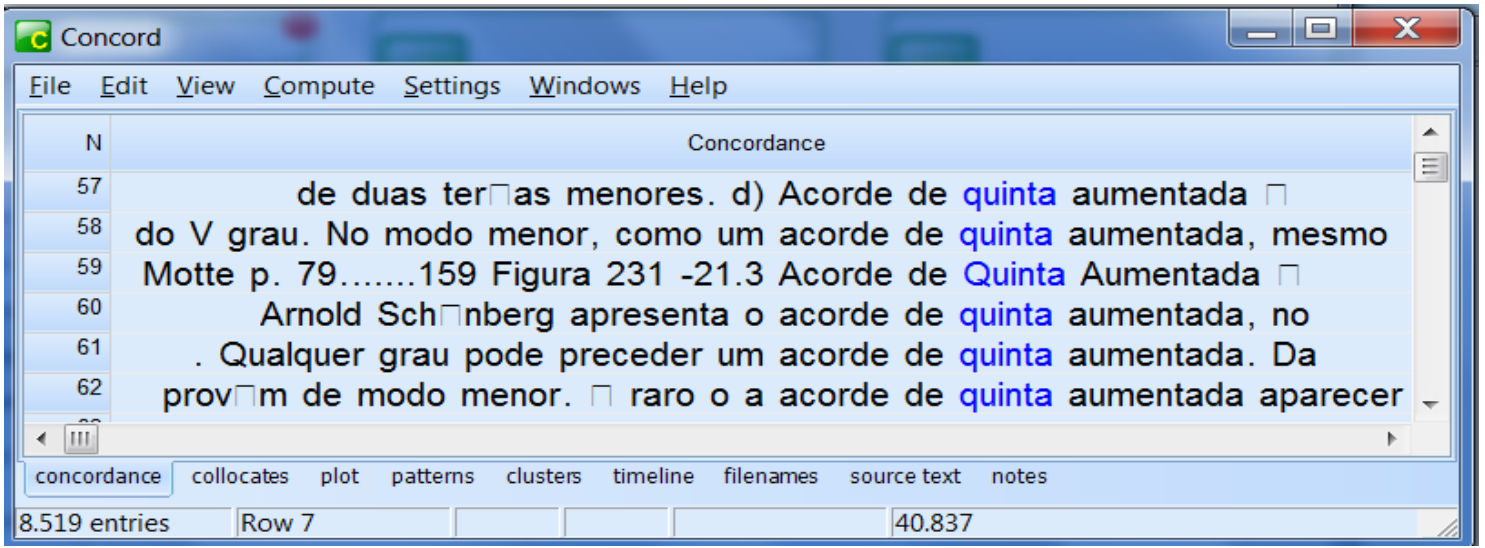

Figura 29 - Linhas de concordância (parciais) de "acorde de quinta aumentada"

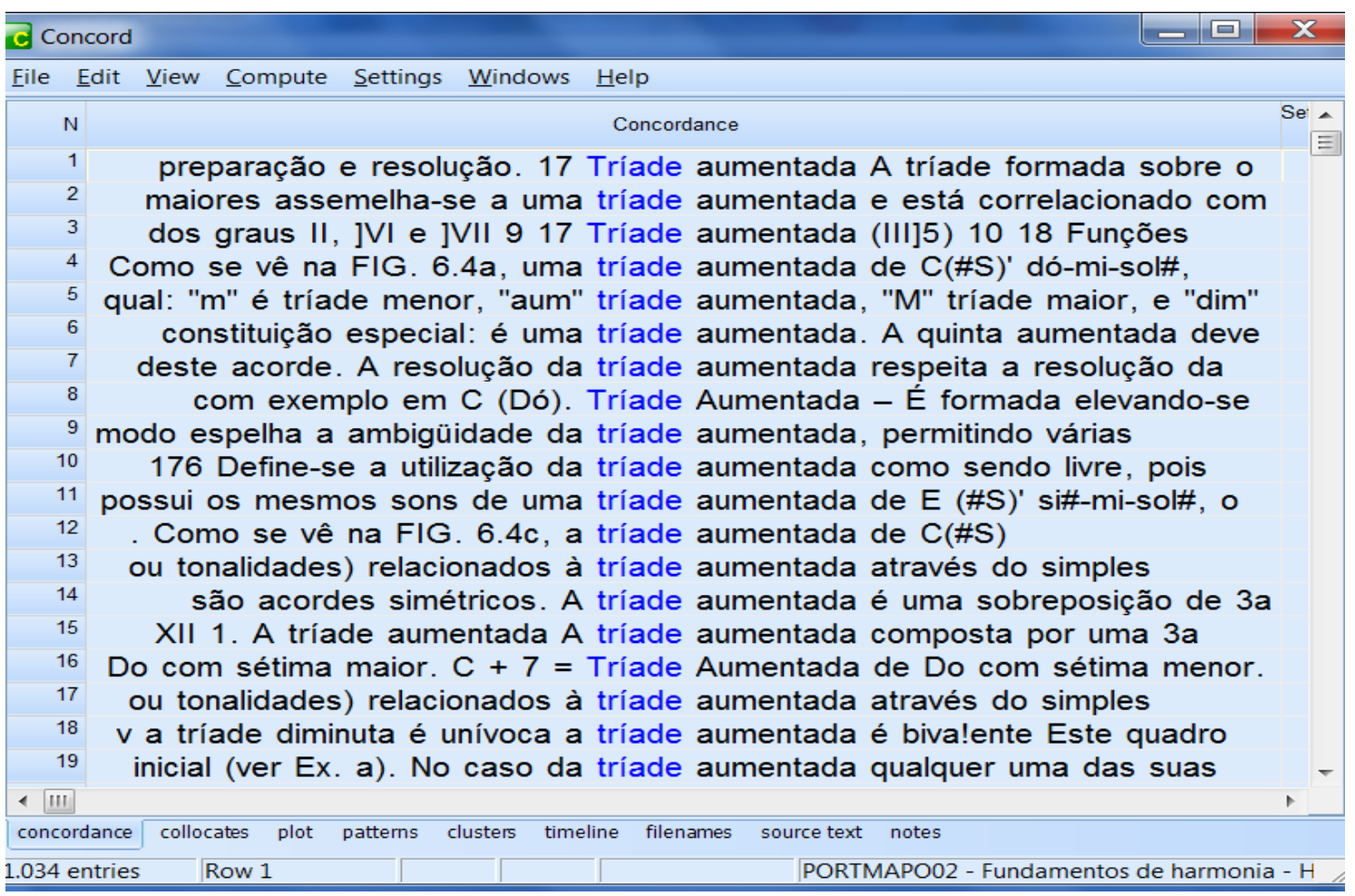

Figura 30 - Linhas de concordância (parciais) de "tríade aumentada" 
Selecionamos do subcorpus acadêmico-científico três trechos em que ocorrem as três colocações:

- A adoção de acordes aumentados e diminutos como representantes de funções secundárias, assim como a não identificação da tonalidade sugerida pelos acordes que representam as funções principais, geram as principais diferenças encontradas nos métodos em uso por Ian Guest e Musiarte em comparação com a Harmonia Funcional. (PORTMDM04)

- Para Schöenberg, o acorde de quinta aumentada pode ocorrer em qualquer grau, alterando-se a quinta, e nos acordes menores alterando-se também a terça. Qualquer grau pode preceder um acorde de quinta aumentada. Da mesma forma, pode-se encadear os acordes de quinta aumentada entre si. (PORTMDM01)

- A tríade aumentada também é considerada como um acorde vagante por ser composta de dois intervalos iguais. Assim como o que ocorre com o acorde de sétima diminuta, a tríade aumentada pertence a várias tonalidades distintas, três maiores e três menores, sendo que suas notas são sensíveis em potencial. A tríade aumentada tem uma série de aplicações nestas tonalidades (PORTMART18)

Embora em certos contextos os termos possam ser utilizados como variantes, "tríade aumentada" e "acorde de quinta aumentada" são mais específicos para o acorde com três notas. Um "acorde aumentado" pode se referir a um acorde com três (na sua formação inicial) ou apresentar mais notas, dependendo do contexto. No trecho a seguir, verifica-se que o autor acrescenta os termos tríade e tétrade para diferenciar o acorde aumentado:

(...) o acorde aumentado tétrade não é simétrico como o acorde aumentado tríade. (PORTMAPO03)

$\mathrm{Na}$ busca por correspondentes, encontramos duas colocações: augmented chord (4 ocorrências) e augmented triad (103 ocorrências). 


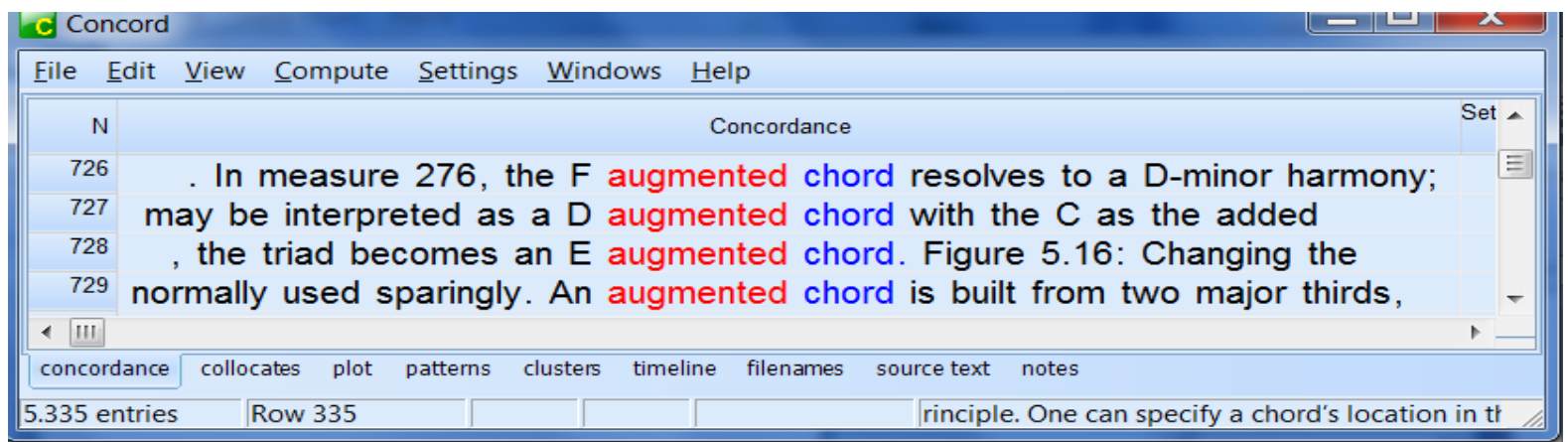

Figura 31 - Linhas de concordância (parciais) de "augmented chord"

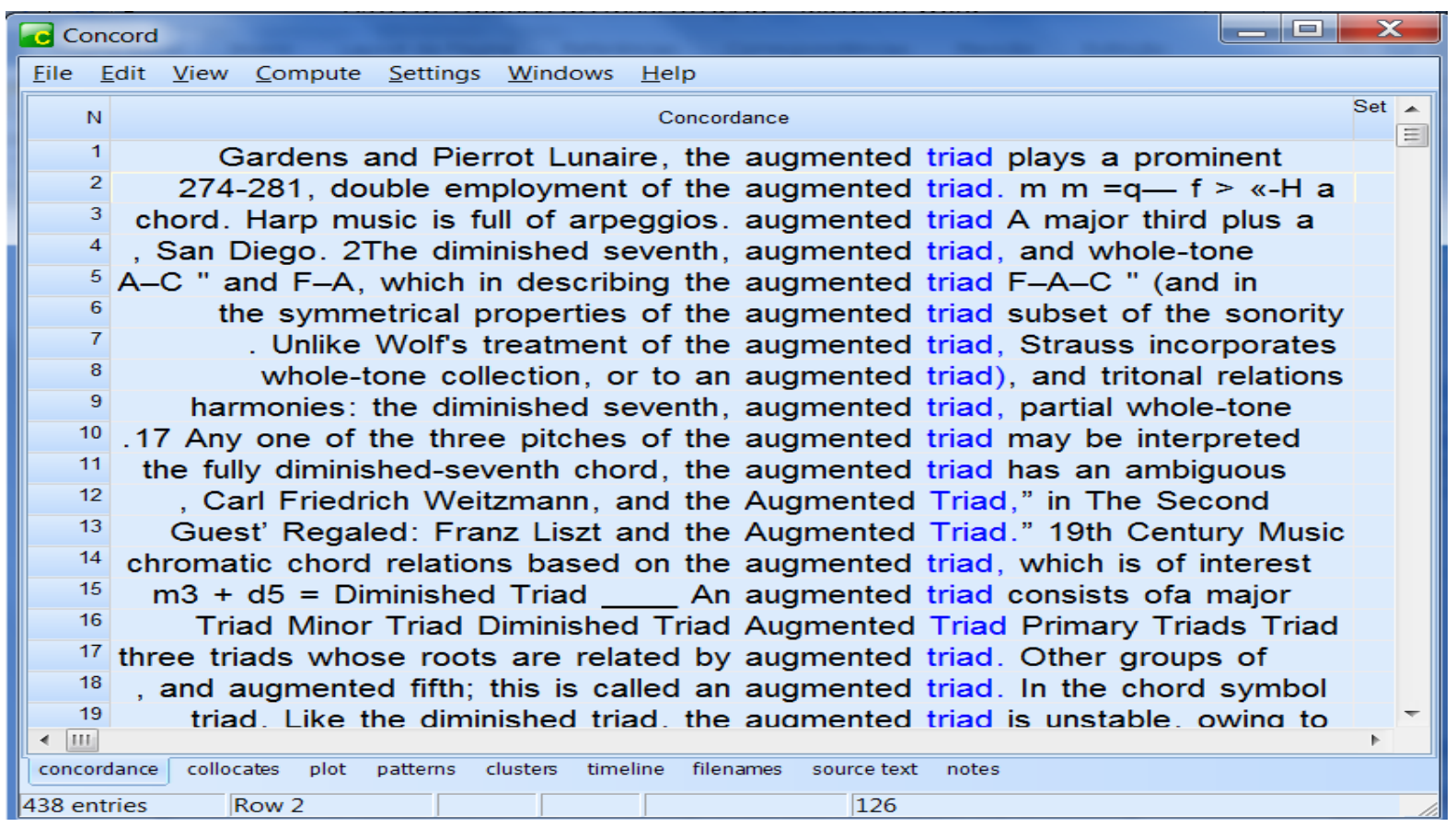

Figura 32 - Linhas de concordância (parciais) de "augmented triad"

Foram encontrados contextos definitórios similares aos de Português para tais colocações:

- An augmented chord is built from two major thirds, which adds up to an augmented fifth (INGMLIV03).

- An augmented triad consists of a major third and an augmented fifth. (INGTMLIV02)

Selecionamos do subcorpus acadêmico-científico, alguns exemplos de uso destas colocações:

- Like the fully diminished-seventh chord, the augmented triad has an ambiguous root that is defined by its context. (INGTMTE02) 
- For example, if, in an augmented $G$ sharp major chord, you rewrite the $D$ double sharp as an E natural, the triad becomes an E augmented chord. (INGTMTE02)

No segundo exemplo, verificamos que o uso da colocação augmented chord reforça a ideia de tríade, pois o termo "triad” é mencionado na oração.

Dessa análise, sugerimos as seguintes correspondências:

- Acorde aumentado $\Leftrightarrow$ Augmented chord

- Acorde de quinta aumentada $\Leftrightarrow$ Augmented triad

- Tríade aumentada $\Leftrightarrow$ Augmented triad

Para todas as entradas acima utilizaremos remissivas.

\section{7) Acorde diminuto, acorde de quinta diminuta, tríade diminuta}

A colocação "acorde diminuto" consta no dicionário DP-DOURADO com a seguinte definição:

Acorde formado por um intervalo de terça menor e uma quinta diminuta, ambos contados a partir da nota fundamental (Dó - Mi bemol - Sol bemol, por exemplo).

Verifica-se pela definição que o "acorde diminuto" é apresentado como uma "tríade diminuta". No corpus de estudo, a colocação (acorde diminuto) apresenta uma frequência alta (315 ocorrências).

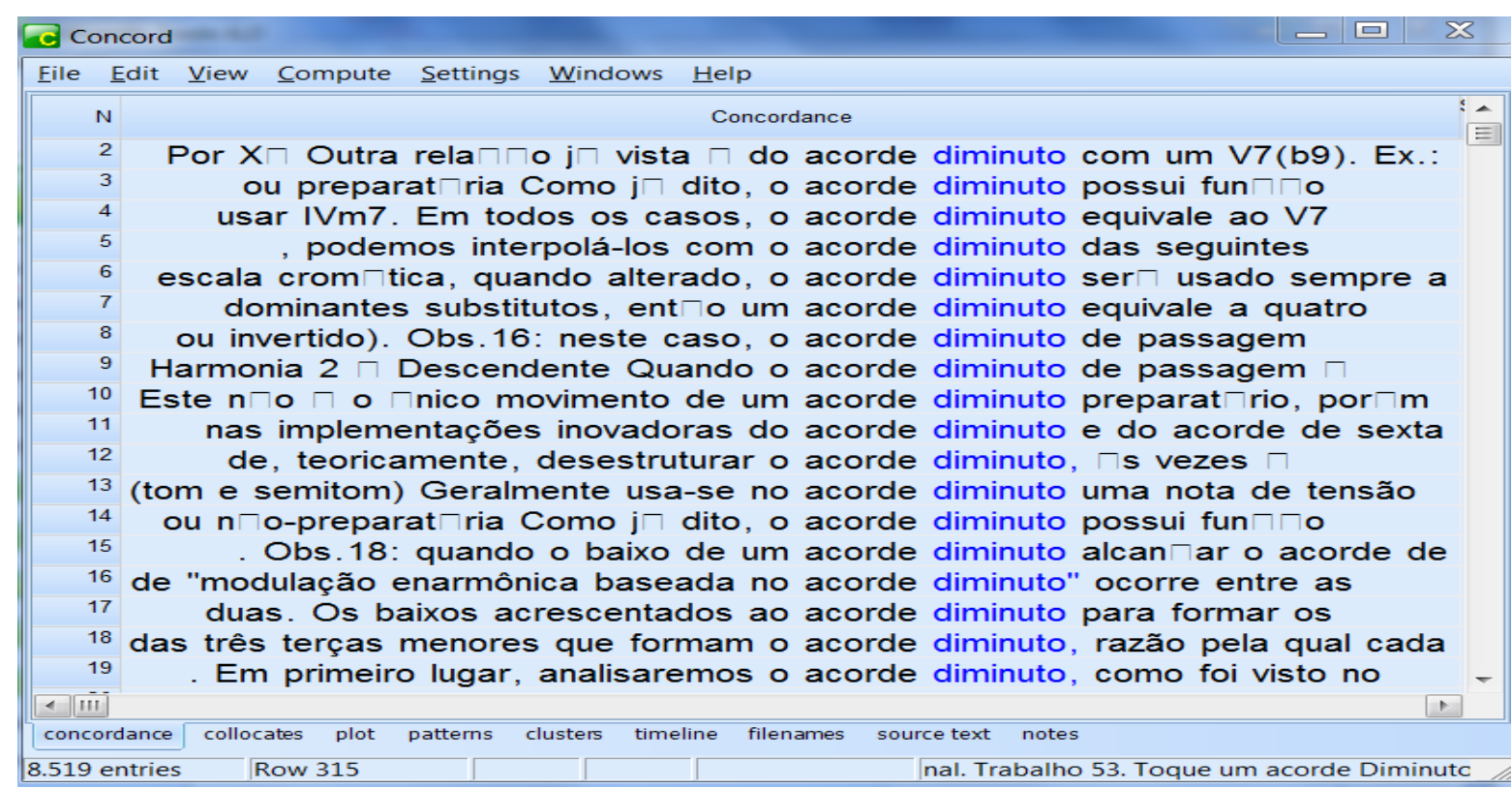

Figura 33 - Linhas de concordância (parciais) de "acorde diminuto" 
Da análise dessas ocorrências, observamos que, em certos contextos, a colocação nem sempre se refere a um acorde com três notas, mas a uma tétrade:

- $O$ acorde diminuto é formado pela sobreposição de três terças menores, relativas à fundamental, terça menor, quinta diminuta e sétima diminuta, dividindo a oitava em quatro partes iguais. (PORTMAPO05)

- Verifica-se aqui a segunda simetria existente na formação das tétrades. $O$ acorde diminuto, conforme demonstrado, possui a mesma digitação a cada um tom e meio. Isto é possível porque as notas constituintes deste acorde também estão equidistantes de terças menores. (PORTMDM03)

No subcorpus instrucional, as colocações "acorde de quinta diminuta" ocorrências) e "tríade diminuta" (45 ocorrências) apresentam conceitos similares:

- Acorde de quinta diminuta. É formado por duas terças menores (ou por uma terça menor e uma quinta diminuta).(PORTMLIV02)

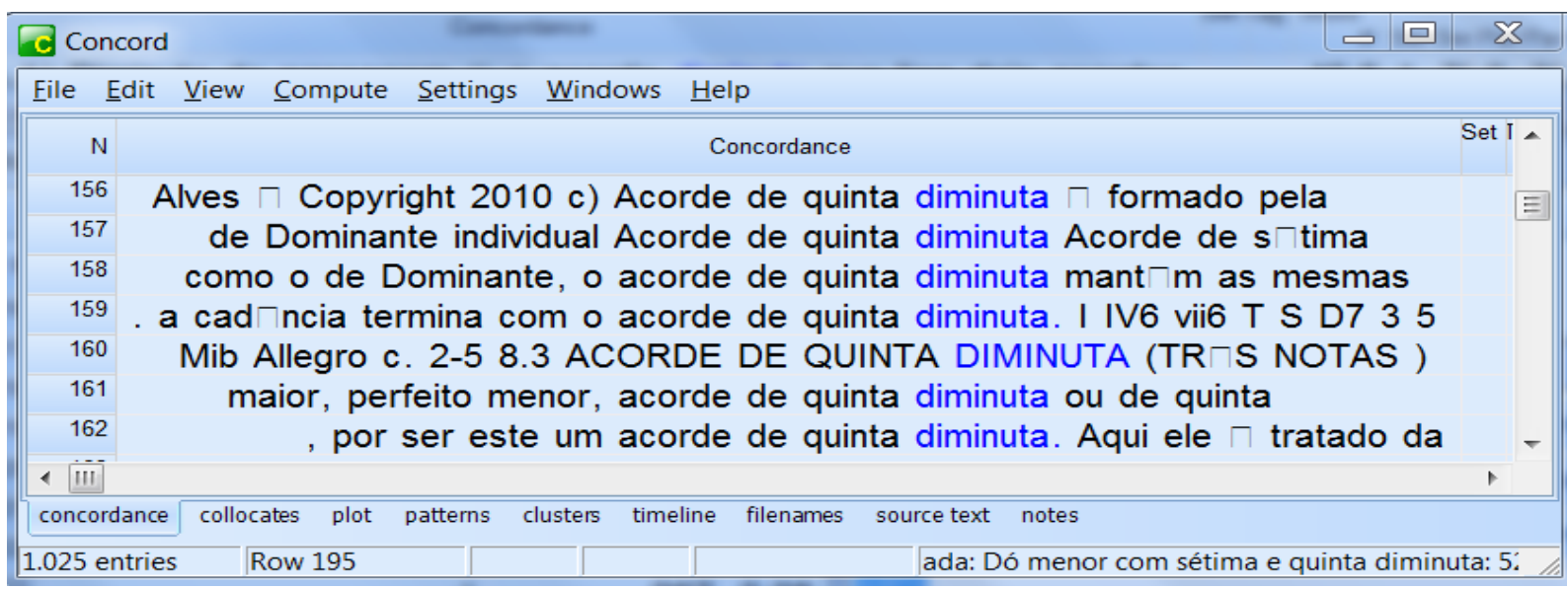

Figura 34 - Linhas de concordância de "acorde de quinta diminuta"

- Tríade diminuta. É formada pela fundamental, terça menor e quinta diminuta e se caracteriza, também, pela superposição de duas terças menores. (PORTMLIV07) 


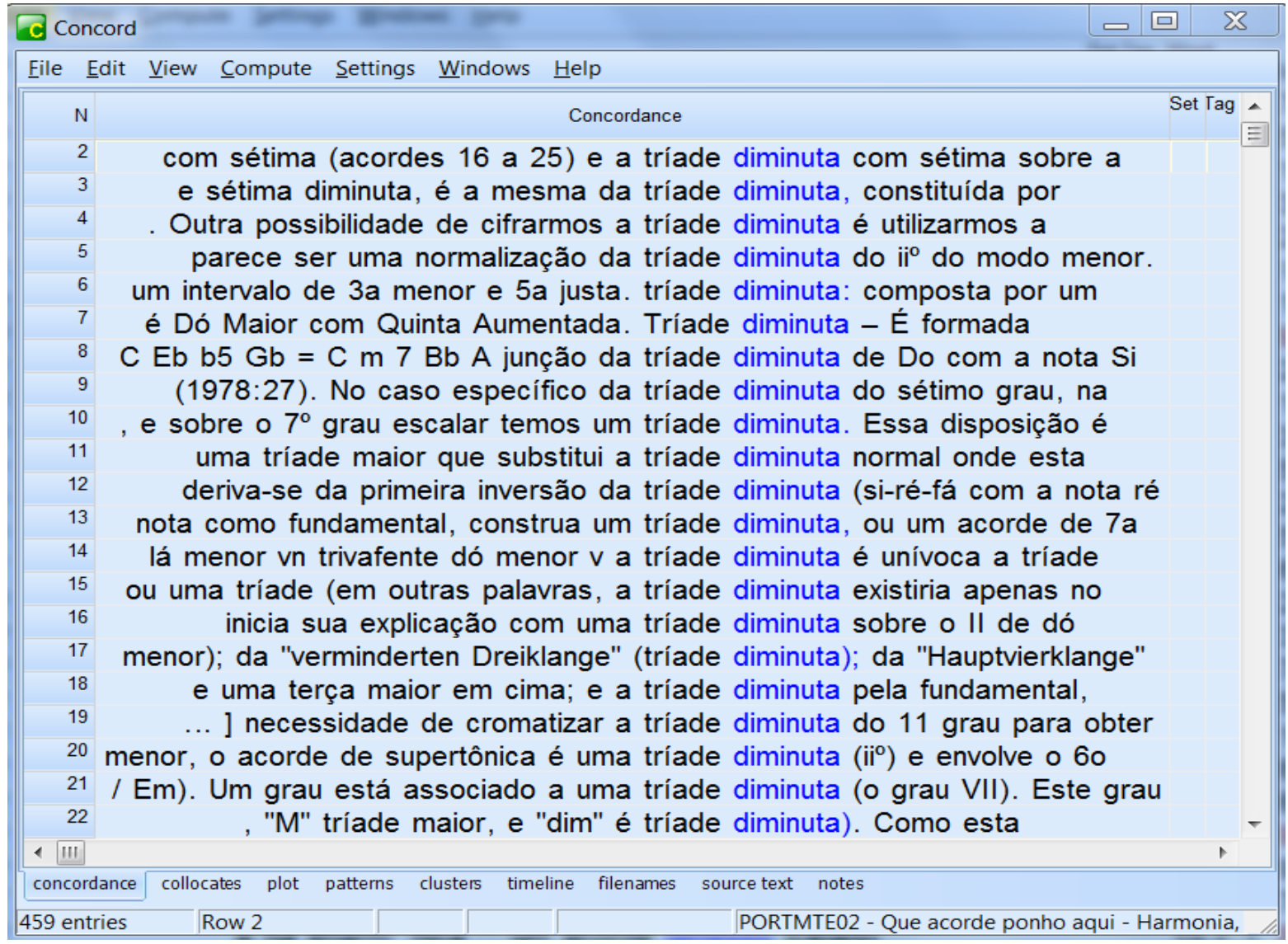

Figura 35 - Linhas de concordância (parciais) de "tríade diminuta"

Nos contextos de uso abaixo, verifica-se que as duas colocações são utilizadas para tornar claro que o acorde (diminuto) está no formato de duas terças sobrepostas (3 notas):

- Para a utilização dos acordes sem a alteração, Schöenberg não impõe qualquer restrição aos encadeamentos com estes acordes. Lembrando que estamos tratando até este ponto dos acordes no estado fundamental. Ou seja, para os acordes da chamada escala natural, as instruções de encadeamento continuam as mesmas do modo maior, apenas ressaltando que o acorde de quinta diminuta acontece aqui no II grau e vai exigir a preparação da quinta diminuta por ser um intervalo dissonante. (PORTMDM01)

- Cada grau é representado por algarismo romano (em maiúsculo quando a tríades é maior, e minúsculo quando a tríade é menor), além de uma indicação particular quando se trata de uma tríade diminuta(...) (PORTMART19) 
As colocações correspondentes encontradas no subcorpus Inglês foi diminished chord (42 ocorrências) e diminished triad (67 ocorrências).

\begin{tabular}{|c|c|c|c|}
\hline C Conce & $\square \square$ & $\Sigma$ & \\
\hline File $\underline{E} d$ & dit View Compute Settings Windows $\underline{\text { Help }}$ & & \\
\hline $\mathrm{N}$ & Concordance & Set & $\hat{-}$ \\
\hline 20 & 2.77 "To You" 8 after A; Diminished chord used to facilitate scalar toggling & & \\
\hline 21 & to $G$ octatonic via the diminished chord symbol. The resolution of the $G$ & & \\
\hline 22 & points, including the diminished chord on the sharpened fourth to & & \\
\hline 23 & chord-scales. The diminished chord in this example is labeled G\#o7 & & \\
\hline 24 & to C octatonic via the diminished chord. This octatonic collection is then & & \\
\hline 25 & with a half step). The diminished chord also may be explained as a & & \\
\hline 26 & collection applied to a diminished chord in "To You." Here all & & \\
\hline 27 & E Aminor Chord ii B D F B diminished Chord III C E G C major Chordiv D F & & \\
\hline 28 & up to an augmented fth. A diminished chord is built from two minor thirds, & & \\
\hline 29 & because you can $\neg t$ have a diminished chord as tonic. The next example & & \\
\hline 30 & 2.77 "To You" 8 after A; Diminished chord used to facilitate scalar toggling & & \\
\hline 31 & to A octatonic via the diminished chord. The A octatonic chord-scale & & \\
\hline 32 & to $G$ octatonic via the diminished chord. As is the case with & & \\
\hline 33 & options is clearly the diminished chord. Combining Haerle, Baker, and & & \\
\hline 34 & resolution) as well as a VII diminished chord in A minor.107 107 The G\#0 & & 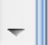 \\
\hline 1 IIII & & 1 & \\
\hline concorda & ance collocates plot patterns clusters timeline filenames source text notes & & \\
\hline 5.335 ent & it resolves. The diminished chord then not o & & \\
\hline
\end{tabular}

Figura 36 - Linhas de concordância (parciais) de "diminished chord"

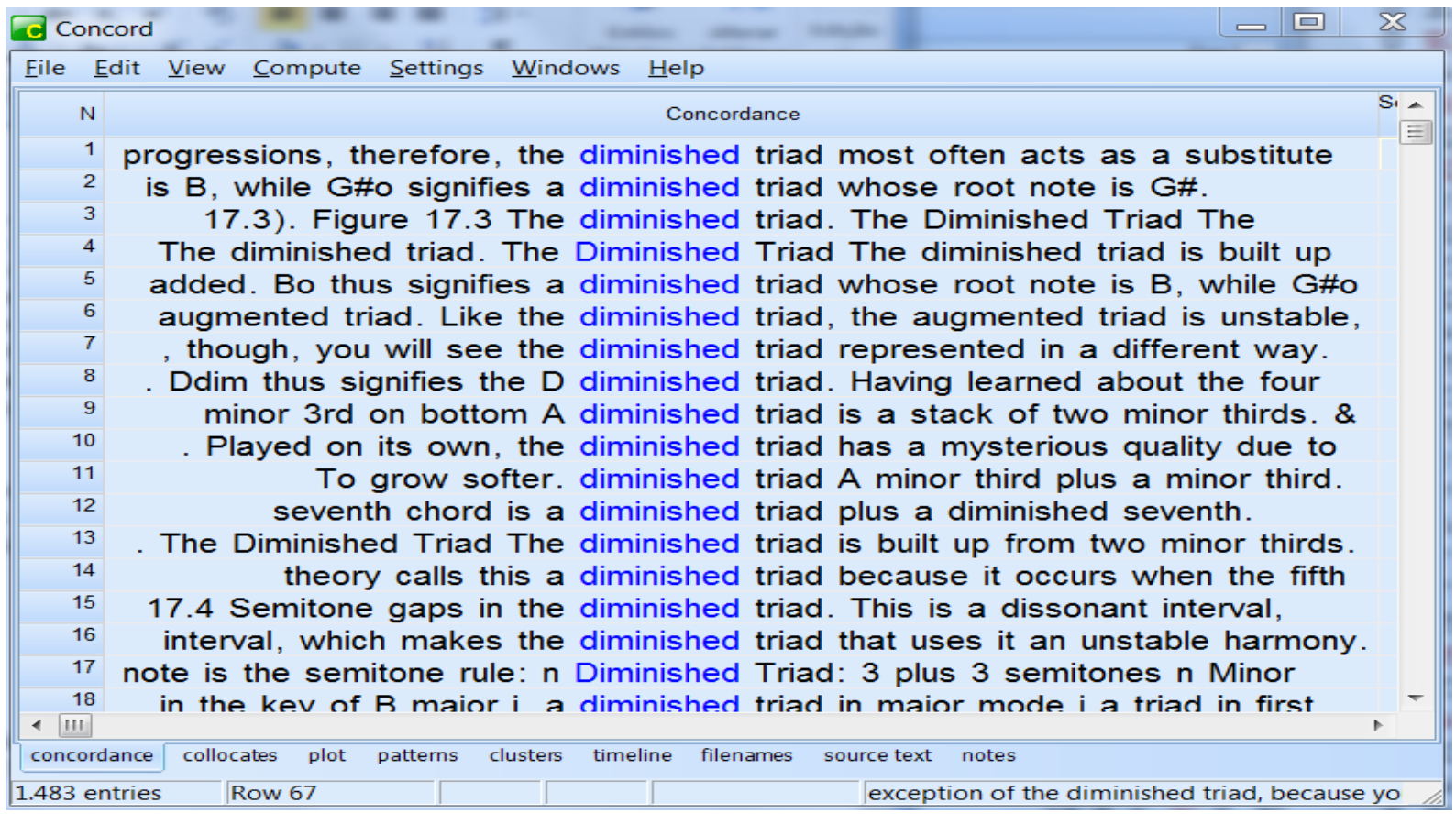

Figura 37 - Linhas de concordância de "diminished triad"

$\mathrm{Na}$ pesquisa realizada em dicionários de termos musicais, encontramos as seguintes definições: 
- Diminished Chord - A chord that has a diminished interval between its highest and lowest notes. (DI-ON MUSIC)

- Diminished Triad - See Triad. The diminished triad, in which both intervals are minor thirds and the outer interval, is a diminished fifth. (DI-HARVARD)

No corpus instrucional, encontramos contextos definitórios similares:

- A diminished chord is built from two minor thirds, which add up to a diminished fifth. (INGTMLIV03)

- A diminished triad consists of a minor third and a diminished fifth. (INGTMLIV02)

Selecionamos do subcorpus acadêmico-científico, alguns exemplos de uso destas colocações:

- But as I have argued previously, the function is the same because the pitch collection actually applied to A diminished chords is the same as D7 chords with alterations. (INGTMDM04)

- In practice the diminished triad built on the second scale degree, found in the minor mode, does not follow the same logic as the diminished triad on the seventh degree. (INGTMTE02)

Comparando os dois exemplos, o uso da colocação diminished triad no exemplo anterior é mais específico do que diminished chords do primeiro exemplo (que compara os acordes com os de Ré com sétima, D7).

Dessa análise, sugerimos as seguintes correspondências:

- Acorde diminuto $\Leftrightarrow$ Diminished chord

- Acorde de quinta aumentada $\Leftrightarrow$ Augmented triad

- Tríade aumentada $\Leftrightarrow$ Augmented triad

Para todas as entradas acima utilizaremos remissivas. 


\section{8) Acorde de sétima, tétrade}

A colocação "acorde de sétima" apresenta frequência bem significativa no corpus de estudo: 213 ocorrências no singular e 128 no plural. É uma das colocações que consta nos dicionários especializados pesquisados:

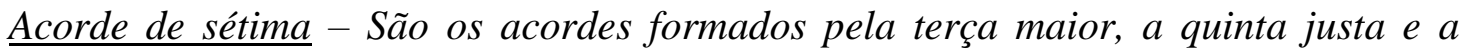
sétima menor. (DP-GALTER)

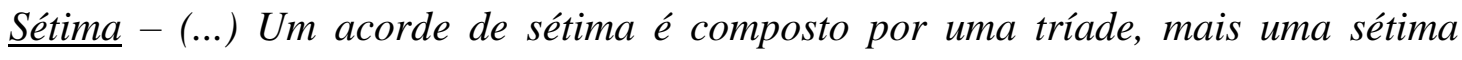
contada a partir de sua fundamental (sol-si-ré-fá, na tonalidade de dó maior). (DPDOURADO)

No subcorpus instrucional, encontramos os seguintes contextos definitórios:

- Acorde de sétima: tem quatro notas diferentes e é formado por três terças sobrepostas. As notas extremas do acorde formam um intervalo de sétima. É chamado de tétrade. (PORTMLIV02)

- Os acordes de sétima são acordes formados pela sobreposição de três terças sobre uma nota fundamental. $O$ acorde é então formado por quatro notas diferentes entre si. Tal como a tríade, os acordes de sétima também têm suas notas denominadas de acordo com seu intervalo a partir da fundamental (PORTMAPO01)

As definições encontradas no corpus partem da característica geral, sem mencionar a qualidade dos intervalos, já que há vários tipos de acordes de sétima. Na definição do dicionário DP-GALTER, o autor especifica apenas um dos “acordes de sétima”. 


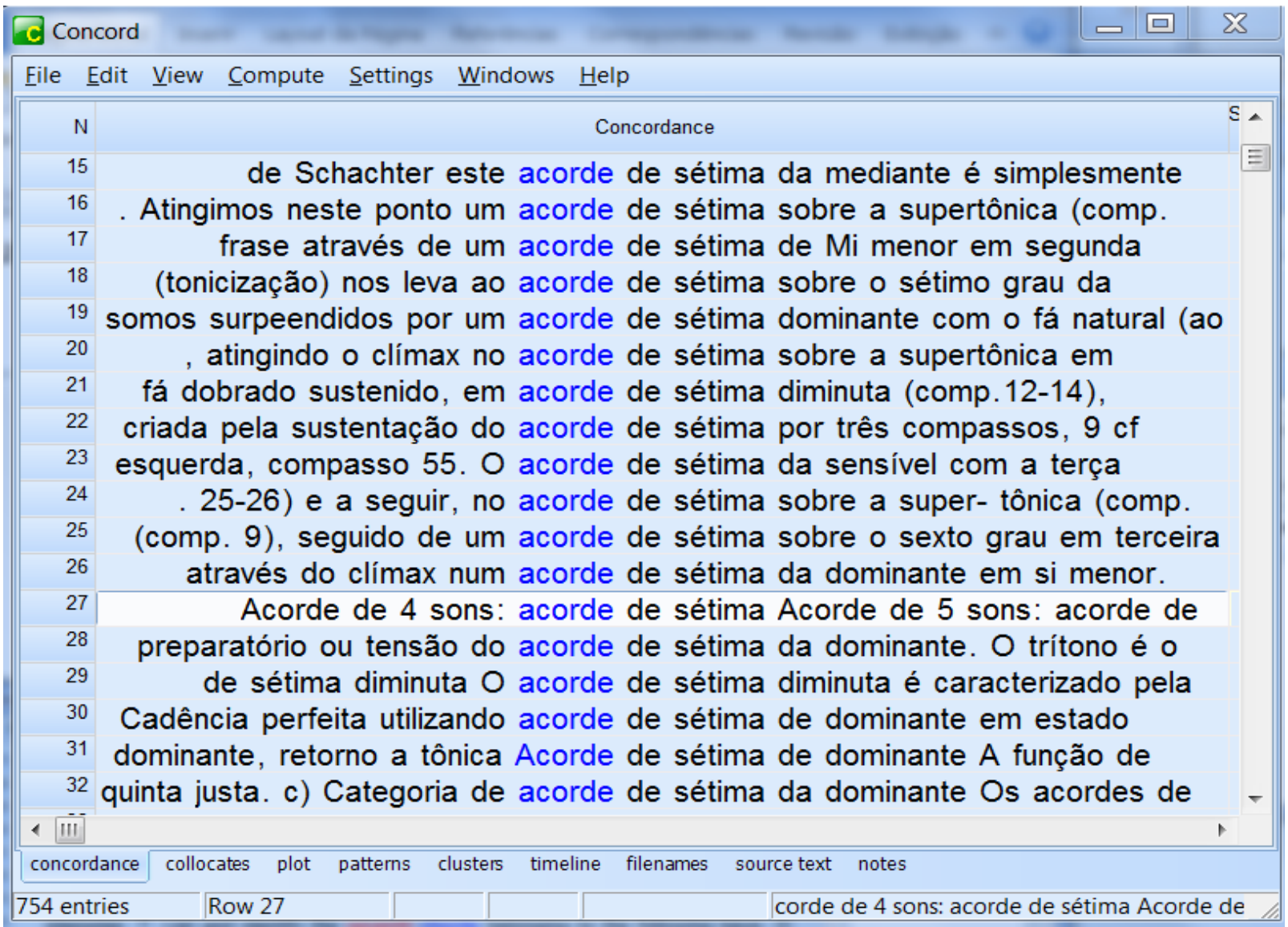

Figura 38 - Linhas de concordância (parciais) de "acorde de sétima"

O termo variante para a colocação "Acorde de sétima" é "Tétrade", que apresenta 242 ocorrências no corpus. Localizamos um contexto definitório no subcorpus instrucional semelhante aos conceitos de acorde de sétima mencionados anteriormente:

- A tétrade é formada pelo agrupamento de quatro sons separados por intervalos de terças sobrepostas. (PORTMLIV07) 


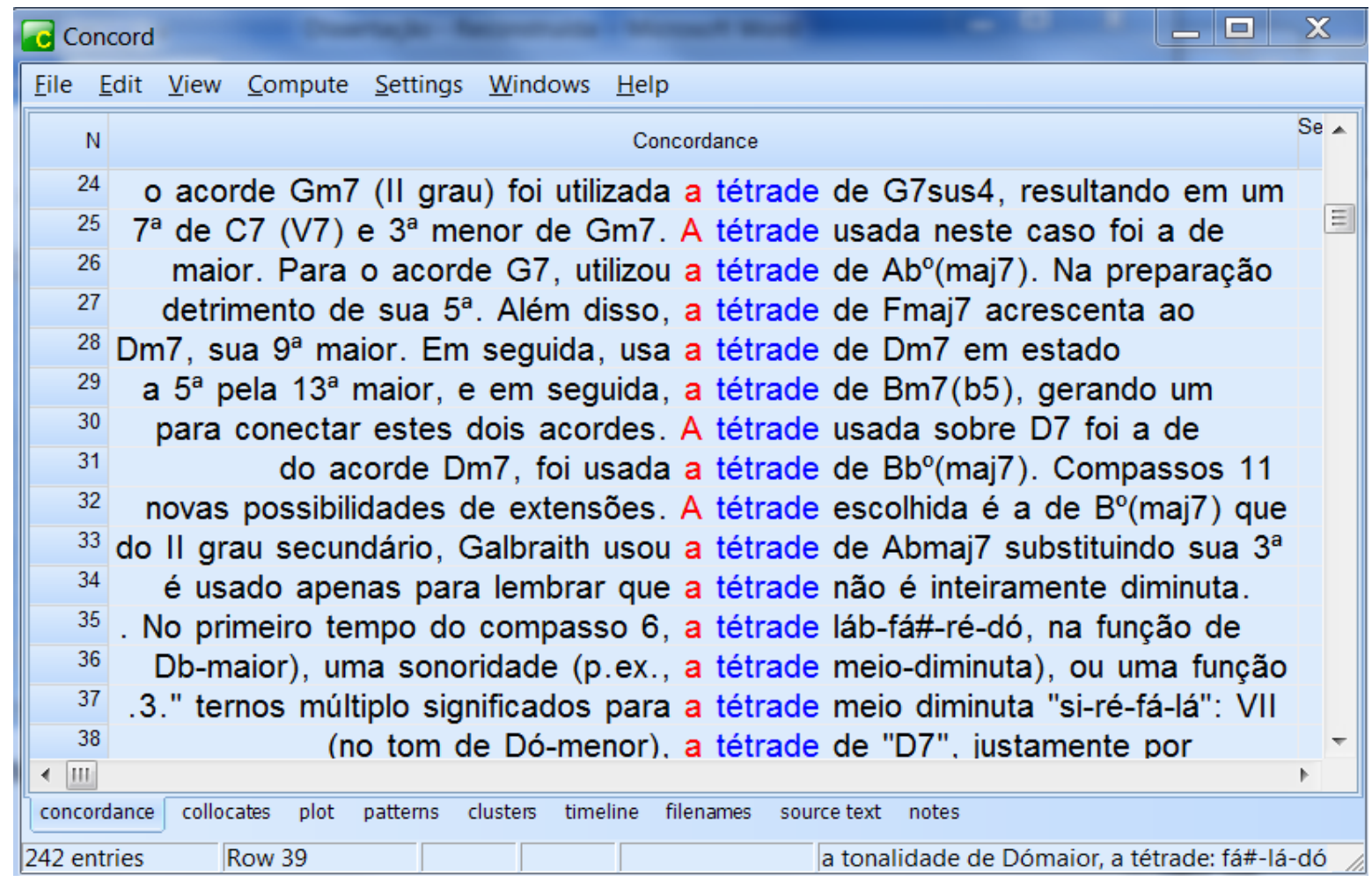

Figura 39 - Linhas de concordância (parciais) de "tétrade"

O trecho a seguir mostra a colocação em contexto de uso:

O acorde de tônica é ouvido apenas na última colcheia do compasso 8, movendo-se imediatamente para um acorde de sétima sobre a subtônica em segunda inversão (comp. 9), seguido de um acorde de sétima sobre o sexto grau em terceira inversão e um acorde de dominante que nos deixa esperando pela resolução da tônica. (PORTMART25)

A colocação correspondente localizada no subcorpus de Inglês foi Seventh chord, com 337 ocorrências. A colocação também foi uma das encontradas na pesquisa aos dicionários de termos musicais, conforme abaixo:

- Seventh chord: A triad with a seventh added (See dominant seventh chord; diminished seventh chord; secondary seventh chord) (DI-OXFORD)

- Seventh chord: A chord formed by the addition of pitches a third, a fifth, and a seventh above the lowest pitch or root, such a chord can be formed on any of seven scale degrees of the major or minor scale, the intervals above the root varying by type (i.e, major, minor, etc) Accordingly for the various types of 
seventh chords that can result, see Harmonic Analysis I; for inversions of seventh chords, see Inversion II; for the types and nomenclature of seventh chords used in jazz and popular music, see Fakebook notation. Since seventh is dissonant with the root (forming a seventh or, in inversion, a second), all seventh is dissonant. In tonal harmony and counterpoint, therefore, the seventh chord requires resolution through the resolution of the dissonant pitch, usually downward by step(...) (DI - HARVARD)

No subcorpus de Estudo, encontramos o seguinte contexto definitório:

- A seventh chord is formed by adding another third above the fifth of the triad. The seventh chord built on the dominant is the most common seventh chord in tonal music. (INGTMLIV02)

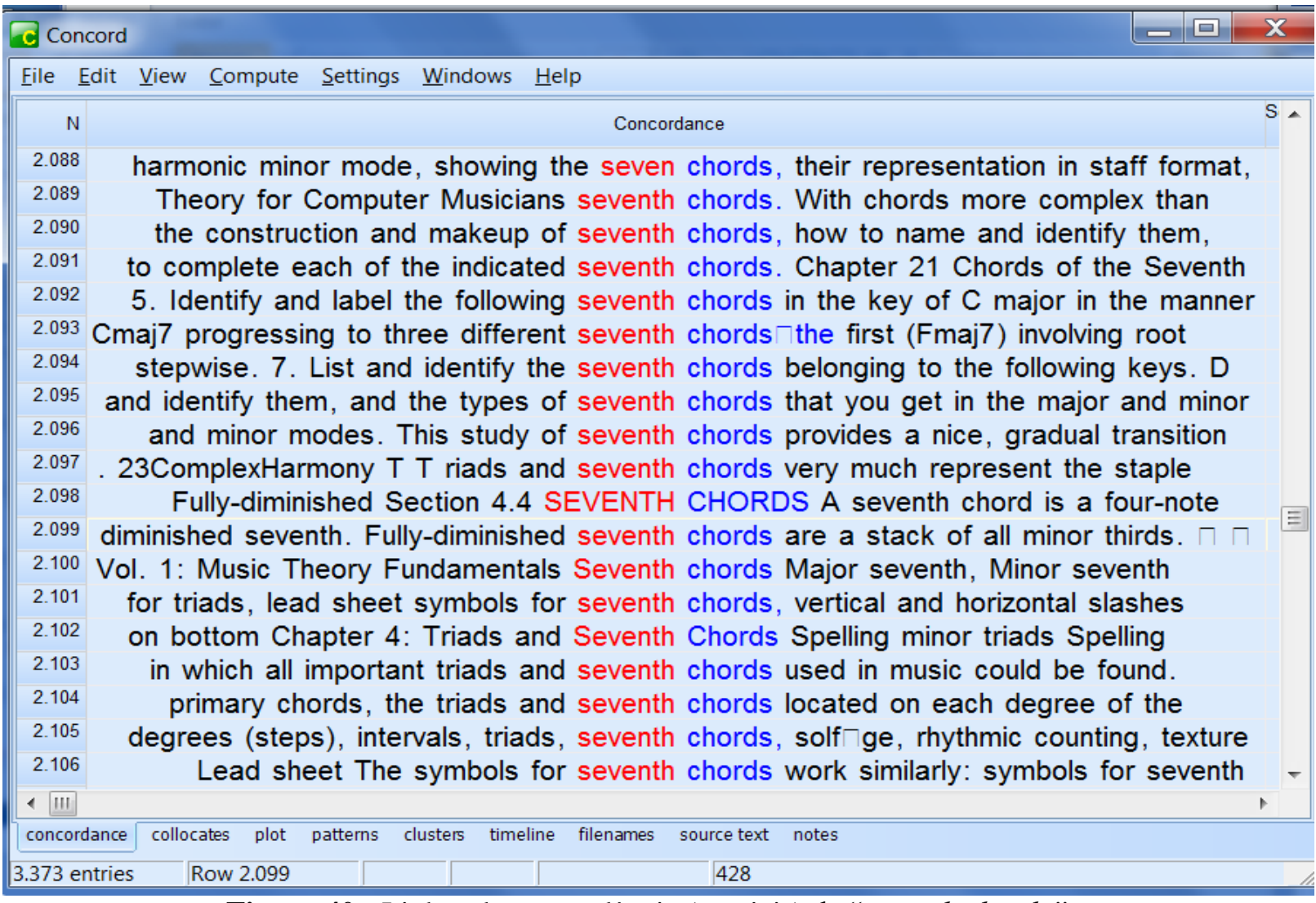

Figura 40 - Linhas de concordância (parciais) de "seventh chords"

Selecionamos o seguinte contexto de uso da colocação: 
In a number of popular styles, static sonorities may be used without necessarily setting up any expectation for resolution. These sonorities may be triads, seventh chords or other extended tertian chords, or diatonic collections. (INGTMART15)

Verificamos na lista de clusters que a colocação "acorde de sétima” dá origem a outras colocações mais específicas, que serão apresentadas em outros subitens: "acorde meiodiminuto", "acorde de sétima diminuta", "acorde de sétima da sensível”, "acorde de sétima da dominante".

Dessa análise, sugerimos as seguintes correspondências:

- Acorde de sétima $\Leftrightarrow$ seventh chord

- Tétrade $\Leftrightarrow$ seventh chord

Para todas as entradas acima utilizaremos remissivas.

\section{9) Acorde meio-diminuto}

A colocação "acorde meio-diminuto" apresenta a frequência de 117 ocorrências. Encontramos no Dicionário DP-DOURADO “Acorde de Meia Diminuta ou Meio Diminuto”, com a seguinte definição:

(Ingl. Half-diminished) Comum na Bossa Nova e no Jazz, consiste em um acorde diminuto com uma sétima menor agregada (dó - mi bemol - sol bemol - s dobrado bemol).

Selecionamos um contexto definitório no subcorpus instrucional, que apresenta uma explicação um pouco mais detalhada:

Acorde meio-diminuto: quinta diminuta e sétima menor $(4$ notas, função subdominante). Este acorde encontra-se no ii (grau) de uma tonalidade menor, cuja base é de quinta diminuta, acrescentado de sétima menor. Aparece geralmente com a terça no baixo, resolve na Dominante e sua função é de Subdominante menor, com quinta e sexta. (PORTMAPO06) 


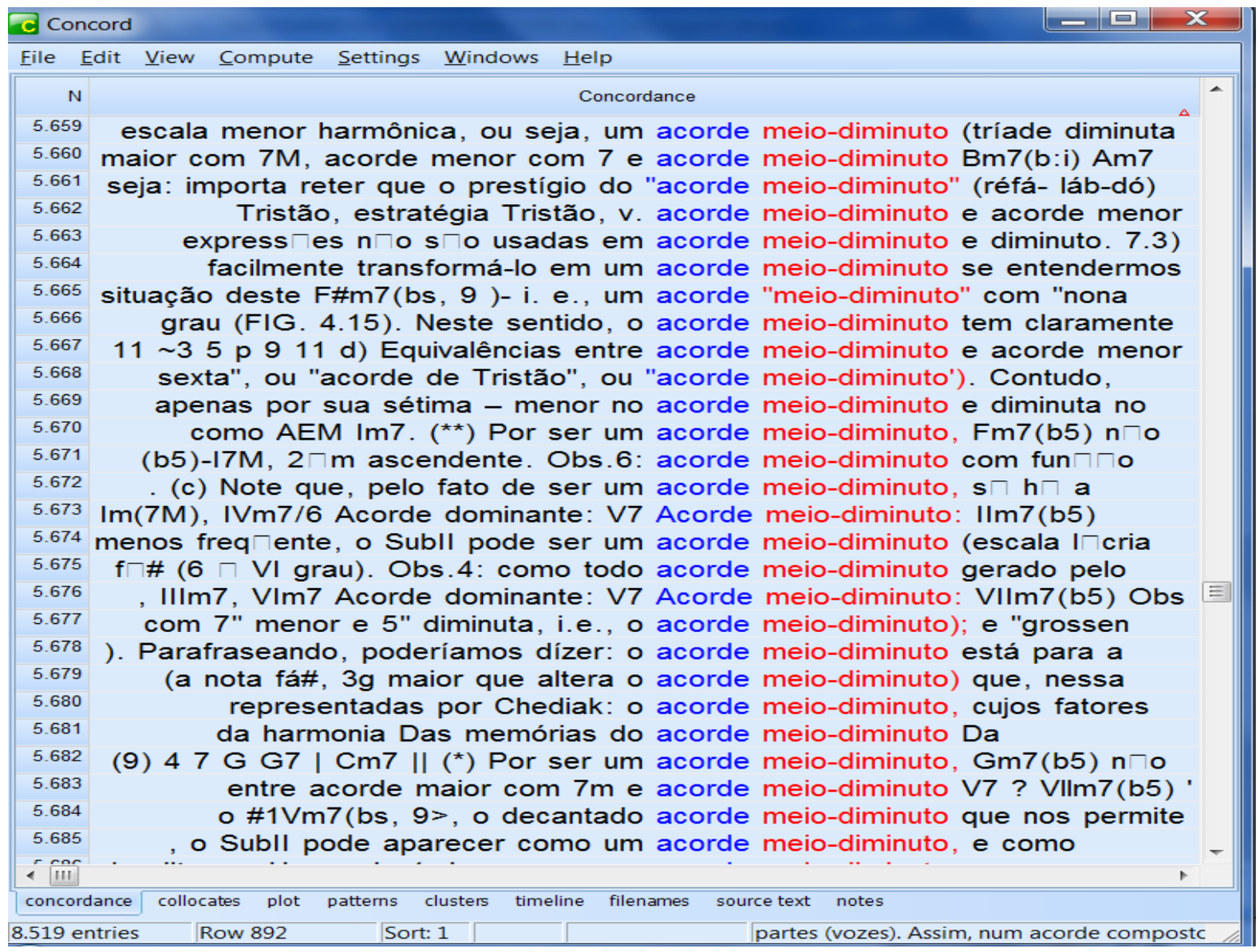

Figura 41 - Linhas de concordância (parciais) de "acorde meio-diminuto"

Para mostrar a colocação em contexto de uso, selecionamos alguns excertos do subcorpus acadêmico-científico:

- No modo menor o lugar natural da tétrade meio-diminuta é o II grau (notas ré-fáláb-dó em Cm:), usualmente tratado como um acorde da função subdominante que, dependendo da posição e da inversão, como já vimos, será cifrado como IIm7(b5) ou IVm6 (o acorde de sexta acrescentada, ou acorde de Rameau no modo menor). Nesse contexto, o acorde meio-diminuto tem função pré-dominante. (PORTMTE02)

- Para a música popular a cadência II-V é fundamental e o VII grau com sétima menor (chamado de meio-diminuto) é entendido antes como um II na cadência II$V$ de um acorde menor e, neste contexto, tem função de subdominante. "Esta ambigüidade faz do acorde meio-diminuto com sétima um útil adjunto nãodominante em passagens que modulam rápida e repetitivamente, aonde o 
compositor deseja evitar temporariamente a estabilização da tonalidade". (PORTMART24)

- Várias referências ao mundo romântico repercutem nessa tentativa de problematizar a memória artística do acorde meio-diminuto. (PORTMTE02)

No subcorpus de Inglês, encontramos a colocação half-diminished seventh chord (39 ocorrências) e a forma reduzida half-diminished chord (17). O trecho abaixo apresenta um contexto definitório:

- A half-diminished seventh has a diminished triad and a minor seventh. (INGTMLIV08)

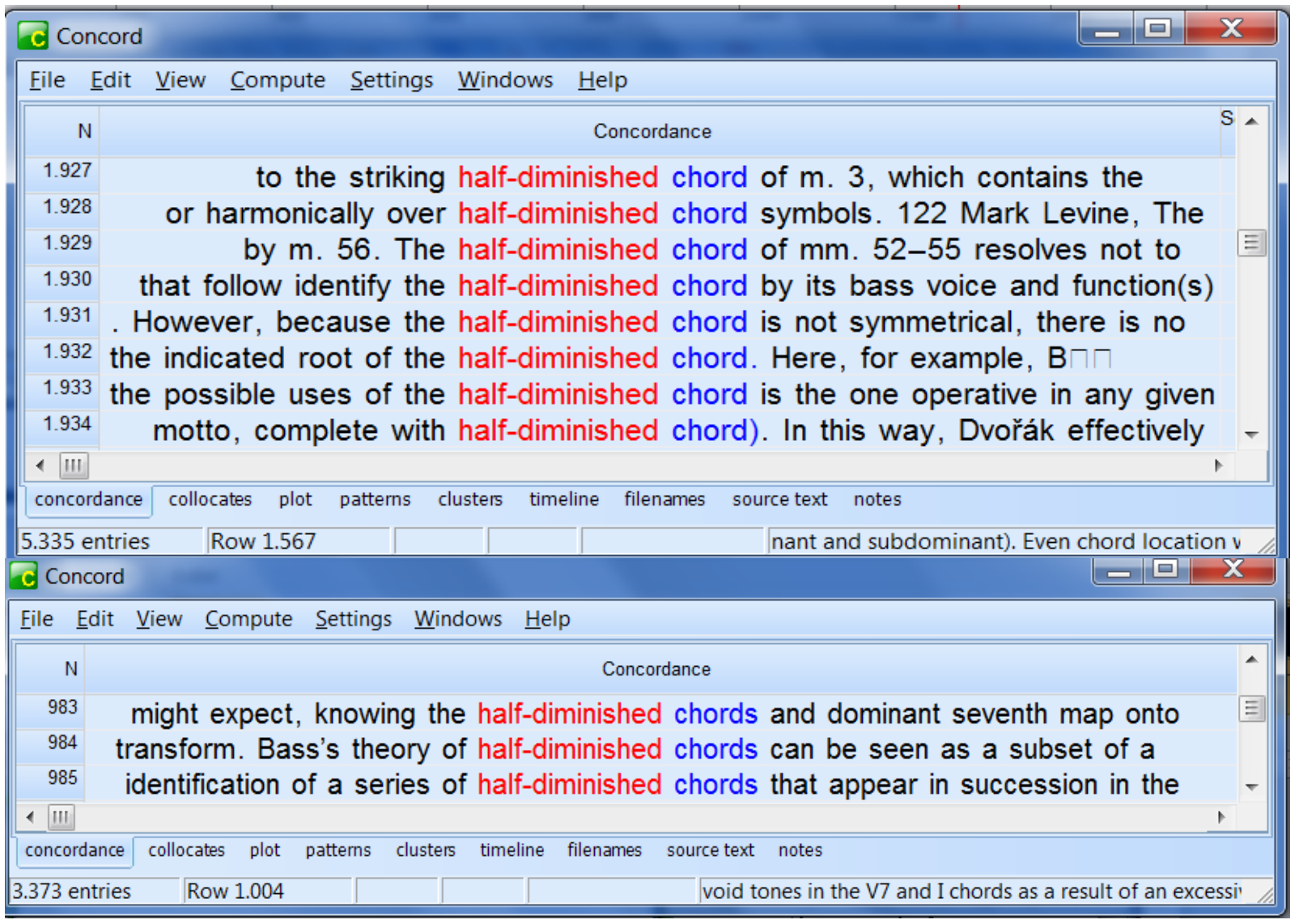

Figura 42 - Linhas de concordância (parciais) de "half-diminished chords" (singular plural) 
Selecionamos o seguinte contexto de uso da colocação:

The use of a half-diminished seventh chord for the beginning of the theme seems patterned after Wagner, as does the appoggiatura in the second measure. (INGTMDM01)

A partir da observação dos excertos anteriores, verifica-se que as colocações Acorde meio diminuto e Half-diminished seventh chord ( e a forma reduzida half-diminished chord) são correspondentes.

\section{0) Acorde de sétima diminuta, tétrade diminuta}

A colocação "acorde de sétima diminuta” apresenta a frequência de 59 ocorrências.

No capítulo 2, mencionamos que a colocação foi encontrada no dicionário DPGALTER. Nesta obra, ela apresenta a seguinte definição:

- Acorde de sétima diminuta: são os acordes constituídos pela terça menor, quinta diminuta e a sétima diminuta. (DP-GALTER)

Também localizamos uma variante dessa colocação no dicionário DP-DOURADO:

- Sétima da Diminuta: Acorde construído sobre uma tríade diminuta acrescida de uma sétima menor alterada descendentemente, contada a partir da tônica (do-mi bemol - sol bemol - si dobrado bemol)

No corpus de estudo, não encontramos ocorrência para a colocação "sétima da diminuta". Das 80 ocorrências do agrupamento "sétima diminuta", 59 co-ocorrem com acorde de. Das 21 ocorrências restantes, apenas 3 são formas reduzidas de acorde de sétima diminuta; sendo as outras referentes aos termos nota e intervalo.

Selecionamos os seguintes contextos definitórios do subcorpus instrucional:

- É o acorde de quinta diminuta mais sétima diminuta. É encontrado frequentemente no grau VII da escala menor - forma harmônica e melódica ascendente. (PORTMLIV02) 
- Caracteriza-se pela terça menor, quinta diminuta e sétima diminuta. É construído diatonicamente sobre o VII grau da escala menor harmônica, grau este de função dominante. Caracteriza-se, também, pela presença de dois trítonos. (PORTMLIV07).

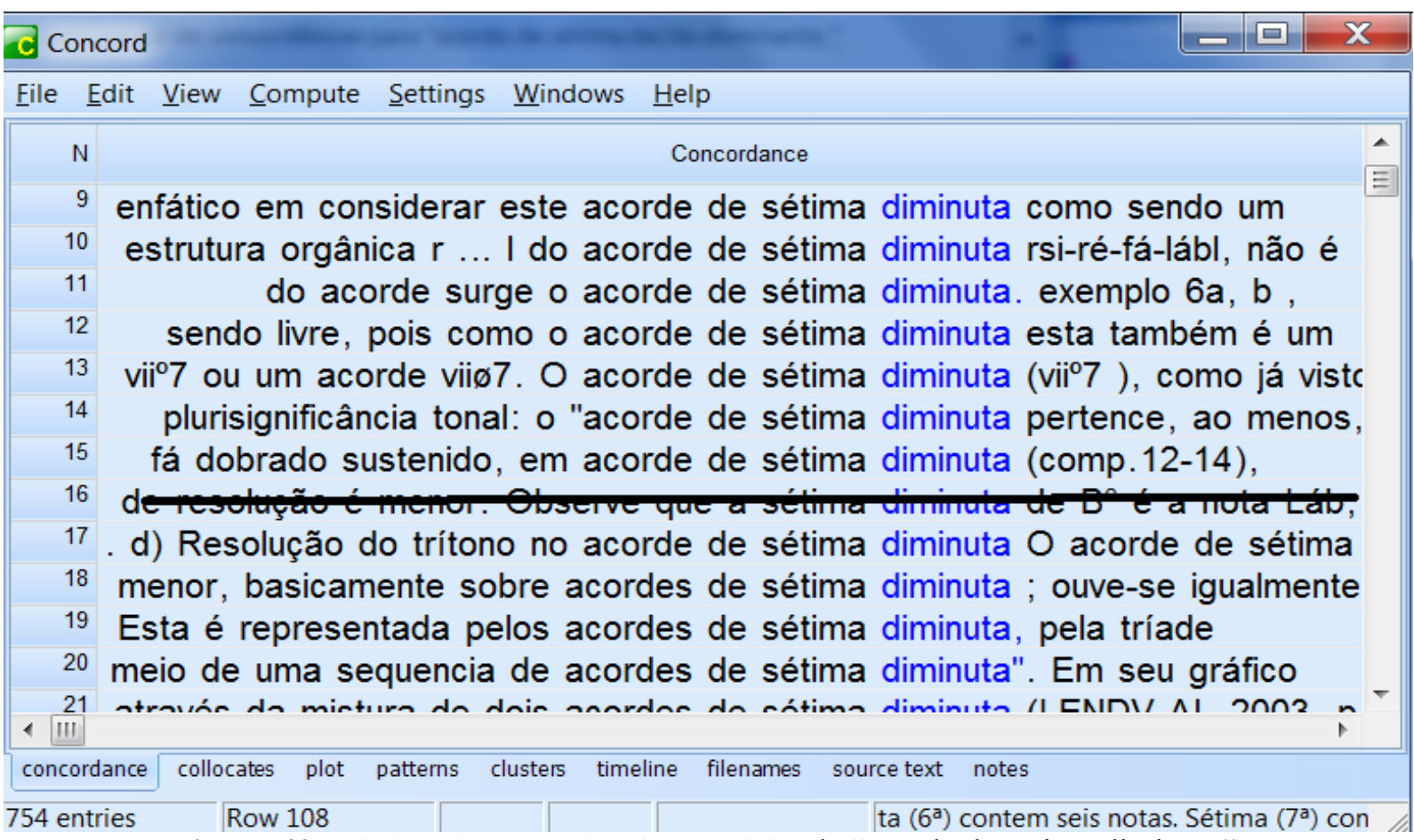

Figura 43 - Linhas de concordância (parciais) de "acorde de sétima diminuta"

O termo variante para a colocação acorde de sétima diminuta é tétrade diminuta, que apresenta 23 ocorrências no corpus. O contexto definitório extraído do subcorpus instrucional apresenta:

Tétrade diminuta: Formada por dois trítonos sobrepostos. (PORTMAPO04) 


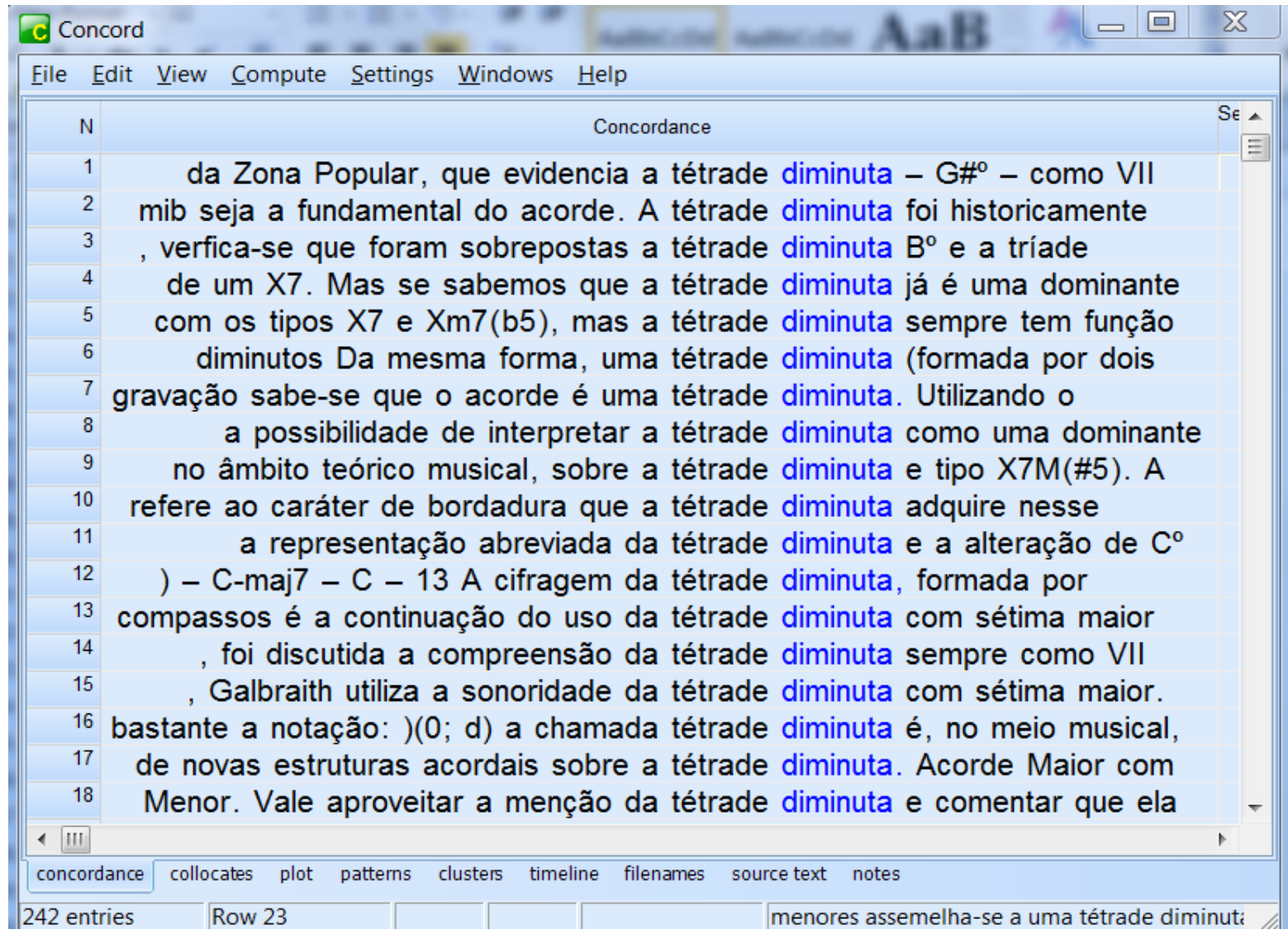

Figura 44 - Linhas de concordância (parciais) de "tétrade diminuta"

- A tríade aumentada também é considerada como um acorde vagante por ser composta de dois intervalos iguais. Assim como o que ocorre com o acorde de sétima diminuta, a tríade aumentada pertence a várias tonalidades distintas, três maiores e três menores, sendo que suas notas são sensíveis em potencial. (PORTMART18)

- A tétrade diminuta foi historicamente gerada pelo VII grau da Escala Menor Harmônica e costuma ser compreendida como uma dominante com nona menor e sem fundamental. Mas o diminuto em questão não é, nem enarmonicamente, VII grau de Dó Maior ou Menor, sendo, portanto, dominante de outro tom: ou seja, é um acorde modulante. (PORTMTE01)

No subcorpus de Inglês, encontramos a colocação diminished seventh chord (102 ocorrências) e fully-diminished seventh chord (14 ocorrências). O trecho abaixo apresenta um contexto definitório: 
- The diminished seventh chord is symmetrical, being composed entirely of minor thirds. (INGTMLIV07)

- A fully-diminished seventh chord is a diminished triad plus a diminished seventh. Fully-diminished chords are usually referred to as, simply, "diminished". (INGTMLIV08)

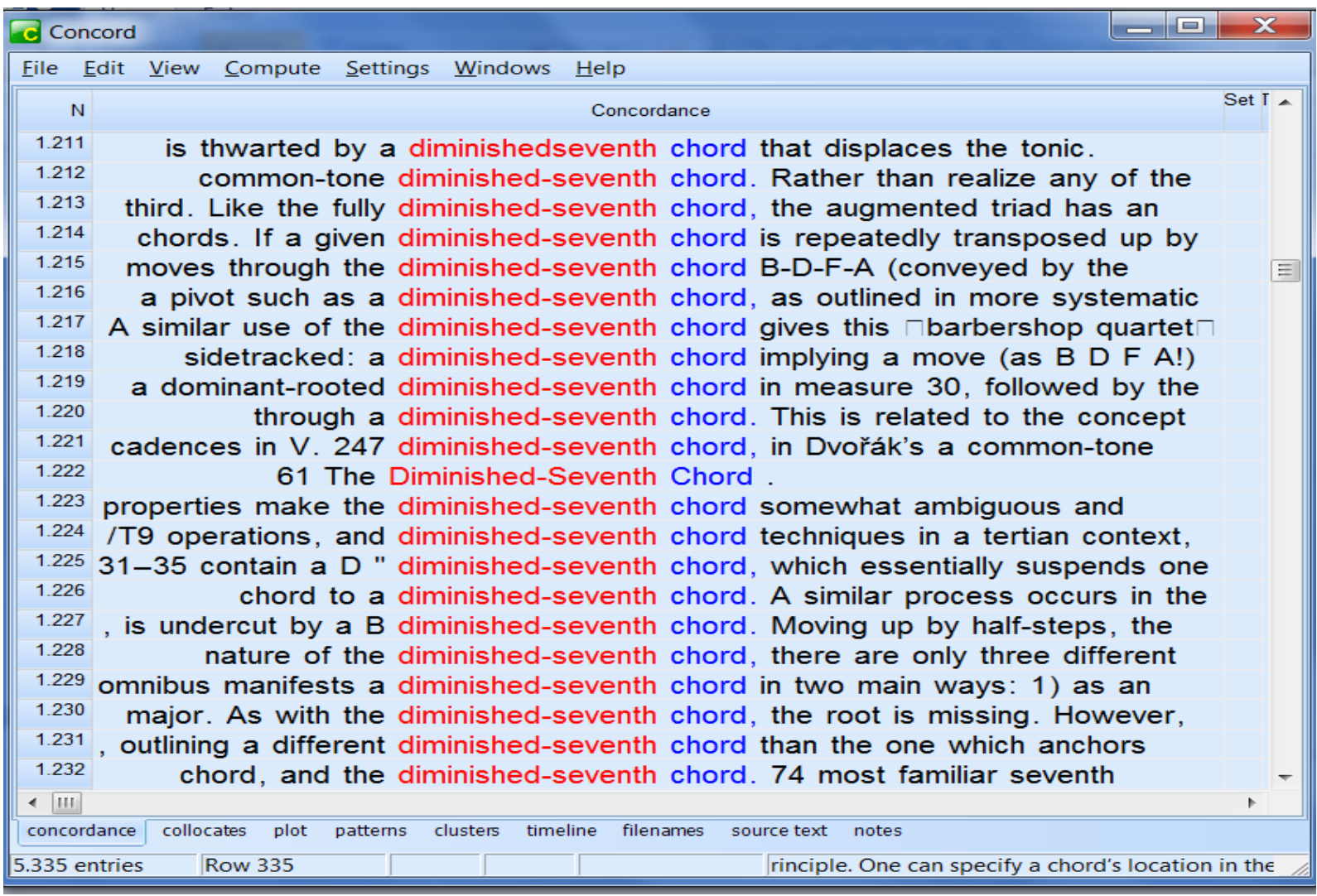

Figura 45 - Linhas de concordância (parciais) de "diminished-seventh chords"

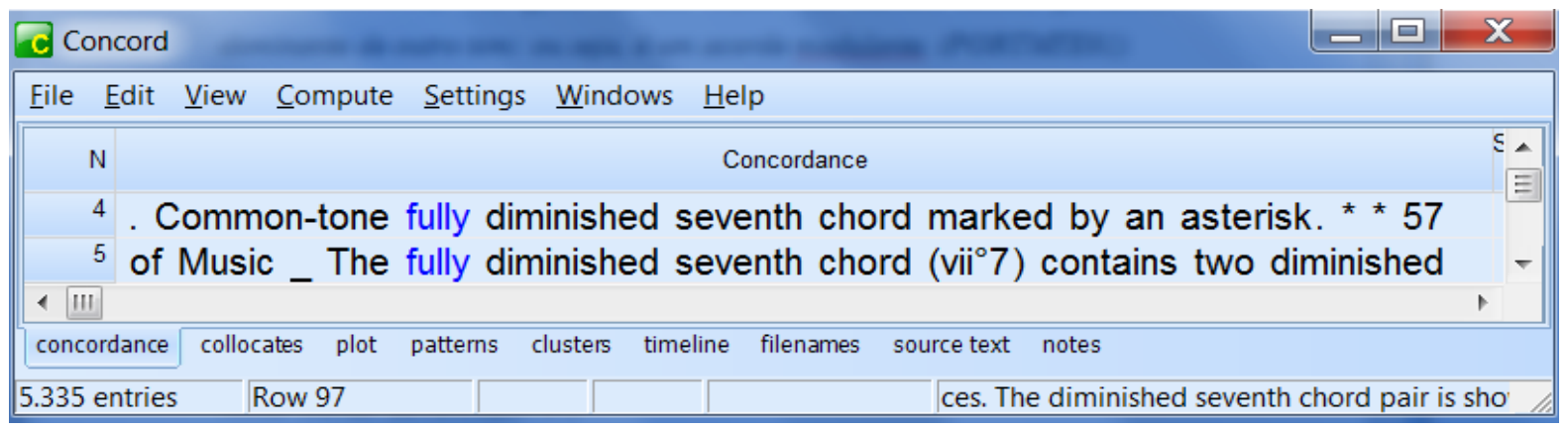

Figura 46 - Linhas de concordância (parciais) de "fully diminished seventh chords"

Selecionamos os seguintes contextos de uso das colocações: 
- The diminished seventh chord plays an important role in transforming the V7-I framework; it adds welcomed chromaticism and "improves" the voice leading between the participating chords. (INGTMART19)

- There are, then, as far as the sonority and the components are concerned, only three diminished seventh chords. Since, however, there are twelve minor keys, every diminished seventh chord must belong to at least four minor keys. (INGTMTE02)

- Salient Features include a sequence of fully diminished seventh chords, upward resolutions of chordal sevenths, and common-tone augmented-sixth chords. (INGTMDM01)

Dessa análise, sugerimos a seguinte correspondência:

- Acorde de sétima diminuta $\Leftrightarrow$ diminished seventh chord / fully diminished seventh chord

- Tétrade diminuta $\Leftrightarrow$ Diminished seventh chord / fully diminished seventh chord

\section{1) Acorde suspenso, acorde sus, acorde de quarta suspenso, acorde sus 4}

Neste item agrupamos os termos "acorde suspenso", "acorde sus", “acorde de quarta suspensa", "acorde sus 4", por apresentarem contextos definitórios semelhantes e serem utilizados como variantes. Em Harmonia popular, "acorde sus" e "acorde sus 4" são formas simplificadas utilizadas para as colocações "acorde suspenso" e "acorde de quarta suspensa", respectivamente.

Apresentam as seguintes frequências: 5 ocorrências para "acorde suspenso", 4 para “acorde sus", 4 para acorde "sus 4" e 1 para "acorde de quarta suspenso". 


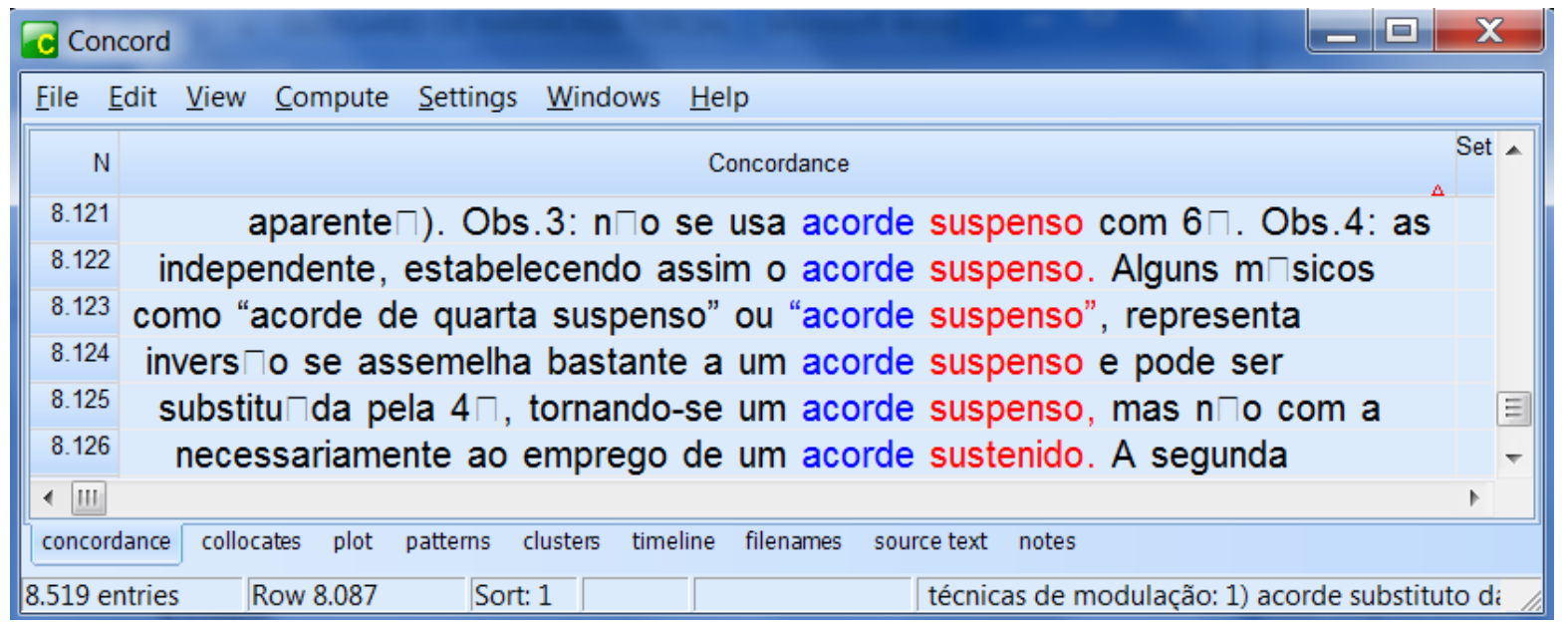

Figura 47 - Linhas de concordância (parciais) de "acorde suspenso"

\begin{tabular}{|c|c|c|}
\hline C Concord & & \begin{tabular}{|l|l|l|} 
& $\square$ & $X$ \\
\end{tabular} \\
\hline File Edit & View Compute Settings Windows $\underline{\text { Help }}$ & \\
\hline N & Concordance & Set $/$ \\
\hline 8.113 & de quarta e sétima, conhecido por acorde "sus" (abreviacão de & \\
\hline 8.114 & (I grau da tonalidade). No caso do acorde "sus", se respeitada as regras & \\
\hline 8.115 & notas do acorde - baixo cifrado. O acorde "sus" pode ser considerado & $\equiv$ \\
\hline 8.116 & acorde, uma vez que, atualmente, o acorde "sus" é utilizado de muitas & - \\
\hline 1 III & & 1 \\
\hline concordance & collocates plot patterns clusters timeline filenames source text notes & \\
\hline 8.519 entries & técnicas de modulação: 1) acorde substitut & ato di \\
\hline
\end{tabular}

Figura 48 - Linhas de concordância (parciais) de "acorde sus"

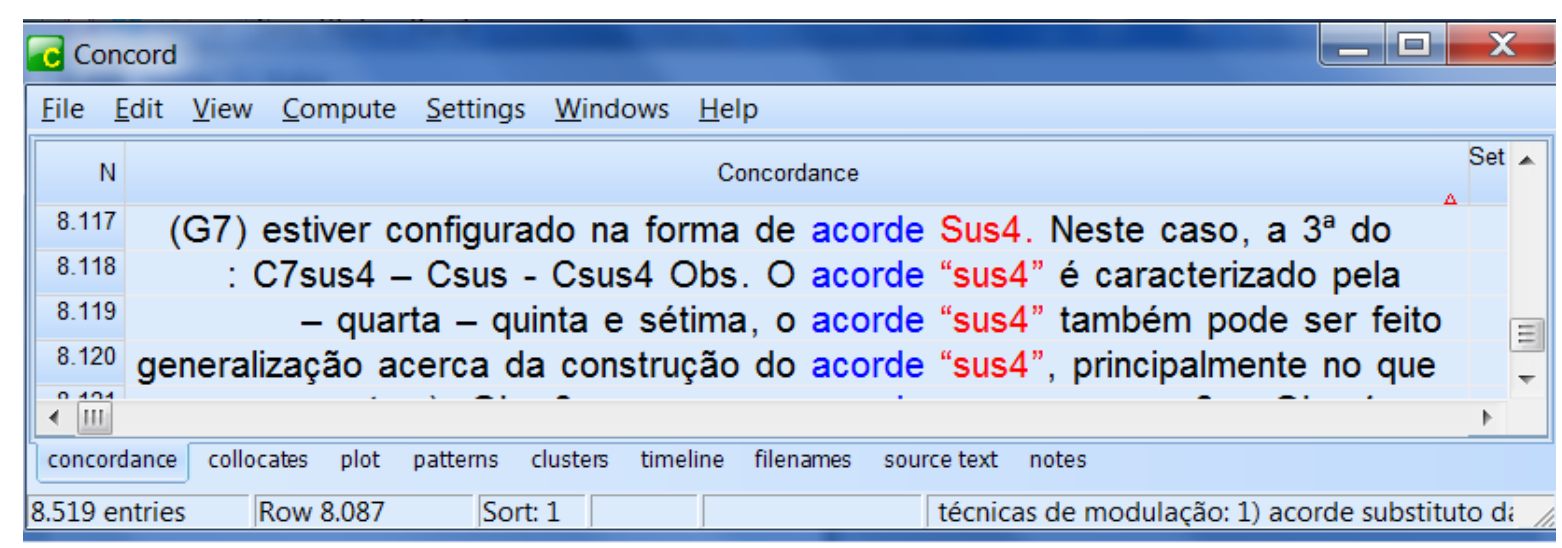

Figura 49 - Linhas de concordância (parciais) de "acorde sus4"

O excerto a seguir foi extraído de um texto que faz análise harmônica de música popular:

- A cifra do tipo X(sus4), conhecida no Brasil como "acorde de quarta suspenso" ou "acorde suspenso", representa algumas harmonias muito comuns no Jazz, principalmente dominantes sem terça. O "sus" vem da 
palavra inglesa "suspension" - suspensão - que equivale à nota melódica conhecida como "retardo" em português. (PORTMTE01)

- Acorde de quarta e sétima, conhecido por acorde "sus" (abreviação de suspensa) é formado por meio da substituição da $3^{a}$ do acorde pela $4^{a}$ - daí sua nomenclatura. A origem deste acorde se remete a um procedimento cadencial extremamente importante da harmonia tradicional conhecido como cadência I / V/ I, onde o I grau da cadência é um acorde em $2^{a}$ inversão cifrado de acordo com os intervalos formados entre a nota do baixo e as demais notas do acorde - baixo cifrado. (PORTMDM03)

Em Inglês, encontramos as colocações correspondentes: suspended chord (3 ocorrências), sus chord (4 ocorrências), suspended fourth chord (11 ocorrências) e sus4 chord (1 ocorrência):

- Commonly called "sus4" or simply "sus" chords, these are triads in which the fourth scale step replaces the third. Because the third is the strongest marker of the chord quality, replacing the third with the fourth creates a feeling of being suspended, waiting for a resolution to return the chord to its original quality. Although the sus chord itself contains no third, its quality is implied by its resolution. (INGTMLIV09)

- The suspended fourth chord (also called the sus4 chord) gets its name because it takes the third of a chord and suspends it by raising it a half step to a fourth (hence the name of this type of chord), before resolving the chord back to its usual form. So, a Csus 4 consists of $C, F$ (instead of $E$ ), and $G$. The fourth $(F)$ then moves back down to the third, which is E, thus resolving the chord back to the major triad (C, E, G). (INGTMLIVO6)

- A suspended chord is when the third is swapped for a note that lies on either side of it. (INGTMLIV04) 


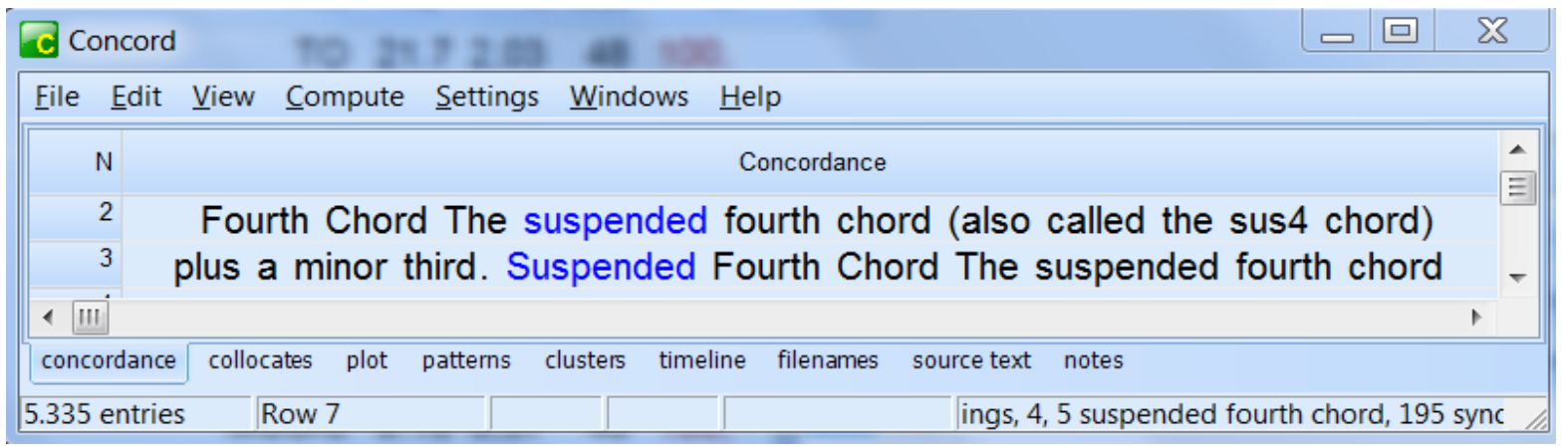

Figura 50 - Linhas de concordância (parciais) de "suspended Fourth Chord"

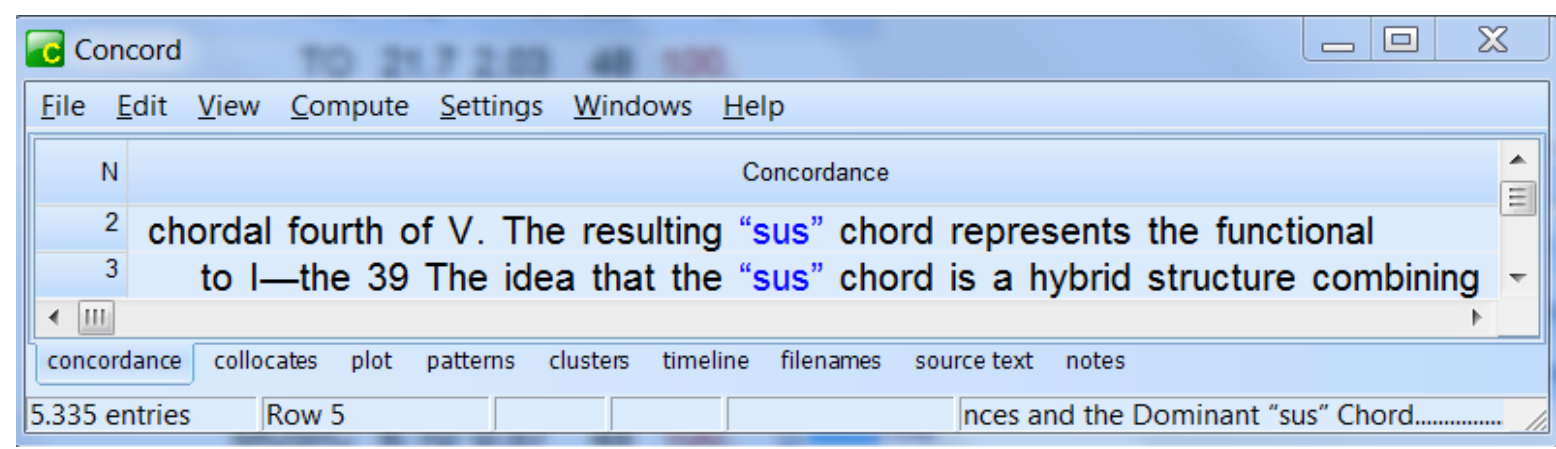

Figura 51 - Linhas de concordância (parciais) de "sus chord"

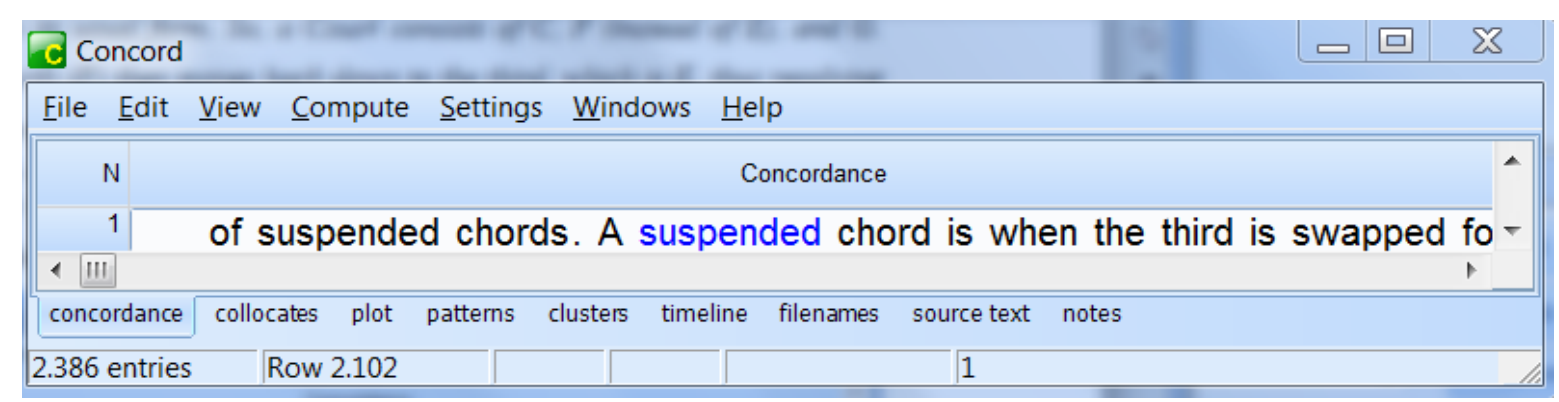

Figura 52 - Linha de concordância de "suspended chord"

Dessa análise, seguem as seguintes correspondências respeitando, as estruturas das colocações:

- Acorde suspenso $\Leftrightarrow$ suspended chord

- Acorde de quarta suspenso $\Leftrightarrow$ suspended fourth chord

- Acorde sus $\Leftrightarrow$ Sus chord

- Acorde sus4 $\Leftrightarrow$ sus4 chord 


\section{2) Acorde invertido, Inversão dos acordes}

A colocação "acorde invertido" tem a frequência de 24 ocorrências no corpus de estudo e foi localizada no dicionário DP-GALTER com a seguinte definição:

É o acorde, no qual a terça $\left(3^{a}\right)$, a quinta $\left(5^{a}\right)$ ou a sétima $\left(7^{a}\right)$ passa a ser a nota mais grave do acorde, fazendo uma troca, uma inversão com a fundamental.

A colocação, no corpus de estudo, apresenta um contexto definitório semelhante:

Acorde invertido: É quando a terça, a quinta ou a sétima vai para o baixo, isto é, fica sendo a nota mais grave do acorde. Quando a terça vai para o baixo, diz-se que o acorde está na primeira inversão; quando é a quinta que vai para o baixo, tem-se uma segunda inversão; e quando vai a sétima, uma terceira inversão. (PORTMLIV07)

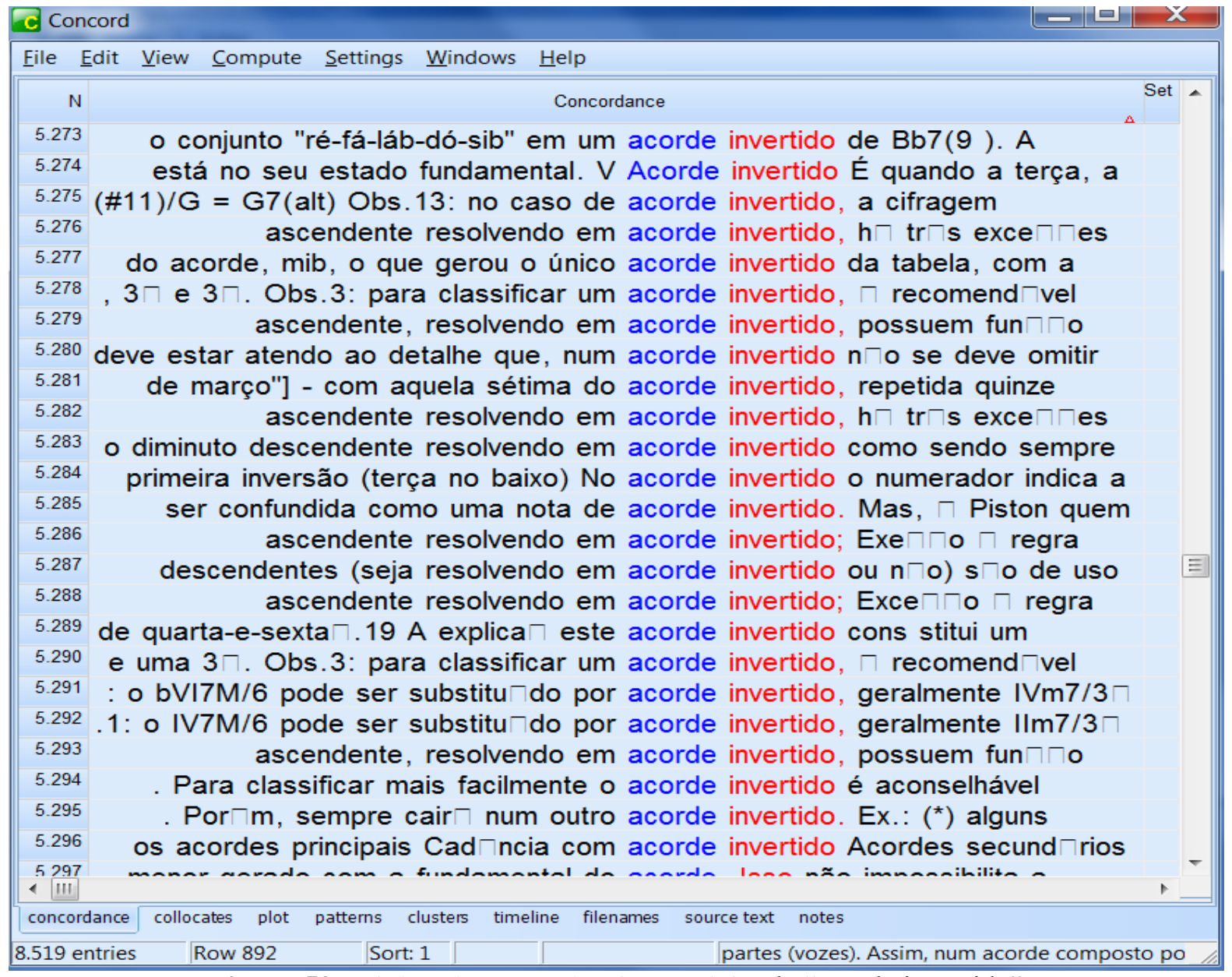

Figura 53 - Linhas de concordância (parciais) de "acorde invertido"

Selecionamos os seguintes contextos de uso das colocações: 
Kostka \& Payne comentam que o pedal começa como uma nota do acorde, a deixa de ser, e enfim, volta a ser uma nota do acorde. Outro detalhe é que a nota pedal pode ser confundida como uma nota de acorde invertido. (PORTMDMO1)

Também é utilizada a colocação "inversão de acordes", que se refere aos tipos de inversão que o acorde sofre. Apresenta 43 ocorrências com o termo acorde na forma singular e plural. Como exemplos, temos:

Inversão de acordes: Inverter um acorde consiste em passar sua nota inferior para uma oitava acima (tríades e tétrades). Ao inverter um acorde, as notas continuam sendo as mesmas, mas dispostas em localizações diferentes. (PORTMLIV04)

O mesmo texto (PORTMLIV04) menciona os seguintes tipos de inversões:

Inversão de tríades - As tríades possuem três posições: Estado Fundamental - EF (terças sobrepostas); Primeira Inversão (começa na segunda nota $-3^{a}$ do acorde); Segunda Inversão (começa na terceira nota $-5^{a}$ do acorde). Exemplo em Dó Maior $(C)$ :

Inversão de tétrades - As tétrades possuem quatro posições: Estado Fundamental — EF (terças sobrepostas); Primeira Inversão (começa na segunda nota $-3^{a}$ do acorde); Segunda Inversão (começa na terceira nota $-5^{a}$ do acorde); Terceira Inversão (começa na quarta nota $-7^{a}$ do acorde). Exemplo em Dó Maior com Sétima Maior (C7M).

O autor aponta quatro recursos básicos para se obter uma sonoridade característica da Bossa Nova: o uso de tensões; as substituições harmônicas; a inversão dos acordes; e o encadeamento das vozes internas dos mesmos. (PORTMART15)

Em Inglês, encontramos a colocação "inverted chord" (11 ocorrências) como correspondente de acorde invertido e "chord inversion" (02 ocorrências) para "inversão de acordes" O contexto definitório selecionado do subcorpus instructional é bem semelhante ao de Português:

Inverted chords occur when a note other than the root occurs in the bass. There are two kinds of inverted chords: In first inversion chords, the third is in the bass, and in second inversion chords, the fifth is in the bass. (INGTMLIV04) 


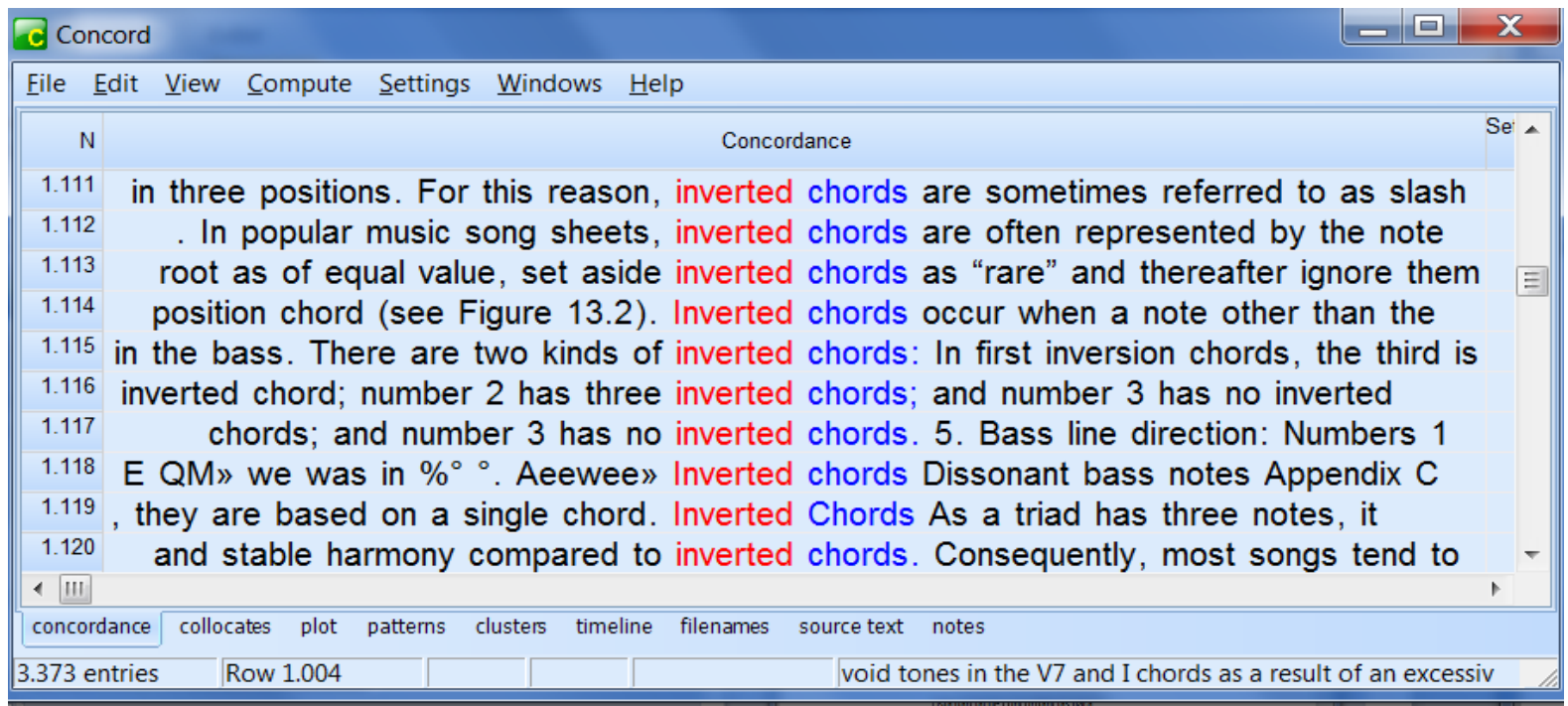

Figura 54 - Linhas de concordância (parciais) de "inverted chords"

O trecho abaixo apresenta um contexto de uso das colocações:

Most investigations into the harmony of rock treat every chordal root as of equal value, set aside inverted chords as "rare" and thereafter ignore them, rely upon discredited concepts such as "retrogression," and leave unconsidered the ramifications of voice leading upon chord identity, function, embellishment and harmonic expansion. I will here cite Stephenson 2002 as perhaps the most developed of all such studies, for all its good points in other domains. (INGTMART 24)

This observation may dampen the ringing endorsement of the Harmonic Series of the above paragraph (puns intended): it seems that even in the absence of the ideal Harmonic Series (due to the chord inversion) (INGTMART28)

A partir da análise, verificamos as seguintes correspondências:

Acorde invertido $\Leftrightarrow$ Inverted chord

Inversão do acorde $\Leftrightarrow$ Chord inversion

No glossário, haverá remissivas entre essas colocações. 


\section{3) Acorde de sexta}

A colocação acorde de sexta tem a frequência de 472 ocorrências no corpus de estudo, definido conforme um trecho de um texto do Subcorpus Instrucional:

Acorde de sexta: quando os acordes de 3 sons se acham na primeira inversão (a terça do acorde figura no baixo) sua cifragem é 6, e são formadas de terça e sexta. Estes acordes não podem ser empregados incompletos, ou seja, nesses acordes não se faz supressão de nota, deve ser usados sempre completos. (PORTMLIV10)

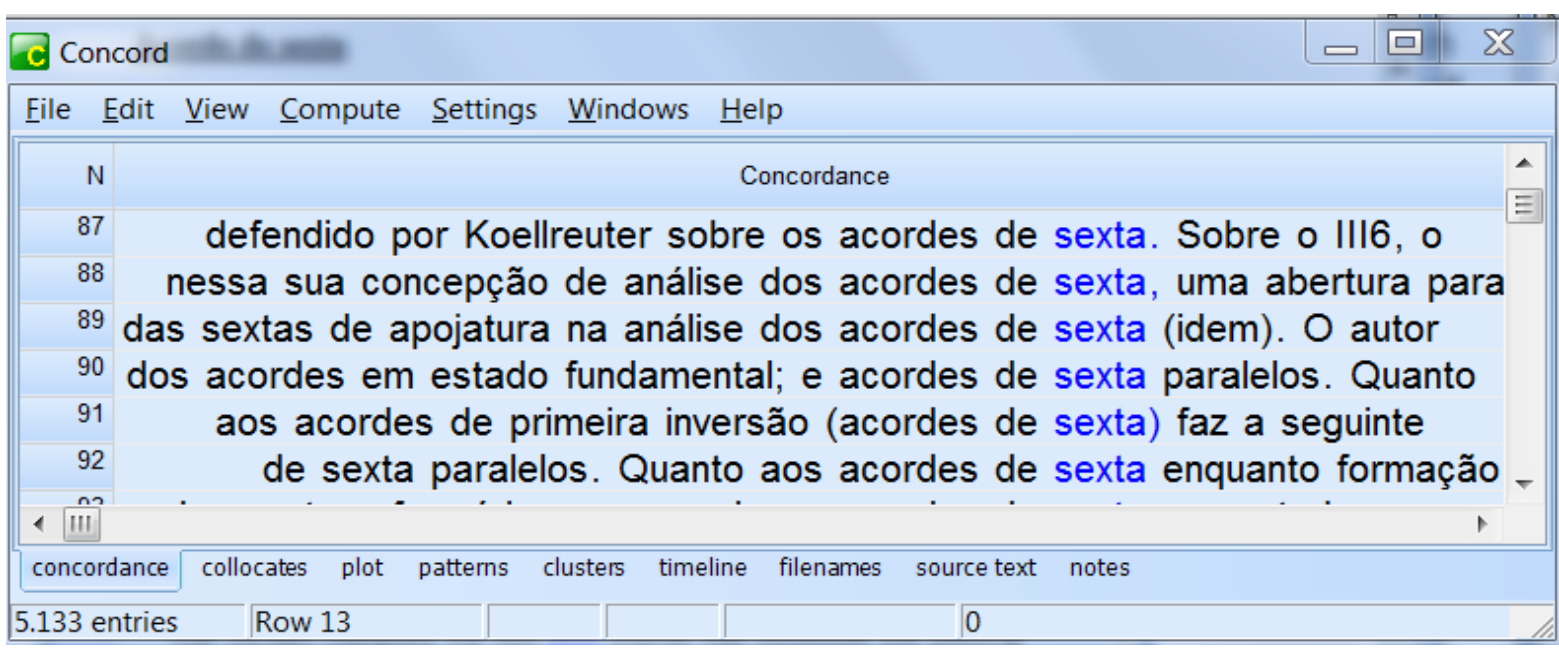

Figura 55 - Linhas de concordância (parciais) de "acordes de sexta"

O trecho abaixo apresenta um contexto de uso da colocação:

Pode-se antever nessa sua concepção de análise dos acordes de sexta, uma abertura para certa dissolução dos limites de individualidade dos acordes, tendência a ser reafirmada pela segunda lei tonal. (PORTMART14)

Em Inglês, a colocação correspondente encontrada foi sixth chord, com a frequência de 40 ocorrências. 


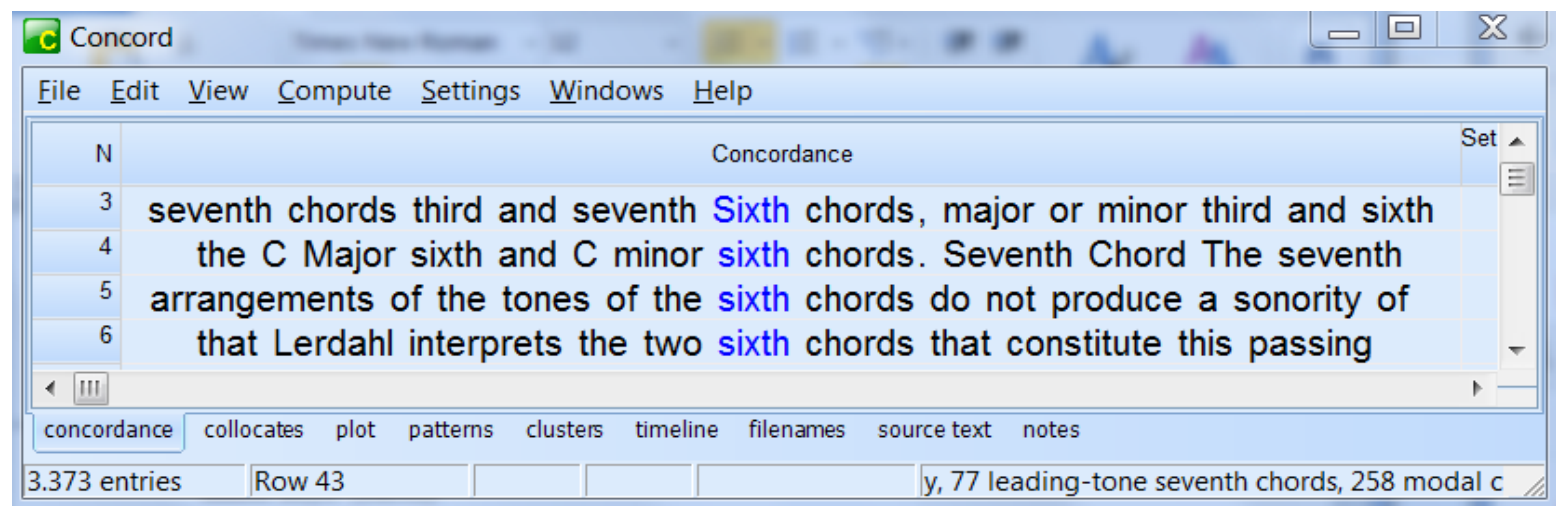

Figura 56 - Linhas de concordância (parciais) de "sixth chords"

No dicionário DI-HARVARD, a colocação é definida como acorde em primeira inversão:

A triad in first inversion (i.e, with the third as the lowest-sounding pitch, e,g, E-G-C), so called because the root then forms a sixth with the lowest-sounding pitch while the fifth of the triad forms a third.

O mesmo dicionário menciona ao final da definição para o acorde, uma remissiva para o termo Added sixth chord, que é uma tríade com sexta adicionada.

Não encontramos um contexto definitório para a colocação no nosso subcorpus em inglês, mas um contexto de uso referente ao acorde em primeira inversão:

Some limited variation of the patterns above is possible. For example, the II-V-I progression can end with a sixth chord, rather than a major or minor seventh, when the II chord has its third as the lowest note (i.e., when it is in first inversion).(INGTMLIV07)

A colocação acorde de sexta apresenta colocações derivadas como: "Acorde de sexta aumentada", "acorde de sexta aumentada alemã" (variante: "acorde de sexta germânica"), "acorde de sexta aumentada italiana", "acorde de sexta napolitana". E também apresenta a colocação acorde de sexta acrescentada (de Rameau), que como veremos não se trata de um acorde invertido, mas sim um acorde de subdominante (tríade) com uma nota adicionada (que é a sexta). Tais colocações serão detalhadas em outros itens.

Encontramos no corpus, trechos que comentam sobre o caráter polissêmico do termo "Sexta" na Música e que é um fator importante que deve ser observado no processo de tradução: 
A ênfase no termo "sexta" se justifica por uma conjunção de arrazoados conhecidos no universo da harmonia de escola: sexta é uma medida do intervalo que, à maneira das práticas teóricas do baixo contínuo, faz referência objetiva à extensão de sexta menor (oito semitons) que se forma entre a nota do baixo (no caso, a nota ré) e a dissonância (sib) acrescentada ao acorde (Dm). Sexta também pode indicar a própria nota (sib), a singular sexta menor sobre acorde menor, caso excepcional no sistema tonal que, por isso, justifica um rótulo diferenciador: sexta napolitana. [...] Sexta pode denominar também a primeira inversão de um acorde, neste caso, o pressuposto acorde perfeito maior sobre o segundo grau rebaixado (bII6). Observa-se então que o termo sexta é polissêmico, com ele a teoria não elimina totalmente o valor de ambiguidade que, artisticamente, é uma das estimadas riquezas desta figura de harmonia. (PORTMART18)

$\mathrm{Na}$ consulta aos dicionários de termos musicais em Inglês, a colocação foi encontrada no dicionário DI-HARVARD. A obra apresenta uma definição extensa em que se verifica o caráter polissêmico do termo.

\section{4) Acorde de quarta e sexta}

“Acorde de quarta e sexta" (11 ocorrências) é uma colocação encontrada no dicionário de temos musicais (DP - DOURADO). A entrada apresenta uma remissiva para a variante acorde de sexta e quarta. Na consulta ao corpus de estudo, não encontramos ocorrências para a variante "acorde de sexta e quarta".

- Na Harmonia tradicional, a segunda inversão de uma tríade, em que as notas são dispostas uma sexta e uma quarta, respectivamente, acima da mais grave (sol-dó-mi). (DP - DOURADO)

No subcorpus instrucional, encontramos um contexto definitório semelhante ao apresentado no dicionário: 
- Acorde de quarta e sexta: Tríade em segunda inversão. A quinta da tríade é a nota mais grave. Intervalos formados a partir do baixo: quarta e sexta. (PORTMLIVO1)

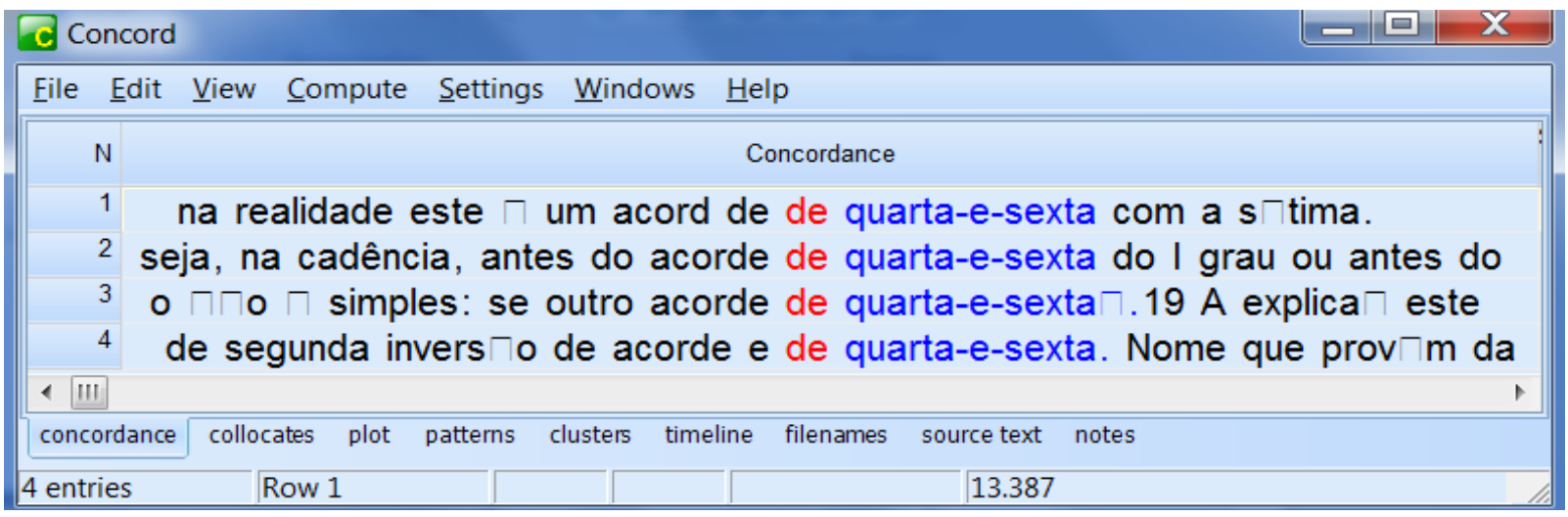

Figura 57 - Linhas de concordância de "acorde de quarta-e-sexta"

Selecionamos o seguinte contexto de uso do subcorpus acadêmico-científico:

O modelo harmônico para a segunda cadência foi construído a partir do próprio motivo escolhido, com algumas mudanças de acordes, como por exemplo, a introdução de um arpejo a mais no quarto compasso (acorde de lá maior com sétima) e da pequena fermata no acorde de quarta e sexta, no meio da cadência. (PORTMART12)

Na busca pelo termo correspondente, encontramos no Subcorpus de inglês a colocação six-four chord (27 ocorrências). A colocação foi encontrada nos dicionários de termos musicais em Inglês, com as seguintes definições:

- A chord consisting of three notes, the bass note, the interval of a fourth above the bass note, and a sixth above the bass note. This is used in figured bass and implies a second inversion chord with six-four indicating the intervals of the two notes above the bass note (DI-OXFORD).

- A triad in second inversion (i.e. with the fifth as the lowest-sounding pitch, e.g, G$C-E$ ), so called because the third of the triad then forms a sixth with the lowestsounding pitch while the root forms a fourth; it is notated in thoroughbass notation an in harmonic analysis with the figures 6/4. Because of the interval of a fourth sounds above the lowest pitch such a chord is normally treated in tonal 
music as a dissonance and must be resolved. It is often introduced as a suspension. An especially familiar cadence resolves the tonic six-four chord to dominant, which in turn moves to the tonic in root position $(I 6 / 4-V-I)$. The cadenza I concertos is often a elaboration of the progression from tonic six-four to dominant (DI - HARVARD).

O contexto definitório retirado do Subcorpus Instrucional apresenta uma explicação semelhante ao que encontramos no subcorpus de Português:

- When the notes of a triad are so arranged that the original fifth becomes the lowest tone, the triad is said to be in the second inversion, and in this position is known as the six-four chord, the intervals between the bass and the upper voices being sixth and fourth. (INGTMLIV11)

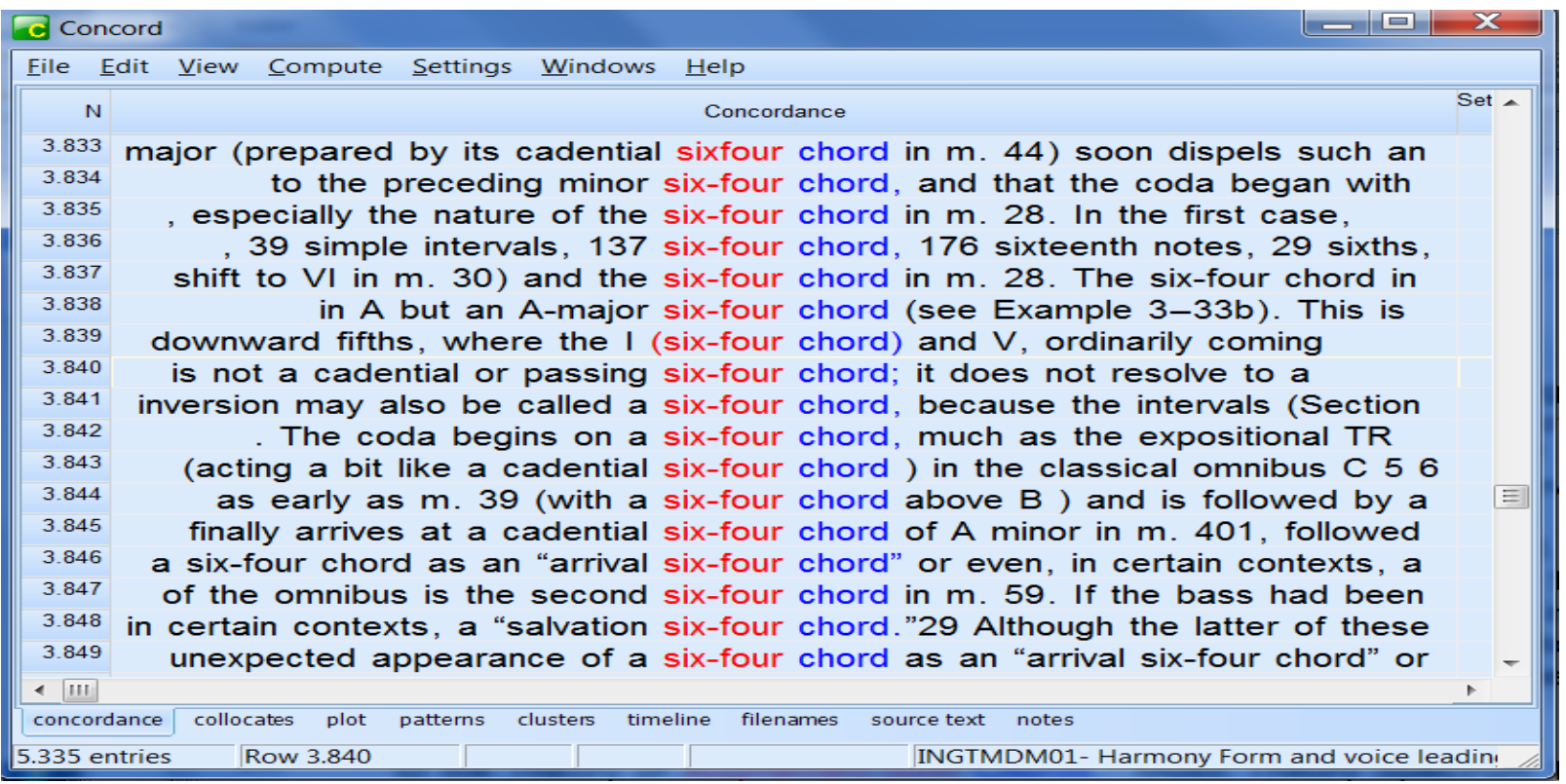

Figura 58 - Linhas de concordância (parciais) de "six-four chord"

Na figura acima, observam-se nas linhas 3840 e 3845 colocações derivadas como: passing six-four chord e cadential six-four chord, que serão detalhadas em outros itens.

Exemplo de uso da colocação six-four chord extraído do subcorpus acadêmicocientífico:

- "Schoenberg's example 74 illustrates a downward step progression as a sum of two downward fifths, where the I (six-four chord) and $V$, ordinarily coming 
between this dominant $(V / V)$ and the closing chord are often left out. (INGTMTE02)

\section{5) Acorde diatônico}

A colocação "acorde diatônico" tem a frequência de 213 ocorrências, definida de acordo um trecho de um texto do Subcorpus Instrucional:

Acorde formado por notas pertencentes a uma escala diatônica. (PORTMLIV02)

A definição de escala diatônica também foi encontrada no corpus:

- Escala diatônica é a sucessão de oito sons (notas) conjuntos guardando de um para outro intervalo de tom ou de semitom. Os tons e semitons contidos na escala diatônica são chamados naturais. A cada uma das notas da escala, de acordo com a sua função na própria escala, dá-se o nome de grau. Tem a escala diatônica, por conseguinte, 8 graus, sendo o VIII grau a repetição do I. Os graus da escala são assim denominados: I grau - tônica; II grau - supertônica; III grau mediante; IV grau - subdominante; V grau - dominante; VI grau superdominante; VII grau-sensível; VIII grau - tônica. (PORTMLIV03)

- A escala diatônica é uma escala heptatônica. A palavra "dia” (do grego) significa "através", "entre”. A palavra "diatônico" (do grego) significa "através da sucessão de tons". Diaton (do grego) é o intervalo que separa duas notas conjuntas não cromáticas. Escalas diatônicas: Antigas (Modos. Ex: modo dórico), Modernas (Maiores e menores. Ex. Escala Ré Maior).

(PORTMLIV02) 


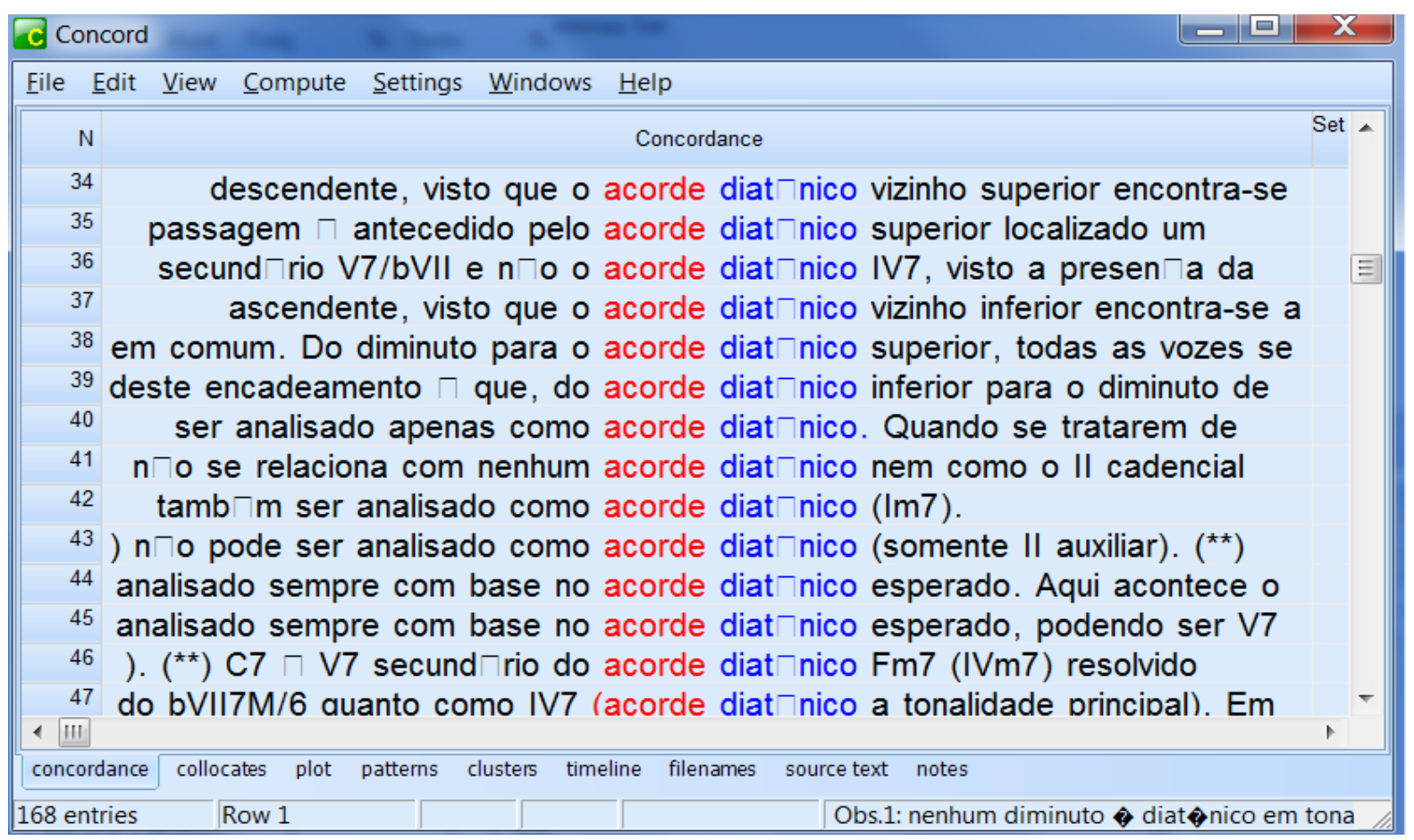

Figura 59 - Linhas de concordância (parciais) de "acorde diatônico"

Exemplo de uso da colocação acorde diatônico extraído do subcorpus acadêmicocientífico:

Por fim, temos a possibilidade de um acorde diatônico se transformar em tônica com o auxílio de acordes característicos de empréstimo modal, ou seja, com a utilização de acordes de empréstimo modal que não são possíveis na primeira tonalidade ou são mais apropriados à segunda tonalidade. (PORTMTE02)

Na busca pelo termo correspondente, encontramos no Subcorpus de Inglês a colocação diatonic chord (17 ocorrências), com o seguinte contexto definitório:

Most chords in tonal music are made up only of notes from the scale on which the passage is based (...). Chords of this kind are called diatonic chords. (INGTMLIV12) 


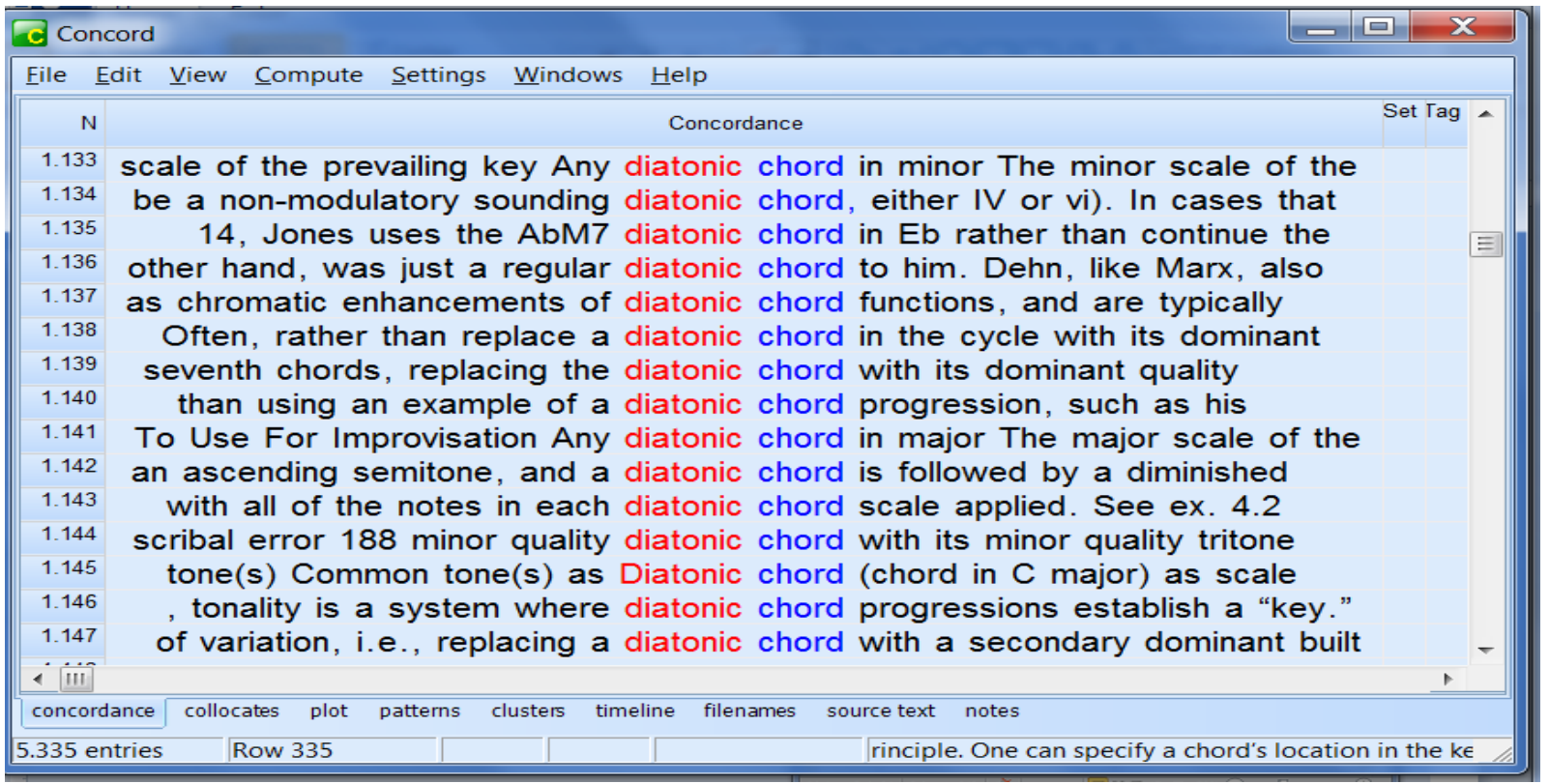

Figura 60 - Linhas de concordância (parciais) de "diatonic chord"

O trecho a seguir apresenta um contexto de uso da colocação diatonic chord:

In the opening of chapter 3 I refer to this as the first level of variation, i.e., replacing a diatonic chord with a secondary dominant built on the same scale degree. (INGTMDM04)

\section{6) Acorde não-diatônico}

A colocação "acorde não-diatônico" apresenta no corpus apenas 5 ocorrências, apenas no plural. Localizamos no corpus de estudo instrucional o seguinte contexto definitório:

Acordes não diatônicos são aqueles que possuem uma ou mais notas estranhas à tonalidade (escala) onde ele se encontra. (PORTMLIV07)

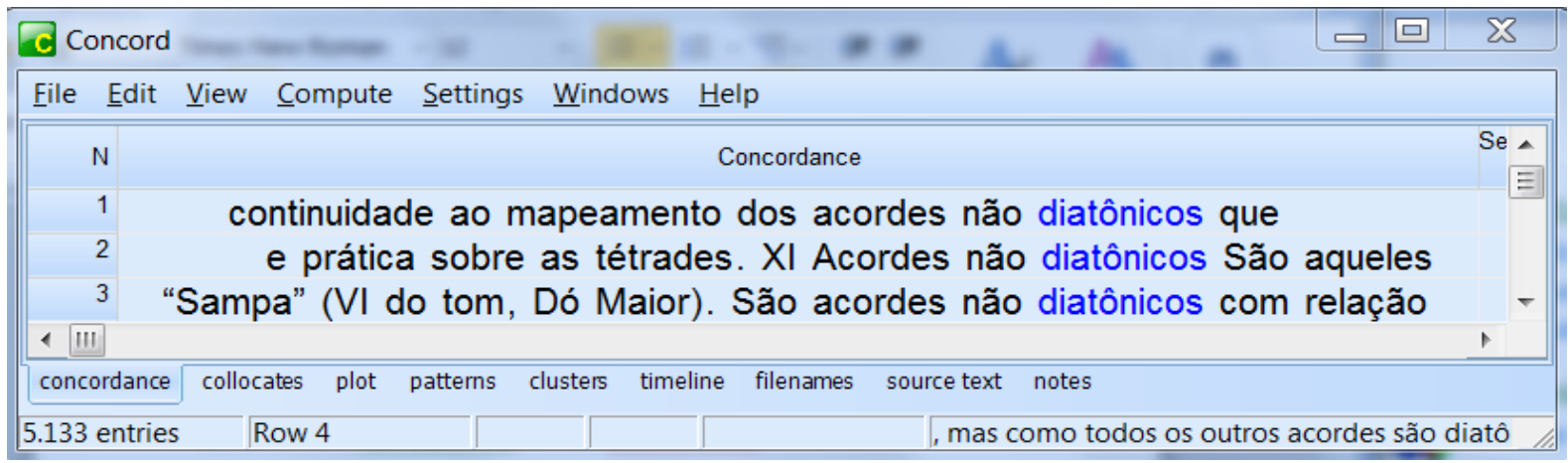

Figura 61 - Linhas de concordância parciais de "acordes não-diatônicos" 
No Subcorpus acadêmico-científico, encontramos o seguinte contexto de uso para a colocação:

Os Capítulos 1 a 6 cuidam da revisão, da contextualização, do levantamento e cruzamento circunstanciado de referências, do repertório e da memória teórica e poética, do questionamento e discussão a respeito de determinadas abordagens interpretativas sobre assuntos como: os fundamentos diatônicos da tonalidade, a atribuição funcional dos acordes e áreas tonais, a inclusão teórico-normativa de acordes não diatônicos, os meios de preparação alterados e as vizinhanças de terceira que envolvem transformações cromáticas.(PORTMDM02)

Na busca por correspondente no Subcorpus de Inglês, encontramos a colocação “nondiatonic chord" (com 6 ocorrências, em apenas 2 aparece o uso do hífen):

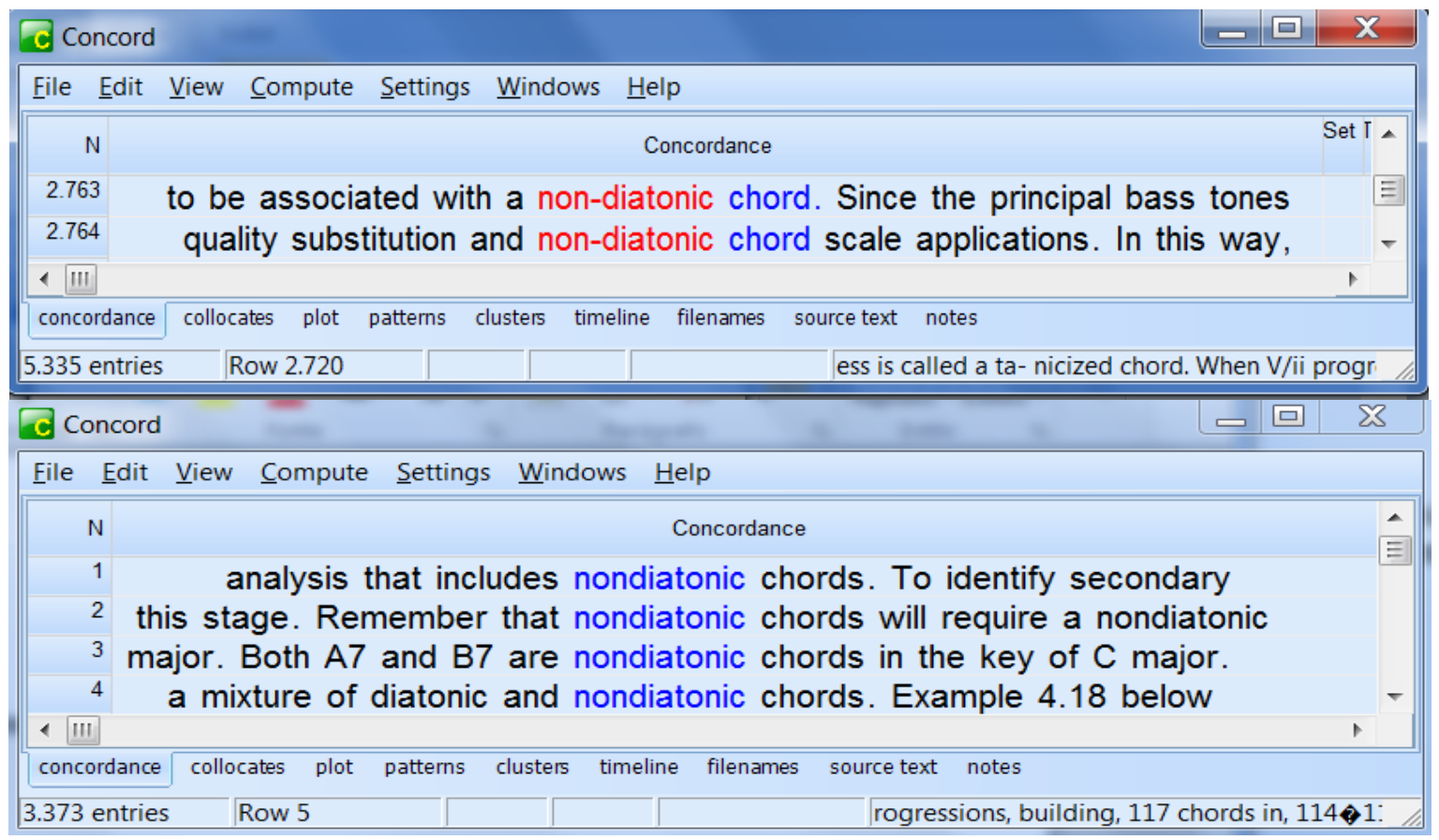

Figura 62 - Linhas de concordância (parciais) de "non-diatonic chord" (singular e plural)

Não encontramos contextos definitórios, mas trechos que indicam que a colocação é empregada no mesmo sentido que em Português: 
- Notice that two chords in the excerpt, $A 7$ and B7, are not listed with the diatonic chords for C major. Both A7 and B7 are nondiatonic chords in the key of C major. (INGTMLIV02)

- In example 4.16 we saw a II-V progression expanded with a mixture of diatonic and nondiatonic chords. (INGTMDM04)

\section{7) Notas do acorde}

Encontramos as colocações variantes "notas do acorde" (66 ocorrências) ou "notas de acorde" (9 ocorrências), com os seguintes contextos definitórios:

- $\quad$ Notas do acorde - são notas da estrutura básica do acorde (pertencentes a uma escala diatônica). (PORTMAPO03)

- Escala de Acorde é a escala formada pelo conjunto das notas que caracterizam o acorde, chamadas "Notas de Acorde", e as notas que o enriquecem, chamadas Notas de Tensão. (PORTMART04)

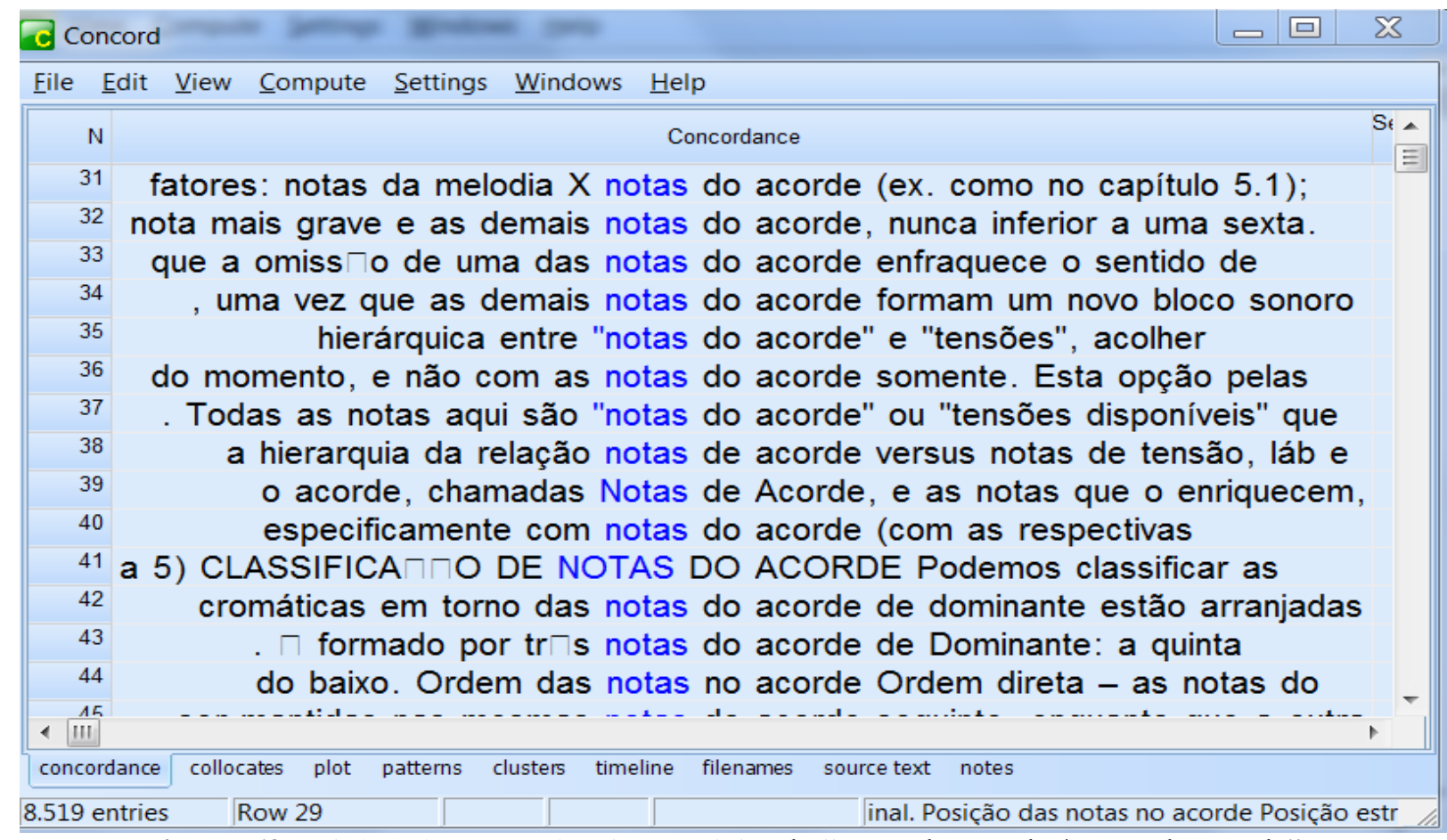

Figura 63 - Linhas de concordância (parciais) de "notas do acorde / notas de acorde" 
Analisando as linhas de concordância do corpus, destacamos alguns contextos de uso em que a colocação é empregada com o significado exposto anteriormente:

- Todas as notas aqui são "notas do acorde" ou "tensões disponíveis" que praticamente se igualam no interior dessa gama que (com diferentes rótulos) vem sendo gradualmente aculturada (maturada) desde os primórdios da tonalidade. (PORTMDM02)

- Os acordes formados a partir do IV grau da escala, como podemos observar na representação acima, não possuem notas evitadas. Porém, por se tratar de um acorde que pode configurar-se de diversas maneiras, é necessário que se estabeleçam certos critérios de combinações entre notas de acorde e extensões harmônicas. (PORTMDM03)

Em inglês, encontramos a colocação correspondente "chord tone" com uma frequência de 88 ocorrências no corpus de estudo. O contexto abaixo traz uma explicação sobre a colocação:

- Harmonic tones should be familiar to you by now. They are the chord tones: root, third, or fifth. Nonharmonic tones (nonchord tones) are pitches that sound along with a chord but are not chord pitches. ( INGTMLIV02) 


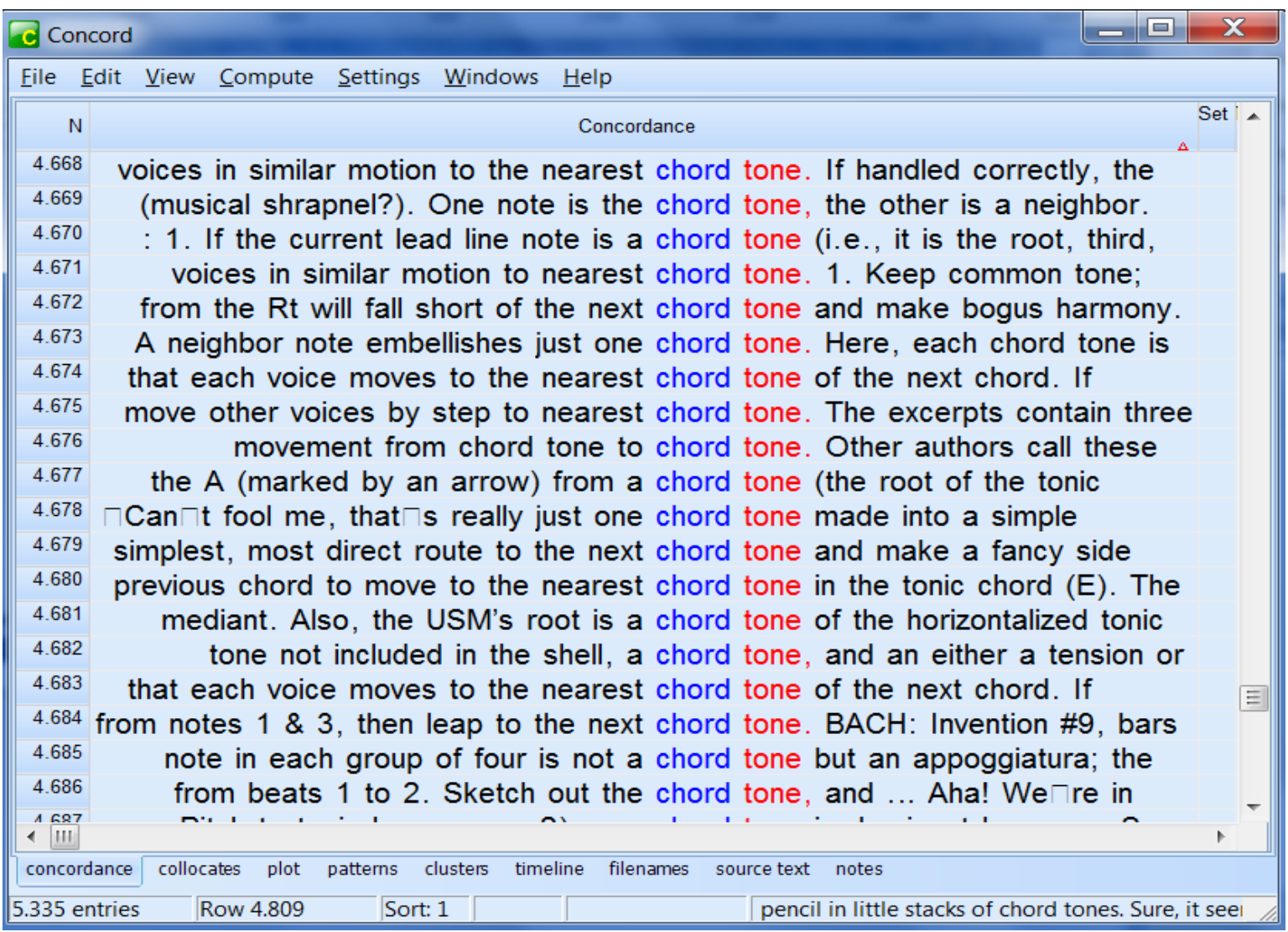

Figura 64 - Linhas de concordância (parciais) de "chord tone"

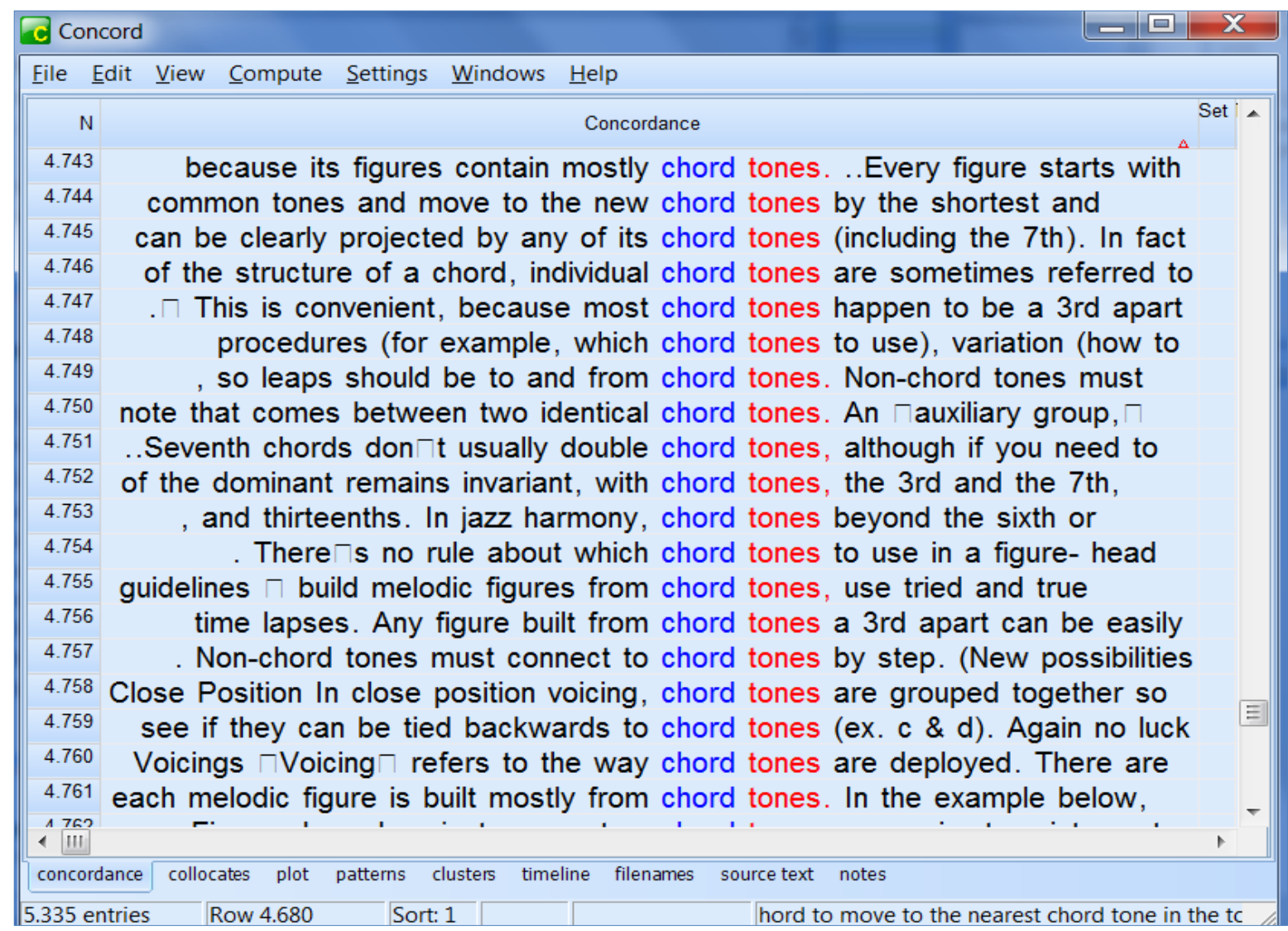

Figura 65 - Linhas de concordância (parciais) de "chord tones" 
Como exemplo, o trecho a seguir apresenta um contexto de uso em que a colocação "chord tone" é empregada com o mesmo significado que a colocação correspondente em Português:

- Because a chord symbol suggests multiple options for chord-scale applications, any of these chord-scales may be applied and any note in one of the possible chord-scale applications is a compatible tone (and therefore, a possible chord tone). (INGTMDM04)

\section{8) Notas estranhas ao acorde}

A colocação "notas estranhas ao acorde" apresenta a frequência de 11 ocorrências no subcorpus de português. De acordo com o trecho retirado do subcorpus instrucional, elas:

São aquelas que não fazem parte do acorde, mas que são usadas para ornamentar uma melodia. São os seguintes os fenômenos que caracterizam as notas estranhas: bordadura, nota de passagem, retardo, antecipação, apoggiatura e escapada. (PORTMLIV06)

Uma variante da colocação é Notas estranhas à harmonia que, de acordo como o contexto definitório encontrado no subcorpus, são descritas como:

Uma nota estranha à harmonia (NEH) é uma nota, diatônica ou cromática, que não pertence a um acorde, ou seja, à duração de um determinado acorde. Esta nota pode ser uma nota estranha durante toda a sua duração ou, se a harmonia mudar durante a duração desta nota, ela pode se tornar uma nota real de um acorde. (PORTMAPOO1)

Em alguns livros-texto do subcorpus, a tipologia de notas estranhas é mencionada na parte temática sobre "Figuração Melódica”, "Notas Ornamentais', “Ornamentos”, etc,

- A figuração é um aspecto essencial da composição e da música tonal. Ela compreende a movimentação melódica que emprega consonâncias e dissonâncias, com ou sem deslocamentos rítmicos e que pode ocorrer em qualquer voz ou, até 
mesmo, em todas. Seu emprego mais comum é na voz mais aguda por tratar-se geralmente da melodia. Notas diatônicas (notas da escala) ou notas cromáticas podem ser empregadas na figuração. As notas assumidas como figurações melódicas podem ser classificadas em tipos diferentes, admitindo-se algumas variantes. São eles: $\underline{\text { Arpejo, }}$ Nota de passagem, Bordadura, $\underline{\text { Apojatura, }}$ Suspensão ou Retardo, Antecipação. (PORTMLIV01)

- NOTAS ORNAMENTAIS: No pensamento polifônico (séculos XIV, XV e XVI) predominava o tratamento das vozes em movimentos melódicos. No pensamento harmônico do período Barroco (séculos XVII e parte do XVIII), estes movimentos resultaram nas chamadas notas ornamentais ou auxiliares da harmonia e podem ser classificadas como: antecipação, apojatura, bordadura, escapada, passagem e retardo, segundo a função desempenhada no trecho. Esta prática estende-se até o século XIX como uma das características da música harmônica tonal. (PORTMLIV06)

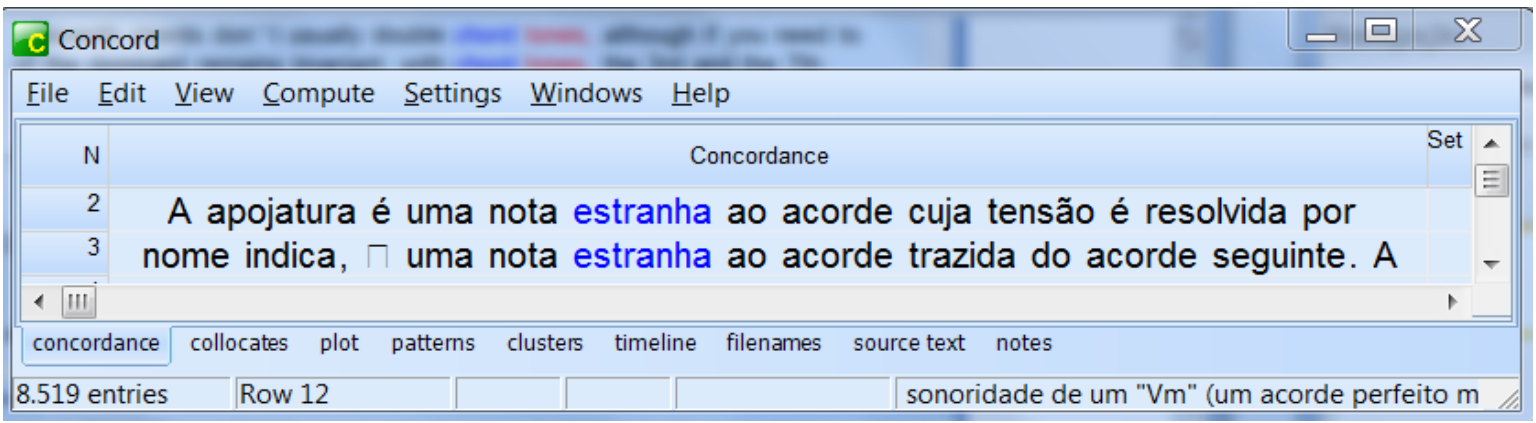

Figura 66 - Linhas de concordância (parciais) de "nota estranha ao acorde"

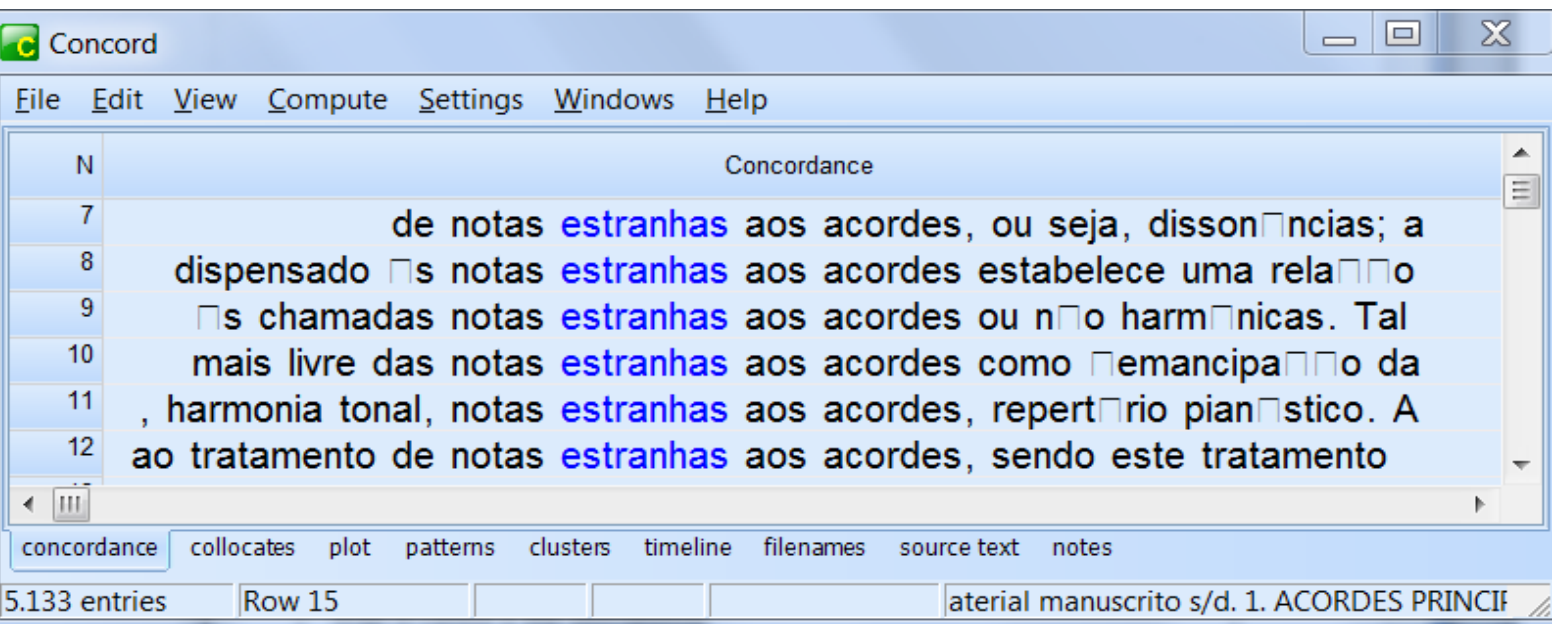

Figura 67 - Linhas de concordância (parciais) de "notas estranhas ao acordes" 
Selecionamos a seguir um contexto de uso, extraído do subcorpus acadêmicocientífico:

- Para que possa ser estabelecido um parâmetro analítico, optou-se por dar início a um estudo voltado ao aspecto harmônico examinando, em princípio, o tópico específico do tratamento dado às chamadas notas estranhas aos acordes ou não harmônicas. (PORTMART06)

Na busca por correspondente em Inglês, encontramos a colocação "non-chord tone”, que apresenta um número de ocorrências bem maior que a correspondente em Português: 67 ocorrências (formas singular e plural somadas).

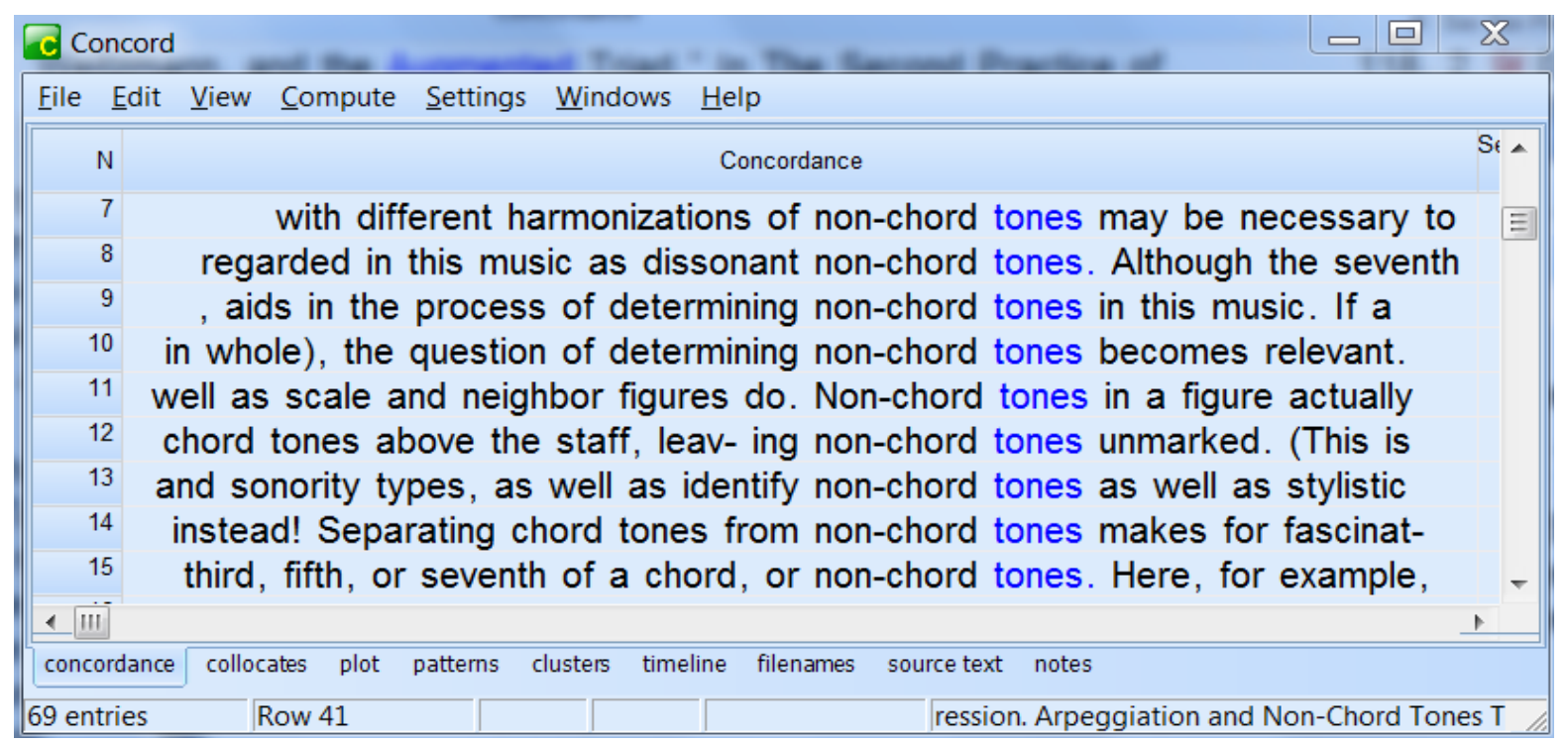

Figura 68 - Linhas de concordância (parciais) de "non-chord tones"

Selecionamos o seguinte contexto definitório extraído do subcorpus instrucional:

Non-chord tones (abbreviated NCT) is a tone, either diatonic or chromatic, that is not a member of the chord. The tone might be an NCT throughout its duration, or, if the harmony changes before the tone does, the tone might be as NCT for only a portion of its duration. (INGTMLIV12)

Do corpus acadêmico-científico, extraímos o seguinte contexto de uso:

Cadential IVs often support the non-chord tone in the upper voice, which further contributes to their being heard as cadential rather than neighboring or pre-dominant; other 
examples of this include “All I've Got To Do," graphed in Section 5 as Example 15, and “Nowhere Man” from Rubber Soul (not analyzed in this study).(INGTMART10)

Elaboramos um quadro com os tipos de notas ornamentais (notas estranhas) e os correspondentes com trechos retirados do corpus de estudo:

\begin{tabular}{|c|c|}
\hline Notas estranhas ao acorde & Non-chord tones \\
\hline $\begin{array}{l}\text { Bordadura } \\
\text { A Bordadura apresenta-se como uma } \\
\text { dissonância em tempo fraco ou parte fraca } \\
\text { do tempo, que parte de uma nota de } \\
\text { acorde por movimento de segunda acima } \\
\text { (bordadura superior) ou abaixo } \\
\text { (bordadura inferior) e retorna } \\
\text { obrigatoriamente, para a mesma nota de } \\
\text { origem. (PORTMLIV01) }\end{array}$ & $\begin{array}{l}\text { Neighboring tone } \\
\text { The neighboring tone is used to embellish a } \\
\text { single tone. It may appear above the main } \\
\text { tone (upper neighbor) or below it (lower } \\
\text { neighbor), and it may be diatonic or } \\
\text { chromatic.(INGTMLIV12) }\end{array}$ \\
\hline $\begin{array}{l}\text { Notas de passagem } \\
\text { São aquelas que preenchem o espaço entre } \\
\text { duas notas diferentes de um mesmo acorde } \\
\text { ou de acordes diferentes. Normalmente, a } \\
\text { nota de passagem é uma dissonância } \\
\text { usada entre duas consonâncias para } \\
\text { preencher um intervalo de terça. Ela pode } \\
\text { ser ascendente ou descendente, não } \\
\text { acentuada ou acentuada, e diatônica ou } \\
\text { cromática. (PORTMLIV01) }\end{array}$ & $\begin{array}{l}\text { Passing tone } \\
\text { The passing ton is used to fill the space } \\
\text { between two other tones. The two other tones } \\
\text { may belong either to the same or to different } \\
\text { chords, or they might be NCTs themselves. } \\
\text { Usually the space them is a third, either up or } \\
\text { down, and the passing tone is given whatever } \\
\text { scale degree lies in between. (INGTMLIV12) }\end{array}$ \\
\hline $\begin{array}{l}\underline{\text { Retardo }} \\
\text { Constitui-se de três partes: preparação } \\
\text { (posiciona-se em tempo fraco ou parte }\end{array}$ & $\begin{array}{l}\underline{\text { Retardation }} \\
\text { A retardation is similar to a suspension, but it }\end{array}$ \\
\hline
\end{tabular}




\begin{tabular}{|c|c|}
\hline $\begin{array}{l}\text { fraca de tempo, em consonância com o } \\
\text { acorde); retardo (tempo forte ou parte } \\
\text { forte de tempo, criando, de preferência, } \\
\text { uma dissonância com o acorde); resolução } \\
\text { (tempo fraco ou parte fraca de tempo, em } \\
\text { consonância). (PORTMLIV06) }\end{array}$ & $\begin{array}{l}\text { delays a stepwise ascend and resolves } \\
\text { upward. (INGTMLIV12) }\end{array}$ \\
\hline $\begin{array}{l}\text { Suspensão } \\
\text { A suspensão origina-se quando uma nota } \\
\text { do acorde (consonância), na troca de } \\
\text { harmonia, em tempo forte ou parte forte do } \\
\text { tempo, fica mantida e se transforma em } \\
\text { dissonância. Nesse momento ela passa a } \\
\text { ser classificada como suspensão ou } \\
\text { retardo.(PORTMLIV01) } \\
\text { (A autora apresenta uma nota de rodapé } \\
\text { explicando que para } \\
\text { (INGTMLIV12), quando a resolução é } \\
\text { ascendente, a nota passa a ser classificada } \\
\text { como retardo.) }\end{array}$ & $\begin{array}{l}\text { Suspension } \\
\text { A suspension is a NCT that delays a stepwise } \\
\text { descent in a line. A suspension involves three } \\
\text { phases: preparation, suspension, and } \\
\text { resolution. Suspension that occur in a voice } \\
\text { other than the bass are classified by the } \\
\text { intervals between the bass and the suspension } \\
\text { and between the bass and the resolution. } \\
\text { (INGTMLIV12) }\end{array}$ \\
\hline $\begin{array}{l}\text { É uma nota estranha ao acorde trazida do } \\
\text { acorde seguinte. A antecipação pode ser } \\
\text { atingida por grau conjunto ou por salto. } \\
\text { Porém, como norma, costuma ser } \\
\text { alcançada por grau conjunto, ter um valor } \\
\text { rítmico pequeno e ocorrer em tempo fraco } \\
\text { ou parte fraca do tempo. (PORTMLIV01) }\end{array}$ & $\begin{array}{l}\text { Anticipation } \\
\text { The ancipation is an unaccented nonchord } \\
\text { tone, but, given that it can be considered the } \\
\text { mirror opposite of the suspension, it is } \\
\text { included at this point. The anticipation } \\
\text { appears before the chord to which it belongs } \\
\text { actually sounds, usually creating a } \\
\text { dissonance with the already-sounding chord. } \\
\text { (INGTMLIV13) }\end{array}$ \\
\hline
\end{tabular}




\begin{tabular}{|c|c|}
\hline Apojatura / Apogiatura & Appoggiatura \\
\hline $\begin{array}{l}\text { É uma dissonância atacada em tempo forte } \\
\text { ou parte forte do tempo que se resolve por } \\
\text { grau conjunto, em uma consonância, A } \\
\text { forma mais usual de emprego da apojatura } \\
e ́ \text { a de dissonância atacada por salto } \\
\text { descendente, em tempo forte e que se } \\
\text { resolve por grau conjunto descendente, em } \\
\text { uma consonância. (PORTMLIV01) }\end{array}$ & $\begin{array}{l}\text { An appoggiatura is a NCT that is approached } \\
\text { by leap and resolved by step. In most cases, } \\
\text { appoggiaturas are accented, approached by } \\
\text { ascending leap, and resolved by descending } \\
\text { step. (INGTMLIV12) }\end{array}$ \\
\hline Escapada. & Escape tone \\
\hline $\begin{array}{l}\text { É uma bordadura incompleta atingida por } \\
\text { grau conjunto (geralmente ascendente) } \\
\text { cuja resolução sed ápor salto, no sentido } \\
\text { oposto. A escapada é normalmente um } \\
\text { dissonância não acentuada e com valor } \\
\text { rítmico curto. (PORTMLIV01) }\end{array}$ & $\begin{array}{l}\text { The contour of the escape tone is the reverse } \\
\text { of that of the appoggiatura, because the } \\
\text { escape tone is aproached by step and left by } \\
\text { leap in the opposite direction. Escape tones } \\
\text { are usually submetrical, unaccented, and } \\
\text { diatonic. They are often used in sequence to } \\
\text { ornament a scalar line. (INGTMLIV12) }\end{array}$ \\
\hline Dupla Bordadura & Neighbor group \\
\hline $\begin{array}{l}\text { É a combinação de duas dissonâncias na } \\
\text { qual a primeira se apresenta como uma } \\
\text { bordadura superior, seguida, } \\
\text { imediatamente, pela segunda como } \\
\text { bordadura inferior, ou vice-versa. Assim, a } \\
\text { primeira aparece como uma bordadura } \\
\text { incompleta (tempo fraco ou parte do tempo } \\
\text { fraca) e a segunda como uma apojatura } \\
\text { (tempo forte ou parte do tempo forte). } \\
\text { (PORTMLIV01) }\end{array}$ & $\begin{array}{l}\text { A common method of embellishing a single } \\
\text { tone involves a combination of two NCTs in } \\
\text { succession, the first being an escape tone, the } \\
\text { second an appoggiatura. (INGTMLIV12) }\end{array}$ \\
\hline
\end{tabular}




\begin{tabular}{|l|l|}
\hline Pedal & Pedal point \\
O emprego do pedal consiste na & Pedal point is a stationary pitch that begins \\
manutenção de uma nota, em qualquer & as a chord tone, then becomes a NCT as the \\
voz, por vários compassos e por várias & harmonies change, and finally ends up as a \\
trocas de harmonias. Tais trocas de & chord tone again. Pedal points usually occur \\
acordes geram harmonias dissonantes, & in the bass, but they occasionally occur in \\
principal atrativo no uso do pedal. & other parts as well. (INGTMLIV12) \\
$\begin{array}{l}\text { Embora possa aparecer em qualquer voz, } \\
\text { seu uso é mais frequente no baixo }\end{array}$ & \\
mantendo a fundamental do I grau (pedal & \\
de tônica) ou findamental do V grau (pedal & \\
de dominante) (PORTMLIV01) &
\end{tabular}

Quadro 14 - Tipos de notas ornamentais e seus correspondentes em Inglês

\section{9) Acorde alterado}

"Acorde alterado" é uma das colocações que foi encontrada nos dicionários pesquisados:

Acorde em que algumas notas são alteradas ascedendente ou descendentemente, provocando dissonâncias. (DP - DOURADO)

No subcorpus de português, a colocação tem uma frequência de 55 ocorrências no singular e 37 no plural. 


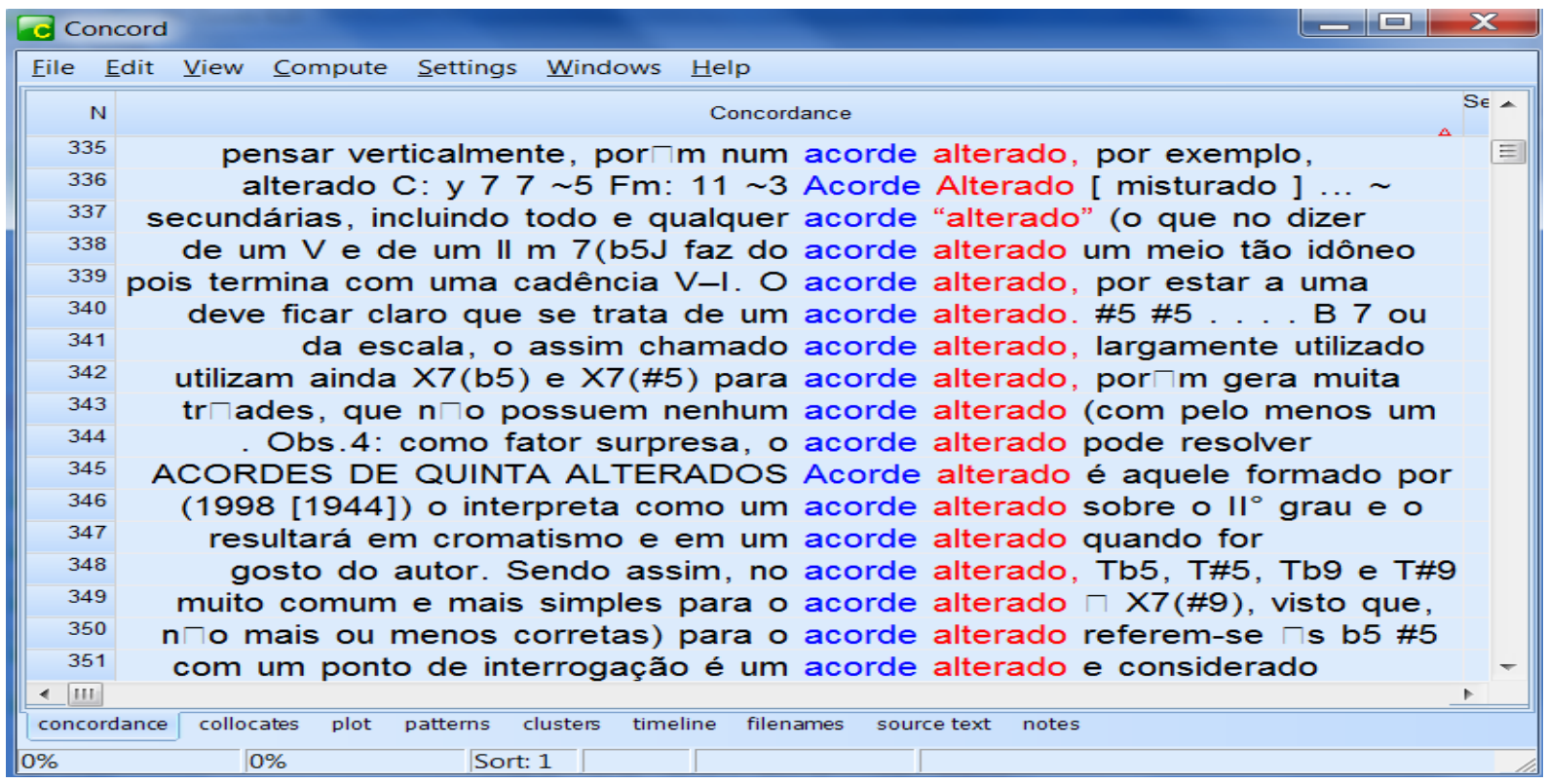

Figura 69 - Linhas de concordância (parciais) de "acorde alterado"

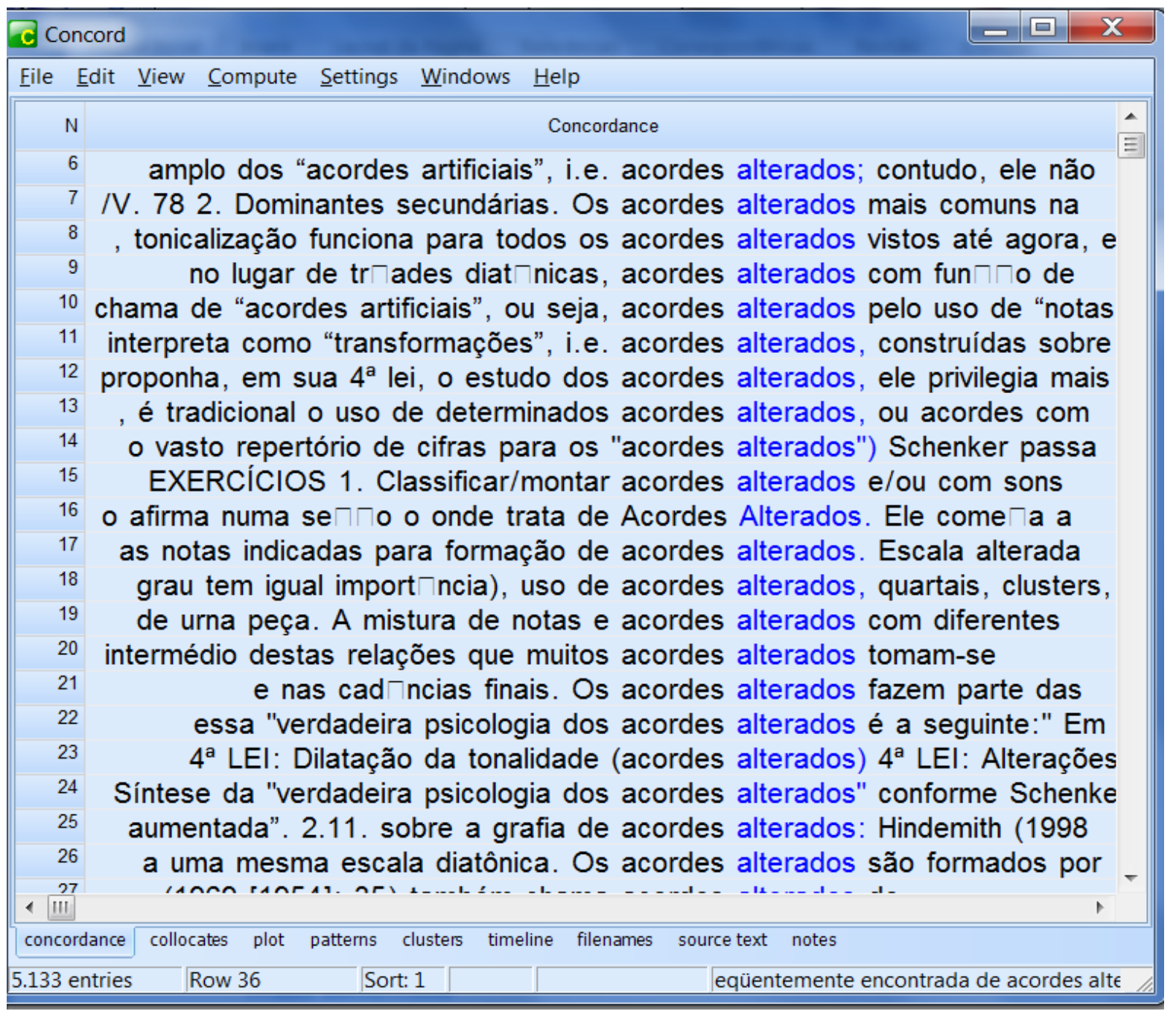

Figura 70 - Linhas de concordância (parciais) de "acordes alterados" 
Encontramos alguns contextos definitórios no subcorpus instrucional e selecionamos:

- $\quad$ Acordes alterados são formados por notas pertencentes a uma escala alterada. É construído elevando ou abaixando as notas diatônicas. A característica do acorde alterado é o intervalo de terça diminuta entre as notas do acorde (a outra terça é maior ou menor). Na formação da escala alterada não devem ser alterados os graus I-III-V. (PORTMLIV02)

- Acorde alterado é considerado um acorde estranho à tonalidade principal de um trecho. (PORTMAPO01).

- O termo é usado para designar acordes que, embora pertencendo ao campo harmônico de uma tonalidade, apresentam notas que ampliam o seu âmbito e alteram notas da escala. Devido à surpresa proporcionada pelas notas alteradas, estes acordes são utilizados como recursos expressivos, principalmente nos pontos culminantes, onde há maior tensão harmônico-melódica e nas cadências finais. Os acordes alterados fazem parte das regiões dos acordes principais da tonalidade, Subdominante e Dominante. (PORTMTAPO06)

Analisando o subcorpus acadêmico-científico, verificamos os seguintes contextos de uso da colocação acorde alterado:

- o acorde vagante pode assumir a seguinte gama de alterações: X7 (9, \#11, 13). O modo sobre o VII grau da Escala Menor Melódica é o modo Superlócrio e corresponde a um acorde meio diminuto. Porém, na prática da música popular esse modo é denominado Escala Alterada e é associado a um acorde de Sétima Dominante conhecido na teoria da música popular como acorde alterado. (PORTMART04)

- Sobre o nome e a grafia dados às dominantes dos demais graus da escala (dominantes secundárias): Hindemith (1998 [1944]: 84) as chama de “dominantes secundárias" ou "auxiliares”; por vezes, Schoenberg (1969 [1954]:

6) as indica sem distinção com relação a seus correspondentes diatônicos (ex.: 
usa "III2" para indicar uma dominante do relativo menor, ou "V/vi”), embora ele geralmente reserve para estas dominantes a classificação específica de “dominantes artificiais" (p. 17), no contexto mais amplo dos "acordes artificiais", i.e. acordes alterados; contudo, ele não cria uma grafia especial para estas "dominantes artificiais", grafando-as com numerais romanos cruzados horizontalmente (p. 16), ou seja, com a mesma grafia usada para qualquer “acorde artificial”, um grupo que ultrapassa em muito o âmbito das dominantes secundárias, incluindo todo e qualquer acorde alterado (o que no dizer Schoenberguiano inclui diminutos, aumentados, sexta napolitana, etc.) (PORTMART21)

Em Inglês, encontramos no subcorpus "Altered chords", que apresenta a frequência de 22 ocorrências.

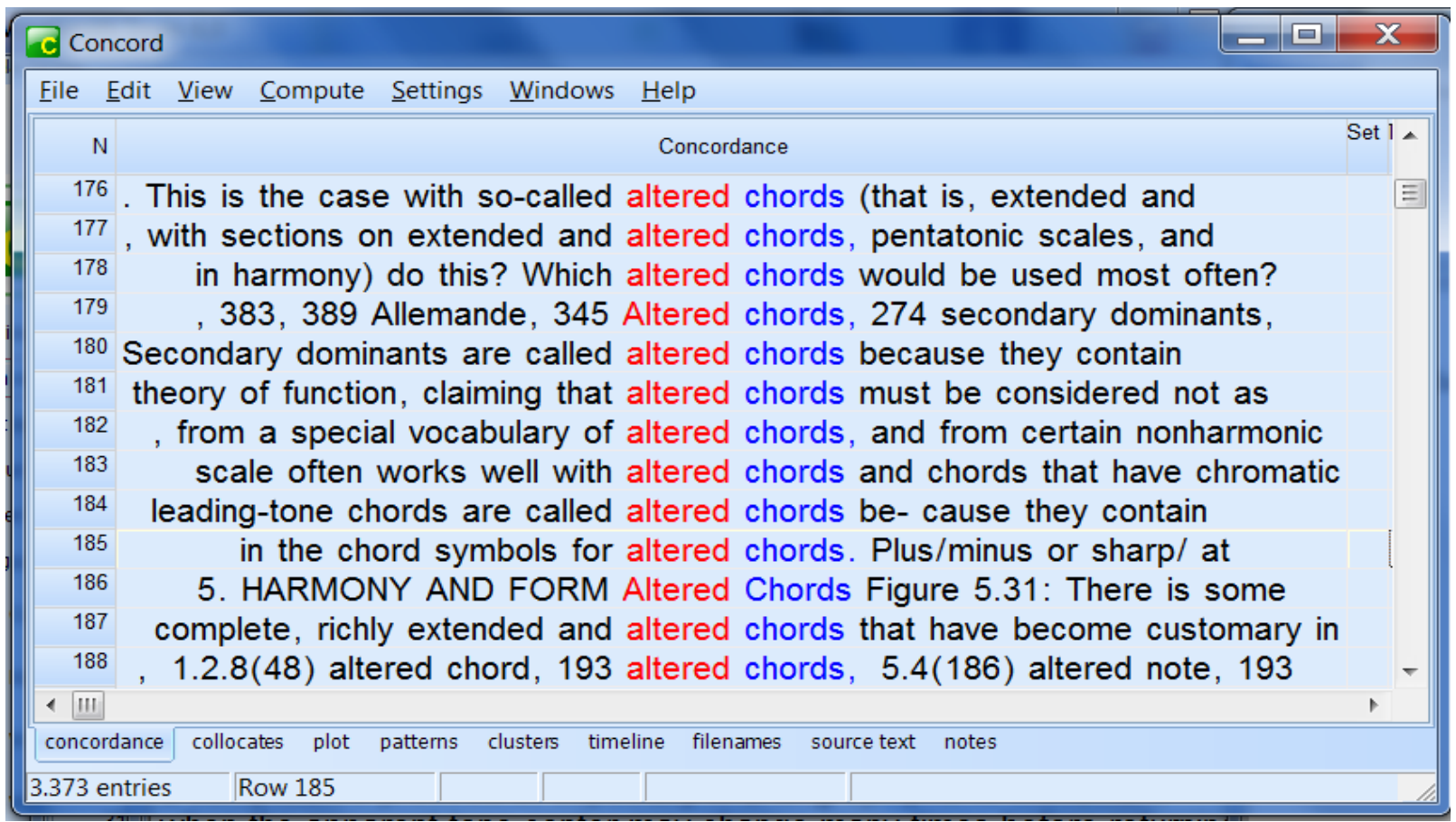

Figura 71 - Linhas de concordância ( parciais) de "altered chord" no singular e no plural

A colocação foi encontrada no dicionário DI-OXFORD, com a seguinte definição:

A chord which has one or more of its notes chromatically altered by accidentals foreign to the key. The most common altered chords are the "Neapolitan sixth and the three kinds of augmented sixth.

No subcorpus instrucional, encontramos as seguintes definições: 
- If a note in the chord is not in the major or minor scale of the root of the chord, it is an altered note and makes the chord an altered chord (INGMLIV03).

- Chords that employ chromaticism are called altered chords, and the most commonly encountered altered chord in tonal music is the secondary function. (INGMLIV12)

- All other chords - those using notes not in the scale - are called altered chords. (INGTMLIV12)

Em contexto de uso retirado do subcorpus acadêmico-científico, selecionamos:

- Secondary dominants are called altered chords because they contain nondiatonic tones-tones that are not found in the prevailing key. (INGMLIV02)

(...) the derivation of altered chords, such as altered sixth chords, would be located on this level since they constitute derivations of core functional chords (INGMART20).

Chromatic tones began to appear in music long before the common-practice period, and by the beginning of that period were an important part of its melodic and harmonic resources. Chromatic tones arise in music partly from inflection of scale degrees in the major and minor modes, partly from secondary dominant harmony, from especial vocabulary of altered chords, and from certain nonharmonic tones. (INGTMLIV11)

Analisando as linhas de ocorrências nos dois idiomas, nota-se que a colocação remete inicialmente a notas estranhas à tonalidade encontrada no acorde. Contudo, é o contexto de uso que mostrará que alteração é essa (dominantes secundárias, acordes artificiais, escala alterada, cromatismo, etc.)

Verificamos que em alguns contextos acorde alterado e acorde cromático são variantes. No glossário, indicaremos remissivas.

\section{0) Acorde cromático}


A colocação "acorde cromático" tem a frequência de 5 ocorrências no corpus de estudo de Português. Para entender o adjetivo cromático, extraímos do corpus o termo Cromatismo em contexto definitório:

- $O$ cromatismo pode ser resumido como ocorrências de notas estranhas aos acordes, ou seja, notas cromáticas que não fazem parte da constituição real de acordes. O cromatismo harmônico passa a ocorrer quando passamos a introduzir notas cromáticas (notas de outras tonalidades) em uma tonalidade principal. As formas de introdução destas notas cromáticas à uma tonalidade são geralmente utilizadas na música tonal como uma função tonal secundária, ou seja, um acorde que tem sua função tonal relacionada diretamente com uma outra tônica que não a tônica principal da passagem ou da peça musical. (PORTMAPO01)

Entendendo o acorde cromático como aquele que possui notas estranhas à tonalidade do trecho musical, selecionamos alguns contextos de uso (do subcorpus acadêmicocientífico):

- Denis Delair [falecido após 1727] divide suas instruções para a realização dos baixos cifrados em duas categorias: accompagnements ordinaires, abrangendo majoritariamente os acordes diatônicos, e accompagnements extraordinaires, constituído principalmente de acordes cromáticos. (PORTMTE02)

- O objetivo deste trabalho foi abordar, a partir de uma seleção de músicas da obra de Tom Jobim, aspectos da escolha de caminhos harmônicos alternativos, possibilitados pelo uso de cromatismos. Antes, porém, de comentar os dados levantados em tal análise, faz-se necessário definir os conceitos relativos a tais acordes cromáticos e suas possibilidades de aplicação. (PORTMART22)

No primeiro trecho, acordes cromáticos se apresentam como distintos dos "acordes diatônicos”, ou seja, eles possuem notas que não pertencem à tonalidade. No segundo caso, num contexto de música popular, o autor se refere a acordes de empréstimo modal utilizados na música popular, especificamente na de Tom Jobim. 


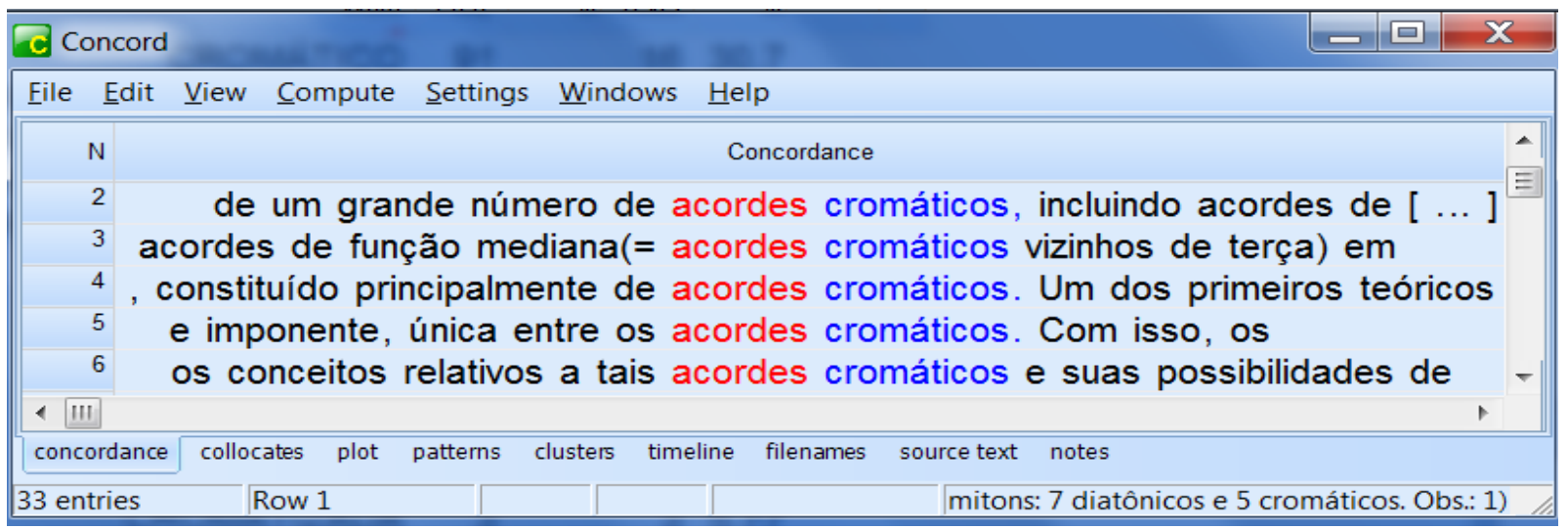

Figura 72 - Linhas de concordância ( parciais) de "acordes cromáticos"

Encontramos no subcorpus de inglês, a colocação "chromatic chord", com 16 ocorrências.

Do corpus instrucional, extraímos um contexto definitório:

Most chords in tonal music are made up only of notes from the scale on which the passage is based. That is, if a passage is in G major, most of the chords contain only notes found in the G major scale. Chords of this kind are called diatonic chords. All other chords-those using notes not in the scale-are called altered or chromatic chords. (INGTMLIV02)

A passagem acima apresenta o colocado "alterado" como uma variante de cromático.

Os seguintes excertos, extraídos do corpus acadêmico-científico, mostram contextos de uso da colocação:

- Richmond Browne's position-finding interval between and may be further expanded to be a sign of dominant function for any chromatic chord in which this tritone appears.(INGTMART14)

- Charles Smith's 1986 article on extravagant function considers chromaticism a combination of harmonic and contrapuntal motion (Smith 1986, 103-105). This perspective justifies a series of alternative dominants that replace the diatonic scale-step with or, and among them are three chromatic half-diminished sevenths, reproduced in Example 2a. To Smith, the chromatic chords are selfsufficient; they act as delicate dominants due to their context and the presence of the leading tone (Smith 1986, 126-127) (INGTMART14) 


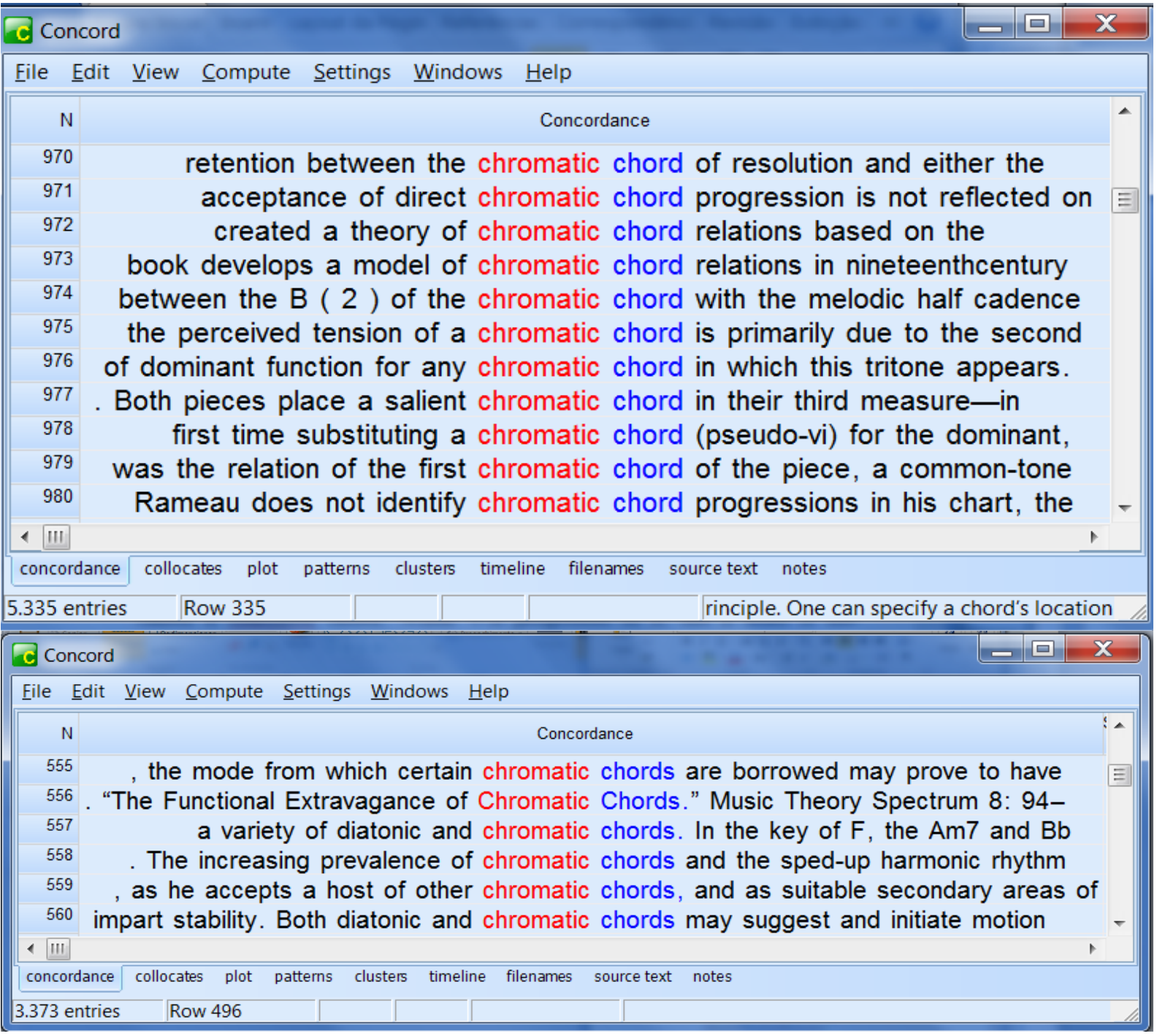

Figura 73 - Linhas de concordância (parciais) de "chromatic chord" no singular e plural"

Verificamos que em alguns contextos acorde alterado e acorde cromático são variantes. No glossário, indicaremos remissivas.

\section{1) Acorde bordadura}

A colocação "acorde bordadura" tem 8 ocorrências no subcorpus de português. No exemplo abaixo, verifica-se que a colocação remete ao significado do termo "bordadura" (vide item 20), encontrado no subcorpus instrucional, relacionado aos temas "Figuração Melódica e Notas Ornamentais", que são notas estranhas ao acorde, usadas com o fim de ornamentar a melodia: 
- No seguinte exemplo observa-se que há uma nota comum entre os acordes, esta nota é a fundamental do acorde de resolução, seja ele uma tríade ou uma tétrade. A função deste acorde é puramente ornamental, isto é, o acorde é um acorde bordadura ou um acorde de passagem. (PORTMAPO01)

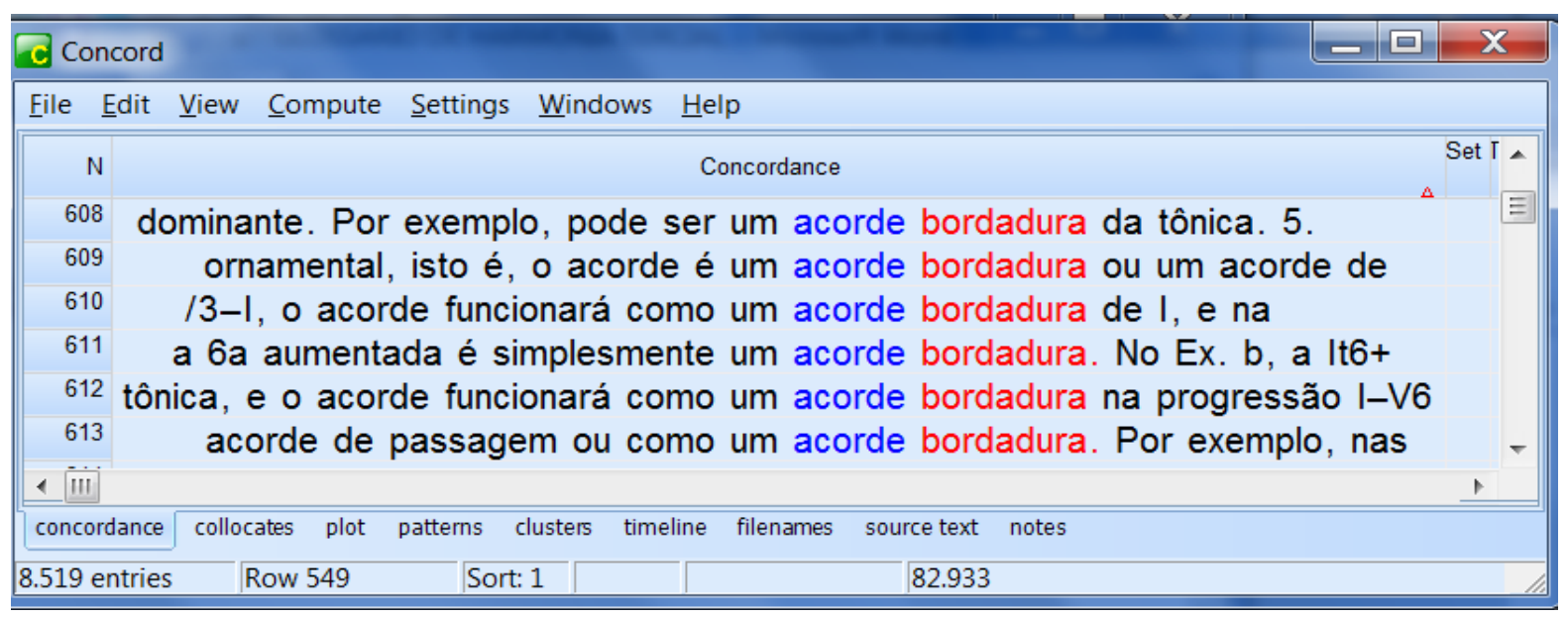

Figura 74 - Linhas de concordância parciais de "acorde bordadura"

Analisando as linhas de concordância, encontramos a variante "Acorde de bordadura", com apenas duas ocorrências:

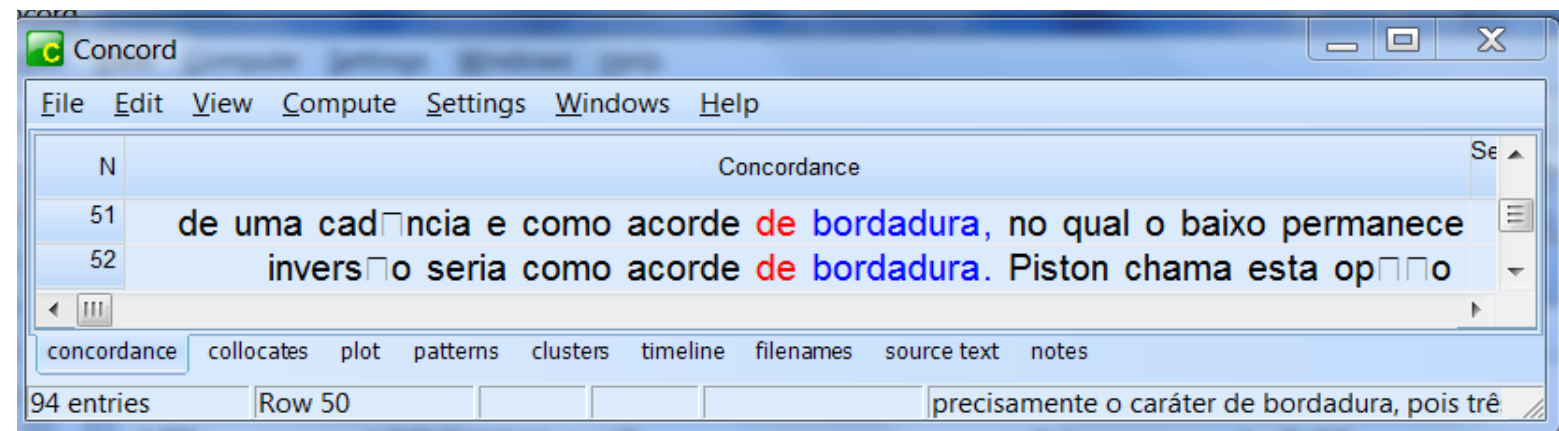

Figura 75 - Linhas de concordância de "acorde de bordadura"

Em inglês, o termo correspondente de "bordadura" é "neighboring tone", e de "dupla bordadura" é "neighbor group", conforme detalhado no item 18 (Notas estranhas ao acorde). Os contextos definitórios encontrados no corpus instrucional de Português e Inglês para os termos bordadura, dupla bordadura, Neighboring tone, Neighbor group foram:

Bordadura: A Bordadura apresenta-se como uma dissonância em tempo fraco ou parte fraca do tempo, que parte de uma nota de acorde por movimento de segunda 
acima (bordadura superior) ou abaixo (bordadura inferior) e retorna obrigatoriamente, para a mesma nota de origem. (PORTMLIV01)

Dupla Bordadura: É a combinação de duas dissonâncias na qual a primeira se apresenta como uma bordadura superior, seguida, imediatamente, pela segunda como bordadura inferior, ou vice-versa. Assim, a primeira aparece como uma bordadura incompleta (tempo fraco ou parte do tempo fraca) e a segunda como uma apojatura (tempo forte ou parte do tempo forte). (PORTMLIV01)

Neighboring tone: The neighboring tone is used to embellish a single tone. It may appear above the main tone (upper neighbor) or below it (lower neighbor), and it may be diatonic or chromatic. (INGTMLIV12)

Neighbor group: A common method of embellishing a single tone involves a combination of two NCTs in succession, the first being an escape tone, the second an appoggiatura. (INGTMLIV12)

A common method of embellishing a single tone involves a combination of two NCTs in succession, the first being an escape tone, the second an appoggiatura. (INGTMLIV12)

A partir destas informações e analisando contextos, encontramos a colocação correspondente de "acorde bordadura": "neighbor chord" (35 ocorrências) e "neighboring chord" (7 ocorrências).

Chords made up mostly or entirely of neighbor- and/or passing-tones are common in jazz. (...) Neighbor chords - Often, an entire chord is used as if it were a neighbor note. (INGTMLIV07)

Traditional music theory gives precise definitions of various embellishing tones neighbor, passing, changing, escaped, anticipation, suspension, etc. - and prescribes how they are to be treated. The jazz musician can choose to observe these prescriptions or not. (INGTMLIV07)

Em alguns contextos (observados em algumas linhas de concordância da Figura 76) co-ocorre com os colocados upper, lower, chromatic, embellishing, confirmando um acorde 
com notas estranhas e referir-se a bordadura superior e inferior (upper neighbor chord e lower neighbor chord, respectivamente).

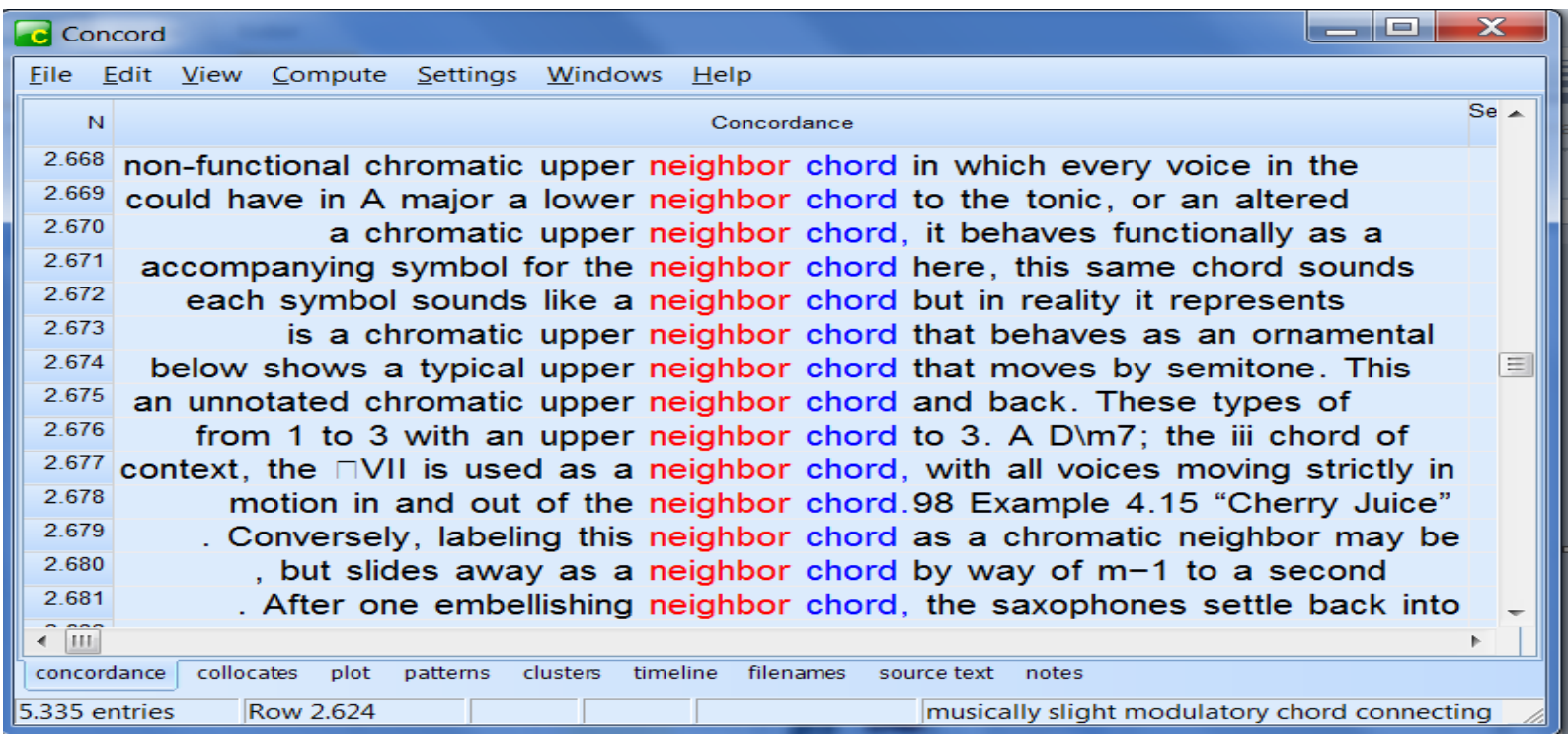

Figura 76 - Linhas de concordância (parciais) de "neighbor chord"

Exemplos de uso extraídos do subcorpus acadêmico-científico:

- And although there is no accompanying symbol for the neighbor chord here, this same chord sounds on the downbeat of two, where there is an accompanying symbol. (INGTMDM04)

- In fact, each part of the tonal template described in this section of the chapter is visible in Example 3.28: a tonic prolongation pattern (mm. 1-3) moves from 1 to 3 with an upper neighbor chord to 3. (INGTMDM02)

- Were we to analyze the IV chord of the S phrase as a neighboring chord to I (i.e., within the progression $I-I V-I$ ). (INGTMART10)

A partir da observação da lista de colocados para o termo chord, encontramos um colocado que tem um significado abrangente para acordes com notas ornamentais: embellishing chord. Essa colocação tem a frequência de 14 ocorrências no corpus de estudo. 


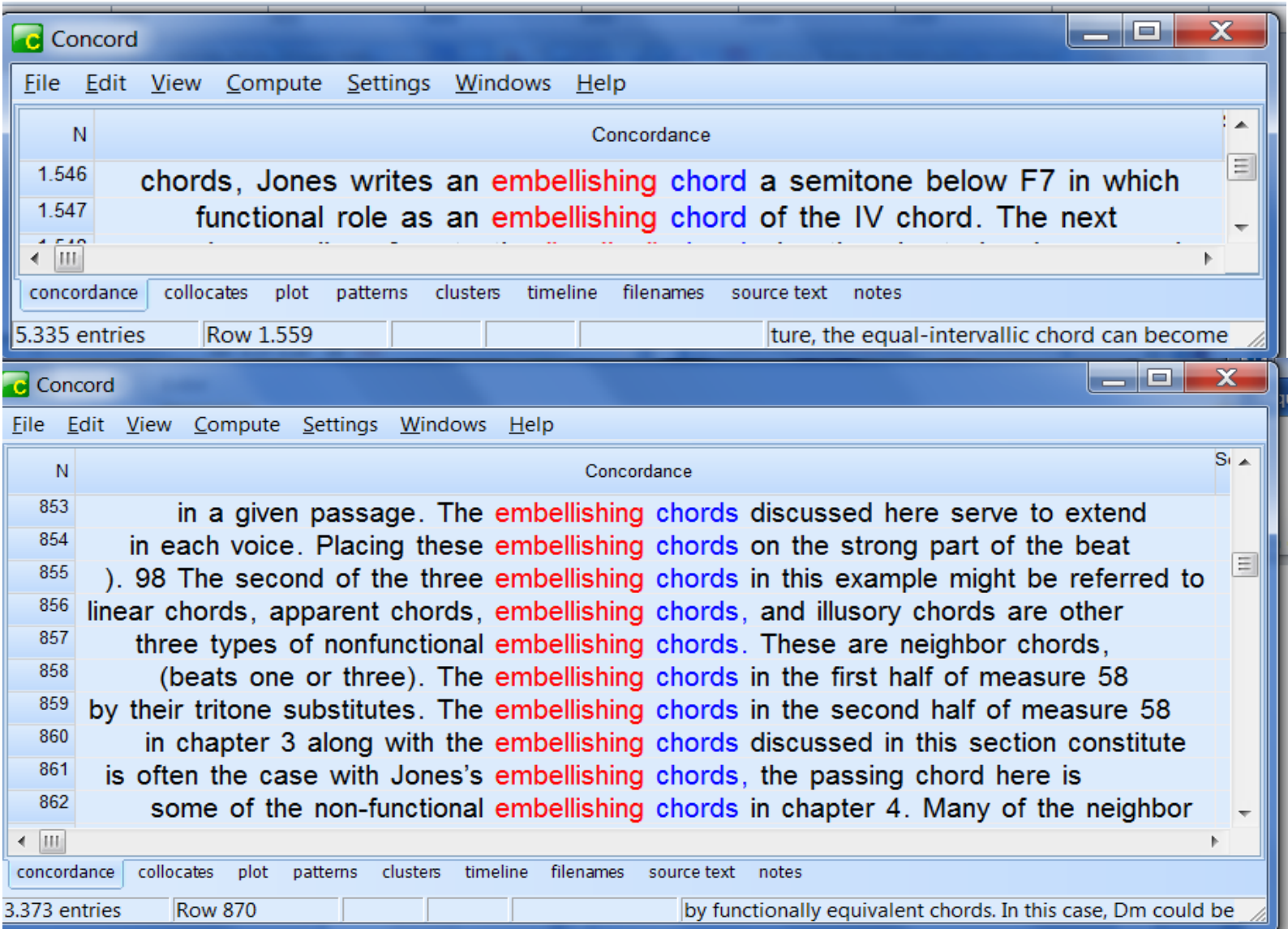

Figura 77 - Linhas de concordância parciais de "embellishing chords"

No contexto a seguir "embellishing chord" refere-se a um "passing chord" (acorde de passagem):

Between these two functional chords, Jones writes an embellishing chord a semitone below F7 in which each voice is shifted down a half step from the destination chord. And as is often the case with Jones's embellishing chords, the passing chord here is unaccompanied by a chord symbol. (INGTMDM04)

\section{2) Acorde de passagem}

A colocação acorde de passagem tem frequência de 33 ocorrências (somadas formas singular e plural) no subcorpus de português. Vejamos alguns excertos retirados do corpus instrucional e do acadêmico-científico: 
- No exemplo 2-16, o acorde assinalado (si meio diminuto, em primeira inversão) pode ser classificado como um acorde de passagem que liga o i grau (ré menor) ao vii ${ }^{\circ}$ (dó\# diminuto, em primeira inversão). A classificação como um acorde de passagem se justifica por seu valor rítmico, pela constatação de que anota si (do tenor) foi atingida por salto e sua pouca autonomia harmônica. Neste compasso, apenas o $i$ grau (ré $m$ ) e o vii têm um significado harmônico relevante. (PORTMLIV01)

- O VII grau invertido é comumente encontrado como um acorde de passagem entre I grau na fundamental e o I grau na primeira inversão. (PORTMDM01)

- Todo acorde em segunda inversão deve ser empregado com cuidado. Seu uso mais aconselhável é como acorde de passagem, em tempo fraco. É frequente seu uso como acorde de passagem na troca de vozes. Neste caso, quase todas as vozes se movem como figuração melódica e, por vezes, a quinta do acorde vem dobrada. (PORTMLIV01)

- O principal emprego da sexta nota da subida da menor melódica é como nota de passagem. As tríades ou tétrades que empregam esta nota (ii, IV e vi ${ }^{\circ}$ ) normalmente cumprem o papel de acordes de passagem ou figural apenas como simultaneidade resultante de movimentos melódicos empregados em vozes diferentes. (PORTMAPO06)

Embora não tenha sido encontrado contexto definitório no corpus de estudo de Português para a colocação, a partir da leitura dos excertos anteriores, verificamos algumas características gerais que podem ser encontradas em acordes de passagem: usado como elo entre os acordes anterior e posterior a ele, em tempo fraco do compasso, possuir notas estranhas à tonalidade, tríades que possuem a sexta nota da escala.

"Passagem" também é um colocado de "notas"; juntos apresentam a seguinte definição:

Notas de passagem: São aquelas que preenchem o espaço entre duas notas diferentes de um mesmo acorde ou de acordes diferentes. Normalmente, a nota de passagem é uma dissonância usada entre duas consonâncias para 
preencher um intervalo de terça. Ela pode ser ascendente ou descendente, não acentuada ou acentuada, e diatônica ou cromática. (PORTMLIV01)

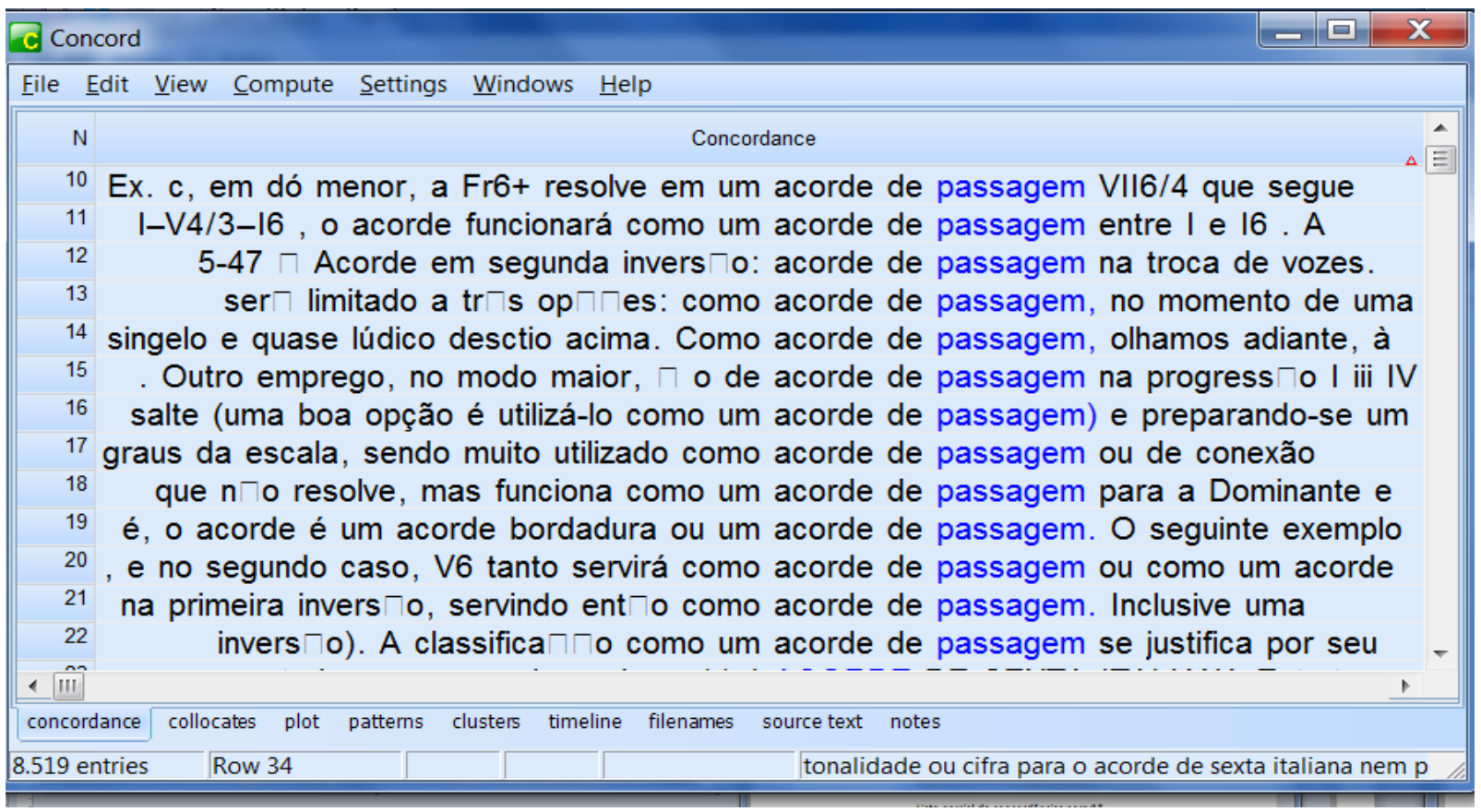

Figura 78 - Linhas de concordância (parciais) de "acorde de passagem"

Na busca por correspondente em Inglês, encontramos a colocação passing chord (59 ocorrências) Ela também foi localizada no dicionário DI - HARVARD, com a seguinte definição:

A chord occuring with the prolongation of some harmony and introduced over a passing tone in the bass; also any chord whose function is clearly subordinate to those preceding and following and one or more of whose elements is introduced as a passing tone.

No subcorpus instructional, o contexto definitório complementa a informação do dicionário e reforça a nossa constatação.

- A passing chord is a nondiatonic chord that connects, or passes between, the notes of two diatonic chords. (INGTMLIV02)

Foram selecionados do subcorpus acadêmico-científico os seguintes contextos de uso: 
- This can be interpreted as a passing chord (along with V/ii in measure 8) within a larger motion from IV to ii.(INGMART08)

- The use of upper and lower chromatic neighbors as well as passing and double passing chords is not only idiomatic, but greatly enhances the structure of the progression. (INGTMART19)

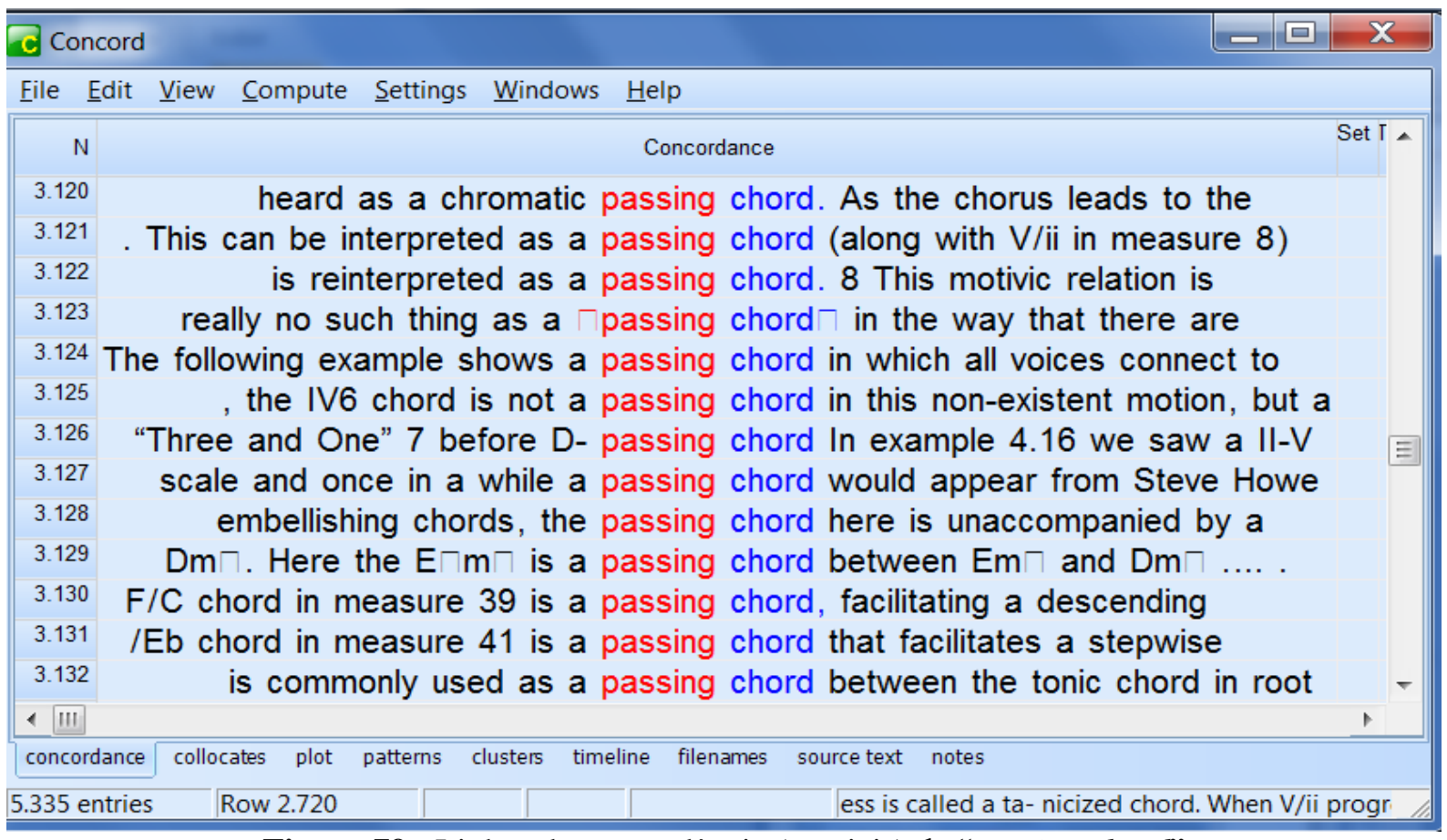

Figura 79 - Linhas de concordância (parciais) de "passing chord"

Neste item, acorde de passagem tem um significado abrangente, podendo se referir a alguns tipos de acordes de passagem. A colocação "Acorde de quarta e sexta de passagem" se refere a um tipo mais específico de acorde de passagem e será discutida no item 57.

No glossário, utilizaremos remissivas para essas colocações.

\section{3) Acorde pedal}

No subcorpus de Português a colocação acorde pedal apresenta apenas cinco ocorrências. No item 18 sobre "Notas estranhas ao acorde", apontamos contextos definitórios para o termo "pedal", que é um constituinte da colocação analisada: 
- Pedal: O emprego do pedal consiste na manutenção de uma nota, em qualquer voz, por vários compassos e por várias trocas de harmonias. Tais trocas de acordes geram harmonias dissonantes, principal atrativo no uso do pedal. Embora possa aparecer em qualquer voz, seu uso é mais frequente no baixo mantendo a fundamental do I grau (pedal de tônica) ou fundamental do V grau (pedal de dominante) (PORTMLIV01)

- Kostka \& Payne comentam que o pedal começa como uma nota do acorde, a deixa de ser, e enfim, volta a ser uma nota do acorde. Outro detalhe é que a nota pedal pode ser confundida como uma nota de acorde invertido. (PORTMDM01)

Com base nesses contextos definitórios, deduz-se que os acordes que sustentam a nota pedal são denominados acordes pedais.

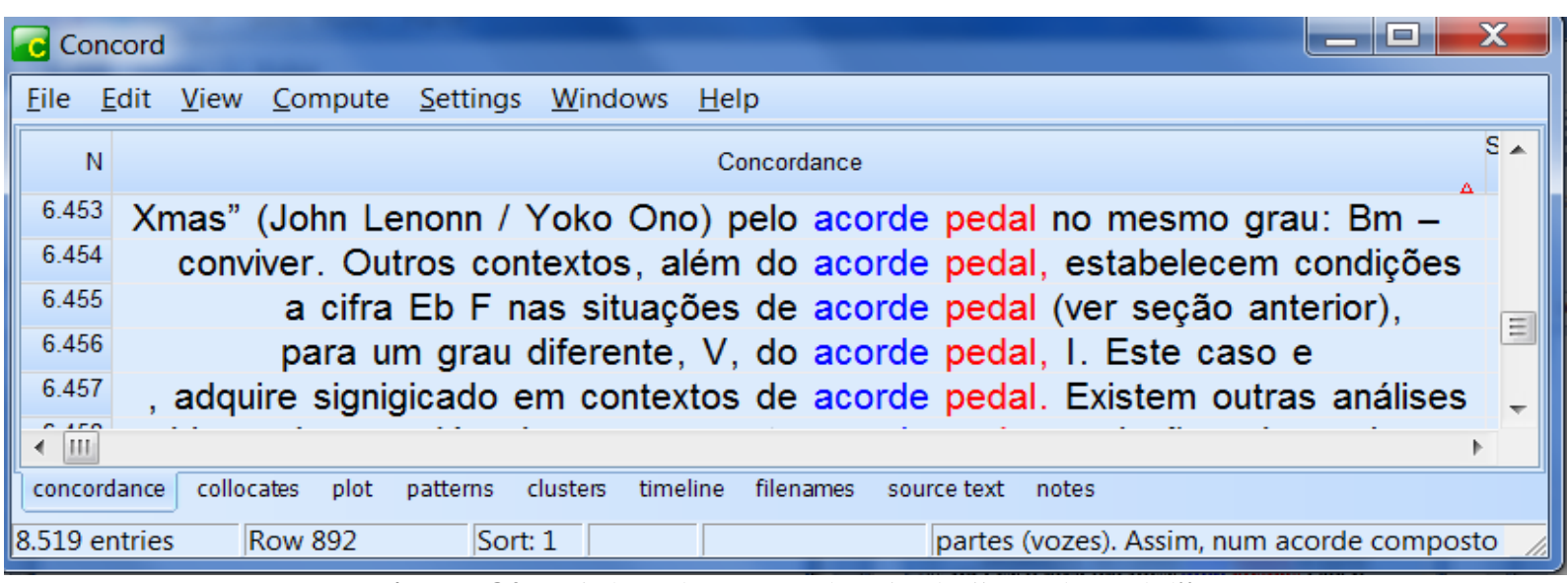

Figura 80 - Linhas de concordância de "acorde pedal"

O trecho abaixo foi extraído do subcorpus acadêmico-científico e mostra o uso da colocação em contexto de uso:

Nesse sentido, daria certo, por exemplo, a substituição da nota pedal sobre o II grau da "Happy Xmas" (John Lennon / Yoko Ono) pelo acorde pedal no mesmo grau. (PORTMDM02)

$\mathrm{Na}$ busca por correspondente em Inglês, encontramos a colocação pedal chord, com apenas duas ocorrências. Da mesma forma que em Português, relacionamos aqui o conceito do termo correspondente de Pedal, que é "Pedal point":

Pedal point - Pedal point is a stationary pitch that begins as a chord tone, then becomes a NCT as the harmonies change, and finally ends up as a chord tone again. 
Pedal points usually occur in the bass, but they occasionally occur in other parts as well. (INGTMLIV12)

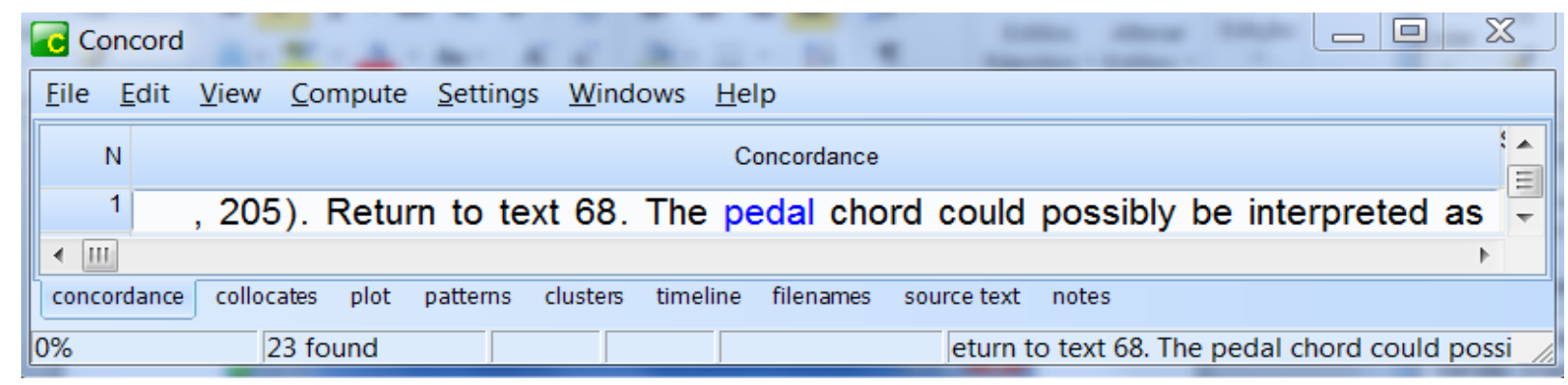

Figura 81 - Linhas de concordância de "pedal chord"

O excerto abaixo foi extraído do subcorpus acadêmico-científico e mostra o uso da colocação em contexto de uso:

The pedal chord could possibly be interpreted as a $\mathrm{V}$, but given the intense lydian bent of the E.T. score at large, this cadential chord should count as a subtraction of attribute 5 all the same. (INGTMART07)

\section{4) Acorde errante, acorde vagante}

Neste subitem agrupamos as colocações "acorde errante" (15 ocorrências) e "acorde vagante" (77 ocorrências) por serem variantes do mesmo conceito e traduções já conhecidas da colocação "vagrant chord" (utilizada por Schoenberg). Os trechos abaixo foram extraídos do subcorpus acadêmico-científico e apresentam descrições e contextos de uso das colocações:

- Acordes vagantes: Apresentam funções múltiplas. Atuam como acordes que podem ser introduzidos depois de qualquer acorde. Tais acordes não pertencem somente a uma tonalidade de forma exclusiva; mas sim, podem pertencer a varias, a praticamente todas tonalidades sem mudar sua forma. Ainda estes acordes são derivados das transformações e tem função múltipla por apresentarem uma construção especifica. Os casos mais evidentes são os acordes de sétima diminuta, a tríade aumentada e o acorde de sexta aumentada e suas inversões. Estes acordes apresentam uma falta de sentido claro, de definição de sua fundamental, o que 
torna o seu sentido vago, isto é, sem uma relação definida com a tônica. (PORTMART18)

- Os chamados "acordes errantes" ("Vagrant Chords") de Schoenberg são, basicamente, aqueles mesmos que, desde os tempos de Vogler, são costumeiramente apontados como os campeões da franca plurisignificância tonal: o "acorde de sétima diminuta pertence, ao menos, a oito tonalidades ou regiões"; "cada triade aumentada pertence (...) a seis tonalidades ou regiões. "(PORTMTE02)

- (...) a discussão do "acorde Tristão" como um acorde vagante é definida por Schoenberg quando este propõe várias interpretações para o mesmo acorde. (PORTMART18)

- Os acordes de sexta aumentada são casos típicos de acordes vagantes. (PORTMART04)

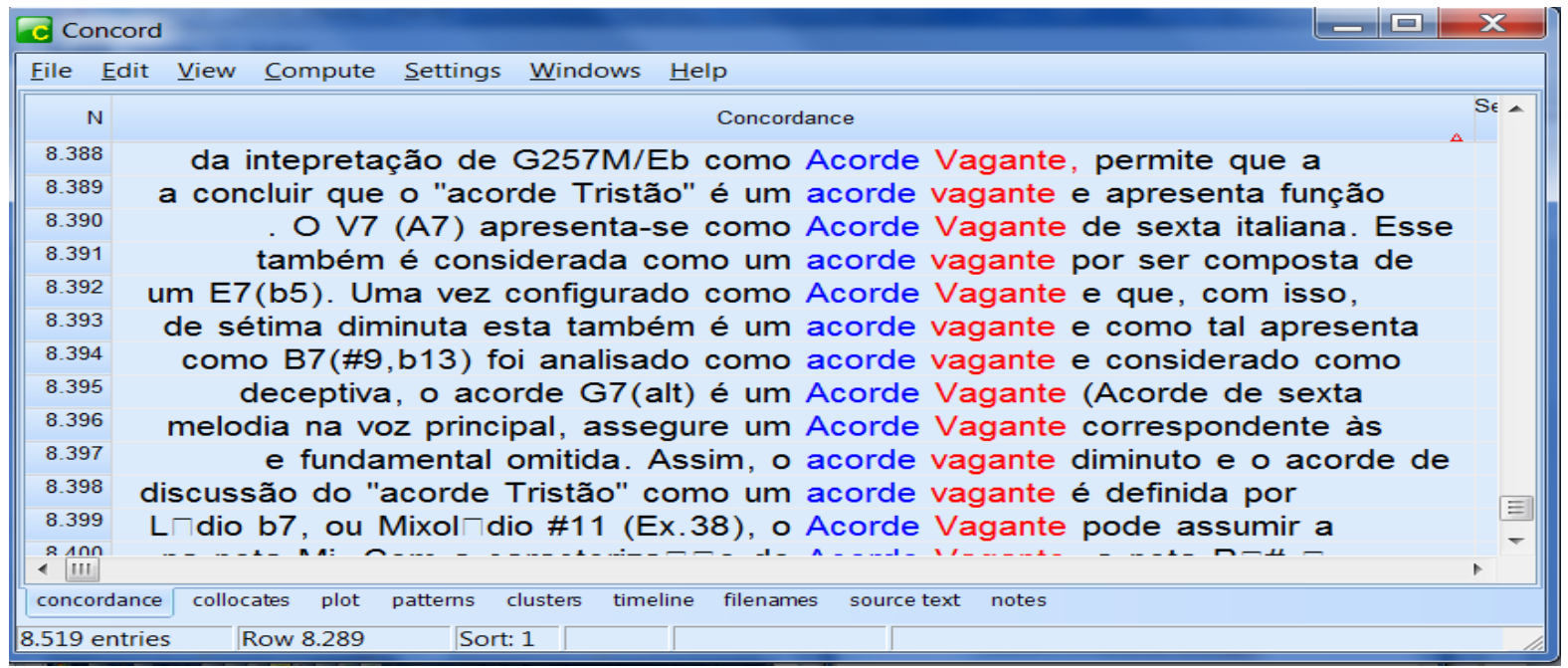

Figura 82 - Linhas de concordância (parciais) de "acorde vagante"

No subcorpus inglês, a colocação correspondente (vagrant chord) apresenta 33 ocorrências. Os trechos selecionados abaixo apresentam contexto definitório e de uso extraídos do subcorpus acadêmico-científico (também referenciando obras teóricas de Schoenberg): 
- Vagrant chords represent an important step in the development of tonality. Vagrant chords, a term coined by Schoenberg in his book Theory of Harmony, are defined as wandering, ambiguous harmonies. Any sonority which wanders away from the central tonality or has multiple meanings within a harmonic context may be considered a vagrant chord. Vagrant harmonies distinguished by their intervallic constitution include the augmented triad, diminished seventh chord, whole-tone chord, and perfect-fourth chord. These four types of chords all share three characteristics: 1) they all have the same interval between adjacent degrees, 2) they do not have, because of their physical nature, a single comprehensible root, and 3) they all are capable of multiple meanings and resolutions. (INGTMART27)

- The F dominant-seventh chord is not, by any means, the only vagrant chord of the second class in this song. Throughout Strauss' lied, he treats most of the dominant sevenths as vagrant chords as they undergo irregular resolutions. For example, the opening dominant-seventh chord in first inversion (V 6/5 of IV), in the three measure introduction of the song, clearly demonstrates how a vagrant chord's irregular resolution can lead to a distant region and undermine the central tonality. (INGTMART27)

- Schoenberg considers the fully-diminished-seventh to be a vagrant chord; "Such a chord belongs to no key exclusively; rather, it can belong to many, to practically all keys without changing its shape. (INGTMTE02) 


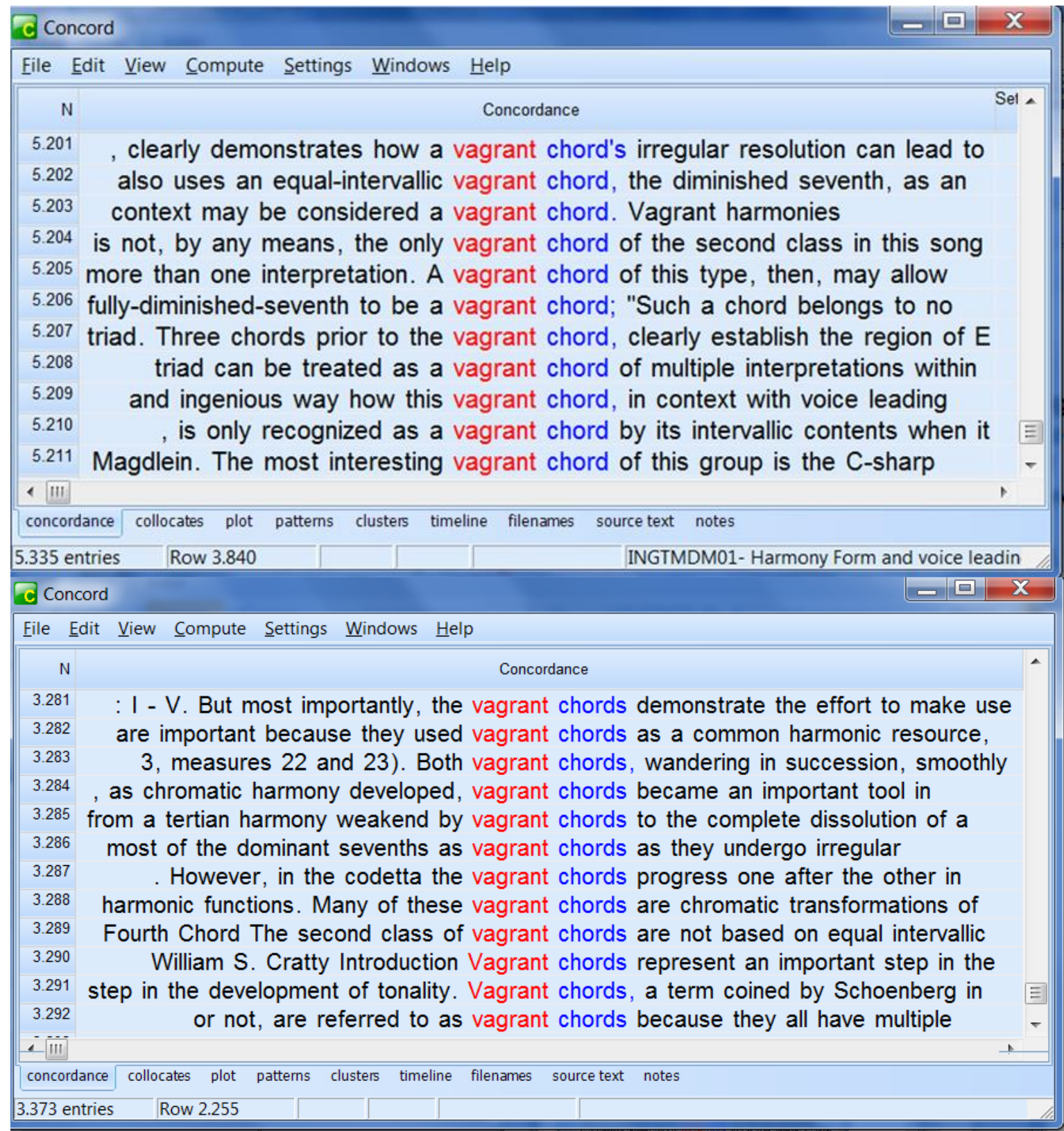

Figura 83 - Linhas de concordância (parciais) para "vagrant chord(s)"

No glossário, as entradas para "Acorde errante" e "acorde vagante" apresentarão remissivas.

\section{5) Acorde de empréstimo modal}

A colocação "acorde de empréstimo modal" apresenta 41 ocorrências no subcorpus de Português. 
. No subcorpus instrucional, encontramos o seguinte conceito definitório:

- A palavra modal vem de modo. Modo é a maneira de como os tons e semitons são distribuídos entre os graus da escala. Acordes do modo (tonalidade) menor usados no modo (tonalidade) maior paralelo e vice-versa são denominados acordes de empréstimo modal AEM. Os acordes de empréstimo modal podem ser derivados também de qualquer modo (dórico, lídio, mixolídio, etc.) (PORTMLIV07)

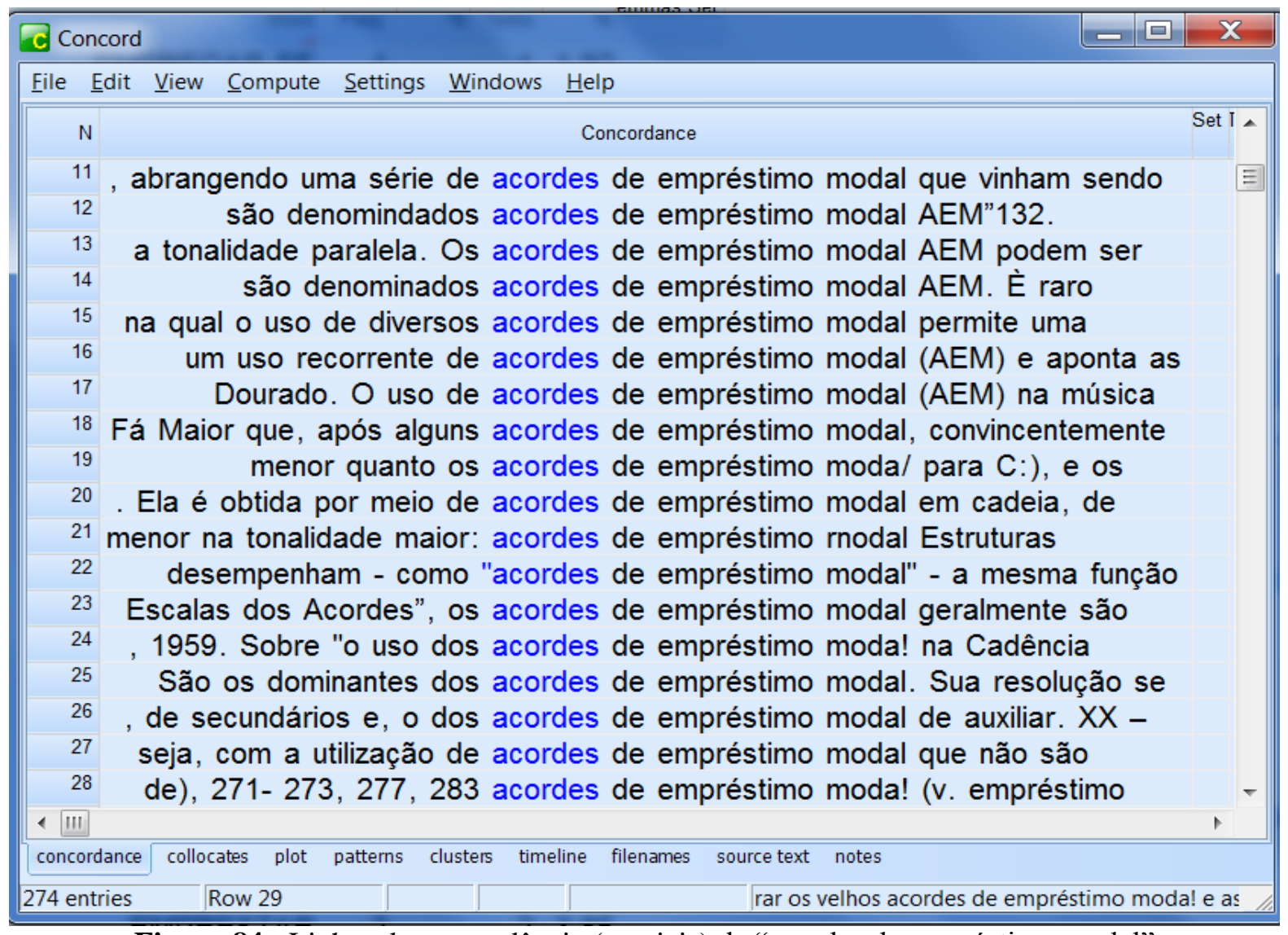

Figura 84 - Linhas de concordância (parciais) de "acordes de empréstimo modal"

Os trechos abaixo foram retirados do subcorpus acadêmico-científico para exemplificar o uso:

- O estudo detalhado a partir do conceito de acorde de empréstimo modal mostrase útil para identificar elementos harmônicos que ocorrem de maneira consistente na obra de Jobim. Cromatismos, funções harmônicas e condução melódica estão interligados na abordagem que Jobim utiliza, na qual o uso de diversos acordes 
de empréstimo modal permite uma grande liberdade na composição de melodias simples, que sustentadas por harmonias diversificadas permitem um caráter único para sua obra musical. (PORTMART22)

- Schöenberg, por exemplo, inclui como empréstimo modal todos os acordes provenientes dos modos eclesiásticos com as respectivas alterações do sexto e sétimo graus da escala, o que implica que, até mesmo as dominantes secundárias são por ele classificadas como acordes de empréstimo modal.

$O$ autor que menos se aprofunda neste item é Piston. Alguns pontos são apresentados no capítulo que fala sobre tonalidade, e, os pontos mais importantes estão no capítulo sobre modulação Kostka \& Payne são os autores que abordam de forma mais sucinta os acordes de empréstimo modal, porém, não menos dedicada. Para Kostka \& Payne e Piston são considerados acordes de empréstimo modal os acordes provenientes da homônima menor. (PORTMDM01)

$\mathrm{Na}$ busca por correspondente no subcorpus de inglês, encontramos a colocação "Borrowed chord" (com 6 ocorrências):

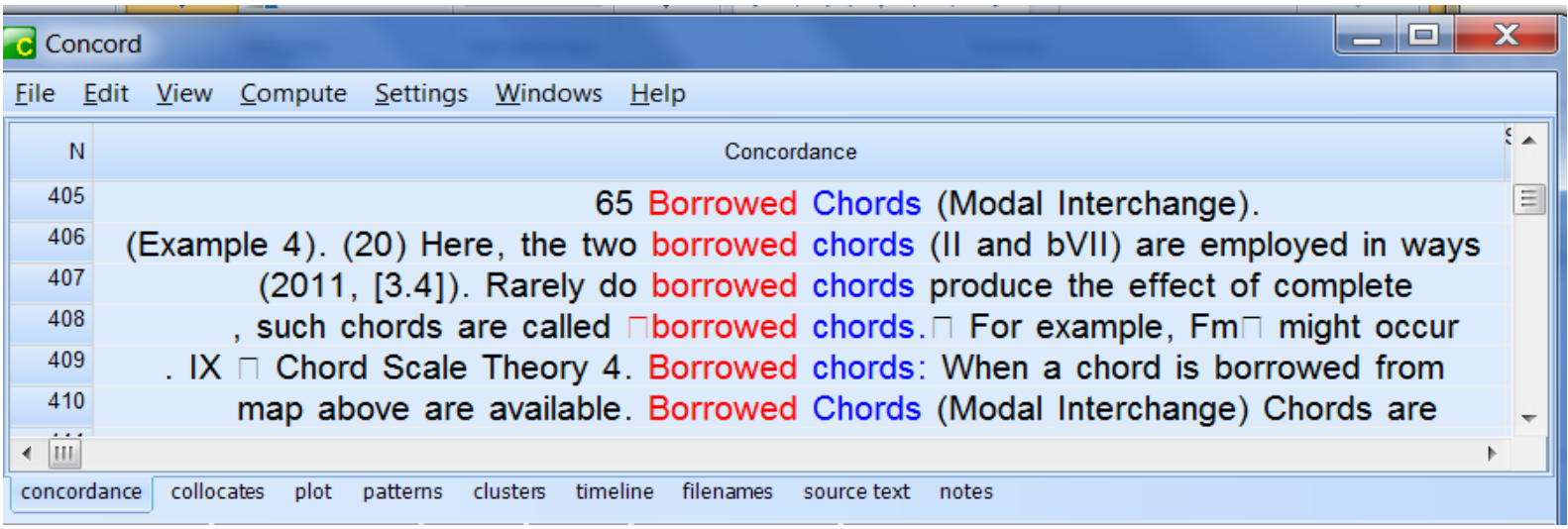

Figura 85 - Linhas de concordância de "borrowed chords"

No subcorpus instrucional, encontramos alguns contextos definitórios correspondem ao que encontramos em Português:

- Borrowed Chords: Chords taken from a different tonality or modality. (INGTMLIV07) 
- Borrowed chords are those that are in a diatonic key, but require accidentals not in the key signature when used in a parallel key. (INGTMLIV02)

- Borrowed Chords: When a chord is borrowed from the parallel major or minor, it is usually best to use the scale that would accompany that chord in the key from which it is borrowed. For example, if an FmÏ chord is used in the context of $C$ major, we identify it as IV in the parallel minor key, $C$ minor, and therefore use the $C$ minor scale with the lowered sixth degree (and probably the lowered seventh degree as well) for improvisation. (INGTMLIV07)

Selecionamos um excerto, extraído do subcorpus acadêmico-científico, que mostra um contexto de uso da colocação:

- Rarely do borrowed chords produce the effect of complete modal change; however, the mode from which certain chromatic chords are borrowed may prove to have motivic relevance within a given song (18)... (INGTMART04)

\section{6) Acorde de Tristão}

A colocação "acorde de Tristão" tem a frequência de 49 ocorrências no subcorpus de estudo. O termo "Tristão" é uma referência à ópera "Tristão e Isolda" do compositor alemão Richard Wagner (1813-1883).

Como observaremos em um dos contextos abaixo, o acorde tem essa denominação pelo uso marcante na obra citada. Apresentamos alguns trechos, extraídos do subcorpus de Português, que descrevem o acorde:

- $O$ acorde de Tristão se tornou famoso ao ser utilizado na abertura da ópera "Tristão e Isolda", de Richard Wagner. Ele já havia sido utilizado anteriormente, mas não da maneira que Wagner o utilizou, com funções diferentes criadas por enarmonia.

- A "configuração arquetípica" do "acorde de Tristão" é, como sublinha Menezes (2006, p. 45), "trítono + terça maior + quarta", contudo, o 
estabelecimento e conservação dessa arquetipia se dá também, e, principalmente, em função das diversas grandezas musicais (notas, melodias, timbres, acordes, dinâmicas, etc.) e extra-musicais (argumento literário, enredo dramático, sentidos da trama, gestos, cenários) que ambientam a aparição deste acorde. (PORTMTE02)

- Todas estas interpretações levam a concluir que o "acorde Tristão" é um acorde vagante e apresenta função múltipla. (PORTMART18)

(Neste último exemplo, percebemos o uso de uma variação, sem a preposição “de".)

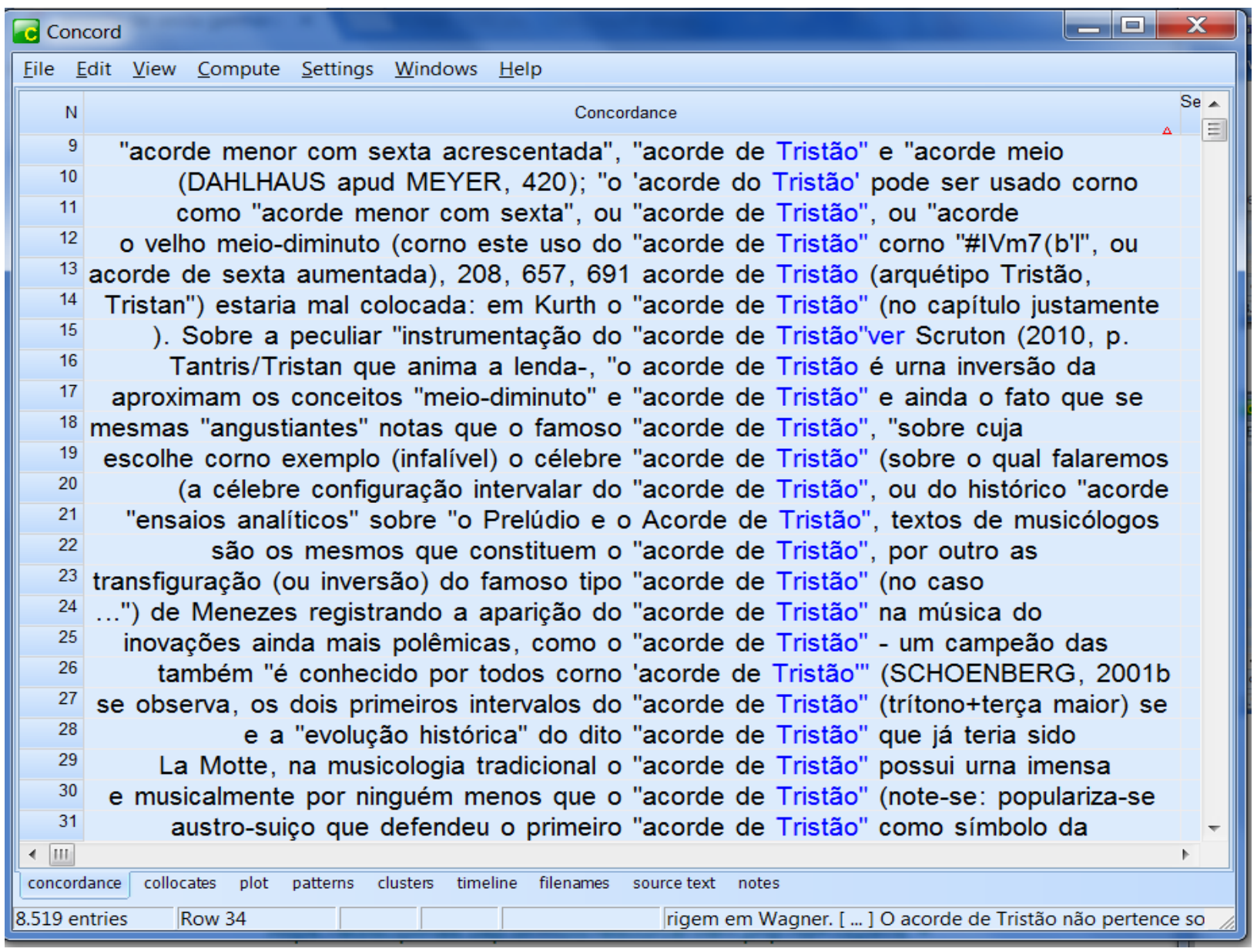

Figura 86 - Linhas de concordância (parciais) de "acorde de Tristão"

Na busca por correspondente, localizamos no subcorpus de inglês, a colocação Tristan chord (3 ocorrências). É uma das colocações encontradas nos dicionários de termos musicais em Inglês e apresenta definições que também menciona a mesma origem (Ópera Tristão e Isolda de Wagner): 
- The chord F-b-D\#'-G\#'or an enharmonic spelling of it, so called because it is the first chord in Wagner's Opera “Tristan und Isolde (1859), which it pervades. (DI-OXFORD)

- A chord named after the first chord in Richard Wagner's Tristan und Isolde. The original Tristan chord consists of F,b, D sharp, but the same applies to any chord with the same intervals. It is also called half-diminished seventh chord. (DI-ON MUSIC)

No subcorpus de estudo, encontramos apenas três contextos de uso, dentre os quais selecionamos o seguinte:

- In the years following the debut of the Tristan chord, a number of works have continued the dialogue on how half-diminished sevenths function. (INGTMART14)

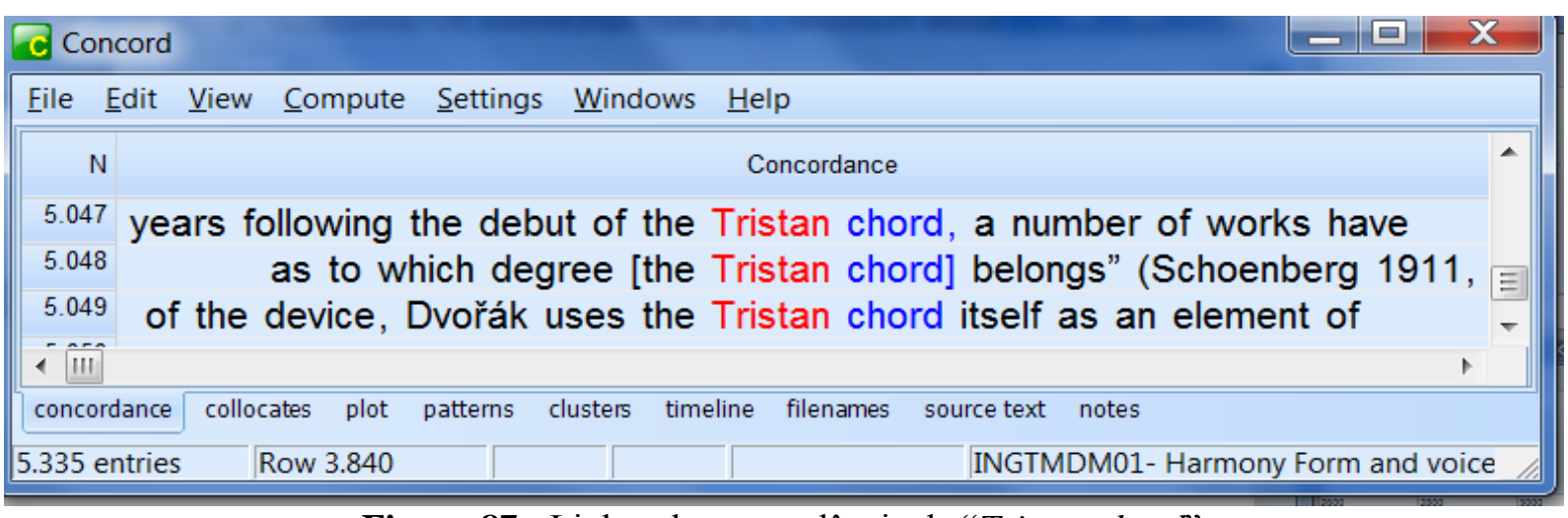

Figura 87 - Linhas de concordância de "Tristan chord"

\section{7) Acorde arpejado, Acorde quebrado}

No dicionário DP - DOURADO, o termo "acorde quebrado" apresenta remissiva para Arpejo. Já no dicionário DP- GALTER, verificamos a seguinte definição:

Acorde quebrado - quando as notas não são emitidas na sua ordem natural.

No subcorpus de português, encontramos apenas 8 ocorrências para a colocação. Selecionamos dois contextos definitórios:

- Acorde quebrado: É quando as notas de um acorde são tocadas sucessivamente. No violão usa-se dizer, também, acorde dedilhado. (PORTMLIV07) 
- Acorde quebrado é a denominação que se dá ao grupo de notas que formam um acordo disposto melodicamente numa ordem que não seja a habitual (isto é, fundamental, terça, quinta e sétima), que é também conhecida como arpejo. (PORTMLIV09)

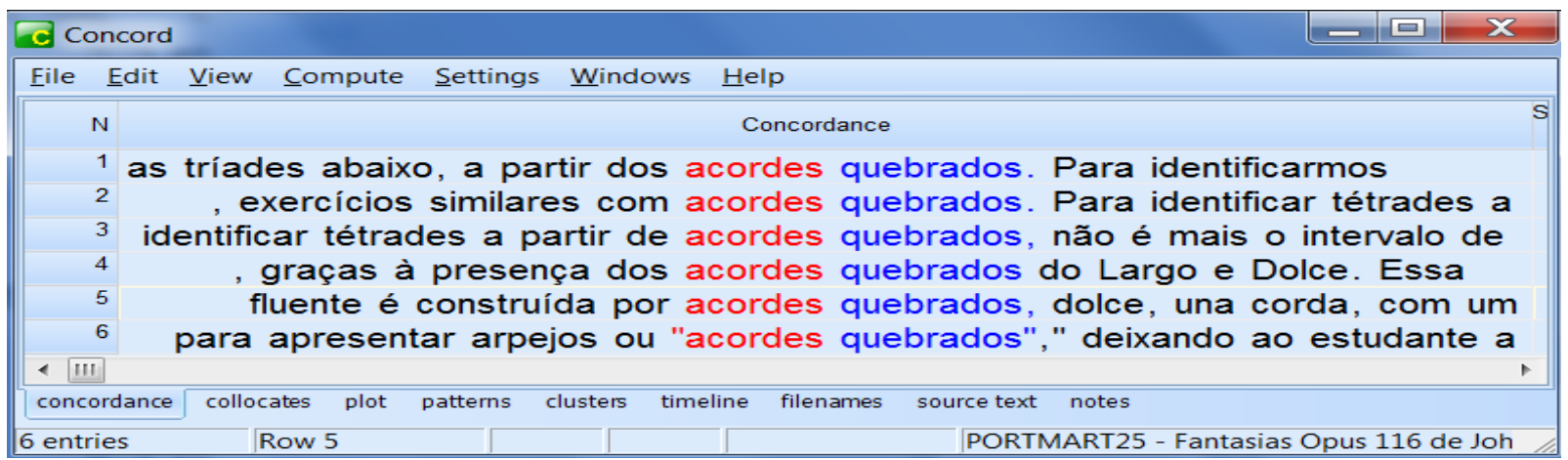

Figura 88 - Linhas de concordância (parciais) de "acordes quebrados"

O termo "arpejo", utilizado como variante de "acorde quebrado", apresenta o seguinte contexto definitório, extraído do subcorpus de estudo de português:

- Arpejo: O termo arpejo descreve o emprego de notas do acorde de forma sucessiva em ordem direta ou "quebrada”. Arpejo em ordem direta e quebrada Este tipo de figuração é mais comum na musica instrumental. Suas principais vantagens são as de oferecer um padrão de acompanhamento, de servir para conectar registros contrastantes em uma melodia, para propiciar uma maior atividade rítmica ou como recurso timbrístico. (PORTMLIV01) 


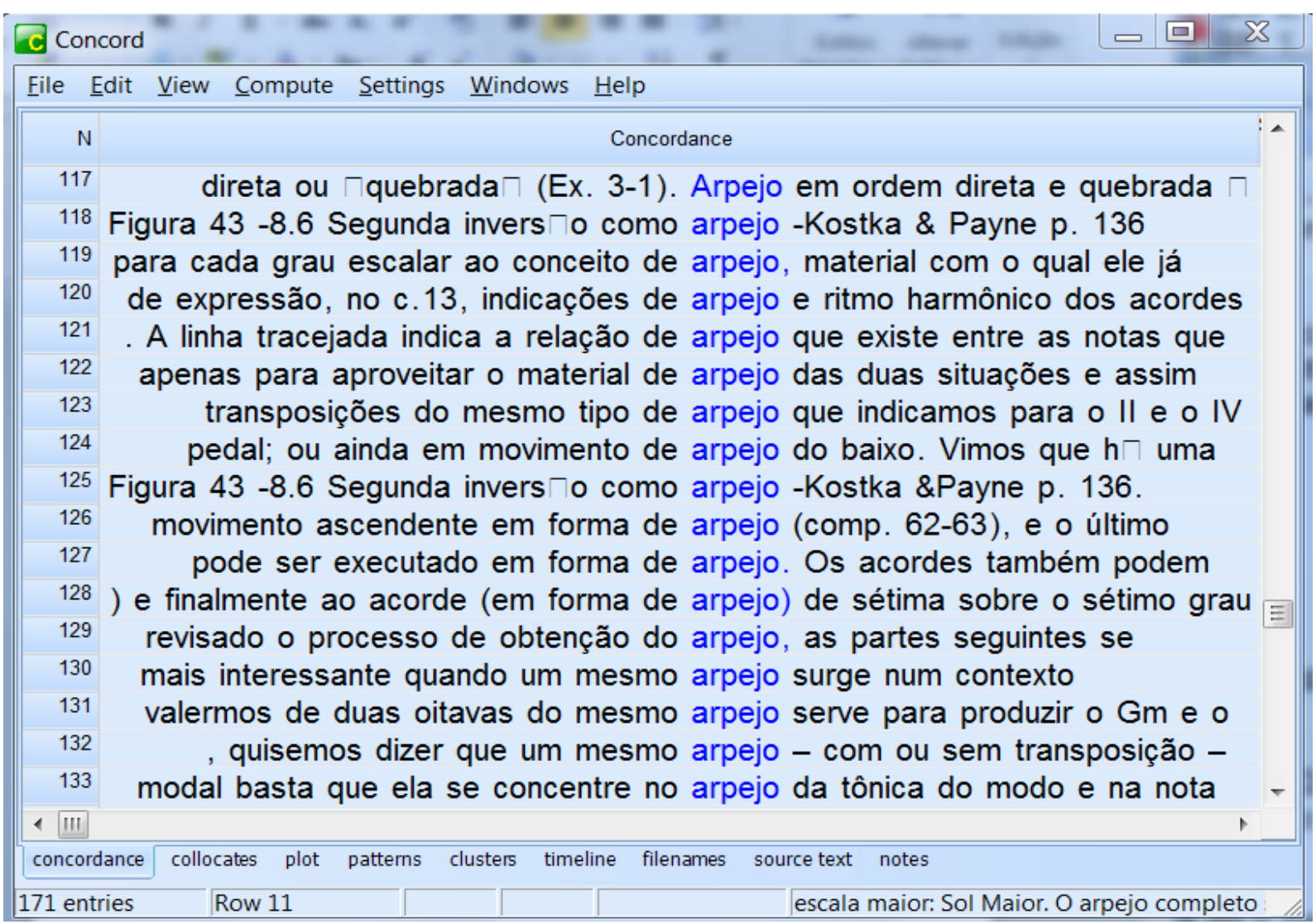

Figura 89 - Linhas de concordância (parciais) de "arpejo"

Encontramos também a colocação "acorde arpejado" (7 ocorrências) como variante de acorde quebrado e arpejo:

Acorde arpejado - É quando as notas de um acorde são tocadas sucessivamente (PORTMLIV07).

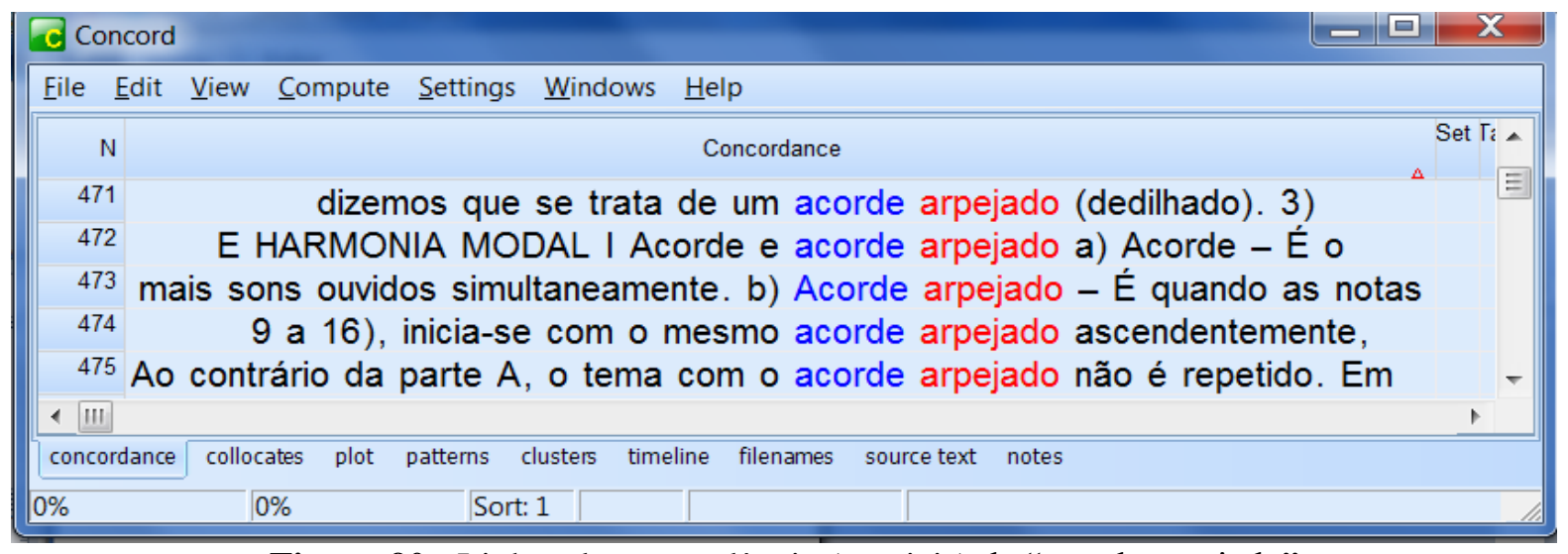

Figura 90 - Linhas de concordância (parciais) de "acorde arpejado"

No subcorpus acadêmico-científico, encontramos os seguintes contextos para acordes quebrados e acorde arpejado: 
- No terceiro elemento temático a melodia fluente é construída por acordes quebrados, dolce, una corda, com um acompanhamento arpejado na mão esquerda em mi menor (comp. 37-40) - como podemos verificar no exemplo 15 abaixo - indo para lá Maior (comp. 41), e dó\# menor (comp.43). (PORTMART25)

- A parte $B$ (compassos 9 a 16), inicia-se com o mesmo acorde arpejado ascendentemente, agora na dominante, levando à appoggiatura. (PORTMART11)

$\mathrm{Na}$ busca por correspondentes em Inglês, encontramos: arpeggiated chords, arpeggio e broken chords.

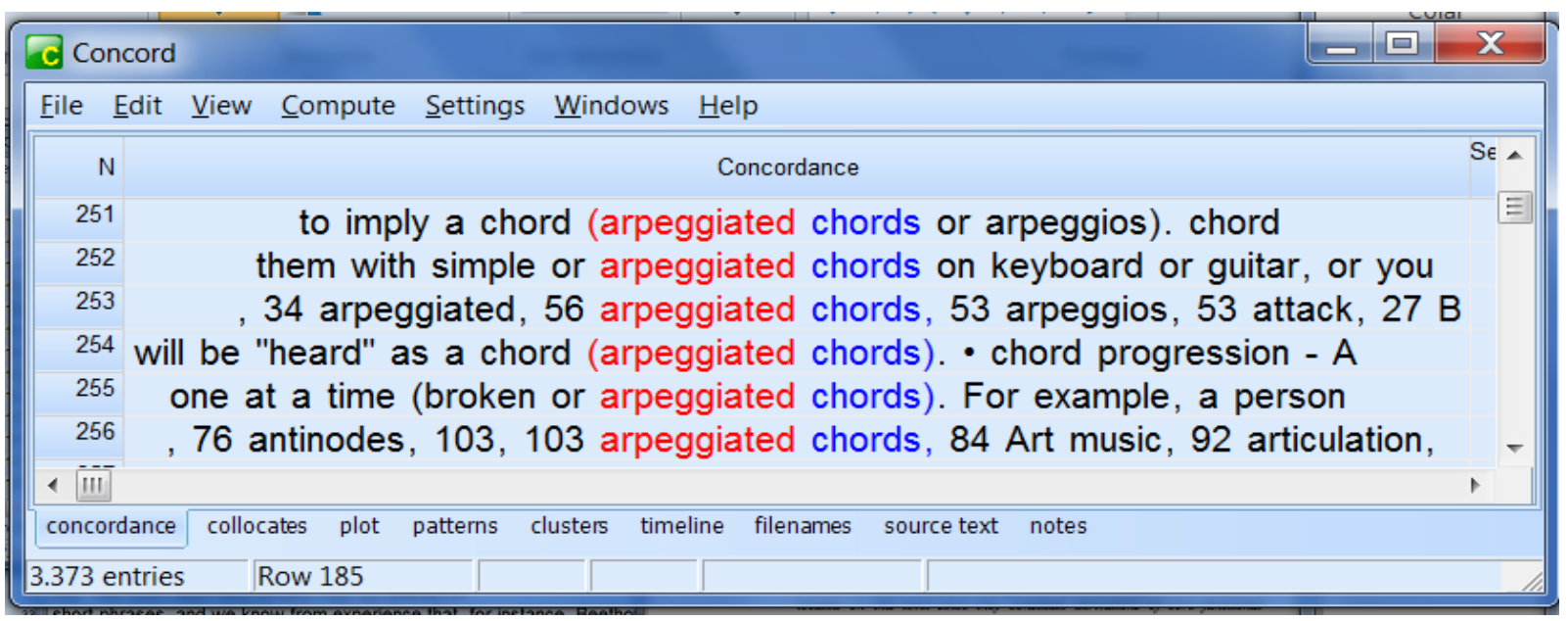

Figura 91 - Linhas de concordância (parciais) de "arpeggiated chords"

\begin{tabular}{|c|c|c|}
\hline \multicolumn{3}{|c|}{ 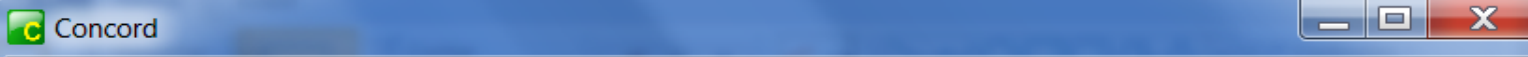 } \\
\hline \multicolumn{3}{|c|}{ File Edit View Compute Settings Windows Help } \\
\hline N & Concordance & Set 4 \\
\hline 858 & \multirow{7}{*}{$\begin{array}{l}\text { in Chapter } 3 \text { ), is essentially a broken chord } \sqcap \text { you } \neg \text { re simply play- ing one } \\
\text { (as opposed to a broken chord). sostenuto pedal The middle } \\
\text { a harp, } \rightarrow \text { is another name for a broken chord. Harp music is full of arpeggios. } \\
\text { accompaniment, homophonic: broken chord accompaniment, heterophonic } \\
\text { separated. Another name for a broken chord is an arpeggio. chord Three or } \\
\text { far left side of the keyboard. broken chord A chord in which the notes are }\end{array}$} & \multirow[t]{6}{*}{$\equiv$} \\
\hline 859 & & \\
\hline 860 a h & & \\
\hline 861 & & \\
\hline 862 se & & \\
\hline 863 & & \\
\hline 1 III & & \multirow[t]{2}{*}{1} \\
\hline concordance & collocates plot patterns clusters timeline filenames source text notes & \\
\hline 5.335 entries & rinciple. One can specify a chord's location & \\
\hline
\end{tabular}

Figura 92 - Linhas de concordância (parciais) de "broken chords" 


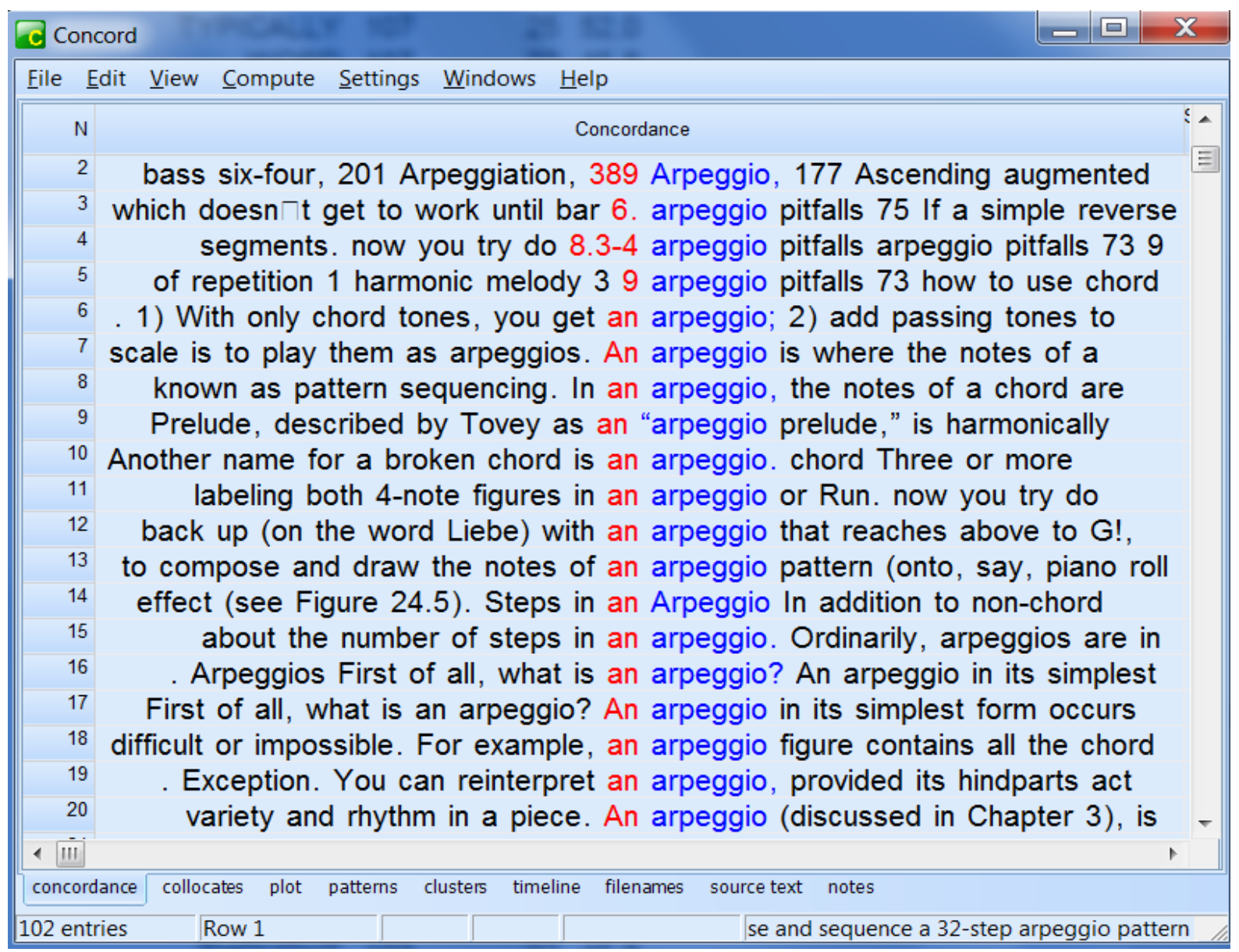

Figura 93 - Linhas de concordância (parciais) de "arpeggio"

A colocação "broken chord” (23 ocorrências no subcorpus de estudo, somadas as formas singular e plural) foi encontrada nos três dicionários de termos musicais em Inglês, com as seguintes definições:

- Broken chord - the playing of octaves as single notes, sounded separately rather than simultaneously ( DI-OXFORD)

- Broken chords - Any chords that has an augmented interval between its highest and lowest notes (DI - ON MUSIC)

- Broken chord - Arpeggio; also any figure in which the pitches of a chord are stated successively, e.g. the Alberti Bass (DI-HARVARD)

No subcorpus instrucional, encontramos os seguintes contextos definitórios para "broken chord":

- When a chord is broken, the notes in the chord are separated. This gives the chord a sense of movement, and allows variety and rhythm in a piece. An arpeggio 
(discussed in Chapter 3), is essentially a broken chord-you're simply playing one note of the chord at a time. (INGTMLIV06)

- A chord in which the notes are separated. Another name for a broken chord is arpeggio (INGTMLIVO6).

- The notes of each chord may be played all at once (block chords), or they may be played one at a time (broken or arpeggiated chords). (INGTMLIV06).

- An arpeggio is where the notes of a chord are played as a sequence of notes.

$\mathrm{Na}$ análise dos contextos, observamos o uso da colocação "block chords" (36 ocorrências) para sinalizar que as notas do acorde são tocadas simultaneamente:

- The notes of the chord may be played at the same time (block chords), or may be played separately with some overlap, or may be played separately but in a quick enough succession that they will be "heard" as a chord or understood to imply a chord (arpeggiated chords or arpeggios). (INGTMLIV01)

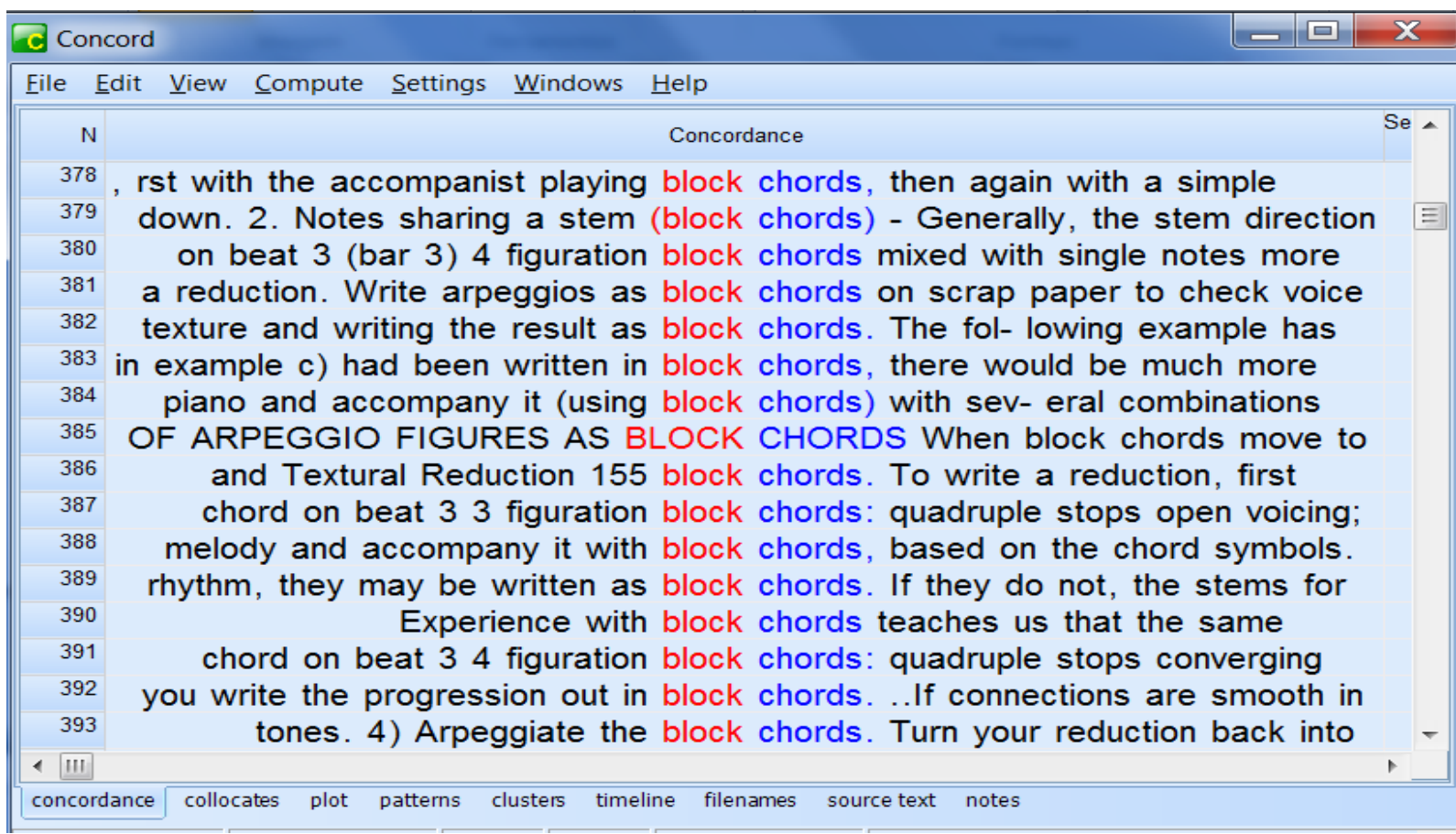

Figura 94 - Linhas de concordância (parciais) de "block chords"

Em Português, acorde arpejado, arpeggio e acorde quebrado são utilizados para sinalizar que as notas do acorde não são tocadas de forma simultânea, já que sem essa 
informação, subtende-se que as notas soam simultaneamente. Percebemos que os contextos indicam que acorde arpejado e acorde quebrado compartilham o mesmo conceito.

Dessa análise, realizamos as seguintes correspondências:

- Acorde arpejado $\Leftrightarrow$ Arpeggiated chord, arpeggio

- Arpejo $\Leftrightarrow$ Arpeggio

- Acorde quebrado $\Leftrightarrow$ Broken chord, arpeggio

Serão utilizados remissivas entre as colocações.

\section{8) Acorde napolitano, Acorde de sexta napolitana}

Neste item foram agrupadas as colocações "acorde de sexta napolitana" (120 ocorrências) e "acorde napolitano" (110 ocorrências).

A colocação também foi encontrada no dicionário DP-DOURADO, na forma reduzida (omissão do termo "acorde"):

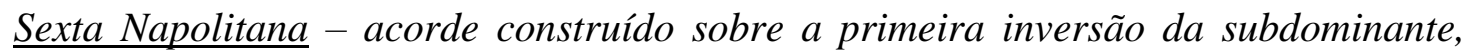
com o terceiro e sexto graus menores. Fá - Lá bemol - Ré bemol, na tonalidade de dó maior.

Verificamos em um dos textos do subcorpus instrucional de português que, além das características mencionadas no dicionário, o texto aponta uma diferença entre as duas colocações:

- $O$ acorde de sexta napolitana é a subdominante menor com sexta menor, a qual é uma nota alterada na escala. Seu uso começa nessa forma, para depois aparecer como um acorde de terça maior e quinta justa, o acorde napolitano. Ambos são mais frequentes nas tonalidades menores e pertencem a região da subdominante. Resolvem em acorde de dominante. As duas formas desse acorde foram largamente utilizadas em toda a história da música tonal. (PORTMAPO01)

Em outro texto específico de Teoria Musical, encontramos um contexto seguinte sucinto: 
- Acorde de Sexta Napolitana - Acorde frígio na primeira inversão. (PORTMLIV02)

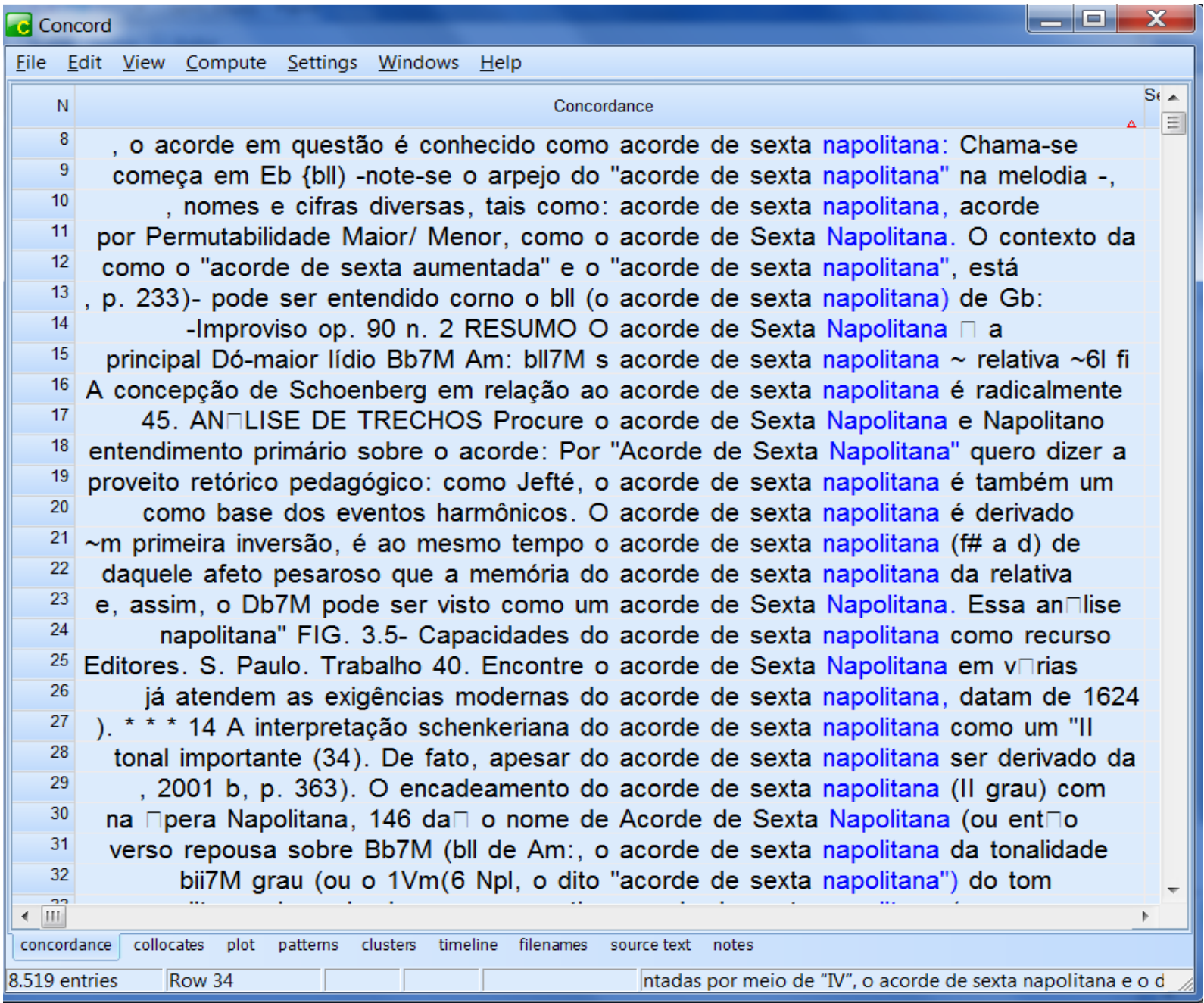

Figura 95 - Linhas de concordância (parciais) de "acorde de sexta napolitana" 


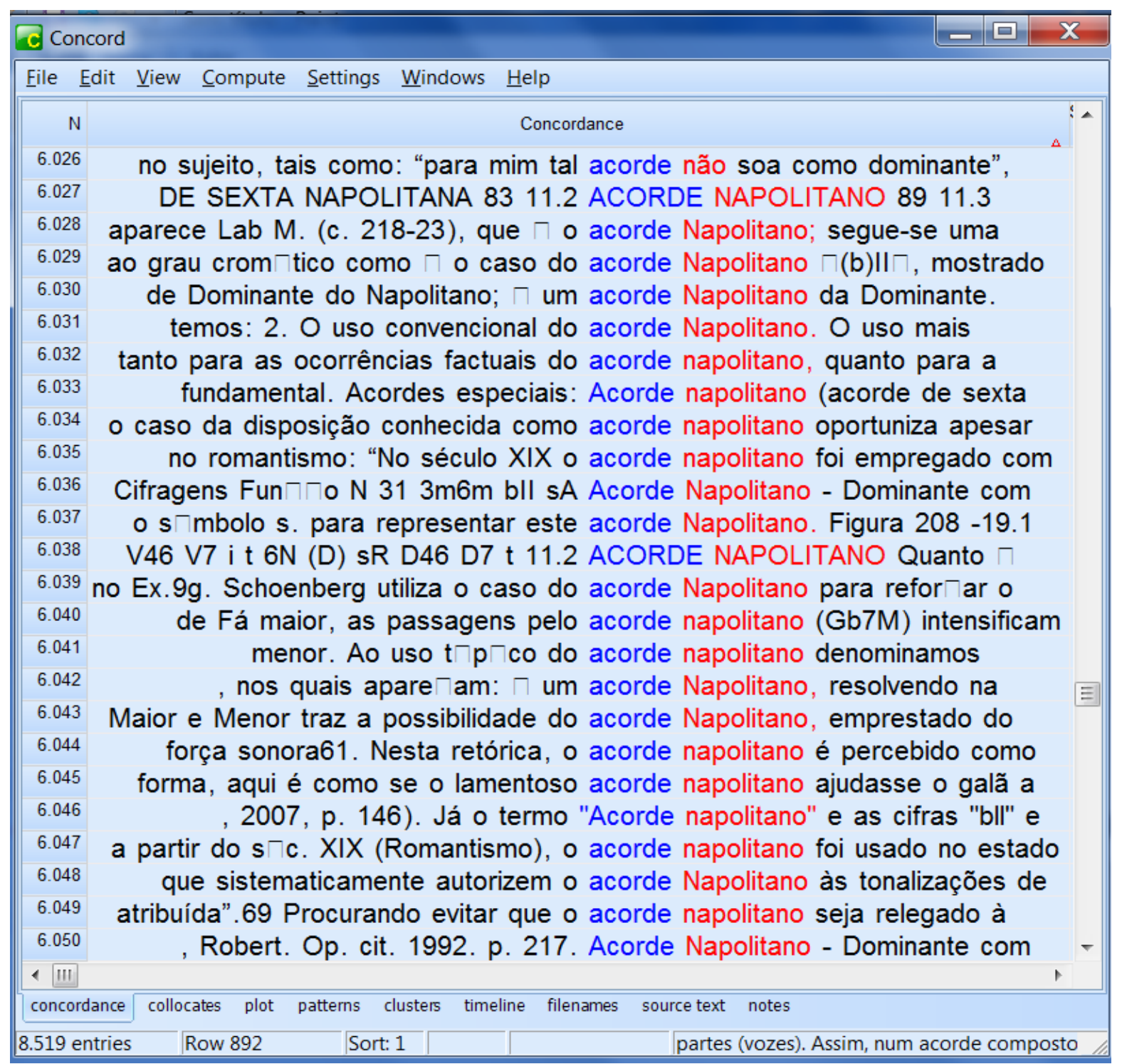

Figura 96 - Linhas de concordância (parciais) de "acorde napolitano"

Verificamos que a diferença apontada anteriormente em um dos contextos definitórios parece levantar discussão na área musical:

- Mantendo, com Riemann, a exemplificação na tonalidade de Lá-menor, temos que, no geral, os comentadores distinguem dois principais estados desta harmonia: "ré-fá-sib" dito "acorde de sexta napolitana" e "sib-ré-fá" dito "acorde napolitano". Notando que estas duas disposições das mesmas notas estão presentes em diversos repertórios, grosso modo, considera-se que o acorde de sexta napolitana, o estado ré-fá-sib, e em tonalidade menor, associa-se aos estilos mais antigos, tradicionais ou conservadores. Neste caso, a nota diatônica ré, 
posicionada na voz mais grave, é interpretada como o baixo fundamental, enquanto que a nota não diatônica, sib, é racionalizada como nota ornamental, uma dissonância acrescentada ao IVm. Tal interpretação persiste e, convivendo com outras, envolve-se em inevitáveis mal-entendidos, pois, eventualmente, o anfibológico estado ré-fá-sib é visto como uma primeira inversão.(PORTMART28)

Daí observamos o uso das duas formas, sem valorização dessa diferença, categorizando ambos como "acordes napolitanos:

Este acorde usado na ópera Napolitana, daí o nome de Acorde de Sexta Napolitana (ou então somente Napolitano), trata-se de uma subdominante em modo menor com sexta menor em vez da quinta, na sua origem, uma sexta menor com retardo de quinta. (PORTMDM01)

Na busca por correspondentes em inglês, encontramos as colocações Neapolitan sixth chord (2), Neapolitan sixth (10) e Neapolitan chord (9). Neapolitan Sixth é a forma reduzida da colocação Neapolitan sixth chord.

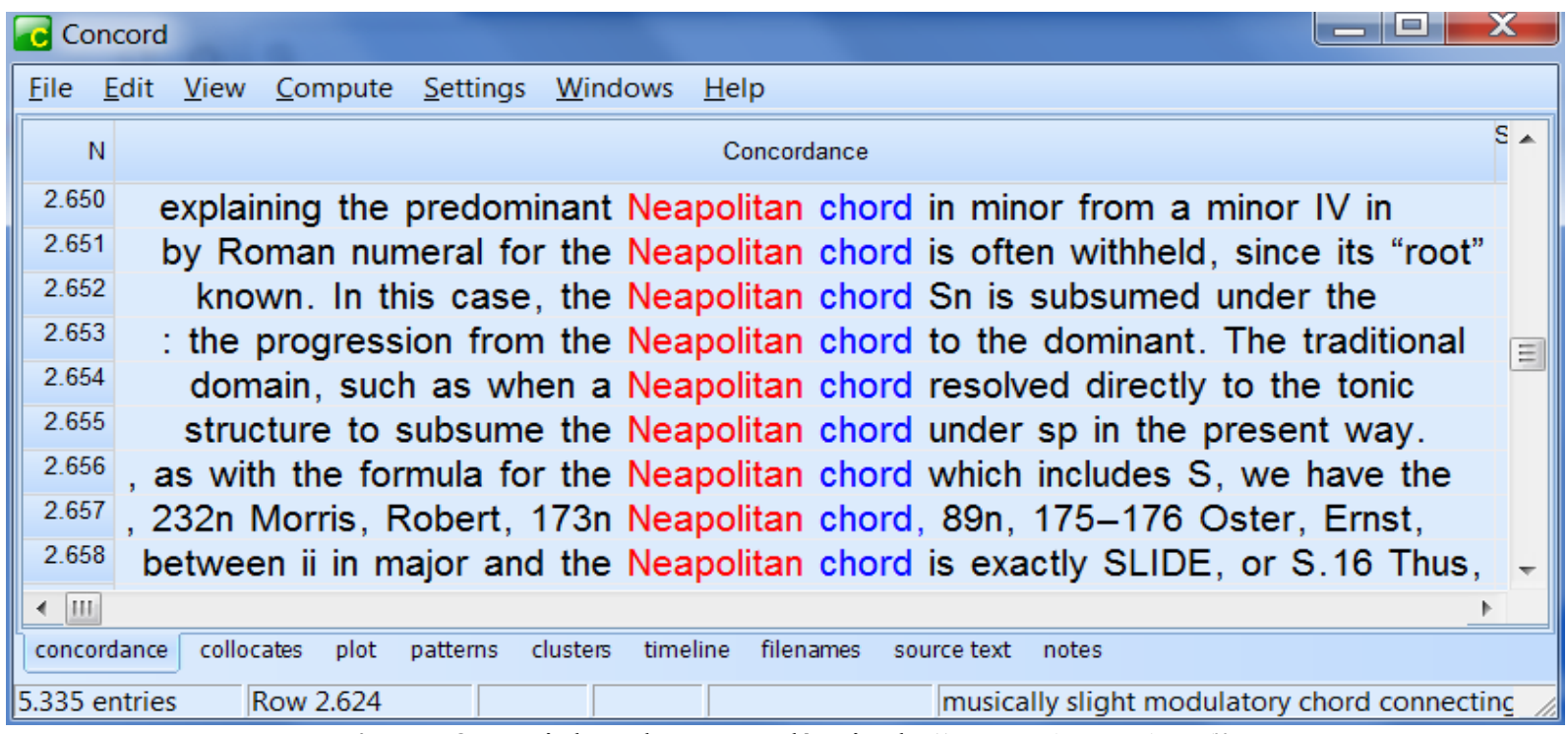

Figura 97 - Linhas de concordância de "Neapolitan chord" 


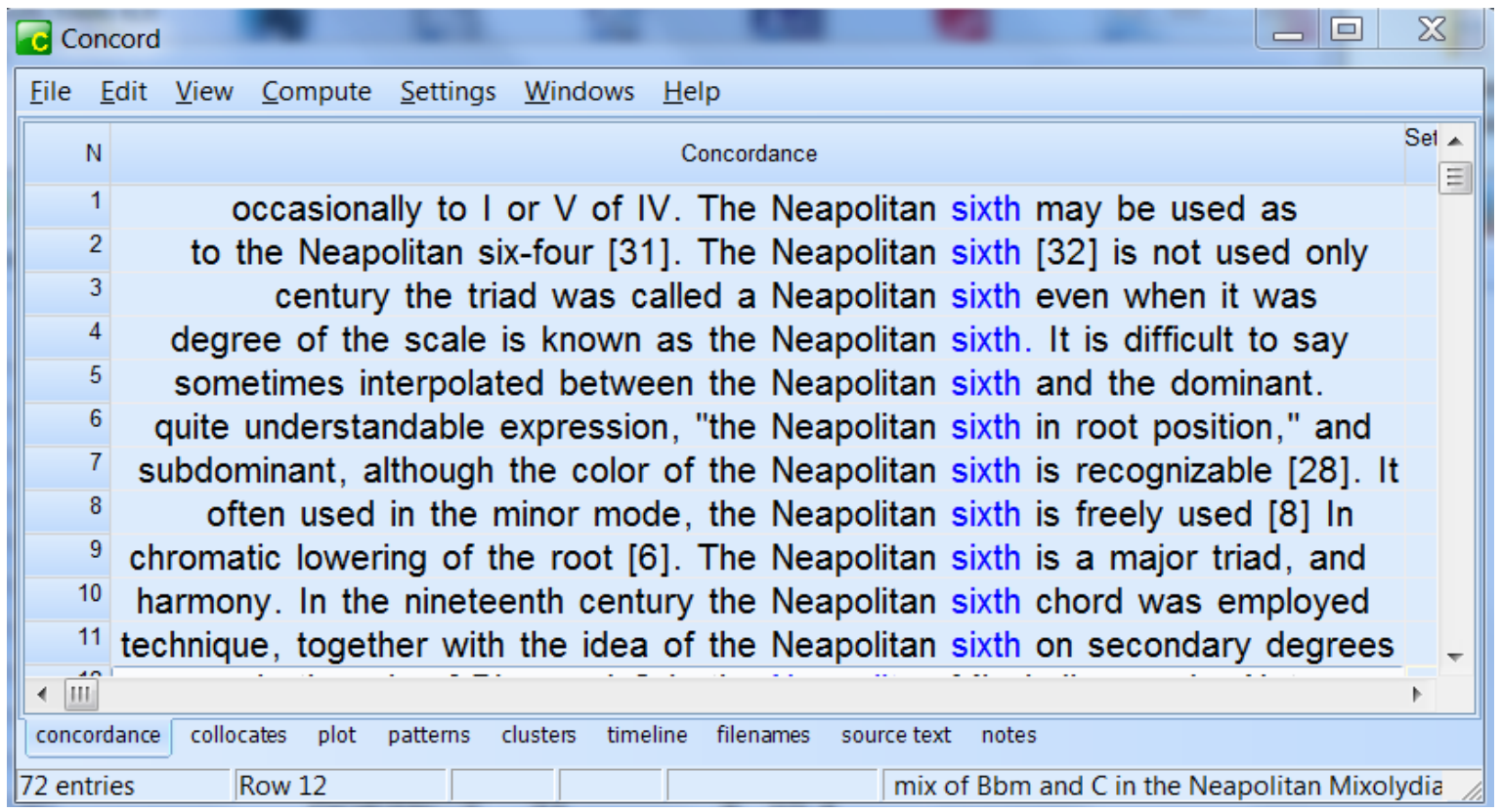

Figura 98 - Linhas de concordância de "Neapolitan sixth"

A partir dos contextos definitórios a seguir, verifica-se que assim como em Português, há autores que mencionam a diferença no uso das duas colocações:

- Neapolitan chord - It is a major triad constructed upon the lowered second scale degree. It is usually found in the minor mode and in first inversion and usually moves toward $V$. In fact, the first inversion is so typical that the Neapolitan triad is often referred to as the Neapolitan sixth chord. (INGTMLIV12)

- The major triad whose root is the chromatically lowered second degree of the scale is known as the Neapolitan sixth. It is difficult to say what is "Neapolitan" about this chord, but the name is universally accepted. In the eighteenth century it was used primarily in the first inversion, hence the sixth. Later in the nineteenth century the triad was called a Neapolitan sixth even when it was used in root position. (INGTMLIV11)

- However, several other contexts for the Neapolitan may be encountered (1) it may appear in root position or, rarely, in second inversion. In both cases, the bass will probably be doubled in a four-part texture. (2) the Neapolitan may occur in the major mode (3) the Neapolitan chord may be tonicized. (4) In a modulation the common chord may be a Neapolitan in either key. (5) It may, on occasion, serve a function other than that of a pre-dominant chord. (6) In rare instances, the Neapolitan may include a seventh. (INGTMLIV12) 
Selecionamos dois excertos, extraídos do subcorpus acadêmico-científico, que apresentam contextos de uso das colocações:

- In music theory, harmony is a well-researched area, and there are dozens of taxonomies for tonal harmony phenomena. Most theories concentrate on classifying chord types and deducing complex phenomena from basic (diatonic) chords (such as explaining the pre-dominant Neapolitan chord in minor from a minor IV in which the minor sixth replaces the fifth and results in a first inversion chord). (INGTMART20)

- This technique, together with the idea of the Neapolitan sixth on secondary degrees, produces great enrichment of the tonality.(INGTMTE02)

Tanto em Português como em Inglês, a colocação algumas vezes é utilizada na forma reduzida: "Sexta Napolitana" ou "Neapolitan Sixth".

A análise dos contextos nos mostrou que as correspondências entre tais colocações devem ser realizadas de forma cautelosa pelo tradutor, observando a escolha realizada no texto original. No glossário, utilizaremos remissivas. Optamos por conservar as formas das variantes na tradução:

Acorde de sexta napolitana $\Leftrightarrow$ Neapolitan sixth chord

Sexta Napolitana $\Leftrightarrow$ Neapolitan sixth

Acorde napolitano $\Leftrightarrow$ Neapolitan chord

\section{9) Acorde de sexta aumentada}

A colocação "acorde de sexta" aumentada tem a frequência de 310 ocorrências no corpus em virtude de fazer parte da composição de outras colocações como: "acorde de sexta aumentada alemã", "acorde de sexta aumentada francesa" e "acorde de sexta aumentada italiana”. 
Encontramos no subcorpus instrucional, a seguinte descrição para o acorde:

Acordes de sexta aumentada são construídos no grau VI da escala, um semitom abaixo, e usam um intervalo de sexta aumentada. São usados com função de dominante da dominante, com a sexta aumentada sendo resolvida por movimento contrário. (PORTMAPO04)

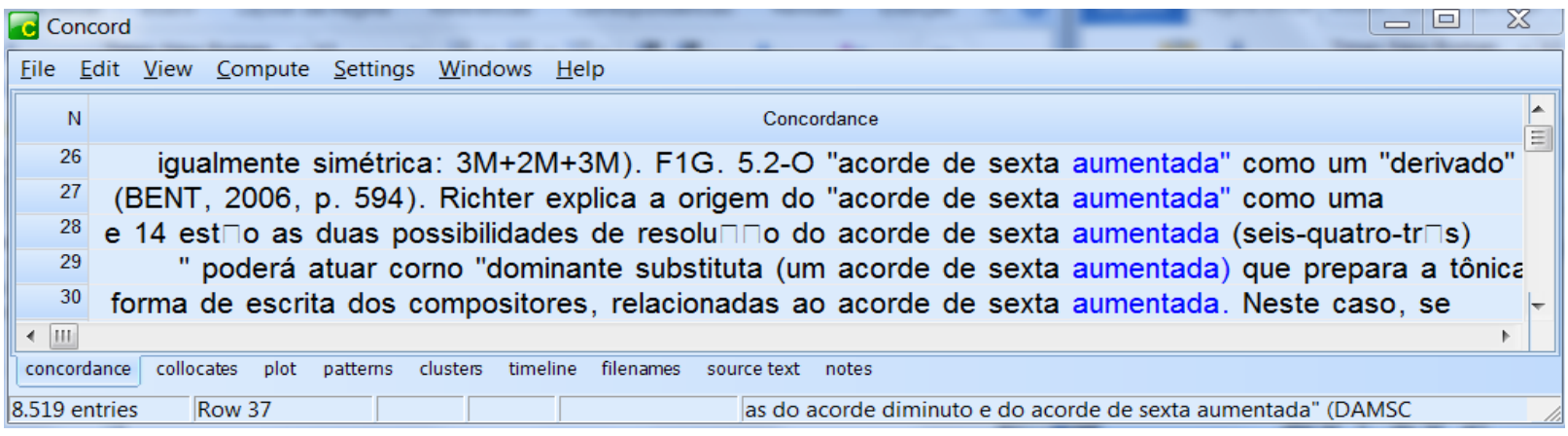

Figura 99 - Linhas de concordância (parciais) de "acorde de sexta aumentada"

O contexto de uso a seguir foi retirado do subcorpus acadêmico-científico:

Considerando o sistema de escalas temperadas, os acordes de sexta aumentada podem receber interpretações diferentes, mas tem, na verdade, o mesmo som. Sendo assim, poderia ser questionado qual deve ser a análise correta ou qual função representa exatamente o que as distintas análises determinam.

$\mathrm{Na}$ busca por correspondentes em Inglês, encontramos a colocação Augmented sixth chord, com 12 ocorrências. A colocação foi também localizada na pesquisa ao dicionário de termos musicais DI-OXFORD:

Augmented sixth chord - The chords of the augmented sixth are altered chords, built on the flattened submediant.(...) The so-called 'Italian' and 'French' sixths usually resolve onto the dominant chord, and the 'German' sixth onto the dominant or the second inversion of the tonic; the German sixth may also, by an enharmonic change, be transformed into a 'dominant seventh of the flattened supertonic (in C Major, Db Major or minor). 


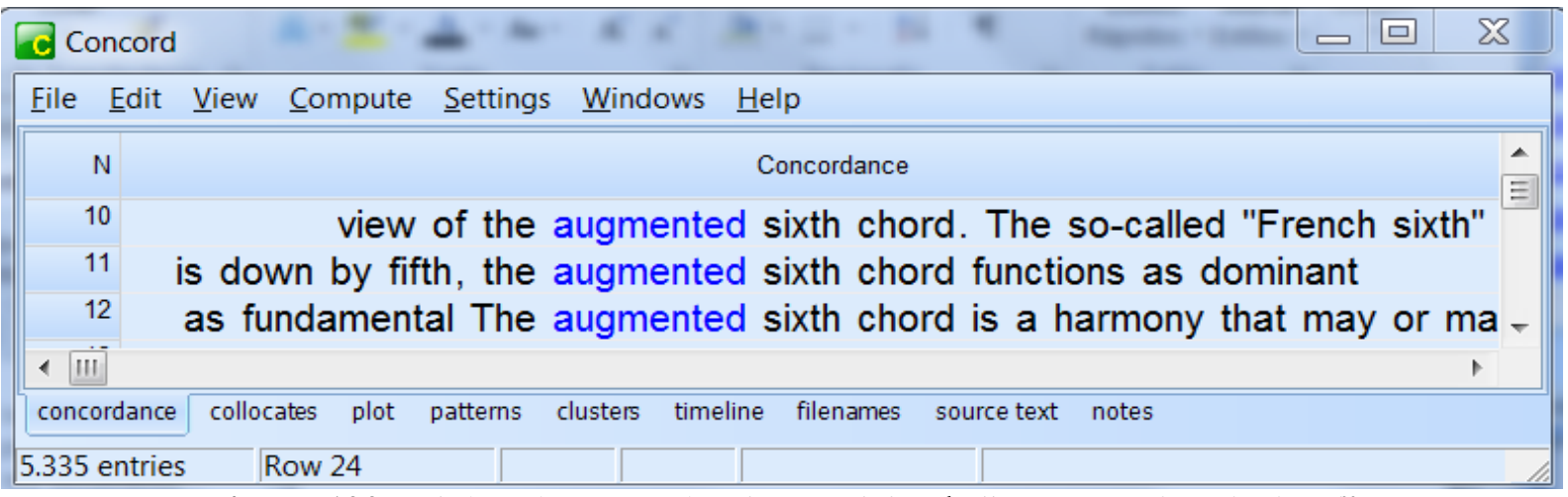

Figura 100 - Linhas de concordância (parciais) de "augmented sixth chord"

No subcorpus acadêmico-científico, encontramos um contexto definitório, com uma explicação semelhante que resume as definições dadas no dicionário mencionado e no contexto definitório extraído do subcorpus de Português:

The augmented sixth chord is a harmony that may or may not contain its fundamental, depending upon which of its three forms is used. The augmented sixth, in its most common contextual setting, resolves to the dominant. In keeping with the assumption that the strongest succession is down by fifth, the augmented sixth chord functions as dominant preparation; therefore it is assigned the fundamental associated with the second scale degree... (INGTMTE02)

Também do subcorpus acadêmico-científico, extraímos o seguinte contexto de uso:

In Schubert's practice, the downward leading tone was most often accompanied by the leading tone proper, yielding an augmented sixth chord of some kind. This type of use of the augmented sixth was theoretically reified in Tchaikovsky's harmony text (1871), which shows the normative resolution of an augmented sixth chord built above directly to the tonic. (INGTMDM01)

No glossário, apresentaremos remissivas para as colocações derivadas: "acorde de sexta aumentada alemã" (ou "acorde de sexta germânica"), "acorde de sexta aumentada francesa" e "acorde de sexta aumentada italiana", que serão descritas nos próximos itens. 
30) Acorde de sexta aumentada alemã, acorde de sexta alemã, acorde de sexta germânica, sexta alemã

Neste subitem reunimos colocações variantes do mesmo conceito: "acorde de sexta aumentada alemã" (9 ocorrências), "acorde de sexta alemã" (5 ocorrências), "sexta alemã" (4) e "acorde de sexta germânica" (16 ocorrências).

Nos contextos a seguir, verifica-se a descrição do acorde como invertido (em primeira inversão ou de quinta e sexta):

- Acorde de sexta aumentada alemã é um acorde alterado na $1^{a}$ inversão (PORTMLIV02)

- Acorde de sexta germânica: É a primeira derivação do acorde de sexta aumentada apresentada por Schoenberg em Harmonia, demonstrado através da transformação do "acorde de quinta e sexta sobre o II grau do modo maior, elevando-se a terça e a fundamental, e rebaixando-se a quinta. (PORTMART04)

- Nestes compassos iniciais da Toccata em Ré-menor, o II grau pré-dominante (misol-sib-ré) está invertido e alterado como sib-fá-ré-sol\#. Escapando ao que Rameau pôde normalizar alguns anos depois, o fá do tenor, como "b9 de um E7 sem fundamental e com quinta bemol no baixo", gera o tipo que, na teoria erudita contemporânea, ficaria conhecido como "acorde sexta aumentada alemã.$($ PORTMTE02)

- O Dominante Individual Substituto, ou simplesmente subV é muitíssimo utilizado no repertório da bossa nova. Na teoria tradicional da harmonia é conhecido como acorde de sexta alemã .(PORTMDM04)

- Aqui pensamos mais na versão conhecida como "sexta alemã ", que é o tipo de acorde com sexta aumentada mais utilizado na Música Popular, facilitando a comparação que almejamos. (PORTMTE01) 


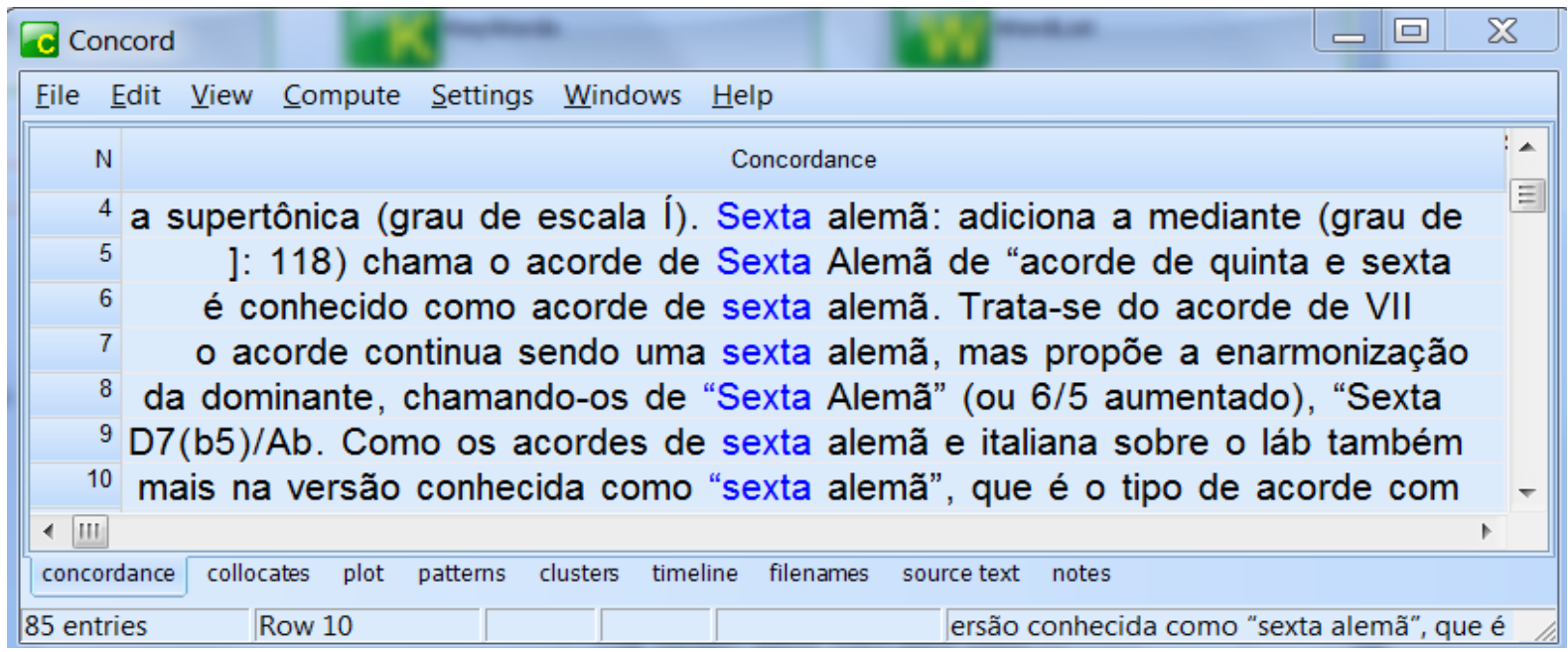

Figura 101 - Linhas de concordâncias das variantes "acorde de sexta alemã " e

"sexta alemã"

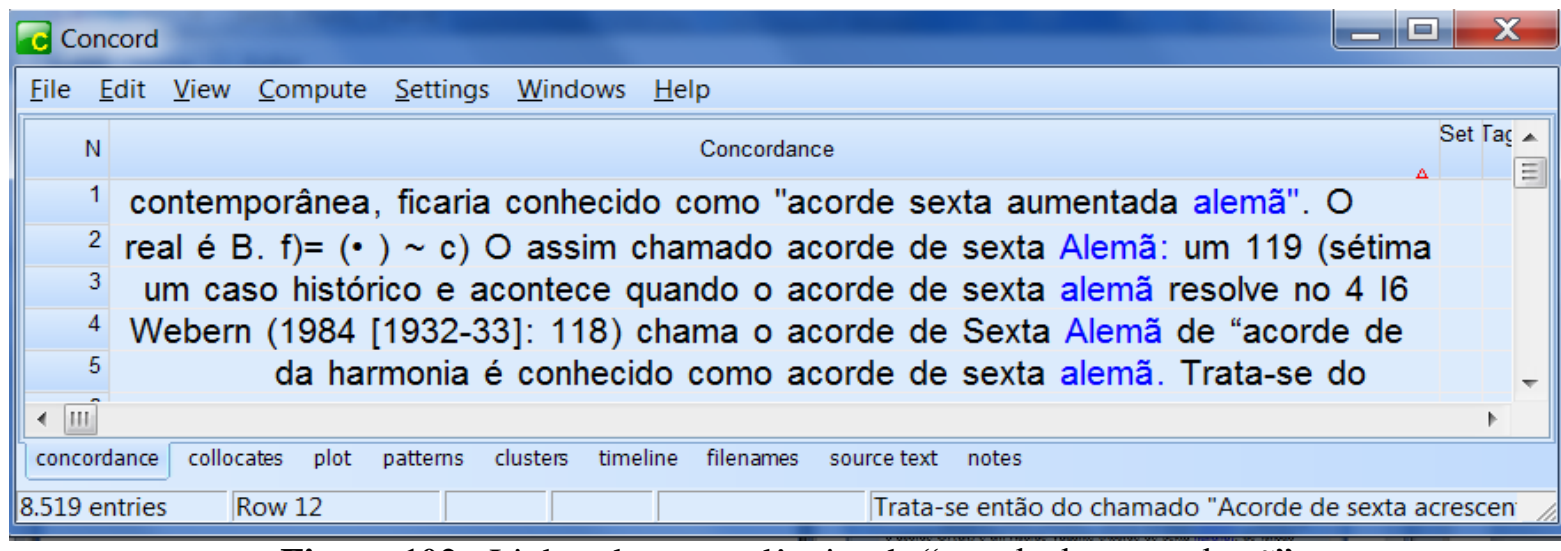

Figura 102 - Linhas de concordâncias de "acorde de sexta alemã"

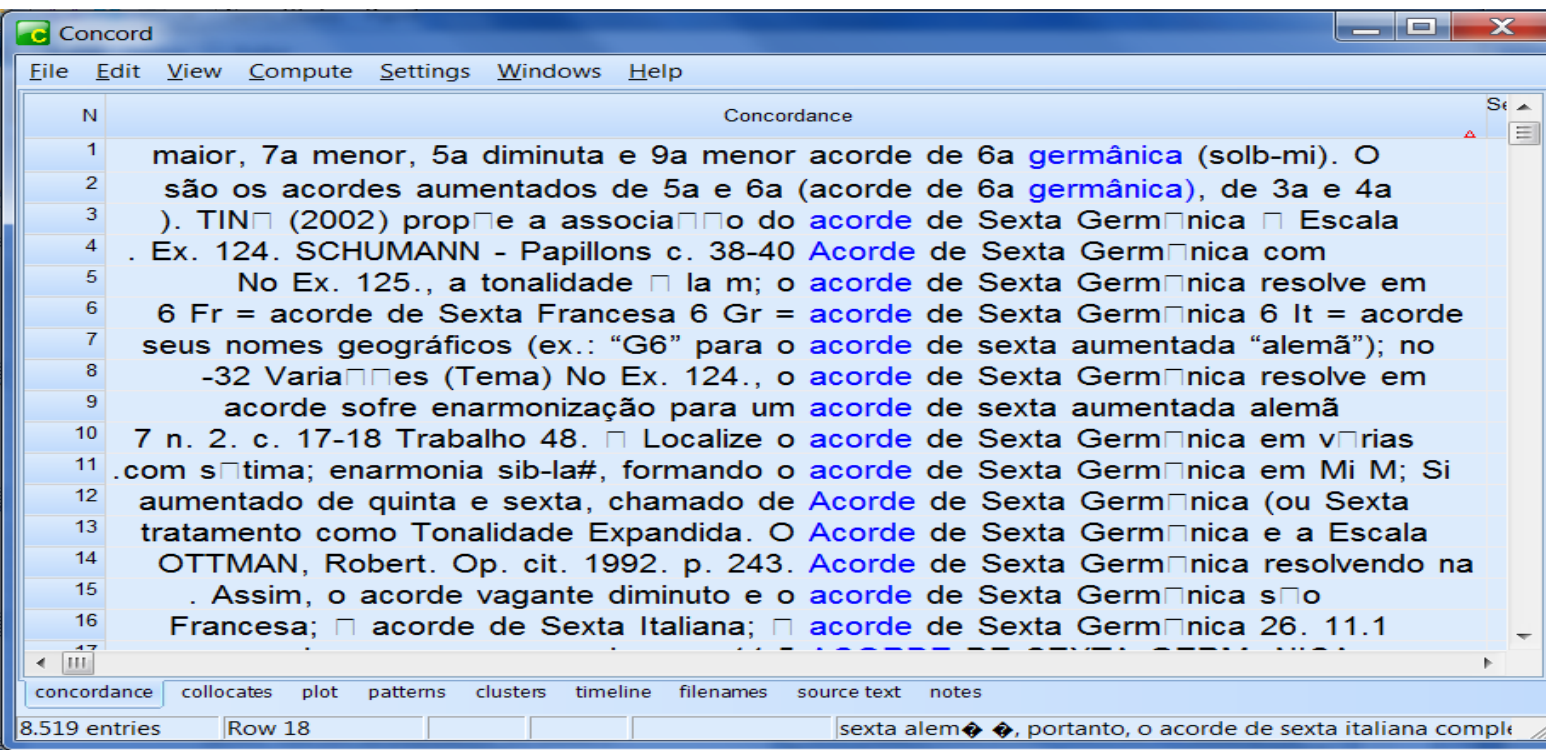

Figura 103- Linhas de concordâncias (parciais) de "acorde de sexta germânica" 
Em Inglês, encontramos como correspondentes as colocações "German augmentedsixth chord" (12) e "German sixth chord"(2) . Observamos que também o uso das colocações sem o termo chord (forma reduzida).

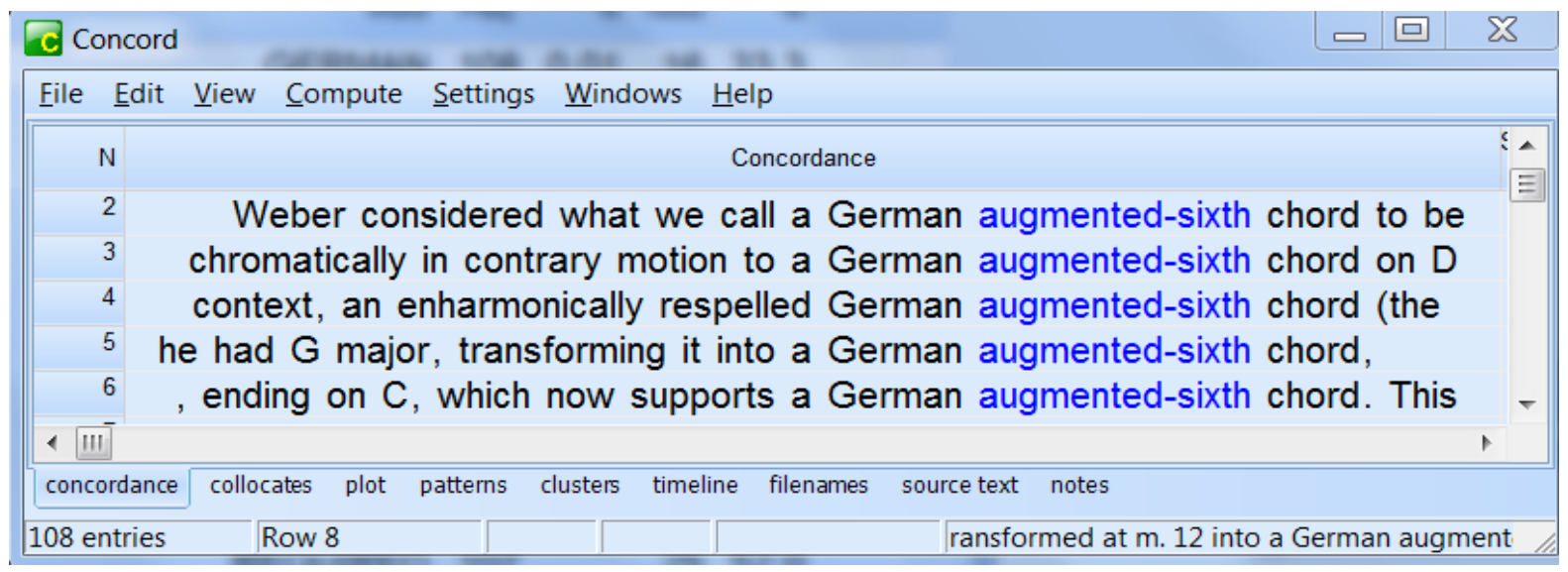

Figura 104 - Linhas de concordâncias (parciais) de "German augmented-sixth chord"

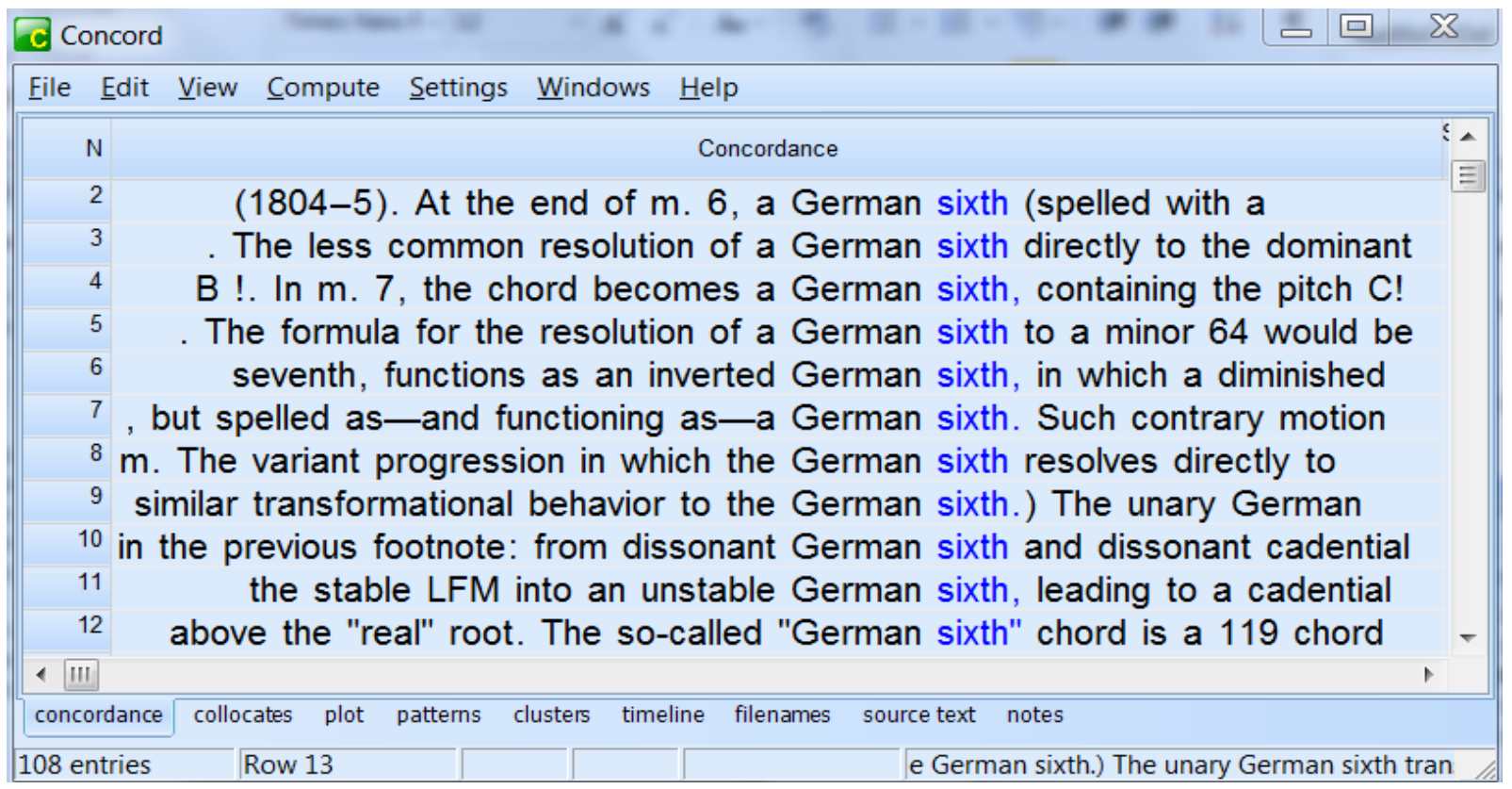

Figura 105 - Linhas de concordâncias (parciais) de "German sixth (chord)"

O contexto definitório encontrado no subcorpus de inglês é similar à explicação dada para o acorde em Português: 
- The so-called "German sixth" chord is a chord with a major third, diminished fifth, minor ninth, and the root is missing; in the key of a minor, it is spelled D\#-F$A-C$; the "real" root is $B$ and the chord usually appears in second inversion reckoned above the "real" root. (INGTMTE02)

Selecionamos um contexto em que são utilizadas as variantes:

- In the final cadence of "In a Sentimental Mood" (1935) the dominant is replaced with a tritone substitute, labeled $G$ dominant seventh in the chord charts, but spelled as-and functioning as - a German sixth. (INGTMART18)

- To this end, Harrison shows that Gottfried Weber considered what we call a German augmented-sixth chord to be a rootless altered V9 or a II9 depending on whether the following chord was a tonic or dominant (...) (INGTMDM01)

- Accordingly, the chord resembles what Harrison terms the "dual" German-sixth chord.(INGTMDM01)

Dessa análise, sugerimos a seguinte correspondência entre as variantes:

- Acorde de sexta aumentada alemã $\Leftrightarrow$ German augmented-sixth chord

- Acorde de sexta alemã $\Leftrightarrow$ German sixth chord

- Sexta Alemã $\Leftrightarrow$ Sixth Chord

- Acorde de sexta Germânica $\Leftrightarrow$ German sixth chord

\section{1) Acorde de sexta aumentada francesa, acorde de sexta francesa, sexta francesa}

Neste subitem reunimos colocações variantes do mesmo conceito: "acorde de sexta aumentada francesa" (7 ocorrências), "acorde de sexta francesa" (29 ocorrências) e "sexta francesa" (5 ocorrências).

No subcorpus instrucional de português, localizamos dois contextos definitórios:

- Acorde de sexta francesa: É um acorde de dominante com sétima, a quinta alterada uma segunda menor abaixo. Este acorde aparece na maioria das vezes 
na tonalidade menor, com a quinta alterada no baixo. Resolve sempre no acorde de dominante da tonalidade tendo, por conseguinte, a função de dominante da dominante. Na resolução ouvem-se duas notas em movimento contrário num intervalo de segunda menor: a sensível, terça da dominante, caminhando em movimento ascendente; a quinta alterada no baixo, em movimento descendente. (PORTMAPO06)

- Acorde de sexta aumentada francesa é um acorde de sétima alterado na $2^{a}$ inversão (3M-3D-3M). (PORTMLIV02)

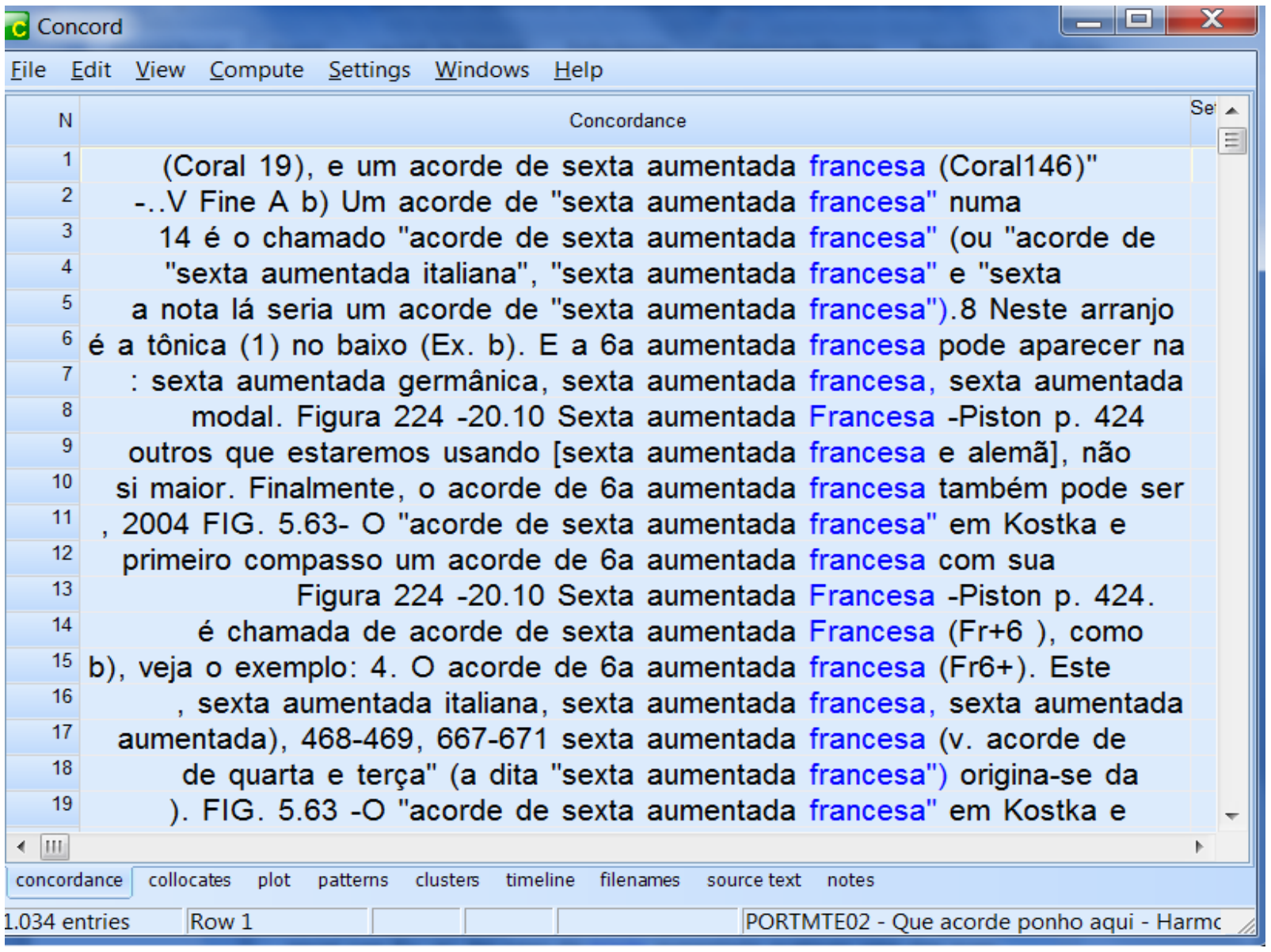

Figura 106 - Linhas de concordância de "acorde de sexta aumentada francesa" 


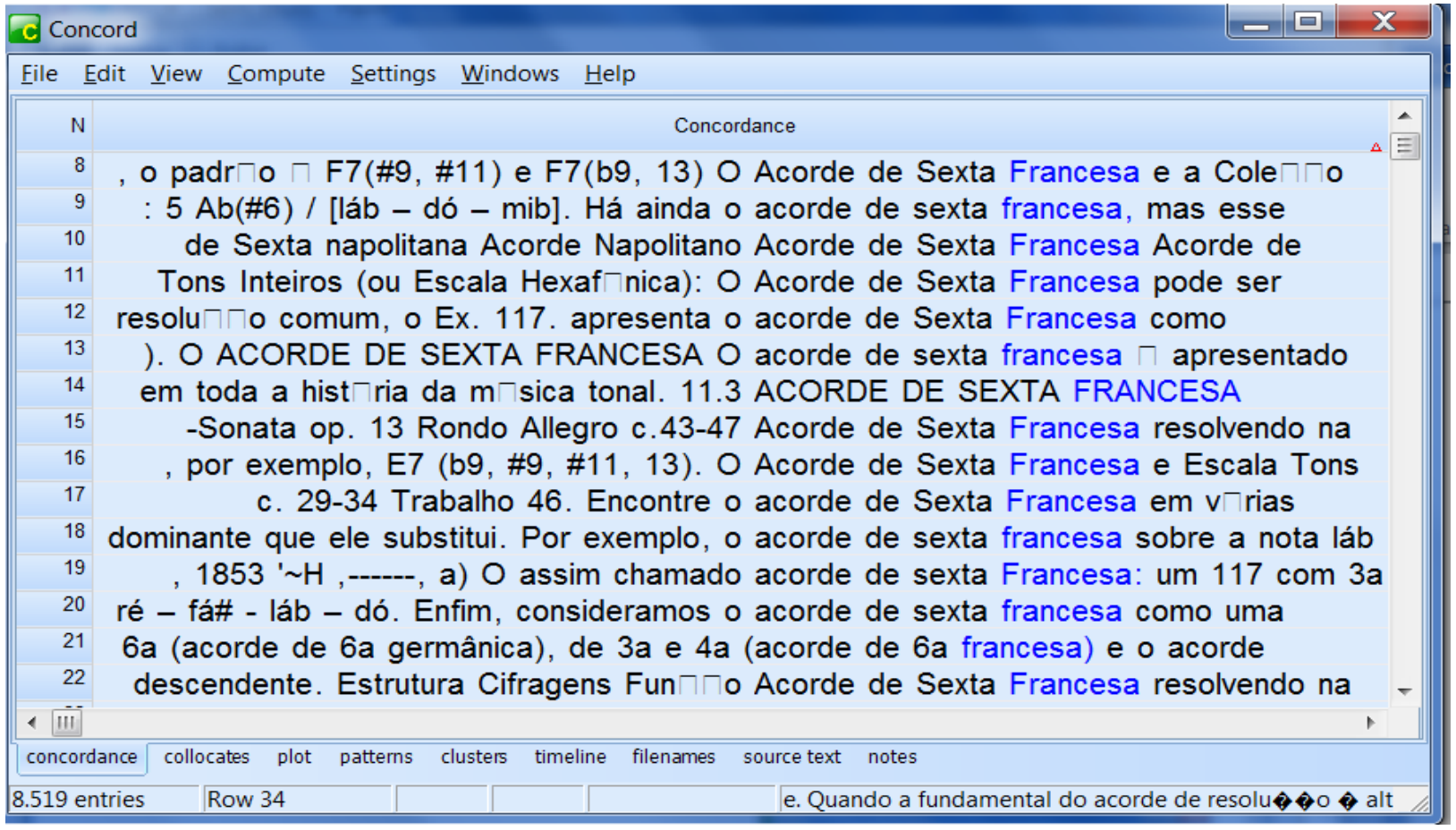

Figura 107 - Linhas de concordância (parciais) de "acorde de sexta francesa"

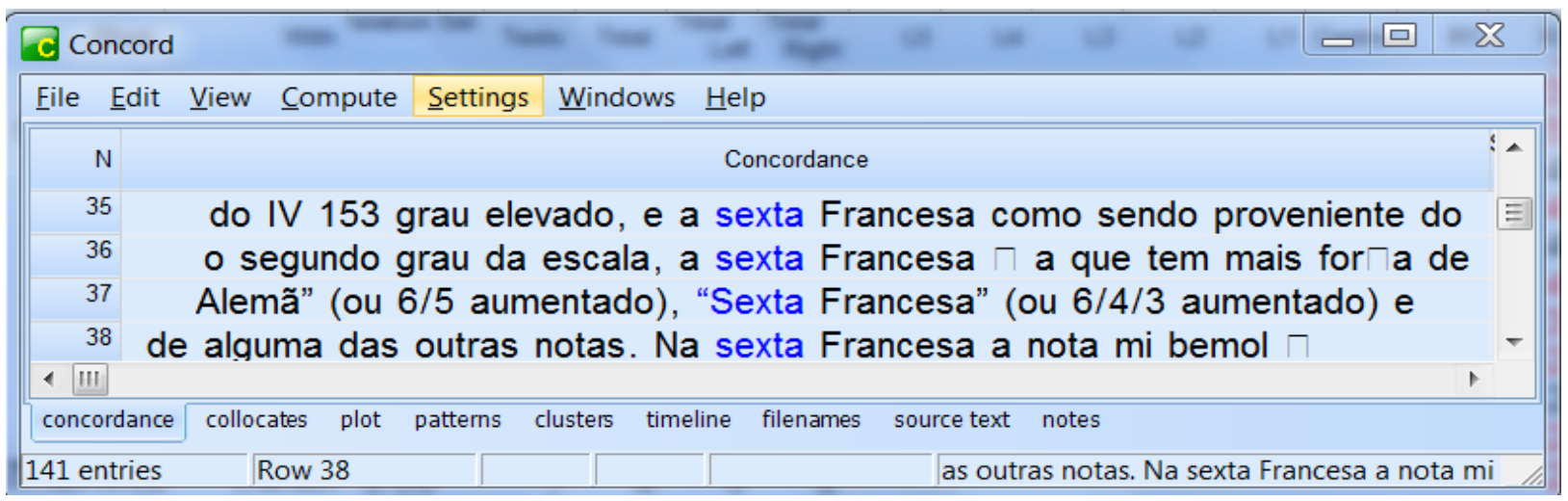

Figura 108 - Linhas de concordância (parciais) de "sexta francesa"

No subcorpus acadêmico-científico, localizamos contextos de uso com as três variantes:

- O acorde 14 é o chamado "acorde de sexta aumentada francesa" (ou acorde de dominante substituta", como é conhecido em algumas práticas teóricas da música popular). (PORTMTE02)

- $O$ acorde de sexta francesa é apresentado por Hindemith como sendo um acorde Dominante 7 com quinta diminuta na segunda inversão. (PORTMART05) 
- Hindemith os interpreta como formas alteradas de acordes de sétima da dominante, chamando-os de "Sexta Alemã" (ou 6/5 aumentado), "Sexta Francesa" (ou 6/4/3 aumentado) e "Sexta Italiana". (PORTMART21)

$\mathrm{Na}$ busca por correspondente para as colocações, encontramos "French augmented sixth chord" (7 ocorrências), "French sixth-chord" (1 ) e "French sixth" (9). No dicionário DI-HARVARD, a colocação "French sixth" apresenta remissiva para "Sixth chord".

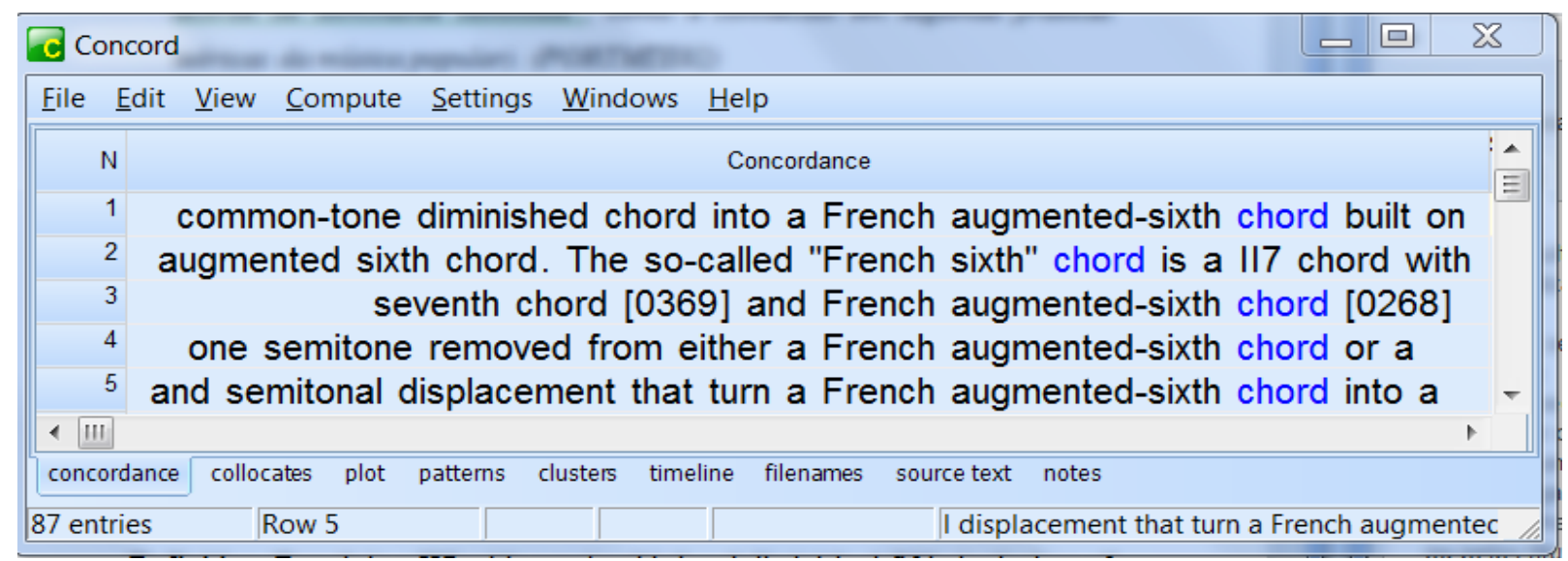

Figura 109 - Linhas de concordância de "French augmented sixth chord"e

"French sixth chord"

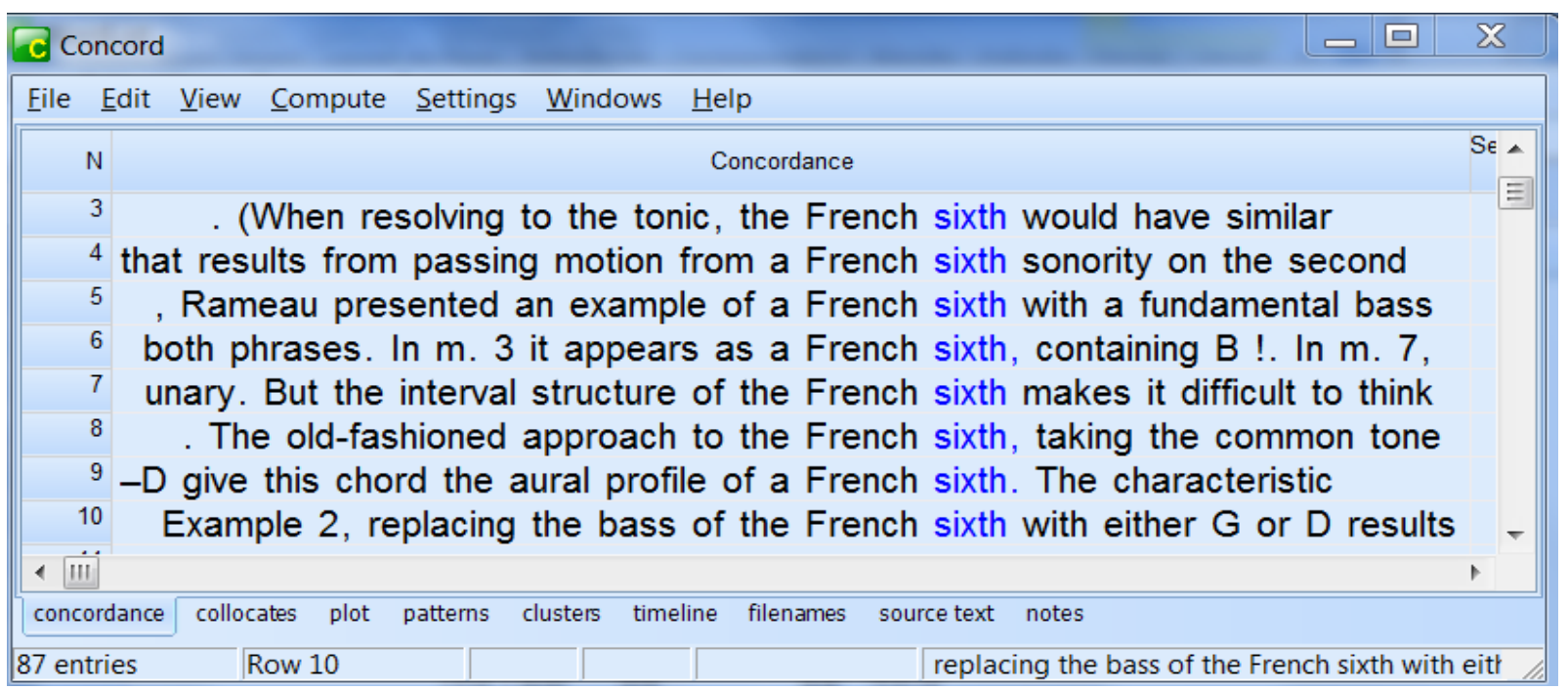

Figura 110 - Linhas de concordância de "French sixth"

A partir da análise das concordâncias, encontramos o seguinte contexto definitório: 
The so-called French sixth chord is a II7 with a major third and diminished fifth, in the key of a minor, it is spelled B-D\#-F-A; the root is B and the chord usually appears in second inversion. (INGTMTE02).

Verificamos que em Inglês também ocorre as formas variantes:

- The quasi-SLIDE transformation and semitonal displacement that turn a French augmented-sixth chord into a dominant seventh (shown in Example 5-8) are answered and balanced by the zigzag motion of oblique tenths shown in mm.11922 of Example 5-9.(INGTMDM01)

- Rameau presented an example of a French sixth with a fundamental bass a diminished fifth below. (INGTMART18)

Assim como na colocação do item anterior, observamos o uso das colocações sem o termo chord (forma reduzida).

Dessa análise, relacionamos a seguinte correspondência entre as variantes:

- Acorde de sexta aumentada francesa $\Leftrightarrow$ French augmented-sixth chord

- Acorde de sexta francesa $\Leftrightarrow$ French sixth chord

- Sexta francesa $\Leftrightarrow$ French sixth

\section{2) Acorde de sexta aumentada italiana, acorde de sexta italiana, sexta italiana}

Neste subitem reunimos colocações variantes do mesmo conceito: acorde de sexta aumentada italiana (11 ocorrências), acorde de sexta italiana (26 ocorrências) e sexta italiana (7 ocorrências).

Os contextos definitórios encontrados no subcorpus de português trazem as seguintes explicações:

- É o acorde de quinta alterado na $1^{a}$ inversão. (PORTMLIV02)

- É formado por três notas do acorde de dominante: a quinta alterada no baixo, a sétima e a terça no soprano. (PORTMAPO06) 


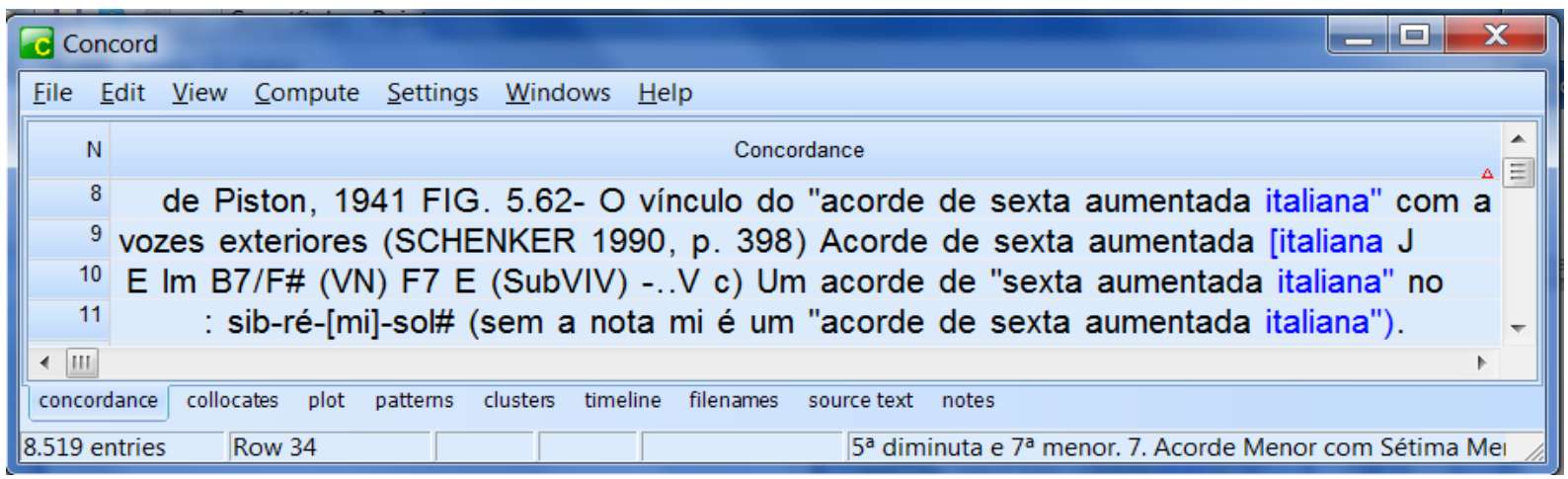

Figura 111 - Linhas de concordâncias de "acorde de sexta aumentada italiana"

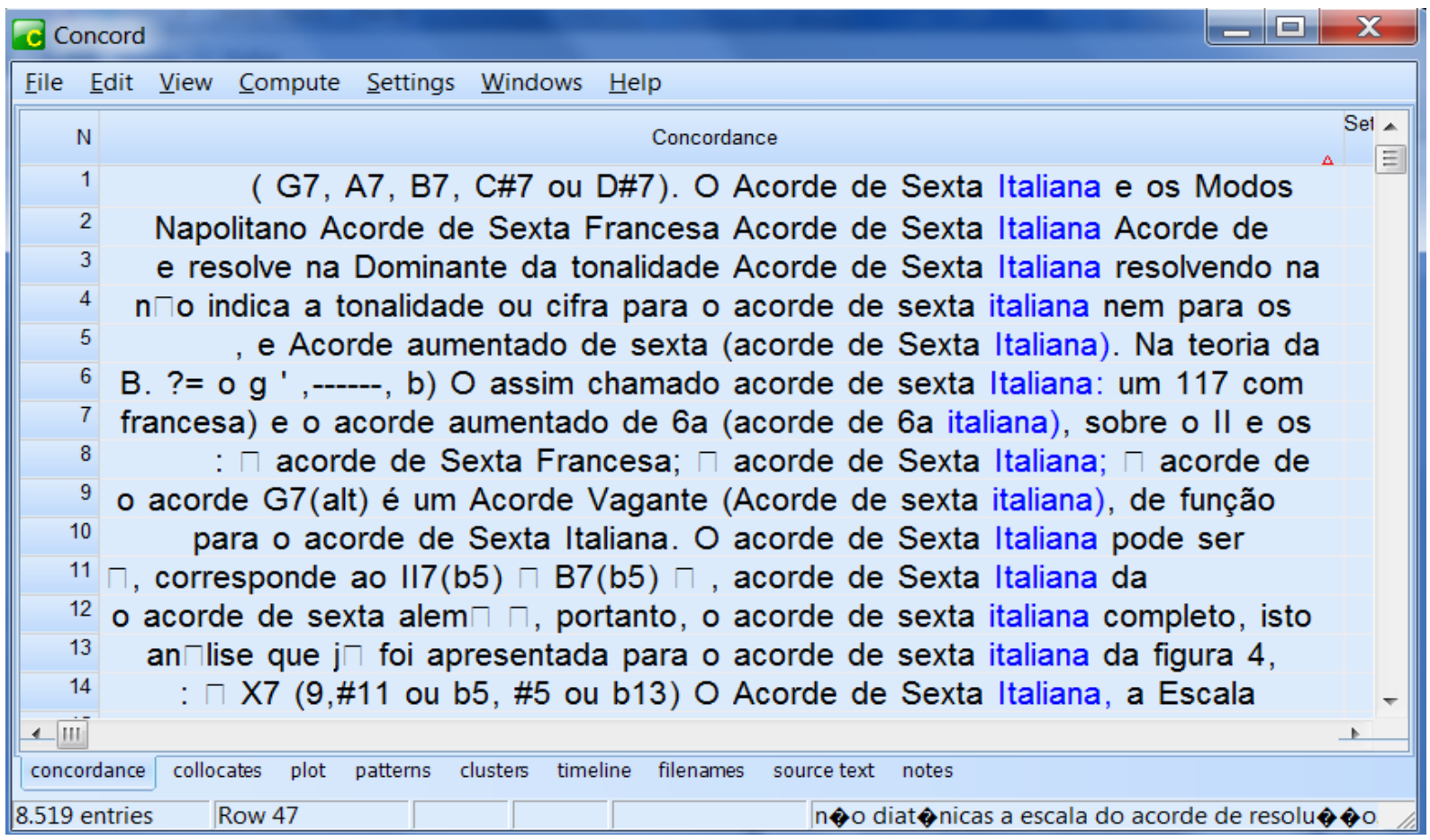

Figura 112 - Linhas de concordância (parciais) de "acorde de sexta italiana"

No subcorpus acadêmico-científico, localizamos contextos de uso com as três variantes - Acorde de sexta aumentada italiana, acorde de sexta italiana e sexta italiana:

- Em Ré menor, o II grau seria mi-sol-sib-ré, mas dado ao superlativo da situação ouvimos a versão super, a inversão com alteração: sib-ré-[mi]-sol\# (sem a nota mi é um "acorde de sexta aumentada italiana"). (PORTMTE02)

- Hindemith (1949, p. 92) 5 afirma ser frequente o uso de acordes a três vozes obtidos por omissão de uma das vozes do acorde Dominante em forma alterada. 
Este procedimento sobre o acorde de sexta alemã gera o acorde de sexta italiana, tendo a mesma resolução que o acorde do qual se originou. (PORTMART05)

- Segundo o autor, estes nomes: sexta Italiana, sexta Germânica e sexta Francesa, não são universais, mas eles têm ganhado aceitação e, da mesma forma que a sexta Napolitana, não se tem uma fonte segura de onde provém os nomes. (PORTMDM01)

$\mathrm{Na}$ busca por correspondente para as colocações, encontramos Italian augmented sixth chord (2 ocorrências), Italian sixth-chord (2 ocorrência) e Italian sixth (2), com os seguintes contextos:

- In most cases augmented sixth chords contain more than two pitch classes. When a third pitch class is included, it is usually the tonic pitch. This combination of tones is referred to as an Italian augmented sixth chord. (INGTMLIV12)

- The so-called "Italian sixth" chord is a II7 chord with a major third and diminished fifth and the root is missing; in the key of a minor, it is spelled D\#-FA; the "real" root is $B$ and the chord usually appears in second inversion reckoned above the "real" root. (INGTMTE02)

- On beat 3 of the second measure (m. 67), the enharmonic reinterpretation of $B$ dominant seventh, V7/III, as an Italian sixth that moves down in parallel to A dominant seventh (...) (INGTMART18)

No dicionário DI-HARVARD, a colocação “Italian sixth" apresenta remissiva para "Sixth chord".

Analisando as concordâncias nas duas línguas, a correspondência entre as colocações é:

- Acorde de sexta aumentada italiana $\Leftrightarrow$ Italian augmented-sixth chord

- Acorde de sexta italiana $\Leftrightarrow$ Italian sixth chord

- Sexta italiana $\Leftrightarrow$ Italian sixth

33) Acorde de sexta acrescentada (de Rameau), Acorde de Rameau 
Neste item reunimos as colocações "acorde de sexta acrescentada" (de Rameau) e "acorde de Rameau" por serem variantes do mesmo conceito. "acorde de sexta acrescentada" tem a frequência de 12 ocorrências e "acorde de Rameau", 11 ocorrências.

No subcorpus de estudo, encontramos contextos definitórios para as colocações que apresentam detalhes sobre o acorde:

- Este acorde, também denominado accord de la sixte ajoutee de Rameau (16831764), tem especial importância, porquanto a sexta é sempre a sexta do tom. A sexta acrescentada é tão característica para a subdominante quanto à sétima o é para a dominante. Pode-se considerar o acorde de sexta acrescentada como um reforço quase tão importante para a cadência plagal, quanto o acorde de sétima de dominante para a cadência autêntica. Emprega-se somente na posição fundamental. A sexta pode ser empregada omitindo-se a quinta e dobra-se a fundamental. (PORTMLIV06)

- No modo menor o lugar natural da tétrade meio-diminuta é o II grau (notas ré-fáláb-dó em Cm:), usualmente tratado como um acorde da função subdominante que, dependendo da posição e da inversão, como já vimos, será cifrado como Ilm7(b5) ou 1Vm6 (o acorde de sexta acrescentada, ou acorde de Rameau no modo menor).(PORTMLIV02)

A partir dos contextos verifica-se que as colocações "acorde de sexta acrescentada" $\mathrm{e}$ “acorde de Rameau” são denominações para o mesmo acorde. 


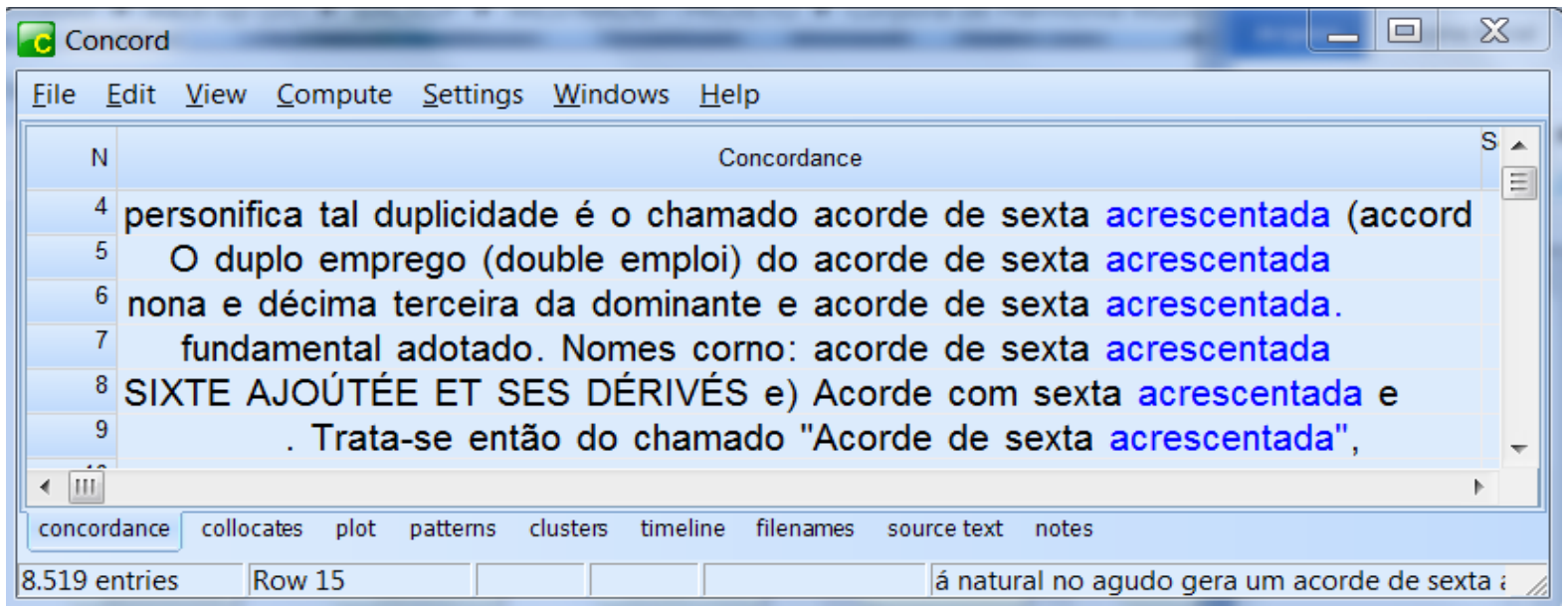

Figura 113 - Linhas de concordância parciais de "acorde de sexta acrescentada"

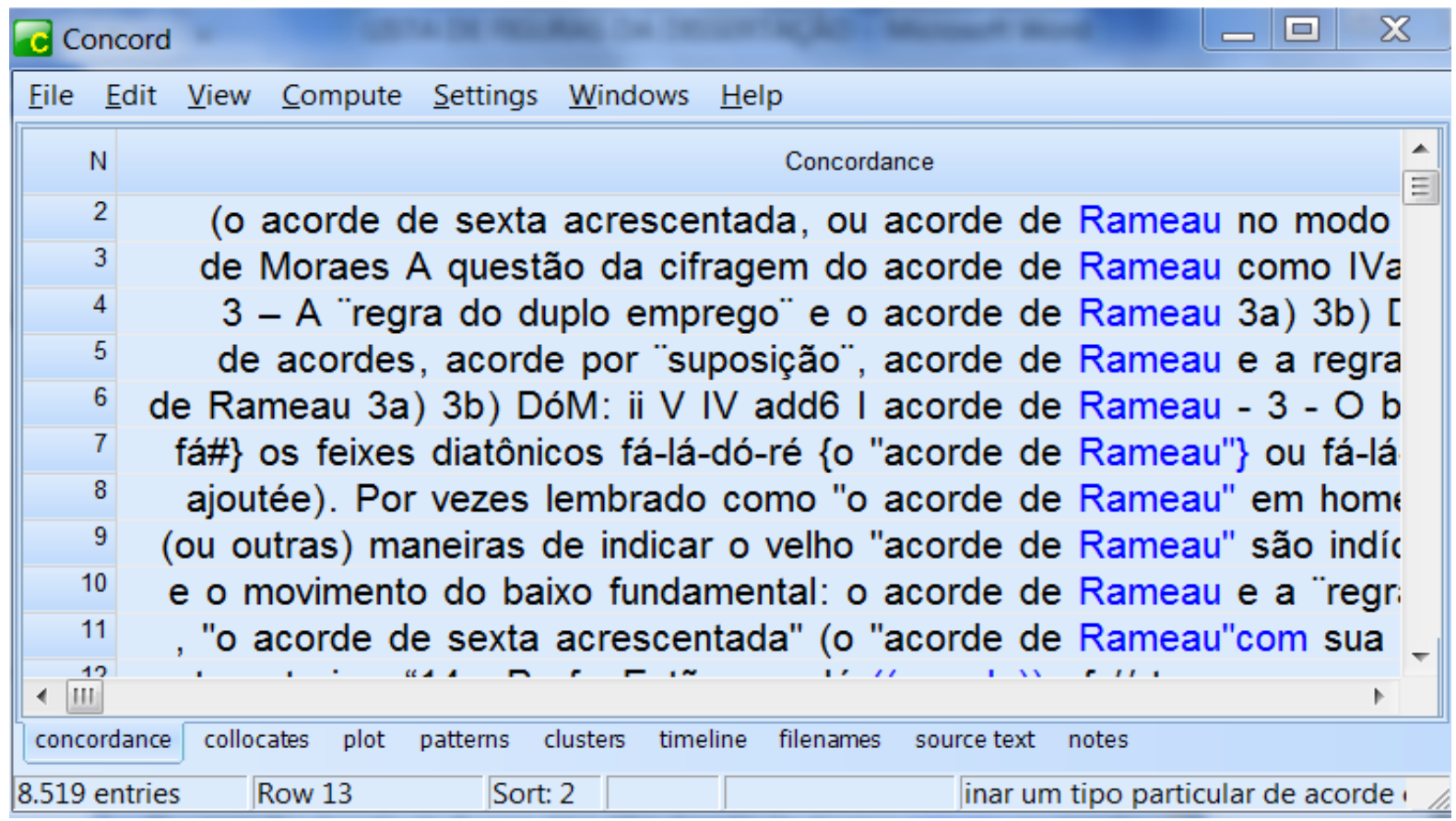

Figura 114 - Linhas de concordância de "acorde de Rameau"

Nos excertos abaixo, apresentamos uma discussão sobre o acorde de acordo com diferentes abordagens sobre análise harmônica e um contexto de uso para ambos os termos:

- A questão da cifragem do acorde de Rameau como IV add6 ou com ii65 pela harmonia tradicional permanece ainda discutida e sem unanimidade. Autores como Walter Piston e Stefan Kostka concordam e comentam sobre a dificuldade em adotar uma única cifragem como representativa desta sonoridade. Eles atribuem ao contexto, isto é, ao direcionamento cadencial da progressão harmônica e a condução das vozes a tarefa de indicar a melhor 
solução para a cifragem. Ambos, em seus tratados de harmonia citam Rameau e apóiam-se na "regra do duplo emprego" e "no movimento do baixo fundamental " para expor e explicar a cifragem deste acorde em análises de exemplos musicais. Entretanto, para Arnold Schoenberg, em seu tratado de Harmonia, não existe impasse, é assumido sempre como ii. A harmonia funcional interpreta este acorde sempre como subdominante. A harmonia funcional interpreta este acorde sempre como subdominante. Koellreutter, em seu livro de harmonia funcional também faz alusão a Rameau, e sem dubiedade o trata como acorde de subdominante com $6^{a}$ adicionada (KOELLREUTTER, 1978, pp. 24-25). Na música popular é comum encontrar exemplos em que predomina a cifragem deste acorde, no modo menor, como iv 6add. (PORTMART20)

- $\mathrm{O}$ acorde que personifica tal duplicidade é o chamado acorde de sexta acrescentada (accord de sixte ajoutée). Por vezes lembrado como "o acorde de $\underline{\text { Rameau }} "$ em homenagem a quem definitivamente teria dado destaque teórico a tal recurso artístico em publicações que circularam nos grandes centros urbanos modernos. (PORTMTE02)

Encontramos como correspondente em Inglês a colocação "Added sixth chord", com (4 ocorrências). A colocação também foi encontrada em dois dicionários de termos musicais em Inglês:

- A sixth added above the root of a triad, or the chord thus produced; thus f-a-c'd'. The traditional theory of chord inversion derived from Rameau requires such a structure to be viewed as the first inversion of a seventh chord (the root in this example being $d$, making the chord a ii 7 in the context of $C$ Major and implying a resolution to the dominant). But Rameau himself observed that the chord can also function as an embellished triad (usually, as in this example in C Major, the subdominant) and thus resolve in different ways. Chords are often used in Jazz and popular music as embellished triads and are specified by the letter indicating the root of the triad followed by the Arabic numeral G (e.g. F6), as from what is termed the minor seventh chord.(DI-HARVARD) 
- A triad, usually the subdominant, with an extra note, the sixth (in the key o $C$ Major: $f-a-c-d)$; this chord can be thought of as the supertonic seventh chord in first inversion. In strict Harmony, the chord should resolve onto the dominant or tonic chord, but many composers have used it purely for effect. It is a popular final chord in Jazz.(DI-OXFORD)

Verifica-se que em um dos dicionários, a colocação remete a Rameau e na segunda definição, trata-se do mesmo acorde.

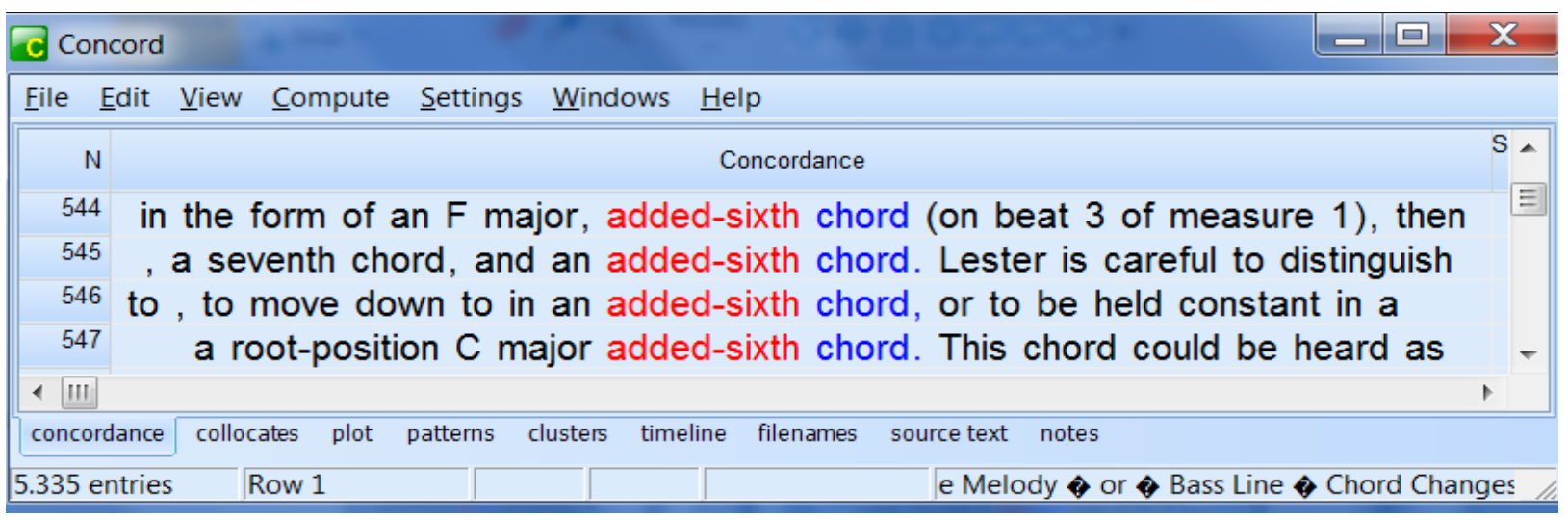

Figura 115 - Linhas de concordância de "added-sixth chord"

Encontramos no subcorpus alguns trechos, que mostra a colocação e a variante Addedsixth em contexto de uso:

- For example, Lester, Compositional Theory, p. 206, uses the term to apply to Rameau's dissonance-motivated chord types: "Rameau had proposed three chordal functions: tonic, dominant, and subdominant." For Rameau, who did not use the term "function," these are respectively represented as a triad, a seventh chord, and an added-sixth chord. Lester is careful to distinguish his use of the term from modern usage.(INGTMLIV10)

- In between, the tonic chords of these two keys actually fuse together, first in the form of an F major, added-sixth chord (on beat 3 of measure 1), then as a rootposition D minor seventh chord (on the following downbeat). (INGTMART16)

- A second result is its strong emphasis of $F$ as the sixth above the bass (notated as a diminished seventh, from $B$ to $F$ ), another of the added sixths that give both the harmonic and melodic components so much character. (INGTMART14) 
No glossário, utilizaremos remissivas para as colocações em Português.

\section{4) Acorde de nona}

A colocação "acorde de nona" tem a frequência de 38 ocorrências no corpus de estudo.

No dicionário DP - DOURADO, a colocação apresenta essa definição:

Acorde que emprega o intervalo de nona em relação ao baixo (Dó - Mi - Sol - Si Bemol-Ré).

Encontramos no subcorpus instrucional um contexto definitório:

- Acorde de nona é um acorde de cinco sons. Consiste num acorde de sétima ao qual se acrescenta mais uma terça. O intervalo entre as notas extremas é uma nona. Podem ser formados 14 acordes de nona diatônicos no estado fundamental (sete acordes de sétima diatônicos, acrescidos de terça maior e menor) incluindo as inversões, são 54 acordes. O mais usado é o acorde formado sobre a dominante e tons maiores e menores. (PORTMLIV02)

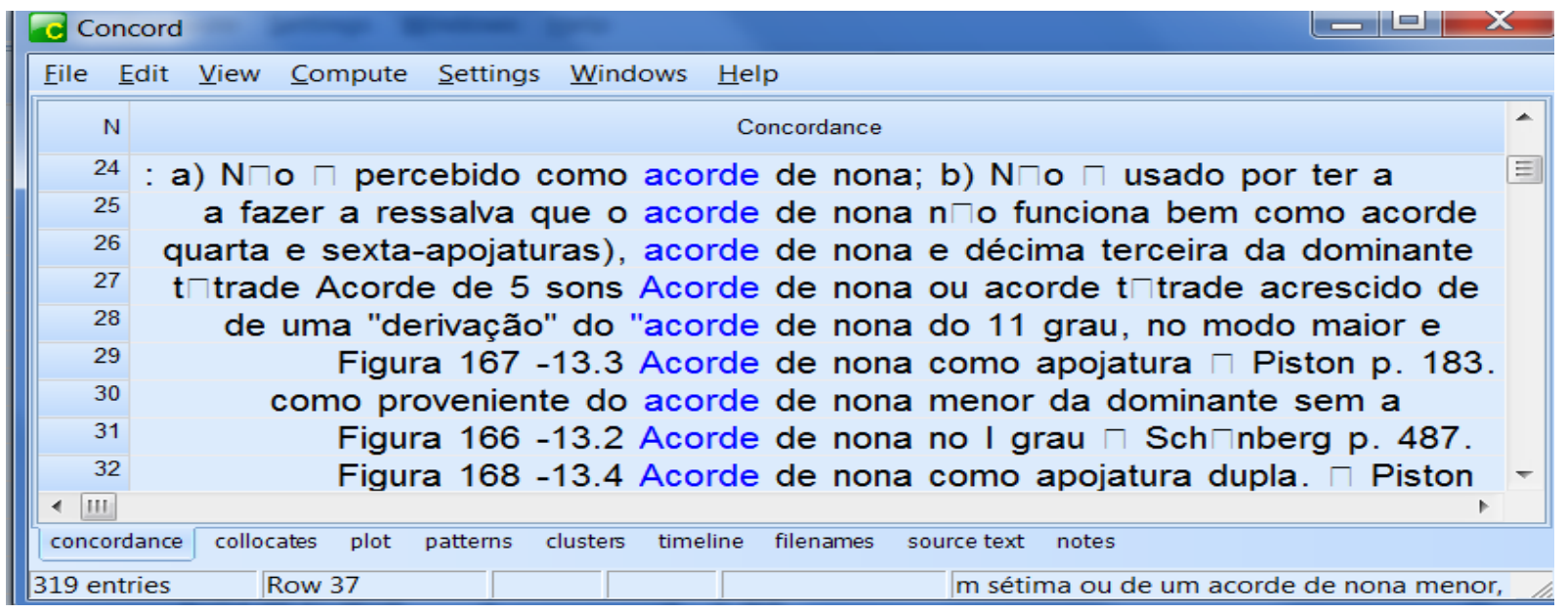

Figura 116 - Linhas de concordância de "acorde de nona"

No subcorpus acadêmico-científico, verificamos o seguinte contexto de uso: 
Quanto às inversões dos acordes de nona, Schöenberg afirma que os antigos teóricos afirmavam que os acordes de nona eram ruins e que suas inversões não existiam. (PORTMDM01)

$\mathrm{Na}$ busca por correspondente, encontramos a colocação Ninth chord, com 32 ocorrências:

Assim como em Português, a colocação também foi encontrada no dicionário como:

- A chord having usually, but no necessarily, five tones, the interval between the base note and the highest note being a ninth. The other notes in the chord would be the root, third, fifth, and seventh, in the $C$ chord below, the root is $C$, the third is $E$, the fifh is $G$, the seventh is $B$, and the ninth is D. (DI - ON MUSIC)

No seguinte contexto extraído do subcorpus instrucional, ela recebe essa definição:

Ninth chords are constructed by adding the interval of a major ninth to an existing seventh chord, regardless of its quality. (INGTMLIV02) 


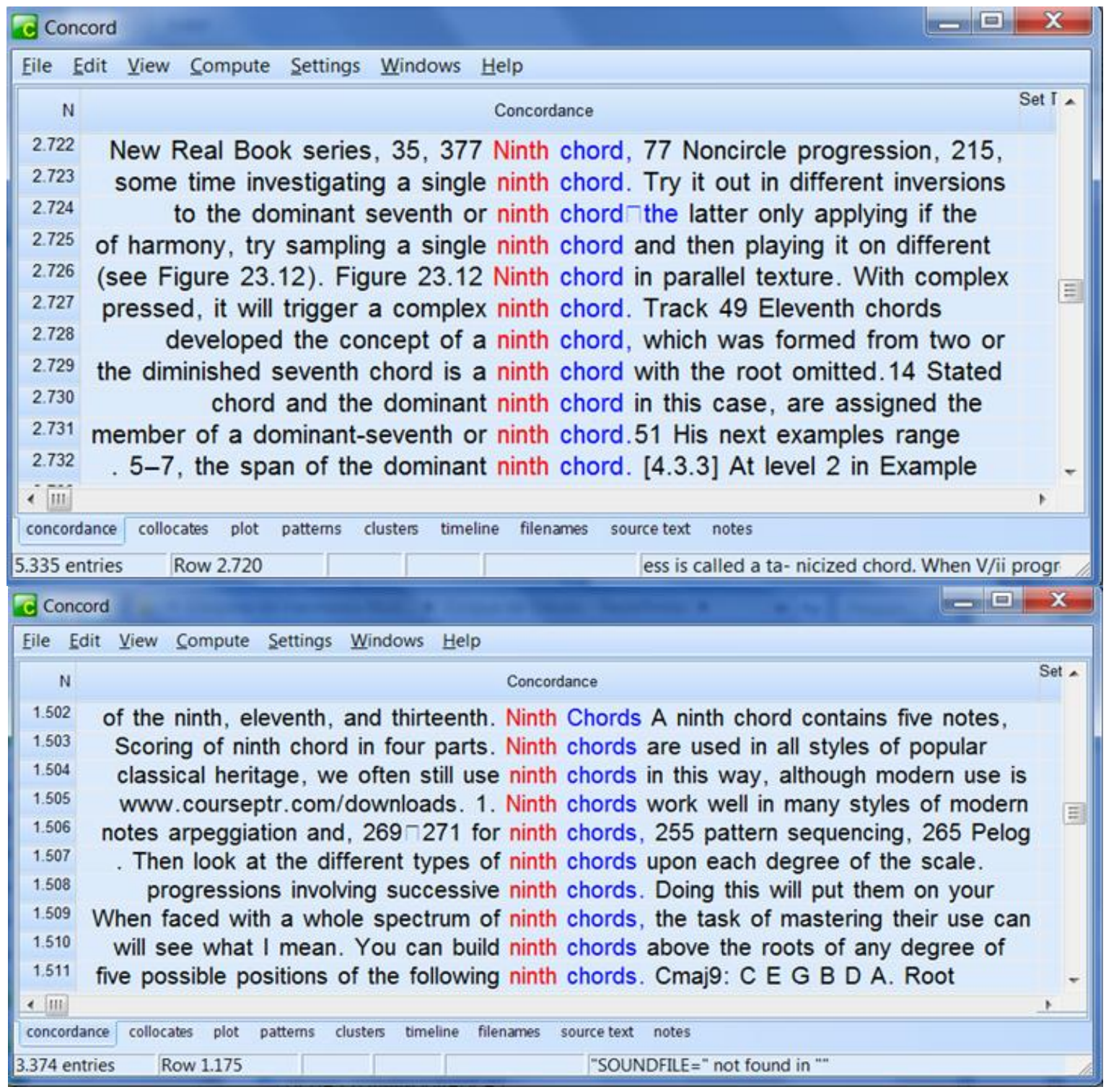

Figura 117 - Linhas de concordância de "ninth chord" (singular e plural)

Selecionamos alguns trechos do subcorpus acadêmico-científico, em que a colocação aparece em contexto de uso:

The ninth chord served as raw material from which Capellen could derive other chords. (INGTMTE01)

\section{5) Acorde de décima primeira}

A colocação "acorde de décima primeira" tem uma frequência baixa no corpus de estudo: 4 ocorrências. No corpus instrucional, encontramos os seguintes contextos definitórios: 
- Acorde de décima primeira: É um acorde de seis sons: Consiste num acorde de nona ao qual se acrescenta mais uma terça o intervalo entre as notas extremas é uma décima primeira. (PORTMLIV02)

- Acordes de décima primeira: São os acordes de nona (naturais ou artificiais) com agregação de uma terça criando os acordes de décima primeira. Esses acordes são ainda mais livres que os acordes de nona artificiais, dispensando qualquer preparação e, frequentemente, recaindo sobre resoluções excepcionais. (PORTMLIV10)

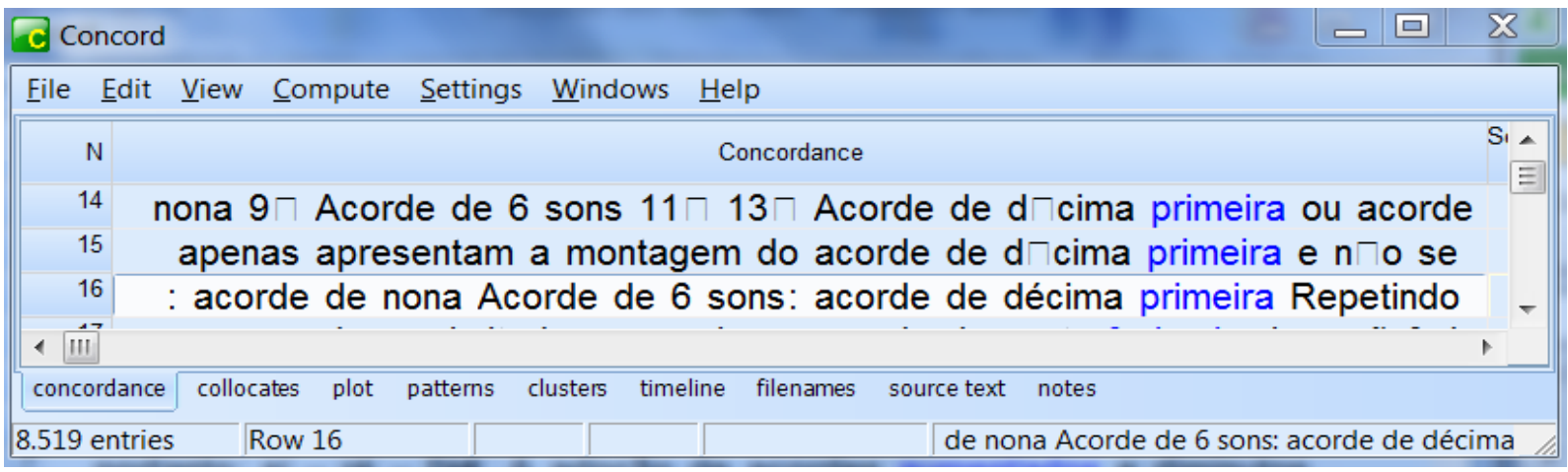

Figura 118 - Linhas de concordância (parciais) de "acorde de décima primeira"

O trecho a seguir apresenta um contexto de uso da colocação:

Piston é o que mais comenta sobre estes acordes. A décima primeira pode aparecer num acorde de dominante ou não. A nona pode ser uma nota melódica ou harmônica, dependendo da situação que se encontra. Esta ambiguidade é ainda mais presente no acorde de décima primeira e décima terceira. (PORTMDM01)

No corpus de estudo de Inglês, encontramos a colocação correspondente "Eleventh chord", com doze ocorrências. 


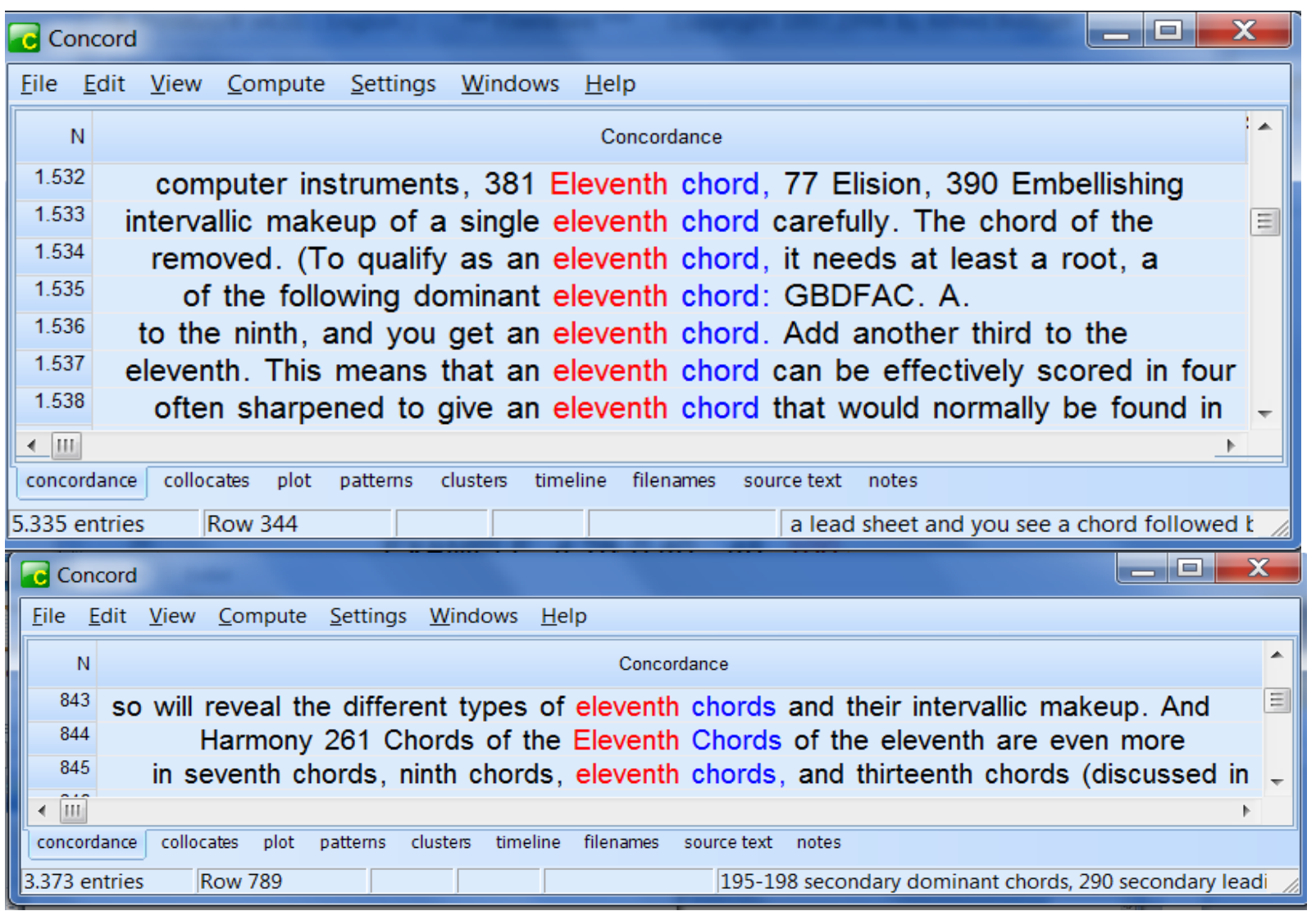

Figura 119 - Linhas de concordância (parciais) de "eleventh chord” (sing/plural)

A colocação (e a variante reduzida Eventh) foi uma das encontradas nos dicionários de termos musicais em Inglês pesquisados, com as seguintes definições:

- Eleventh chord - A chord having up to six notes, the interval between the root note and the highest note being the interval of an eleventh. (DI - ON MUSIC)

- Eleventh - see interval, chord. (The superposition of thirds may be extended to include ninth, eleventh, and thirteenth chords, each of which takes its name from the interval that separates the lowest and highest pitches when the chord is the most compact form of root position. (DI - HARVARD)

No corpus de estudo instrucional, selecionamos o seguinte contexto definitório:

- Eleventh chords are created in theory by adding a perfect eleventh interval to an existing ninth chord. In practice, however, there are exceptions: major ninth and dominant ninth chords: because the perfect eleventh is a minor ninth interval 
above the major third interval above the major third degree of each of these chords, and because this interval is generally considered harsh or dissonant to the ear, the eleventh is raised a half step to reduce the dissonance; Minor ninth and minor ninth chords: because these chords contain a minor third the extreme dissonance is not present, so no alteration of the eleventh is required. (INGTMLIV04)

Embora, em Inglês, a colocação tenha sido encontrada apenas no subcorpus instrucional, as análises dos trechos mostrou que o significado empregado é o mesmo que em Português.

\section{6) Acorde de décima terceira}

A colocação "acorde de décima primeira" tem uma frequência no corpus de estudo de três ocorrências. No corpus instrucional, encontramos os seguintes contextos definitórios:

- Acorde de décima terceira: É um acorde de sete sons. Consiste num acorde de décima primeira ao qual se acrescenta mais uma terça. $O$ intervalo entre as notas extremas é uma décima terceira. (PORTMLIV02)

- São os acordes de décima primeira acrescidos de uma terça que dão origem aos acordes de décima terceira. Gozam também de absoluta liberdade quanto à preparação e resolução das dissonâncias. (PORTMLIV10)

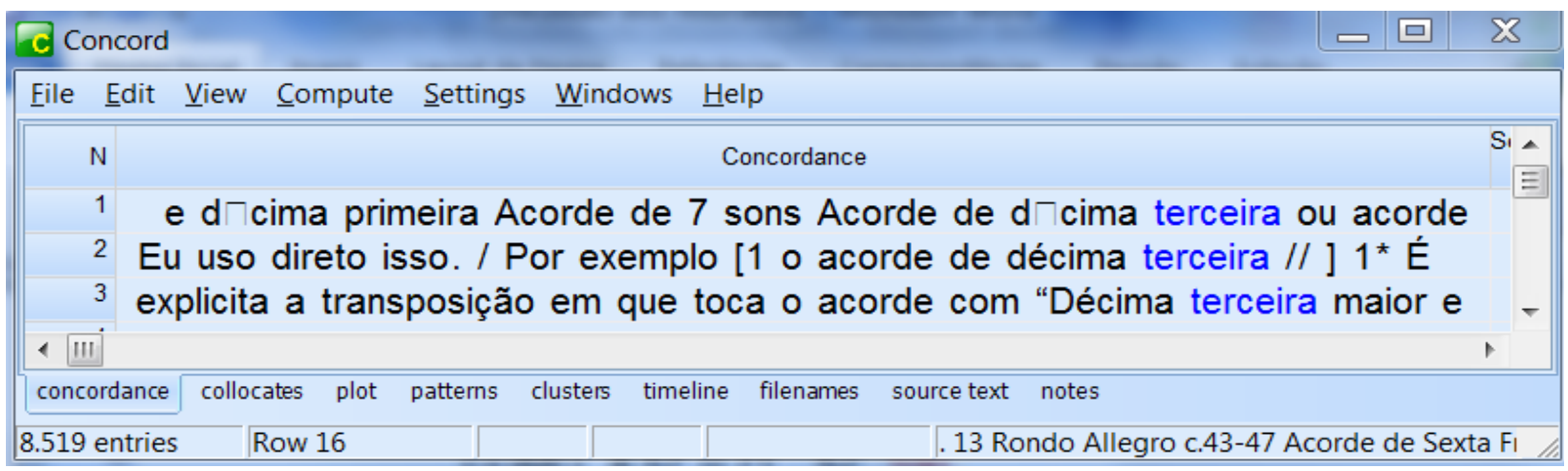

Figura 120 - Linhas de concordância de "acorde de décima terceira" 
O trecho a seguir, extraído do subcorpus acadêmico-científico, apresenta um contexto de uso:

Esta ambiguidade é ainda mais presente no acorde de décima primeira e décima terceira. (PORTMDM01)

A colocação correspondente, encontrada no subcorpus de Inglês, foi "Thirteenth chord", a qual apresentou 29 ocorrências.

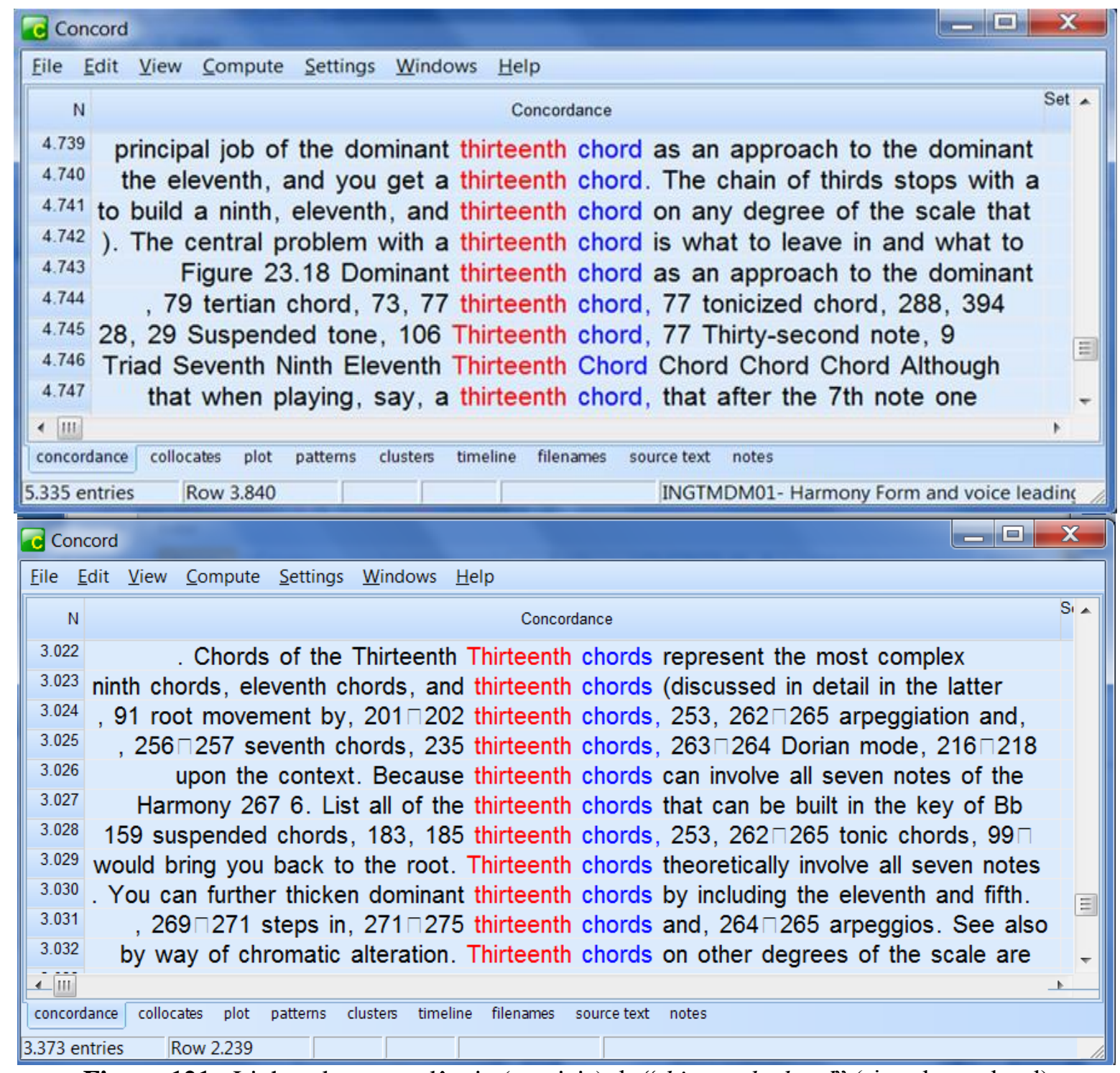

Figura 121 - Linhas de concordância (parciais) de "thirteenth chord" (singular e plural)

A colocação foi uma das encontradas nos dicionários de termos musicais em Inglês pesquisados, com as seguintes definições: 
- A chord having usually, but not necessarily, seven notes, the interval between the root note and the highest note being the interval of a thirteenth. The other notes in the chord would be the root, third, fifth, seventh, ninth, eleventh, and thirteenth. In the " $C$ " chord below, the root is $C$, the third is $E$, the fifth is $G$, the seventh is $B$, the ninth is $D$, the eleventh is $F$, and the thirteenth is $A$. In many situations, the fifth, ninth and eleventh notes are omitted from a thirteenth chord. (DI - ON MUSIC )

- $\quad$ Thirteenth - see interval, chord. (The superposition of thirds may be extended to include ninth, eleventh, and thirteenth chords, each of which takes its name from the interval that separates the lowest and highest pitches when the chord is the most compact form of root position). (DI - HARVARD)

Do corpus de estudo instrucional, selecionamos o seguinte contexto definitório, que reforça o que foi explicado nos dicionários:

Complete thirteenth chords are built by adding the interval of a major, thirteenth to an existing eleventh chord (...) The most common note to leave out of thirteenth chord is the eleventh. If a thirteenth chord does contain a eleventh, and the eleventh is altered, the alteration must be written into the name of the chord, eg. C13 (\#11) (INGTMLIV02)

Assim como a colocação (em Inglês) do subitem anterior, thirteenth chords foi encontrada apenas no corpus instrucional. Contudo, os trechos selecionados confirmam que a colocação correspondente é utilizada com o mesmo significado que em Português.

\section{7) Acordes principais, acordes primários, tríades principais}

Neste item agrupamos as colocações acordes principais e acordes primários por apresentarem o mesmo conceito em determinados textos do subcorpus, relacionados à abordagem funcional. "Acordes principais" tem a frequência de 46 ocorrências e "acordes primários", 5 ocorrências e "tríade principais" (4 ocorrências). Selecionamos do subcorpus de Português contextos definitórios que detalham tais colocações:

- Os chamados acordes principais possuem três funções: Tônica, Subdominante e Dominante. O relacionamento entre eles e a Tônica se dá pelo intervalo de quinta Justa e o movimento entre estes três acordes na ordem Tônica, Subdominante, 
Dominante, Tônica, forma a cadência perfeita completa, possível de se encontrar tanto nos inícios e terminações de frases elou de trechos, como na base da construção de peças tonais. (PORTMAPO06)

- Os acordes principais serão Maiores em uma tonalidade Maior e menores em uma tonalidade menor. Somente o acorde de Dominante é sempre Maior. Para entender as funções, é preciso considerar que esses acordes não são isolados, só podem existir um em relação ao outro. (PORTMAPO06)

- $\quad$ "As harmonias de tônica, dominante e subdominante constituem os três pilares do sistema tonal; todas as demais harmonias são derivadas destes três acordes primários". (PORTMTE02)

- É interessante sublinhar aqui que esta ideia de formação das escalas maior e menor a partir das tríades principais de I, IV e $V$ é bastante antiga e já é mencionada por teóricos como Heinrich Christoph Koch (1749-1816) (ver RUDD, 1992, p. 27-29). (PORTMART09)

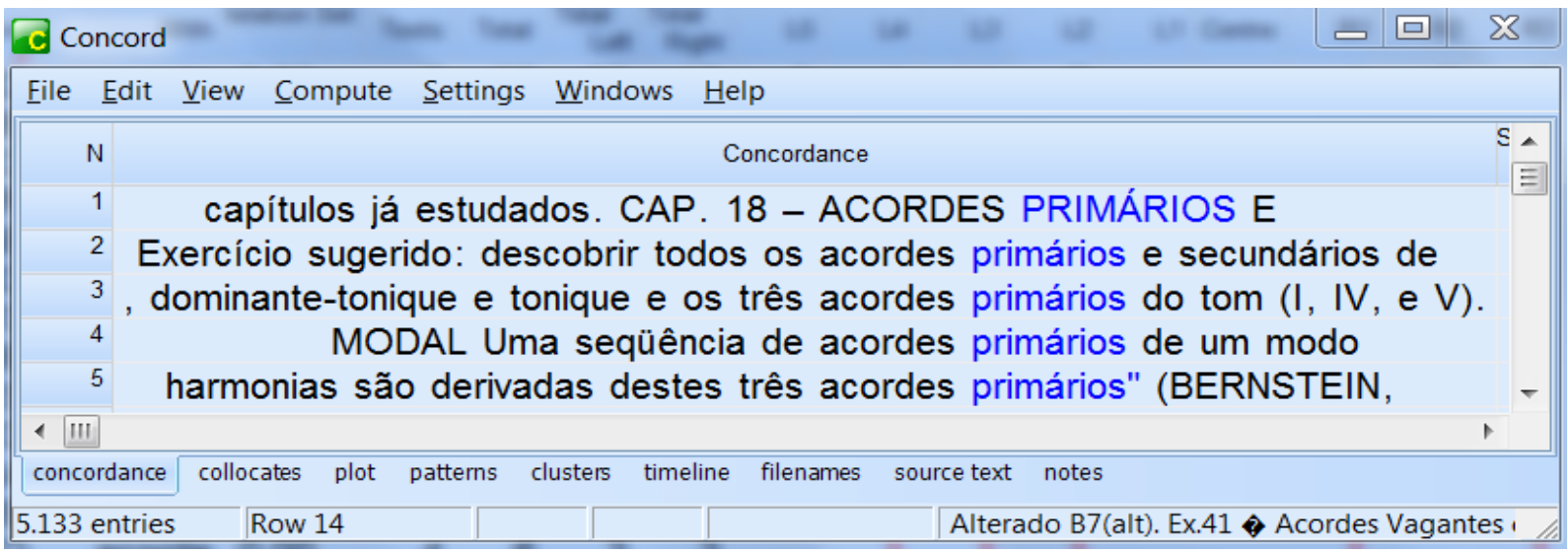

Figura 122 - Linhas de concordância (parciais) de "acorde primário"(singular e plural) 


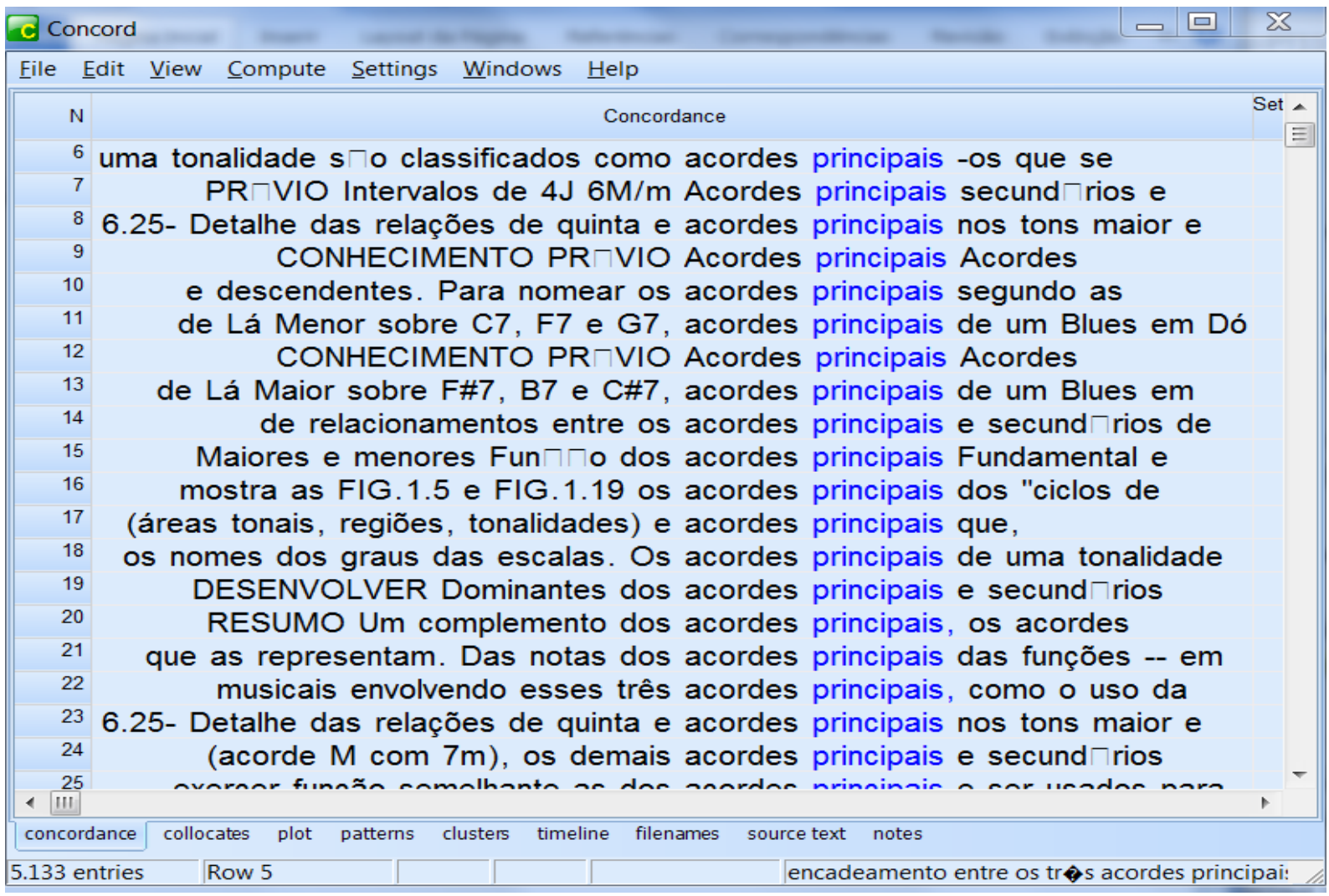

Figura 123 - Linhas de concordância (parciais) de "acordes principais"

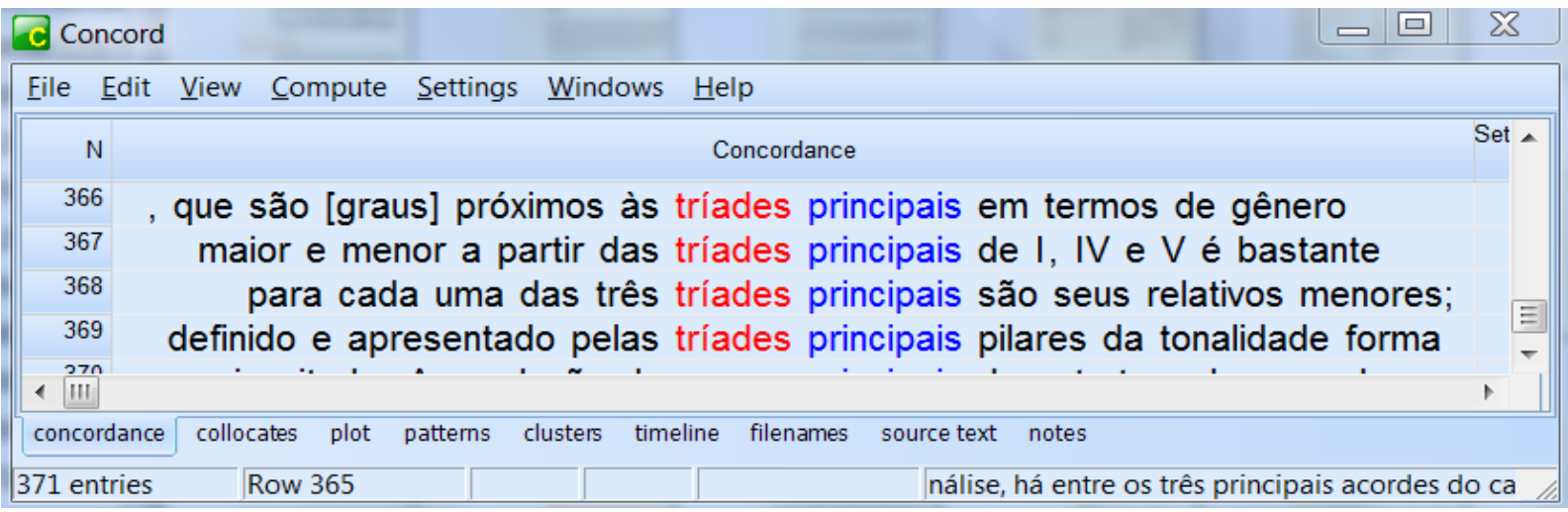

Figura 124 - Linhas de concordância (parciais) de "tríades principais"

No exemplo abaixo, as colocações são utilizadas com o significado mencionado anteriormente (relacionado às três funções: tônica, dominante e subdominante):

- Trata-se, portanto, de um sistema de inter-relações entre os acordes, que opera com base na existência de um centro tonal e três funções principais, atribuídas aos graus I, V e IV. Ainda no capitulo intitulado "Teoria das funções”, Brisolla recorre a uma análise da formação dos acordes principais 
do campo harmônico da escala maior e de relações entre si e entre eles e a escala. (PORTMART14)

- Kopp observa ainda que, nas análises de Rameau, não há correspondência unívoca entre os três tipos sous-dominante, dominante-tonique e tonique e os três acordes primários do tom (I, IV, e V). (PORTMTE02)

- Os principais substitutos para cada uma das três tríades principais são seus relativos menores; assim, VI substitui I; III substitui V e II substitui IV. (PORTMART26)

Em Inglês, encontramos a colocação correspondente primary chords, com 43 ocorrências. Nos contextos abaixo, verificamos que o uso da colocação apresenta o mesmo significado que em Português:

- First, while he does put forward the notion that a key is defined by its tonic, dominant and subdominant chords, Weber in turn describes these three primary chords as an outgrowth of the major scale, thus characterizing them as dependent on some other musical element. (INGTMLIV10)

- For example, listen to Bob Dylan's “Blowing in the Wind." This song in its entirety only uses the three primary chords - tonic, subdominant, and dominant.(INGTMLIV04) 


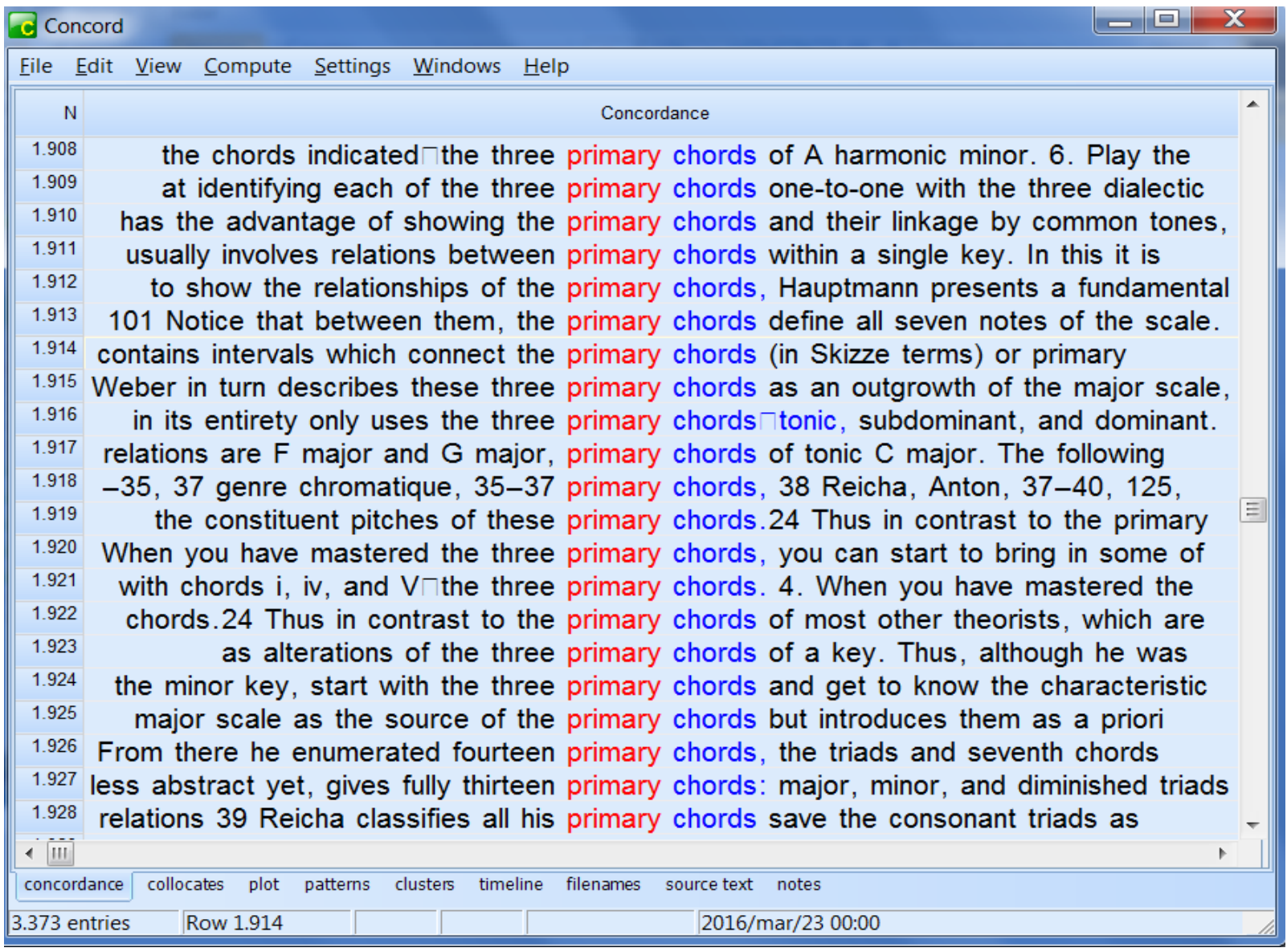

Figura 125 - Linhas de concordância parciais de "primary chord"(singular e plural)

Verificamos também que, em Inglês, a colocação "primary triads" (21 ocorrências) também é uma variante, utilizada com o mesmo conceito:

- The triads built on the tonic, subdominant, and dominant are often referred to as primary triads because of their strong relationship to each other the tonic stands in the center of the tonal system, with the dominant a perfect fifth above and the subdominant a perfect fifth below. (INGTMLIV02)

- At the next level, that of the primary triads, the three components are tonic, subdominant, and dominant; their interrelationship is unmediated by third(...) (INGTMLIV10)

- In the major tonality, the three primary triads (I, IV, and V) are all major, while in the minor tonality ( $i, i v$, and $v$ ) they are all minor. (INGTMLIV04)

- the characterization of individual chords as tonic (T), subdominant (S), or dominant (D) in function; and (2) the notion that the so-called primary triads, 
$I$, IV, and $V$ somehow embody the essence of each of these functional categories. (INGTMART21)

Nos dicionários especializados foram as colocações registradas são:

- Acorde primários - Os acordes principais que definem a tonalidade: tônica, subdominante e dominante (Dó, Fá e Sol, na tonalidade de Dó Maior). (DPDOURADO)

- $\quad$ Primary triads (chords)- The tonic, subdominant and dominant triad in any key; in the view of Schenker Theory, the tonic and dominant triads only. (DIHARVARD)

Como se nota, a colocação "acordes principais" não consta como verbete em Português.

A correspondência sugerida entre as colocações, mantendo as semelhanças morfológicas são:

Acordes principais, acordes primários $\Leftrightarrow$ Primary chords

Tríades principais $\Leftrightarrow$ Primary triads

\section{8) Acorde de tônica}

Em textos de Harmonia Funcional, o termo "tônica" está relacionado ao conceito de função. Há três funções principais: dominante, subdominante e tônica. A colocação "acorde de função tônica" não é tão convencional quanto "acorde de tônica", o que será constatado posteriormente. Observamos que essa tendência de reduzir componentes de uma colocação é bem comum em relação à nomenclatura dos acordes, e desse processo surgem colocações variantes. Utilizadas em um mesmo texto, a presença de mais de uma variante pode indicar recurso de estilo do autor. 


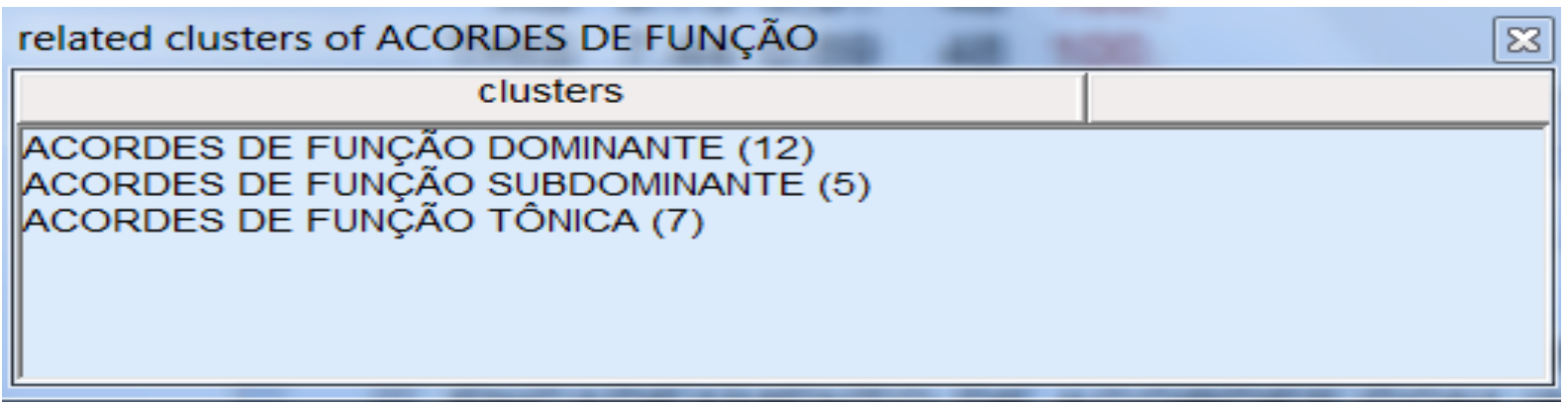

Figura 126 - Clusters relacionados a "acordes de função" e suas ocorrências no subcorpus de português

A colocação acorde de tônica tem a frequência de 24 ocorrências no corpus de estudo. $\mathrm{Na}$ pesquisa aos dicionários de termos musicais, ela foi encontrada na forma reduzida (tônica):

Tônica: Acorde montado sobre o primeiro grau da escala (DP-DOURADO).

No subcorpus instrucional, encontramos alguns contextos definitórios:

- Tônica é a função de sentido conclusivo, de repouso. Geralmente é o acorde que finaliza um tema musical. O acorde principal da função tônica é o I grau... (PORTMAPO03)

- $\quad \underline{\text { Tonica }}$ (ou I grau) é o acorde perfeito maior que se localiza no centro dos três únicos acordes perfeitos da escala, separados por intervalos de quinta.(PORTMART19)

Em um dos textos do corpus instrucional, observamos o uso da colocação variante: acorde tônico (13 ocorrências apenas num único texto). Nos demais textos em que a colocação ocorre, ela aparece como acorde de tônica:

Esta progressão acima é chamada de back-door ("porta dos fundos”), nome este provavelmente originado do fato do acorde tônico ser alcançado por um dominante localizado um tom abaixo de sua fundamental. (PORTMAPO05) 


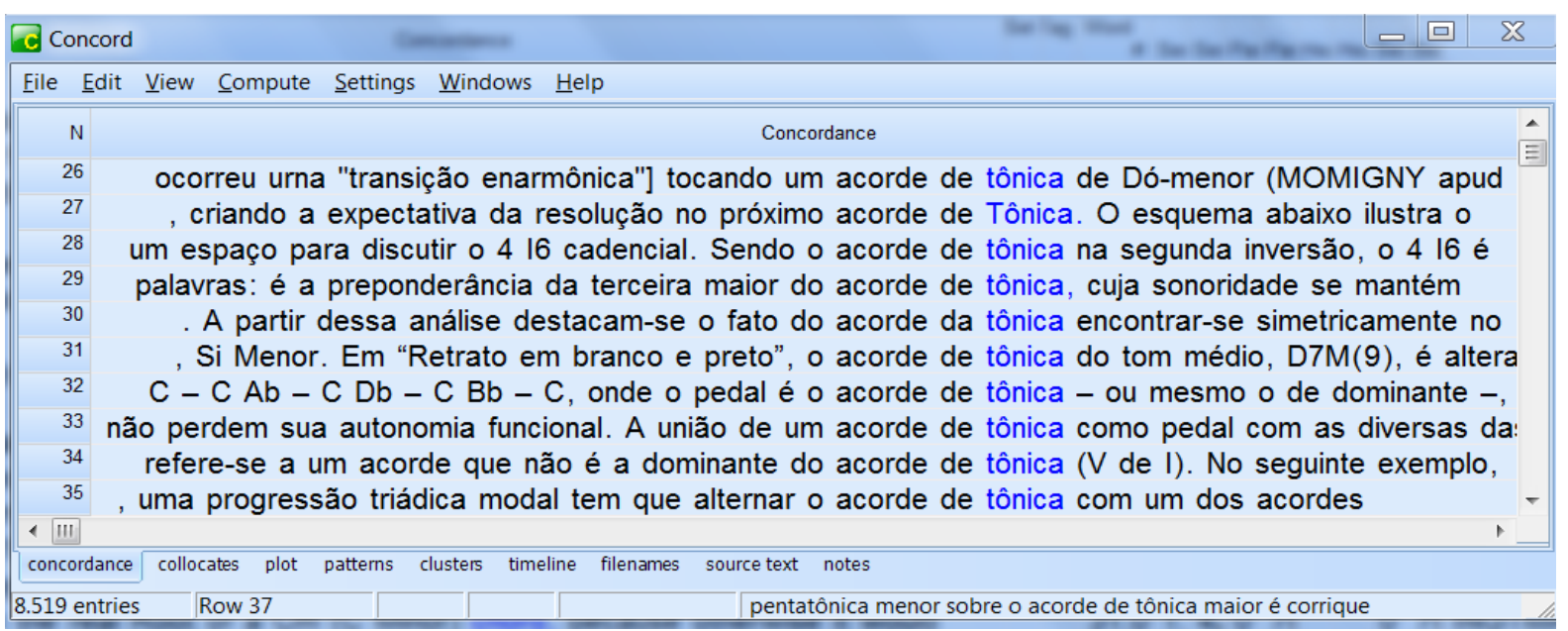

Figura 127 - Linhas de concordância (parciais) de "acorde de tônica"

Selecionamos do subcorpus acadêmico científico, alguns contextos em que a colocação é usada:

- A "cadência interrompida" pode ser considerada como um modo funcional de resolver, pois se procura detalhar como a "interrupção" ocorre por meio da comparação entre a função do acorde esperado com o acorde de "engano". Normalmente se espera o acorde de tônica (I grau) após a dominante. (PORTMTE01)

Em Inglês, encontramos a colocação correspondente "Tonic chord", com 147 ocorrências. A colocação foi encontrada no dicionário de termos musicais, com uma definição similar às já mencionadas anteriormente em Português:

Tonic chord - The chord that is used upon the tonic of a key or scale, the I chord. (DION MUSIC) 


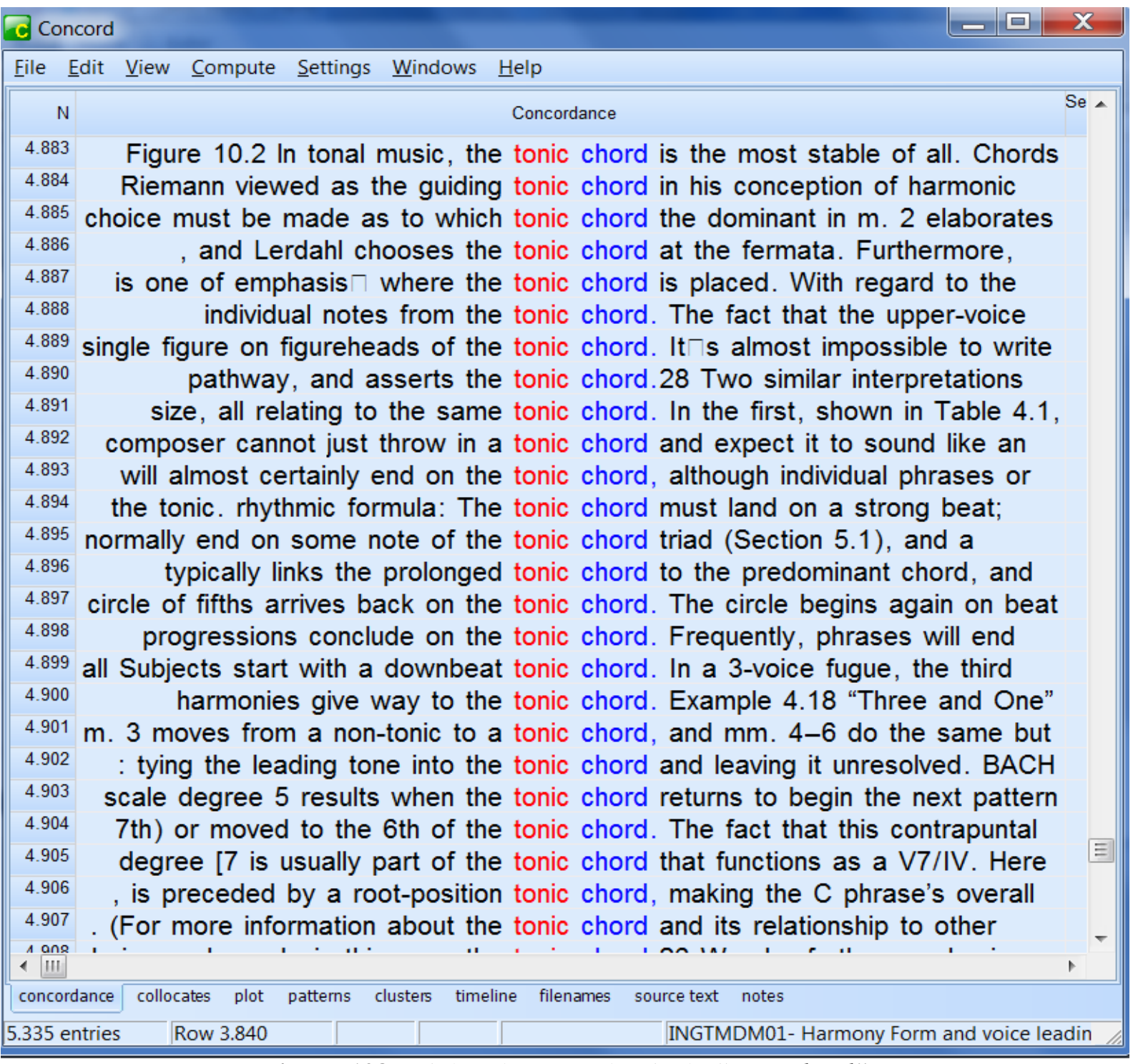

Figura 128 - Linhas de concordância de "tonic chord"

O contexto definitório encontrado no subcorpus de inglês também apresenta a mesma explicação sobre o acorde:

- A tonic chord is the prime or home chord. For example, the C Major chord is a tonic chord $(C, E, G)$. It is the first chord of the C Major scale. (INGTMLIV 06)

Selecionamos dois contextos de uso em que a colocação é utilizada:

- The unequivocal statement of the tonic chord is avoided until the end of the song. (INGTMART27) 
- The tonic chord in these cases should be thought of more as a complex made up of melodic strands with shared qualities of both modes. (INGTMDM02)

Observamos neste item, a ocorrências de variantes lexicais em Português (Acorde de tônica, acorde tônico e tônica). Utilizaremos remissivas no glossário.

\section{9) Acorde de dominante, Acorde dominante}

A colocação "acorde de dominante" apresenta uma alta frequência no corpus de estudo: 280 ocorrências. A forma variante da colocação, acorde dominante também apresenta uma frequência alta: 123 ocorrências. Observamos também que a forma reduzida "dominante" também é utilizada. Acordes de função dominante apresenta apenas 12 ocorrências no subcorpus de português.

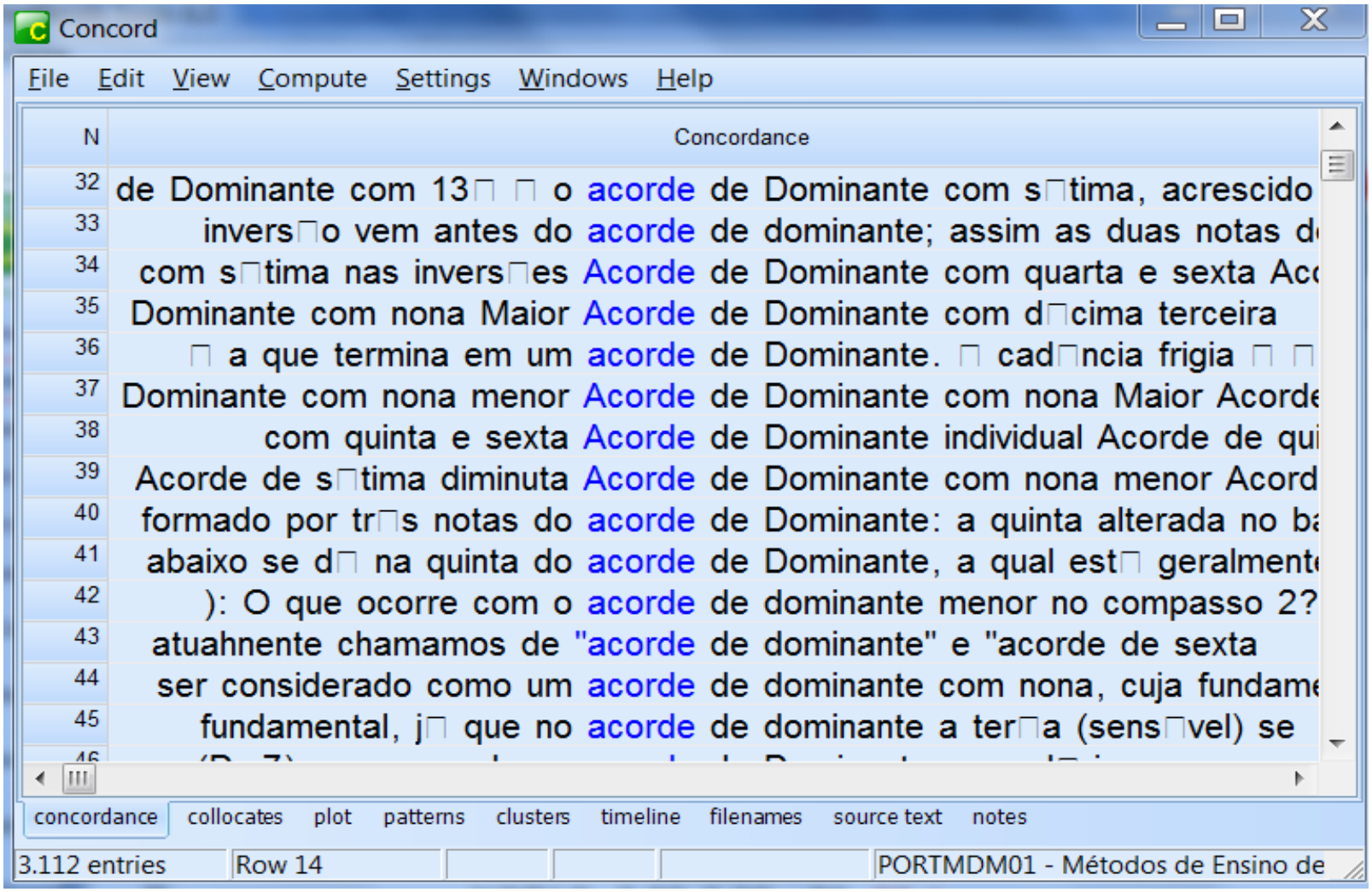

Figura 129 - Linhas de concordância de "acorde de dominante" 


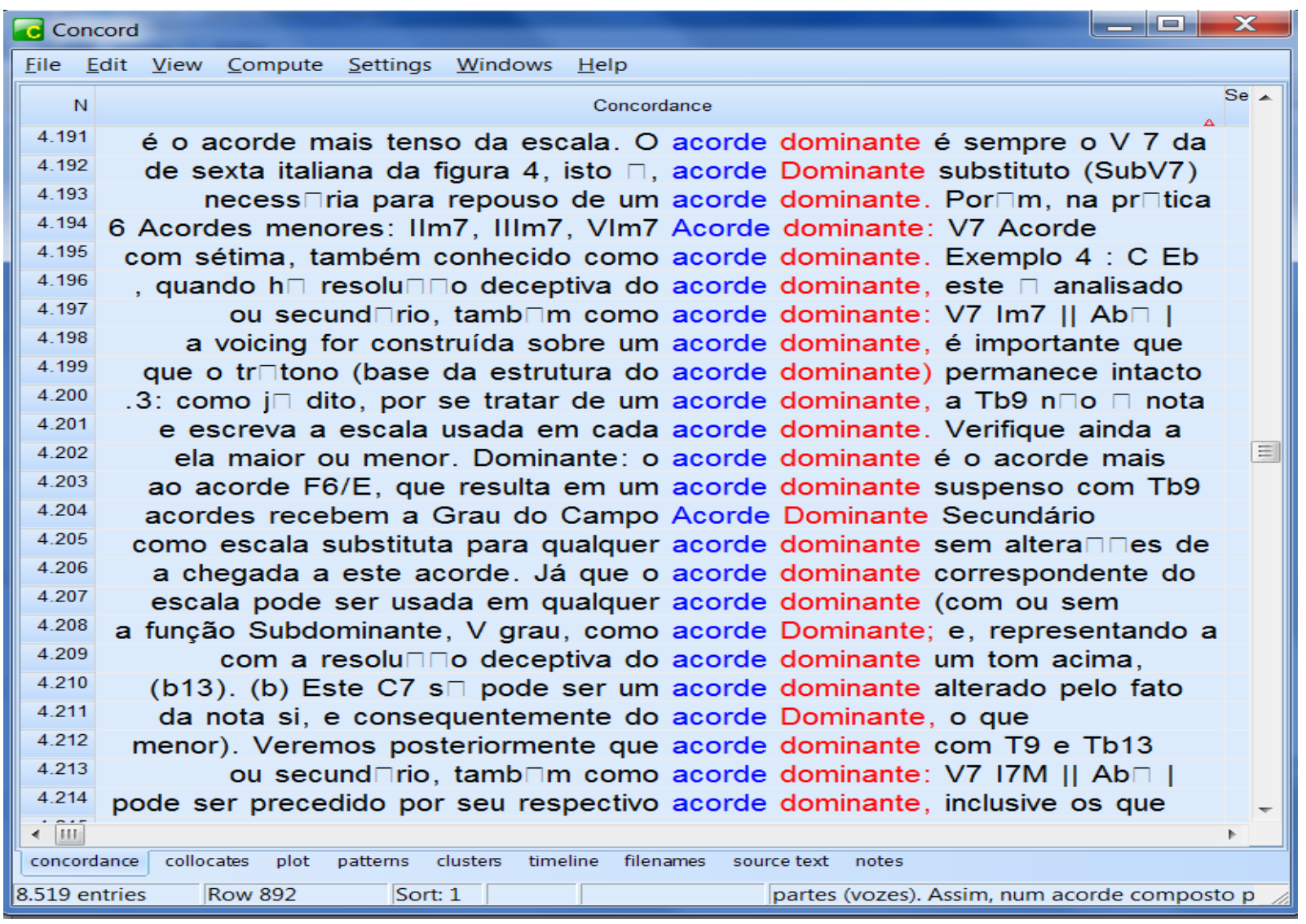

Figura 130 - Linhas de concordância parciais de "acorde dominante"

No dicionário DP - DOURADO, ela é encontrada na forma reduzida "dominante":

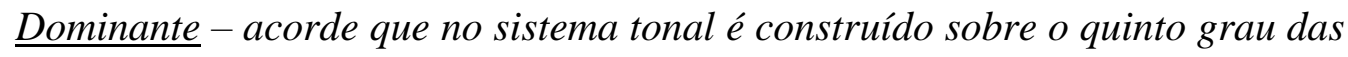
escalas maiores e menores. Constitui o momento de tensão que tende a se resolver no acorde de tônica ou principal (Ex.: Sol, dominante na tonalidade de Dó maior ou Menor).

No subcorpus instrucional, encontramos os seguintes contextos definitórios:

- Acorde de dominante: acorde formado pelo V grau no modo Maior e menor. (PORTMLIV02)

- Considerando-se um acorde como Tônica, ou ponto de partida, o acorde de Dominante encontra-se à distância de uma quinta justa acima. A 
característica do acorde de Dominante é o movimento que realiza para o de Tônica. Este movimento se dá através da nota chamada sensível, ou a terça do acorde de dominante, que se movimenta meio tom acima para a nota fundamental do acorde de Tônica. Todos os acordes podem ser usados com a fundamental no baixo e na primeira inversão, com a terça no baixo. (PORTMAPO06)

- $O$ acorde de dominante aparece de formas diferentes, sendo necessário seu reconhecimento. À sua base de terça maior e quinta justa, podem ser acrescentadas notas que passam a fazer parte de sua estrutura, como: sétima, nona, décima primeira e décima terceira. (PORTMAPO06)

Os excertos a seguir, retirados do subcorpus acadêmico-científico, apresentam contextos de uso das colocações:

- Voltando ao assunto das progressões harmônicas em tons menores, nossa atenção se centrará sobre o acorde de dominante como o fator harmônico mais poderoso. (PORTMTE02)

- Assim, serão considerados acordes dominantes, somente os acordes construídos sobre o $V$ grau das escalas menores - harmônica e melódica. (PORTMDM03)

- Com essa nomenclatura especialmente diferenciada, reafirmando novamente o emblema distinguir para unir, Rameau valoriza o fato de que nos diferentes momentos das progressões por quinta descendentes as dominantes (i.e., as tétrades) não são mesmo iguais: em termos ramistas, os ciclos que se observam no interior de uma tonalidade se compõem de dominantes (acordes maiores e menores com sétimas maiores e menores) e da dominante tonique (o $V 7$ grau propriamente diferenciado, acorde maior com sétima menor e em clara preparação para um acorde com função de I grau).(PORTMTE02)

Na busca por correspondentes em Inglês, encontramos no subcorpus: Dominant chord (58 ocorrências). Como variante, encontramos a forma reduzida Dominant.

As duas formas foram encontradas nos dicionários de termos musicais abaixo: 
- Dominant chord - the chord or triad that is based on the fifth tone of the scale. In the key of $C$, the dominant triad would consist of $G, B$ and $D$. (A dominant seventh chord is a dominant chord with a seventh added; in the key of $C$, the dominant seventh chord would consist of $G, B, D$ and $F)$. (DI - ON MUSIC)

- Dominant - The fifth scale degree of the major or minor scale. The triad and the seventh chord built on this degree as root are the dominant triad and dominant seventh, respectively. As part of a cadence, both of these chords are most often resolved to the tonic triad because of the presence in both of the leading tone and the supertonic. The relationship of dominant and tonic expressed in such a cadence, which is a function of both counterpoint and harmony, is the most powerful in tonal music and is fundamental to the structure to tonal melodies and of both small - and large-scale forms. When serving as the root of a chord, the fifth scale degree is identified in harmonic analysis by the numeral $V$ or the letter $D$ (for dominant). Secondary dominants are the dominants of degrees other than the tonic and are designated as follows: V of II (or simply V/II; e.g in the key of C, the fifth above D, namely A), V of III (V/III) etc. (DI - HARVARD)

No subcorpus instrucional encontramos um contexto definitório para a colocação:

- The dominant chord always occurs on degree five of the scale. Therefore, in the scale of $C$ major, the dominant chord is a $G$ major triad. (INGTMLIV04) 


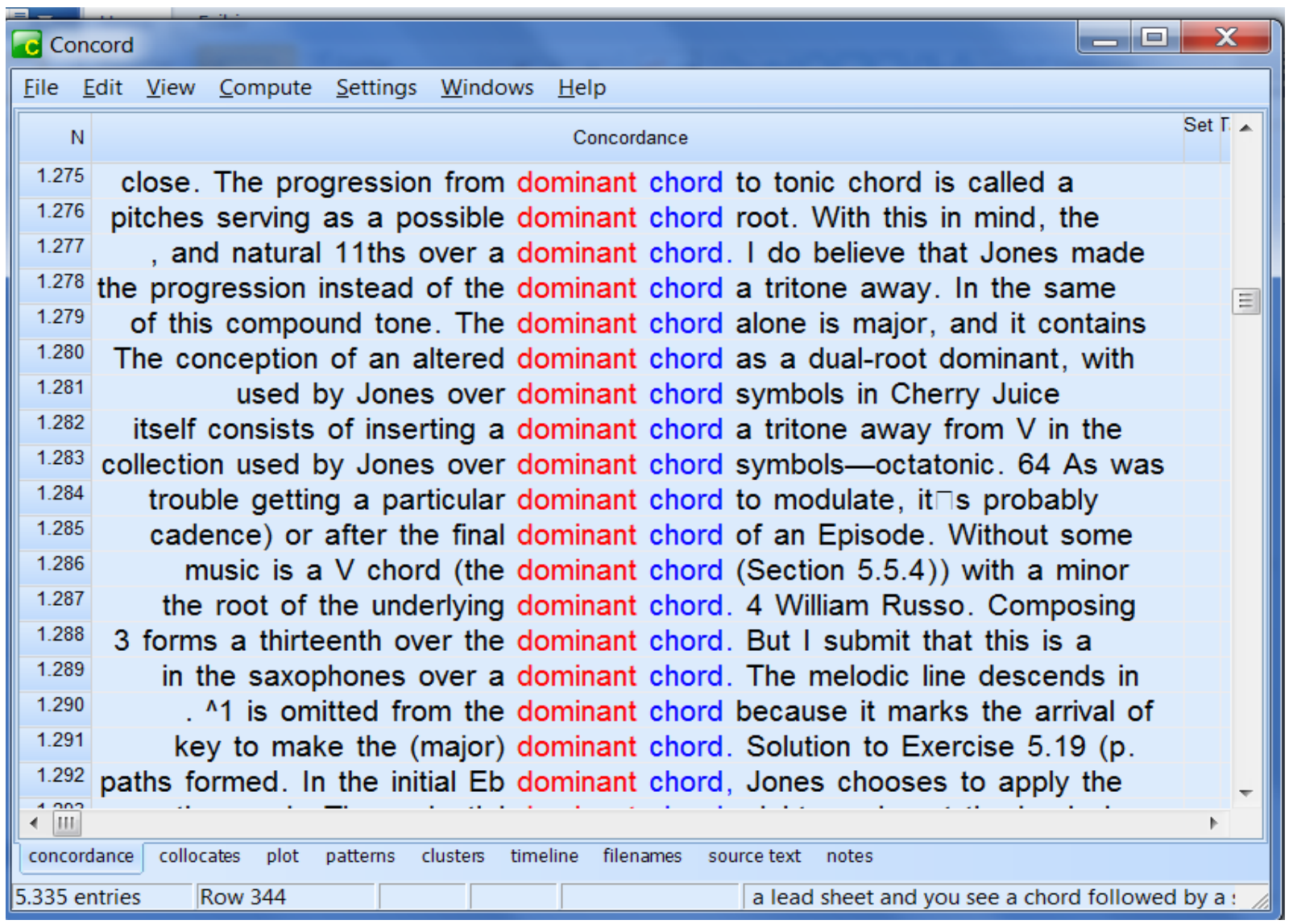

Figura 131 - Linhas de concordância (parciais) de "dominant chord"

Retiramos do subcorpus acadêmico-científico, alguns trechos que apresentam contextos de uso das colocações:

- If, for example, Jones had followed Eb diminished whole tone with A Lydian dominant, he would have recycled the same pitch collection and therefore created a potentially static contrapuntal situation in which both dominant chords are essentially the same save for the bass note.(INGTMDM04)

- In this progression it is clear that the IV chord fulfills the function of the absent dominant chord, occurring after the pre-dominant IIsharp and leading back to I. (INGTMART10)

Observamos neste item, a ocorrências de variantes lexicais em Português (Acorde de dominante, acorde dominante e dominante) e Inglês (Dominant chord e Dominant). Utilizaremos remissivas no glossário. 
A partir da observação da lista de clusters, verificamos que outras colocações estendidas são derivadas de "acorde de dominante": acorde de dominante com sétima (acorde de sétima da dominante), acorde de dominante com nona (acorde de nona da dominante), acorde de dominante substituta, acorde de dominante secundária. Tais colocações serão detalhadas em outros itens.

\section{0) Acorde de subdominante}

A colocação "acorde de subdominante" tem 43 ocorrências no subcorpus de Português. Foi uma das colocações que aparece em dicionário de termos musicais pesquisado no capítulo 2, com a forma reduzida:

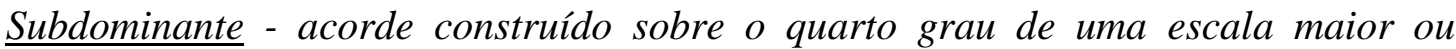
menor, como Fá Maior, na tonalidade de Dó maior. (DP-DOURADO)

No subcorpus instrucional, encontramos os seguintes contextos definitórios:

- $O$ acorde de subdominante acha-se à distancia de uma quinta justa abaixo da Tônica. (PORTMLIV06)

- A função subdominante tem como característica o sentido meio suspensivo e possui uma sensação de afastamento da tônica. O acorde principal desta função é o IV grau (...) (PORTMLIV03).

Extraímos do subcorpus acadêmico-científico, um contexto de uso da colocação, que confirma o significado exposto anteriormente:

- A partir dessa análise destacam-se o fato do acorde da tônica encontrar-se simetricamente no centro entre os acordes do quarto e do quinto grau e a presença da sensível tonal (sétimo grau) no acorde da dominante e da sensível modal (quarto grau) no acorde da subdominante. (PORTDMART14) 


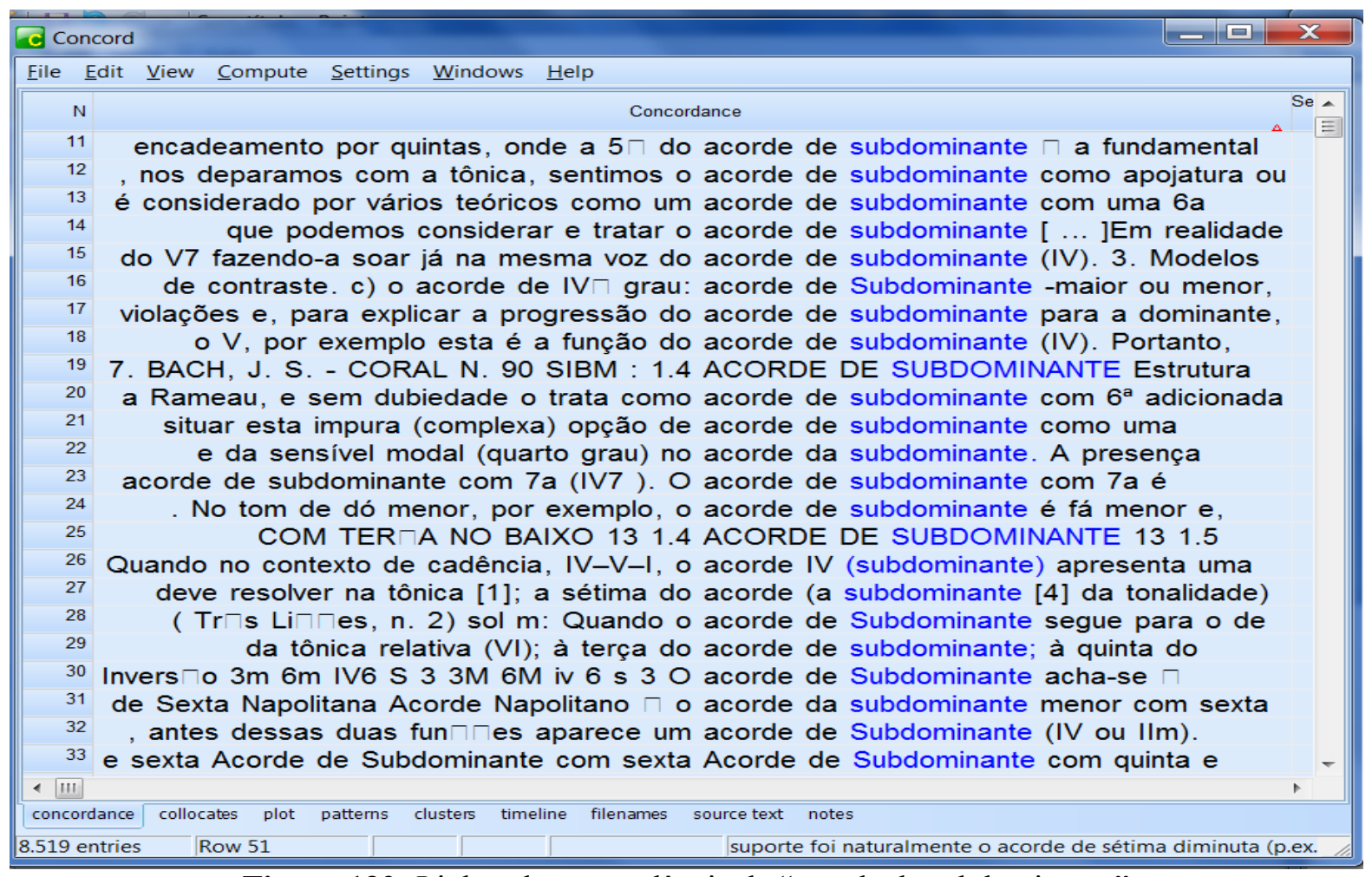

Figura 132- Linhas de concordância de "acorde de subdominante"

Também encontramos a forma reduzida em um texto que faz análise de Harmonia da music popular:

O II como subdominante, C\#m7(b5) deve ser antecedido pelo acorde do tipo X7M um semitom abaixo, C7M (III grau do tom inicial). (PORTMTE01)

Como correspondente de acorde de subdominante, encontramos a colocação Subdominant chord, com 10 ocorrências. Assim como em Português, a colocação também aparece em dicionário de termos musicais na Língua Inglesa:

Subdominant chord: a chord which uses as its root the subdominant note of a key.; the IV chord, the chord based upon the fourth tone of the scale. (DI-ON MUSIC)

Localizamos no subcorpus instrucional, um contexto definitório similar:

The subdominant chord is always built upon the fourth degree of either major or minor mode. (INGTMLIV04) 
O excerto a seguir, extraído do subcorpus acadêmico-científico, mostra um contexto de uso da colocação:

Another use of 2 is as the root of a post-cadential II as a replacement for the subdominant chord (...) (INGTMDM01)

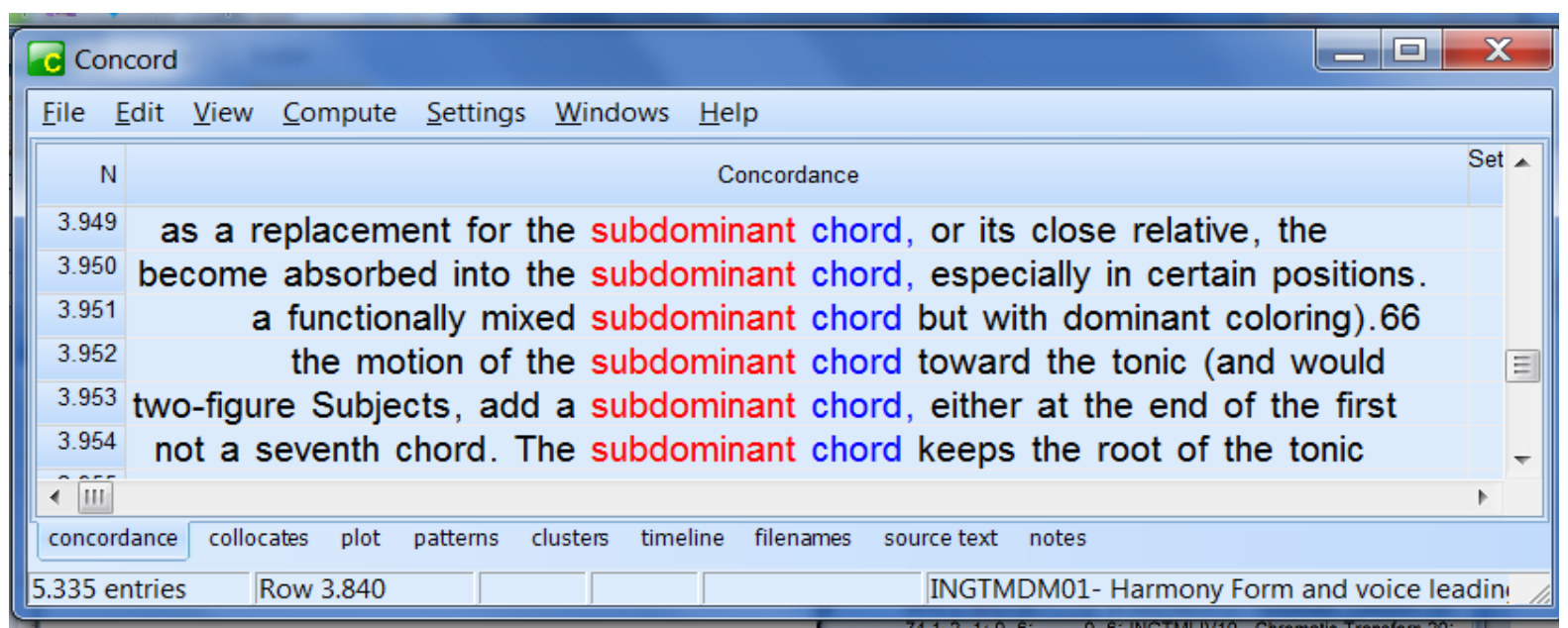

Figura 133 - Linhas de concordância de "subdominant chord"

Observamos neste item, a ocorrências de variantes lexicais em Português (Acorde de subdominante e subdominante). Utilizaremos remissivas no glossário.

\section{1) Acorde de sétima da dominante, Acorde de dominante com sétima}

A colocação "acorde de sétima da dominante" (13 ocorrências) e acorde de dominante com sétima (19 ocorrências) são variantes do mesmo conceito. No Dicionário DPDOURADO, encontramos a variante reduzida "sétima da dominante":

Acorde que consiste em uma tríade construída sobre o quinto grau de uma escala, acrescida de uma sétima contada a partir de sua fundamental (sol-si-ré-fá, na tonalodade de dó maior).

Localizamos no subcorpus de português os seguintes contextos definitórios: 
- De todos os acordes dissonantes naturais é o acorde de sétima da dominante o que se usa com mais frequência. Tem este acorde duas notas atrativas: 1) sensível (3 ${ }^{a}$ do acorde) que resolve subindo tônica. 2) a sétima do acorde que resolve descendo por grau conjunto. Há neste acorde três notas que não devem ser suprimidas: a fundamental, a terça (sensível) e a sétima. Assim sendo, a nota que se suprime neste acorde é a quinta. (PORTMLIV10)

- É o acorde maior com sétima menor. É encontrado no grau $V$ da escala maior e no grau $V$ da escala menor - forma harmônica e melódica ascendente, mas pode aparecer também em outro grau que não seja a dominante (por exemplo no grau VII da escala menor, forma primitiva). (PORTMLIV02)

- "Partindo de um acorde maior, é possivel acrescentar-se a ele uma sétima menor, o que o transformará em um acorde de dominante com sétima. (PORTMLIV06)

- Os acordes de sétima da dominante se caracterizam pelo trítono entre a terça maior e a sétima menor, dando origem ao som preparatório ou de tensão do acorde de sétima da dominante. (PORTMLIV07)

- Acorde de dominante com sétima: acorde maior com sétima menor (PORTMAPO06)

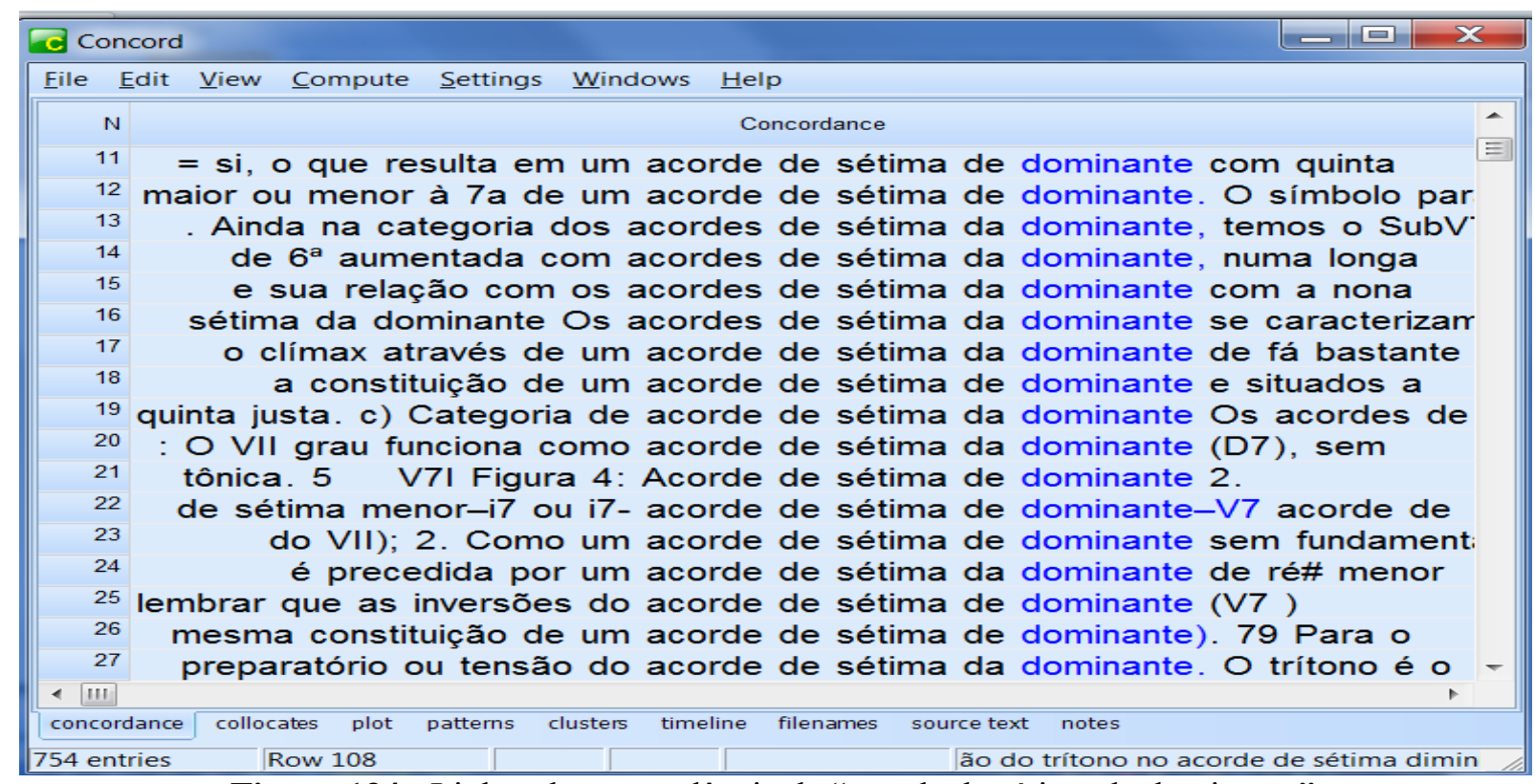

Figura 134 - Linhas de concordância de "acorde de sétima da dominante" 
Extraímos do subcorpus acadêmico-científico alguns contextos de uso em que as colocações ocorrem:

- Para Schoenberg: "O fato de que o som do acorde de 6/5 (4/3, 2 ou 6) aumentada ser idêntico ao som de um acorde de sétima de dominante pode, agora, ser facilmente explorado por tratar (introduzindo e continuando) este como se fosse o outro [V7]"(47). (PORTMART18)

- $O$ acorde de dominante com sétima contém a nota característica como um componente do trítono diatônico. (PORTMART01)

- A dinâmica que até agora era em torno do piano e piano dolce, atinge o forte no compasso 18, que é sustentado através do clímax num acorde de sétima da dominante em si menor. (PORTMART25)

$\mathrm{Na}$ busca por correspondente em Inglês, encontramos a colocação Dominant seventh chord, com a frequência de 148 ocorrências no subcorpus de inglês.

A colocação foi localizada no dicionário DI-HARVARD, no texto relacionado à entrada "Seventh chord" (acorde de sétima):

"When formed on fifth scale degree or dominant, the chord is termed a dominant seventh chord. Because of presence in this chord of both the fourth and the seventh scale degrees, any given dominant seventh chord can exist in only on key. It therefore strongly implies a single tonic and is often resolved by the tonic triad. The progression from dominant seventh to tonic is termed a dominant-seventh cadence and is one of the most familiar and powerful progressions in tonal music.

Analisando as linhas de concordâncias, encontramos contextos definitórios similares ao encontrado no dicionário e próximo aos descritos em Português:

- The dominant seventh chord is a diatonic seventh chord built on the fifth scale degree of the major, harmonic minor, and ascending melodic minor scales. The 
major triad (root, third, fifth) and minor seventh (from root to seventh) create a distinctive sound that is universal linked to the dominant function. (INGTMLIV02)

- Unlike the dominant triad, the dominant seventh chord contains a dissonance - the seventh factor. (INGTMLIV02)

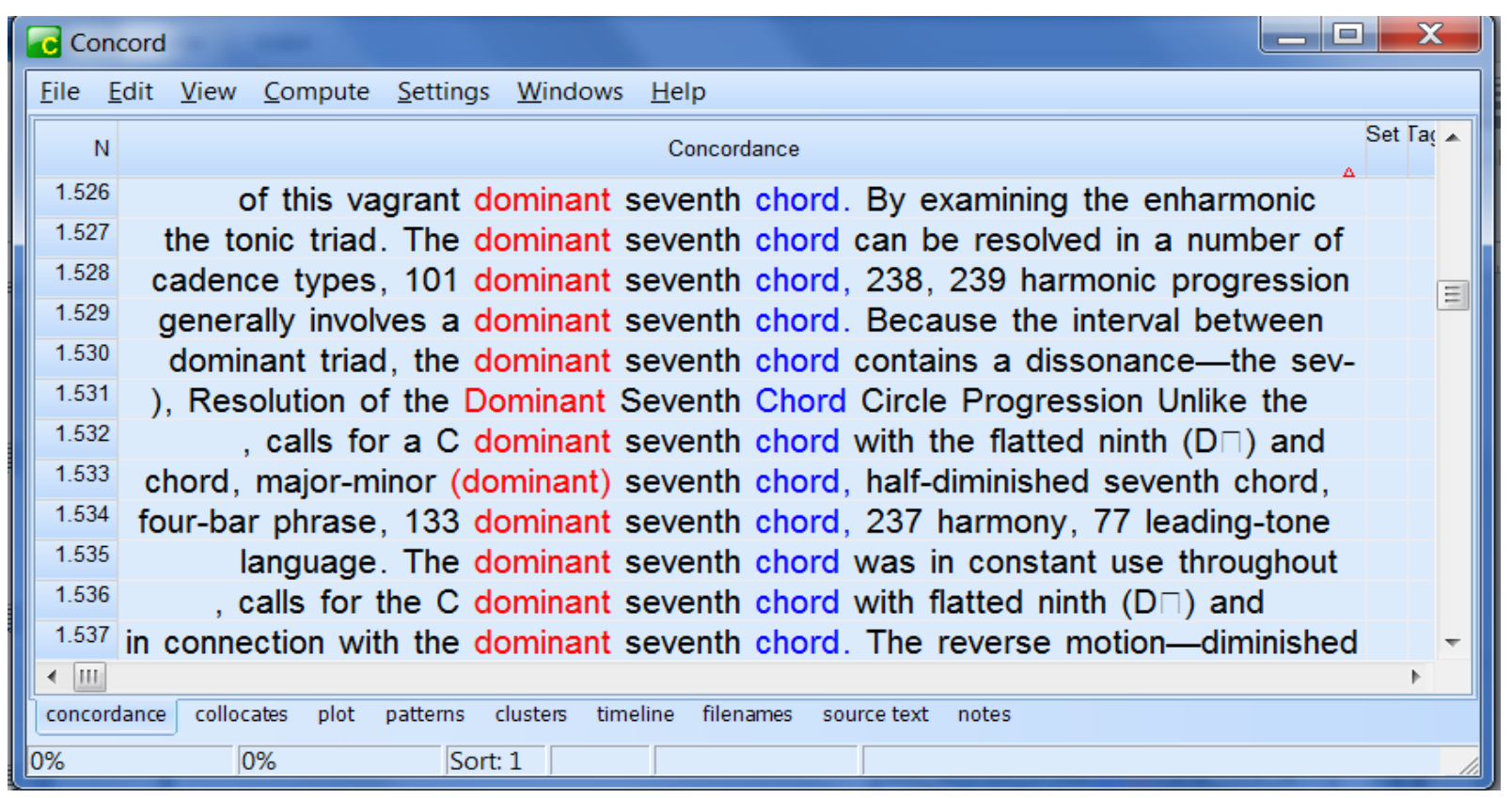

Figura 135 - Linhas de concordância de "dominant seventh chord"

No dicionário DI-OXFORD, a colocação dominant seventh chord apresenta a seguinte definição:

The dominant chord with the note a 7 th from its root added (thus in $C$ major the chord is $G-B-D-F)$

O excerto a seguir, extraído do subcorpus acadêmico-científico, um contexto de uso da colocação:

As can be seen from the set-class forms of the example, the three tetrachords of $\mathrm{mm}$. 106-14 are related by parsimonious voice leading; this is not entirely surprising, since any dominant-seventh chord is only one semitone removed from either a French augmented-sixth chord or a fully-diminished seventh chord. (INGTMDM01) 


\section{2) Acorde de sétima da sensível}

A colocação "acorde de sétima da sensível" apresenta 4 ocorrências no corpus de estudo. Encontramos alguns contextos definitórios para a colocação:

- Acorde de sétima da sensível: É o acorde de quinta diminuta e sétima menor. É encontrado frequentemente no grau VII da escala maior, mas pode aparecer também em outros graus. (PORTMLIV02)

- Kostka \& Payne já apresentam mais comentários sobre a sétima da sensível. Eles definem este acorde como sendo um meio diminuto (quinta diminuta com sétima menor), tendo função de dominante. Sua resolução normal é diretamente na tônica, podendo passar pelo V grau. (PORTMDM01)

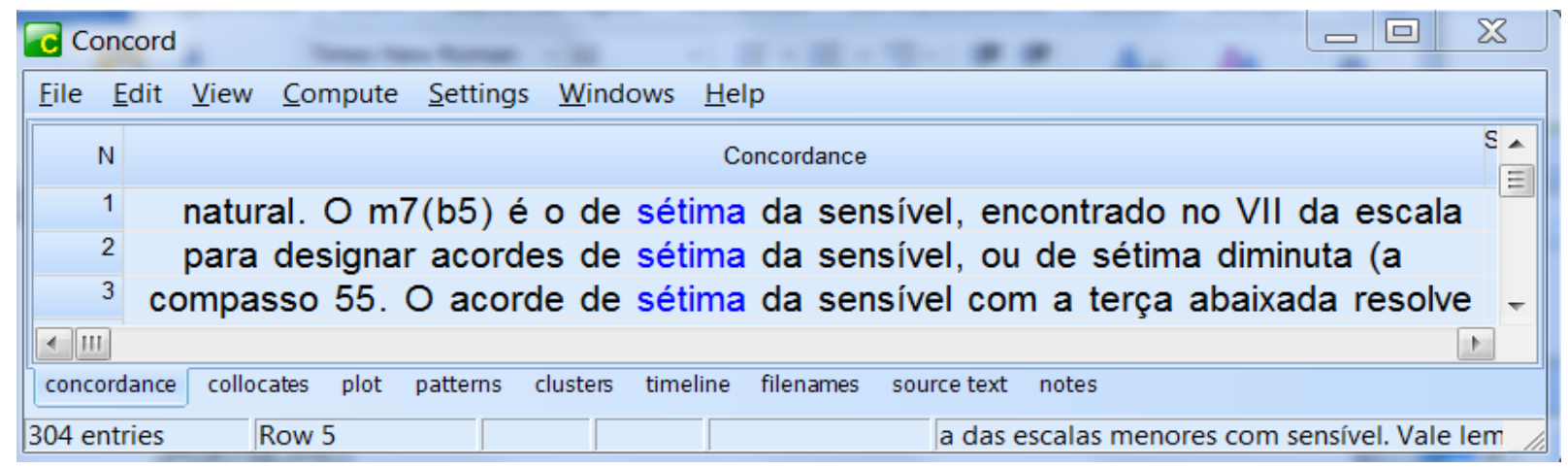

Figura 136 - Linhas de concordância de "acorde de sétima da sensível”

O contexto de uso a seguir (extraído de um texto que faz análise harmônica da música popular) explica sobre o acorde de sétima construído sobre o VII grau das escalas menor harmônica e maior (denominado sensível):

A sensível funciona como um grau de preparação da tônica e acabou por engendrar a função de dominante. O VII grau da escala menor harmônica, assim como o VII da maior, não apenas é o acorde construído sobre a nota da sensível, como é um acorde muito semelhante à dominante construída sobre o V grau. Praticamente todo livro de Harmonia apresenta a possibilidade de interpretar a tétrade diminuta como uma dominante com nona menor e a sensível se localiza a um semitom abaixo da tônica.(PORTMTE01) 
No próximo contexto de uso, a colocação é utilizada em um texto em que a análise harmônica é baseada na Harmonia funcional:

(...) no contexto da harmonia funcional, Koellreutter (1978: 21-23) usa a letra "D" (indicativa da função harmônica de dominante) cortada por uma barra diagonal e com um "7" ao lado para designar tríades diminutas (construídas sobre a sensível da escala maior ou menor harmônica) e a mesma letra " $D$ " cortada por uma barra diagonal e com um "9" ao lado para designar acordes de sétima da sensível, ou de sétima diminuta (a interpretação alegada é que trata-se, na verdade, de um acorde de nona da dominante sem a fundamental, daí a sétima do diminuto ser interpretada como nona da dominante). (PORTMART21)

Foi a colocação correspondente "Leading-tone seventh chord"(48 ocorrências) que motivou a busca pela colocação em Português. O contexto definitório extraído do subcorpus instrucional apresenta com mais detalhes sobre a colocação:

Closely related to the dominant seventh chord are the leading-tone seventh chords. Like their triad counterpart, these leading-tone seventh chords often function as dominant substitutes but can also appear as harmonic embellishments in linear passages. Diatonic leading-tone seventh chords are built on the seventh scale degree of the major, harmonic minor, and ascending melodic minor scales. In major keys, the quality of the chord is diminished-minor $(\mathrm{dm})$. Diminished-minor is also known as half-diminished. In minor keys, the quality is diminished-diminished (dd), but the name is usually abbreviated to diminished or fully diminished. (INGTMLIV02)

A partir da explicação em Inglês, verificamos que o "acorde de sétima da sensível" pode ser um acorde de sétima diminuta ou acorde meio-diminuto, dependendo de qual escala diatônica ele é derivado. O que de comum entre as explicações é o fato de o acorde ter função de dominante. 


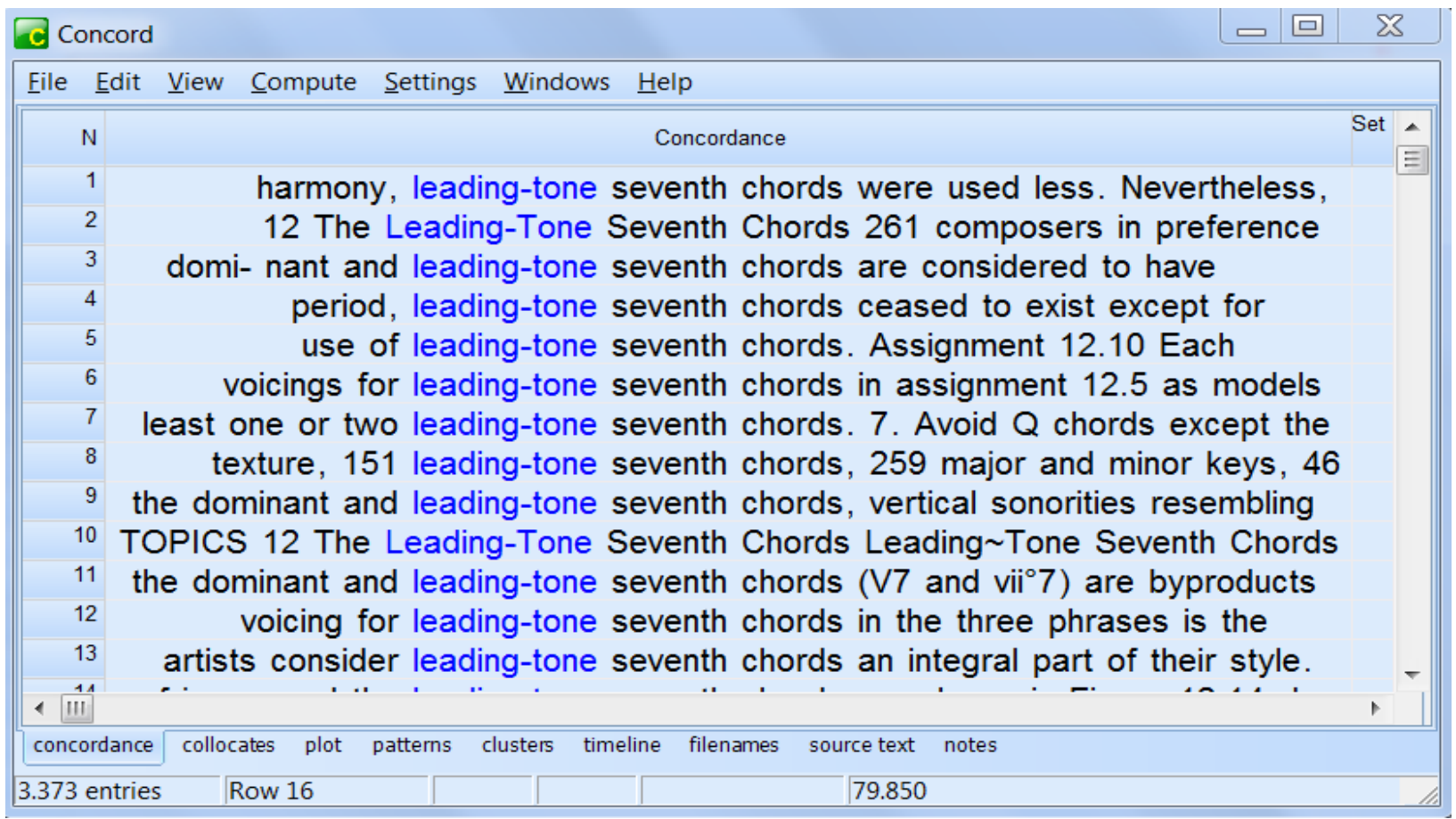

Figura 137 - Linhas de concordância de "leading-tone seventh chord"

43) Acorde de nona da dominante, acorde de dominante com nona

A colocação "acorde de nona da dominante" (6 ocorrências) e acorde de dominante com nona (5 ocorrências) são colocações variantes do mesmo conceito, conforme excertos abaixo, retirados do subcorpus instrucional:

- $O$ acorde de nona de dominante é encontrado quando se acrescenta uma terça maior ou menor à sétima de um acorde de sétima de dominante. O símbolo para este acorde é V9. (PORTMAPO01)

- Acorde de nona da dominante maior: formado sobre o $V$ grau das escalas maiores. Para formar esse acorde acrescenta-se uma terça maior ao acorde de sétima da dominante. Acorde de nona da dominante menor: formado sobre o $\mathrm{V}$ grau das escalas menores. Para formá-lo acrescenta-se uma terça menor ao acorde de sétima da dominante. (PORTMLIV02) 
- A base do acorde de Dominante com nona menor é o acorde de Dominante com sétima, ao qual se acrescenta mais uma terça menor. É a nona menor em relação à fundamental. Como é formado por cinco notas, na escrita a quatro vozes omitese a quinta. (PORTMAPO06)

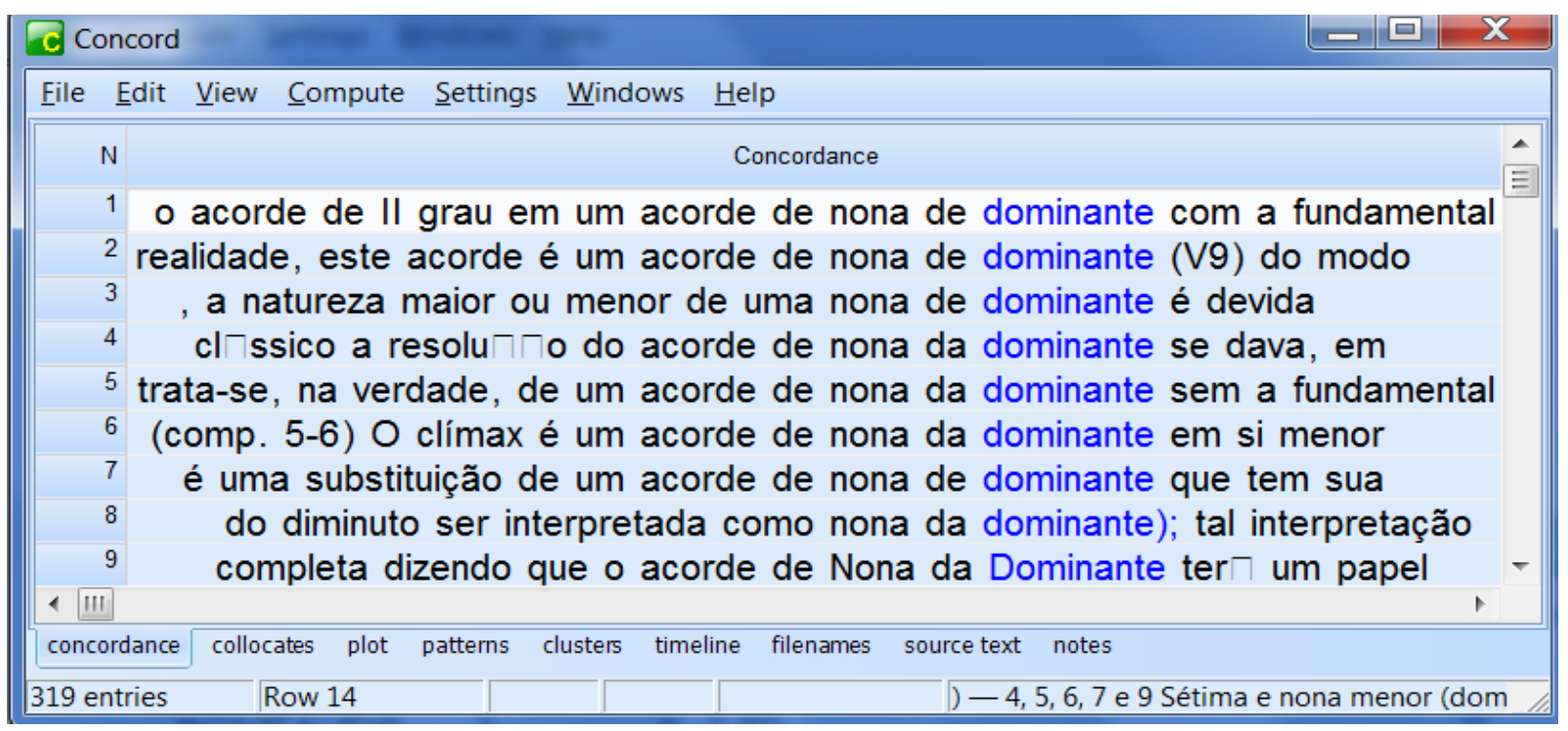

Figura 138 - Linhas de concordância parciais de "acorde de nona da dominante"

No dicionário DP- Dourado, a colocação é encontrada na forma reduzida " Nona da Dominante", e apresenta a seguinte definição: "um acorde de sétima da dominante, acrescido de uma nona (na tonalidade de dó maior, por exemplo: sol-si-ré-fá-lá”.

No subcorpus acadêmico-científico, verificamos o seguinte contexto de uso:

- Conforme Piston, um intervalo de décima terceira sobre um acorde dominante pode ou não ser tratado melodicamente, isto é, como dissonância a ser resolvida (apojatura ou retardo), podendo muitas vezes ser absorvido como nota integrante dessa harmonia. O mesmo ocorreria com a nona, sendo que já no período clássico a resolução do acorde de nona da dominante se dava, em alguns casos, através do arpejamento do fator dissonante, princípio aplicado a nenhum outro acorde na prática comum (também chamado dissolução por alguns teóricos). (PORTMART06) 
- Na seção d, transforma-se o acorde de II grau em um acorde de nona de dominante com a fundamental omitida. (PORTMART18)

Na busca por correspondente, encontramos a colocação Dominant ninth chord (11 ocorrências), cujo contexto definitório diz:

- One of the most commonly used ninth chords is the dominant ninth chord, which is built on the fifth degree of the scale. Generally, the dominant ninth is used to enhance the resolution of dominant seventh chord to the tonic. (INGTMLIV02)

Os excertos extraídos do subcorpus acadêmico-científico abaixo mostram contextos de uso da colocação:

- As it is in a dominant-ninth chord, where it functions as an upper neighbor to the dominant. (INGTMDM01)

- The fully-diminished-seventh chord B-D-F-Ab has four pitches in common with the dominant ninth chord $G-B-D-F-A b$.(INGTMTE02)

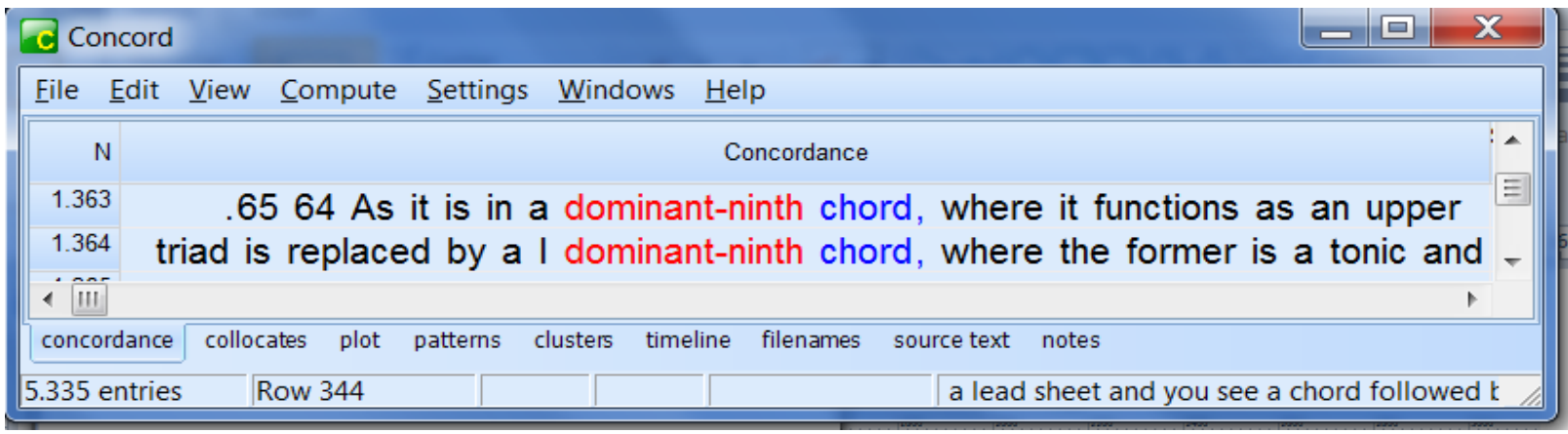

Figura 139 - Linhas de concordância de "dominant-ninth chord"

No glossário, apresentaremos remissiva para as variantes.

\section{4) Acordes secundários}

A colocação "acordes secundários" apresenta a frequência de 28 ocorrências no subcorpus de Português. 
A partir da análise das linhas de concordâncias, verificamos que os acordes secundários substituem os acordes principais (I-tônica, IV-subdominante e V-dominante), conforme contextos definitórios a seguir:

- Acorde secundário: entende-se por acorde secundário aquele que contém a nota característica do acorde na sua sétima, nona, ou décima primeira. (PORTMAPO06)

- Acordes secundários são os que se relacionam por terças menores ou maiores aos acordes principais. A estrutura dos acordes secundários é sempre maior ou menor. Quanto à função, os acordes secundários ampliam a função dos principais e muitas vezes o substituem. (PORTMAPO06)

- Estes acordes aparecem muitas vezes substituindo os principais. O encadeamento do acorde de Dominante para um destes secundários é bastante usado e sempre apresenta surpresa. Os acordes secundários formam novas cadências, como a que é conhecida como cadência interrompida e também possibilitam variar a cadência perfeita. (PORTMAPO06)

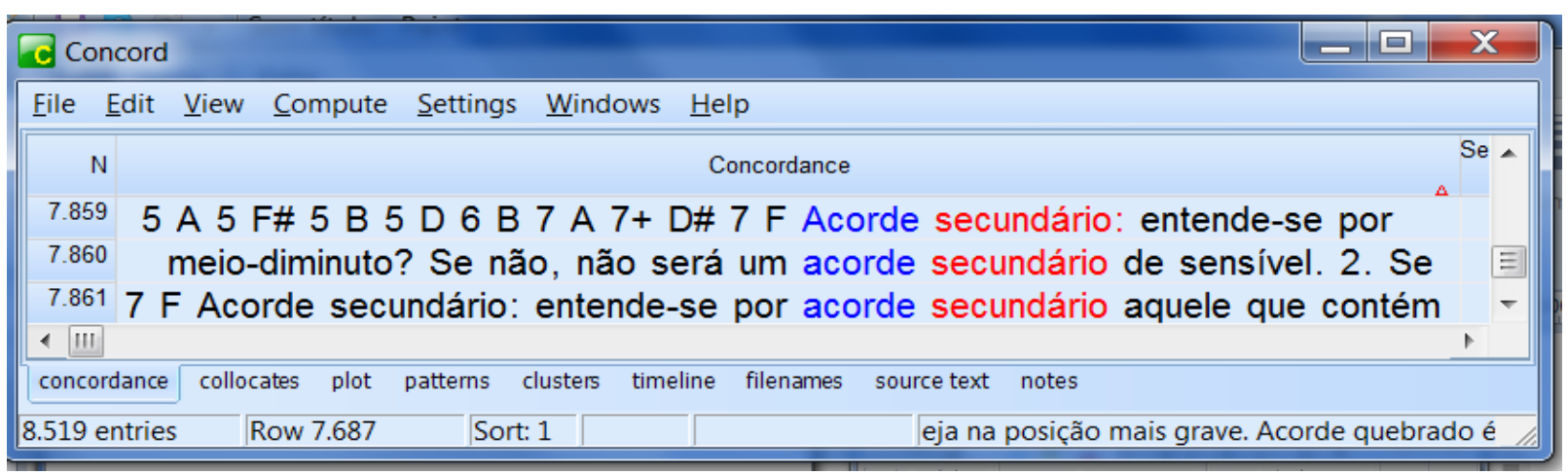

Figura 140 - Linhas de concordância parciais de "acorde secundário"

Em Inglês, encontramos como correspondente, a colocação "secondary chord" ( 13 ocorrências). 


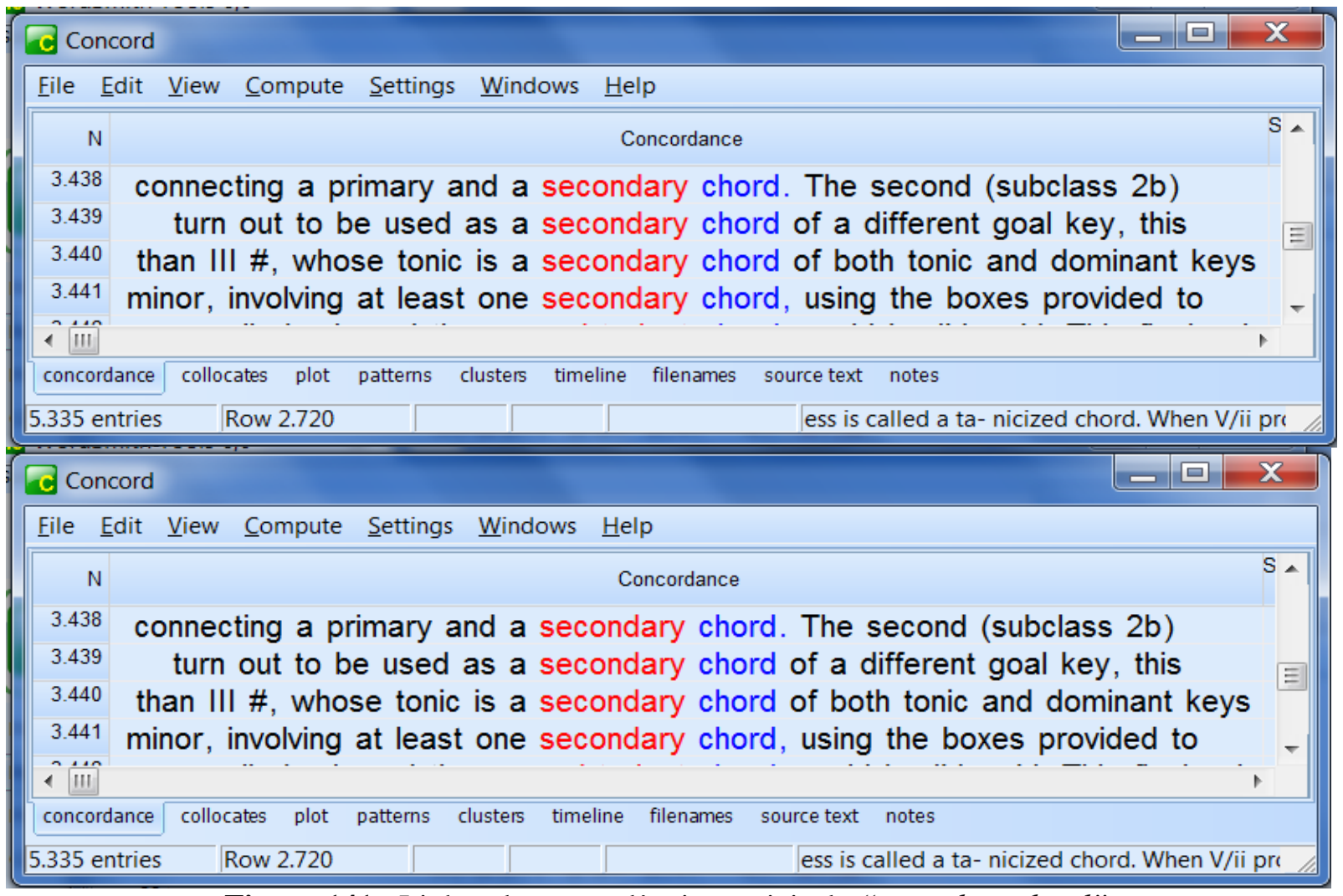

Figura 141 - Linhas de concordância parciais de "secondary chord"

- By saying this Schenker most likely means that III " defines a harmonic area which is more at variance with its harmonic context, and thus freer of it than III \#, whose tonic is a secondary chord of both tonic and dominant keys. (INGTMLIV10)

- In contrast, Smetana's use of iii6 prolongs vi emphasizing the "secondary chords" of the key. (INGTMDM01)

Pela análise, verificamos que a colocação "acordes secundários" e "secondary chords" são denominações genéricas para a categoria de acordes secundários. Analisando linhas de concordâncias, encontramos "acorde de dominante secundária", que será discutida no item 45. Utilizaremos remissiva entre essas colocações.

\section{5) Acordes relativos e anti-relativos}

As colocações acordes relativos (25 ocorrências) e acordes anti-relativos (3) foram agrupadas neste item pela relação conceitual que compartilham, entretanto não são termos 
variantes. Tais colocações são frequentes em textos que abordam Harmonia funcional. Os trechos extraídos do mesmo texto do subcorpus instrucional detalham as características de ambas:

- Os acordes relativos de uma função maior são menores e sua fundamental encontrase terça menor abaixo da fundamental do acorde da função que representam; já os acordes relativos de uma função menor são maiores e sua fundamental encontra-se terça menor acima da fundamental do acorde da função que representam. (PORTMAPO03)

- os acordes anti-relativos de uma função maior são menores e sua fundamental encontra-se terça maior acima da fundamental da função que representam; já os acordes anti-relativos de uma função menor são maiores e sua fundamental encontrase terça maior abaixo da fundamental da função que representam. (PORTMAPO03)

Para tornar claro o que foi exposto nestes trechos, extraímos do corpus um contexto de uso:

- Dó Maior e Lá Menor são tonalidades relativas. C e Am são acordes relativos $e$ compartilham duas notas comuns: C contém dó - mi - sol e Am contém lá-dómi. (PORTMTE02)

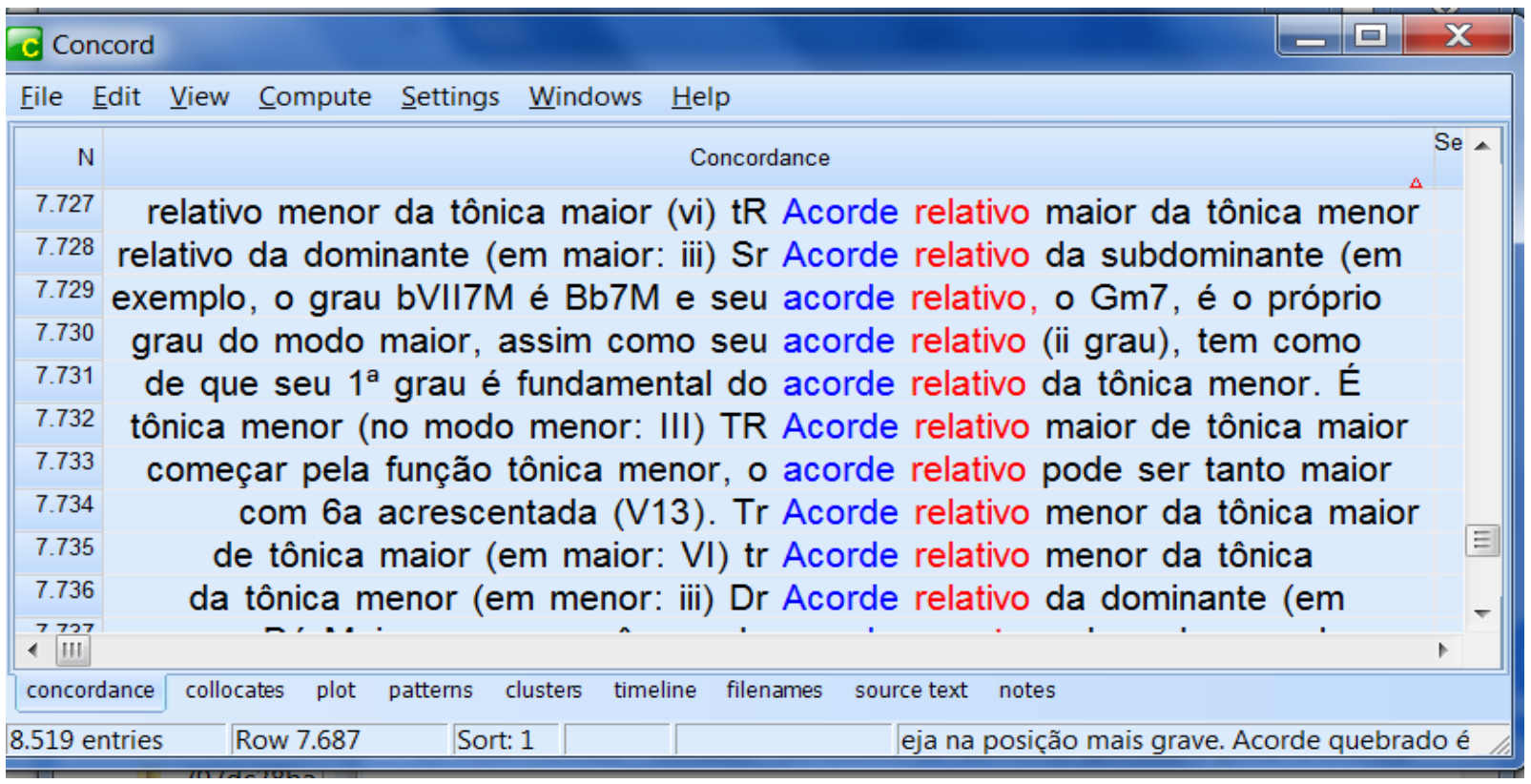

Figura 142 - Linhas de concordância parciais de "acorde relativo" 
O excerto retirado do subcorpus acadêmico-científico traz um exemplo de uso da colocação:

- Em conformidade com as cifras correntes no jargão funcional brasileiro (como se vê mais adiante), os termos "Terzwechsel" e "Leittonwechsel" referem-se aos movimentos que conhecemos como "progressão entre acordes relativos e entre anti-relativos" (i.e., os vizinhos de terça de modalidade oposta ou pertencentes ao mesmo diatonismo). (PORTMTE02)

$\mathrm{Na}$ busca por correspondentes, encontramos a colocação "relative chords", cuja frequência no subcorpus de inglês é de 18 ocorrências. Encontramos os seguintes contextos definitórios, que descrevem com mais detalhes a colocação:

- For example, a functional C major triad would have as its relative chord a triad containing the notes $C$ and $E$, with $A$ substituting for $G$. The resulting $A$ minor triad is the tonic of the relative minor - thus Parallelklang, or "relative chord."(INGTMLIV10)

- The relative chord is a triad which contains the root and third of its functional archetype, but whose other tone is a substitution of the sixth for the fifth. (INGTMLIV10)

- In minor, Riemann explains, the relative chord of the dominant includes the note a sixth below the prime, or fifth of the chord; this note is also the seventh of the dominant in traditional terms. For example, $D$ in A minor is [E G B]; adding the under-sixth yields [DE $G B], D$ as well being the seventh of $E$; suppressing the under-fifth yields [D G B], or a "seeming" G major chord. (INGTMLIV10) 


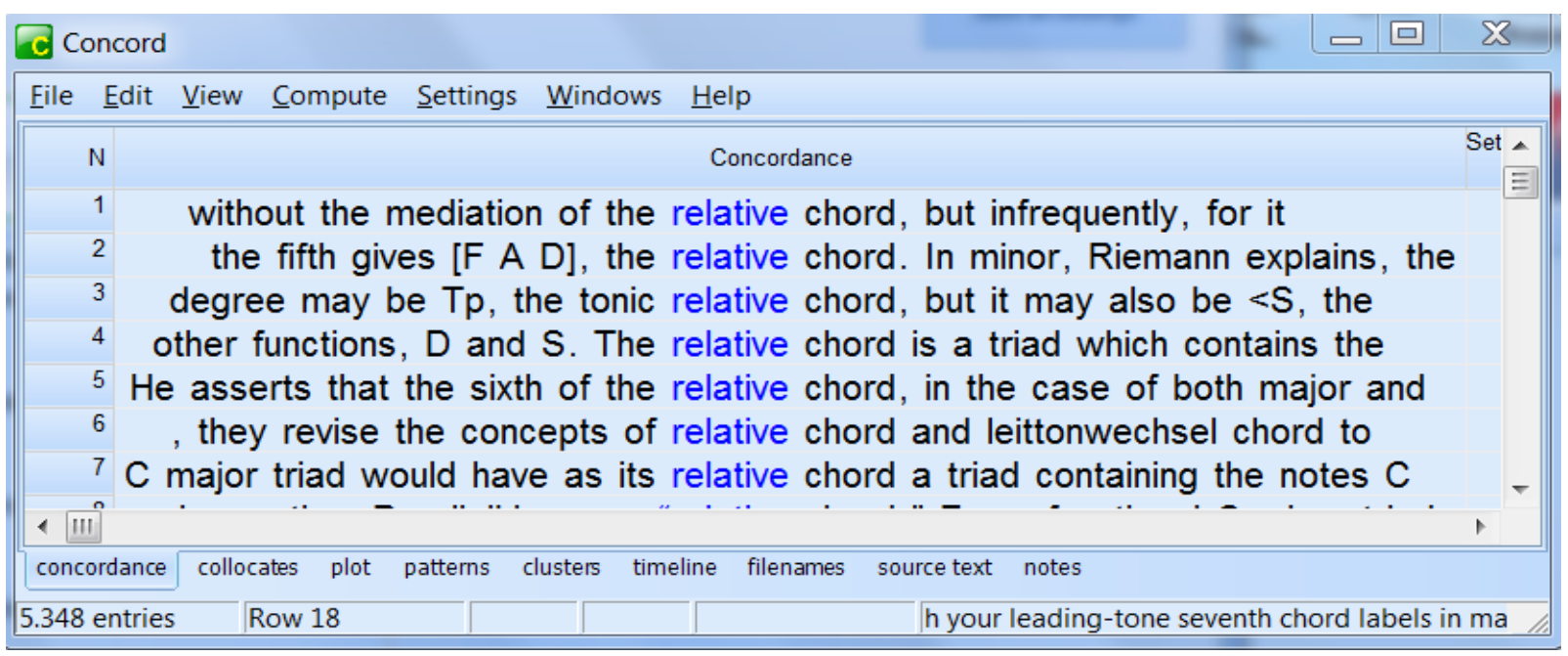

Figura 143 - Linhas de concordância parciais de "relative chord"

Tivemos dificuldades em encontrar um correspondente para a colocação acorde antirelativo, uma vez que quase não há contextos. Encontramos apenas duas referências à tradução do termo que vem do Alemão, no mesmo texto:

- (...) os termos "Terzwechsel" e "Leittonwechsel" referem-se aos movimentos que conhecemos como "progressão entre acordes relativos" e entre "antirelativos.(PORTMTE02)

- O termo "Leittonwechselklange" (literalmente troca de sensível), conforme a nomenclatura funcional que se pratica no Brasil, foi traduzido como "antirelativa"

A partir desse texto, encontramos um texto em Inglês que também explica a tradução do termo Alemão para o Inglês:

- Riemann defines two principal classes of mixed chord or Nebenklang, both of whose functions are determined by the majority element. These are the Parallelklang, or relative chord, and the Leittonwechselklang, or leading-tone change chord. (INGTMLIV10)

Pelas explicações dos contextos acima, o correspondente de "acorde anti-relativo", que se refere ao termo em alemão Leittonwechselklang é "leading-tone change chord". 


\section{6) Acorde de dominante secundária}

Encontramos no corpus de estudo de Português, a colocação "acorde de dominante secundária" (6 ocorrências) e suas variantes "dominante secundária" (78 ocorrências), "dominante secundário" e "acorde dominante secundário" (5 ocorrências).

No subcorpus instrucional, encontramos o seguinte contexto definitório:

- Dominante secundário: São os dominantes dos demais graus diatônicos, caracterizados também pelo movimento do baixo do V/II, V/III, V/IV, etc; quarta justa ascendente ou quinta justa descendente. (PORTMLIV07)

- Dominantes secundárias. Os acordes alterados mais comuns na música tonal são as dominantes secundárias (...) Uma dominante secundária de qualquer acorde deve ser uma tríade maior ou um acorde maior com sétima menor (acorde de sétima de dominante). É importante mencionar que uma dominante secundária refere-se a um acorde que não é a dominante do acorde de tônica (V de I). (PORTMAPO01)

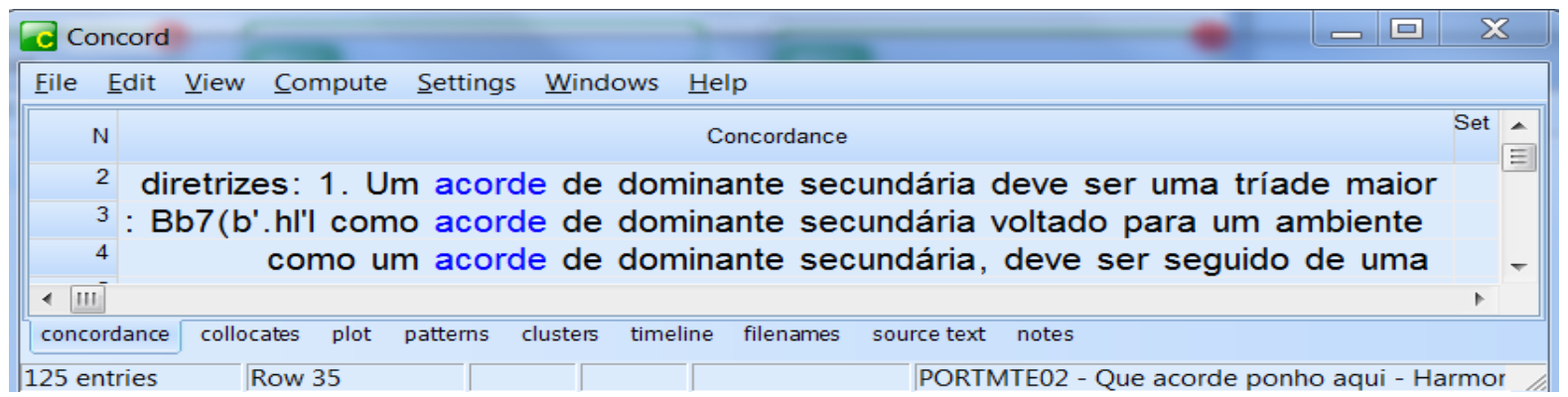

Figura 144 - Linhas de concordância de "acorde de dominante secundária"

No subcorpus acadêmico-científico, encontramos o seguinte contexto de uso:

- No Ex.34, o acorde de sétima diminuta "C\#”, estranho à tonalidade de Dó maior, situado uma segunda menor abaixo do $\operatorname{IIm} 7$ (Dm7), corresponde ao acorde de dominante secundária com nona abaixada situado uma quarta abaixo do IIm, ou seja VI7(b9) (A7(b9)). (PORTMART04) 


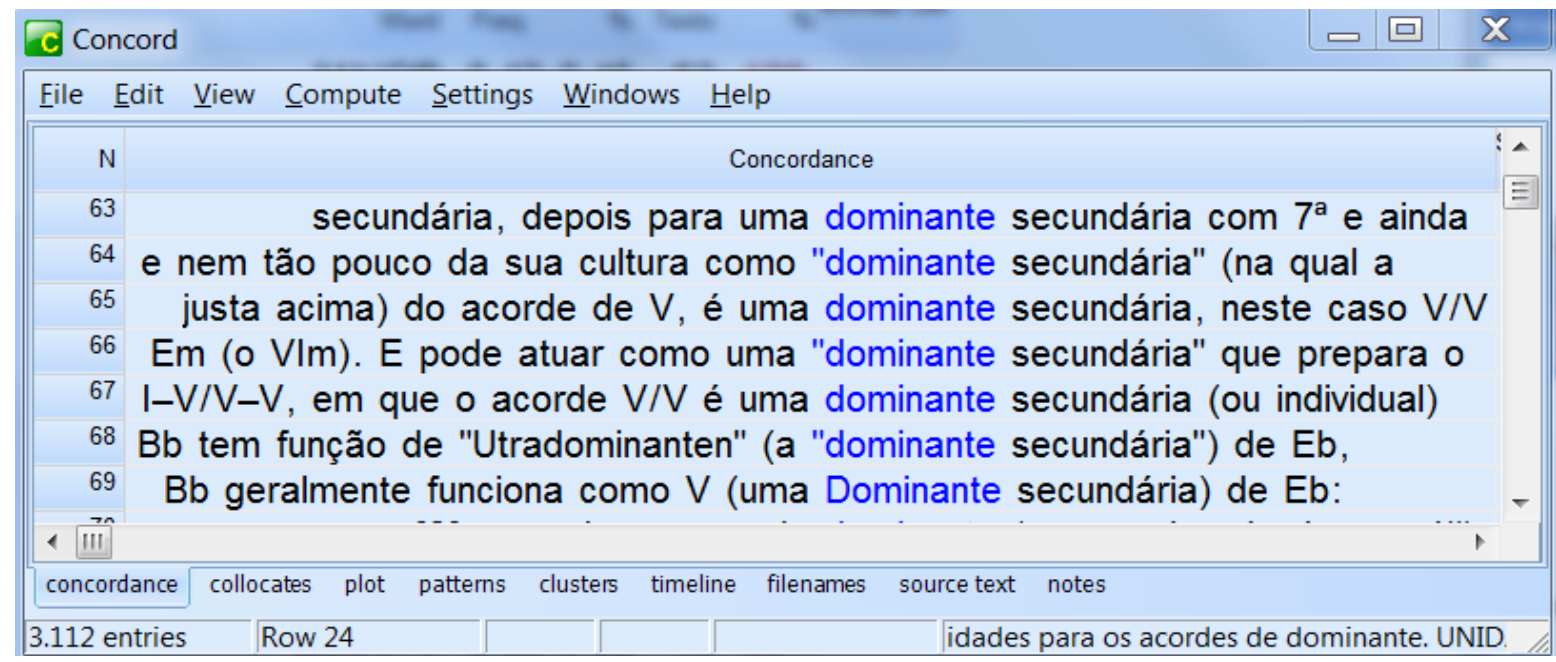

Figura 145 - Linhas de concordância de "dominante secundária"

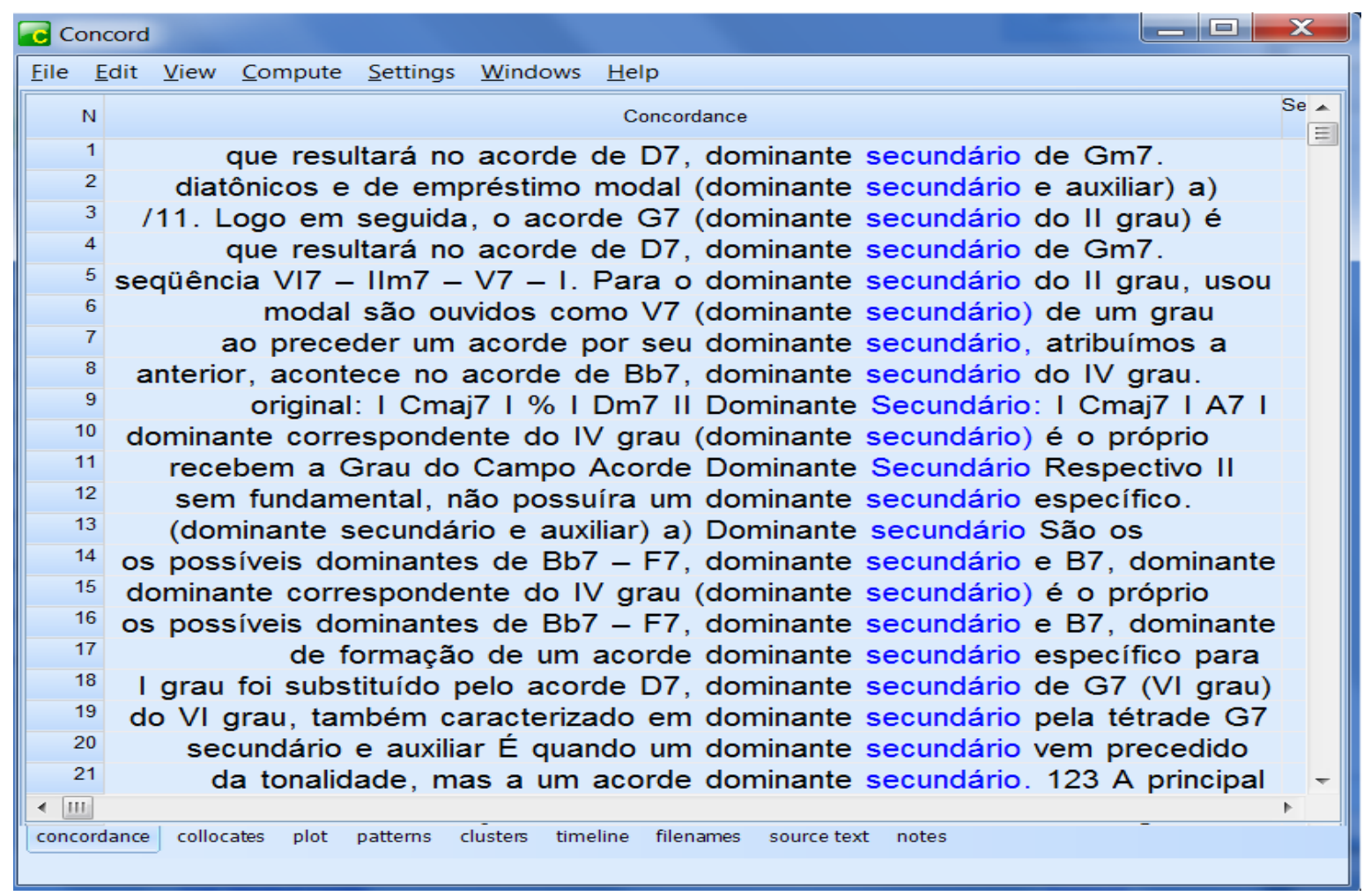

Figura 146 - Linhas de concordância de "acorde dominante secundário / dominante secundário"

Localizamos no subcorpus de Inglês as colocações correspondentes: Secondary dominant chord (2) e Secondary dominant (69 ocorrências). 
No dicionário de termos musicais (DI - HARVARD) "Secondary dominant" aparece não como uma entrada e sim como parte da definição de Dominant:

Secondary dominants are the degrees other than the tonic and are designated as follow: V of II (or simply V/II; e.g. in the key of $C$, the fifth above D, namely A), V of III (V/III) etc.

No corpus de estudo instrucional, localizamos os seguintes contextos definitórios:

- Secondary dominants are chords that are altered to sound like dominants. This means changing triads to make them major and changing seventh chords to make them major-minor. Any major or minor diatonic triad may be preceded by a chord that is, in effect, its dominant or leading tone.(INGTMLIV02)

- The idea of secondary dominant harmony is that a chord other than the tonic is preceded by its own dominant seventh, ninth, eleventh, and so on. This has the effect of temporarily tonicizing that particular chord. However, this process of tonicization is so fleeting and temporary that it is not regarded as being a proper modulation. This type of chord is called a secondary dominant.(INGTMLIV04)

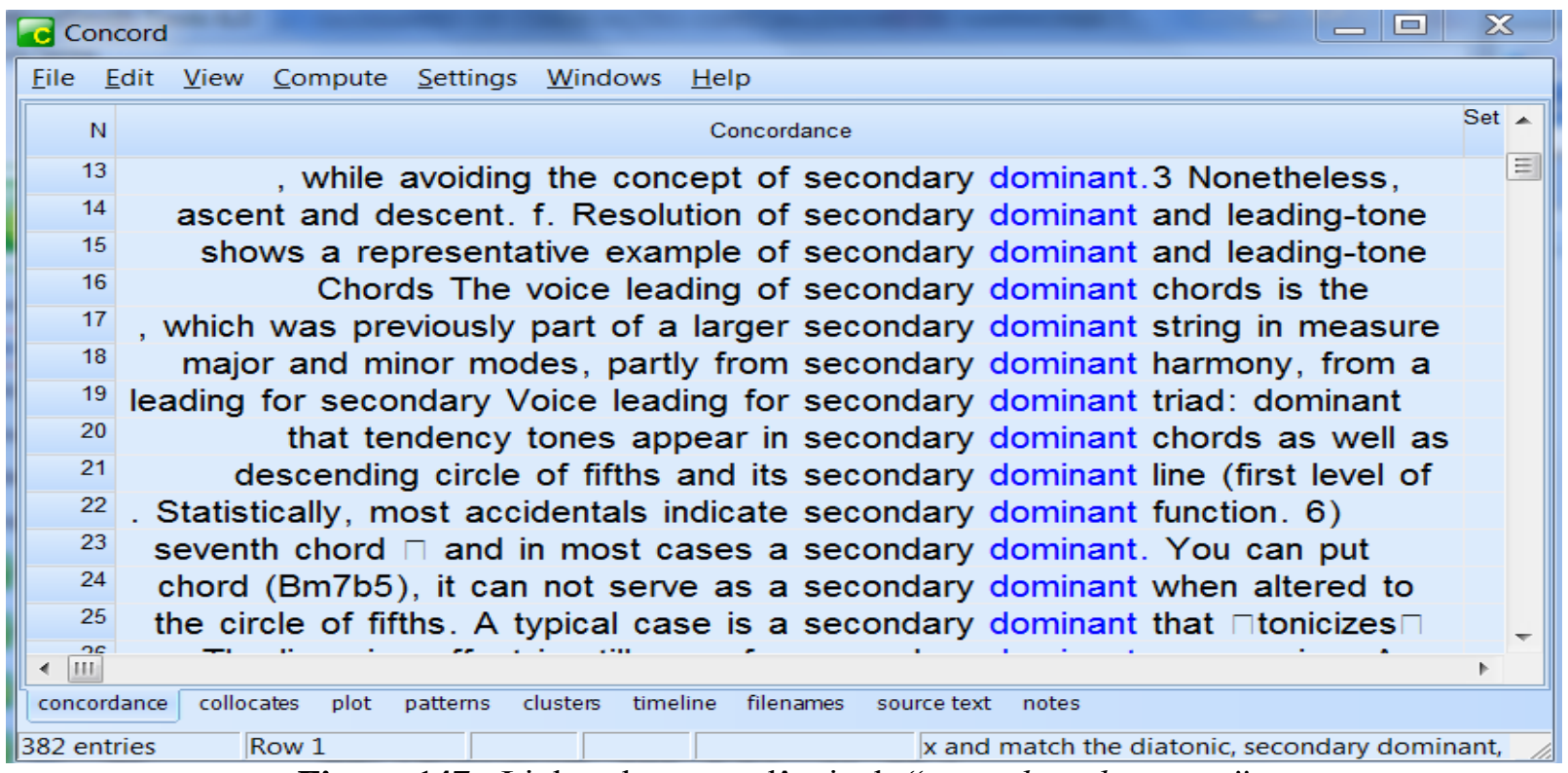

Figura 147 - Linhas de concordância de "secondary dominant"

Selecionamos o trecho abaixo do subcorpus acadêmico-instrucional: 
- Inflected triads, such as B minor/major (m. 28) and E minor/major (m. 32), are too brief to obscure a sense of diatonicism, as they quickly assume their purpose as secondary dominants. (INGTMART29)

- Riemann's only justification in bringing the F\# into his arguments is to make the relationship between $G$ and $D$ stronger by implying a secondary dominant chord based on D to elevate the status of G. (INGTMTE01)

Em relação à tradução dos termos variantes, sugerimos conservar as estruturas:

Acorde de dominante secundária $\Leftrightarrow$ Dominant secondary chord

Dominante secundário, dominante secundária $\Leftrightarrow$ Dominant secondary

\section{7) Acorde de dominante substituta}

Acorde de "dominante substituta" apresenta a frequência de 37 ocorrências no corpus de estudo, especificamente aos textos voltados para análise harmônica da música popular do subcorpus acadêmico-científico. A forma abreviada "acorde subV7" apresenta 16 ocorrências e "acorde substituto", 19 ocorrências. Não encontramos contextos definitórios no subcorpus instrucional, contudo, encontramos alguns trechos que ajudam a compreender o contexto em que ela aparece:

- Dentre outros fatores (questões de gênero e estilo, de defesa de campo, de autoimagem, das demandas comerciais do ensino da teoria musical, etc.), o prestígio técnico-teórico desta nomenclatura e conceituação - tratada aqui como estratégia menor melódica - está associado (emblematicamente, mas não exclusivamente) ao prestígio do chamado "acorde de dominante substituta" ("Sub V7"), o acorde que é conhecido na teoria tradicional como "acorde de sexta aumentada”.(PORTMTE02)

- Como se sabe, são muitos e diversos os pontos de vista sobre este acorde "láb-dóré-fá\#" no tom de Dó-menor ou Dó maior. Mais recentemente - desde aproximadamente a segunda metade do século $X X$, devido a fatores igualmente diversos, dentre eles o avanço dos estudos formais e das publicações técnicoteóricas nos campos da música popular - evidenciou-se urna espécie de 
divergência entre os cultores do "acorde de dominante substituta" (pelo lado da jazz theory e da chamada harmonia funcional que se pratica no campo da música popular cifrada) versus os defensores do "acorde de sexta aumentada" (pelo lado da teoria erudita, escrita com semibreves na pauta, a teoria da harmonia tradicional ou de escola). (PORTMTE02)

- Assim, contribuindo para tornar o sistema "SubV7 (lídio b7)" algo mais abstrato, retorcido e versátil, consolidou-se uma estratégia capaz de gerar um conjunto de desenhos percebidos como mais inusitados: recursos "substitutos" para resonorizar o popular "acorde de dominante substituta" que, então - para alguns e a partir de determinado momento -, se considera um meio de preparação insuficiente, demasiadamente desgastado e comum.

(PORTMTE02)

Observamos que há variantes para a colocação: "acorde subV7" (forma abreviada): sub (substituta) V (quinto grau que está relacionado à função dominante) e 7 (acorde com sétima). Em alguns contextos, são chamadas de "acordes substitutos" (da dominante).

Também observamos a forma variante "acorde substituto da dominante", cuja colocação não possui uma estrutura fixa.

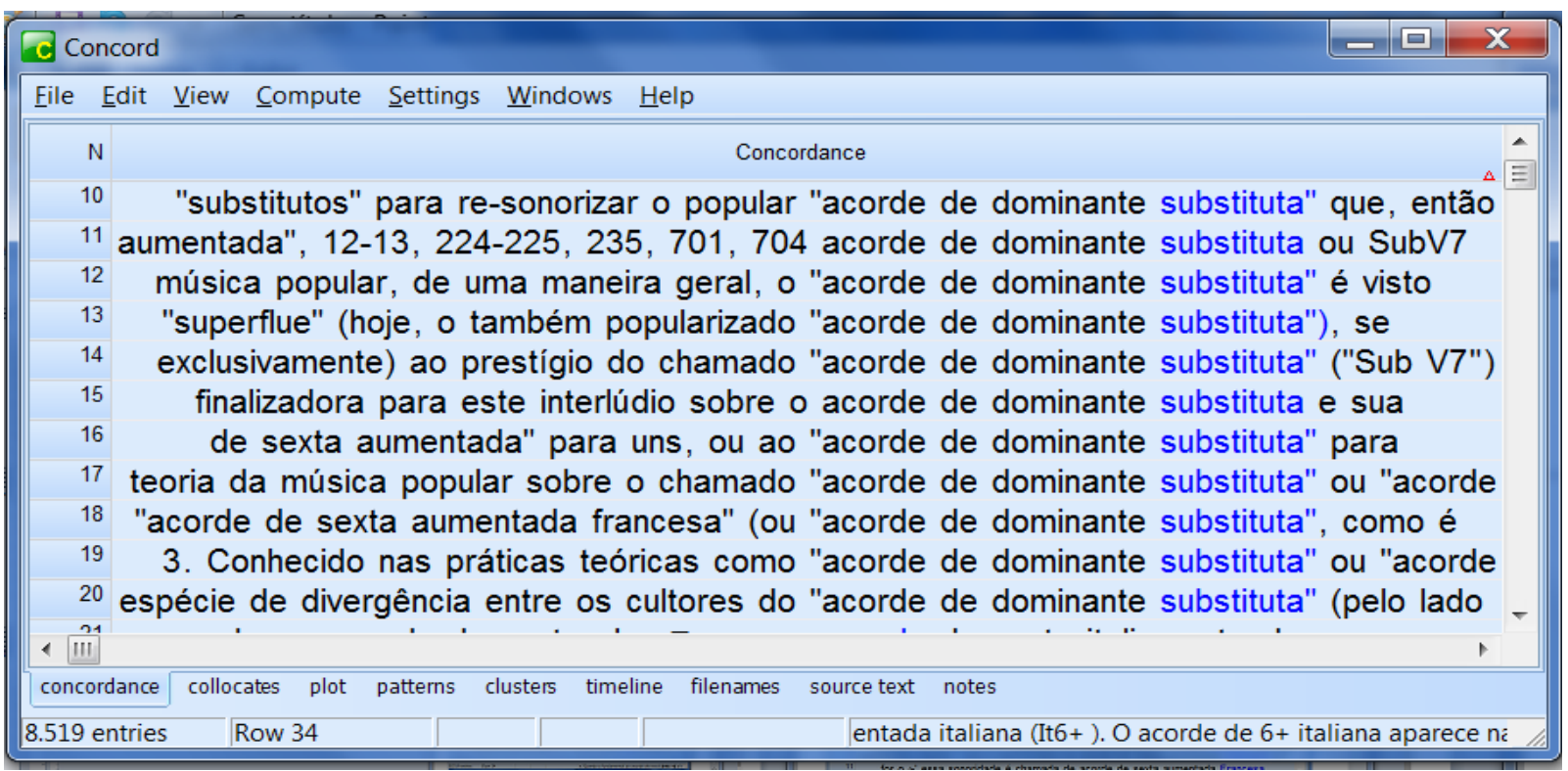

Figura 148 - Linhas de concordância de "acorde de dominante substituta" 


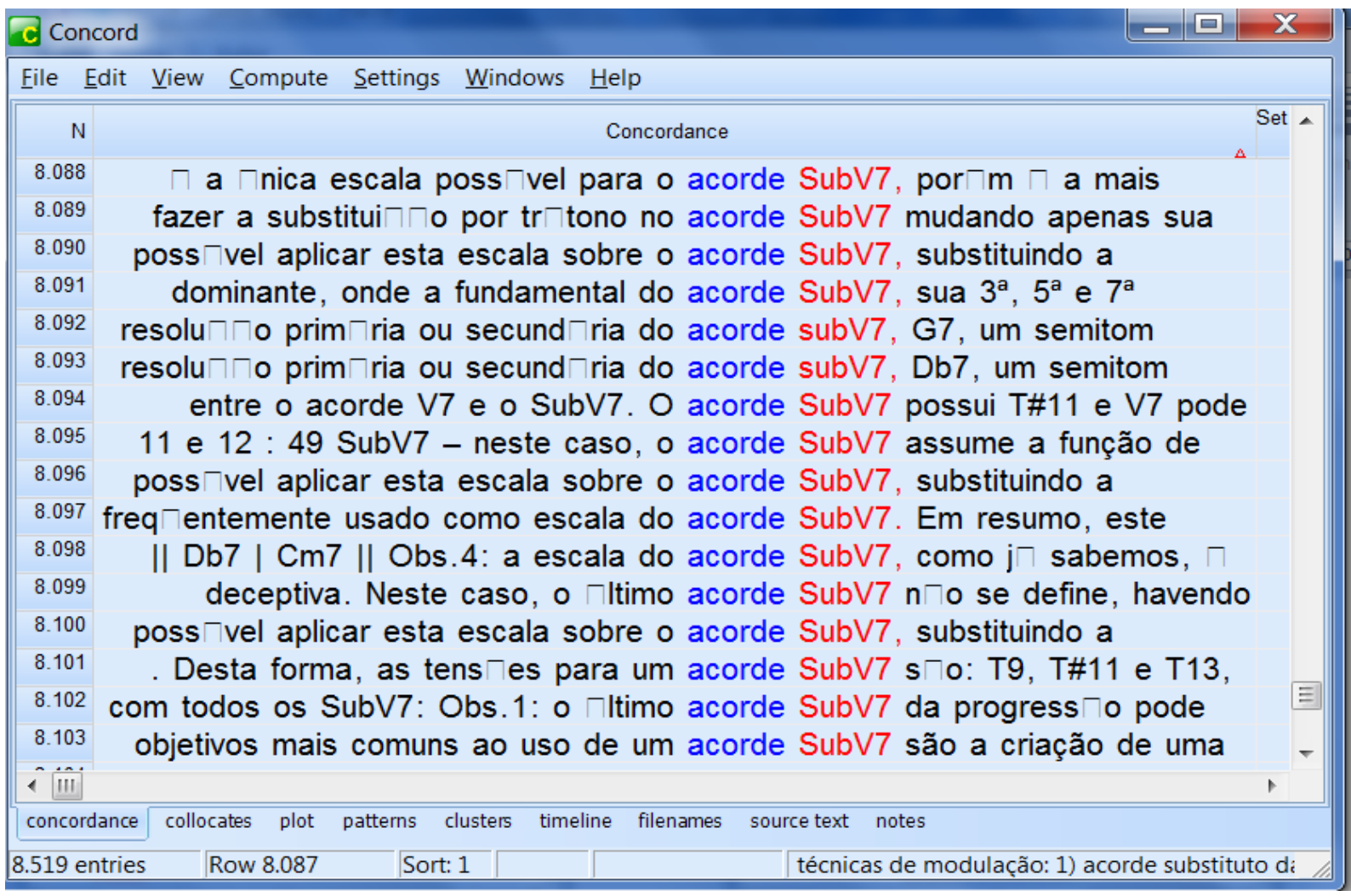

Figura 149 - Linhas de concordância de "acorde subV7”

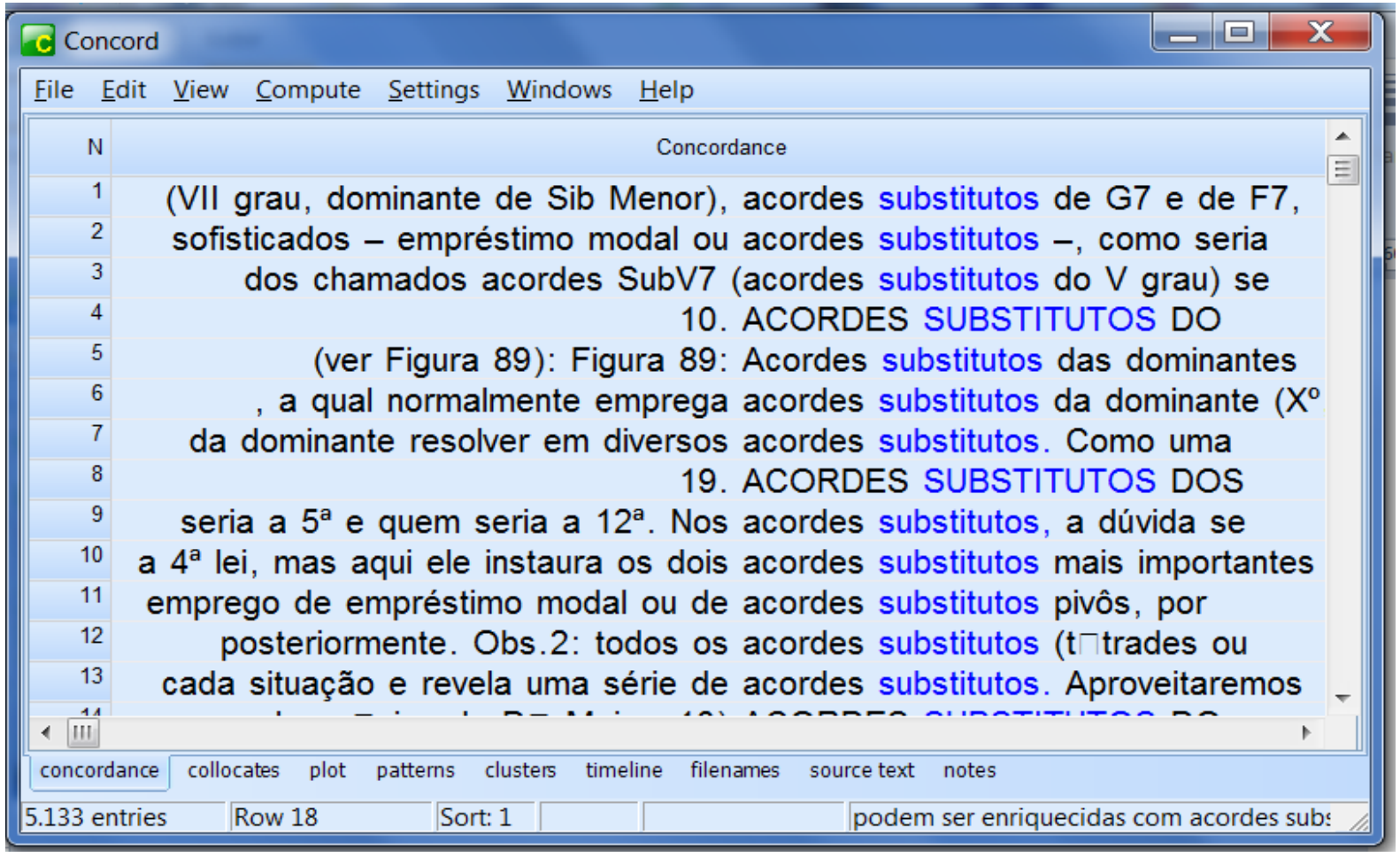

Figura 150 - Linhas de concordância de "acordes substitutos" 
No subcorpus acadêmico científicos de Inglês, em textos que tratam de análise da harmonia relacionada ao jazz e à música popular, encontramos os seguintes correspondentes: Tritone substitution chord (19), tritone substitute chords (7), tritone substitute (56 ocorrências) e dominant substitute chord (2). Tais colocações também foram encontradas na forma reduzida, sem o termo "chord".

$\mathrm{Na}$ consulta aos dicionários de termos musicais descrita no capitulo 2, a colocação substitution chord é uma das entradas do dicionário DI-HARVARD e apresenta a seguinte definição:

A chord that can be substituted for another while retaining its harmonic function. Jazz makes use of a variety of such chords (often chromatically altered), especially in the performance of popular songs or standards that are adapted for the jazz repertory. The tritone substitution, for example, replaces a dominant or dominant seventh chord with a seventh or ninth chord on the lowered supertonic.

Nos excertos a seguir (extraídos do subcorpus acadêmico-científico), as colocações aparecem em contexto de uso:

- $\quad$ One of the most common chord substitutions, mentioned in nearly every jazz theory book that mentions chord substitutions, is the tritone substitution chord, which is a variation of the ii-V7-I prototype. The substitution itself consists of inserting a dominant chord a tritone away from $V$ in the place of $V$. This results in a descending chromatic bass line and a ii-bII7-I progression. (INGTMDM04)

- In theory, tritone substitutes replace dominants, and this is indeed their most usual function. In practice, however, tritone substitution is also applied to chords without a tritone-typically dominant preparations such as vi and ii, either preserving the original chord qualities or recasting them as dominant sevenths. (INGMART18)

- Augmented-sixth chords and tritone substitutes have long been recognized as enharmonic equivalents. Their relationship is generally described as two different perspectives on the same syntactic structure: in classical terminology, an augmentedsixth chord; in jazz, a tritone substitute. (INGMART18) 
- Although it resolves irregularly, it satisfies Charles Smith's criterion for a dominant substitute chord; that is, that the operative element is the upward resolution of 4, the dominant's own leading tone. (INGTMDM01)

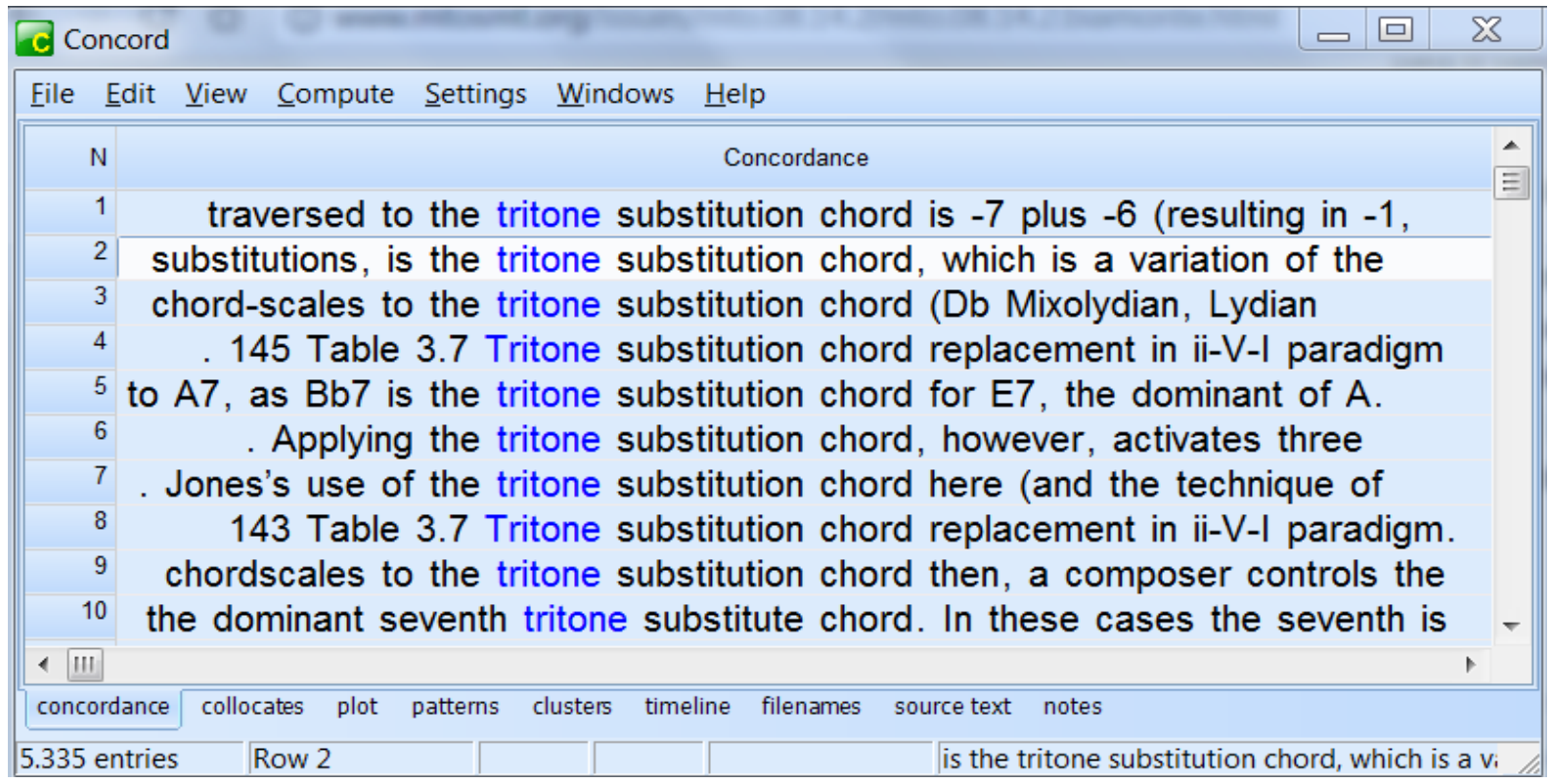

Figura 151 - Linhas de concordância de "tritone substitution chord / tritone substitute chord"

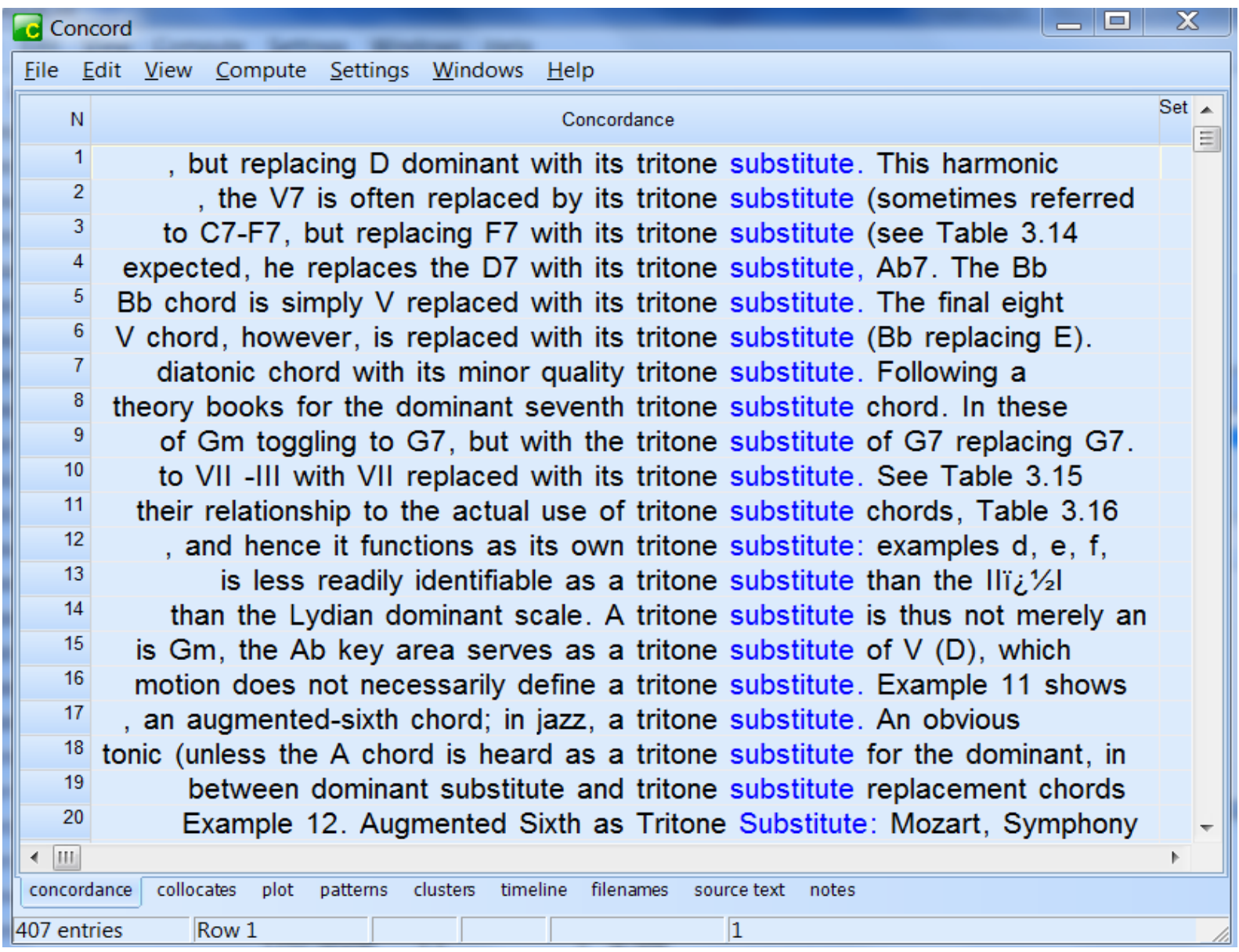

Figura 152- Linhas de concordância de "tritone substitute" 


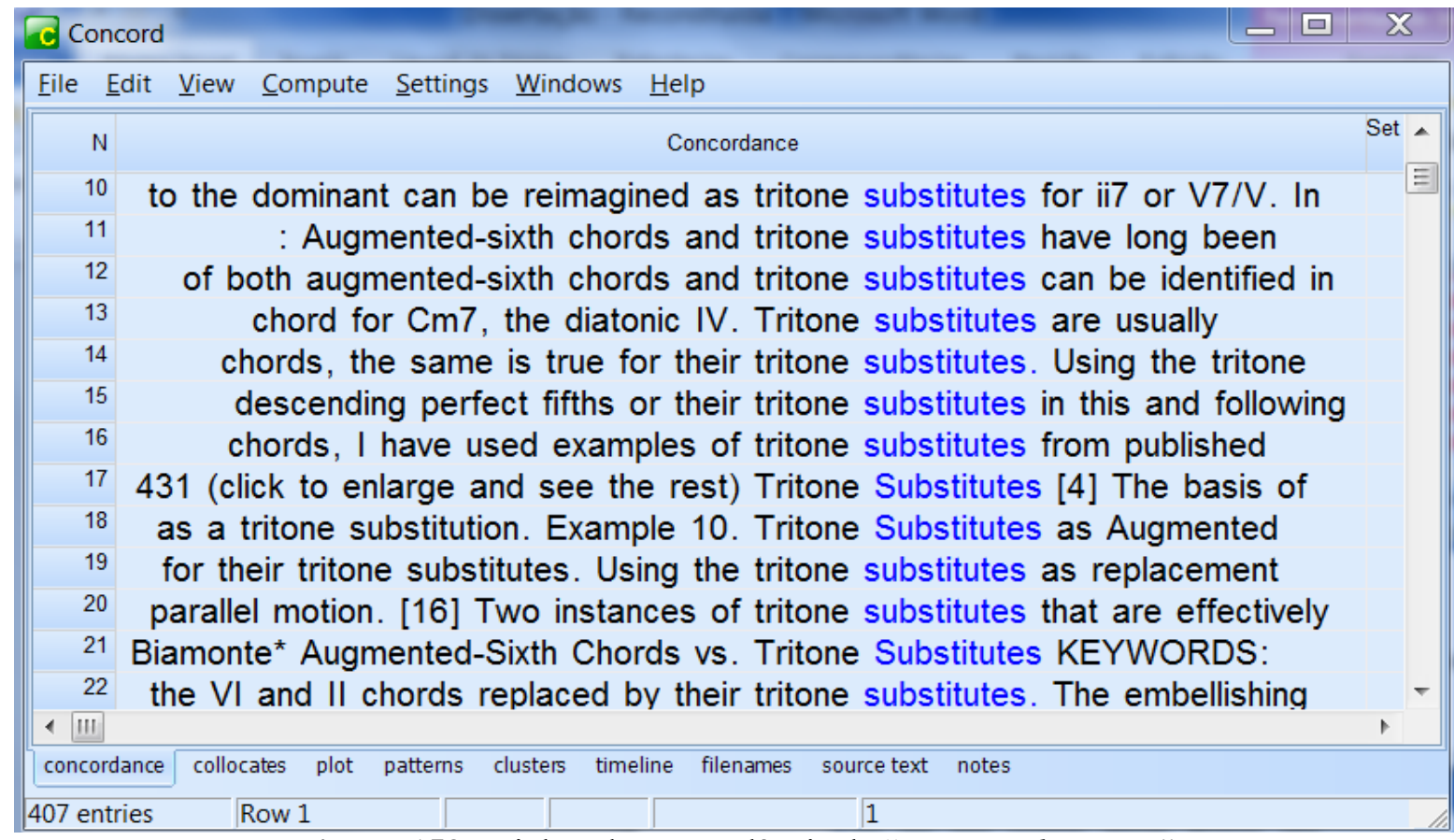

Figura 153 - Linhas de concordância de "tritone substitutes"

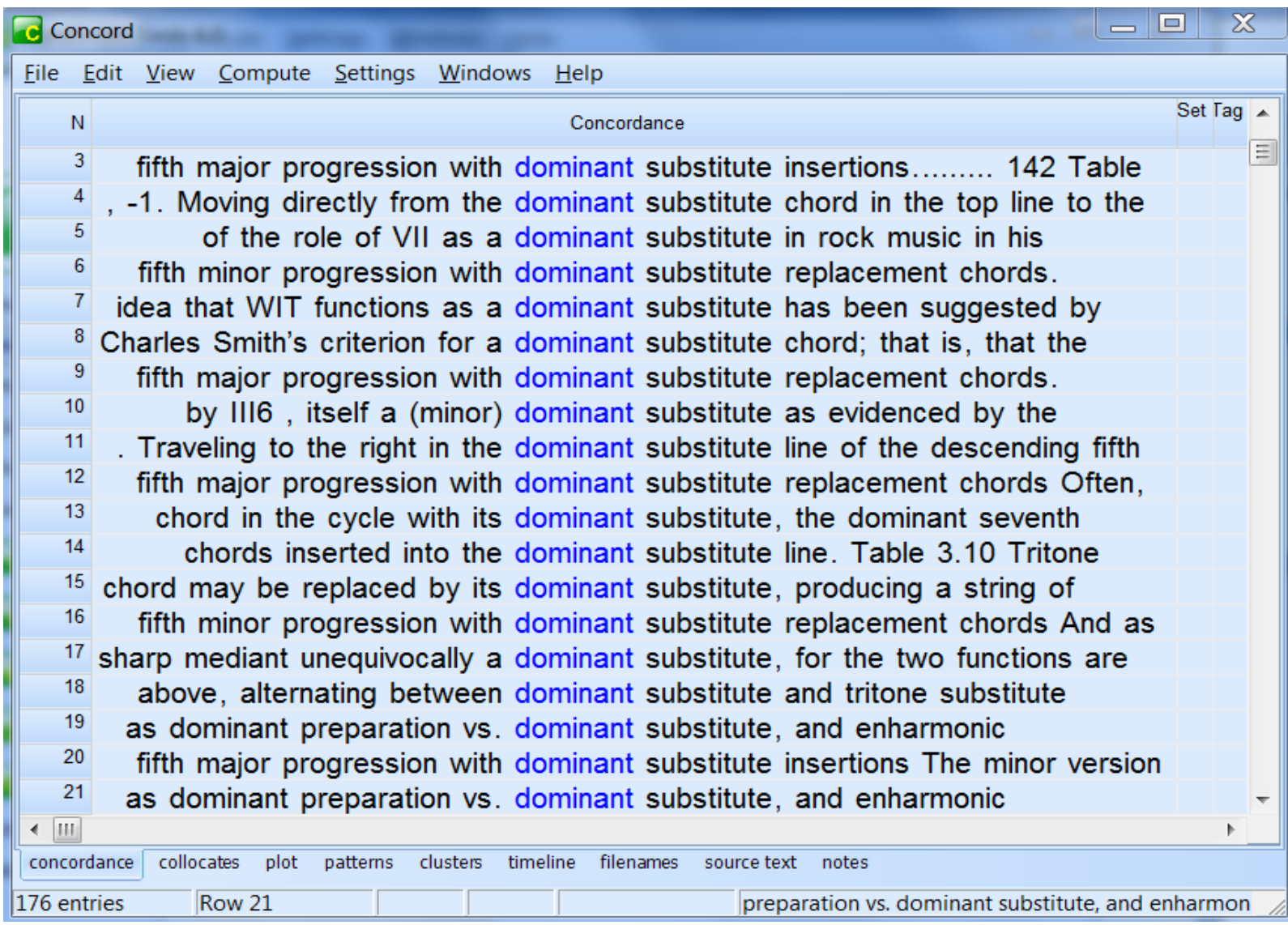

Figura 154 - Linhas de concordância de "dominant substitute

/ dominant substitute chord" 
Observa-se que há dois contextos de uso em ambos idiomas que mencionam sobre o emprego dos termos "acorde de dominante substituta" e "acorde de sexta aumentada" como variantes (este é uma denominação utilizada na Harmonia Tradicional, enquanto que aquele na Harmonia Funcional aplicada ao Jazz e à musica popular). Mencionaremos essa observação no glossário.

A partir da análise, relacionamos as correspondentes, preservando as estruturas, como:

Acorde de dominante substituta (Acorde subV7), Dominante substituta $\Leftrightarrow$ Tritone substitution chord, tritone substitute e dominant substitute chord.

\section{8) Acorde tonicalizado / Acorde tonicizado}

A busca pelas colocações deste item foi motivada pelas ocorrências da colocação correspondente em inglês "tonicized chord" (14 ocorrências), que se refere a um acorde que, em determinado trecho da harmonia, tem uma função temporária de tônica. $\mathrm{O}$ termo "tonicalização" (tonicization, em Inglês) tem a frequência de 30 ocorrências, distribuídas em 3 textos. Em Português, encontramos um contexto definitório:

Entende-se por tonicalização a aplicação imediata de um acorde de dominante individual que funciona em nível localizado e dentro de um contexto tonal maior. Por exemplo, na progressão (em dó maior) $I-V / V-V$, em que o acorde $V / V$ é uma dominante secundária (ou individual) da dominante da tônica, diz-se então que o acorde $V$ foi tonicalizado. Assim, tonicalização funciona para acordes alterados, $e$ que tem um efeito puramente local e imediato, o que não implica necessariamente em mudança de região tonal ou modulação. (PORTMAPO01)

Também encontramos 45 ocorrências para o termo "tonicização" (frequente em 5 textos), apresentando conceito similar:

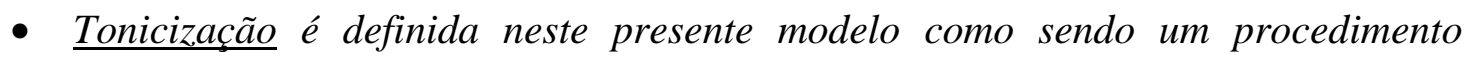
modulatório no qual uma estrutura harmônica pertencente ao campo harmônico da região ativada pela fórmula tonal é prolongada prefixalmente por meio de uma outra estrutura harmônica emprestada do campo harmônico que tem como tônica a própria estrutura a ser prolongada.(PORTMART09)

A partir do trecho abaixo, verificamos a aceitação dos dois termos variantes: 
- Da noção de tonicização. Abarcando vários meios de preparação o termo tonicização, ou tonicalização, tornou-se mais ou menos corrente nas práticas teóricas da música popular. (PORTMTE02)

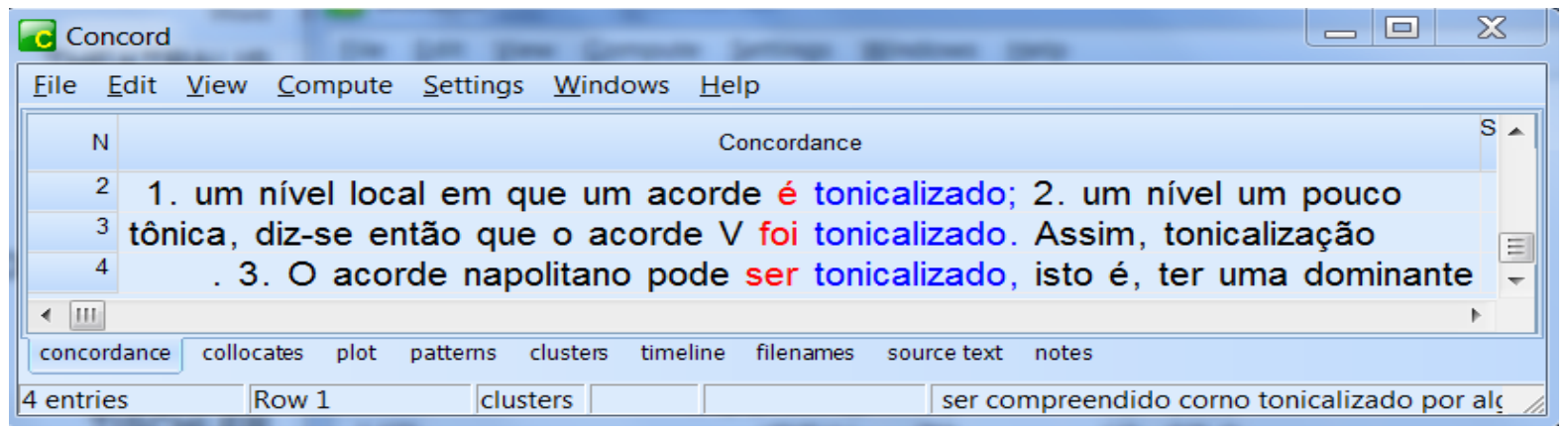

Figura 155 - Linhas de concordância do predicativo "tonicalizado"

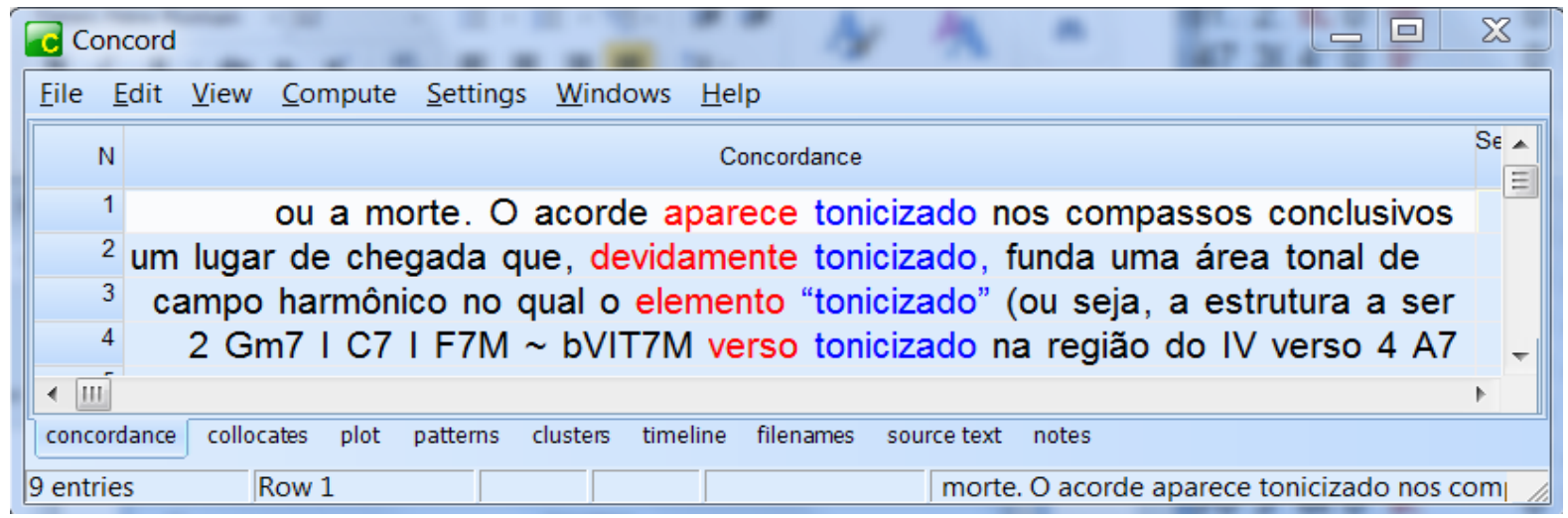

Figura 156 - Linhas de concordância do predicativo "tonicizado"

Verificamos que as formas verbais no particípio (tonicalizado / tonicizado) são candidatas a formar as colocações sinônimas em Português "acorde tonicalizado", "acorde tonicizado", pelo emprego do particípio como predicativo do sujeito, observado em orações das linhas de concordância das figuras 154 e 155. Ainda não podemos dizer que ambas colocações são convencionais, já que na nossa pesquisa ao corpus (e também em fontes externas, por meio de busca de contextos na Internet) não encontramos ocorrências para o agrupamento "Acorde tonicalizado". Contudo, por conta do uso recorrente da colocação em inglês, há uma tendência de que esses agrupamentos (acorde tonicalizado e acorde tonicizado) se tornem colocações convencionais em textos especializados em Português (originais e/ou traduzidos).

Em inglês, foram encontrados os seguintes contextos definitórios para a colocação correspondente: 
- $\quad$ Tonicized chord - A chord that functions temporarily as a tonic (having been preceded by a secondary dominant.) (INGTMLIV02).

- In circle progression, the chord to which secondary dominants progresses is called a tonicized chord. (INGTMLIV02).

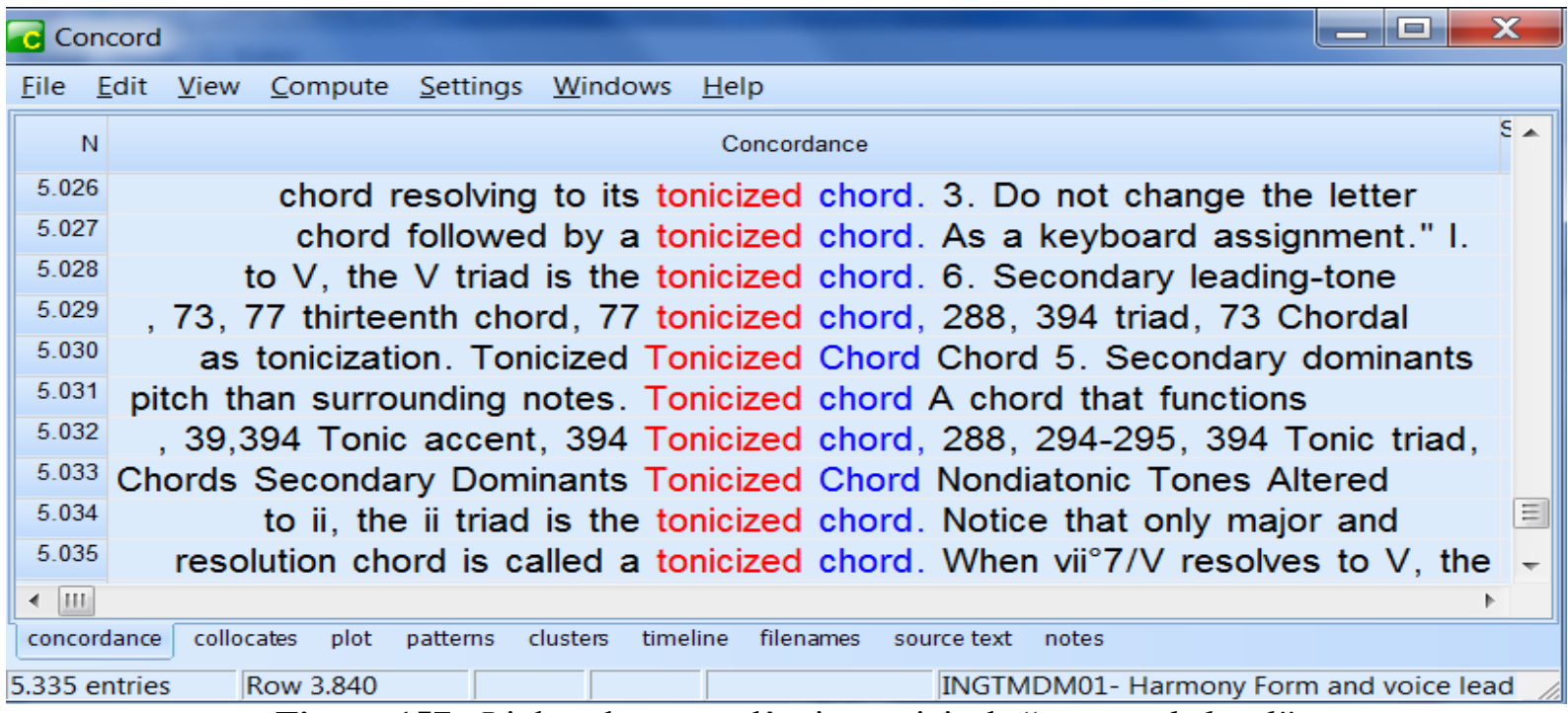

Figura 157 - Linhas de concordância parciais de "tonicized chord"

\section{9) Voicing}

A partir da colocação Chord Voicing (25 ocorrências no subcorpus de inglês), chegamos ao correspondente em Português "Voicing". Investigando a lista de palavras em Português, verificamos que o uso do termo é convencional e apresenta uma frequência alta: 180 ocorrências.

Encontramos o seguinte contexto definitório no subcorpus instrucional:

Voicing é uma palavra inglesa que, numa tradução livre para aplicações musicais, significaria o ato de trabalhar com vozes. No caso específico da Harmonia, o voicing de um acorde é a disposição na qual as suas notas se apresentam. (PORTMLIV09) 


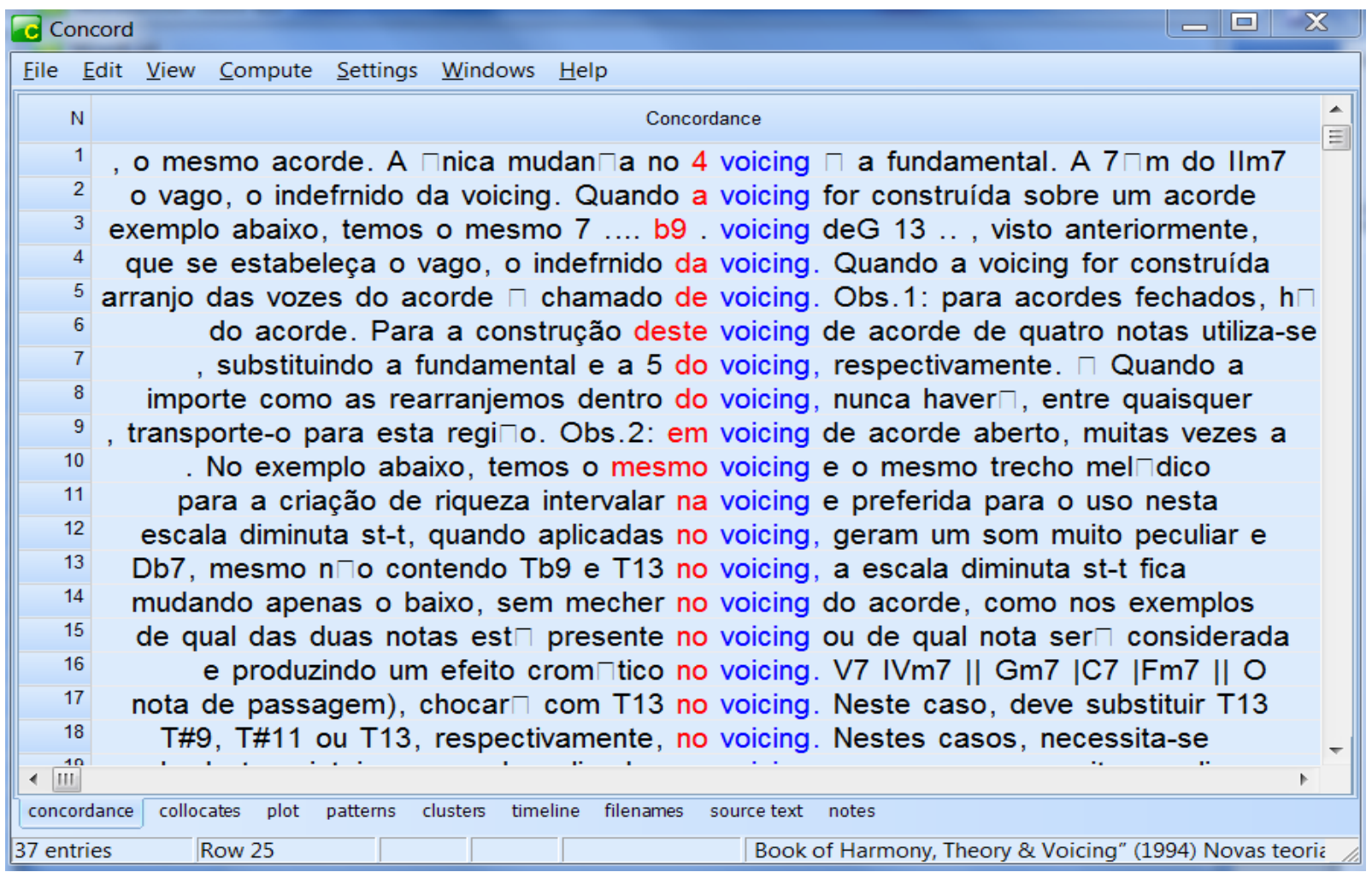

Figura 158 - Linhas de concordância parciais de "voicing"

A partir dessa explicação, buscamos outros contextos de uso e encontramos:

- Na prática, quem define a inversão é o baixo, não importando a disposição das notas do acorde. Este arranjo das vozes do acorde é chamado de voicing. (PORTMAPO05)

- A palavra "abertura" se refere à maneira como as notas individuais de um acorde estão distribuídas. Uma vez que se estabeleça a posição do acorde (estado fundamental, $1^{a}, 2^{a}$ ou $3^{a}$ inversões) elegendo assim, sua nota mais grave, as demais notas poderão estar dispostas de várias outras formas. O termo "abertura" ainda não é tão comumente empregado, sendo o seu correlato em inglês - voicing, mais frequentemente utilizado. (PORTMDM03)

Observamos que o termo ocorre em textos relacionados à Harmonia aplicada ao contexto da música popular (em Português). Em alguns textos o termo é utilizado como substantivo feminino e em outros, masculino. 
Em inglês, localizamos dois contextos definitórios sobre a colocação "Chord voicing". O primeiro deles descreve características do acorde, de forma similar aos contextos encontrados em Português:

- Chord voicing refers to the ordering of the notes (root, third, fifth) above the lowest note. Changing the chord voicing does not change the inversion. (INGTMLIV08)

- "Voicing" refers to the way chord tones are deployed. There are many different approaches to chord voicing. The choice of which approach to use is partly a matter of what kind of musical group is involved: solo keyboard, piano trio, big band, soli group, vocal jazz ensemble, etc. The choice of approach is also affected by the aesthetic preferences of the performer, composer, or arranger. And, finally, the choice of approach is affected by the background and training of the performer, composer, or arranger. Musicians who have had training in traditional harmony, counterpoint, and orchestration are likely to use more sophisticated voicing techniques, while musicians with less formal training are more likely to use automatic techniques based on the mechanical application of a few voicing rules. (INGTMLIV07) 


\begin{tabular}{|c|c|}
\hline Conco & 口回| \\
\hline File Ed & dit View Compute S Settings Windows Help \\
\hline $\mathrm{N}$ & Concordance \\
\hline 5.022 & above the lowest note. Changing the chord voicing does not change the \\
\hline 5.023 & Wonder sometimes keeps the entire chord voicing built on ii \\
\hline 5.024 & 13 sounds simultaneously with $\# 5$ in a chord voicing. What I believe to be \\
\hline 5.025 & a situation in which every note in the chord voicing is a poten \\
\hline 5.026 & melodies and expansive P4/P5-laden chord voicing more traditionally linked \\
\hline 5.027 & 35 Chord Voicing Styles. \\
\hline 5.028 & created with only one or two voices. Chord Voicing Styles The voicing of \\
\hline 5.029 & are many different approaches to chord voicing. The choice of which \\
\hline 5.030 & root third on bottom fifth on bottom Chord voicing refers to the ordering of \\
\hline 5.031 & alterations. Example 8. Tritone-Related Chord Voicings(17) (click to enlarge \\
\hline 5.032 & 32 VI. Chord Voic \\
\hline 5.033 & chorus. Not only are the chords (and chord voicings) with which he uses to \\
\hline 5.034 & Jazz Theory VI $\sqcap$ Chord Voicings VI. Chord Voicings $\sqcap$ Voicing $\neg$ refers to \\
\hline 5.035 & to your ears. Change ngerings and chord voicin \\
\hline 5.036 & (c, $\mathrm{d}$, and $\mathrm{e})$. I have used simple ch \\
\hline 5.037 & Gb13.. ....Fmaj9.. .......... VI $\sqcap$ Chord Voicings $\sqcap$ Shells $\sqcap 5$ In the shell \\
\hline 5.038 & all of the tunes? Jazz Theory VI $\sqcap$ Chord Voicings VI. Chord Voicings \\
\hline 5.039 & a porch light. Improvise various block chord voicir \\
\hline $5.040 \mathrm{n}$ & novel chord progressions and distinctive chord \\
\hline$\frac{5 n+1}{1111}$ & \\
\hline concordar & ance collocates plot patterns clusters timeline filenames source text notes \\
\hline 5.335 entr & concentrate of \\
\hline
\end{tabular}

Figura 159 - Linhas de concordância parciais de "chord voicing”

Este é um dos casos em que ocorre empréstimo de um termo estrangeiro, no caso em Inglês, para o Português.

\section{0) Encadeamento dos acordes}

No subcorpus de Português encontramos 49 ocorrências para a colocação "encadeamento de acordes". Observamos que a colocação ocorre em alguns contextos do gênero instrucional relacionada ao tema condução de vozes.

Foram localizados dois contextos definitórios para a colocação:

- Encadeamento de acordes - refere-se ao movimento de um acorde para outro, procurando manter as notas comuns na mesma voz e fazer as demais seguirem o caminho mais curto. (PORTMAPO06) 
- Por encadeamento de acordes entende-se a melhor maneira de se fazer uma boa condução de vozes. (PORTMAPO01)

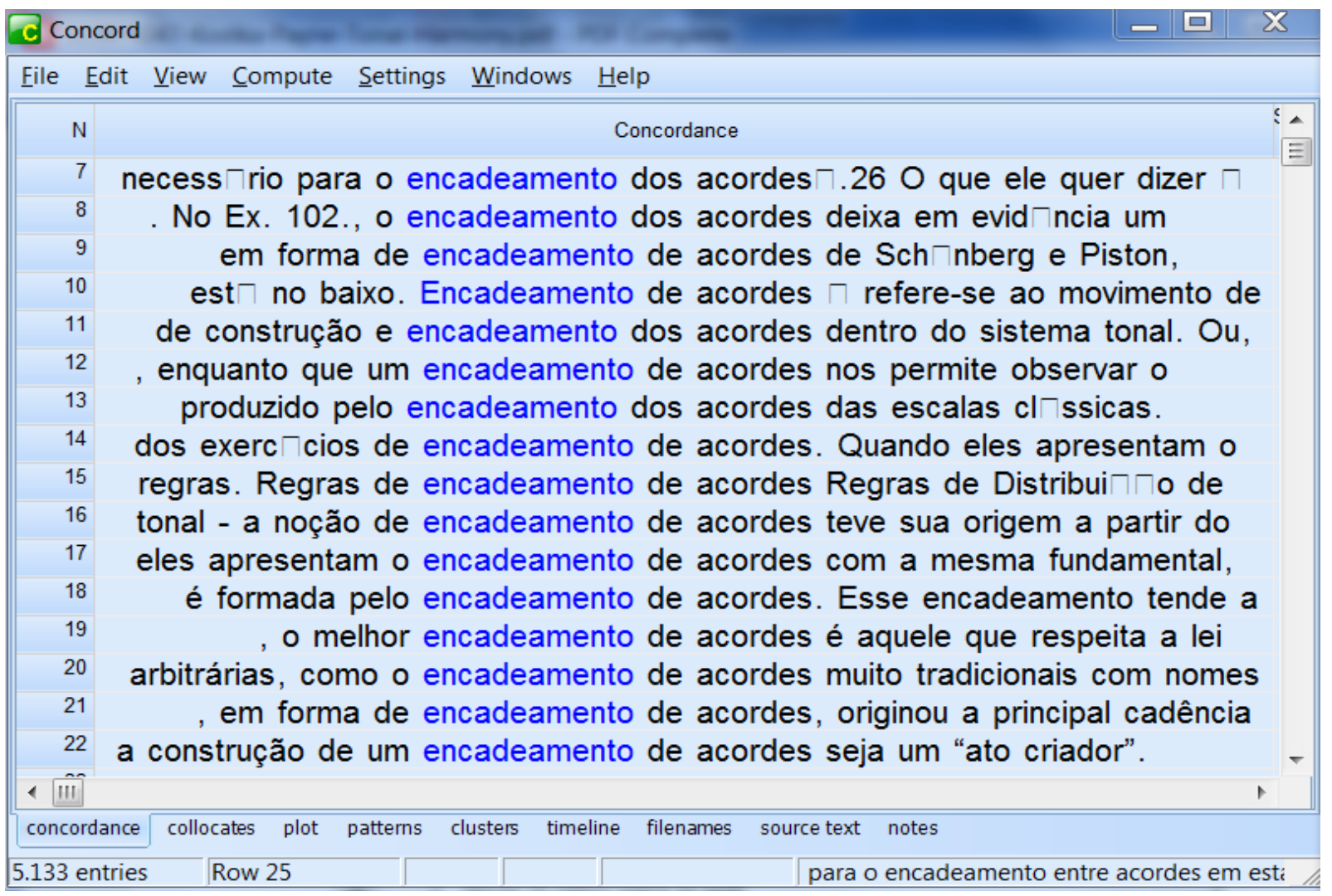

Figura 160 - Linhas de concordância parciais de "encadeamento de acordes"

Selecionamos alguns contextos de uso, extraídos de textos do subcorpus acadêmico científico, em que a colocação ocorre:

- Segundo Schönberg o aluno deve escrever o encadeamento de acordes a quatro vozes como se estas fossem realmente para um quarteto vocal. (PORTMDM01)

- Uma teoria harmônica, por sua vez, deve dar conta destes dois aspectos, isto é, sistematizar e classificar os aglomerados sonoros (acordes) e as combinações entre eles (encadeamento de acordes). E é disso que o sistema harmônico tonal trata. (PORTMDM04).

Em Inglês, encontramos como termo correspondente a colocação voice leading (381 ocorrências), como uma variante de part-writing, no subcorpus de Inglês. Encontramos o seguinte contexto definitório: 
Voice leading (or part writing) may be defined as the ways in which chords are produced by the motions of individual musical lines. (...) For various reasons, many theory texts have based their approach to voice leading upon the style of the four-voice choral harmonizations by J. S. Bach. (INGTMLIV12)

Beginning with this chapter and continuing through volume $l$ and much of volume 2, we will place considerable emphasis on the voice-leading practices of the eighteenth and nineteenth century composers. Four-part writing demonstrates in an uncomplicated fashion the principles that are the basis of compositions from this time period. (INGTMLIV02)

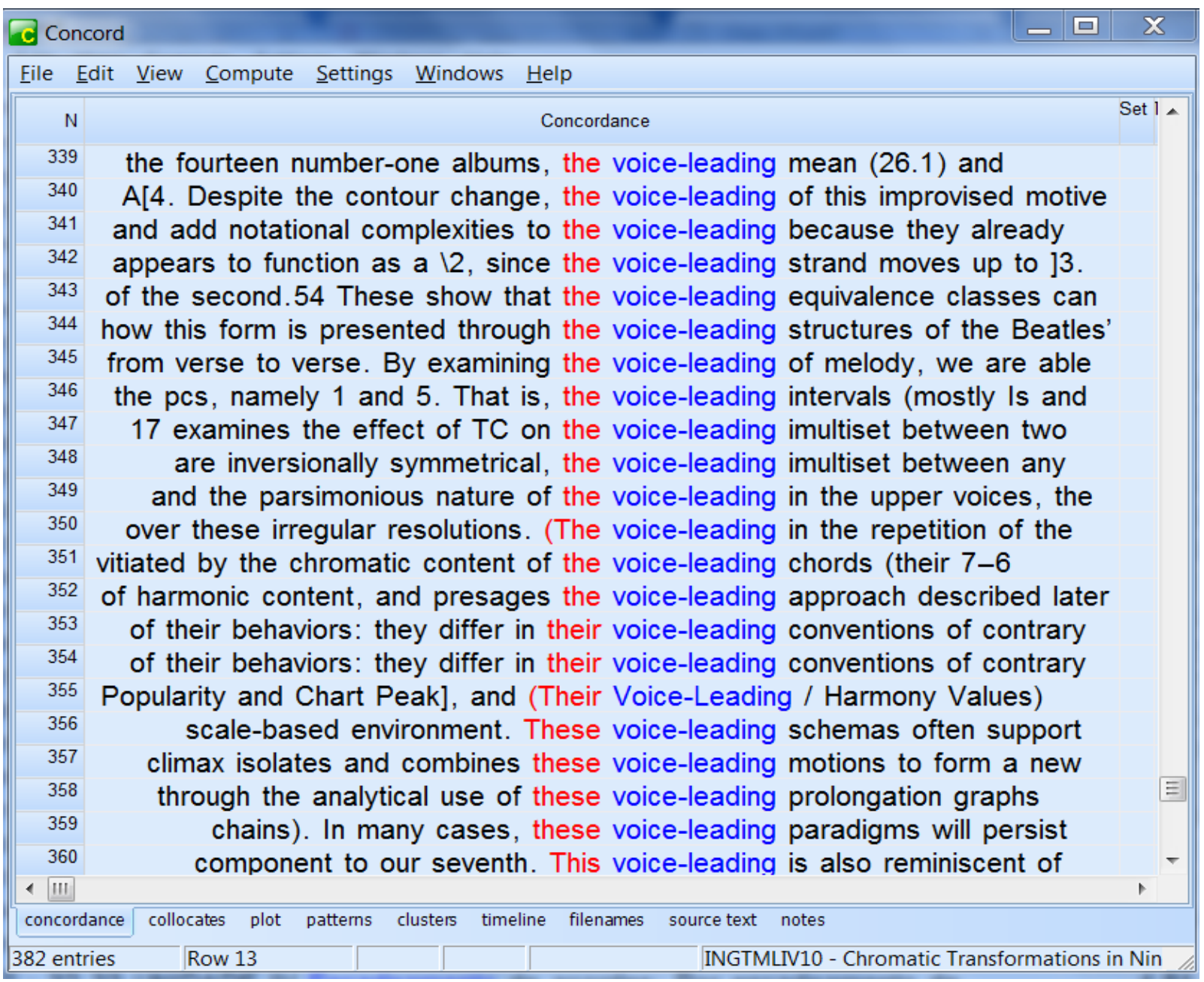

Figura 161 - Linhas de concordância parciais de "voice-leading”

Extraímos do subcorpus acadêmico-científico um excerto que mostra a colocação em contexto de uso: 
- This voice-leading is also reminiscent of what has become known as Schoenberg's "Law of the Shortest Way," for the motion is as slight as possible.(13) In sum, Example $1 b$ results in a sonority that has a similar number of dominant elements as it does subdominant ones, and creates this effect with function-specific voiceleading.( INGTMART14)

Encontramos no dicionário DP-DOURADO, a colocação "voice leading” traduzida como "condução de vozes". Não encontramos entrada para a colocação "Encadeamento de acordes".

A definição de condução de vozes encontrada no corpus aponta semelhanças no uso das duas colocações:

- A condução das vozes deve obedecer a certos critérios: preferentemente, utilizar o mínimo de movimento: manter sons comuns entre acordes movimentar-se por intervalos pequenos (especialmente graus conjuntos), evitar saltos grandes. (PORTMAPO02)

\section{1) Progressão dos acordes}

A colocação "progressão de acordes" tem a frequência de 16 ocorrências no corpus de estudo. Como variante, encontramos "progressão harmônica" (30 ocorrências). Observamos nas linhas de concordância que o uso de "progressão" (sem colocados) é bastante recorrente.

A colocação Progressão harmônica foi encontrada em dicionário de termos musicais com a seguinte definição:

Na Harmonia, sequencia de acordes encadeada de maneira lógica. No Blues e em algumas formas jazzísticas dele derivadas, a estrutura harmônica (Blues Progression) é préconvencionada entre os músicos, sendo fundamental a improvisação (sequencia harmônica).(DP-DOURADO)

No subcorpus de Português, encontramos contextos da colocação e das variantes:

- David Kopp observa que "função não diz respeito à progressão de acordes, mas sim, ao significado dos acordes que estão unidos nas progressões" (PORTDMART26) 
- Na tonalidade de Bb maior, a introdução começa sobre uma progressão harmônica bastante encontrada na Música Popular e caracterizada pela seqüência I-IVm. (PORTMDM03)

- Uma progressão tem a função de estabelecer ou contradizer uma tonalidade. A combinação de harmonias nas quais uma progressão consiste depende de seu propósito - se este é estabelecimento, modulação, transição, contraste ou reafirmação. (PORTMART18)

- Os acordes que participam de uma progressão, não são estruturas isoladas; na verdade, exercem funções harmônicas específicas que conferem à harmonia movimento e coerência. (PORTMDM04)

De acordo com os excertos, no contexto da música tonal, a progressão é uma sequência de acordes, cuja combinação harmônica entre tais acordes conduz a um fim específico.

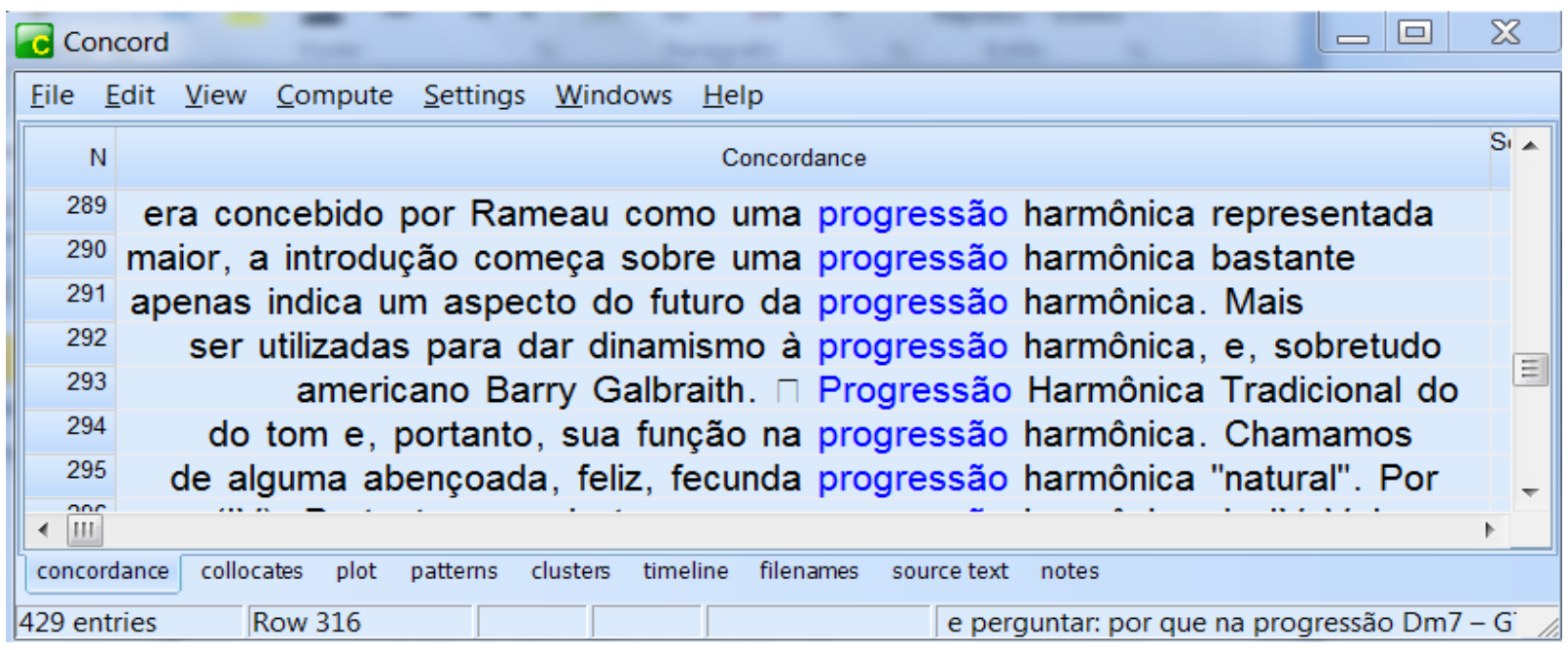

Figura 162 - Linhas de concordância parciais de "progressão harmônica"

Em inglês, encontramos como correspondente a colocação chord progression, cuja frequência no corpus é de 128 ocorrências. Também encontramos a variante harmonic progression, que apresenta a frequência de 136 ocorrências.

No dicionário de termos musicais, encontramos o termo "progression" definido da seguinte forma:

Progression - a succession of two or more chords; also chord progression; harmonic progression; in Jazz and popular music also termed changes. (DI - HARVARD)

No subcorpus instrucional, localizamos contextos definitórios similares: 
- A serie of chords played one after another is a chord progression. (INGTMLIV01)

- Harmonic progression - movement from one chord to the next; a succession of chords or a chord progression.(INGTMLIV02)

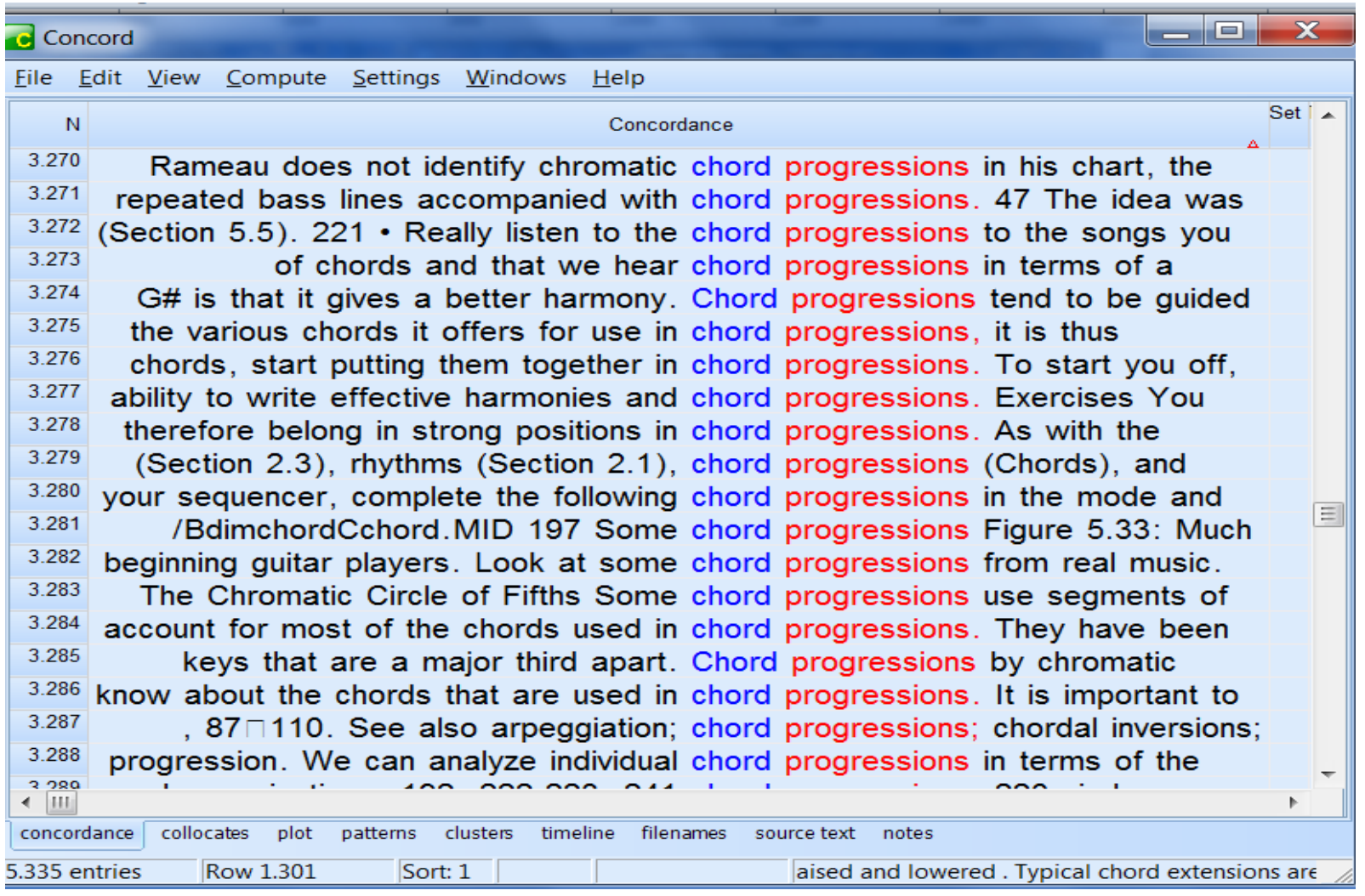

Figura 163 - Linhas de concordância parciais de "chord progressions"

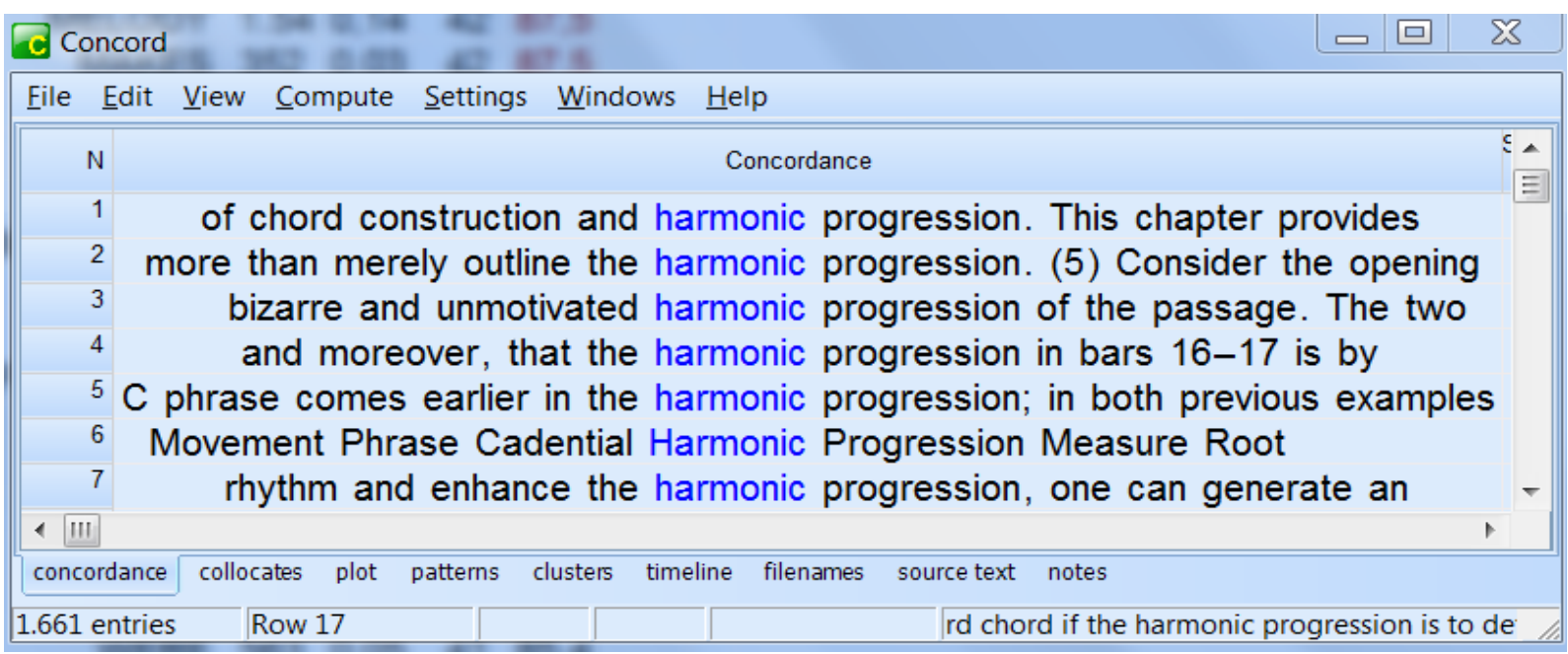

Figura 164 - Linhas de concordância parciais de "harmonic progression" 
Extraímos do subcorpus acadêmico-científico alguns excertos que mostram as colocações em contexto de uso:

- This gospel figure does not neatly agree with the chord progression here, and as in other instances, it creates momentary tensions between melody and harmony. (INGTMDM02)

- In the original chord progression, the melodic motion $E b-F$ in the penultimate measure is supported with the diatonic ii7-V7 progression. (INGTMART14)

- The overall harmonic progression in the verse is VI-II-IVnatural-I. This progression supports a-descent in the upper voice, with the arrival on coinciding with the cadence on I. (INGTMART10)

Dessa análise, sugerimos as seguintes correspondências:

Progressão de acordes $\Leftrightarrow$ Chord progression

Progressão harmônica $\Leftrightarrow$ Harmonic Progression

As colocações serão apresentadas no mesmo verbete.

\section{2) Acorde interpolado}

A colocação "acorde interpolado" tem a frequência de 15 ocorrências no subcorpus de Português. É uma das colocações encontradas em dicionário de termos musicais, com a seguinte definição:

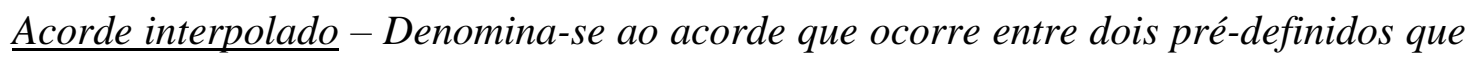
fazem parte de um conjunto (clichê) harmônico.(DP-GALTER)

No subcorpus instrucional, localizamos os seguintes contextos:

- Note que nos exemplos acima, o Db7 é um acorde interpolado, pois se encontra no meio de um II cadencial primário (ex.s 1, 2 e 3) e de um dominante primário (ex. 4). (PORTMAPO05) 
- Acordes interpolados são os que estão no meio de uma progressão. Exemplo de acorde interpolado em progressão ii-V-I: Dm-Bb-G-C. Exemplo de acorde interpolado em resolução de dominante: G-Bb-C. (Teoria Musical AvançadaJulio Drehmer) Neste trecho, o acorde interpolado é o Bb (Si bemol).

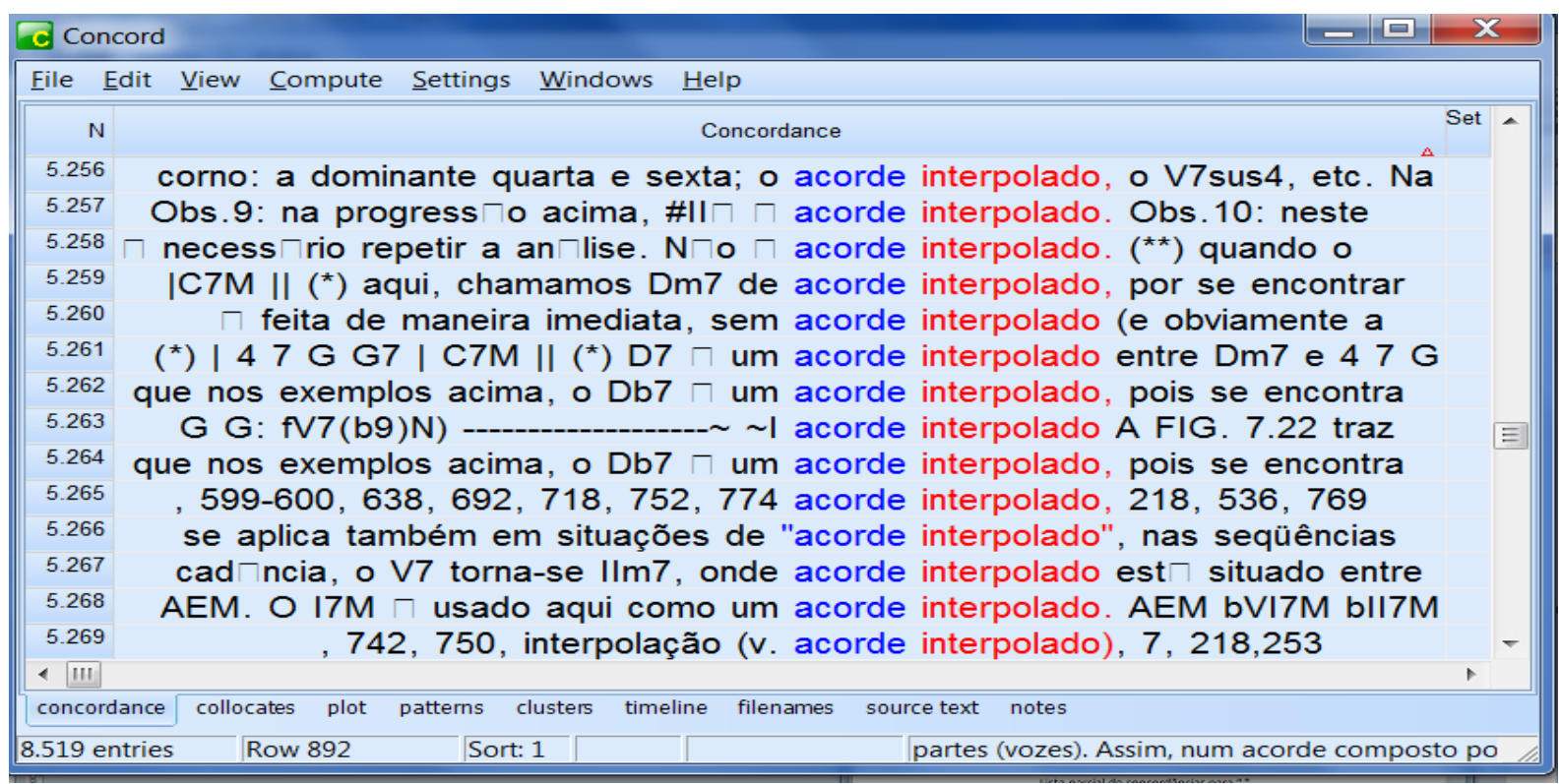

Figura 165 - Linhas de concordância de "acorde interpolado"

Extraímos do subcorpus acadêmico-científico um excerto que mostra a colocação em contexto de uso:

Arno Roberto Von Buettner (2004, p.31) apresenta uma série de procedimentos de ampliação harmônica, no contexto da música popular, dentre eles, a Interpolação Harmônica, que “... acontece quando, numa cadência, o V7 torna-se IIm7, onde acorde interpolado está situado entre duas Dominantes" (PORTMART04)

$\mathrm{Na}$ busca por correspondente em Inglês, localizamos a colocação "interpolated chord", apresentando a frequência de 3 ocorrências, no plural. Como contexto definitório, localizamos o seguinte excerto que apresenta mais detalhes sobre o conceito:

If a voice leading chord is preceded by its own dominant, supertonic, or subdominant, or a combination of these, the result is a more elaborate structure called an “interpolation”. The interpolated chords are typically built on raised or lowered steps of the prevailing scale or are borrowed from parallel key. (INGTMLIV07) 


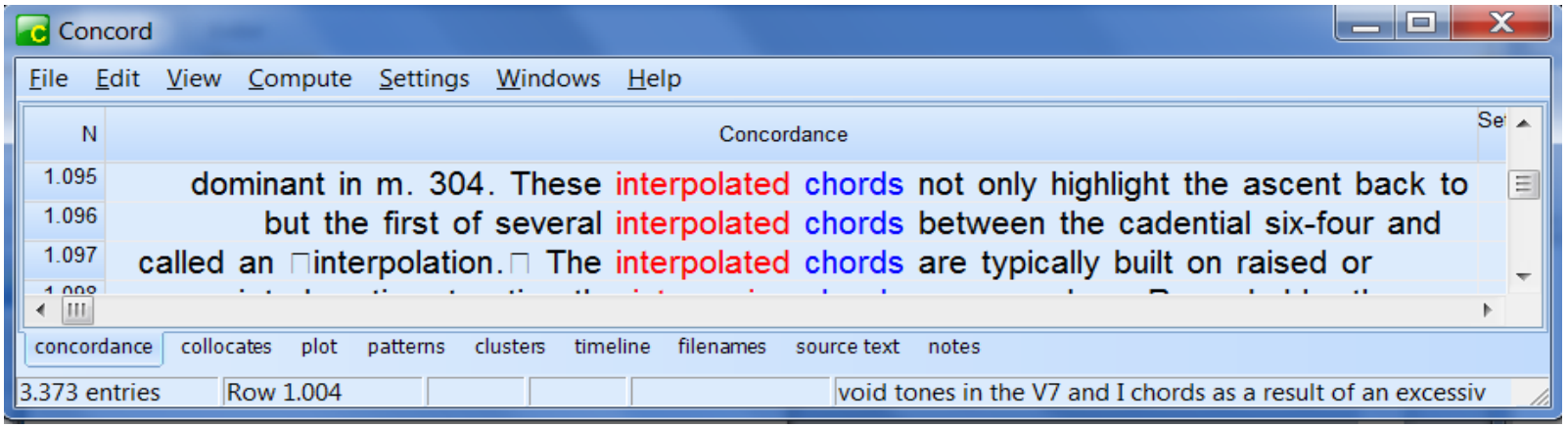

Figura 166 - Linhas de concordância de "interpolated chords"

Os exemplos abaixo mostram contextoss de uso da colocação:

- These interpolated chords not only highlight the ascent back to the obligatory register, they provide an associative harmonic link to the opening half-diminished seventh and the structural keys that it generated. (INGTMDM01)

- This chord is left before it can resolve to its five-three; thus, the A-minor harmony of $m .301$ is not a deceptive resolution but the first of several interpolated chords between the cadential six-four and its resolution to a root-position dominant in $\mathrm{m}$. 304. (INGTMDM01)

\section{3) Acorde de preparação, acorde pré-dominante}

O uso do binômio "preparação e resolução" é convencional em Harmonia (25 ocorrências no corpus de estudo) e está relacionado ao modo como as dissonâncias são tratadas. Como vimos anteriormente, o conceito de dissonância depende muito da abordagem harmônica utilizada, sendo um campo fértil para discussões entre especialistas. Desta forma, a preparação e resolução de acordes dissonantes dependerá muito da abordagem harmônica adotada.

Na nossa investigação, verificamos que a colocação "acorde de preparação" tem a frequência de 13 ocorrências no subcorpus de estudo.

Selecionamos um excerto de um texto (que segue uma abordagem harmônica funcional para análise de música popular), em que acordes de preparação e de resolução são 
subdivididos com base na função. Acordes de preparação, por exemplo, estão relacionados com a função dominante:

Função Dominante: Acordes de preparação. Proporcionam tensão, geram instabilidade. São responsáveis pela necessidade de movimento harmônico entre os acordes. (PORTMDM03)

O mesmo texto explica:

$O$ princípio de movimento entre os acordes, baseado na relação de preparação e resolução, faz com que os acordes de uma tonalidade assumam funções específicas para cada situação. Podemos generalizar que acordes com função de preparação se caracterizam pela necessidade de proporcionar instabilidade harmônica. São acordes cujo potencial harmônico pode ser amplamente de conflito, expectativa. (PORTMDM03)

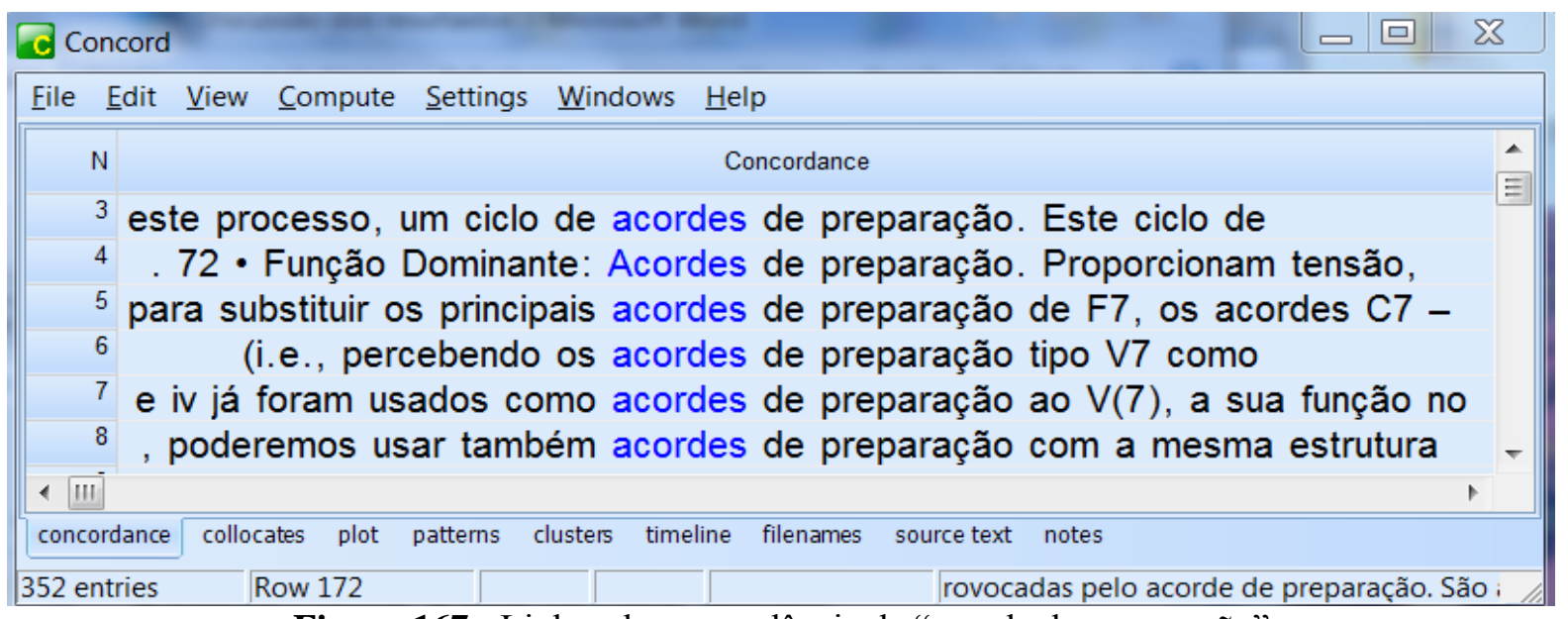

Figura 167 - Linhas de concordância de "acorde de preparação"

Selecionamos outros excertos em que a colocação é utilizada:

- Para gerar mais movimento harmônico, baseado na relação de preparação e resolução entre os acordes, proporcionou dentro do mesmo compasso, um movimento tônica-dominante, utilizando uma tétrade de Emaj7b5 (mi-sol\#-sibré\#), em estado fundamental, para substituir os principais acordes de preparação de F7, os acordes $C 7$ - dominante principal e Gb7 - dominante substituto.(PORTMART29) 
- Com isso, focando os lugares de chegada (i.e., percebendo os acordes de preparação tipo V7 como coadjuvantes)... (PORTMTE02)

No subcorpus de Inglês, analisando contextos semelhantes, encontramos a colocação dominant preparation chord (2 ocorrências) e dominant preparation na forma reduzida.

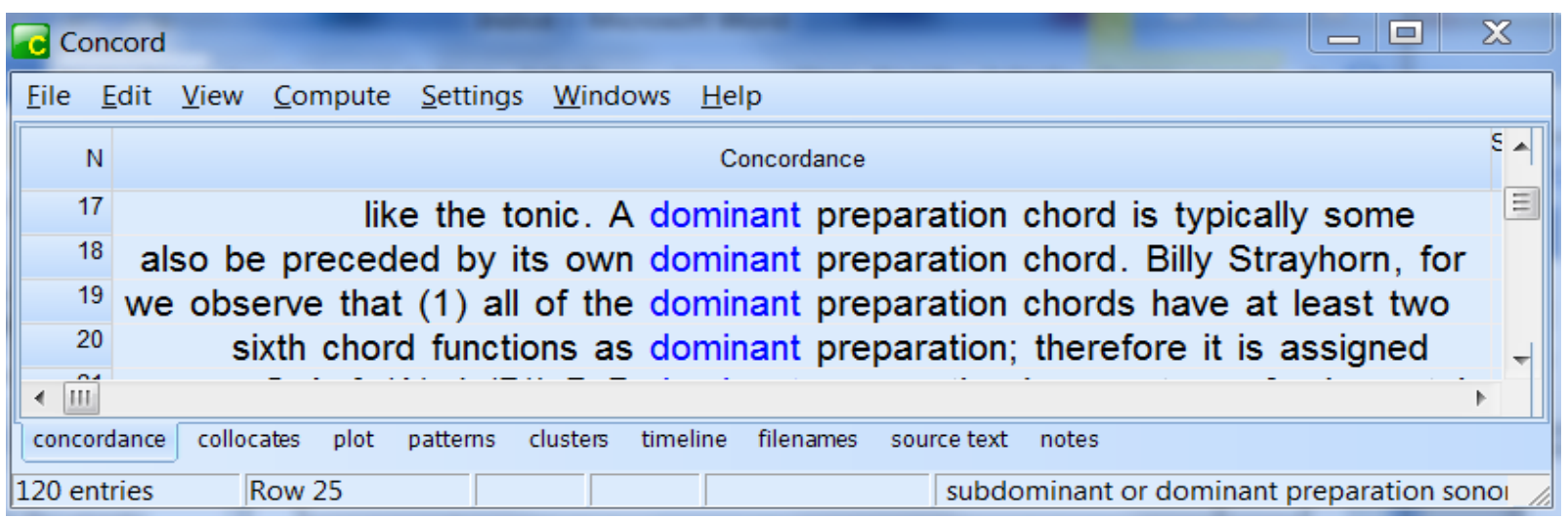

Figura 168 - Linhas de concordância (parciais) de" dominant preparation chord " $\mathrm{e}$ "dominant preparation"

Extraímos do subcorpus de Inglês o seguinte contexto para Dominant Preparation:

Three functions - Dominant Preparation, Dominant, and Tonic - are needed to establish a key. A single major or minor chord is undefined. Prefacing it with its own dominant somewhat clarifies its meaning, but the situation is still ambiguous. A third chord is needed to "prepare" the dominant - that is, to make it sound like the dominant - after which the original major or minor chord will sound unambiguously like the tonic. A dominant preparation chord is typically some form of II or IV. (INGTMLIV07)

Observando o trecho (de um texto relacionado à Teoria do Jazz, que menciona na análise harmônica a vertente funcional), verifica-se que "dominant preparation" antecede a dominante. O trecho exemplifica que os acordes típicos dessa função são: II (Supertônica) e IV (subdominante). A partir do contexto dessa colocação, examinamos a colocação "predominant chord" (ou "predominant chord", variante sem hífen), com 17 ocorrências, e comparamos os contextos: 
Whereas tonic and dominant functions are sufficient to create coherent musical passages, a third harmonic functions adds a new dimension to our sense of harmonic tension and resolution. These chords are called pre-dominants because they precede the dominant. The most important pre-dominant chords are IV and ii. (INGTMLIV13)

De acordo com o trecho, o termo predominant também se refere ao acorde que antecede a dominante, sendo os principais acordes pré-dominantes: a supertônica e a subdominante.

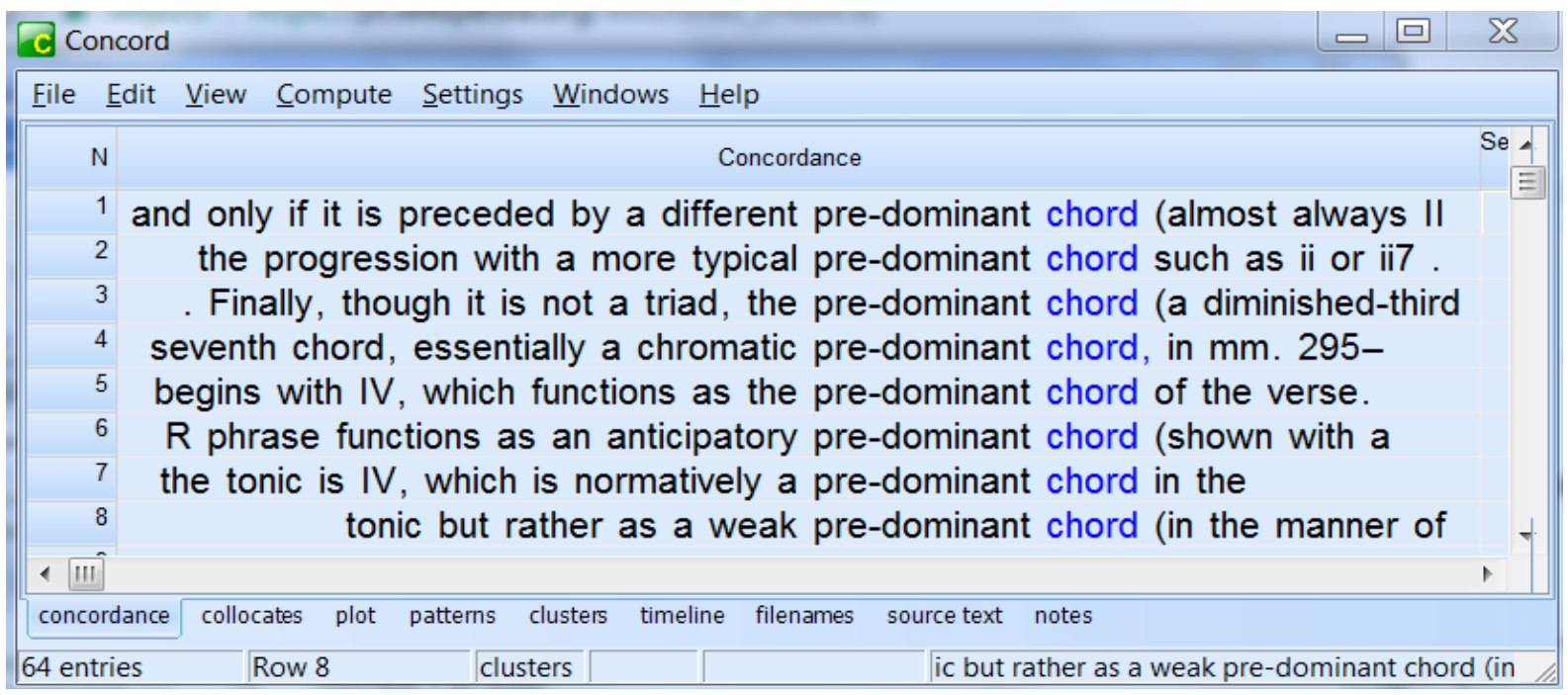

Figura 169 - Linhas de concordância de "pre-dominant chord"

Os excertos a seguir, extraídos do subcorpus acadêmico-científico, apresentam contextos de uso da colocação:

- $\quad$ The D phrase then begins with IV, which functions as the pre-dominant chord of the verse. (INGTMART10)

- Construed in this way, the application of the common-practice functional system to rock would seem to fail immediately: the data in Table 2 suggests that the most common chord to precede the tonic is $I V$, which is normatively a pre-dominant chord in the common-practice system.(INGTMART12)

No subcorpus de português, encontramos a colocação correspondente de predominant chord: acorde pré-dominante. Ela apresenta uma baixa frequência no subcorpus de português. 
Os trechos abaixo, extraído de um mesmo texto, apresentam contextos de uso da colocação e do termo:

- Em função deste raciocínio de base ramista, alguns autores consideram os acordes pré-dominantes como derivados da sous-dominante, $i . \quad e$, transformações do feixe ré-fá-lá-dó. (PORTMTE02)

- Hoje podemos dizer que, nestes casos, "(SubV7/V7)" e "S" são igualmente "pré-dominantes", mas tal expressão técnica-teórica é relativamente recente e não é necessariamente reconhecida por todos. (PORTMTE02)

Na nossa análise, o uso da expressão "pre-dominant" tem frequencia maior em Inglês, combinando com os termos função e acorde. Em Português, "pré-dominante" ocorre mais com o termo "função" (16 ocorrências). Destacamos um trecho que explica a diferença entre acordes de função pré-dominante e subdominante:

A FIG. 4.11 está organizada a partir da memória ampliada de uma progressão tipo IIV-1. No lugar II (FIG. 4.11a, b, c, d) estão reunidos acordes (graus, tensões, notas e escalas) com função subdominante (aqueles que podem anteceder o $V$ numa cadência, mas que podem também desempenhar função de um lugar de chegada) elou com função pré-dominante (acordes que, necessariamente, antecedem o $V$ formando combinações cadenciais variantes da progressão tipo II-V-I).(PORTMTE02)

De acordo com os trechos analisados, sugerimos as correspondências:

Acorde pré-dominante $\Leftrightarrow$ Predominant chord, Pre-dominant chord

Acorde de preparação (da dominante) $\Leftrightarrow$ Dominant Preparation chord

\section{4) Acorde de resolução}

A colocação "acorde de resolução" tem a frequência de 166 ocorrências no subcorpus de português. Como foi explicado no item anterior, o uso do binômio "preparação e resolução" é convencional em Harmonia (25 ocorrências no corpus de estudo) e está relacionado com o modo como as dissonâncias são preparadas e resolvidas. Como vimos 
anteriormente, o conceito de dissonância depende muito da abordagem harmônica utilizada e gera discussões entre especialistas.

Não encontramos contextos definitórios, então selecionamos alguns contextos em que a colocação é utilizada:

- Todo acorde de resolução funciona como tonalidade principal (I grau) ou secundária (demais graus) e, para cada um deles, existe uma tonalidade paralela localizada a uma distância de trítono da sua fundamental. Estes dois acordes estão intrinsecamente ligados por dois acordes dominantes em comum. (PORTMAPO05)

- Tais acordes podem ser intercambiáveis aos acordes dominantes por possuírem em sua estrutura, o mesmo trítono, intervalo este responsável pela tensão harmônica do acorde, resolvida no acorde de resolução. (PORTMDM03)

- O exemplo em questão mostra que, se por um lado o VI6 não se encaixa como representante do VI na cadência de engano, tampouco é satisfatório como acorde de resolução (isto é, como representante da tônica) para uma cadência autêntica. (PORTMART14)

Da análise dos três trechos, concluímos que o "acorde de resolução" funciona como um antídoto à tensão causada pelo acorde anterior, trazendo uma sensação de repouso. 


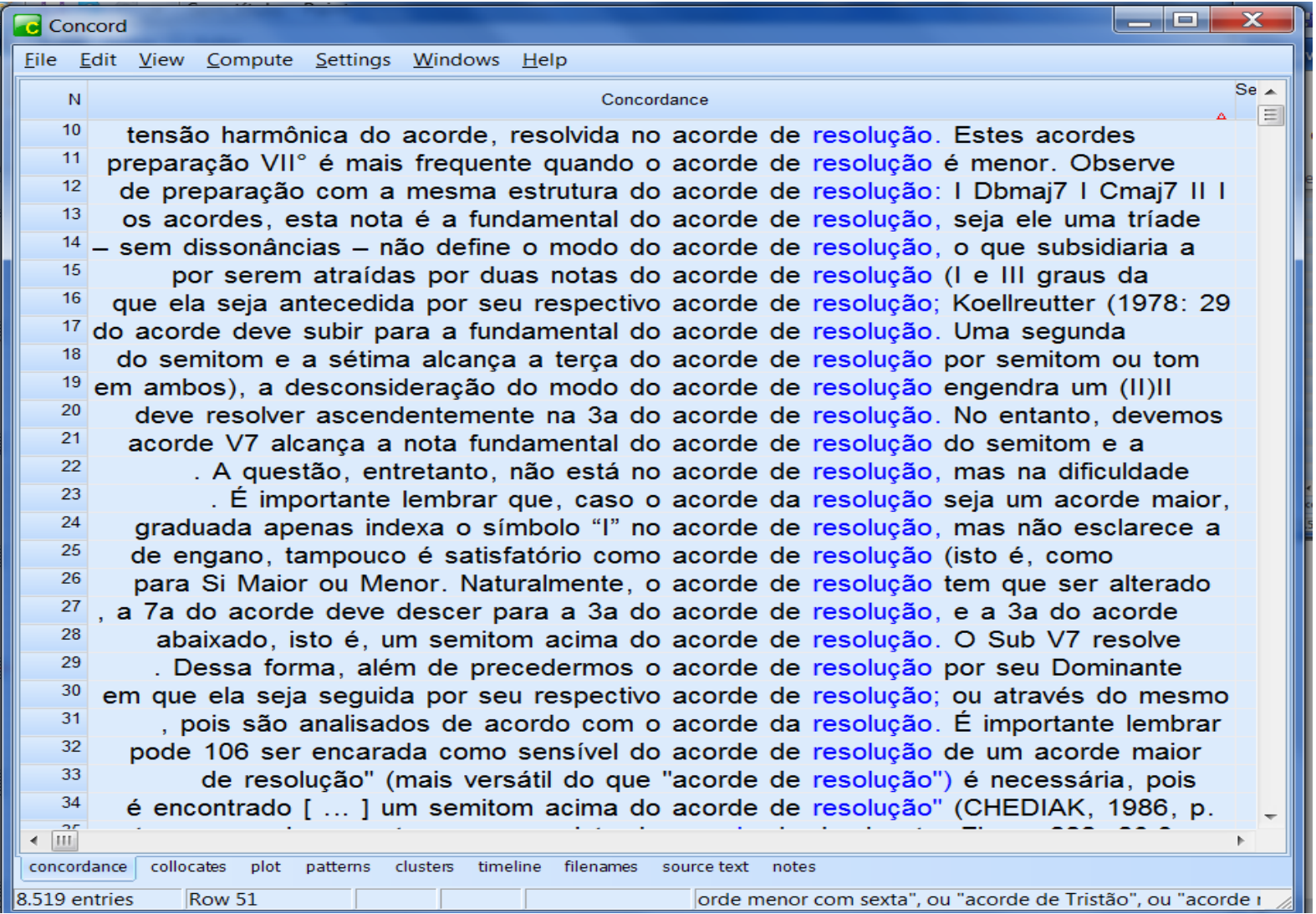

Figura 170 - Linhas de concordância parciais de "acorde de resolução"

No subcorpus de inglês, encontramos as colocações correspondentes "resolution chord" (4) e "chord of resolution"(14 ocorrências):

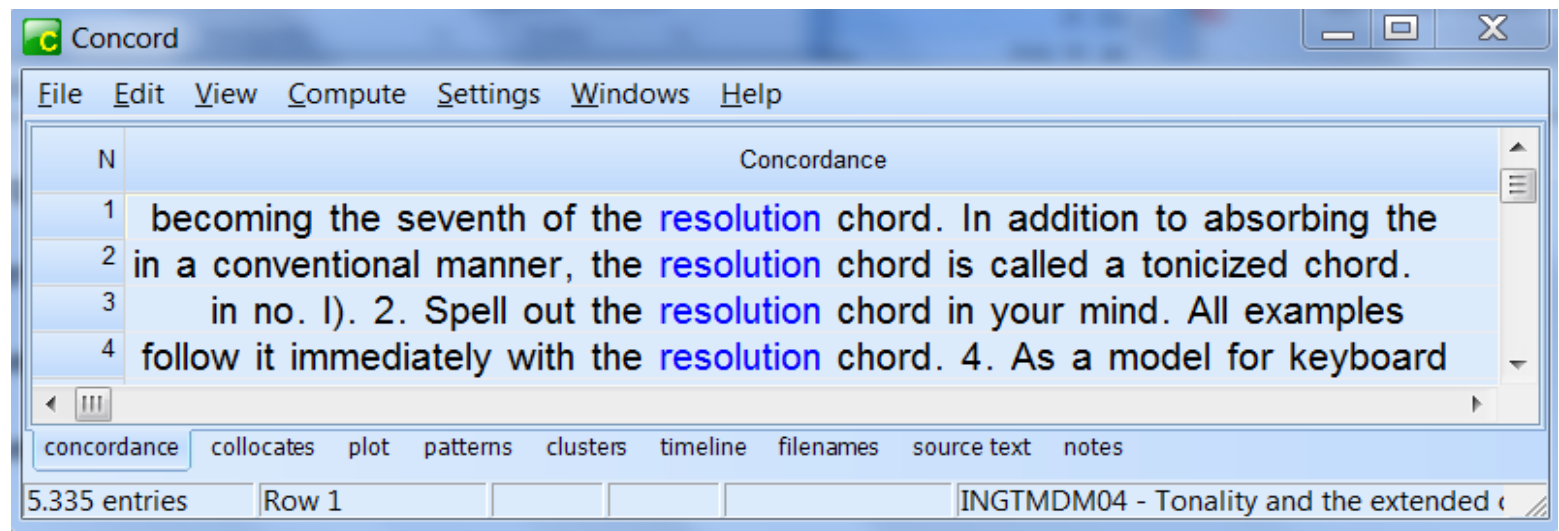

Figura 171 - Linhas de concordância de "resolution chord" 


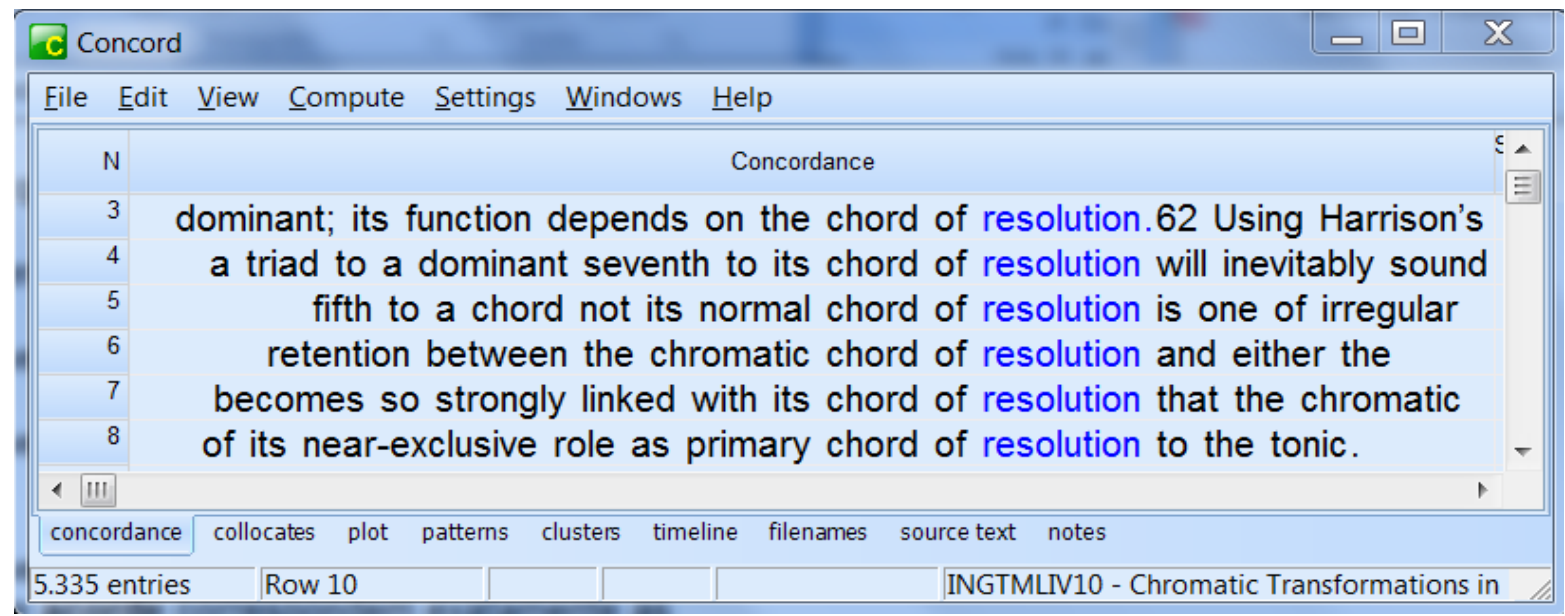

Figura 172 - Linhas de concordância de "chord of resolution"

Nos excertos abaixo, verificamos que as colocações correspondentes apresentam significado próximo ao da colocação em Português, em relação à sensação de repouso (relacionada à função tônica):

- In a common-practice deceptive cadence, the chord of resolution is felt as a tonic substitute, and still requires a second attempt at cadencing to capture the proper original key. In a CMCR, by contrast, the chord of resolution is a stable tonic, fit for either concluding a cue or initiating a new musical paragraph in its own key. (INGTMART07)

- When secondary leading-tone chords resolve in a conventional manner, the resolution chord is called a tonicized chord. When vii $7 / N$ resolves to $V$, the $V$ triad is the tonicized chord. (INGTMLIV02)

\section{5) Acorde cadencial}

A colocação "acorde cadencial" tem a frequência de 40 ocorrências no corpus de estudo. O termo cadencial, assim como acorde de passagem, é utilizado de forma abrangente. $\mathrm{O}$ adjetivo cadencial se reporta ao termo cadência, que em Harmonia significa uma sequência de acordes que finalizam uma frase, um período ou uma peça, podendo ter caráter conclusivo ou não (LIMA, 2008). Um exemplo de cadência é a formada pela dominante (V) e a tônica (I), conhecida como cadência perfeita, pois traz a sensação de conclusão. 
O trecho a seguir foi retirado do subcorpus acadêmico-científico e mostra a colocação em contexto de uso:

Na próxima seção, as cadências básicas serão expandidas: avaliaremos todas as dissonâncias que os acordes cadenciais suportam como notas reais ou de passagem. (PORTMTE01)

A partir da definição do termo cadência e da análise do excerto acima, pode-se deduzir que "acordes cadenciais" são aqueles que fazem parte de uma dada cadência.

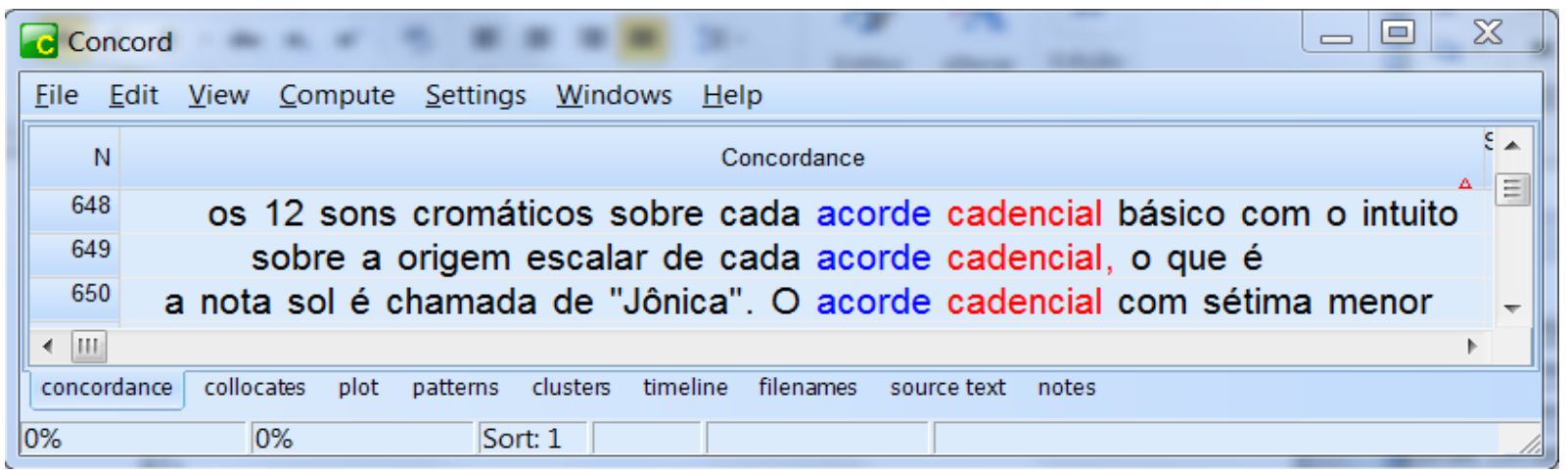

Figura 173 - Linhas de concordância (parciais) de "acorde cadencial"

Na busca por correspondente em Inglês, localizamos a colocação "cadential chord", cuja frequência é de 14 ocorrências.

- If IV and $V$ are the most common pre-tonic cadential chords in rock, one might ask why this is so. (INGTMART12)

- And in the second movement of the Third String Quartet, a recurring emphasis on pitch class $C$ within an E minor context ultimately leads to a final cadential chord that simultaneously suggests E minor, C major, and C minor.(INGMART16)

No primeiro excerto, os "acordes cadenciais" (que antecedem a tônica) são a subdominante e a dominante; e no segundo, o "acorde cadencial" (final) pode ser um dos três sugeridos: Mi menor, Dó maior ou Dó menor). Nesses exemplos verificamos que a colocação é utilizada de forma abrangente, referindo-se, de fato, aos acordes pertencentes a uma dada cadência. 


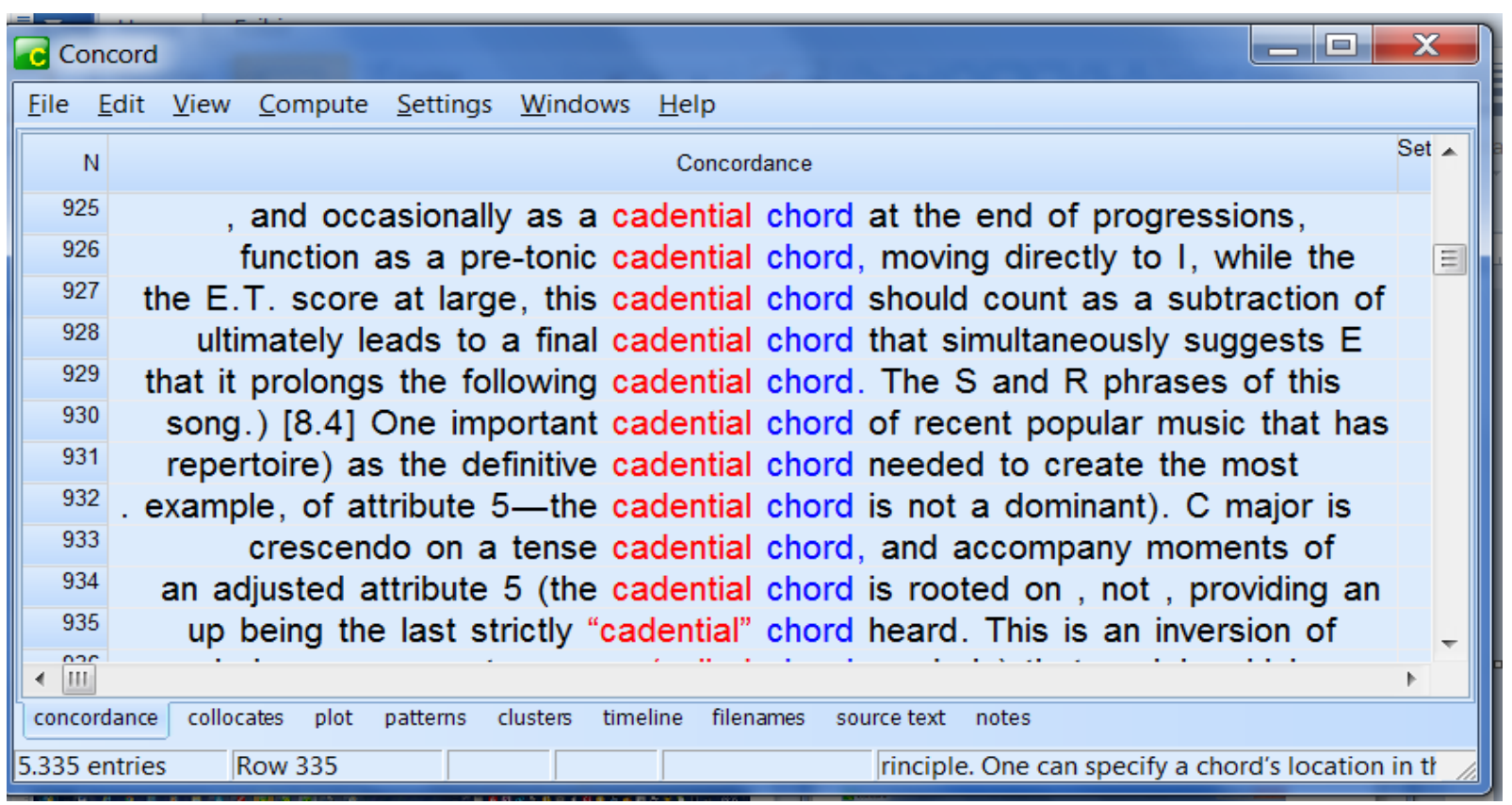

Figura 174 - Linhas de concordância (parciais) de "cadential chord"

No item seguinte, será detalhado um tipo de acorde cadencial que é o "acorde de quarta e sexta cadencial".

\section{6) Acorde de quarta e sexta cadencial}

A colocação "acorde de quarta e sexta cadencial" tem uma frequência baixa (4 ocorrências) no subcorpus de estudo. A investigação foi motivada pela análise da lista de concordâncias geradas para a colocação "acorde de quarta e sexta".

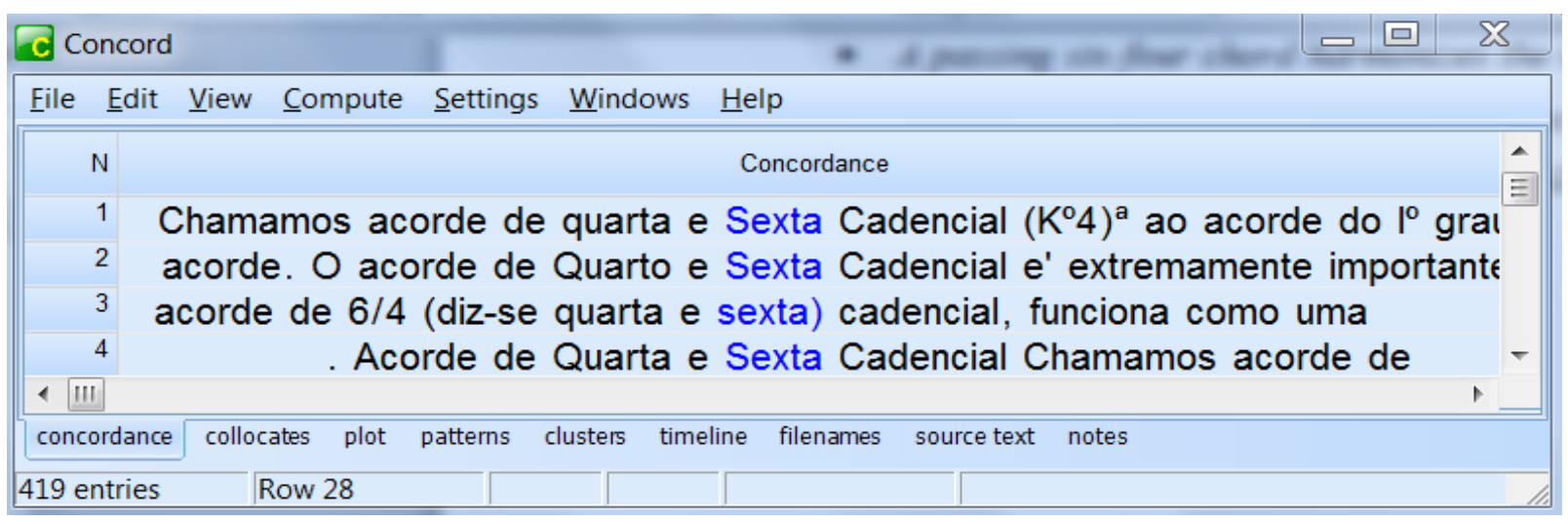

Figura 175 - Linhas de concordância de "acorde de quarta e sexta cadencial" 
No subcorpus instrucional, localizamos dois contextos definitórios:

- O acorde de quarta e sexta cadencial funciona como uma preparação forte para o acorde de dominante. Na realidade o acorde de quarta e sexta cadencial $\left(2^{a}\right.$ inversão) é considerado como uma apojatura dupla de um acorde de V ou V7. Para que o acorde tenha esta função claramente definida é necessário que esteja em tempo forte. (PORTMAPO01)

- Chamamos acorde de quarta e sexta cadencial ao acorde do lo grau na segunda inversão que precede a Dominante nas cadências. Apesar de ser construído com os sons do acorde do 1 " grau, este acorde é instável, por causa do intervalo de 4" com o baixo. Portanto, sua função se aproxima da Dominante. O baixo $\left(5^{\circ}\right.$ do acorde sobre o $l^{o}$ grau) deve ser dobrado, reforçando esta função harmônica. Este acorde precede o acorde de Dominante nas Cadências, sempre em tempo ou parte forte. Deverá vir precedido pelo subdominante. (PORTMLIV08)

Não encontramos contextos de uso no subcorpus acadêmico-científico de Português, contudo as definições encontradas auxiliaram na localização do correspondente em inglês Cadential six-four chord, com 5 ocorrências. Verificamos também que a variante Cadential six-four apresenta 26 ocorrências.

No subcorpus instrucional de Inglês, encontramos o contexto definitório a seguir:

- The cadential six-four chord is a tonic six-four that delays the arrival of the $V$ chord that follows it. It totally depends upon the $V$ chord for it meaning, and it should not be thought of as a substitute for a tonic triad in root position or first inversion. The cadential six-four occurs in a metrically stronger position than the $V$ chord that it delays. (INGTMLIV12) 


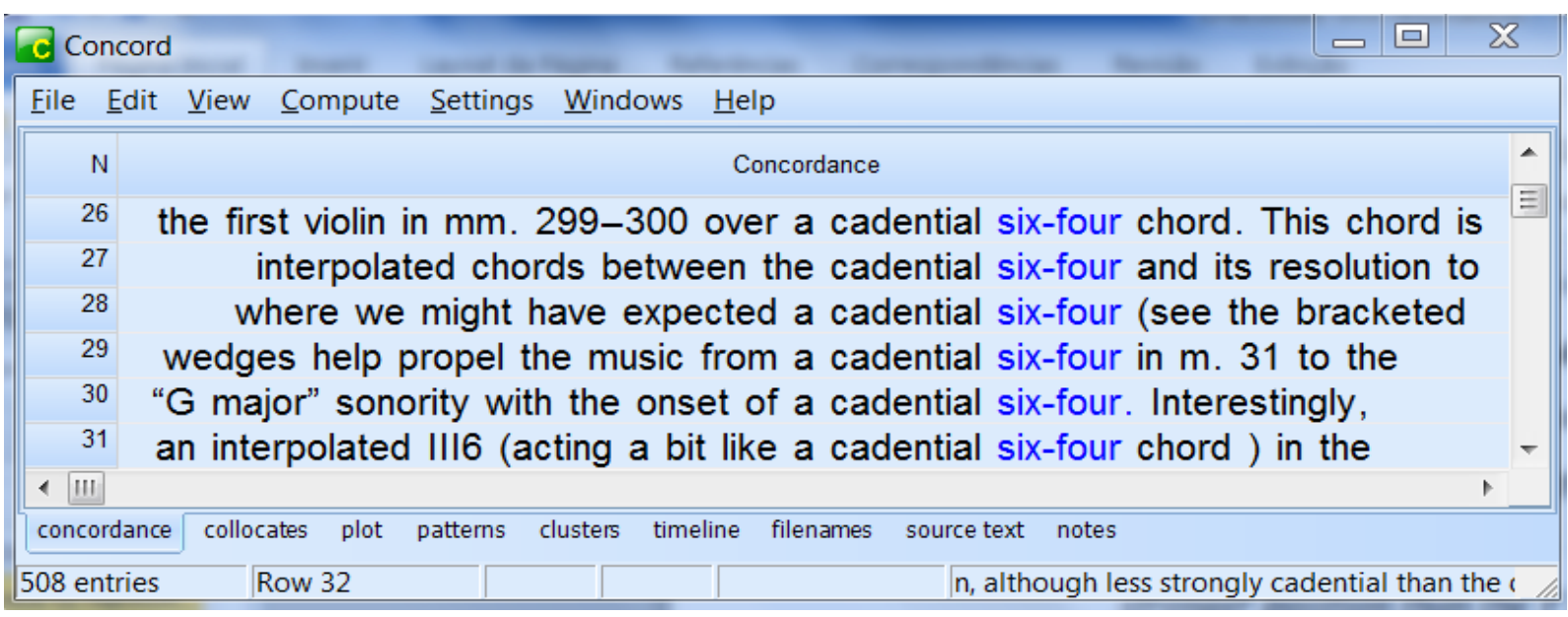

Figura 176 - Linhas de concordância de "cadential six-four chord"

Os trechos extraídos do subcorpus acadêmico-científico apresentam alguns contextos de uso da colocação:

- Cadential six-four chords are notated in the analyses in a two-level fashion, with a "I 6/4 - V" within a larger " $V$ "; the latter analysis was used here. (INGTMART02)

- Moving up by half-steps, the bass finally arrives at a cadential six-four chord of A minor in $m .401 \ldots$ (INGTMDM01)

- the A-minor harmony of $m .301$ is not a deceptive resolution but the first ofseveral interpolated chords between the cadential six-four and its resolution to a rootposition dominant in m. 304. (INGTMDM01)

A forma reduzida acorde de passagem é uma colocação com sentido mais abrangente e será utilizada como remissiva no glossário.

\section{7) Acorde de quarta e sexta de passagem}

A colocação acorde de quarta e sexta de passagem tem uma frequência baixa (2 ocorrências) no subcorpus de estudo. A investigação foi motivada pela análise da lista de concordâncias geradas para a colocação "acorde de quarta e sexta" (item 15). 
No subcorpus de estudo, encontramos o seguinte contexto definitório:

$O$ acorde de quarta e sexta de passagem. As tríades também podem aparecer em $2^{a}$ inversão e como acordes de passagem. Como tal, o acorde de passagem deve estar em tempo fraco. Qualquer uma das tríades pode ser usada como um acorde de quarta e sexta de passagem, no entanto, as mais comuns são os acordes de V6/4 e I6/4, tanto em maior quanto em menor. (PORTMAPO01)

A colocação correspondente em Inglês localizada foi "passing six-four chord" (2 ocorrências), que apresenta um contexto definitório similar:

A passing six-four chord harmonizes the middle note of a three-note scalar figure in the bass. The most common passing six-four chords are the V 6/4 and the I 6/4 chords, and they usually fall on a weak beat.(INGTMLIV12)

No subcorpus acadêmico-científico encontramos o seguinte context de uso:

- This is not a cadential or passing six-four chord; it does not resolve to a rootposition chord and seems a goal in its own right. (INGTMDM01)

A forma reduzida "acorde de passagem" é uma colocação com sentido mais abrangente e será utilizada como remissiva no glossário.

\section{8) Sucessão de acordes, Sequência de acordes}

A colocação "sucessão de acordes" tem a frequência de 10 ocorrências no subcorpus de Português. A busca pela colocação foi motivada pela correspondente em Inglês, "chord succession" que tem uma frequência relevante de 35 ocorrências. 


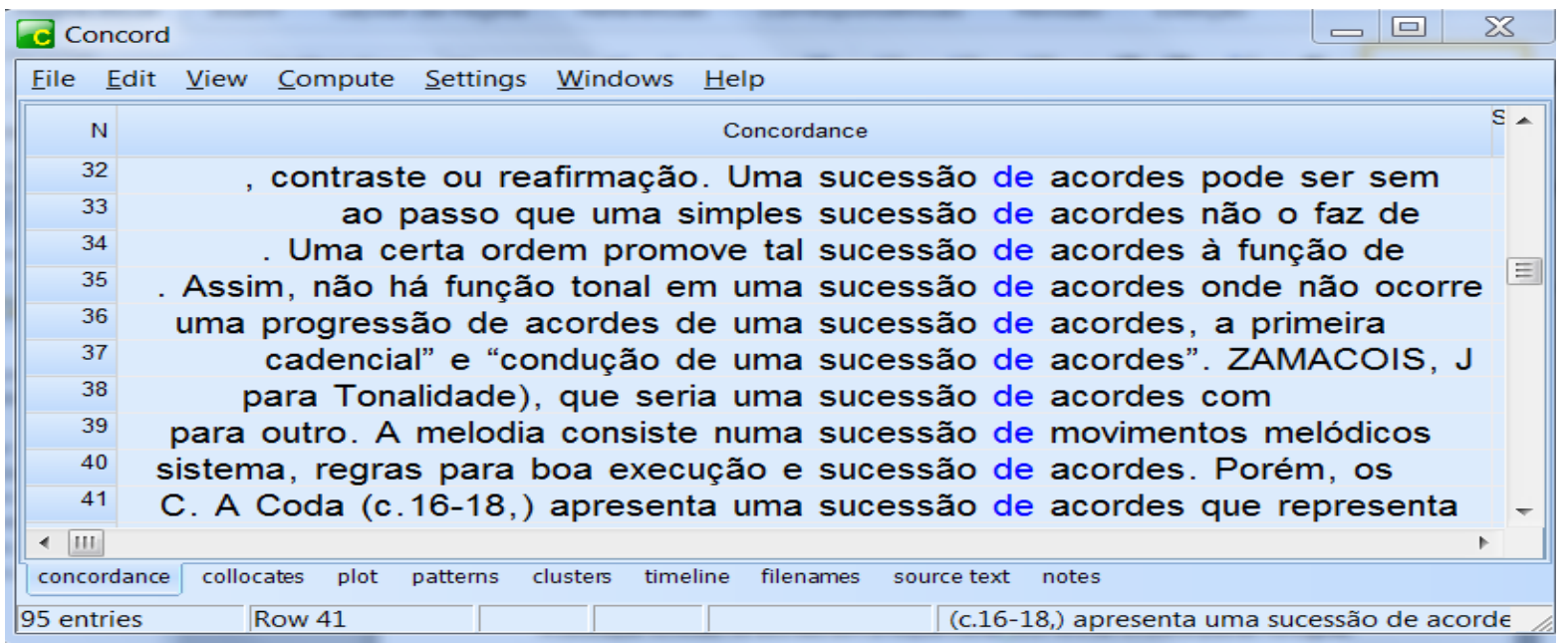

Figura 177 - Linhas de concordância (parciais) de "sucessão de acordes"

Selecionamos alguns contextos de uso em que "sucessão de acordes" aparece:

- Na teoria schoenberguiana a função tonal depende diretamente do relacionamento entre acordes que expressam uma tonalidade. Assim, não há função tonal em uma sucessão de acordes onde não ocorre uma expressão tonal. (PORTMART18)

- Nesta obra, Rameau aponta um importante conceito chamado Tonart (que poderia ser traduzido para Tonalidade), que seria uma sucessão de acordes com dissonâncias encerrando com uma consonância. (PORTMART19)

- A Coda (c.16-18,) apresenta uma sucessão de acordes que representa as quatro regiões harmônicas da estrutura da peça (Ex.24).(PORTMART07)

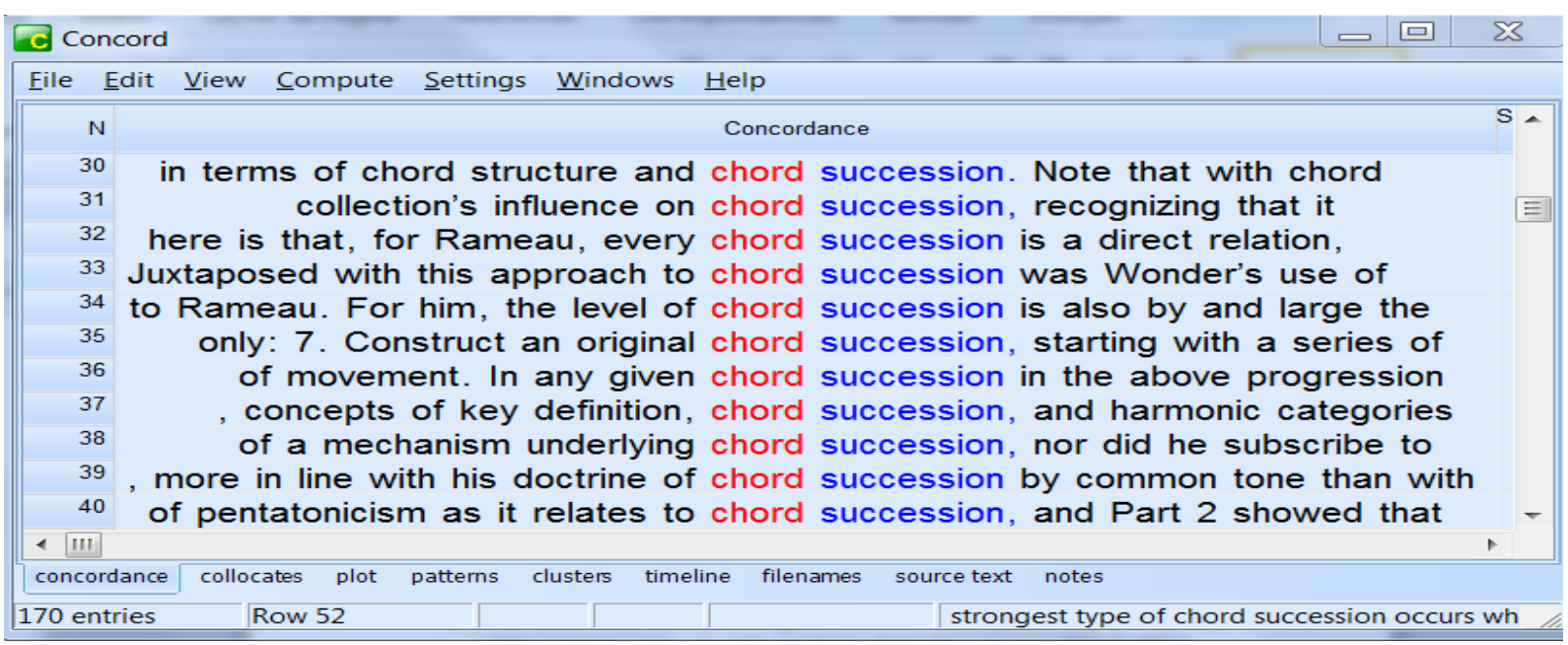

Figura 178 - Linhas de concordância (parciais) de "chord succession" 
- Schoenberg explains that the strongest type of chord succession occurs when the fundamental of a given harmony becomes one of the subordinate pitches of the following harmony.(INGTMTE02)

- This hierarchical system, analogous with the relative positioning of the pitches of the overtone series, provides the basis of chord succession. (INGTMTE02)

- A recognition of the forces of voice leading upon harmony is vital to an interpretation of chord succession here (...) (INGTMART24)

- In any given chord succession in the above progression there are some voices that hold a common tone, some that move by semitone, and others move by a tone or larger.(INGTMDM04)

Outra colocação utilizada com o mesmo sentido de "sucessão de acordes" é "sequência de acordes" (19 ocorrências):

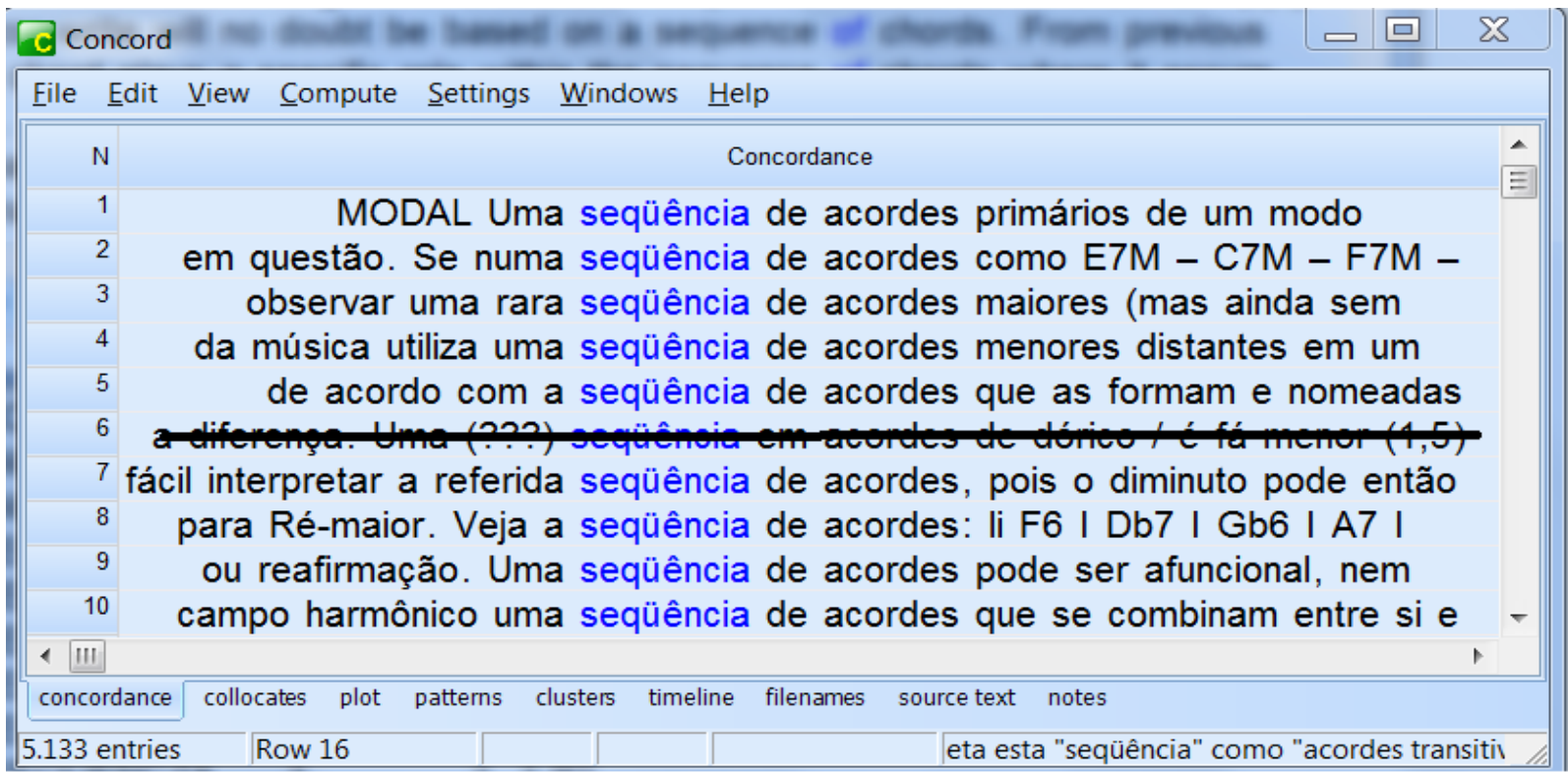

Figura 179 - Linhas de concordância (parciais) de "sequência de acordes"

Um uso comum da colocação "sequencia de acordes" é em descrições:

- As cadências são sequências típicas de acordes, que formam a "pontuação" do trecho musical. Elas são classificadas de acordo com a sequência de acordes que as formam e nomeadas de acordo com a sensação tonal (de tensão/relaxamento) que transmitem (...)(PORTMAPO04) 
- Funcionalmente, cada dominante da passagem forma sozinha a sua própria semifórmula tonal e de certa forma é por isso que, neste caso, a sequência de acordes não “(...) consegue expressar inequivocamente uma região ou tonalidade” (SCHOENBERG, 1969, p. 3).(PORTMART19)

Em Inglês, encontramos como correspondentes as variantes chord sequence (10 ocorrências) e sequence of chords (8 ocorrências).

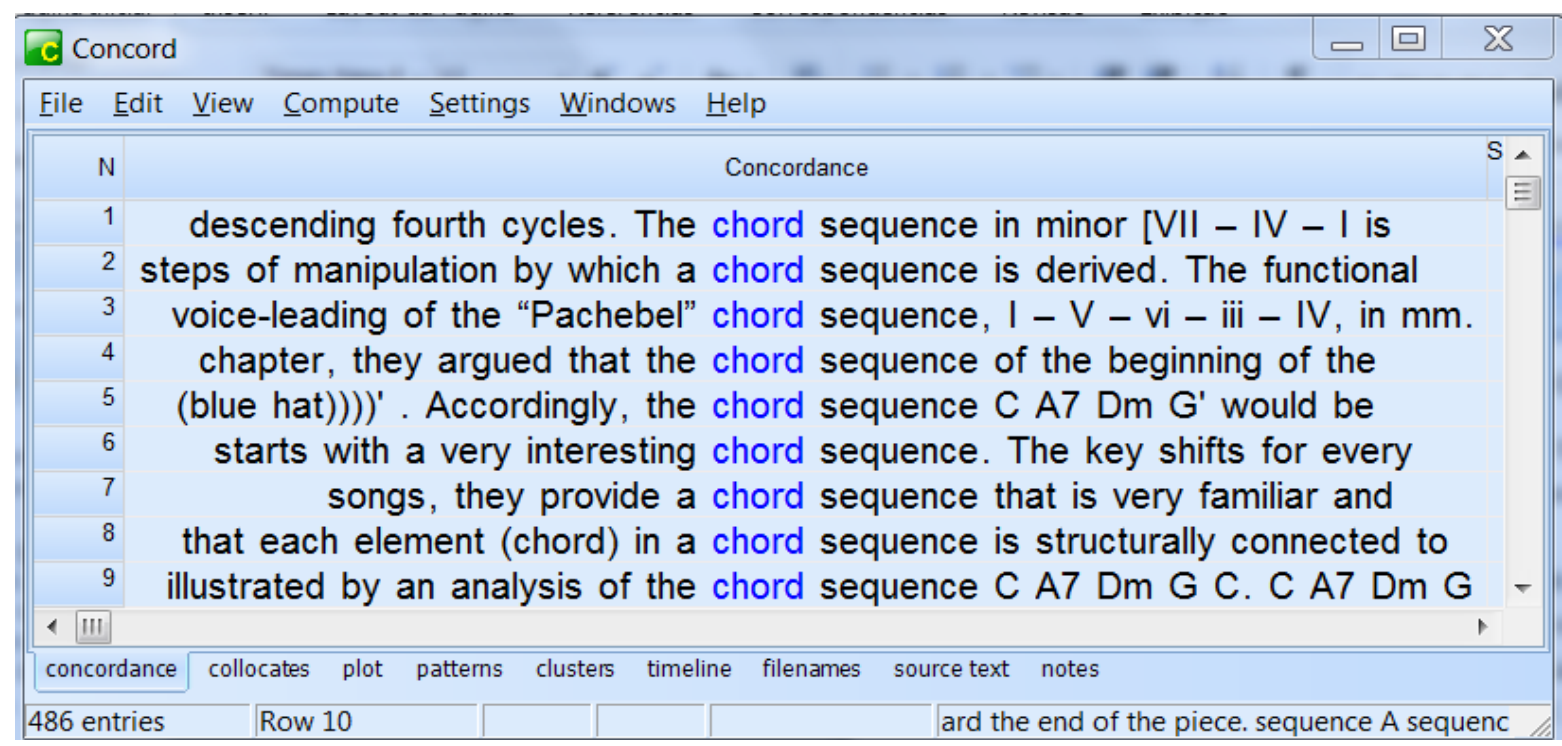

Figura 180 - Linhas de concordância (parciais) de "chord sequence"

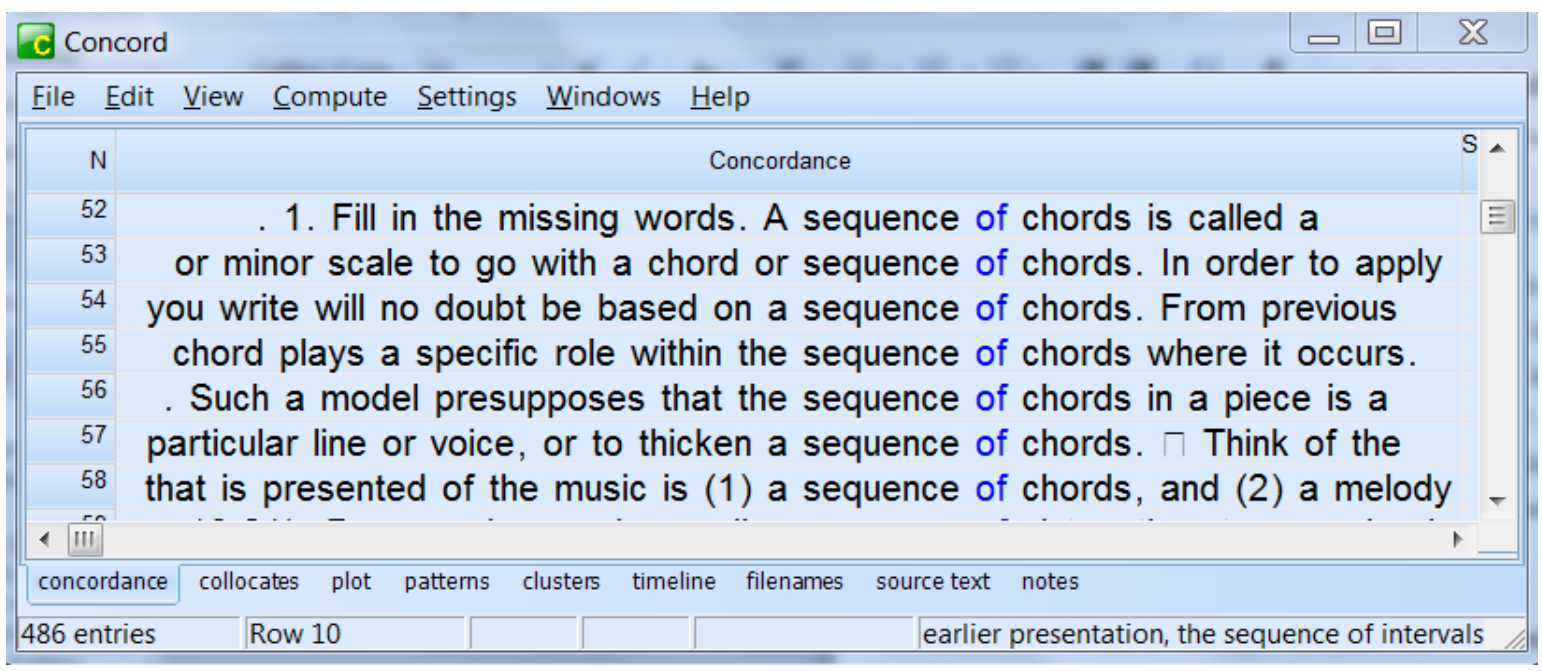

Figura 181 - Linhas de concordância (parciais) de "sequence of chords"

Selecionamos alguns contextos em que as colocações ocorrem: 
- Typically a jazz soloist wants to know what scale to use to improvise a melody over a particular chord or sequence of chords.(INGTMLIV07)

- In contrast to the classical format, where every single note is written out explicitly, in fake book format all that is presented of the music is (1) a sequence of chords, and (2) a melody line. (INGTMART28)

- This principle states that each element (chord) in a chord sequence is structurally connected to its preceding or succeeding chord or chord group in a dependency relationship.(INGTMART20)

- The horizontal lines at level $b$ indicate the linear intervallic pattern of consecutive tenths that drive the voice-leading of the "Pachebel" chord sequence, $I-V-v i-$ iii-IV, in mm.(INGTMDM02)

$\mathrm{Na}$ análise das concordâncias, verificamos que chord sequence e sequence of chords são opções utilizadas com o termo "sequence", porém encontramos ocorrências no corpus para succession of chords. As 35 ocorrências de "chord succession" indicam que a estrutura da colocação é fixa.

$\mathrm{Na}$ relação entre os correspondentes, utilizaremos remissivas. No glossário, as correspondências por colocação serão:

Sequência de acordes $\Leftrightarrow$ chord sequence, sequence of chords

Sucessão de acordes $\Leftrightarrow$ chord succession

\section{9) Acorde comum, acorde pivô}

Em Português, as colocações "acorde comum" e "acorde pivô" aparecem no subcorpus em contextos relacionados à modulação (mudança de uma tonalidade para outra). Neste contexto, tais acordes funcionam como uma ponte, levando de uma tonalidade a outra.

"Acorde pivô" foi uma das colocações que aparecem em dicionário de termos musicais:

- Acorde pivô - Acorde que possui funções diversas em duas tonalidades distintas e serve como ponte modulatória em uma sequencia harmônica. (DP-DOURADO) 
No levantamento de listas de concordâncias do subcorpus de Português, verificamos que acorde comum apresenta 18 ocorrências e acorde pivô, 31. Nos contextos abaixo, percebemos a função de tais acordes:

- A modulação diatônica se processa por um acorde comum às duas tonalidades: a original e a nova. Esse acorde é analisado segundo as funções que desempenha em cada uma. (PORTMAPO06)

- (No processo de modulação), os chamados acordes neutros ou acordes pivôs, são acordes que pertencem a ambas tonalidades e vão servir de mediadores entre elas. (PORTMTE01)

- Schoenberg chama de acorde neutro; Piston chama de acorde pivố; Kostka \& Payne chamam de acorde comum. O fato é que a função é a mesma para os três (PORTMTE01)

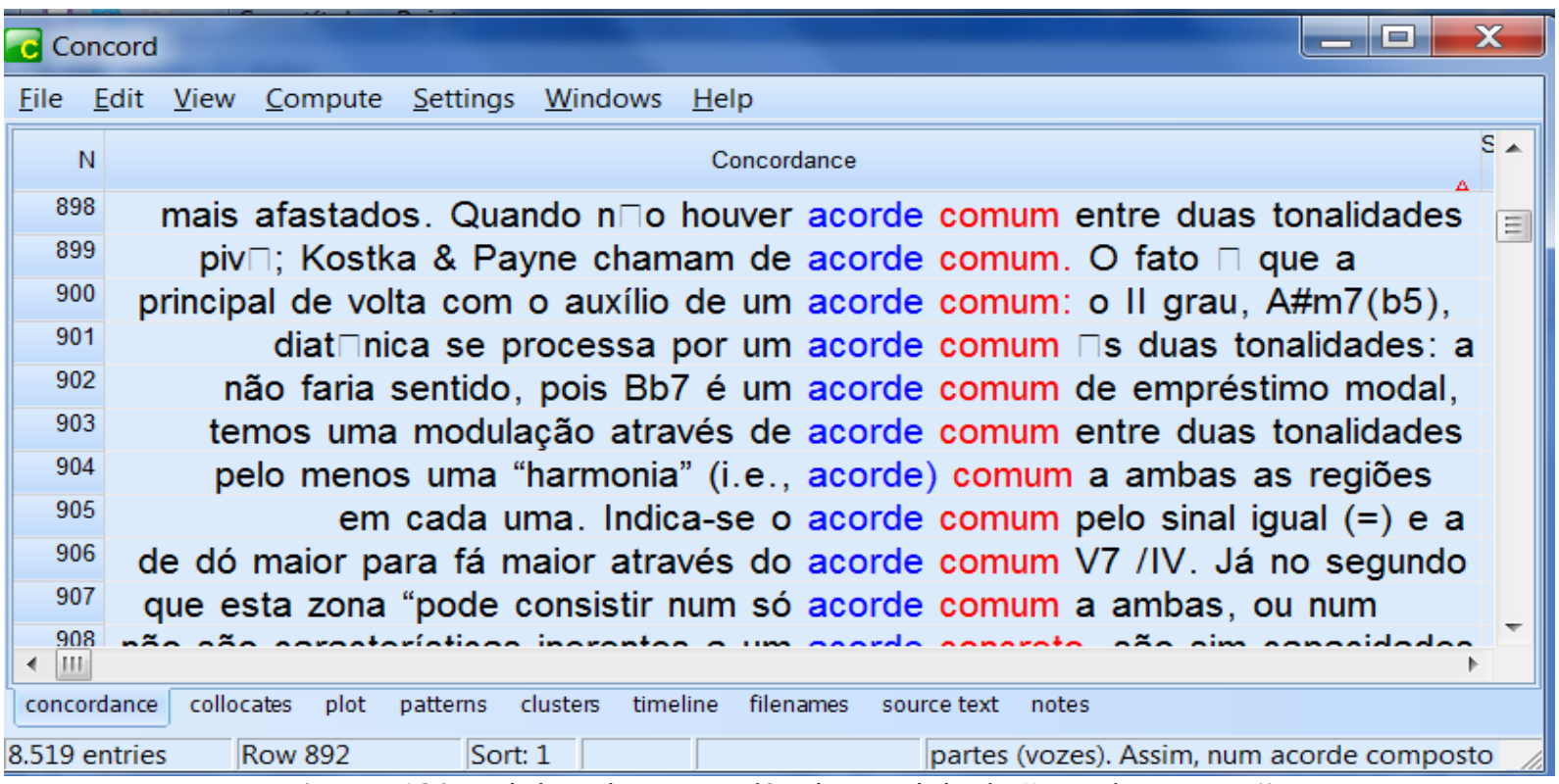

Figura 182 - Linhas de concordância parciais de "acorde comum" 


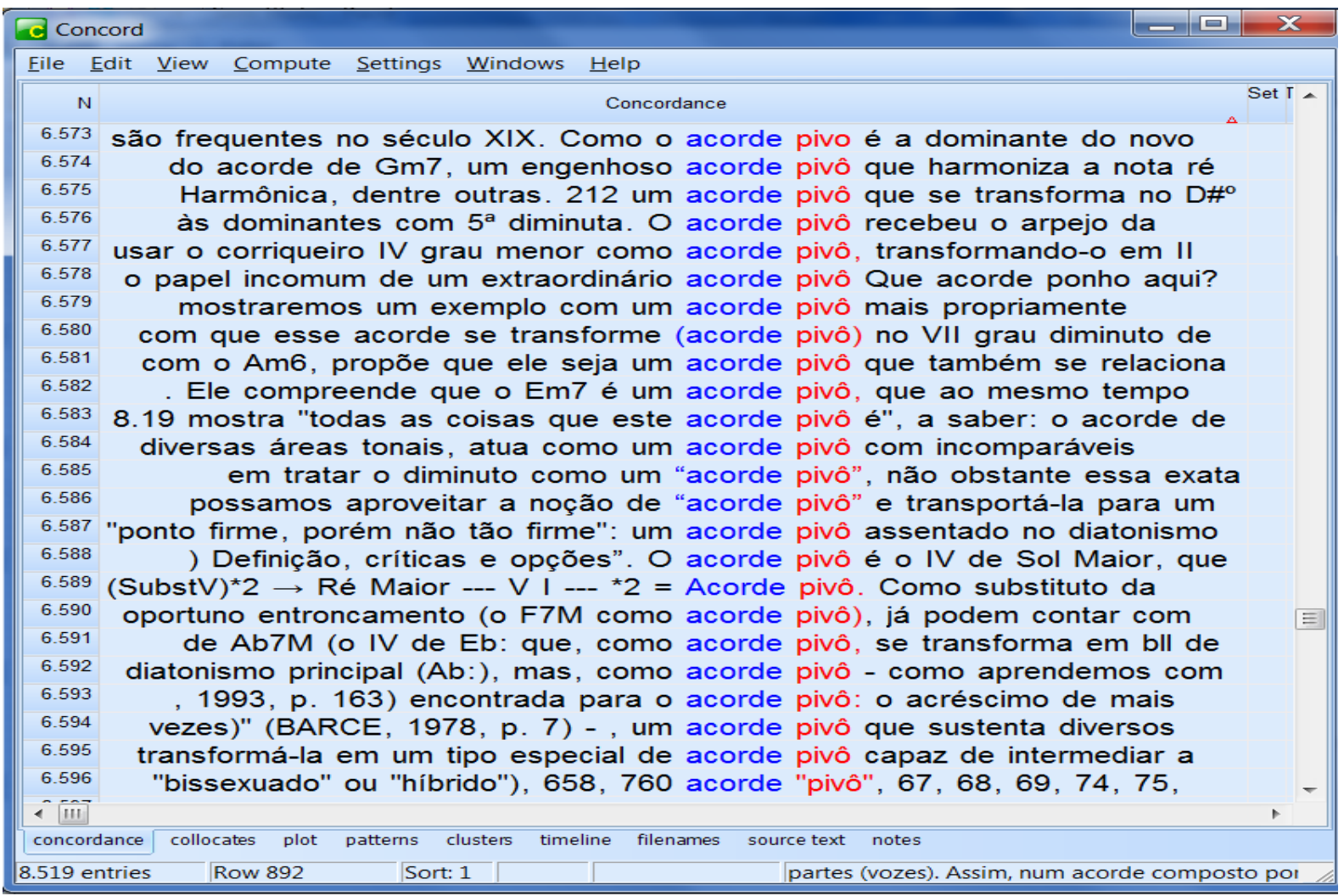

Figura 183 - Linhas de concordância parciais de "acorde pivô"

Para exemplificar, extraímos dois contextos de uso dessas colocações extraídos do subcorpus acadêmico-científico:

\section{Exemplos:}

- "Nó na Garganta" traz o tom principal de volta com o auxílio de um acorde comum: o II grau, A\#m7(b5), do tom principal, Sol\# Menor, é o mesmo acorde que o VII grau da melódica do tom médio, Si Menor. (PORTMTE01)

- $O$ acorde de sexta aumentada pode ser usado numa modulação como acorde pivô em substituição ao acorde de sétima da dominante. (PORTMDM01)

Encontramos no subcorpus de inglês, os seguintes correspondentes: common chord e pivot chord.

Tais colocações também foram encontradas em dicionários de termos musicais com as seguintes definições: 
- Common chord - A triad in which the fifth is perfect, i.e, the major or minor triad. In American usage, only the major triad is so described. (DI-OXFORD)

- Common chord - A chord consisting of the root, third and fifth; a triad. (DI - ON MUSIC)

- Common chord - Major triad. (DI - HARVARD)

E para a colocação pivot chord, encontramos nos dicionários os seguintes contextos definitórios:

- Pivot Chord - In the process of modulation, a chord that has a particular harmonic function in the initial key but a different function in the second key; the harmony following the pivot chord is in the new key. (DI-OXFORD)

- $\quad$ Pivot chord - see Modulation. (DI - HARVARD)

Observa-se que as definições dos dicionários para common chord referem-se à forma do acorde, ou seja, uma tríade maior ou menor, sem especificar seu uso no processo de modulação. A definição de common chord, na descrição dos dicionários, aproxima-se da definição de tríade maior, ou acorde perfeito maior. Com o colocado "common" encontramos o termo triad, no seguinte contexto definitório:

Common triads are called common for the simple reason that they form the majority of the chords used in music. There are two kinds of common triads - the major triad and the minor triad. (INGTMLIV04)

Já na definição de pivot chord, é descrito seu papel no processo de modulação.

No subcorpus instrucional de inglês, encontramos contextos definitórios em que o significado de common chord é próximo ao de pivot chord:

- A common chord, meaning a chord that is common to each of two keys, offers a smooth introduction to the new key, since it is diatonic to both the old and the new key. This common chord is often called a pivot chord because it becomes a sort of middle ground between the two keys. (INGTMLIV02)

- A chord that is common to two keys as a way of leaving the old key and entering the new key in a modulation. The chord that the two keys have in common is called 
the pivot chord, because from it the progression can "pivot" in either direction.

(INGTMLIVO9)

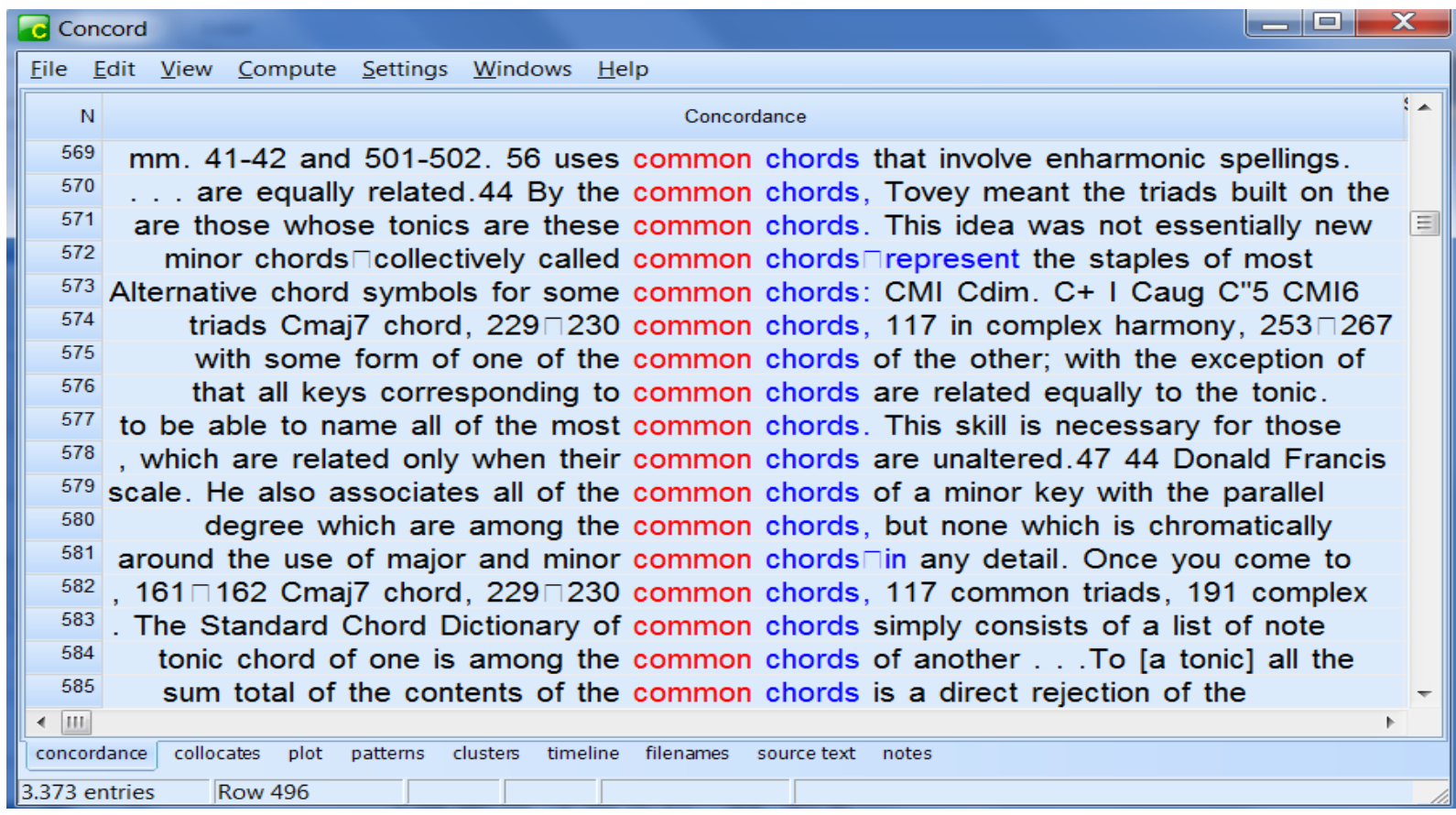

Figura 184 - Linhas de concordância parciais de "common chords"

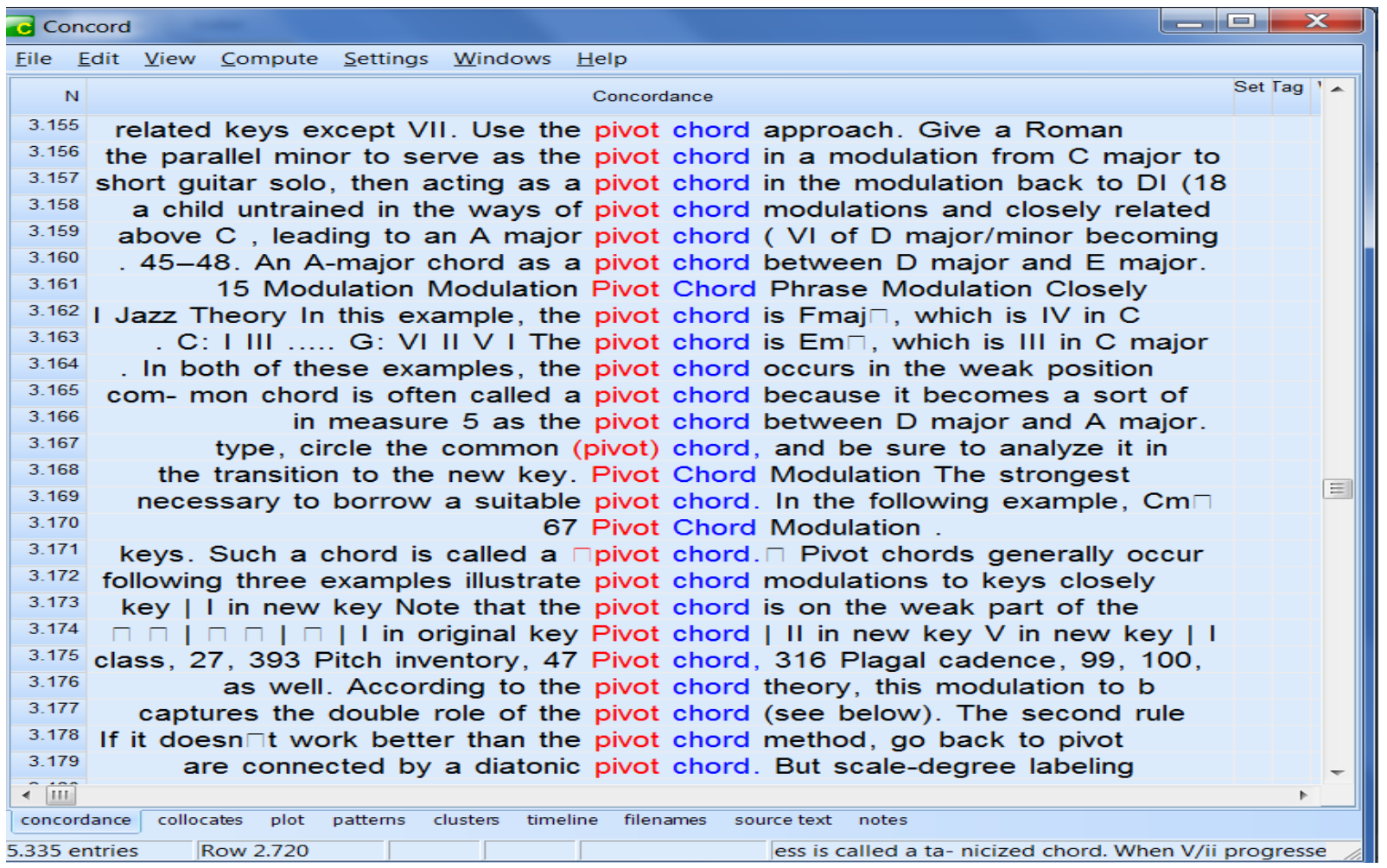

Figura 185 - Linhas de concordância parciais de "pivot chord" 
Os dois exemplos abaixo, extraídos de textos do subcorpus acadêmico-científico, mostram as colocações em contexto de uso. Nos dois casos, o tema é modulação:

- However, Strauss's use of vagrant harmonies enlarges the number of keys related by common chord. (INGTMTEO2)

- When the modulation is initiated through pivot chords in the sequence that may belong to two adjacent keys, the double generation of the pivot chord from two different branches of the parse tree constitutes the preferred form of analysis that captures the double role of the pivot. (INGTMART20)

Com base nas linhas de concordância, verificamos que os contextos apontam para essas correspondências:

- Acorde comum $\Leftrightarrow$ Common chord, common triad

- Acorde pivô $\Leftrightarrow$ Pivot chord

Como observamos no item "Acorde Perfeito", encontramos a tradução de Common chord, em dicionários especializados, como tríade maior, ou acorde perfeito maior. No subcorpus de inglês, encontramos a colocação "Common triad" como tríade maior e menor, que corresponde ao "acorde perfeito". Acrescentaremos uma nota ao verbete sobre os dois significados.

\section{0) Modulação através de acorde comum}

"Modulação através de acorde comum" é uma colocação estendida em que a base é o termo modulação (que corresponde à troca ou à mudança de tonalidade). Neste caso, a colocação estendida é um dos tipos de modulação e, de acordo com o subcorpus instrucional tem o seguinte significado:

Na modulação através de acorde comum, um acorde é considerado como pertencente a dois centros tonais distintos e exerce uma função de ligação na troca de tônica ou região tonal.(PORTMLIV01)

A busca por essa colocação foi motivada pela correspondente em Inglês Common chord modulation (4 ocorrências). 


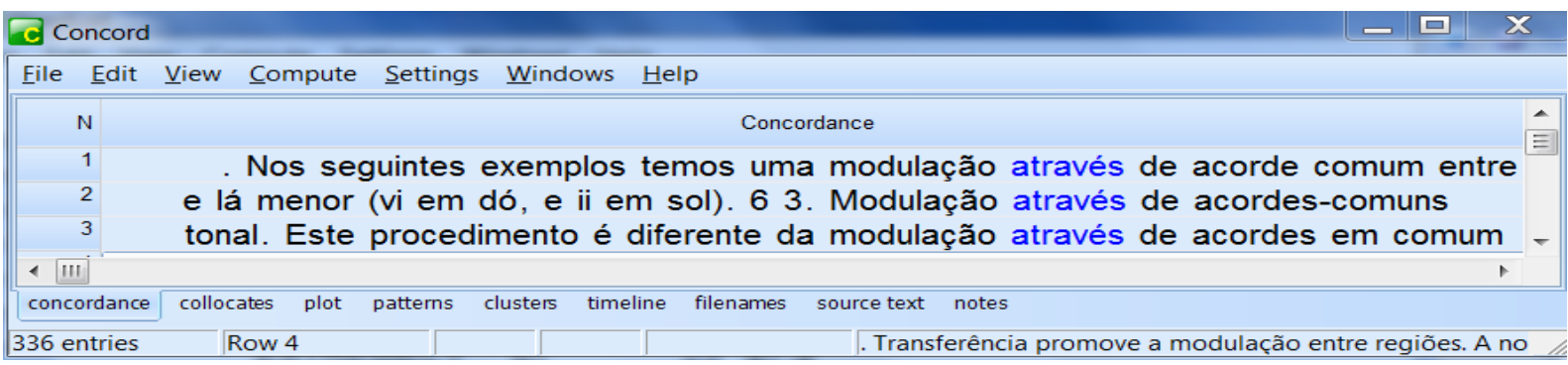

Figura 186 - Linhas de concordância parciais de "modulação através de acorde comum/acordes comuns"

Em Português, encontramos apenas 3 ocorrências e, como se observa nas linhas de concordância, a colocação não apresenta rigidez na composição.

Para o correspondente em Inglês, encontramos o seguinte contexto definitório, similar ao de Português:

- Common-chord modulation is the name given to a modulation where a common chord (or chords) exists. (INGTMLIV02)

Como exemplo, extraímos do subcorpus, o seguinte contexto de uso:

- Analysis of mm. 16-18 in the key of C may show a better diatonic fit, but a modulation from C directly to D (via V6/II, m. 18, beat 4) would be unexplainable as a common chord modulation to a closely related key. (INGTMART29)

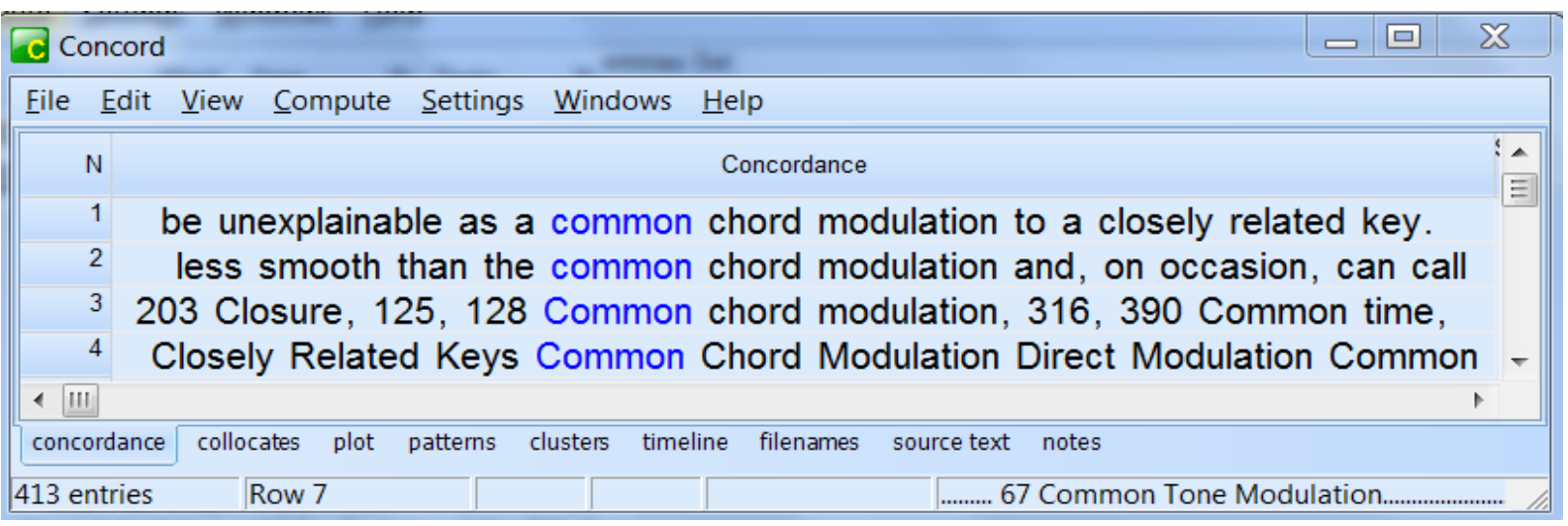

Figura 187 - Linhas de concordância (parciais) de "common chord modulation" 


\section{1) Cifra}

A busca pelo termo "cifra" foi motivada pela colocação correspondente "chord symbol" que no subcorpus de Inglês apresenta frequência de 136 ocorrências. Em Português, “cifra” apresenta 397 ocorrências. Cifra é a notação utilizada na música popular.

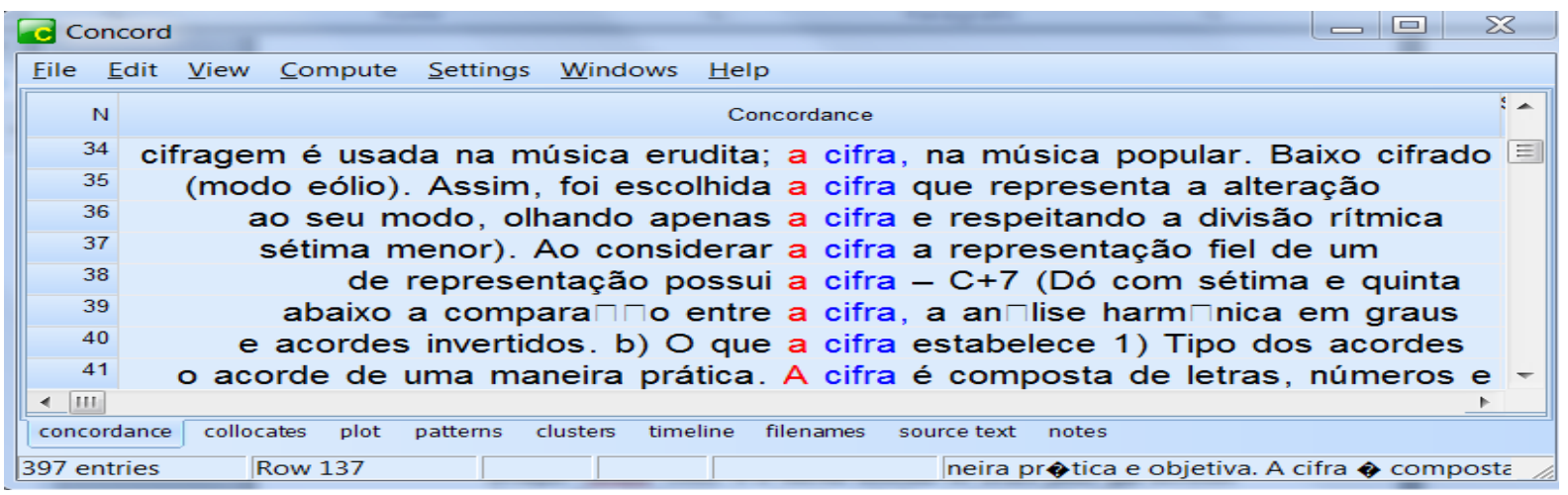

Figura 188 - Linhas de concordância (parciais) do termo "cifra"

Selecionamos alguns excertos com contextos definitórios e de uso em que o termo aparece. O primeiro exemplo foi extraído do subcorpus instrucional e os demais, do subcorpus acadêmico-científico:

- Cifras são símbolos criados para representar o acorde de uma maneira prática e objetiva. A cifra é composta de letras, símbolos e sinais. É o sistema predominante em música popular. (PORTMAPO03)

- A cifra é a grafia musical típica da Zona Popular. Foram os materiais e instituições associados a essa zona que a difundiram e legitimaram. O repertório popular hoje é, na maioria das vezes, registrado na forma de melodia cifrada; leadsheet em inglês. (PORTMTE01)

- Enquanto a cifra é praticamente indispensável na práxis da Música Popular, a Música Erudita é totalmente dependente da partitura tradicional. (PORTMTEO1)

- A atitude de Delamont, ao usar a cifra graduada para "analisar" os acordes, uma prática oriunda dos manuais de jazz, e a cifra alfabética para escrever os arranjos (Strunk, 1988), é a mesma utilizada no Brasil pelos que escrevem livros sobre harmonia ou arranjo voltados exclusivamente para a música popular. (PORTMART13)

- Assim, foi escolhida a cifra que representa a alteração efetuada na quinta do acorde, excluindo a possibilidade de uma interpretação equivocada na formação deste. (PORTMDM03) 
A colocação correspondente "chord symbol" foi uma das colocações encontradas em um dos dicionários de termos musicais pesquisados (DI-ON MUSIC), cuja definição é bem extensa e especifica cada elemento da cifra: qualidade do acorde, tensões adicionadas, alterações e símbolos. Extraímos o seguinte trecho da definição:

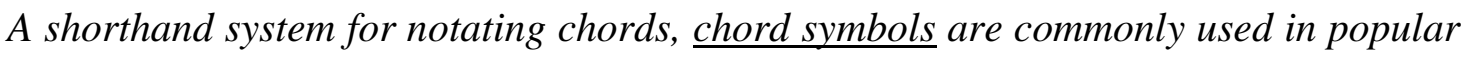
and jazz music as guide for the performer to improvise the melody or accompaniment. This is an alternative to Roman numeral notation indicating individual chords without regard to the chord progression.

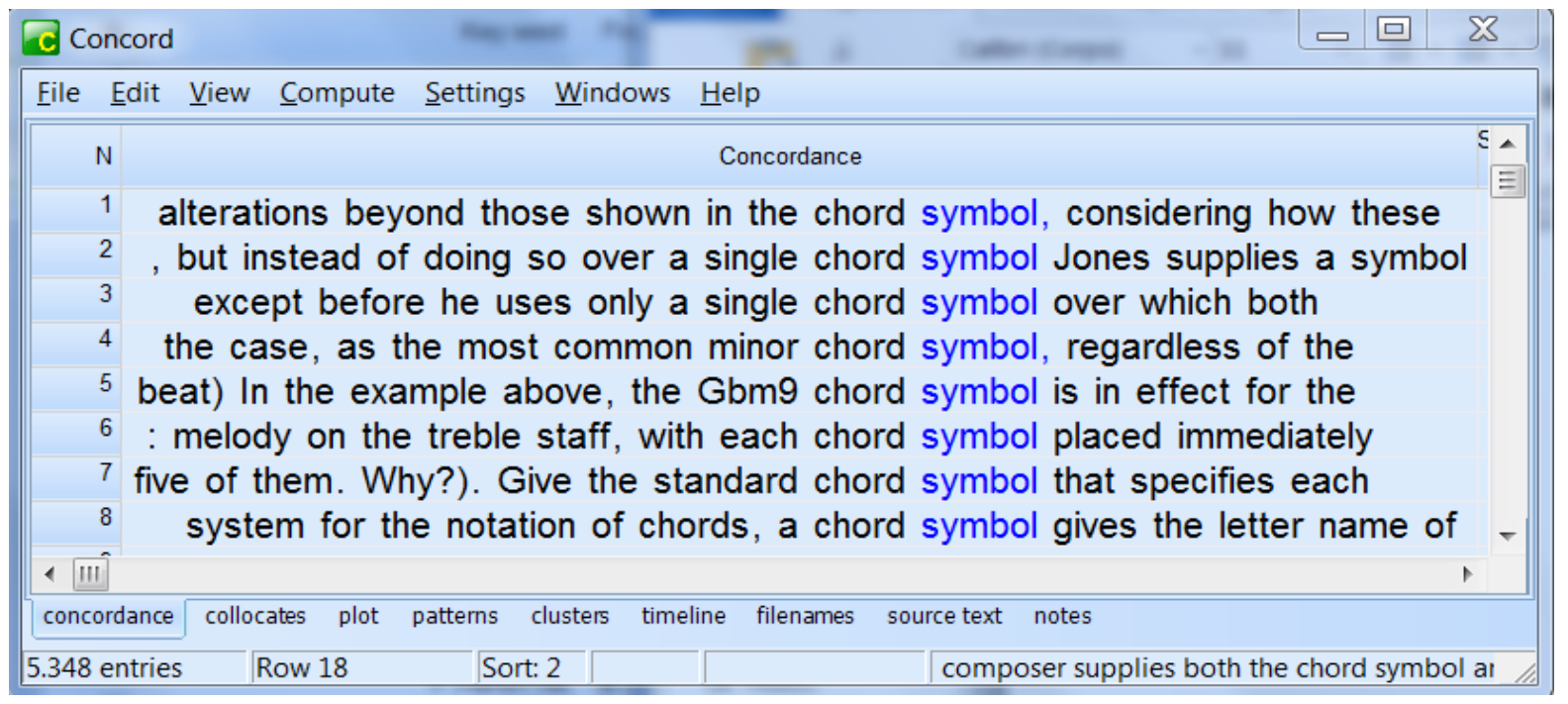

Figura 189 - Linhas de concordância (parciais) de "chord symbol"

Selecionamos alguns contextos, retirados do subcorpus de inglês, em que a colocação chord symbol aparece:

- Some general words of advice about tensions: When they are desired, ninths, elevenths, and thirteenths should always be indicated in a chord symbol. (INGTMLIV07)

- If a chord symbol says to "add13", on the other hand, this usually means that only the thirteenth is added. (INGTMLIV03)

- $\quad$ The three chord symbols in this measure are Bb7, Fm7, and Bb. (INGTMDM04) 


\subsection{Análise da composição das colocações especializadas}

Neste item realizaremos dois tipos de análise das colocações estudadas neste trabalho. A primeira análise está relacionada com a composição das colocações e a segunda, relacionada com os tipos mais comuns de variantes.

\subsubsection{Tipologia das colocações especializadas do corpus de estudo}

Neste subitem, apresentaremos a análise das estruturas das colocações encontradas no corpus. A nossa análise é baseada na tipologia das colocações proposta por Tagnin (2013) e nas colocações especializadas estendidas por Orenha-Ottaiano (2013), mencionadas na Fundamentação Teórica.

A estrutura das colocações especializadas e estendidas relacionadas no nosso glossário é bastante heterogênea. Para facilitar a análise, distribuímos as colocações em grupos. No subitem 5.2.1.1 apresentaremos as colocações adjetivas e nominais dos subcorpora Português e Inglês. No item 5.2.1.2 apresentaremos as colocações especializadas estendidas em Português e Inglês, subdividindo-as de acordo com as categorias gramaticais comuns encontradas nas estruturas de tais colocações.

\subsubsection{Colocações especializadas: adjetivas, nominais e com numerais}

As colocações adjetivas em Português são compostas de um substantivo (que é o termo) e de um adjetivo (o colocado, que é o co-ocorrente). As colocações nominais são compostas de dois substantivos ou dois substantivos com uma preposição entre eles. As colocações com numerais, muito comuns no domínio da Música, são compostas por numerais que podem ser acompanhados de substantivos, adjetivos e/ou preposições. O quadro a seguir apresenta as colocações especializadas (considerando as variantes): 


\begin{tabular}{|c|c|c|}
\hline \multicolumn{3}{|c|}{ IDIOMA: PORTUGUÊS } \\
\hline Colocações Adjetivas & Colocações Nominais & Colocações com numerais \\
\hline $\begin{array}{l}\text { Acorde alterado } \\
\text { Acorde arpejado } \\
\text { Acorde aumentado } \\
\text { Acorde cadencial } \\
\text { Acorde comum } \\
\text { Acorde consonante } \\
\text { Acorde cromático } \\
\text { Acorde diatônico } \\
\text { Acorde diminuto } \\
\text { Acorde dissonante } \\
\text { Acorde errante } \\
\text { Acorde interpolado } \\
\text { Acorde invertido } \\
\text { Acorde maior } \\
\text { Acorde menor } \\
\text { Acorde Napolitano } \\
\text { Acorde perfeito } \\
\text { Acorde quebrado } \\
\text { Acorde suspenso } \\
\text { Acorde tonicalizado } \\
\text { Acorde tonicizado } \\
\text { Acorde tônico } \\
\text { Acorde vagante } \\
\text { Acordes primários } \\
\text { Acordes principais } \\
\text { Acordes relativos } \\
\text { Acordes secundários } \\
\text { Tétrade diminuta } \\
\text { Tríade aumentada } \\
\text { Tríade diminuta } \\
\text { Tríade maior } \\
\text { Tríade menor } \\
\text { Tríades primárias } \\
\text { Dominante secundária } \\
\text { Dominante substituta }\end{array}$ & $\begin{array}{l}\text { Acorde de dominante } \\
\text { Acorde de subdominante } \\
\text { Acorde de tônica } \\
\text { Acorde bordadura } \\
\text { Acorde de passagem } \\
\text { Acorde de preparação } \\
\text { Acorde de resolução } \\
\text { Acorde de sensível } \\
\text { Acorde de Tristão } \\
\text { Acorde pedal } \\
\text { Acorde pivô } \\
\text { Encadeamento dos acordes } \\
\text { Notas do acorde } \\
\text { Progressão dos acordes } \\
\text { Sequência de acordes } \\
\text { Sucessão de acordes }\end{array}$ & $\begin{array}{l}\text { Acorde de décima-primeira } \\
\text { Acorde de décima-terceira } \\
\text { Acorde de nona } \\
\text { Acorde de sétima } \\
\text { Acorde de sexta } \\
\text { Sexta napolitana } \\
\text { Sexta italiana } \\
\text { Sexta alemã } \\
\text { Sexta germânica } \\
\text { Sexta francesa }\end{array}$ \\
\hline
\end{tabular}

Quadro 15 - Colocações Adjetivas, Nominais e com numerais em Português

As colocações adjetivas em Inglês são compostas de um adjetivo (o colocado, que é o co-ocorrente) e de um substantivo (que é o termo). Já as colocações nominais são compostas por dois substantivos (colocado + termo) ou dois substantivos com uma preposição entre eles (colocado + preposição + termo). O quadro a seguir apresenta as colocações (considerando as variantes): 


\section{IDIOMA: INGLÊS}

\begin{tabular}{|c|c|c|}
\hline Colocações Adjetivas & Colocações Nominais & $\begin{array}{l}\text { Colocações com } \\
\text { numerais }\end{array}$ \\
\hline $\begin{array}{l}\text { Altered chord } \\
\text { Arpeggiated chord } \\
\text { Augmented chord } \\
\text { Augmented triad } \\
\text { Borrowed chord } \\
\text { Broken chord } \\
\text { Cadential chord } \\
\text { Chromatic chord } \\
\text { Common chord } \\
\text { Consonant chord } \\
\text { Diatonic chord } \\
\text { Diminished chord } \\
\text { Diminished triad } \\
\text { Dissonant chord } \\
\text { Dominant chord } \\
\text { Harmonic progression } \\
\text { Harmonic progression } \\
\text { Interpolated chord } \\
\text { Inverted chord } \\
\text { Major chord } \\
\text { Major triad } \\
\text { Minor chord } \\
\text { Minor triad } \\
\text { Neapolitan chord } \\
\text { Nondiatonic chord } \\
\text { Passing chord } \\
\text { Pre-dominant chord } \\
\text { Primary chord } \\
\text { Primary triad } \\
\text { Relative chord } \\
\text { Secondary chord } \\
\text { Secondary dominant } \\
\text { Subdominant chord } \\
\text { Substitute dominant } \\
\text { Suspended chord } \\
\text { Tonic chord } \\
\text { Tonicized chord } \\
\text { Vagrant chord } \\
\end{array}$ & $\begin{array}{l}\text { Chord of resolution } \\
\text { Resolution chord } \\
\text { Chord progression } \\
\text { Chord succession } \\
\text { Chord sequence } \\
\text { Chord symbol } \\
\text { Chord tone } \\
\text { Voicing chord } \\
\text { Tristan chord } \\
\text { Sequence of chords } \\
\text { Pedal chord } \\
\text { Neighbor chord } \\
\text { Non-chord tones }\end{array}$ & $\begin{array}{l}\text { Six-four chord } \\
\text { Sixth chord } \\
\text { Eleventh chord } \\
\text { Thirteenth chord } \\
\text { Ninth chord } \\
\text { Neapolitan sixth } \\
\text { Italian sixth } \\
\text { German sixth } \\
\text { French sixth }\end{array}$ \\
\hline
\end{tabular}

Quadro 16 - Colocações Adjetivas e Nominais em Inglês

Comparando os quadros 15 e 16, observamos que nos dois subcorpora, a quantidade de colocações adjetivas supera a quantidade de colocações nomimais. 


\subsubsection{Colocações especializadas estendidas}

Na nossa análise, as colocações especializadas estendidas foram agrupadas de acordo com as categorias gramaticais verificadas na estrutura da colocação.

Em Português, a extensão varia de 3 a 7 componentes na estrutura, sendo que o termo (substantivo) ocupa a primeira posição no sintagma.

\section{Colocações especializadas estendidas do subcorpus de português}

Colocações composta por: substantivo + adjetivo + adjetivo

Acorde perfeito maior

Acorde perfeito menor

$\underline{\text { Substantivo + preposição + substantivo ou numeral + Adjetivo }}$

Acorde de dominante secundária

Acorde de dominante substituta

Acorde de empréstimo modal

Acorde de quinta aumentada

Acorde de quinta diminuta

Acorde de sétima diminuta

Acorde de sexta alemã

Acorde de sexta italiana

Acorde de sexta francesa

Acorde de sexta germânica

Acorde de sexta napolitana

Acorde de quarta suspensa

Acorde de sexta acrescentada

Acorde de sexta aumentada

$\underline{\text { Substantivo + Adjetivo + preposição (com artigo) + substantivo }}$

Notas estranhas ao acorde

Notas estranhas à harmonia

$\underline{\text { Substantivo + preposição + numeral + Adjetivo + Adjetivo }}$

Acorde de sexta aumentada alemã

Acorde de sexta aumentada italiana

Acorde de sexta aumentada francesa

$\underline{\text { Substantivo + advérbio + preposição + Substantivo + Adjetivo }}$

Modulação através de acorde comum

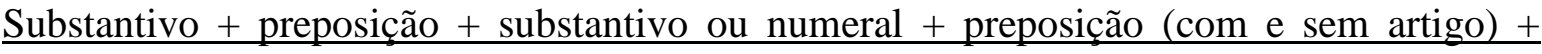
Substantivo

Acorde de dominante com nona 
Acorde de nona da dominante

Acorde de dominante com sétima

Acorde de sétima da dominante

Acorde de sétima da sensível

Substantivo + preposição + numeral + conjunção + numeral + adjetivo

Acorde de quarta e sexta cadencial

$\underline{\text { Substantivo + preposição + substantivo + conjunção + numeral + preposição + substantivo }}$

Acorde de quarta e sexta de passagem

Quadro 17 - Colocações especializadas estendidas do subcorpus de português

Em Inglês, a extensão das colocações especializadas estendidas varia de 3 a 4 componentes na estrutura, sendo que o termo (substantivo) ocupa a última posição no sintagma.

\section{Colocações especializadas estendidas do subcorpus de inglês}

$\underline{\text { Substantivo ou adjetivo }+ \text { substantivo }+ \text { substantivo }}$

Dominant preparation chord

Dominant ninth chord

Dominant seventh chord

Tritone substitution chord

Adjetivo + Substantivo ou numeral ou adjetivo + Substantivo

Added-sixth chord

Augmented sixth chord

Cadential six-four chord

Common chord modulation

French sixth chord

German sixth chord

Diminished seventh chord

Italian sixth chord

Passing six-four chord

Neapolitan sixth chord

Secondary dominant chord

Suspended fourth chord

$\underline{\text { Subtantivo ou Adjetivo + Adjetivo + Substantivo }}$

Tritone substitute chord

Dominant substitute chord 
Advérbio +Adjetivo + Numeral + Substantivo

Half-diminished seventh chord

Fully diminished seventh chord

$\underline{\text { Adjetivo +Adjetivo + Numeral }+ \text { Substantivo }}$

French augmented-sixth chord

German augmented sixth chord

Italian augmented sixth chord

$\underline{\text { Adjetivo }+ \text { Substantivo }+ \text { Numeral }+ \text { Substantivo }}$

Leading-tone seventh chord

Quadro 18 - Colocações especializadas estendidas do subcorpus de inglês

Nota-se que na formação das colocações estendidas em Inglês (quadro 18), as categorias gramaticais que se repetem são substantivo e adjetivo.

\subsection{Análise das relações semânticas entre colocações}

$\mathrm{Na}$ fase de análise das colocações e busca de correspondentes, observamos e agrupamos algumas colocações que apresentavam denominações diferentes, mas que em determinados contextos apresentam o mesmo significado. Como é o caso dos grupos:

- Acorde maior, acorde perfeito maior, tríade maior

- Acorde menor, acorde perfeito menor, tríade menor

- Acorde aumentado, acorde de quinta aumentada, tríade aumentada

- Acorde comum, acorde pivô

- Acorde diminuto, acorde de quinta diminuta, tríade diminuta

- Acorde de sétima, tétrade

- Acorde de sétima diminuta, tétrade diminuta

- Acorde errante, acorde vagante

- Acordes principais, acordes primários, tríades principais

- Sequência de acordes, sucessão de acordes

Em relação às variações, observamos que algumas variantes apresentam estruturas que diferem pela ordem sintática dos elementos e escolha das preposições, mas apresentam a mesma definição: 
- Acorde de sétima da dominante, acorde de dominante com sétima

- Acorde de nona da dominante, acorde de dominante com nona

Em outros casos, uma das variantes não tem preposição, mas também o significado é o mesmo:

- Acorde de tônica, acorde tônico

- Acorde de dominante, acorde dominante

Encontramos também as variantes terminológicas do tipo lexical, descrito no Capítulo 3 - Fundamentação Teórica. Esse tipo de variante é caracterizado pela redução ou expansão dos itens que compõem a colocação, sem alteração conceitual. Observamos vários casos e montamos dois quadros: as variantes encontradas em Português e em Inglês.

\section{Variantes terminológicas linguísticas lexicais em Português:}

Acorde de dominante secundária $\Leftrightarrow$ dominante secundária

Acorde de dominante substituta $\Leftrightarrow$ dominante substituta

Acorde de função dominante $\Leftrightarrow$ acorde de dominante $\Leftrightarrow$ acorde dominante $\Leftrightarrow$ dominante

Acorde de função tônica $\Leftrightarrow$ acorde de tônica $\Leftrightarrow$ tônica

Acorde de sexta aumentada alemã $\Leftrightarrow$ Acorde de sexta alemã $\Leftrightarrow$ sexta alemã

Acorde de sexta aumentada francesa $\Leftrightarrow$ Acorde de sexta francesa $\Leftrightarrow$ sexta francesa

Acorde de sexta aumentada italiana $\Leftrightarrow$ Acorde de sexta italiana $\Leftrightarrow$ sexta italiana

Acorde de sexta napolitana $\Leftrightarrow$ sexta napolitana

Quadro 19 - Variantes terminológicas linguísticas lexicais em Português

\begin{tabular}{|l|}
\hline Variantes terminológicas linguísticas lexicais em Inglês: \\
\hline Chord voicing $\Leftrightarrow$ voicing \\
\hline Dominant chord $\Leftrightarrow$ Dominant \\
\hline Dominant seventh chord $\Leftrightarrow$ Dominant seventh \\
\hline French augmented sixth chord $\Leftrightarrow$ French sixth chord $\Leftrightarrow$ French sixth \\
\hline German augmented sixth chord $\Leftrightarrow$ German sixth chord $\Leftrightarrow$ German sixth \\
\hline Italian augmented sixth chord $\Leftrightarrow$ Italian sixth chord $\Leftrightarrow$ Italian sixth \\
\hline
\end{tabular}




\begin{tabular}{|l|}
\hline Leading-tone seventh chord $\Leftrightarrow$ Leading-tone seventh \\
\hline Neapolitan sixth chord $\Leftrightarrow$ Neapolitan sixth \\
\hline Secondary dominant chord $\Leftrightarrow$ Secondary dominant \\
\hline Subdominant chord $\Leftrightarrow$ Subdominant \\
\hline Tonic chord $\Leftrightarrow$ Tonic \\
\hline Tritone substitute chord $\Leftrightarrow$ tritone substitute
\end{tabular}

Quadro 20 - Variantes terminológicas linguísticas lexicais em Inglês

Analisando os contextos em que as variantes terminológicas lexicais ocorrem, observa-se que elas tanto aparecem em textos distintos como em um mesmo texto. Quando ocorrem em um só texto, geralmente estão relacionadas à escolha do autor, como recurso estilístico, evitando a repetição da estrutura mais extensa. Mas na maioria dos casos, observamos uma tendência de usar a menor estrutura e omitir o termo "acorde" ou "chord".

Nos dicionários especializados pesquisados, verificamos que em Português, especialmente no DP-DOURADO, ocorre com mais frequência o uso das variantes lexicais reduzidas, tais como: dominante, dominante secundária, nona, nona da dominante, sétima, sétima da diminuta, sétima da dominante, sexta alemã, sexta francesa, sexta italiana, sexta napolitana, subdominante e tônica.

Em Inglês, observamos a forma reduzida sem "chord" apenas em Neapolitan sixth (como entrada de dois dicionários especializados DI-HARVARD e DI-ON MUSIC).

\subsubsection{Alguns problemas causados pelas variantes terminológicas linguísticas lexicais em textos sobre Harmonia}

Constatamos que é comum em textos dessa especialidade a ocorrência de palavras que co-ocorrem com mais de um termo e que muitas vezes são empregadas sozinhas. Resultantes do processo de redução do sintagma (que aqui tratamos como colocação), tais variantes lexicais acabam gerando efeito polissêmico em determinados contextos, como é o caso de tônica, dominante, subdominante, cuja frequência no subcorpus de português é alta. Tais termos podem se referir à nota, ao acorde e à função. $\mathrm{O}$ mesmo acontece com os correspondentes em Inglês Tonic, dominant, subdominant. 
Também podem gerar dúvidas na interpretação, termos cujo significado remete a intervalo, nota e acorde. Palavras que apresentam um número alto de ocorrências no subcorpus, tais como sexta e sétima, e suas correspondentes sixth e seventh, são exemplos de palavras sujeitas à polissemia. O mesmo acontece com "nona" (ninth), verificado nessa forma reduzida em dicionário especializado (pesquisado).

A desambiguação é resolvida com exemplos de uso, em que os termos são empregados de forma específica. Em contextos que podem gerar dúvida, o uso da variante não reduzida (no caso em que o termo acorde está presente ele é a base) ajuda a resolver o problema de polissemia. Essa é a proposta do glossário com exemplos de uso autênticos: ajudar o tradutor a escolher a colocação adequada para determinado contexto, a partir da consulta aos exemplos de uso. 


\section{CAPÍTULO 6}

\section{MODELO DE VERBETE}

Neste item, apresentamos a nossa proposta de verbete. Nosso glossário tem como público alvo tradutores. As colocações especializadas estão organizadas, como entrada, em ordem alfabética. Primeiramente, apresentamos na direção Inglês-Português, com os contextos de uso em inglês e, na sequência, direção Português-Inglês, a entrada é em português com contextos de uso em português. A constituição da microestrutura do verbete é composta de: colocação na língua de partida, colocação na língua de chegada, variantes lexicais ou denominativas (se houver), contexto definitório (se houver), contexto de uso, remissiva e notas explicativas (quando necessário).

As colocações na língua de partida e na língua de chegada estão em destaque na faixa preta. Abaixo da faixa, entre [ ] aparecem as variantes (se a colocação tiver).

Os textos extraídos do corpus estão escritos em itálico. Geralmente os primeiros trechos são extraídos do subcorpus instrucional, e são contextos definitórios (utilizados como informações adicionais e em alguns casos, como exemplos, quando não há ocorrências de uso no subcorpus acadêmico-científico).

Os símbolos a seguir são utilizados para sinalizar as seguintes informações:

* Contexto de uso da colocação, extraída do subcorpus acadêmico-científico, em que a comunicação é realizada de especialista para especialista.

$\Rightarrow$ Remissivas. Utilizadas para fazer conexão entre termos semanticamente relacionados

Notas explicativas do autor

Ao final de cada contexto de uso, encontra-se entre parênteses a indicação do texto fonte (codificado), extraído do subcorpus. 


\section{INGLÊS - PORTUGUÊS}

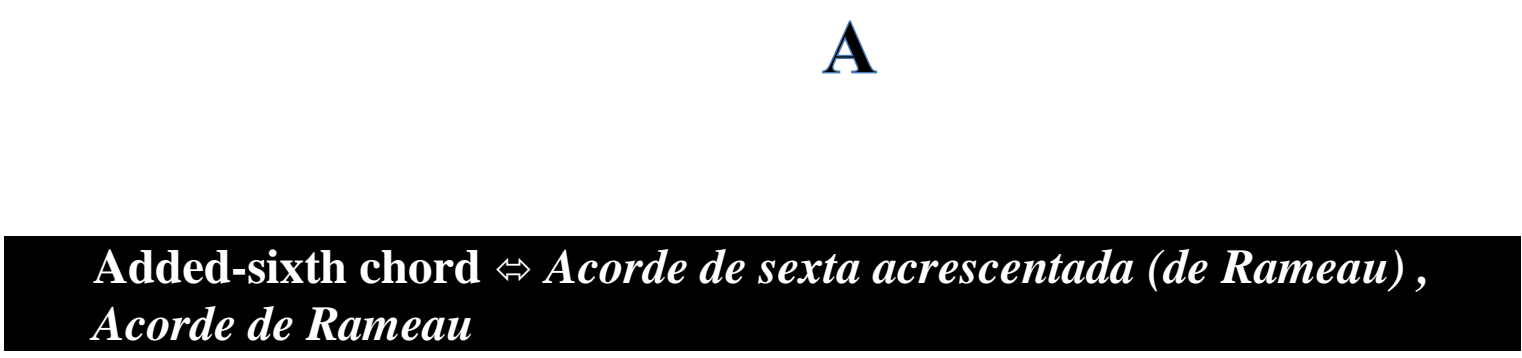

$>$ A triad with a sixth added above the root

For example, Lester, Compositional Theory, p. 206, uses the term to apply to Rameau's dissonance-motivated chord types: "Rameau had proposed three chordal functions: tonic, dominant, and subdominant." For Rameau, who did not use the term "function," these are respectively represented as a triad, a seventh chord, and an added-sixth chord. Lester is careful to distinguish his use of the term from modern usage.(INGTMLIV10)

* In between, the tonic chords of these two keys actually fuse together, first in the form of an F major, added-sixth chord (on beat 3 of measure 1), then as a rootposition D minor seventh chord (on the following downbeat). (INGMART16)

* A second result is its strong emphasis of $F$ as the sixth above the bass (notated as a diminished seventh, from $B$ to $F$ ), another of the added sixths that give both the harmonic and melodic components so much character. (INGMART14)

\section{Altered chord $\Leftrightarrow$ Acorde alterado}

If a note in the chord is not in the major or minor scale of the root of the chord, it is an altered note and makes the chord an altered chord (INGMLIVO3).

Chords that employ chromaticism are called altered chords, and the most commonly encountered altered chord in tonal music is the secondary function (INGMLIV12).

All other chords - those using notes not in the scale - are called altered chords 
(INGTMLIV12).

Secondary dominants are called altered chords because they contain nondiatonic tones-tones that are not found in the prevailing key. (INGMLIV02)

* (...) the derivation of altered chords, such as altered sixth chords, would be located on this level since they constitute derivations of core functional chords (INGMART20).

$\Rightarrow$ See CHROMATIC CHORD

\section{Arpeggiated chord $\Leftrightarrow$ Acorde arpejado, arpejo}

[Also known as Arpeggio]

The notes of each chord may be played all at once (block chords), or they may be played one at a time (broken or arpeggiated chords). (INGTMLIVO6).

$\Rightarrow$ See BROKEN CHORDS

\section{Augmented chord $\Leftrightarrow$ Acorde aumentado}

[Also known as Augmented triad]

An augmented chord is built from two major thirds, which adds up to an augmented fifth (INGMLIV03).

* For example, if, in an augmented $G$ sharp major chord, you rewrite the D double sharp as an E natural, the triad becomes an E augmented chord. (INGTMTEO2) 


\section{Augmented sixth chord $\Leftrightarrow$ Acorde de sexta aumentada}

* The augmented sixth chord is a harmony that may or may not contain its fundamental, depending upon which of its three forms is used. The augmented sixth, in its most common contextual setting, resolves to the dominant. In keeping with the assumption that the strongest succession is down by fifth, the augmented sixth chord functions as dominant preparation; therefore it is assigned the fundamental associated with the second scale degree... (INGTMTE02)

* In Schubert's practice, the downward leading tone was most often accompanied by the leading tone proper, yielding an augmented sixth chord of some kind. This type of use of the augmented sixth was theoretically reified in Tchaikovsky's harmony text (1871), which shows the normative resolution of an augmented sixth chord built above directly to the tonic. (INGTMDM01)

$\Rightarrow$ See GERMAN AUGMENTED-SIXTH CHORD, ITALIAN AUGMENTED-SIXTH CHORD, FRENCH AUGMENTED-SIXTH CHORD.

\section{Augmented triad $\Leftrightarrow$ Acorde de quinta aumentada, tríade aumentada}

[Also known as Augmented chord]

An augmented triad consists of a major third and an augmented fifth. (INGTMLIVO2)

Like the fully diminished-seventh chord, the augmented triad has an ambiguous root that is defined by its context. (INGTMTE02)

$\Rightarrow$ See AUGMENTED CHORD 


\section{Borrowed chord $\Leftrightarrow$ Acorde de empréstimo modal}

Borrowed Chords: Chords taken from a different tonality or modality. (INGTMLIV07)

Rarely do borrowed chords produce the effect of complete modal change; however, the mode from which certain chromatic chords are borrowed may prove to have motivic relevance within a given song (18)... (INGTMART04)

\section{Broken chord $\Leftrightarrow$ Acorde quebrado}

[Also known as arpeggio, arpeggiated chord]

When a chord is broken, the notes in the chord are separated. This gives the chord a sense of movement, and allows variety and rhythm in a piece. An arpeggio (discussed in Chapter 3), is essentially a broken chord-you're simply playing one note of the chord at a time. (INGTMLIVO6)

A chord in which the notes are separated. Another name for a broken chord is arpeggio (INGTMLIVO6).

$\Rightarrow$ See ARPEGGIATED CHORD

\section{Cadential chord $\Leftrightarrow$ Acorde cadencial}

- If IV and V are the most common pre-tonic cadential chords in rock, one might ask why this is so. (INGTMART12)

* And in the second movement of the Third String Quartet, a recurring emphasis on 
pitch class $C$ within an E minor context ultimately leads to a final cadential chord that simultaneously suggests E minor, C major, and C minor.(INGMART16)

$\Rightarrow$ See CADENTIAL SIX-FOUR CHORD

\section{Cadential six-four chord $\Leftrightarrow$ Acorde de quarta e sexta cadencial}

The cadential six-four chord is a tonic six-four that delays the arrival of the $V$ chord that follows it. It totally depends upon the V chord for it meaning, and it should not be thought of as a substitute for a tonic triad in root position or first inversion. The cadential six-four occurs in a metrically stronger position than the $V$ chord that it delays. (INGTMLIV12)

Moving up by half-steps, the bass finally arrives at a cadential six-four chord of A minor in $m$. 401 ... (INGTMDM01)

$\Rightarrow$ SEE CADENTIAL CHORD

\section{Chord of resolution $\Leftrightarrow$ Acorde de resolução}

[Also known as Resolution chord]

* In a common-practice deceptive cadence, the chord of resolution is felt as a tonic substitute, and still requires a second attempt at cadencing to capture the proper original key. In a CMCR, by contrast, the chord of resolution is a stable tonic, fit for either concluding a cue or initiating a new musical paragraph in its own key. (INGTMART07)

* When secondary leading-tone chords resolve in a conventional manner, the resolution chord is called a tonicized chord. (INGTMLIV02). 


\section{Chord progression $\Leftrightarrow$ Progressão dos acordes, Progressãa} Harmônica

[Also known as HARMONIC PROGRESSION]

A serie of chords played one after another is a chord progression. (INGTMLIV01)

Harmonic progression - movement from one chord to the next; a succession of chords or a chord progression.(INGTMLIV02)

* This gospel figure does not neatly agree with the chord progression here, and as in other instances, it creates momentary tensions between melody and harmony. (INGTMDM02)

* In the original chord progression, the melodic motion $E b-F$ in the penultimate measure is supported with the diatonic ii7-V7 progression. (INGTMART14)

\section{Chord sequence $\Leftrightarrow$ Sequência de acordes}

[Also known as SEQUENCE OF CHORDS, CHORD SUCCESSION]

* Typically a jazz soloist wants to know what scale to use to improvise a melody over a particular chord or sequence of chords.(INGTMLIV07)

* In contrast to the classical format, where every single note is written out explicitly, in fake book format all that is presented of the music is (1) a sequence of chords, and (2) a melody line. (INGTMART28)

* This principle states that each element (chord) in a chord sequence is structurally connected to its preceding or succeeding chord or chord group in a dependency relationship.(INGTMART20)

* The horizontal lines at level $b$ indicate the linear intervallic pattern of consecutive tenths that drive the voice-leading of the "Pachebel" chord sequence, $I-V-v i-$ iii-IV, in mm.(INGTMDM02) 


\section{Chord symbol $\Leftrightarrow$ Cifra}

Set of letters and numerals, used as a shorthand indication of chords. It is used, for example, in Jazz, folk and pop music.

Some general words of advice about tensions: When they are desired, ninths, elevenths, and thirteenths should always be indicated in a chord symbol. (INGTMLIV07)

* If a chord symbol says to "add13", on the other hand, this usually means that only the thirteenth is added. (INGTMLIV03)

The three chord symbols in this measure are Bb7, Fm7, and Bb. (INGTMDM04)

\section{Chord succession $\Leftrightarrow$ Sucessão de acordes}

[Also known as CHORD SEQUENCE. SEQUENCE OF CHORDS]

* Schoenberg explains that the strongest type of chord succession occurs when the fundamental of a given harmony becomes one of the subordinate pitches of the following harmony.(INGTMTE02)

* This hierarchical system, analogous with the relative positioning of the pitches of the overtone series, provides the basis of chord succession. (INGTMTE02)

* A recognition of the forces of voice leading upon harmony is vital to an interpretation of chord succession here (...) (INGTMART24)

* In any given chord succession in the above progression there are some voices that hold a common tone, some that move by semitone, and others move by a tone or larger.(INGTMDM04)

$\Rightarrow$ See CHORD SEQUENCE, CHORD PROGRESSION 


\section{Chord tone $\Leftrightarrow$ Notas do acorde}

Harmonic tones should be familiar to you by now. They are the chord tones: root, third, or fifth. Nonharmonic tones (nonchord tones) are pitches that sound along with a chord but are not chord pitches. ( INGTMLIV02)

* Because a chord symbol suggests multiple options for chord-scale applications, any of these chord-scales may be applied and any note in one of the possible chordscale applications is a compatible tone (and therefore, a possible chord tone). (INGTMDM04)

* See NONCHORD TONE

\section{Chord Voicing - Voicing}

[Also known as VOICING]

Chord voicing refers to the ordering of the notes (root, third, fifth) above the lowest note. Changing the chord voicing does not change the inversion. INGTMLIV08

"Voicing" refers to the way chord tones are deployed. There are many different approaches to chord voicing. The choice of which approach to use is partly a matter of what kind of musical group is involved: solo keyboard, piano trio, big band, soli group, vocal jazz ensemble, etc. The choice of approach is also affected by the aesthetic preferences of the performer, composer, or arranger. And, finally, the choice of approach is affected by the background and training of the performer, composer, or arranger. Musicians who have had training in traditional harmony, counterpoint, and orchestration are likely to use more sophisticated voicing techniques, while musicians with less formal training are more likely to use automatic techniques based on the mechanical application of a few voicing rules. (INGTMLIV07) 


\section{Chromatic chord $\Leftrightarrow$ Acorde cromático}

Most chords in tonal music are made up only of notes from the scale on which the passage is based. That is, if a passage is in $G$ major, most of the chords contain only notes found in the $G$ major scale. Chords of this kind are called diatonic chords. All other chords-those using notes not in the scale-are called altered or chromatic chords. (INGTMLIVO2)

* Richmond Browne's position-finding interval between and may be further expanded to be a sign of dominant function for any chromatic chord in which this tritone appears.(INGTMART14)

Charles Smith's 1986 article on extravagant function considers chromaticism a combination of harmonic and contrapuntal motion (Smith 1986, 103-105). This perspective justifies a series of alternative dominants that replace the diatonic scale-step with or, and among them are three chromatic half-diminished sevenths, reproduced in Example 2a. To Smith, the chromatic chords are selfsufficient; they act as delicate dominants due to their context and the presence of the leading tone (Smith 1986, 126-127) (INGTMART14)

* See Altered CHORD

\section{Common chord $\Leftrightarrow$ Acorde comum, acorde perfeito}

[Also known as PIVOT CHORD]

A common chord, meaning a chord that is common to each of two keys, offers a smooth introduction to the new key, since it is diatonic to both the old and the new key. This common chord is often called a pivot chord because it becomes a sort of middle ground between the two keys. (INGTMLIVO2)

A chord that is common to two keys as a way of leaving the old key and entering the new key in a modulation. The chord that the two keys have in common is called the pivot chord, because from it the progression can "pivot" in either direction. (INGTMLIV09) 
Common triads (common chords) are called common for the simple reason that they form the majority of the chords used in music. There are two kinds of common triads the major triad and the minor triad. (INGTMLIV04)

* However, Strauss's use of vagrant harmonies enlarges the number of keys related by common chord. (INGTMTEO2)

\section{See PIVOT CHORD}

\section{Common chord modulation $\Leftrightarrow$ Modulação através de acorde comum}

Common-chord modulation is the name given to a modulation where a common chord (or chords) exists. INGTMLIV02

* Analysis of mm. 16-18 in the key of C may show a better diatonic fit, but a modulation from C directly to D (via V6/II, m. 18, beat 4) would be unexplainable as a common chord modulation to a closely related key (INGTMART29)

\section{Consonant chord $\Leftrightarrow$ Acorde consonante}

Notes that sound good together when played at the same time are called consonant. Chords built only of consonances sound pleasant and "stable"; you can listen to one for a long time without feeling that the music needs to change to a different chord. (INGTMLIVO)

Major and minor triads are consonant chords because they contain only consonant intervals. (INGTMLIV11)

* Tone scales used in Western music are also based on intervals or frequency ratios of simple integers, such as the octave (2:1), the fifth (3:2), and the major third (5:4). When several instruments play a consonant chord such as a major triad (domi-so), harmonics will match so that no beats will occur. (INGMART28) 


\title{
D
}

\section{Diatonic chord $\Leftrightarrow$ Acorde diatônico}

Most chords in tonal music are made up only of notes from the scale on which the passage is based (...). Chords of this kind are called diatonic chords. (INGTMLIV12)

* In the opening of chapter 3 I refer to this as the first level of variation, i.e., replacing a diatonic chord with a secondary dominant built on the same scale degree. (INGTMDM04)

$\Rightarrow$ See NONDIATONIC CHORD

\section{Diminished chord $\Leftrightarrow$ Acorde diminuto}

\author{
[Also known as Diminished triad] \\ $\Rightarrow$ See DIMINISHED TRIAD, DIMINISHED SEVENTH CHORD
}

\section{Diminished seventh chord $\Leftrightarrow$ Acorde de sétima diminuta, tétrade diminuta}

[Also known as Fully-diminished seventh chord]

The diminished seventh chord is symmetrical, being composed entirely of minor thirds. (INGTMLIV07)

A fully-diminished seventh chord is a diminished triad plus a diminished seventh. Fully-diminished chords are usually referred to as, simply, "diminished". 
(INGTMLIV08)

* There are, then, as far as the sonority and the components are concerned, only three diminished seventh chords. Since, however, there are twelve minor keys, every diminished seventh chord must belong to at least four minor keys. (INGTMTE02)

Salient Features include a sequence of fully diminished seventh chords, upward resolutions of chordal sevenths, and common-tone augmented-sixth chords. (INGTMDM01)

\section{Diminished triad $\Leftrightarrow$ Acorde de quinta diminuta, tríade diminuta}

[Also known as DIMINISHED CHORD]

A diminished triad consists of a minor third and a diminished fifth. (INGTMLIVO2)

In practice the diminished triad built on the second scale degree, found in the minor mode, does not follow the same logic as the diminished triad on the seventh degree. (INGTMTEO2)

\section{Dissonant chord $\Leftrightarrow$ Acorde dissonante}

Because of the looser treatment of dissonance in jazz, a dissonant chord has no obligation to resolve to a chord predicted by the stylistic conventions of classical music.(INGTMLIV07)

* The idea provided by Straus of dissonant chords resolving to consonant ones is problematic in this music. (INGTMDM04) 


\section{Dominant $\Leftrightarrow$ Dominante, Acorde de dominante, Acorde dominante}

[Also known as DOMINANT CHORD]

$\Rightarrow$ See DOMINANT CHORD

\section{Dominant chord $\Leftrightarrow$ Acorde de dominante, acorde dominante}

The dominant chord always occurs on degree five of the scale. Therefore, in the scale of $C$ major, the dominant chord is a G major triad. (INGTMLIV04)

* If, for example, Jones had followed Eb diminished whole tone with A Lydian dominant, he would have recycled the same pitch collection and therefore created a potentially static contrapuntal situation in which both dominant chords are essentially the same save for the bass note.(INGTMDM04)

* In this progression it is clear that the IV chord fulfills the function of the absent dominant chord, occurring after the pre-dominant IIsharp and leading back to I. (INGTMART10)

$\Rightarrow$ See DOMINANT SEVENTH CHORD, DOMINANT NINTH CHORD

\section{Dominant ninth chord $\Leftrightarrow$ Acorde de nona da dominante, acorde de dominante com nona}

One of the most commonly used ninth chords is the dominant ninth chord, which is built on the fifth degree of the scale. Generally, the dominant ninth is used to enhance the resolution of dominant seventh chord to the tonic. (INGTMLIV02)

* As it is in a dominant-ninth chord, where it functions as an upper neighbor to the dominant. (INGTMDM01) 
- The fully-diminished-seventh chord B-D-F-Ab has four pitches in common with the dominant ninth chord $G-B-D-F-A b .(I N G T M T E 02)$

$\Rightarrow$ See DOMINANT CHORD

\section{Dominant preparation chord $\Leftrightarrow$ Acorde de preparação (da} dominante)

Three functions - Dominant Preparation, Dominant, and Tonic - are needed to establish a key. A single major or minor chord is undefined. Prefacing it with its own dominant somewhat clarifies its meaning, but the situation is still ambiguous. A third chord is needed to "prepare" the dominant - that is, to make it sound like the dominant - after which the original major or minor chord will sound unambiguously like the tonic. A dominant preparation chord is typically some form of II or IV. (INGTMLIV07)

$\Rightarrow$ See PRE-DOMINANT CHORD

\section{Dominant seventh chord $\Leftrightarrow$ Acorde de dominante com sétima, acorde de sétima da dominante}

The dominant seventh chord is a diatonic seventh chord built on the fifth scale degree of the major, harmonic minor, and ascending melodic minor scales. The major triad (root, third, fifth) and minor seventh (from root to seventh) create a distinctive sound that is universal linked to the dominant function. (INGTMLIV02)

Unlike the dominant triad, the dominant seventh chord contains a dissonance - the seventh factor. (INGTMLIV02)

* As can be seen from the set-class forms of the example, the three tetrachords of mm. 106-14 are related by parsimonious voice leading; this is not entirely surprising, since any dominant-seventh chord is only one semitone removed from either a French augmented-sixth chord or a fully-diminished seventh chord. (INGTMDM01) 


\section{Dominant substitute chord $\Leftrightarrow$ Acorde de dominante substituta}

$\Rightarrow$ See TRITONE SUBSTITUTION CHORD

\section{Eleventh chord $\Leftrightarrow$ Acorde de décima primeira}

Eleventh chords are created in theory by adding a perfect eleventh interval to an existing ninth chord. In practice, however, there are exceptions: major ninth and dominant ninth chords: because the perfect eleventh is a minor ninth interval above the major third interval above the major third degree of each of these chords, and because this interval is generally considered harsh or dissonant to the ear, the eleventh is raised a half step to reduce the dissonance; Minor ninth and minor ninth chords: because these chords contain a minor third the extreme dissonance is not present, so no alteration of the eleventh is required. (INGTMLIV04)

\section{French augmented sixth chord $\Leftrightarrow$ Acorde de sexta aumentada francesa, Acorde de sexta francesa, sexta francesa}

[Also known as FRENCH SIXTH CHORD, FRENCH SIXTH]

* The so-called French sixth chord is a II7 with a major third and diminished fifth, in the key of a minor, it is spelled B-D\#-F-A; the root is B and the chord usually appears in second inversion. (INGTMTE02).

* The quasi-SLIDE transformation and semitonal displacement that turn a French augmented-sixth chord into a dominant seventh (shown in Example 5-8) are answered and balanced by the zigzag motion of oblique tenths shown in mm.11922 of Example 5-9.(INGTMDM01) 


\section{French Sixth $\Leftrightarrow$ Sexta francesa}

$\Rightarrow$ See FRENCH AUGMENTED SIXTH CHORD

\section{French sixth chord $\Leftrightarrow$ Acorde de sexta francesa}

$\Rightarrow$ See FRENCH AUGMENTED SIXTH CHORD

\section{Fully diminished seventh chord $\Leftrightarrow$ Acorde de sétima diminuta,} tétrade diminuta

$\Rightarrow$ See DIMINISHED SEVENTH CHORD

\section{German augmented sixth chord \\ $\Leftrightarrow$ Acorde de sexta aumentada alemã, Acorde de sexta alemã, Acorde de sexta germânica}

[ Also known as GERMAN SIXTH CHORD, GERMAN SIXTH]

The so-called "German sixth" chord is a chord with a major third, diminished fifth, minor ninth, and the root is missing; in the key of a minor, it is spelled D\#-F-A-C; the "real" root is B and the chord usually appears in second inversion reckoned above the "real" root. (INGTMTE02)

* In the final cadence of "In a Sentimental Mood" (1935) the dominant is replaced with a tritone substitute, labeled $G$ dominant seventh in the chord charts, but spelled as-and functioning as-a German sixth. (INGTMART18) 


\section{German sixth $\Leftrightarrow$ sexta alemẽ}

$\Rightarrow$ See GERMAN AUGMENTED SIXTH CHORD

\section{German sixth chord $\Leftrightarrow$ Acorde de sexta alemã, acorde de sexta} germânica

$\Rightarrow$ See GERMAN AUGMENTED SIXTH CHORD

\section{$\mathbf{H}$}

\section{Half-diminished seventh chord $\Leftrightarrow$ Acorde meio-diminuto}

* The use of a half-diminished seventh chord for the beginning of the theme seems patterned after Wagner, as does the appoggiatura in the second measure. (INGTMDM01)

\section{Harmonic progression $\Leftrightarrow$ Progressão harmônica}

$\Rightarrow$ See CHORD PROGRESSION 


\section{Interpolated chord $\Leftrightarrow$ Acorde interpolado}

If a voice leading chord is preceded by its own dominant, supertonic, or subdominant, or a combination of these, the result is a more elaborate structure called an "interpolation". The interpolated chords are typically built on raised or lowered steps of the prevailing scale or are borrowed from parallel key. (INGTMLIV07)

These interpolated chords not only highlight the ascent back to the obligatory register, they provide an associative harmonic link to the opening half-diminished seventh and the structural keys that it generated. (INGTMDMO1)

This chord is left before it can resolve to its five-three; thus, the A-minor harmony of $m .301$ is not a deceptive resolution but the first of several interpolated chords between the cadential six-four and its resolution to a root-position dominant in $\mathrm{m}$. 304. (INGTMDM01)

\section{Inverted chord $\Leftrightarrow$ Acorde invertido}

Inverted chords occur when a note other than the root occurs in the bass. There are two kinds of inverted chords: In first inversion chords, the third is in the bass, and in second inversion chords, the fifth is in the bass. (INGTMLIV04)

* Most investigations into the harmony of rock treat every chordal root as of equal value, set aside inverted chords as "rare" and thereafter ignore them, rely upon discredited concepts such as "retrogression," and leave unconsidered the ramifications of voice leading upon chord identity, function, embellishment and harmonic expansion. I will here cite Stephenson 2002 as perhaps the most developed of all such studies, for all its good points in other domains (INGTMART24) 


\section{Italian augmented sixth chord $\Leftrightarrow$ Acorde de sexta aumentada italiana, acorde de sexta italiana, sexta italiana}

[Also known as Italian sixth chord, Italian sixth]

In most cases augmented sixth chords contain more than two pitch classes. When a third pitch class is included, it is usually the tonic pitch. This combination of tones is referred to as an Italian augmented sixth chord. (INGTMLIV12)

* The so-called "Italian sixth" chord is a II7 chord with a major third and diminished fifth and the root is missing; in the key of a minor, it is spelled D\#-FA; the "real" root is $B$ and the chord usually appears in second inversion reckoned above the "real" root. (INGTMTEO2)

Italian sixth $\Leftrightarrow$ sexta italiana

$\Rightarrow$ See ITALIAN AUGMENTED SIXTH CHORD

\section{Italian sixth chord $\Leftrightarrow$ Acorde de sexta italiana}

See ITALIAN AUGMENTED SIXTH CHORD

$\mathbf{L}$

\section{Leading-tone seventh chord $\Leftrightarrow$ Acorde de sétima da sensivel}

Closely related to the dominant seventh chord are the leading-tone seventh chords. Like their triad counterpart, these leading-tone seventh chords often function as dominant substitutes but can also appear as harmonic embellishments in linear passages. Diatonic leading-tone seventh chords are built on the seventh scale degree of 
the major, harmonic minor, and ascending melodic minor scales. In major keys, the quality of the chord is diminished-minor $(\mathrm{dm})$. Diminished-minor is also known as halfdiminished. In minor keys, the quality is diminished-diminished (dd), but the name is usually abbreviated to diminished or fully diminished. (INGTMLIV02)

\section{Leading-tone change chord $\Leftrightarrow$ Acorde anti-relativo}

Riemann defines two principal classes of mixed chord or Nebenklang, both of whose functions are determined by the majority element. These are the Parallelklang, or relative chord, and the Leittonwechselklang, or leading-tone change chord. (INGTMLIV10)

$\Rightarrow$ See RELATIVE CHORD

\section{M}

\section{Major chord $\Leftrightarrow$ acorde maior}

[Also known as Major triad]

For the major chord, you count up four semitones to get the third, and then three semitones to get the fifth. (INGTMLIV04)

* The Three Stripped Gears alternate this strain with a contrasting strain using the eight-bar "Spoonful" scheme, represented harmonically as: VI-VI-II-II-V-V-I-I, all major chords. (INGTMART13)

$\Rightarrow$ See MAJOR TRIAD 


\section{Major triad $\Leftrightarrow$ tríade maior, acorde perfeito maior}

[Also known as Major chord]

A major triad consists of a major third and a perfect fifth. (INGTMLIV02)

* The minor third in a major triad could only be indirectly derived from the major third. For Zarlino, the bottom interval of the major triad was of greater importance, and the minor third above it was merely the "residue" that filled in the space between the major third and the fifth in a major triad.(INGTMTE01)

$$
\Rightarrow \text { See MAJOR CHORD }
$$

\section{Minor chord $\Leftrightarrow$ Acorde menor}

[Also known as Minor triad]

If the interval between the root and the third of the chord is the minor third (and the major third is between the third and fifth of the chord), then the triad is a minor chord. (INGTMLIV03)

* If the ninth of the chord sounds in the second of the two chords, it produces the major third of the previous minor chord. (INGTMDM04)

$\Rightarrow$ See MINOR TRIAD

\section{Minor triad $\Leftrightarrow$ Tríade menor, Acorde perfeito menor}

[Also known as Minor chord]

* A minor triad consists of a minor and a perfect fifth. (INGTMLIV02)

* In contrast, the minor third resembled the arithmetic mean, which Zarlino 
considered to be contrary to nature. He classified the minor triad as less perfect harmony, because unlike in the major triad, the elements are not arranged in their “natural” locations. (INGTMTE01)

$\Rightarrow$ See MINOR CHORD

\section{Neapolitan chord $\Leftrightarrow$ Acorde napolitano}

Neapolitan chord - It is a major triad constructed upon the lowered second scale degree. It is usually found in the minor mode and in first inversion and usually moves toward $V$. In fact, the first inversion is so typical that the Neapolitan triad is often referred to as the Neapolitan sixth chord. (INGTMLIV12)

* In music theory, harmony is a well-researched area, and there are dozens of taxonomies for tonal harmony phenomena. Most theories concentrate on classifying chord types and deducing complex phenomena from basic (diatonic) chords (such as explaining the predominant Neapolitan chord in minor from a minor IV in which the minor sixth replaces the fifth and results in a first inversion chord). (INGTMART20)

This technique, together with the idea of the Neapolitan sixth on secondary degrees, produces great enrichment of the tonality.(INGTMTE02)

\section{Neapolitan sixth chord $\Leftrightarrow$ Acorde de sexta napolitana}

$\Rightarrow$ See NEAPOLITAN CHORD 
Neapolitan sixth $\Leftrightarrow$ sexta napolitana

$\Rightarrow$ See NEAPOLITAN CHORD

\section{Neighbor chord $\Leftrightarrow$ Acorde bordadura}

Chords made up mostly or entirely of neighbor- and/or passing-tones are common in jazz. (...) Neighbor chords - Often, an entire chord is used as if it were a neighbor note. (INGTMLIV07)

Traditional music theory gives precise definitions of various embellishing tones neighbor, passing, changing, escaped, anticipation, suspension, etc. - and prescribes how they are to be treated. The jazz musician can choose to observe these prescriptions or not. (INGTMLIV07)

$\Rightarrow$ See PASSING CHORD

\section{Ninth chord $\Leftrightarrow$ Acorde de nona}

Ninth chords are constructed by adding the interval of a major ninth to an existing seventh chord, regardless of its quality. (INGTMLIV02)

* The ninth chord served as raw material from which Capellen could derive other chords. (INGTMTE01)

\section{Non-chord tones $\Leftrightarrow$ Notas estranhas ao acorde}

[Also known as NONHARMONIC TONES

Non-chord tones (abbreviated NCT) is a tone, either diatonic or chromatic, that is not a member of the chord. The tone might be an NCT throughout its duration, or, if the harmony changes before the tone does, the tone might be as NCT for only a portion of its duration (INGTMLIV12). 
Nonharmonic tones (nonchord tones) are pitches that sound along with a chord but are not chord pitches. ( INGTMLIV02)

\section{Nondiatonic chord $\Leftrightarrow$ Acorde não-diatônico}

Notice that two chords in the excerpt, A7 and B7, are not listed with the diatonic chords for $C$ major. Both $A 7$ and $B 7$ are nondiatonic chords in the key of $C$ major. (INGTMLIV02)

* In example 4.16 we saw a II-V progression expanded with a mixture of diatonic and nondiatonic chords. (INGTMDM04)

$$
\Rightarrow \text { See DIATONIC CHORD }
$$

\section{Passing chord $\Leftrightarrow$ Acorde de passagem}

A passing chord is a nondiatonic chord that connects, or passes between, the notes of two diatonic chords. (INGTMLIV02)

* This can be interpreted as a passing chord (along with V/ii in measure 8) within a larger motion from IV to ii.(INGMARTO8)

$\Rightarrow$ See PASSING SIX-FOUR CHORD 


\section{Passing six-four chord $\Leftrightarrow$ Acorde de quarta e sexta de passagem}

A passing six-four chord harmonizes the middle note of a three-note scalar figure in the bass. The most common passing six-four chords are the V 6/4 and the I 6/4 chords, and they usually fall on a weak beat.(INGTMLIV12)

* This is not a cadential or passing six-four chord; it does not resolve to a rootposition chord and seems a goal in its own right. (INGTMDM01)

$\Rightarrow$ See CADENTIAL SIX-FOUR CHORD

\section{Pedal chord $\Leftrightarrow$ Acorde pedal}

Note: Pedal chord is a chord that has a pedal point.

* The pedal chord could possibly be interpreted as a V, but given the intense lydian bent of the E.T. score at large, this cadential chord should count as a subtraction of attribute 5 all the same. (INGTMARTO7)

Pedal point - Pedal point is a stationary pitch that begins as a chord tone, then becomes a NCT as the harmonies change, and finally ends up as a chord tone again. Pedal points usually occur in the bass, but they occasionally occur in other parts as well. (INGTMLIV12)

\section{Pivot chord $\Leftrightarrow$ Acorde pivô}

[Also known as Common chord]

A chord that is common to two keys as a way of leaving the old key and entering the new key in a modulation. The chord that the two keys have in common is called the pivot chord, because from it the progression can "pivot" in either direction. (INGTMLIV09) 
When the modulation is initiated through pivot chords in the sequence that may belong to two adjacent keys, the double generation of the pivot chord from two different branches of the parse tree constitutes the preferred form of analysis that captures the double role of the pivot. (INGTMART20)

$\Rightarrow$ See COMMON CHORD

\section{Pre-dominant chord $\Leftrightarrow$ Acorde pré-dominante}

* The D phrase then begins with IV, which functions as the pre-dominant chord of the verse. (INGTMART10)

* Construed in this way, the application of the common-practice functional system to rock would seem to fail immediately: the data in Table 2 suggests that the most common chord to precede the tonic is $I V$, which is normatively a pre-dominant chord in the common-practice system.(INGTMART12)

$\Rightarrow$ See DOMINANT PREPARATION CHORD

\section{Primary chords $\Leftrightarrow$ Acordes primários, acordes principais}

[Also known as Primary triads]

First, while he does put forward the notion that a key is defined by its tonic, dominant and subdominant chords, Weber in turn describes these three primary chords as an outgrowth of the major scale, thus characterizing them as dependent on some other musical element. (INGTMLIV10)

For example, listen to Bob Dylan's "Blowing in the Wind." This song in its entirety only uses the three primary chords-tonic, subdominant, and dominant.(INGTMLIV04) 


\section{Primary triads $\Leftrightarrow$ Tríades principais}

[Also known as Primary chords]

At the next level, that of the primary triads, the three components are tonic, subdominant, and dominant; their interrelationship is unmediated by thirds, (INGTMLIV10)

In the major tonality, the three primary triads $(I, I V$, and $V)$ are all major, while in the minor tonality (i, $i v$, and $v$ ) they are all minor. (INGTMLIV04)

* the characterization of individual chords as tonic (T), subdominant (S), or dominant (D) in function; and (2) the notion that the so-called primary triads, $I, I V$, and $V$ somehow embody the essence of each of these functional categories. (INGTMART21)

\section{$\mathbf{R}$}

\section{Relative chord $\Leftrightarrow$ Acorde relativo}

The relative chord is a triad which contains the root and third of its functional archetype, but whose other tone is a substitution of the sixth for the fifth. (INGTMLIV10)

For example, a functional $C$ major triad would have as its relative chord a triad containing the notes $C$ and $E$, with $A$ substituting for $G$. The resulting $A$ minor triad is the tonic of the relative minor - thus Parallelklang, or "relative chord." (INGTMLIV10)

$\Rightarrow$ See LEADING-TONE CHANGE CHORD 


\section{Resolution chord $\Leftrightarrow$ Acorde de resolução}

[Also known as CHORD OF RESOLUTION]

$\Rightarrow$ See CHORD OF RESOLUTION

\section{Secondary chords $\Leftrightarrow$ Acordes secundários}

By saying this Schenker most likely means that III " defines a harmonic area which is more at variance with its harmonic context, and thus freer of it than III \#, whose tonic is a secondary chord of both tonic and dominant keys. (INGTMLIV10)

- In contrast, Smetana's use of iii6 prolongs vi emphasizing the "secondary chords" of the key. (INGTMDM01)

$\Rightarrow$ See SECONDARY DOMINANT

\section{Secondary dominant $\Leftrightarrow$ dominante secundária}

* Secondary dominants are chords that are altered to sound like dominants. This means changing triads to make them major and changing seventh chords to make them major-minor. Any major or minor diatonic triad may be preceded by a chord that is, in effect, its dominant or leading tone.(INGTMLIV02).

* The idea of secondary dominant harmony is that a chord other than the tonic is preceded by its own dominant seventh, ninth, eleventh, and so on. This has the effect of temporarily tonicizing that particular chord. However, this process of tonicization is so fleeting and temporary that it is not regarded as being a proper modulation. This type of chord is called a secondary dominant.(INGTMLIV04) 


\section{Secondary dominant chord $\Leftrightarrow$ Acorde de dominante secundária}

$\Rightarrow$ See SECONDARY DOMINANT

\section{Sequence of chords $\Leftrightarrow$ Sequência de acordes}

$\Rightarrow$ See CHORD SEQUENCE, CHORD SUCCESSION

\section{Seventh chord $\Leftrightarrow$ Acorde de sétima, tétrade}

A seventh chord is formed by adding another third above the fifth of the triad. The seventh chord built on the dominant is the most common seventh chord in tonal music. (INGTMLIV02)

* In a number of popular styles, static sonorities may be used without necessarily setting up any expectation for resolution. These sonorities may be triads, seventh chords or other extended tertian chords, or diatonic collections. (INGTMART15)

\section{Six-four chord $\Leftrightarrow$ Acorde de quarta e sexta}

* When the notes of a triad are so arranged that the original fifth becomes the lowest tone, the triad is said to be in the second inversion, and in this position is known as the six-four chord, the intervals between the bass and the upper voices being sixth and fourth. (INGTMLIV11)

* "Schoenberg's example 74 illustrates a downward step progression as a sum of two downward fifths, where the I (six-four chord) and V, ordinarily coming between this dominant $(V / V)$ and the closing chord are often left out. (INGTMTE02)

$\Rightarrow$ SEE CADENTIAL SIX-FOUR CHORD, PASSING SIX-FOUR CHORD 


\section{Sixth chord $\Leftrightarrow$ Acorde de sexta}

$\Rightarrow$ Triad in first inversion; Triad with an added sixth.

Some limited variation of the patterns above is possible. For example, the II-V-I progression can end with a sixth chord, rather than a major or minor seventh, when the II chord has its third as the lowest note (i.e., when it is in first inversion).(INGTMLIV07)

$\Rightarrow$ See AUGMENTED SIXTH CHORD, ADDED SIXTH CHORD

\section{Subdominant chord $\Leftrightarrow$ Acorde de subdominante}

[Also known as SUBDOMINANT]

The subdominant chord is always built upon the fourth degree of either major or minor mode. (INGTMLIV04)

* Another use of 2 is as the root of a post-cadential II as a replacement for the subdominant chord... (INGTMDMO1)

$\Rightarrow$ See TONIC CHORD, DOMINANT CHORD

\section{Suspended chord $\Leftrightarrow$ Acorde suspenso}

$\Rightarrow$ See SUSPENDED FOURTH CHORD 


\section{Suspended fourth chord $\Leftrightarrow$ Acorde de quarta suspensa}

[Also known as SUSPENDED CHORD. Abbreviation SUS4 CHORD]

* The suspended fourth chord (also called the sus4 chord) gets its name because it takes the third of a chord and suspends it by raising it a half step to a fourth (hence the name of this type of chord), before resolving the chord back to its usual form. So, a Csus 4 consists of $C, F$ (instead of $E$ ), and $G$. The fourth $(F)$ then moves back down to the third, which is $E$, thus resolving the chord back to the major triad $(C$, E, G). (INGTMLIV06)

\section{$\mathbf{T}$}

\section{Thirteenth chord $\Leftrightarrow$ Acorde de décima terceira}

Complete thirteenth chords are built by adding the interval of a major, thirteenth to an existing eleventh chord (...) The most common note to leave out of thirteenth chord is the eleventh. If a thirteenth chord does contain a eleventh, and the eleventh is altered, the alteration must be written into the name of the chord, eg. C13 (\#11) (INGTMLIVO2)

\section{Tonic chord $\Leftrightarrow$ Acorde de tônica}

A tonic chord is the prime or home chord. For example, the C Major chord is a tonic chord (C, E, G). It is the first chord of the C Major scale. (INGTMLIV 06)

* The unequivocal statement of the tonic chord is avoided until the end of the song. (INGTMART27)

* The tonic chord in these cases should be thought of more as a complex made up of melodic strands with shared qualities of both modes. (INGTMDM02)

$\Rightarrow$ See DOMINANT CHORD, SUBDOMINANT CHORD 


\section{Tonicized chord $\Leftrightarrow$ Acorde tonicalizado, acorde tonicizado}

Tonicized chord - A chord that functions temporarily as a tonic (having been preceded by a secondary dominant.) (INGTMLIVO2).

In circle progression, the chord to which secondary dominants progresses is called a tonicized chord. (INGTMLIVO2).

\section{Triad $\Leftrightarrow$ Triade, acorde perfeito}

Triad: Strictly speaking, a triad is any three-tone chord. In tertian harmony, a triad is a chord built in superposed thirds. The four types of triads are major, minor, diminished, and augmented. (INGTMLIV02)

* The pivot modulation uses a triad, as a pivotal point, that is considered functional on both tonal levels. (INGTMTEO2)

\section{Tristan chord $\Leftrightarrow$ Acorde de Tristão}

$\Rightarrow$ This chord is the first chord in Wagner's Opera "Tristan und Isolde".

- In the years following the debut of the Tristan chord, a number of works have continued the dialogue on how half-diminished sevenths function. (INGTMART14)

\section{Tritone substitute $\Leftrightarrow$ Acorde de dominante substituta}

$\Rightarrow$ See TRITONE SUBSTITUTION CHORD 


\section{Tritone substitution chord $\Leftrightarrow$ Acorde de dominante substituta}

[Also known as TRITONE SUBTITUTE, DOMINANT SUBSTITUTE CHORD]

* One of the most common chord substitutions, mentioned in nearly every jazz theory book that mentions chord substitutions, is the tritone substitution chord, which is a variation of the ii-V7-I prototype. The substitution itself consists of inserting a dominant chord a tritone away from $V$ in the place of $V$. This results in a descending chromatic bass line and a ii-bII7-I progression. (INGTMDM04)

* In theory, tritone substitutes replace dominants, and this is indeed their most usual function. In practice, however, tritone substitution is also applied to chords without a tritone - typically dominant preparations such as vi and ii, either preserving the original chord qualities or recasting them as dominant sevenths. (INGMART18)

* Augmented-sixth chords and tritone substitutes have long been recognized as enharmonic equivalents. Their relationship is generally described as two different perspectives on the same syntactic structure: in classical terminology, an augmented-sixth chord; in jazz, a tritone substitute. (INGMART18)

* Although it resolves irregularly, it satisfies Charles Smith's criterion for a dominant substitute chord; that is, that the operative element is the upward resolution of 4, , the dominant's own leading tone. (INGTMDMO1)

\section{Tritone substitute chords $\Leftrightarrow$ Acorde de dominante substituta}

$\Rightarrow$ See TRITONE SUBSTITUTION CHORD

\section{Vagrant chord $\Leftrightarrow$ Acorde vagante, acorde errante}

* Vagrant chords represent an important step in the development of tonality. Vagrant chords, a term coined by Schoenberg in his book Theory of Harmony, are defined as wandering, ambiguous harmonies. Any sonority which wanders away from the central tonality or has multiple meanings within a harmonic context may 
be considered a vagrant chord. Vagrant harmonies distinguished by their intervallic constitution include the augmented triad, diminished seventh chord, whole-tone chord, and perfect-fourth chord. These four types of chords all share three characteristics: 1) they all have the same interval between adjacent degrees, 2) they do not have, because of their physical nature, a single comprehensible root, and 3) they all are capable of multiple meanings and resolutions. (INGTMART27)

Schoenberg considers the fully-diminished-seventh to be a vagrant chord; "Such a chord belongs to no key exclusively; rather, it can belong to many, to practically all keys without changing its shape. (INGTMTE02)

\section{Voice-leading $\Leftrightarrow$ Encadeamento dos acordes, condução de vozes}

\section{Also known as PART WRITING}

Voice leading (or part writing) may be defined as the ways in which chords are produced by the motions of individual musical lines. (...) For various reasons, many theory texts have based their approach to voice leading upon the style of the four-voice choral harmonizations by J. S. Bach. (INGTMLIV12)

Beginning with this chapter and continuing through volume $l$ and much of volume 2, we will place considerable emphasis on the voice-leading practices of the eighteenth and nineteenth century composers. Four-part writing demonstrates in an uncomplicated fashion the principles that are the basis of compositions from this time period. (INGTMLIV02) 


\section{PORTUGUÊS - INGLÊS}

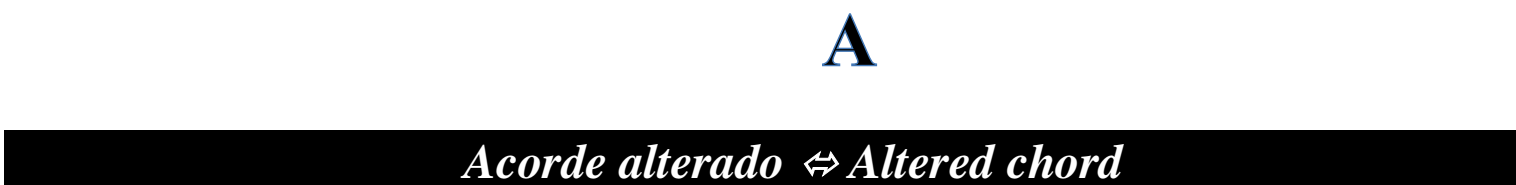

Acorde alterado é considerado um acorde estranho à tonalidade principal de um trecho (PORTMAPOO1).

Acordes alterados são formados por notas pertencentes a uma escala alterada. É construído elevando ou abaixando as notas diatônicas. A característica do acorde alterado é o intervalo de terça diminuta entre as notas do acorde (a outra terça é maior ou menor). Na formação da escala alterada não devem ser alterados os graus IIII-V (PORTMLIVO2).

O termo é usado para designar acordes que, embora pertencendo ao campo harmônico de uma tonalidade, apresentam notas que ampliam o seu âmbito e alteram notas da escala. Devido à surpresa proporcionada pelas notas alteradas, estes acordes são utilizados como recursos expressivos, principalmente nos pontos culminantes, onde há maior tensão harmônico-melódica e nas cadências finais. Os acordes alterados fazem parte das regiões dos acordes principais da tonalidade, Subdominante e Dominante. (PORTMTAPOO6)

* (...) Porém, na prática da música popular esse modo é denominado Escala Alterada e é associado a um acorde de Sétima Dominante conhecido na teoria da música popular como acorde alterado. (PORTMART04)

$\Rightarrow$ Ver ACORDE CROMÁTICO, NOTAS ESTRANHAS AO ACORDE 


\section{Acorde arpejado $\Leftrightarrow$ Arpeggiated chord, arpeggio}

Acorde arpejado - É quando as notas de um acorde são tocadas sucessivamente (PORTMLIV07).

Arpejo: O termo arpejo descreve o emprego de notas do acorde de forma sucessiva em ordem direta ou "quebrada" . Arpejo em ordem direta e quebrada - Este tipo de figuração é mais comum na musica instrumental. Suas principais vantagens são as de oferecer um padrão de acompanhamento, de servir para conectar registros contrastantes em uma melodia, para propiciar uma maior atividade rítmica ou como recurso timbrístico. (PORTMLIV01)

A parte $B$ (compassos 9 a 16), inicia-se com o mesmo acorde arpejado ascendentemente, agora na dominante, levando à appoggiatura. (PORTMART11)

$\Rightarrow$ Ver ACORDE QUEBRADO

\section{Acorde aumentado $\Leftrightarrow$ Augmented chord}

Acorde Aumentado é formado por duas terças maiores sobrepostas (ou por uma terça maior e uma quinta aumentada). (PORTMLIVO2)

A adoção de acordes aumentados e diminutos como representantes de funções secundárias, assim como a não identificação da tonalidade sugerida pelos acordes que representam as funções principais, geram as principais diferenças encontradas nos métodos em uso por Ian Guest e Musiarte em comparação com a Harmonia Funcional. (PORTMDM04)

$\Rightarrow$ Ver ACORDE DE QUINTA AUMENTADA, TRÍADE AUMENTADA 


\section{Acorde bordadura $\Leftrightarrow$ Neighbor chord}

O termo "bordadura" refere-se a notas estranhas à harmonia.

A função deste acorde é puramente ornamental, isto é, o acorde é um acorde bordadura ou um acorde de passagem. (PORTMAPOO1)

A Bordadura apresenta-se como uma dissonância em tempo fraco ou parte fraca do tempo, que parte de uma nota de acorde por movimento de segunda acima (bordadura superior) ou abaixo (bordadura inferior) e retorna obrigatoriamente, para a mesma nota de origem. (PORTMLIV01)

$\Rightarrow$ Ver NOTAS ESTRANHAS AO ACORDE, ACORDE DE PASSAGEM

\section{Acorde cadencial $\Leftrightarrow$ Cadential chord}

$>$ Acordes que fazem parte de uma cadência.

* (...) avaliaremos todas as dissonâncias que os acordes cadenciais suportam como notas reais ou de passagem. (PORTMTE01)

$\Rightarrow$ Ver ACORDE DE QUARTA E SEXTA CADENCIAL

\section{Acorde comum $\Leftrightarrow$ Common chord}

A modulação diatônica se processa por um acorde comum às duas tonalidades: a original e a nova. Esse acorde é analisado segundo as funções que desempenha em cada uma. (PORTMAPOO6) 
* Piston chama de acorde pivô; Kostka \& Payne chamam de acorde comum. O fato é que a função é a mesma (...) (PORTMTE01)

* (...) zona comum a ambas as tonalidades" ou "zona intermediária" (sendo que esta zona "pode consistir num só acorde comum a ambas, ou num grupo de acordes com significado tonal comum”); (PORTMART21)

$\Rightarrow \quad$ Ver ACORDE PIVÔ

\section{Acorde consonante $\Leftrightarrow$ Consonant chord}

Conforme a Teoria Tradicional, os acordes consonantes criam a impressão de estabilidade, relaxamento e tranquilidade. Não exigem Resolução. (PORTMLIV02)

* Contando com a intelecção desta transgressão é que este acorde consonante ("Vm") se fez ouvir como "tensão", i.e., um confronto a uma norma habitual que permitiu a consolidação de uma metáfora musical útil para a representação da afronta aos valores impostos como a normalidade. (PORTMTE02)

$\Rightarrow$ Ver ACORDE DISSONANTE

\section{Acorde cromático $\Leftrightarrow$ Chromatic chord}

O cromatismo pode ser resumido como ocorrências de notas estranhas aos acordes, ou seja, notas cromáticas que não fazem parte da constituição real de acordes... (PORTMAPOO1)

* Denis Delair [falecido após 1727] divide suas instruções para a realização dos baixos cifrados em duas categorias: accompagnements ordinaires, abrangendo majoritariamente os acordes diatônicos, e accompagnements extraordinaires, 
constituído principalmente de acordes cromáticos. (PORTMTE02)

* O objetivo deste trabalho foi abordar, a partir de uma seleção de músicas da obra de Tom Jobim, aspectos da escolha de caminhos harmônicos alternativos, possibilitados pelo uso de cromatismos. Antes, porém, de comentar os dados levantados em tal análise, faz-se necessário definir os conceitos relativos a tais acordes cromáticos e suas possibilidades de aplicação. (PORTMART22)

$\Rightarrow$ Ver ACORDE ALTERADO

\section{Acorde de décima primeira $\Leftrightarrow$ Eleventh chord}

Acorde de décima primeira: É um acorde de seis sons: Consiste num acorde de nona ao qual se acrescenta mais uma terça o intervalo entre as notas extremas é uma décima primeira. (PORTMLIVO2)

* A décima primeira pode aparecer num acorde de dominante ou não. A nona pode ser uma nota melódica ou harmônica, dependendo da situação que se encontra. Esta ambiguidade é ainda mais presente no acorde de décima primeira e décima terceira. (PORTMDMO1)

\section{Acorde de décima terceira $\Leftrightarrow$ Thirteenth chord}

Acorde de décima terceira: É um acorde de sete sons. Consiste num acorde de décima primeira ao qual se acrescenta mais uma terça. O intervalo entre as notas extremas é uma décima terceira. (PORTMLIVO2)

São os acordes de décima primeira acrescidos de uma terça que dão origem aos acordes de décima terceira. Gozam também de absoluta liberdade quanto à preparação e resolução das dissonâncias. (PORTMLIV10)

* Esta ambiguidade é ainda mais presente no acorde de décima primeira e décima terceira. (PORTMDM01) 


\section{Acorde de dominante $\Leftrightarrow$ Dominant chord}

[Variantes: Acorde Dominante, Dominante]

Acorde de dominante: acorde formado pelo $V$ grau no modo Maior e menor. (PORTMLIV02)

Considerando-se um acorde como Tônica, ou ponto de partida, o acorde de Dominante encontra-se à distância de uma quinta justa acima. A característica do acorde de Dominante é o movimento que realiza para o de Tônica. Este movimento se dá através da nota chamada sensível, ou a terça do acorde de dominante, que se movimenta meio tom acima para a nota fundamental do acorde de Tônica. Todos os acordes podem ser usados com a fundamental no baixo e na primeira inversão, com a terça no baixo. (PORTMAPOO6)

* Voltando ao assunto das progressões harmônicas em tons menores, nossa atenção se centrará sobre o acorde de dominante como o fator harmônico mais poderoso. (PORTMTEO2)

Assim, serão considerados acordes dominantes, somente os acordes construídos sobre o V grau das escalas menores - harmônica e melódica. (PORTMDM03)

$\Rightarrow$ Ver ACORDE DE DOMINANTE SECUNDÁRIA, ACORDE DE DOMINANTE SUBSTITUTA

Acorde de dominante com nona $\Leftrightarrow$ Dominant ninth chord

$\Rightarrow$ Ver ACORDE DE NONA DA DOMINANTE 


\section{Acorde de dominante com sétima $\Leftrightarrow$ Dominant seventh chord}

$\Rightarrow$ Ver ACORDE DE SÉTIMA DA DOMINANTE

\section{Acorde de dominante secundária $\Leftrightarrow$ Secondary dominant chord, Secondary dominant}

[Variantes: Dominante secundário, dominante secundária]

Dominante secundário: São os dominantes dos demais graus diatônicos, caracterizados também pelo movimento do baixo do V/II, V/III, V/IV, etc; quarta justa ascendente ou quinta justa descendente. (PORTMLIV07)

Dominantes secundárias. Os acordes alterados mais comuns na música tonal são as dominantes secundárias (...) Uma dominante secundária de qualquer acorde deve ser uma tríade maior ou um acorde maior com sétima menor (acorde de sétima de dominante). É importante mencionar que uma dominante secundária refere-se a um acorde que não é a dominante do acorde de tônica (V de I). (PORTMAPO01)

* No Ex.34, o acorde de sétima diminuta "C\#”", estranho à tonalidade de Dó maior, situado uma segunda menor abaixo do $\operatorname{IIm} 7$ (Dm7), corresponde ao acorde de dominante secundária com nona abaixada situado uma quarta abaixo do IIm, ou seja VI7(b9) (A7(b9)). (PORTMART04)

\section{Acorde de dominante substituta $\Leftrightarrow$ Dominant substitute chord, Tritone substitution chord, Tritone substitute chord, Tritone} substitutes

Abreviação: Acorde SubV7

* Assim, contribuindo para tornar o sistema "SubV7 (lídio b7)" algo mais abstrato, retorcido e versátil, consolidou-se uma estratégia capaz de gerar um conjunto de 
desenhos percebidos como mais inusitados: recursos "substitutos" para resonorizar o popular "acorde de dominante substituta" que, então - para alguns e a partir de determinado momento -, se considera um meio de preparação insuficiente, demasiadamente desgastado e comum.

(PORTMTE02)

* Dentre outros fatores (questões de gênero e estilo, de defesa de campo, de auto-imagem, das demandas comerciais do ensino da teoria musical, etc.), o prestígio técnico-teórico desta nomenclatura e conceituação - tratada aqui como estratégia menor melódica - está associado (emblematicamente, mas não exclusivamente) ao prestígio do chamado "acorde de dominante substituta" ("Sub V7"), o acorde que é conhecido na teoria tradicional como "acorde de sexta aumentada".(PORTMTE02)

\section{Acorde de empréstimo modal $\Leftrightarrow$ Borrowed chord}

A palavra modal vem de modo. Modo é a maneira de como os tons e semitons são distribuídos entre os graus da escala. Acordes do modo (tonalidade) menor usados no modo (tonalidade) maior paralelo e vice-versa são denominados acordes de empréstimo modal AEM. Os acordes de empréstimo modal podem ser derivados também de qualquer modo (dórico, lídio, mixolídio, etc.) (PORTMLIV07)

* O estudo detalhado a partir do conceito de acorde de empréstimo modal mostra-se útil para identificar elementos harmônicos que ocorrem de maneira consistente na obra de Jobim. Cromatismos, funções harmônicas e condução melódica estão interligados na abordagem que Jobim utiliza, na qual o uso de diversos acordes de empréstimo modal permite uma grande liberdade na composição de melodias simples, que sustentadas por harmonias diversificadas permitem um caráter único para sua obra musical. (PORTMART22) 


\section{Acorde de nona $\Leftrightarrow$ Ninth chord}

Acorde de nona é um acorde de cinco sons. Consiste num acorde de sétima ao qual se acrescenta mais uma terça. O intervalo entre as notas extremas é uma nona. Podem ser formados 14 acordes de nona diatônicos no estado fundamental (sete acordes de sétima diatônicos, acrescidos de terça maior e menor) incluindo as inversões, são 54 acordes. $O$ mais usado é o acorde formado sobre a dominante e tons maiores e menores. (PORTMLIVO2)

* Quanto às inversões dos acordes de nona, Schöenberg afirma que os antigos teóricos afirmavam que os acordes de nona eram ruins e que suas inversões não existiam. (PORTMDMO1)

$\Rightarrow$ Ver ACORDE DE NONA DA DOMINANTE

\section{Acorde de nona da dominante $\Leftrightarrow$ Dominant-ninth chord}

[Var. Acorde de dominante com nona]

O acorde de nona de dominante é encontrado quando se acrescenta uma terça maior ou menor à sétima de um acorde de sétima de dominante. O símbolo para este acorde é V9. (PORTMAPO01)

A base do acorde de Dominante com nona menor é o acorde de Dominante com sétima, ao qual se acrescenta mais uma terça menor. É a nona menor em relação à fundamental. Como é formado por cinco notas, na escrita a quatro vozes omite-se a quinta. (PORTMAPOO6)

$\checkmark$ Acorde de nona da dominante maior: formado sobre o $V$ grau das escalas maiores. Para formar esse acorde acrescenta-se uma terça maior ao acorde de sétima da dominante. Acorde de nona da dominante menor: formado sobre o $V$ grau das escalas menores. Para formá-lo acrescenta-se uma terça menor ao acorde de sétima da dominante. (PORTMLIV02)

* Na seção d, transforma-se o acorde de II grau em um acorde de nona de dominante com a fundamental omitida. (PORTMART18) 


\section{Acorde de passagem $\Leftrightarrow$ Passing chord}

o acorde assinalado pode ser classificado como um acorde de passagem que liga o i grau (ré menor) ao viio6 (dó\# diminuto, em primeira inversão). A classificação como um acorde de passagem se justifica por seu valor rítmico, pela constatação de que anota si (do tenor) foi atingida por salto e sua pouca autonomia harmônica. Neste compasso, apenas o i grau (ré m) e o vii ${ }^{\circ}$ têm um significado harmônico relevante. (PORTMLIVO1)

Todo acorde em segunda inversão deve ser empregado com cuidado. Seu uso mais aconselhável é como acorde de passagem, em tempo fraco. É frequente seu uso como acorde de passagem na troca de vozes. Neste caso, quase todas as vozes se movem como figuração melódica e, por vezes, a quinta do acorde vem dobrada. (PORTMLIV01)

O VII grau invertido é comumente encontrado como um acorde de passagem entre I grau na fundamental e o I grau na primeira inversão. (PORTMDM01)

$\Rightarrow$ Ver ACORDE DE QUARTA E SEXTA DE PASSAGEM, NOTAS ESTRANHAS AO ACORDE

\section{Acorde de preparação $\Leftrightarrow$ Dominant Preparation Chord}

* O princípio de movimento entre os acordes, baseado na relação de preparação e resolução, faz com que os acordes de uma tonalidade assumam funções específicas para cada situação. Podemos generalizar que acordes com função de preparação se caracterizam pela necessidade de proporcionar instabilidade harmônica. São acordes cujo potencial harmônico pode ser amplamente de conflito, expectativa. (PORTMDM03)

* Função Dominante: Acordes de preparação. Proporcionam tensão, geram instabilidade. São responsáveis pela necessidade de movimento harmônico entre os acordes. (PORTMDMO3) 
* Com isso, focando os lugares de chegada (i.e., percebendo os acordes de preparação tipo V7 como coadjuvantes)... (PORTMTE02)

$\Rightarrow$ Ver ACORDE PRÉ-DOMINANTE

\section{Acorde de quarta e sexta $\Leftrightarrow$ Six-four chord}

Acorde de quarta e sexta: Tríade em segunda inversão. A quinta da tríade é a nota mais grave. Intervalos formados a partir do baixo: quarta e sexta. (PORTMLIVO1)

* O modelo harmônico para a segunda cadência foi construído a partir do próprio motivo escolhido, com algumas mudanças de acordes, como por exemplo, a introdução de um arpejo a mais no quarto compasso (acorde de lá maior com sétima) e da pequena fermata no acorde de quarta e sexta, no meio da cadência. (PORTMART12)

$\Rightarrow$ Ver ACORDE DE QUARTA E SEXTA CADENCIAL

\section{Acorde de quarta e sexta cadencial $\Leftrightarrow$ Cadential sixth-four chord}

É o acorde de primeiro grau na segunda inversão que precede a dominante nas cadências. Apesar de ser construído com os sons do acorde do I grau, este acorde é instável por causa do intervalo de quarta com o baixo. Portanto, sua função se aproxima da dominante. (PORTMLIVO8)

O acorde de quarta e sexta cadencial funciona como uma preparação forte para o acorde de dominante. Na realidade o acorde de I 6/4 (2 ${ }^{a}$ inversão) é considerado como uma apojatura dupla de um acorde de V ou V7. (PORTMAPOO1) 


\section{Acorde de quarta e sexta de passagem $\Leftrightarrow$ Passing six-four chord}

O acorde de quarta e sexta de passagem. As tríades também podem aparecer em segunda inversão e como acordes de passagem. Como tal, o acorde de passagem deve estar em tempo fraco. Qualquer uma das tríades pode ser usada como um acorde de quarta e sexta de passagem, no entanto, as mais comuns são os acordes de V6/4 e I6/4, tanto em maior quanto em menor. (PORTMAPO01)

$\Rightarrow$ Ver ACORDE DE PASSAGEM

\section{Acorde de quarta suspensa $\Leftrightarrow$ Suspended fourth chord}

\section{Abreviação: ACORDE SUS4}

* A cifra do tipo X(sus4), conhecida no Brasil como "acorde de quarta suspensa" ou “acorde suspenso”, representa algumas harmonias muito comuns no Jazz, principalmente dominantes sem terça. $O$ "sus" vem da palavra inglesa "suspension" - suspensão - que equivale à nota melódica conhecida como "retardo” em português. (PORTMTE01)

$>$ Termos utilizados em Harmonia Popular

\section{Acorde de quinta aumentada $\Leftrightarrow$ Augmented triad}

[Variante : Tríade aumentada]

Acorde de quinta aumentada - É formado pela fundamental, terça maior e quinta aumentada e se caracteriza pela superposição de duas terças maiores (PORTMAPOO3)

* Para Schoenberg, o acorde de quinta aumentada pode ocorrer em qualquer grau, 
alterando-se a quinta, e nos acordes menores alterando-se também a terça. Qualquer grau pode preceder um acorde de quinta aumentada. Da mesma forma, pode-se encadear os acordes de quinta aumentada entre si. (PORTMDM01)

$\Rightarrow$ Ver ACORDE AUMENTADO

\section{Acorde de quinta diminuta $\Leftrightarrow$ Diminished triad}

[Var.: Tríade diminuta]

Acorde de quinta diminuta. É formado por duas terças menores (ou por uma terça menor e uma quinta diminuta). (PORTMLIVO2)

* Para a utilização dos acordes sem a alteração, Schönberg não impõe qualquer restrição aos encadeamentos com estes acordes. Lembrando que estamos tratando até este ponto dos acordes no estado fundamental. Ou seja, para os acordes da chamada escala natural, as instruções de encadeamento continuam as mesmas do modo maior, apenas ressaltando que o acorde de quinta diminuta acontece aqui no II grau e vai exigir a preparação da quinta diminuta por ser um intervalo dissonante. (PORTMDM01)

$\Rightarrow$ Ver ACORDE DIMINUTO, TRÍADE DIMINUTA

\section{Acorde de Rameau $\Leftrightarrow$ Added-sixth chord}

$\Rightarrow$ Ver ACORDE DE SEXTA ACRESCENTADA (DE RAMEAU) 


\section{Acorde de resolução $\Leftrightarrow$ Chord of resolution, Resolution chord}

Todo acorde de resolução funciona como tonalidade principal (I grau) ou secundária (demais graus) e, para cada um deles, existe uma tonalidade paralela localizada a uma distância de trítono da sua fundamental. Estes dois acordes estão intrinsecamente ligados por dois acordes dominantes em comum. (PORTMAPO05)

Assim como foi visto nos acordes Dominantes Secundários a importância da cadência II - V-I no processo de preparação e resolução harmônica, no caso dos acordes Dominantes Substitutos este recurso também se mostra disponível e aplicável. Dessa forma, além de precedermos o acorde de resolução por seu Dominante Substituto, também podemos acrescentar o seu respectivo II grau cadencial - Abm7 - Db7 - Cmaj7. (PORTMDM03)

Ver ACORDE DE PREPARAÇÃO

\section{Acorde de sétima $\Leftrightarrow$ Seventh chord}

[Var.: Tétrade]

Acorde de sétima: tem quatro notas diferentes e é formado por três terças sobrepostas. As notas extremas do acorde formam um intervalo de sétima. É chamado de tétrade. (PORTMLIVO2)

Assim, os acordes de $9^{a}, 11^{a}$ etc. seriam gerados harmonicamente e não melodicamente, pela adição de uma terça ou uma quinta abaixo da fundamental de um acorde de sétima. (PORTMART20)

* A meta é mais uma vez o acorde de sétima sobre o segundo grau, sustentado por três compassos (comp.56-58), depois de uma breve respiração sobre uma cadência perfeita em Fá menor (comp.53-55), confirmando e reforçando a intensidade resultante da sustentação deste mesmo acorde indicada pelo sinal < > em passagens anteriores (comp. 8 e16). (PORTMART25)

$\Rightarrow$ Ver ACORDE DE SÉTIMA DA DOMINANTE, ACORDE DE SÉTIMA DA SENSÍVEL, ACORDE DE SÉTIMA DIMINUTA 


\section{Acorde de sétima de dominante $\Leftrightarrow$ Dominant seventh chord}

[Variantes.: Acorde de sétima com dominante, acorde de dominante da sétima]

Os acordes de sétima da dominante se caracterizam pelo trítono entre a terça maior e a sétima menor, dando origem ao som preparatório ou de tensão do acorde de sétima da dominante. (PORTMLIV07)

De todos os acordes dissonantes naturais é o acorde de sétima da dominante o que se usa com mais frequência. Tem este acorde duas notas atrativas: 1) sensível (terça do acorde) que resolve subindo tônica. 2) a sétima do acorde que resolve descendo por grau conjunto. Há neste acorde três notas que não devem ser suprimidas: a fundamental, a terça (sensível) e a sétima. Assim sendo, a nota que se suprime neste acorde é a quinta. (PORTMLIV10)

"Partindo de um acorde maior, é possivel acrescentar-se a ele uma sétima menor, o que o transformará em um acorde de dominante com sétima. (PORTMAPOO6)

* Para Schoenberg: "O fato de que o som do acorde de 6/5 (4/3, 2 ou 6) aumentada ser idêntico ao som de um acorde de sétima de dominante pode, agora, ser facilmente explorado por tratar (introduzindo e continuando) este como se fosse o outro [V7]"(47). (PORTMART18)

$\Rightarrow$ Ver ACORDE DE DOMINANTE

\section{Acorde de sétima da sensível $\Leftrightarrow$ Leading-tone seventh chord}

É o acorde de quinta diminuta e sétima menor. É encontrado frequentemente no grau VII da escala maior, mas pode aparecer também em outros graus. (PORTMLIV02)

* (...) no contexto da harmonia funcional, Koellreutter (1978: 21-23) usa a letra "D" (indicativa da função harmônica de dominante) cortada por uma barra diagonal e com um "7" ao lado para designar tríades diminutas (construídas sobre a sensível da escala maior ou menor harmônica) e a mesma letra " $D$ " cortada por uma barra 
diagonal e com um "9" ao lado para designar acordes de sétima da sensível, ou de sétima diminuta (a interpretação alegada é que trata-se, na verdade, de um acorde de nona da dominante sem a fundamental, daí a sétima do diminuto ser interpretada como nona da dominante). (PORTMART21)

* O acorde de sétima da sensível com a terça abaixada resolve na tônica já dentro do diminuendo retornando ao tema principal desta seção, como vemos no exemplo 11. (PORTMART25)

\section{Acorde de sétima diminuta $\Leftrightarrow$ Diminished seventh chord, Fully-} diminished seventh chord

[Var.: Tétrade diminuta]

É o acorde de quinta diminuta mais sétima diminuta. É encontrado frequentemente no grau VII da escala menor - forma harmônica e melódica ascendente. (PORTMLIVO2)

Caracteriza-se pela terça menor, quinta diminuta e sétima diminuta. É construído diatonicamente sobre o VII grau da escala menor harmônica, grau este de função dominante. Caracteriza-se, também, pela presença de dois trítonos. (PORTMLIV07)

* O acorde de sétima diminuta é um dos melhores exemplos deste tipo de forma simétrica. Composto por uma sobreposição de terças menores, este acorde apresenta uma forma completamente simétrica, mesmo nas suas inversões não apresenta nenhuma forma assimétrica que possa identificar uma fundamental. (PORTMART18)

$\Rightarrow$ Ver TÉTRADE DIMINUTA 


\section{Acorde de sexta $\Leftrightarrow$ Sixth chord}

Acorde de sexta: quando os acordes de 3 sons se acham na primeira inversão (a terça do acorde figura no baixo) sua cifragem é 6, e são formadas de terça e sexta. Estes acordes não podem ser empregados incompletos, ou seja, nesses acordes não se faz supressão de nota, deve ser usados sempre completos. (PORTMLIV10)

* Pode-se antever nessa sua concepção de análise dos acordes de sexta, uma abertura para certa dissolução dos limites de individualidade dos acordes, tendência a ser reafirmada pela segunda lei tonal.(PORTMART14)

- Observação: $O$ acorde de sexta pode se referir também a uma tríade com sexta acrescentada. (Ver ACORDE DE SEXTA ACRESCENTADA (DE RAMEAU)

Ver ACORDE DE SEXTA AUMENTADA

\section{Acorde de sexta acrescentada (de Rameau) $\Leftrightarrow$ Added-sixth chord}

[Var.: Acorde de Rameau]

Este acorde, também denominado accord de la sixte ajoutee de Rameau (1683-1764), tem especial importância, porquanto a sexta é sempre a sexta do tom. A sexta acrescentada é tão característica para a subdominante quanto a sétima o é para a dominante. Pode-se considerar o acorde de sexta acrescentada como um reforço quase tão importante para a cadência plagal, quanto o acorde de sétima de dominante para a cadência autêntica. Emprega-se somente na posição fundamental. A sexta pode ser empregada omitindo-se a quinta e dobra-se a fundamental. (PORTMLIV06)

* O acorde que personifica tal duplicidade é o chamado acorde de sexta acrescentada (accord de sixte ajoutée). Por vezes lembrado como "o acorde de Rameau" em homenagem a quem definitivamente teria dado destaque teórico a tal recurso artístico em publicações que circularam nos grandes centros urbanos modernos. (PORTMTE02) 


\section{Acorde de sexta alemã $\Leftrightarrow$ German sixth chord}

[Variantes: Acorde de sexta aumentada alemã, sexta alemã, acorde de sexta germânica]

$\Rightarrow$ Ver ACORDE DE SEXTA AUMENTADA ALEMÃ

\section{Acorde de sexta aumentada $\Leftrightarrow$ Augmented Sixth Chord}

Acordes de sexta aumentada são construídos no grau VI da escala, um semitom abaixo, e usam um intervalo de sexta aumentada. São usados com função de dominante da dominante, com a sexta aumentada sendo resolvida por movimento contrário. (PORTMAPO04)

Considerando o sistema de escalas temperadas, os acordes de sexta aumentada podem receber interpretações diferentes, mas tem, na verdade, o mesmo som. Sendo assim, poderia ser questionado qual deve ser a análise correta ou qual função representa exatamente o que as distintas análises determinam. (PORTMART05)

Ver ACORDE DE SEXTA AUMENTADA ALEMÃ, ACORDE DE SEXTA AUMENTADA FRANCESA, ACORDE DE SEXTA AUMENTADA ITALIANA

\section{Acorde de sexta aumentada alemã $\Leftrightarrow$ German augmented sixth} chord

[Variantes : Acorde de sexta alemã, acorde de sexta germânica, sexta alemã]

- Acorde de sexta germânica: É a primeira derivação do acorde de sexta aumentada apresentada por Schoenberg em Harmonia, demonstrado através da transformação do "acorde de quinta e sexta sobre o II grau do modo maior, elevando-se a terça e a fundamental, e rebaixando-se a quinta. (PORTMART04)

- Nestes compassos iniciais da Toccata em Ré-menor, o II grau pré- 
dominante (mi-sol-sib-ré) está invertido e alterado como sib-fá-ré-sol\#. Escapando ao que Rameau pôde normalizar alguns anos depois, o fá do tenor, como "b9 de um E7 sem fundamental e com quinta bemol no baixo", gera o tipo que, na teoria erudita contemporânea, ficaria conhecido como "acorde sexta aumentada alemã".(PORTMTEO2)

- O Dominante Individual Substituto, ou simplesmente subV é muitíssimo utilizado no repertório da bossa nova. Na teoria tradicional da harmonia é conhecido como acorde de sexta alemã.(PORTMDM04)

\section{Acorde de sexta aumentada francesa $\Leftrightarrow$ French augmented sixth} Chord

[Variantes : Acorde de sexta francesa, sexta francesa]

É um acorde de dominante com sétima, a quinta alterada uma segunda menor abaixo. Este acorde aparece na maioria das vezes na tonalidade menor, com a quinta alterada no baixo. Resolve sempre no acorde de dominante da tonalidade tendo, por conseguinte, a função de dominante da dominante. Na resolução ouvem-se duas notas em movimento contrário num intervalo de segunda menor: a sensível, terça da dominante, caminhando em movimento ascendente; a quinta alterada no baixo, em movimento descendente. (PORTMAPOO6)

Acorde de sexta aumentada francesa é um acorde de sétima alterado na segunda inversão. (PORTMLIV02)

* O Acorde de Sexta Francesa pode ser demonstrado através da transformação do acorde de terça e quarta sobre o II grau do modo maior ou menor, elevando-se a terça e rebaixando-se a quinta (SCHOENBERG, 1999, p.365). Em Dó maior, o acorde Dm7/A é transformado e assume a configuração de D7(b5)/Ab. (PORTMART04) 


\section{Acorde de sexta aumentada italiana $\Leftrightarrow$ Italian augmented sixth} chord

[Variantes. : Acorde de sexta italiana, sexta italiana]

O acorde de sexta italiana é o acorde de quinta alterado na primeira inversão. (PORTMLIVO2)

O acorde de sexta aumentada italiana é formado por três notas do acorde de dominante: a quinta alterada no baixo, a sétima e a terça no soprano. (PORTMAPOO6)

* Hindemith (...) afirma ser frequente o uso de acordes a três vozes obtidos por omissão de uma das vozes do acorde Dominante em forma alterada. Este procedimento sobre o acorde de sexta alemã gera o acorde de sexta italiana, tendo a mesma resolução que o acorde do qual se originou. (PORTMART05)

* Em Ré menor, o II grau seria mi-sol-sib-ré, mas dado ao superlativo da situação ouvimos a versão super, a inversão com alteração: sib-ré-[mi]-sol\# (sem a nota mi é um "acorde de sexta aumentada italiana"). (PORTMTEO2)

\section{Acorde de sexta francesa $\Leftrightarrow$ French sixth Chord}

[Var. : Acorde de sexta aumentada francesa, sexta francesa]

Ver ACORDE DE SEXTA AUMENTADA FRANCESA

\section{Acorde de sexta germânica $\Leftrightarrow$ German sixth chord}

[Var. : Acorde de sexta aumentada alemã, acorde de sexta alemã]

Ver ACORDE DE SEXTA AUMENTADA ALEMÃ

\section{Acorde de sexta italiana $\Leftrightarrow$ Italian sixth chord}

[Var. : Acorde de sexta aumentada italiana, sexta italiana]

Ver ACORDE DE SEXTA AUMENTADA ITALIANA 


\section{Acorde de sexta napolitana $\Leftrightarrow$ Neapolitan sixth chord}

O acorde de sexta napolitana é a subdominante menor com sexta menor, a qual é uma nota alterada na escala. Seu uso começa nessa forma, para depois aparecer como um acorde de terça maior e quinta justa, o acorde napolitano. Ambos são mais frequentes nas tonalidades menores e pertencem a região da subdominante. Resolvem em acorde de dominante. As duas formas desse acorde foram largamente utilizadas em toda a história da música tonal. (PORTMAPO01)

Acorde de Sexta Napolitana - Acorde frígio na primeira inversão. (PORTMLIV02)

* Mantendo, com Riemann, a exemplificação na tonalidade de Lá-menor, temos que, no geral, os comentadores distinguem dois principais estados desta harmonia: "ré-fá-sib" dito "acorde de sexta napolitana" e "sib-ré-fá" dito “acode napolitano”. Notando que estas duas disposições das mesmas notas estão presentes em diversos repertórios, grosso modo, considera-se que o acorde de sexta napolitana, o estado ré-fá-sib, e em tonalidade menor, associase aos estilos mais antigos, tradicionais ou conservadores. Neste caso, a nota diatônica ré, posicionada na voz mais grave, é interpretada como o baixo fundamental, enquanto que a nota não diatônica, sib, é racionalizada como nota ornamental, uma dissonância acrescentada ao IVm. Tal interpretação persiste e, convivendo com outras, envolve-se em inevitáveis mal-entendidos, pois, eventualmente, o anfibológico estado ré-fá-sib é visto como uma primeira inversão.(PORTMART28)

Em alguns textos de Harmonia o acorde napolitano e o acorde de sexta napolitano são utilizados como termos variantes do mesmo conceito, e em outros, como acordes diferentes entre si.

$\Rightarrow$ VER ACORDE NAPOLITANO 


\section{Acorde de subdominante $\Leftrightarrow$ Subdominant chord}

[Variante: Subdominante]

A função subdominante tem como característica o sentido meio suspensivo e possui uma sensação de afastamento da tônica. O acorde principal desta função é o IV grau... (Acorde de subdominante) (PORTMLIV03).

O acorde de subdominante acha-se à distancia de uma quinta justa abaixo da Tônica. (PORTMLIV06)

* A partir dessa análise destacam-se o fato do acorde da tônica encontrar-se simetricamente no centro entre os acordes do quarto e do quinto grau e a presença da sensível tonal (sétimo grau) no acorde da dominante e da sensível modal (quarto grau) no acorde da subdominante. (PORTDMART14)

\section{Acorde de tônica $\Leftrightarrow$ Tonic chord}

[Variante: Subdominante]

Tônica é a função de sentido conclusivo, de repouso. Geralmente é o acorde que finaliza um tema musical. O acorde principal da função tônica é o I grau... (Acorde de tônica) (PORTMAPOO3)

Tônica (ou I grau) é o acorde perfeito maior que se localiza no centro dos três únicos acordes perfeitos da escala, separados por intervalos de quinta.(PORTMART19)

Esta progressão acima é chamada de back-door ("porta dos fundos"), nome este provavelmente originado do fato do acorde tônico ser alcançado por um dominante localizado um tom abaixo de sua fundamental.(PORTMAPO05)

* A "cadência interrompida" pode ser considerada como um modo funcional de resolver, pois se procura detalhar como a "interrupção" ocorre por meio da comparação entre a função do acorde esperado com o acorde de "engano". Normalmente se espera o acorde de tônica (I grau) após a dominante. (PORTMTE01)

\section{$\Rightarrow$ Ver ACORDE DE SUBDOMINANTE, ACORDE DE DOMINANTE}




\section{Acorde de Tristão $\Leftrightarrow$ Tristan chord}

[Variante: Acorde Tristão]

O acorde de Tristão ficou conhecido por esta denominação após ter sido usado na abertura da ópera "Tristão e Isolda".

A "configuração arquetípica" do "acorde de Tristão" é, como sublinha Menezes (2006, p. 45), "trítono + terça maior + quarta" (...) (PORTMTE02)

Todas estas interpretações levam a concluir que o "acorde Tristão" é um acorde vagante e apresenta função múltipla. (PORTMART18)

\section{Acorde diatônico $\Leftrightarrow$ Diatonic chord}

Acorde formado por notas pertencentes a uma escala diatônica. (PORTMLIV02)

Escala diatônica é a sucessão de oito sons (notas) conjuntos guardando de um para outro intervalo de tom ou de semitom. Os tons e semitons contidos na escala diatônica são chamados naturais. A cada uma das notas da escala, de acordo com a sua função na própria escala, dá-se o nome de grau. Tem a escala diatônica, por conseguinte, 8 graus, sendo o VIII grau a repetição do I. Os graus da escala são assim denominados: I grau-tônica; II grau-supertônica; III grau-mediante; IV grau-subdominante; V grau - dominante; VI grau - superdominante; VII grau - sensível; VIII grau tônica. (PORTMLIV03)

* Por fim, temos a possibilidade de um acorde diatônico se transformar em tônica com o auxílio de acordes característicos de empréstimo modal, ou seja, com a utilização de acordes de empréstimo modal que não são possíveis na primeira tonalidade ou são mais apropriados à segunda tonalidade. (PORTMTE02) 


\section{Acorde diminuto $\Leftrightarrow$ Diminished chord}

$\Rightarrow$ Ver ACORDE DE SÉTIMA DIMINUTA, TRÍADE DIMINUTA, ACORDE DE QUINTA DIMINUTA

\section{Acorde dissonante $\Leftrightarrow$ Dissonant chord}

Os acordes dissonantes criam a impressão de intranquilidade ou tensão. Soam como se fossem incompletos ou inacabados e sugerem uma resolução num acorde consonante. (PORTMLIVO2)

Dê acordo com os intervalos que os formam, os acordes podem ser classificados como consonantes ou dissonantes. (...) b) Dissonantes - São acordes que contêm um ou mais intervalos consonantes. Ex.: $\cdot$ Acorde de $5^{a}$ diminuta; Acorde de $5^{a}$ aumentada; Todos os acordes de $7^{a}$; Todos acordes com $9^{a}$. (PORTMAPOO3)

* O próprio emprego de acordes dissonantes torna difícil a observação dos ditames de condução de vozes históricos. (PORTMTE02)

* O emprego sistemático dos acordes dissonantes acabou por demandar, dos autores e professores associados à Zona Popular, todo um novo esforço de teorização. (PORTMTE01)

$\Rightarrow$ Ver ACORDE CONSONANTE

\section{Acorde dominante $\Leftrightarrow$ Dominant chord}

$\Rightarrow$ Ver ACORDE DE DOMINANTE 


\section{Acorde errante $\Leftrightarrow$ Vagrant chord}

[Variante: Acorde vagante]

$\Rightarrow$ Ver ACORDE VAGANTE

\section{Acorde interpolado $\Leftrightarrow$ Interpolated chord}

* Note que nos exemplos acima, o Db7 é um acorde interpolado, pois se encontra no meio de um II cadencial primário (ex.s 1, 2 e 3) e de um dominante primário (ex. 4). (PORTMAPOO5)

* Acordes interpolados são os que estão no meio de uma progressão. Exemplo de acorde interpolado em progressão ii-V-I: Dm-Bb-G-C. Exemplo de acorde interpolado em resolução de dominante: $G-B b-C$. (FE-DREMER)

- Observação: Neste trecho, o acorde interpolado é o Bb (Si bemol).

\section{Acorde invertido $\Leftrightarrow$ Inverted chord}

É quando a terça, a quinta ou a sétima vai para o baixo, isto é, fica sendo a nota mais grave do acorde. Quando a terça vai para o baixo, diz-se que o acorde está na primeira inversão; quando é a quinta que vai para o baixo, tem-se uma segunda inversão; e quando vai a sétima, uma terceira inversão. (PORTMLIV07)

* Kostka \& Payne comentam que o pedal começa como uma nota do acorde, a deixa de ser, e enfim, volta a ser uma nota do acorde. Outro detalhe é que a nota pedal pode ser confundida como uma nota de acorde invertido. (PORTMDMO1)

\section{Acorde maior $\Leftrightarrow$ Major chord}

[Variantes: Tríade maior]

Acorde Maior é composto pela fundamental, terça maior e quinta justa. (PORTMLIV02) 
* É importante lembrar que, caso o acorde da resolução seja um acorde maior, a preparação obedece as características do modo maior, ou seja, o II grau se configurará um acorde menor com sétima menor. (PORTMDM03)

\section{- Ver TRÍADE MAIOR, ACORDE PERFEITO MAIOR}

\section{Acorde meio-diminuto $\Leftrightarrow$ Half-diminished seventh chord}

Acorde meio-diminuto: quinta diminuta e sétima menor (4 notas, função subdominante). Este acorde encontra-se no ii (grau) de uma tonalidade menor, cuja base é de quinta diminuta, acrescentado de sétima menor. Aparece geralmente com a terça no baixo, resolve na Dominante e sua função é de Subdominante menor, com quinta e sexta. (PORTMAPOO6)

No modo menor o lugar natural da tétrade meio-diminuta é o II grau (notas ré-fáláb-dó em Cm:), usualmente tratado como um acorde da função subdominante que, dependendo da posição e da inversão, como já vimos, será cifrado como IIm7(b5) ou IVm6 (o acorde de sexta acrescentada, ou acorde de Rameau no modo menor). Nesse contexto, o acorde meio-diminuto tem função pré-dominante. (PORTMTEO2)

* Para a música popular a cadência II-V é fundamental e o VII grau com sétima menor (chamado de meio-diminuto) é entendido antes como um II na cadência II-V de um acorde menor e, neste contexto, tem função de subdominante. "Esta ambigüidade faz do acorde meio-diminuto com sétima um útil adjunto nãodominante em passagens que modulam rápida e repetitivamente, aonde o compositor deseja evitar temporariamente a estabilização da tonalidade" (PORTMART24) 


\section{Acorde menor $\Leftrightarrow$ Minor chord}

[Variantes: Tríade menor]

Acorde Menor - formado por fundamental, terça menor e quinta justa (PORTMAPOO6)

* Outras possibilidades poderiam surgir a partir desse mesmo acorde menor. (PORTMART04)

\section{VER TRÍADE MENOR, ACORDE PERFEITO MENOR}

\section{Acorde não-diatônico $\Leftrightarrow$ Nondiatonic chord}

Acordes não diatônicos são aqueles que possuem uma ou mais notas estranhas à tonalidade (escala) onde ele se encontra. (PORTMLIV07)

* Os Capítulos 1 a 6 cuidam da revisão, da contextualização, do levantamento e cruzamento circunstanciado de referências, do repertório e da memória teórica e poética, do questionamento e discussão a respeito de determinadas abordagens interpretativas sobre assuntos como: os fundamentos diatônicos da tonalidade, a atribuição funcional dos acordes e áreas tonais, a inclusão teórico-normativa de acordes não diatônicos, os meios de preparação alterados e as vizinhanças de terceira que envolvem transformações cromáticas. (PORTMDM02)

\section{Acorde napolitano $\Leftrightarrow$ Neapolitan chord}

$\Rightarrow$ Ver ACORDE DE SEXTA NAPOLITANA

\section{Acorde pedal $\Leftrightarrow$ Pedal chord}

$>$ Nota: Acordes que têm a nota pedal

* Nesse sentido, daria certo, por exemplo, a substituição da nota pedal sobre o II grau da "Happy Xmas" (John Lennon/Yoko Ono) pelo acorde pedal no mesmo 
grau. (PORTMDM02)

* Kostka \& Payne comentam que o pedal começa como uma nota do acorde, a deixa de ser, e enfim, volta a ser uma nota do acorde. Outro detalhe é que a nota pedal pode ser confundida como uma nota de acorde invertido. (PORTMDMO1)

\section{Acorde perfeito maior $\Leftrightarrow$ Major triad}

[Variantes: Tríade Maior]

Acorde perfeito maior. É formado por uma terça maior e uma terça menor sobrepostas (ou por uma terça maior e uma quinta justa). (PORTMLIV02)

* Institui então, que as funções de Tônica, Subdominante e Dominante são, respectivamente, os I, IV e V graus da escala, onde a Tônica (ou I grau) é o acorde perfeito maior que se localiza no centro dos três únicos acordes perfeitos da escala, separados por intervalos de quinta. (PORTMART19)

$\Rightarrow$ Ver ACORDE PERFEITO, ACORDE COMUM

\section{Acorde perfeito menor $\Leftrightarrow$ Minor triad}

[Variantes: Tríade menor]

Acorde perfeito menor: É formado por uma terça menor e uma terça maior sobrepostas (ou por uma terça menor e uma quinta justa).(PORTMLIV02)

* Esse acorde de três sons passava por inferior, fraco e, num sentido hierárquico negativo. Zarlino chama o acorde perfeito menor de affeto tristo-sentimento ruim. (PORTMTE02)

\section{Acorde perfeito $\Leftrightarrow$ Triad}

Acorde perfeito é assim denominado em consequência do intervalo de quinta justa (consonância perfeita) entre a nota mais grave e a nota mais aguda. (PORTMLIV02) 
* Entende-se por "acorde perfeito" a tríade: Acorde de três sons formado por terças sobrepostas. (PORTMART19)

Alguns dicionários especializados traduzem como "Common chord".

$\Rightarrow$ VER ACORDE PERFEITO MENOR, ACORDE PERFEITO MAIOR

\section{Acorde pivô $\Leftrightarrow$ Pivot chord}

* (No processo de modulação), os chamados acordes neutros ou acordes pivôs, são acordes que pertencem a ambas tonalidades e vão servir de mediadores entre elas. (PORTMTE01)

* O acorde de sexta aumentada pode ser usado numa modulação como acorde pivô em substituição ao acorde de sétima da dominante. (PORTMDMO1)

$\Rightarrow$ Ver ACORDE COMUM

\section{Acorde pré-dominante $\Leftrightarrow$ Pre-dominant chord}

$>$ Acorde que precede a dominante (acorde dominante) na cadência (LAITZ, 2008).

* Em função deste raciocínio de base ramista, alguns autores consideram os acordes pré-dominantes como derivados da sous-dominante, i. e., transformações do feixe ré-fá-lá-dó. (PORTMTEO2)

* Hoje podemos dizer que, nestes casos, "(SubV7/V7)" e "S" são igualmente "prédominantes", mas tal expressão técnica-teórica é relativamente recente e não é necessariamente reconhecida por todos. (PORTMTE02)

$\Rightarrow$ Ver ACORDE DE PREPARAÇÃO 


\section{Acorde quebrado $\Leftrightarrow$ Broken chord, arpeggio}

[Var. Acorde arpejado, arpejo)

Acorde quebrado é a denominação que se dá ao grupo de notas que formam um acordo disposto melodicamente numa ordem que não seja a habitual (isto é, fundamental, terça, quinta e sétima), que é também conhecida como arpejo. (PORTMLIV09)

Arpejo: $O$ termo arpejo descreve o emprego de notas do acorde de forma sucessiva em ordem direta ou "quebrada". Arpejo em ordem direta e quebrada - Este tipo de figuração é mais comum na musica instrumental. Suas principais vantagens são as de oferecer um padrão de acompanhamento, de servir para conectar registros contrastantes em uma melodia, para propiciar uma maior atividade rítmica ou como recurso timbrístico. (PORTMLIVO1)

* No terceiro elemento temático a melodia fluente é construída por acordes quebrados, dolce, una corda, com um acompanhamento arpejado na mão esquerda em mi menor (comp. 37-40) - como podemos verificar no exemplo 15 abaixo - indo para lá Maior (comp. 41), e dó\# menor (comp.43). (PORTMART25)

$\Rightarrow$ Ver ACORDE ARPEJADO

Acorde suspenso $\Leftrightarrow$ Suspended chord

$\Rightarrow$ Ver ACORDE DE QUARTA SUSPENSA

\section{Acorde tonicizado $\Leftrightarrow$ Tonicized chord}

[Variante: Acorde tonicalizado]

$\Rightarrow$ Ver ACORDE TONICALIZADO 


\section{Acorde tonicalizado $\Leftrightarrow$ Tonicized chord}

Variante: Acorde tonicizado

Entende-se por tonicalização a aplicação imediata de um acorde de dominante individual que funciona em nível localizado e dentro de um contexto tonal maior. Por exemplo, na progressão (em dó maior) $I-V / V-V$, em que o acorde $V / V$ é uma dominante secundária (ou individual) da dominante da tônica, diz-se então que o acorde V foi tonicalizado. Assim, tonicalização funciona para acordes alterados, e que tem um efeito puramente local e imediato, o que não implica necessariamente em mudança de região tonal ou modulação. (PORTMAPOO1)

Tonicização é definida neste presente modelo como sendo um procedimento modulatório no qual uma estrutura harmônica pertencente ao campo harmônico da região ativada pela fórmula tonal é prolongada prefixalmente por meio de uma outra estrutura harmônica emprestada do campo harmônico que tem como tônica a própria estrutura a ser prolongada.(PORTMART09)

Da noção de tonicização. Abarcando vários meios de preparação o termo tonicização, ou tonicalização, tornou-se mais ou menos corrente nas práticas teóricas da música popular.(PORTMTE02)

* O acorde aparece tonicizado nos compassos (...).(PORTMART09)

\section{Acorde tônico $\Leftrightarrow$ Tonic chord}

Ver ACORDE DE TÔNICA

\section{Acorde vagante $\Leftrightarrow$ Vagrant chord}

Variante: Acorde errante

Acordes vagantes. Apresentam funções múltiplas. Atuam como acordes que podem ser introduzidos depois de qualquer acorde. Tais acordes não pertencem somente a uma tonalidade de forma exclusiva; mas sim, podem pertencer a varias, a 
praticamente todas tonalidades sem mudar sua forma. Ainda estes acordes são derivados das transformações e tem função múltipla por apresentarem uma construção especifica. Os casos mais evidentes são os acordes de sétima diminuta, a tríade aumentada e o acorde de sexta aumentada e suas inversões. Estes acordes apresentam uma falta de sentido claro, de definição de sua fundamental, o que torna o seu sentido vago, isto é, sem uma relação definida com a tônica. (PORTMART18)

* (...)a discussão do "acorde Tristão" como um acorde vagante é definida por Schoenberg quando este propõe várias interpretações para o mesmo acorde. (PORTMART18)

- Os acordes de sexta aumentada são casos típicos de acordes vagantes. (PORTMARTO4)

\section{Acordes primários $\Leftrightarrow$ Primary chords}

[Variantes: Acordes principais, tríades principais]

* "As harmonias de tônica, dominante e subdominante constituem os três pilares do sistema tonal; todas as demais harmonias são derivadas destes três acordes primários". (PORTMTE02)

* Kopp observa ainda que, nas análises de Rameau, não há correspondência unívoca entre os três tipos sous-dominante, dominante-tonique e tonique e os três acordes primários do tom (I, IV, e V). (PORTMTE02)

$\Rightarrow$ Ver ACORDES PRINCIPAIS, TRÍADES PRINCIPAIS 


\section{Acordes principais $\Leftrightarrow$ Primary chords}

[Variantes: Acordes primários, tríades principais]

* Os chamados acordes principais possuem três funções: Tônica, Subdominante e Dominante. O relacionamento entre eles e a Tônica se dá pelo intervalo de quinta Justa e o movimento entre estes três acordes na ordem Tônica, Subdominante, Dominante, Tônica, forma a cadência perfeita completa, possível de se encontrar tanto nos inícios e terminações de frases elou de trechos, como na base da construção de peças tonais. (PORTMAPOO6)

- Os acordes principais serão Maiores em uma tonalidade Maior e menores em uma tonalidade menor. Somente o acorde de Dominante é sempre Maior. Para entender as funções, é preciso considerar que esses acordes não são isolados, só podem existir um em relação ao outro. (PORTMAPO06)

* Trata-se, portanto, de um sistema de inter-relações entre os acordes, que opera com base na existência de um centro tonal e três funções principais, atribuídas aos graus I, V e IV. Ainda no capítulo intitulado "Teoria das funções”, Brisolla recorre a uma análise da formação dos acordes principais do campo harmônico da escala maior e de relações entre si e entre eles e a escala. (PORTMART14)

$\Rightarrow$ Ver ACORDES PRIMÁRIOS, TRÍADES PRINCIPAIS

\section{Acorde relativo $\Leftrightarrow$ Relative chord}

Os acordes relativos de uma função maior são menores e sua fundamental encontra-se terça menor abaixo da fundamental do acorde da função que representam; já os acordes relativos de uma função menor são maiores e sua fundamental encontra-se terça menor acima da fundamental do acorde da função que representam. (PORTMAPOO3) 
* Dó Maior e Lá Menor são tonalidades relativas. C e Am são acordes relativos e compartilham duas notas comuns: C contém dó - mi - sol e Am contém ládó-mi. (PORTMTE02)

Termo usado na Harmonia Funcional

$\Rightarrow$ Ver ACORDE ANTI-RELATIVO

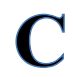

\section{Cifra $\Leftrightarrow$ Chord symbol}

Cifras são símbolos criados para representar o acorde de uma maneira prática e objetiva. A cifra é composta de letras, símbolos e sinais. É o sistema predominante em música popular. (PORTMAPOO3)

* A cifra é a grafia musical típica da Zona Popular. Foram os materiais e instituições associados a essa zona que a difundiram e legitimaram. O repertório popular hoje é, na maioria das vezes, registrado na forma de melodia cifrada; leadsheet em inglês. (PORTMTE01)

* Enquanto a cifra é praticamente indispensável na práxis da Música Popular, a Música Erudita é totalmente dependente da partitura tradicional. (PORTMTE01)

* A atitude de Delamont, ao usar a cifra graduada para "analisar" os acordes, uma prática oriunda dos manuais de jazz, e a cifra alfabética para escrever os arranjos (Strunk, 1988), é a mesma utilizada no Brasil pelos que escrevem livros sobre harmonia ou arranjo voltados exclusivamente para a música popular. (PORTMART13)

* Assim, foi escolhida a cifra que representa a alteração efetuada na quinta do acorde, excluindo a possibilidade de uma interpretação equivocada na formação deste. (PORTMDM03) 


\section{D}

\section{Dominante $\Leftrightarrow$ Dominant (chord)}

[Variantes: Acorde de Dominante, Acorde Dominante]

$\Rightarrow$ Ver ACORDE DE DOMINANTE

\section{Dominante secundária $\Leftrightarrow$ Secondary chords}

[Variantes: Acorde de Dominante, Acorde Dominante]

$\Rightarrow$ Ver ACORDE DE DOMINANTE SECUNDÁRIA

\section{$\mathbf{E}$}

\section{Encadeamento dos acordes $\Leftrightarrow$ Voice-leading}

Encadeamento de acordes - refere-se ao movimento de um acorde para outro, procurando manter as notas comuns na mesma voz e fazer as demais seguirem o caminho mais curto. (PORTMAPOO6)

Por encadeamento de acordes entende-se a melhor maneira de se fazer uma boa condução de vozes. (PORTMAPOO1)

Segundo Schönberg o aluno deve escrever o encadeamento de acordes a quatro vozes como se estas fossem realmente para um quarteto vocal. (PORTMDM01) 
* Uma teoria harmônica, por sua vez, deve dar conta destes dois aspectos, isto é, sistematizar e classificar os aglomerados sonoros (acordes) e as combinações entre eles (encadeamento de acordes). E é disso que o sistema harmônico tonal trata. (PORTMDM04).

Em alguns contextos utilizado no sentido de "condução de vozes"

\section{M}

\section{Modulação através de acorde comum $\Leftrightarrow$ Common chord} modulation

Na modulação através de acorde comum, um acorde é considerado como pertencente a dois centros tonais distintos e exerce uma função de ligação na troca de tônica ou região tonal. (PORTMLIV01)

\section{$\mathbf{N}$}

\section{Notas do acorde $\Leftrightarrow$ Chord tones}

[Variante: Notas de acorde]

Notas do acorde - são notas da estrutura básica do acorde (pertencentes a uma escala diatônica). (PORTMAPO03)

Escala de Acorde é a escala formada pelo conjunto das notas que caracterizam o 
acorde, chamadas Notas de Acorde, e as notas que o enriquecem, chamadas Notas de Tensão. (PORTMART04)

* Todas as notas aqui são "notas do acorde" ou "tensões disponíveis" que praticamente se igualam no interior dessa gama que (com diferentes rótulos) vem sendo gradualmente aculturada (maturada) desde os primórdios da tonalidade. (PORTMDMO2)

* Os acordes formados a partir do IV grau da escala (...) não possuem notas evitadas. Porém, por se tratar de um acorde que pode configurar-se de diversas maneiras, é necessário que se estabeleçam certos critérios de combinações entre notas de acorde e extensões harmônicas. (PORTMDM03)

\section{$\Rightarrow$ Ver NOTAS ESTRANHAS AO ACORDE}

\section{Notas estranhas ao acorde $\Leftrightarrow$ Non-chord tones}

[Variante: Notas estranhas à Harmonia]

São aquelas que não fazem parte do acorde, mas que são usadas para ornamentar uma melodia. São os seguintes os fenômenos que caracterizam as notas estranhas: bordadura, nota de passagem, retardo, antecipação, apoggiatura e escapada. (PORTMLIV06)

Uma nota estranha à harmonia (NEH) é uma nota, diatônica ou cromática, que não pertence à um acorde, ou seja, à duração de um determinado acorde. Esta nota pode ser uma nota estranha durante toda a sua duração ou, se a harmonia mudar durante a duração desta nota, ela pode se tornar uma nota real de um acorde.(PORTMAPO01)

Para que possa ser estabelecido um parâmetro analítico, optou-se por dar início a um estudo voltado ao aspecto harmônico examinando, em princípio, o tópico específico do tratamento dado às chamadas notas estranhas aos acordes ou não harmônicas. (PORTMART06) 


\section{Progressão dos acordes $\Leftrightarrow$ Chord progression}

[Variante: Progressão Harmônica]

Uma progressão tem a função de estabelecer ou contradizer uma tonalidade. A combinação de harmonias nas quais uma progressão consiste depende de seu propósito - se este é estabelecimento, modulação, transição, contraste ou reafirmação. (PORTMART18)

* Os acordes que participam de uma progressão, não são estruturas isoladas; na verdade, exercem funções harmônicas específicas que conferem à harmonia movimento e coerência. (PORTMDM04)

* David Kopp observa que "função não diz respeito à progressão de acordes, mas sim, ao significado dos acordes que estão unidos nas progressões" (PORTDMART26)

* Na tonalidade de Bb maior, a introdução começa sobre uma progressão harmônica bastante encontrada na Música Popular e caracterizada pela seqüência I-IVm. (PORTMDM03)

\section{Sequência de acordes $\Leftrightarrow$ Chord sequence, sequence of chords}

[Variante: Sucessão de acordes]

As cadências são sequências típicas de acordes, que formam a "pontuação" do trecho musical. Elas são classificadas de acordo com a sequência de acordes que as formam e nomeadas de acordo com a sensação tonal (de tensão/relaxamento) que transmitem (...)(PORTMAPO04) 
Funcionalmente, cada dominante da passagem forma sozinha a sua própria semifórmula tonal e de certa forma é por isso que, neste caso, a sequência de acordes não “(...) consegue expressar inequivocamente uma região ou tonalidade" (SCHOENBERG, 1969, p. 3).(PORTMART19)

$\Rightarrow$ Ver SUCESSÃO DE ACORDES

\section{Sexta Alemã $\Leftrightarrow$ German Sixth}

[Variantes: Acorde de sexta aumentada alemã, acorde de sexta alemã, acorde de sexta germânica]

$\Rightarrow$ Ver ACORDE DE SEXTA AUMENTADA ALEMÃ

\section{Sexta Francesa $\Leftrightarrow$ French Sixth}

[Variantes: Acorde de sexta aumentada francesa, acorde de sexta francesa]

$\Rightarrow$ Ver ACORDE DE SEXTA AUMENTADA FRANCESA

\section{Sexta Italiana $\Leftrightarrow$ Italian sixth}

[Variantes: Acorde de sexta aumentada italiana, acorde de sexta italiana]

$\Rightarrow$ Ver ACORDE DE SEXTA AUMENTADA ITALIANA

\section{Sexta Napolitana $\Leftrightarrow$ Neapolitan sixth}

[Variante: Acorde de sexta napolitana]

$\Rightarrow$ Ver ACORDE DE SEXTA NAPOLITANA 


\section{Sucessão de acordes $\Leftrightarrow$ Chord sequence, sequence of chords}

[Variante: Sequência de acordes]

- Na teoria schoenberguiana a função tonal depende diretamente do relacionamento entre acordes que expressam uma tonalidade. Assim, não há função tonal em uma sucessão de acordes onde não ocorre uma expressão tonal. (PORTMART18)

* Nesta obra, Rameau aponta um importante conceito chamado Tonart (que poderia ser traduzido para Tonalidade), que seria uma sucessão de acordes com dissonâncias encerrando com uma consonância, (PORTMART19)

* A Coda (c.16-18,) apresenta uma sucessão de acordes que representa as quatro regiões harmônicas da estrutura da peça (Ex.24).(PORTMART07)

$\Rightarrow$ Ver SEQUÊNCIA DE ACORDES

\section{$\mathbf{T}$}

\section{Tétrade $\Leftrightarrow$ Seventh chord}

[Variante: Acorde de sétima]

A tétrade é formada pelo agrupamento de quatro sons separados por intervalos de terças sobrepostas. (PORTMLIV07)

* Verifica-se aqui a segunda simetria existente na formação das tétrades. (PORTMDM03)

$\Rightarrow$ Ver ACORDE DE SÉTIMA 


\section{Tétrade diminuta $\Leftrightarrow$ Diminished seventh chord}

[Acorde de sétima diminuta]

Tétrade diminuta: Formada por dois trítonos sobrepostos. (PORTMAPO04)

* A tétrade diminuta foi historicamente gerada pelo VII grau da Escala Menor Harmônica e costuma ser compreendida como uma dominante com nona menor e sem fundamental. Mas o diminuto em questão não é, nem enarmonicamente, VII grau de Dó Maior ou Menor, sendo, portanto, dominante de outro tom: ou seja, é um acorde modulante. (PORTMTE01)

$\Rightarrow$ Ver ACORDE DE SÉTIMA DIMINUTA

\section{Tônica $\Leftrightarrow$ Tonic (chord)}

[Variantes: Acorde de tônica, acorde tônico]

$\Rightarrow$ Ver ACORDE DE TÔNICA

\section{Tríade aumentada $\Leftrightarrow$ Augmented triad}

[Variante: Acorde de quinta aumentada]

Tríade Aumentada - A tríade aumentada é formada pela fundamental (1), terça maior (3M) e quinta aumentada e se caracteriza, também, pela superposição de terças maiores (PORTMLIV07)

* A tríade aumentada também é considerada como um acorde vagante por ser composta de dois intervalos iguais. Assim como o que ocorre com o acorde de sétima diminuta, a tríade aumentada pertence à várias tonalidades distintas, três maiores e três menores, sendo que suas notas são sensíveis em potencial. A tríade aumentada tem uma série de aplicações nestas tonalidades (PORTMART18) 


\section{Tríade diminuta $\Leftrightarrow$ Diminished triad}

[Acorde de quinta diminuta]

Tríade diminuta. É formada pela fundamental, terça menor e quinta diminuta e se caracteriza, também, pela superposição de duas terças menores. (PORTMLIV07)

- Cada grau é representado por algarismo romano (em maiúsculo quando a tríades é maior, e minúsculo quando a tríade é menor), além de uma indicação particular quando se trata de uma tríade diminuta(...) (PORTMART19)

$\Rightarrow$ Ver ACORDE DE QUINTA DIMINUTA

\section{Tríade maior $\Leftrightarrow$ Major triad}

[Variantes: Acorde perfeito maior, acorde maior]

Tríade Maior. É formada pela fundamental, terça maior e quinta justa e se caracteriza, também, pela superposição de uma terça maior e uma terça menor. (PORTMLIV07)

A definição de uma fundamental de um acorde qualquer é devida em grande parte a sua forma assimétrica, por exemplo, em uma tríade maior encontramos uma terça menor acima de uma maior, e reconhecemos uma fundamental em parte por esta forma assimétrica. (PORTMART18)

VER ACORDE PERFEITO MAIOR, ACORDE MAIOR 


\section{Tríade menor $\Leftrightarrow$ Minor triad}

[Variantes: Acorde perfeito menor, acorde menor]

Tríade menor: É formada pela fundamental, terça menor e quinta justa que se caracteriza, também, pela superposição de uma terça menor e maior. (PORTMLIV07)

* Junto a isto há que se nomear a aparição da tríade menor de dominante na cadência, com uma resolução sobre a tônica maior ou menor (PORTMTE02)

VER ACORDE PERFEITOMENOR, ACORDE MENOR

\section{Tríades principais $\Leftrightarrow$ Primary triads}

[Variantes: Acordes principais, acordes primários]

* É interessante sublinhar aqui que esta ideia de formação das escalas maior $e$ menor a partir das tríades principais de I, IV e V é bastante antiga (...) (PORTMARTO9)

* Os principais substitutos para cada uma das três tríades principais são seus relativos menores; assim, VI substitui I; III substitui V e II substitui IV. (PORTMART26)

$\Rightarrow$ Ver ACORDES PRINCIPAIS, ACORDES PRIMÁRIOS 


\section{Voicing $\Leftrightarrow$ Voicing chord}

Voicing é uma palavra inglesa que, numa tradução livre para aplicações musicais, significaria o ato de trabalhar com vozes. No caso específico da Harmonia, o voicing de um acorde é a disposição na qual as suas notas se apresentam. (PORTMLIV09)

Na prática, quem define a inversão é o baixo, não importando a disposição das notas do acordes. Este arranjo das vozes do acorde é chamado de voicing. (PORTMAPO05)

* A palavra "abertura" se refere à maneira como as notas individuais de um acorde estão distribuídas. Uma vez que se estabeleça a posição do acorde (estado fundamental, $1^{a}, 2^{a}$ ou $3^{a}$ inversões) elegendo assim, sua nota mais grave, as demais notas poderão estar dispostas de várias outras formas. O termo "abertura" ainda não é tão comumente empregado, sendo o seu correlato em inglês voicings, mais frequentemente utilizado. (PORTMDM03) 


\section{CONSIDERAÇÕES FINAIS}

Este trabalho teve como objetivo principal propor um modelo de glossário bilíngue de colocações especializadas da área de Harmonia Musical, com base em corpora. A fim de alcançarmos esse objetivo, estabelecemos os seguintes objetivos específicos: compilação de um corpus comparável português-inglês de Harmonia Musical a partir do qual pudéssemos realizar um levantamento das colocações derivadas de "acorde", observando a frequência de uso de tais estruturas para determinar o caráter de convencionalidade; identificação, no subcorpus Inglês, das colocações mais frequentes para o termo correspondente "chord"; análise comparativa dos resultados, relacionando os termos correspondentes nos dois idiomas; análise de aspectos comunicativos e culturais relacionados à terminologia e à linguagem de especialidade; preenchimento das fichas terminológicas e elaboração de verbetes.

O processo de compilação foi uma das etapas mais trabalhosas do estudo, pois envolveu uma pesquisa bibliográfica sobre os materiais utilizados na disciplina de Harmonia de instituições de ensino superior e conservatórios, bem como busca na Internet em sites de revistas especializadas, congressos e bibliotecas de faculdades de Música. A etapa seguinte envolveu a conversão de todo o material colhido em txt. Aparentemente uma tarefa simples, mas que demandou alguns meses, uma vez que envolveu digitação e digitalização dos materiais impressos (livros-texto) do subcorpus instrucional. Já em relação aos materiais que compõem o subcorpus acadêmico, colhidos de meio eletrônico, foram dedicadas várias semanas para o levantamento de todos os textos, por envolver duas línguas. Com os textos digitalizados em mãos, foi realizada a limpeza do corpus (eliminação de gráficos, figuras), nomeação dos textos e organização dos materiais por gêneros textuais e idiomas.

Inicialmente, tínhamos a pretensão de compilar um glossário com todos os termos encontrados do campo semântico da Harmonia e suas colocações. Entretanto, optamos por realizar uma análise mais detalhada de um termo que apresentasse um número relevante de ocorrências nos dois subcorpora de estudo e que compusesse diversas colocações. Com base na observação da frequência, optamos pelo termo "acorde", porque ele poderia oferecer um rico estudo linguístico, tendo em vista a quantidade de colocados que co-ocorrem com o termo. Ao mesmo tempo, um estudo que pudesse contribuir de alguma forma para a tarefa de tradutores que lidam com textos da área musical. 
Para compararmos os resultados do levantamento das colocações extraídas do corpus de estudo, realizamos em paralelo um levantamento das colocações (também com os termos chord e acorde) encontradas em dicionários de termos musicais nos dois idiomas, publicados nos últimos trinta anos. A ideia era analisar se as definições apresentadas em dicionários cobriam os significados apresentados no subcorpus acadêmico-científico, que é a fonte de análise do uso dos termos in vivo. Essa comparação entre contextos definitórios, contextos de uso e definições em dicionários abriu um novo horizonte para pesquisa: observação de marcas culturais presentes na forma de descrever os termos nos dicionários e nos textos do corpus de estudo.

Comparando os dois idiomas, observamos que os textos em Inglês, assim como as definições analisadas nos três dicionários do mesmo idioma, mencionados no capítulo 2, apontam uma diferença cultural marcante que é verificada na quantidade de informações que são disponibilizadas aos leitores dessas obras. Essa observação já foi realizada por Navarro (2013) quando menciona a teoria antropológica de Edward Hall, que explica características da comunicação de diversas culturas e aponta duas tendências: low context culture (culturas que tendem a ser mais descritivas ao veicular informações) e high context culture (culturas que utilizam informações de forma sucinta, confiando que o receptor já possui uma parte da informação necessária para entender a mensagem). Isso pode ser constatado a partir da comparação entre os dois subcorpora da pesquisa. Textos do gênero instrucional e da categoria "artigo científico" do gênero acadêmico-científico em inglês são mais extensos e apresentam um volume maior de informações do que os escritos em português. Entretanto, em relação ao repertório de palavras utilizadas nos corpora dos dois idiomas, há uma variedade maior de palavras em português (46.700 types) do que em inglês (28.354).

A partir do levantamento das colocações em dicionários, verificamos que, de fato, contextos de uso são importantes, principalmente para esclarecer termos que possuem mais de um significado e variações para o mesmo conceito. Da mesma forma, a informação sobre variantes terminológicas linguísticas lexicais nas entradas pode ajudar o tradutor a identificar outras denominações para o mesmo conceito.

As colocações especializadas e estendidas ainda são contempladas de forma tímida nos dicionários de especialidade analisados. Para o tradutor, a disponibilização dessas estruturas em obras lexicográficas (como dicionários, glossários e vocabulários especializados) ajuda na elaboração de um texto traduzido mais fluente. 
Outra marca cultural observada é a influência intercultural na formação da terminologia. Embora este estudo não tenha como objetivo a análise de textos traduzidos, já que trabalhamos com textos originais, é marcante a influência da tradução nessa área. A partir da intertextualidade explícita, por meio de referências e citações, verifica-se o uso de intertextos de fontes estrangeiras, bem como traduzidos. Como mencionamos na análise de gêneros textuais, a intertextualidade, no âmbito técnico científico, é um dos fatores que contribui para a importação de novos termos. Uma vez aceitos pela comunidade científica, os termos se cristalizam pelo uso e reuso entre especialistas e tornam-se convencionais. O uso de ferramentas de análise lexical pode também revelar ao analista o uso de intertextualidade em um conjunto de textos, bem como observar, a partir da frequência, quantas vezes um dado autor é mencionado nos textos. No caso desse estudo, a influência multicultural contribui para formação de neologismos e empréstimos linguísticos.

Em relação à metodologia, embora tenha sido baseado em corpora (corpus-based), em determinados momentos ele se tornou corpus-driven, ao apontar aspectos linguísticos e culturais que não perceberíamos tão facilmente manuseando todos os textos de forma mecânica, sem o auxílio das ferramentas de LC.

Após o preenchimento das fichas terminográficas, procedemos à fase de elaboração dos verbetes. Optamos pela ordem alfabética para facilitar a localização dos verbetes. Organizamos as colocações em duas direções: Português-Inglês e Inglês-Português. A microestrutura do verbete apesenta: colocação correspondente, variantes lexicais ou denominativas (se houver), contexto definitório (se houver), contexto de uso, remissiva e notas explicativas (quando necessário).

Neste estudo, não tivemos a pretensão de cobrir de forma exaustiva a terminologia, em relação aos conceitos, aos termos em si, como seria o caso de um dicionário ou vocabulário técnico, mas sim, focalizamos a questão da correspondência entre as combinações terminológicas, as colocações especializadas, em português e inglês.

Lembramos que o foco desta pesquisa é linguístico, de caráter descritivo, baseada na frequência de uso dos termos em contextos reais; portanto não nos cabe julgar ou estabelecer regras do que é certo ou errado no campo da Harmonia, mas apontar para o uso dos termos "acorde" e "chord" in vivo. 
Esperamos que este estudo incentive a criação de novos corpora na área de especialidade musical que possam ser manuseados por tradutores, especialistas e pesquisadores, cujo interesse seja investigar fenômenos linguísticos, culturais relacionados à terminologia e linguagem de especialidade musical; ou que sirvam para a compilação de mais vocabulários e/ou dicionários bilíngues na área.

Como desdobramentos deste estudo, pretendemos continuar investigando colocações especializadas da área de Harmonia, estendendo a análise a outros termos e ampliar o corpus de estudo (o que demandará um pouco mais de tempo). 


\section{REFERÊNCIAS BIBLIOGRÁFICAS}

ALMEIDA, Gladis M. B. A Teoria Comunicativa da Terminologia e a sua prática. São Paulo: Alfa Revista de Linguística, v. 50, n. 2, 2006. Disponível em: <http://seer.fclar.unesp.br/alfa/article/view/1413> Acesso em: 14/06/2015

ANTHONY, L. AntConc (Version 3.4.3) [Computer Software]. Tokyo, Japan: Waseda University, 2014. Disponível em < http://www.laurenceanthony.net/> Acesso em 20/06/2015.

AUBERT, Francis Henrik. Introdução à metodologia da pesquisa terminológica bilíngue. São Paulo: FFLCH/CITRAT, Humanitas, Cadernos de Terminologia, n.2, 2ª edição, 2001.

AUGER,P; ROUSSEAU, L.J. Méthodologie de la recherche terminologique. Québec: Office de la langue française, 1988.

AZENHA JUNIOR, João. Tradução Técnica e Condicionantes Culturais: Primeiros Passos para um Estudo Integrado. São Paulo: FFLCH/USP, Humanitas, 1999.

BAKER, Mona. Corpora in translation studies: an overview and some suggestions for future research. Target, Amsterdam, v. 7, n. 2, 1995, p. 223-243.

BERBER SARDINHA, Tony. Lingüística de Corpus: Histórico e Problemática in DELTA vol.16 no.2, São Paulo, 2000. Disponível em <http://www.scielo.br/scielo.php?script=sci_arttext\&pid=S0102-44502000000200005> Acesso em 20/06/2015.

BERBER SARDINHA. Corpora eletrônicos na pesquisa em tradução. Cadernos de Tradução, Volume 1, n. 9, UFSC, Florianópolis, 2002.

BERBER SARDINHA. Linguística de Corpus. Barueri, SP: Editora Manole, 2004.

BEVILACQUA, Cleci R. Por que e para que a Linguística de Corpus na Terminologia. In BEVILACQUA, Cleci; TAGNIN, Stella O. Corpora na Terminologia. São Paulo: Hub Editorial, 2013.

BOURIGAULT, D; SLODZIAN, M. Por uma terminologia textual. Cadernos de tradução, n.17, 2004. Tradução de Sandra Loguercio de Pour une terminologie textuelle. Terminologies nouvelles no 19, Rint, Bruxelles, ACTES DES TROISEMES JOURNEE TERMINOLOGIE ET INTELLIGENCE ARTIFICIELLE (TIA'99), Nantes, 1999. 
BRISOLLA, Cyro Monteiro. Princípios de harmonia funcional. São Paulo: Annablume, 2006 [1979].

CABRÉ, M. T. La terminología: representación y comunicación: elementos para una teoría de base comunicativa y outros artículos. Barcelona: Institut Universitari de Lingüística Aplicada, 1999.

CABRÉ, M. T. Theories of terminology: their description, prescription and explanation. In Terminology, v.9, n.2, p.163-200, 2003.

CAMARA, F. A. Sobre Harmonia: Uma proposta de perfil conceitual. Tese de Doutorado. Belo Horizonte, Minas Gerais: Faculdade de Educação de Minas Gerais, 2008.

CAMARGO, D.C; HASMANN, D. S. Proposta de elaboração de um glossário bilíngue de termos simples, expressões fixas e semifixas da área de Sensoriamento Remoto. São Paulo: Caderno Seminal Digital Ano 19, $\mathrm{n}^{\circ}$ 19, V. 19, 2013. Disponível em:<http://www.epublicacoes.uerj.br/index.php/cadernoseminal/article/view/12066/9447> Acesso em: $01 / 07 / 2015$

CAMINHA, A. O. MHITS - Um Sistema Tutor em Harmonia Musical. Dissertação (Mestrado em Ciência da Computação), Ciência da Computação, Universidade Federal da Paraíba, Paraíba, 2000.

CORPAS PASTOR, G.Manual de fraseológica española. Madrid: Gredos, 1996.

COSTA, A. R. O gênero textual artigo científico: estratégias de organização. II Semana de Ciência e Tecnologia - IPFE, Pernambuc, 17 a 21 de outubro de 2011. Disponivel em <http://www.ufrgs.br/napead/repositorio/objetos/edital19/corpora/organiza\%C3\%A7\%C3\%A 3o\%20do\%20artigo\%20cientifico_modulo\%201.pdf> Acesso em: 01/07/2015

COSTA, A. Aspectos da aprendizagem de colocações em Português L2. LUÍS, A. Estudos de Linguística, Vol 1. Coimbra: FTC, 2011 b.

CUNHA, A. L. Expressões idiomáticas: da linguagem publicitária para a sala de aula. Dissertação (Mestrado) Curso de Linguistica. Universidade Federal de Minas Gerais. Belo Horizonte: 2012. Disponível em:

$<$ http://www.bibliotecadigital.ufmg.br/dspace/bitstream/handle/1843/LETR-

8UBNJN/1516m.pdf?sequence=1> Acesso em: 04 jan. 2017.

DAYRELL, C. O uso de corpora para o estudo da tradução: objetivos e pressupostos. Tradução em Revista, Rio de Janeiro, v. 2, 2005, p.87-102, 29 out. 2015. Faculdades Católicas. http://dx.doi.org/10.17771/pucrio.tradrev.25346. Disponível em: <https://www.maxwell.vrac.puc-rio.br/25346/25346.PDFXXvmi>. Acesso em: 25 mar. 2017. 
DEMAI, F. M. Um dicionário terminológico da área de ortopedia técnica: descrição e análise. 2006. 390 f. Dissertação (Mestrado). Curso de Linguística. Departamento de Lingustica, Faculdade de Filosofia, Letras e Ciências Humanas, Universidade de São Paulo. São Paulo: 2006.

DI-FELIPPO, A; ALMEIDA, G.M.B. Uma metodologia para o desenvolvimento de wordnets terminológicas em português do Brasil. São Paulo: TradTerm, n.16, 2010.

FARIA, L.C. F. Análise da proposta metodológica das disciplinas de Harmonia Musical do curso Superior de Tecnologia em Produção Fonográfica. Trabalho de Conclusão de Especialização. Presidente Prudente, SP: Universidade do Oeste Paulista, 2010.

FAULSTICH, E. Base metodológica para pesquisa em socioterminologia: termo e variação. Brasília: Centro Lexterm, 1995.

FAULSTICH, E. A função social da terminologia. In RODRIGUES; ALVES, GOLDSTEIN. Seminário de filologia e língua português. São Paulo: Humanitas/FFLCH/USP, 1999.

FIRTH, J.R. Modes of Meaning. In: FIRTH, J.R. (Ed). Papers in Linguistics. 1934-1951. Oxford: Oxford University Press, 1957.

GALVÃO, M.C.B. A linguagem de especialidade e o texto técnico-científico: notas conceituais. Transinformação, Campinas, v. 16, n.3, p. 241-251, setembro-dezembro, 2004.

GALTER,Vidal. Dicionário da Música. Teoria Musical, Danças, Festas, Ritmos, Definições e Conceitos Gerais, Folclore e Ilustrações. Brasília: Vidal Galter, 2013

HALLIDAY, M.A. K. Categories of the theory of grammar. Word, v. 17, n. 3, p. 241$292,1961$.

HEYLEN, D.; MAXWELL,K. Lexical functions and the translation of collocations. In Proceedings of the $13^{\text {th }}$ International Conference on Computational Linguistics. Kyoto, Japan, p. 298-305, 1994.

KRIEGER, M. G.; FINATTO, M. J. B. Introdução à terminologia: teoria e prática. São Paulo: Contexto, 2004.

KRISTEVA, J. Introdução à Semanálise. São Paulo: Perspectiva, 1974.

HAUSMANN, F.J. Die Makierung im allgemeinen einsprachigen Wörterbuch: eine Ubersicht. In Haussmann, F. J. et al (ed.), vol. 1989. 
HINDEMITH, Curso condensado de harmonia tradicional: com predomínio de exercícios e um mínimo de regras. Tradução de Souza Lima. São Paulo: Vitale, 1998.

KOELLREUTER, Hans Joachim. Harmonia Funcional introdução à teoria das funções harmônicas. São Paulo: Ricordi Brasileira, 1980.

KOSTKA, S; PAYNE, D. Tonal Harmony with introduction to Twentieth-Century Music. New York: McGraw -Hill, 2013 [1989].

KOCH, I. G.V. O texto e a construção de sentidos. 3 ed. São Paulo: Contexto, 2000.

KRIEGER, M. G.; FINATTO, M. J. B. Introdução à terminologia: teoria e prática. São Paulo: Contexto, 2004.

(LATHAM, Alison. The Oxford Dictionary of musical terms. USA, New York: Oxford University Press Inc., 2004)

LEECH, G. Corpora and theories of linguistic performance. In: SVARTVIK, J. (org). Directions in corpus linguistics. Proceedings of Nobel Symposium 82, Stockholm, 4-8 August 1991: Berlim/Nova York, De Gruyter, p. 105-27.

LEIBRUDER, A. P, Gêneros do discurso na escola: mito, conto, cordel, discurso político, divulgação científica, In: Brandão, H. N. (org.), “Aprender e ensinar com textos”, Vol. 5, São Paulo: Cortez, 2002. pp. 229-269.

LIMA, M. R. R. Harmonia: uma abordagem prática. São Paulo: Marisa Ramires Rosa de Lima, 2008.

L'HOMME, M. C. Understanding Specialized Lexical Combinations. In: Terminology, v. 6, n. 1,2000 , p. $89-110$.

L'HOMME, M. C; BERTRAND, C. Specialized lexical combinations: should they be described as collocations or in terms of selectional restrictions? In: Proceedings. Ninth Euralex International Congress, p. 497-506, 2000.

MARCUSCHI, L. A. Gêneros textuais: definição e funcionalidade. In: DIONISIO, A. P. et al. (org.) Gêneros textuais e ensino. Rio de Janeiro: Lucerna, 2002, p. 19-36.

MATUDA, S. A. A fraseologia do futebol: um estudo bilíngue português-inglês direcionado pelo corpus. 2011. 304 f. Dissertação (Mestrado) - Curso de Estudos Linguísticos e Literários em Inglês. Departamento de Letras Modernas da Faculdade de Filosofia, Letras e Ciências Humanas, Universidade de São Paulo, Sao Paulo, 2011. 
MOTTE, D. Manuale di Armonía. Firenze: La Nuova Italia Editrice. 1988

NAVARRO, S. L. M. Glossário bilíngue de colocações da hotelaria: um modelo à luz da Linguística de Corpus. 2011. 204 f. Dissertação (Mestrado) - Curso de Estudos Linguísticos e Literários em Inglês. Departamento de Letras Modernas da Faculdade de Filosofia, Letras e Ciências Humanas, Universidade de São Paulo, Sao Paulo, 2011.

NETTLES, B. Harmony, Vol. 1, 2,3. Boston: Berklee Press, 1987.

On Music Dictionary. USA: Connect for Education Inc., 2015. Disponível em: < http://dictionary.onmusic.org/> Acesso em 20/04/2016.

OLOHAN, Maeve (2004). Introducting corpora in translation studies, London/New York: Routledge, 2004.

ORENHA-OTTAIANO, A. Colocações especializadas estendidas sob a ótica da terminologia a partir de corpora. In TAGNIN, Stella \& BEVILACQUA, Cleci. Corpora na Terminologia. São Paulo: Hub Editorial, 2013.

ORENHA-OTTAIANO, A. Semelhanças e diferenças entre colocações e colocações especializadas. In ORTIZ-ALVAREZ, M (Org.). Tendencias atuais na pesquisa descritiva e aplicada em fraseologia e paremiologia. 1 ed. Campinas: Editora Pontes, 2012, v. 2, p. $147-$ 163.

ORENHA-OTTAIANO, A. Unidades fraseológicas especializadas: colocações e colocações estendidas em contratos sociais e estatutos sociais traduzidos no modo juramentado e nãojuramentado. 2009. 282 f. Tese (Doutorado). Curso de Estudos Linguísticos. IBILCE. Universidade Estadual Paulista. São José do Rio Preto: 2009.

ORENHA-OTTAIANO, A. A compilação de um glossário de colocações na área de jornalismo de Negócios, baseado em corpus comparável. 2004. 246 f. Dissertação (Mestrado). Curso de Estudos Linguísticos e Literários em Inglês. Departamento de Letras Modernas. Faculdade de Filosofia, Letras e Ciências Humanas. Universidade de São Paulo: São Paulo, 2004.

PAGANO, A et al; Traduzir com autonomia: estratégias para o tradutor em formação. São Paulo: Contexto, 2000.

PERSICHETTI, V. Twentieth-Century Harmony. New York. Norton \& Company, 1961.

PISTON, W. Harmony. New York: W.W. Norton \& Company, 1987.

PY, B. M. A. A harmonia na música popular brasileira: reflexões sobre a prática e a teoria da harmonia e seu desenvolvimento através da canção do século XX. Dissertação (Mestrado). Vol. III, 110f. Centro de Letras e Artes. Universidade Federal do Estado do Rio de Janeiro: 
Rio de Janeiro, 2006. Disponível em: <http://www.unirio.br/ppgm/arquivos/dissertacoes/bruno-py> Acesso em 01 fev. 2017

RAMEAU, JP. Treatise on Harmony. New York: Dover Publications. 1971. [1722]

RANDEL, Don Michael. The Harvard Dictionary of Music. 4th ed. USA: The Belknap Press of Havard University Press, 2003

REGER, M. On the theory of modulation. Boca Raton. Kalmus: 1903

RIEMANN, Hugo. Harmony Simplified or The theory of the tonal functions of chords. London: Augener \& Co., 1903 [1893].

SAGER, J. C. English Special Languages:principles and practice in Science and Technology. Wesbaden: Brandsteller: 1980.

SALES, Rodrigo. Teoria Comunicativa de Terminologia (TCT) como aporte teórico para a representação do conhecimento especializado. VII ENANCIB - Encontro Nacional de Pesquisa em Ciência da Informação 28 a 31/10/2007. Bahia, 2007. Disponível em: <http://enancib.ibict.br/index.php/enancib/viiienancib/paper/view/2845/1973 >Acesso em: $01 / 07 / 2015$

SELISTRE, I. C. T. Colocações, transferência linguística e elaboração de dicionários bilíngues escolares (inglês/português - português/inglês). Acta Scientiarum. Language and Culture, Maringá, v. 32, n. 2, p. 271-278, 2010.

SINCLAIR, J. Corpus, concordance, collocation: Describing English language. Oxford: Oxford University Press, 1991.

SINCLAIR, J. Corpus and text: basic principles. In: WYNNE, M. (Ed.) Developing linguistic corpora: a guide to good practice. Oxford: Oxbow Books, 2005. p.1-16. Disponível em: $<$ http://ahds.ac.uk/linguistic-corpora/>. Acesso em: 01/05/2015.

SCHOENBERG, A. Funções Estruturais da Harmonia. Tradução de Eduardo Seincman. São Paulo: Via Lettera, 2004.

SCHOENBERG, A. Harmonia. Tradução Marden Maluf. São Paulo: Editora UNESP, 2001.

SCOTT, Mike. WordSmith Tools version 6, Liverpool: Lexical Analysis Software, 2015. Disponível em:

<http://www.lexically.net/downloads/version6/HTML/index.html?getting_started.htm> Acesso em: 27/06/2015 
TAGNIN, S. E. O. Expressões idiomáticas e convencionais. São Paulo: Ática, 1989.

TAGNIN, S. E. O. O jeito que a gente diz. São Paulo: Disal, 2013.

TAGNIN, S. E. O. A Linguística de Corpus na e para Tradução. In VIANA, Vander \& TAGNIN, Stella E. O. Corpora na Tradução, São Paulo: Hub Editorial, 2015.

TEMERMANN, R, Towards new ways of terminology description. In The sociocognitive approach. Amsterdam: John Benjamins Publishing Co., 2000.

TRAVAGLIA, Luiz Carlos. A caracterização de categorias de texto: tipos, gêneros e espécies. ALFA, São Paulo, v. 51 n. 1, p. 39-79. 2007a. Disponível em: http://www.alfa.ibilce.unesp.br/download/v51-1/03-Travaglia.pdf.

TOURY, G. The nature and role of norms in literary translation. In: HOLMES, J.; LAMBERT, J; VAN DEN BROECK, R. (Ed.). Literature and translation. Leuven: ACCO, 1978 p. 83-100 [Versão revisada em VENUTI, L. (Ed.). The translation studies reader. London/New York: Routledge, 2000, p. 198-211].

VIANA FILHO, D. F. O gênero textual dissertação: um caso de referenciação anafórica. Dissertação (Mestrado) Curso de Linguística. Departamento de Letras, Universidade Federal de Pernambuco. Pernambuco: UPFE, 2006. Disponível em:

<http://www.pgletras.com.br/2006/dissertaoes/diss-daniel.pdf> Acesso em: 01 jul. 2015

WEBCORP. Research and Development Unit for English Studies, Birmingham City University, 1999-2016. Disponível em <http://www.webcorp.org.uk/live/> em 25/07/2017

WEBER, G; Versuch einer geordneten Theorie der Tonsetzkunst. Mainz: B. Schott's Sohnen, 1832.

\section{DICIONÁRIOS:}

CUNHA, A.G. Dicionário etimológico da Lingua Portuguesa. $4^{\mathrm{a}}$ ed. São Paulo: Lexikon, 2010.

DOURADO, H. A. Dicionário de termos e expressões da música. São Paulo: Editora 34, 2004.

GALTER,V.. Dicionário da Música. Teoria Musical, Danças, Festas, Ritmos, Definições e Conceitos Gerais, Folclore e Ilustrações. Brasília: Vidal Galter, 2013

HARPER, D. Online Etymology Dictionary. USA: Douglas Harper, 2001. Disponível em:< http://www.etymonline.com/> Acesso em 20 jul 2017 
LATHAM, A. The Oxford Dictionary of musical terms. USA, New York: Oxford University Press Inc., 2004)

On Music Dictionary. USA, Virginia: Connect For Education Inc, 2015. Acesso em 01/07/2017 (Disponível em: < https://dictionary.onmusic.org/>)

RANDEL, D. M. The Harvard Dictionary of Music. 4th ed. USA: The Belknap Press of Havard University Press, 2003

\section{CORPUS DE ESTUDO}

\section{$\underline{\text { INGLESS }}$}

BAROLSKY, D; MARTENS, P. Rendering the Prosaic Persuasive - Gould and the Performance of Bach's C-minor Prelude (WTC1). Music Theory Online, v. 18, n. 1, abr. 2012. Disponível em: <http://mtosmt.org/issues/mto.12.18.1/mto.12.18.1.barolsky_martens.php> Acesso em $25 / 07 / 2017$

BENWARD, B.; SAKER, M. Music in Theory and Practice. USA: Mc Graw-Hill, 2008.

BIAMONTE, N. Augmented-Sixth Chords vs Tritone Substitutes. Music Theory Online, v. 14, n. 2, jun. 2008. Disponível em: $<$ http://www.mtosmt.org/issues/mto.08.14.2/mto.08.14.2.biamonte.html > Acesso em $25 / 07 / 2017$

BILLS, D. C. Harmony and structure in Richard Strauss's Macbeth . Thesis (Master in Music). Graduate Council of the University of North Texas, Texas, 1996. Disponível em: < https://digital.library.unt.edu/ark:/67531/metadc278998/> Acesso em 25/07/2017

BRASKY, J. T. Extraordinary Function and the Half-Diminished Seventh in the song of the Wood Dove. Music Theory Online, v. 16, n. 1, fev. 2010. Disponível em: $<$ http://www.mtosmt.org/issues/mto.10.16.1/mto.10.16.1.brasky.html> Acesso em $25 / 07 / 2017$

BROWN, S. C. Axis tonality and submediant in the music of Shostakovich. Music Theory Online, v. $15, \quad$ n. 2, jun. 2009. Disponível em: < http://www.mtosmt.org/issues/mto.10.16.1/mto.10.16.1.malawey.html> Acesso em $25 / 07 / 2017$

CLEMENT, Brett G. Scale systems and large-scale form in the music of yes. Music Theory Online, v. 21, n.1, mar. 2015. Disponível em $<$ http://www.mtosmt.org/issues/mto.15.21.1/mto.15.21.1.clement.html> Acesso em $25 / 07 / 2017$ 
CRATTY, W. S. The Role of Vagrant Harmonies in Selected Lieder by Wolf, Strauss and Schoenberg. A Journal of Compositional and Theorical Research in Music.v. IV/2, 1988. Disponível em: < http://www.ex-tempore.org/cratty/cratty.htm> Acesso em 25/07/2017

DOLL, C. Definitions of 'Chord' in the Teaching of Tonal Harmony. Dutch Journal of Music Theory, v.18, n. 2, 2013. Disponível em: <http://upers.kuleuven.be/sites/upers.kuleuven.be/files/page/files/2013_discussiechord.pdf> Acesso em 25/07/2017

DOLL, C. Transformation in Rock Harmony: an explanatory strategy. USA: GAMUT, 2009. Disponível em: <https://rucore.libraries.rutgers.edu/rutgers-lib/45575/ > Acesso em $25 / 07 / 2017$

EVERETT, W. Making Sense of Rock's Tonal Systems. Society for Music Theory. v. 10, n. 4, dez. 2004. Disponível em: http://www.mtosmt.org/issues/mto.04.10.4/mto.04.10.4.w_everett.html> Acesso em $25 / 07 / 2017$

FUENTES, David. Figuring out Melody. USA: Calvin University, 2010.

HEETDERKS, D. J. A tonal revolution in Fifhts and Semitones - Aaro Copland's: Quiet City. Music Theory Online, v. 17, n. 2, jul. 2011. Disponível em: $<$ http://www.mtosmt.org/issues/mto.11.17.2/mto.11.17.2.heetderks.html> Acesso em $25 / 07 / 2017$

HEETDERKS, D. J. Hipster Harmony - The Hybrid Syntax of Seventh Chords in PostMillennial Rock. Music Theory Online, v. 21, n. 2, jun. 2015. Disponível em: $<$ http://www.mtosmt.org/issues/mto.15.21.2/mto.15.21.2.heetderks.html > Acesso em $25 / 07 / 2017$

HEWITT, Michael. Music Theory for Computer Musicians. USA: Cengage Learning, 2008.

HORN, K; HURON, D. On the changing use of the major and minor modes 1750-1900. Music Theory Online , v. 21, n. 1, mar. 2015. Disponível em <https://www.questia.com/library/journal/1P3-3946659031/on-the-changing-use-of-themajor-and-minor-modes-1750-1900> Acesso em 25/07/2017

JOHNSTON, B. Modal Idioms and Their Rhetorical Associations in Rachmaninoff's Works. Music Theory Online, v. 20, n. 4, dez. $2014 . \quad$ Disponível em <http://www.mtosmt.org/issues/mto.14.20.4/mto.14.20.4.johnston.pdf> Acesso em $25 / 07 / 2017$

KOPP, David. Chromatic Transformations in Nineteenth-century music. USA: Cambridge, 2002.

KOSTKA, S; PAYNE, D.; ALMÉN, B. Tonal Harmony: with an introduction to twentieth -century music. New York: McGraw Hill, 2013. 
LAITZ, S. G. The complete musician: An integrated approach to tonal theory, analysis, and listening. New York: OUP, 2008.

LEHMAN, F. Hollywood cadences - music and the structure of cinematic expectation. Music

Theory Online, v. 19, n. 4, dez. 2013. Disponível em: $<$ http://www.mtosmt.org/issues/mto.13.19.4/mto.13.19.4.lehman.html> Acesso em $25 / 07 / 2017$

LOVE, S. C. Possible Paths - Schemata of Phrasing and Melody in Charlie Parker's Blues. Music Theory Online, v. 18, n. 3, set. 2012. Disponível em: <http://mtosmt.org/issues/mto.12.18.3/mto.12.18.3.love.html> Acesso em 25/7/2017

LOVELL, J. An exploration of melody harmony and improvisation in the Music of Stevie Wonder. Dissertation (PhD). School of Music and Dance and Graduate School of the University of Oregon, Oregon, 2012. Disponível em: <https://scholarsbank.uoregon.edu/xmlui/bitstream/handle/1794/12947/Lovell_oregon_0171A _10565.pdf?sequence=1> Acesso em 25/07/2017

MALAWEY, V. Harmonic Stasis and Oscillation in Björk's Medúlla. Music Theory Online, v. 16, n. $1, \quad$ jan. 2010. Disponível em: $<$ http://www.mtosmt.org/issues/mto.10.16.1/mto.10.16.1.malawey.html> Acesso em $25 / 07 / 2017$

NOBILE, D. F. Form and Voice Leading in Early Beatles Song. Music Theory Online, v. 17, n. 3 out. 2011. Disponível em: < http://www.mtosmt.org/issues/mto.11.17.3/mto.11.17.3.nobile.html> Acesso em 25/07/2017

PARTRIDGE, D. J. Harmony Form and voice leading in the mature works of Antonin Dvorak. Dissertation (PhD in Music). The City University of New York, New York, 2012. Disponível em: <http://pqdtopen.proquest.com/doc/1212707968.html?FMT=ABS>Acesso em 25/07/2017

PERRY, L. From Modality to Tonality: The Reformulation of Harmony and Structure in Seventeenth-Century Music. USA: University of Puget Sound, 2011. Disponível em: $<$ http://soundideas.pugetsound.edu/cgi/viewcontent.cgi?article $=1079 \&$ context=summer_resea rch> Acesso em 25/07/2017

PISTON, Walter. Harmony. USA: W. W. Norton \& Company, 1987.

ROGERS, M. A. Tonality and the extended common practice in the music of Thad Jones. Dissertation (phD). University of North Texas. Texas, 2015. Disponível em: < https://digital.library.unt.edu/ark:/67531/metadc801875/> Acesso em 25/07/2017

ROHRMEIER, M. Towards a generative syntax of tonal harmony. Journal of Mathematics and Music, v. 5, n.1, p. 35-53, mar. 2011. Disponível em: $<$ http://www.tandfonline.com/doi/abs/10.1080/17459737.2011.573676> Acesso em $25 / 07 / 2017$ 
ROTHGEB, J. Re- Eytan Agmon on Functional Theory. Music Theory Online, v.2, n. 1, jan. 1996.

Disponível

em: <http://www.mtosmt.org/issues/mto.96.2.1/mto.96.2.1.rothgeb.html> Acesso em 25/07/2017

SAMAROTTO, F. "Plays of Opposing motion":Contra-structural melodic impulses in voiceleading analysis. Music Theory Online, v. 15, n. 2, jun. 2009. Disponível em: < https://openmusiclibrary.org/article/85421/> Acesso em 25/07/2017

SCHMIDT-JONES, C. The Basic Elements of Music. Texas: Rice University, 2008.

SCHMIDT-JONES, C. Understanding Basic Music Theory. Texas: Rice University, 2007.

SMITH, S. Jazz Theory. USA: UMass Lowell, 2008

STOIA, N. Mode, Harmony, and Dissonance Treatment in American Folk and Popular Music, c. 1920 - 1945. Music Theory Online, v. 16, n. 3, ago. 2010. Disponível em: <http://www.mtosmt.org/issues/mto.10.16.3/mto.10.16.3.stoia.html> Acesso em: 25/07/2017

STRAUS, J. Total voice leading. Music Theory Online, v. 20, n. 2, jun. 2014. Disponível em <http://www.mtosmt.org/issues/mto.14.20.2/mto.14.20.2.straus.html> Acesso em 25/07/2017

TACHOVSKY, T. Hugo Riemann's concept of tonality. Thesis (Master in Arts) Department of Music of the University of North Carolina at Chapel Hill, Chapel Hill, 2007. Disponível em: <https://cdr.lib.unc.edu/indexablecontent/uuid:2e926d2a-4c42-48bd-8b6e501fee73a61a> Acesso em 25/07/2017

<https://cdr.lib.unc.edu/indexablecontent/uuid:2e926d2a-4c42-48bd-8b6e-501fee73a61a>

TAUBE, H; BURNSON. W.A. Software for teaching Music Theory. USA: University of Illinois at Champaign-Urbana, 2009 Disponível em $<$ http://camil.music.illinois.edu/software/choralecomposer/doc/Software\%20for\%20Teaching \%20Music\%20Theory.pdf> Acesso em 25/07/2017

TAYLOR, M. S ; STOUFFER, T. Teach Yourself Visually Piano. New Jersey: Wiley, 2006.

TEMPERLEY, D. Composition, Perception, and Schenkerian Theory. Music Theory Spectrum, [s.1.], v. 33, n. 2, p.146-168, out. 2011. Oxford University Press (OUP). http://dx.doi.org/10.1525/mts.2011.33.2.146.

TEMPERLEY, D. The Cadential IV in Rock. Music Theory Online, v. 17, n. 1, apr 2011. Disponível em:<http://www.mtosmt.org/issues/mto.11.17.1/mto.11.17.1.temperley.html > Acesso em 25/07/2017

TEREFENKO, D. Jazz Transformations of the ii7-V7-I Progression. Current Research in Jazz, v. 1, 2009. Disponível em: <http://www.crj-online.org/v1/CRJJazzTransformations.php> Acesso em 25/07/2017 
WILKERSON, D. S. Harmony Explained: Progress Towards a Scientific Theory of Music. USA: Cornell University: 2014. Disponível em: <https://arxiv.org/abs/1202.4212 > Acesso em 25/07/2017

WYATT, K; SCHROEDER, C . Harmony and Theory. USA: Hal Leonard Online, 1998. YUST, J. Voice-Leading Transformation and Generative Theories of Tonal Structure. Music $\begin{array}{lllllll}\text { Theory Online, } & \text { v. } & 21, & \text { n. } & 4, & \text { dez. } & 2015 \text {. }\end{array}$ $<$ http://www.mtosmt.org/issues/mto.15.21.4/mto.15.21.4.yust.html> Disponível em $25 / 07 / 2017$

\section{PORTUGUÊS}

ALMADA, C. Harmonia Funcional. São Paulo: Editora Unicamp, 2012

ALMEIDA, S. Um modelo de realização de baixo contínuo - 2o movimento da sonata em si menor BWV 1030 para flauta e cravo obbligato de J.S. Bach. Música Hodie, v.6, n. 1, p.2334, 2006. Disponível em <https://www.revistas.ufg.br/musica/article/view/1663/11994> Acesso em 25/07/2017

ALVES, C.G. Curso Básico de Harmonia. São Paulo: ELAM, 2010.

ALVES, L. Teoria Musical: Lições essenciais. São Paulo: Irmãos Vitale, 2004.

ARAUJO, F.; BOREM; A Harmonia tonal de Schoenberg: uma proposta para a análise, realização e composição de lead sheets. Per Musi, Belo Horizonte, n. 28, pp 35-69, 2013. Disponível em: <http://www.scielo.br/pdf/pm/n28/a05n28.pdf > Acesso em 25/07/2017

ARAUJO, F; BOREM, F. Variação Progressiva de Schoenberg em Hermeto Pascoal - análise e realização de duas lead sheets do Calendário do som. Per Musi, Belo Horizonte, n. 28, p.70-95, julho-dezembro 2013. Disponível em: <http://www.scielo.br/scielo.php?pid=S151775992013000200006\&script=sci_abstract\&tlng=pt> Acesso em 25/07/2017

BATALHA, R.S. Composição e pesquisa de música tonal na contemporaneidade. Anais do III SIMPOM, Rio de Janeiro, n.3, 2014. Disponível em: <http://www.seer.unirio.br/index.php/simpom/article/view/4659> Acesso em 25/07/2017

BATISTA, A.C. Tétrades: um estudo de Harmonia aplicado à guitarra elétrica. (Mestrado em Música), UNICAMP, Campinas, $2006 . \quad$ Disponível em: <http://www.reposip.unicamp.br/xmlui/handle/REPOSIP/284363> Acesso em 25/07/2017

BITTENCOURT, M. A. Apresentação de uma reforma simbológica para a análise harmônica funcional do repertório tonal. XIX Congresso da ANPPOM. Curitiba, Departamento de Artes, UFPR. $\quad 2009 . \quad$ Ago. Disponível em: <http://www.dmu.uem.br/aulas/harmonia/Bittencourt_artigoAnppom09.pdf> Acesso em $25 / 07 / 2017$ 
BITTENCOURT, M.A. O arcabouço de uma proposta de metodologia analítica para o tonalismo do século XIX - uma revisão taxonômica da teoria da modulação. Música Hodie, Goiânia, v. 13, n.1, p. 134-154, 2013. Disponível em:

<https://www.revistas.ufg.br/musica/article/view/25811> Acesso em 25/07/2017

BRISOLLA, C. Princípios de Harmonia Funcional. 2a Ed. São Paulo: Annablume, 2006.

CAMARA, F. A. Sobre Harmonia: uma proposta de perfil conceitual. Tese (Doutorado), Faculdade de Educação de Minas Gerais, Belo Horizonte, 2008. Disponível em: <http://www.bibliotecadigital.ufmg.br/dspace/handle/1843/BFRO-7PEHLP> Acesso em $25 / 07 / 2017$

CAMINHA, A. O. MHITS: Um Sistema Tutor em Harmonia Musical. Dissertação (Mestrado), Ciência da Computação, Universidade Federal da Paraíba, Paraíba, 2000. Disponível em: <http://docs.computacao.ufcg.edu.br/posgraduacao/dissertacoes/2000/Dissertacao_AdrianoDe OliveiraCaminha.pdf> Acesso em: 25/07/2017

CARVALHO, A. O uso das tétrades na linguagem harmônica de Barry Galbraith. São Paulo, Keep on playing, 2017. Disponível em:<http://www.keeponplaying.com.br/wpcontent/uploads/2016/03/Artigo-O-Uso-das-T\%C3\%A9trades-na-LinguagemHarm\%C3\%B4nica-de-Barry-Galbraith.pdf> Acesso em 25/07/2017

CASTELÕES, L.E. Propostas de Teoria Musical Comparada. Revista Eletrônica de Musicologia, v. XIV set. 2010. Disponível em: <http://www.rem.ufpr.br/_REM/REMv14/06/propostas_teoria_musical_comparada.html> Acesso em 25/07/2017

CHEDIAK, A. Harmonia e Improvisação. Vol 1. São Paulo: Irmãos Vitale, 2009.

CHUEKE, Z. Fantasias Opus 116 de Johannes Brahms: análise para intérpretes. Rio Grande do Sul: Em Pauta, v. 20 n. 34/35, 2012. Disponível em: <http://seer.ufrgs.br/EmPauta/article/view/39707> Acesso em 25/07/2017

CORREA, A. F.; KERR, D. M. Função e refuncionalização. Em pausta, v. 15, n. 25, jul- dez. 2004. Disponível em: <http://seer.ufrgs.br/EmPauta/article/view/8509> Acesso em $25 / 07 / 2017$

COSTA, R.L.M. Apontamentos sobre o estudo da harmonia - por uma abordagem abrangente. ANPPOM - $15^{\circ}$ Congresso, p. 318-326, $2005 . \quad$ Disponível em <http://www4.unirio.br/mpb/textos/AnaisANPPOM/anppom\%202005/sessao7/rogerio_costa.pdf> Acesso em : 25/07/2017.

DUDEQUE, N. Harmonia Tonal I e II. São Paulo: Norton Dudeque, 2003.

DUDEQUE, N. Schoenberg e a função tonal. Revista Eletrônica de Musicologia, v. 2, 1 out 1997. Disponível em: 
<http://www.rem.ufpr.br/_REM/REMv2.1/vol2.1/Schoenberg/Schoenberg\%20e\%20a\%20Fu ncao.html> Acesso em 25/07/2017

FAGERLANDE, M. Duas cadências para a sonata em Ré Maior para flauta e cravo obbligato, WQ.83, de C.Ph.E. Bach. Música Hodie, v. 8, n.1, p. 27-35, 2008. Disponível em $<$ https://www.revistas.ufg.br/musica/article/view/4562/12304> Acesso em 25/07/2017

FAGUNDES, M. D. Teoria da Música Vol 1 - São Paulo: Keyboard, 2004.

FARIA, A. G. Harmonia Funcional , arranjos e a velha condução de vozes. Em Pauta, Porto

Alegre, v. 18, n. 30, p. 81-94, 2007. Disponível em <http://seer.ufrgs.br/EmPauta/article/view/7463> Acesso em 25/07/2017

FARIA, L.C.F. Analise da proposta metodológica das disciplinas Harmonia Musical do Curso Superior de Tecnologia em Produção Fonográfica. TCC apresentado a Pró-Reitoria de Pesquisa e Pós-Graduação da UNOESTE, 2008. Disponível em $<$ https://www.academia.edu/1854426/Sobre_o_Ensino_de_Harmonia > Acesso em $25 / 07 / 2017$

FIGUEIREDO, J. C. O acorde de sexta aumentada: interpretações diferentes para o mesmo fenômeno sonoro. Thesis, São Paulo, ano IV, n. 17, p. 18-19, $1^{\circ}$ semestre 2012. Disponível em: <http://www.cantareira.br/thesis2/ed_17/2_julio.pdf> Acesso em 25/07/2017

FREITAS, S. P. R. Da harmonia pela harmonia - sobre formalismo e seus impactos na ideia de harmonia funcional. Revista do Conservatório de Música da UFPEL, Pelotas, n.5, p.135, 2012. Disponível em:

<https://periodicos.ufpel.edu.br/ojs2/index.php/RCM/article/download/2477/2313> Acesso em $25 / 07 / 2017$

FREITAS, S.P.R. Memórias e histórias do acorde napolitano e de suas funções em certas canções da música popular no Brasil. Revista do Instituto de Estudos Brasileiros. São Paulo, n. 59, 2014. Disponível em <http://www.scielo.br/pdf/rieb/n59/0020-3874-rieb-5900015.pdf> Acesso em 25/07/2017

FREITAS, S. P.R. Que acorde ponho aqui - Harmonia, práticas teóricas e o estudo de planos tonais em música popular. Tese (Doutorado), Música, Insituto de Artes da UNICAMP, Campinas, 2010. Disponível em: <https://archive.org/details/QueAcordeTeseFREITASVersaoO1O52o11.pdf> Acesso em 25/07/2017.

FREIRE, R. D; OLIVEIRA; H.M. O uso de acordes de empréstimo modal (AEM) na música de Tom Jobim. ANPPOM, 15 ${ }^{\circ}$ Congresso, 2005. Disponível em: $<$ http://antigo.anppom.com.br/anais/anaiscongresso_anppom_2005/sessao16/ricardofreire_hei toroliveira.pdf> Acesso em 25/07/2017

GOMES, Alan. Harmonia I e II. Brasília: Alan Gomes: 2010. 
KOENTOPP, M. Métodos de Ensino de Harmonia nos cursos de graduação musical. Dissertação (Mestrado), Departamento de Música, Universidade Federal do Paraná, Paraná, 2010. Disponível

em: <http://acervodigital.ufpr.br/bitstream/handle/1884/24368/Dissertacao\%20Marco\%20Koen topp.pdf?sequence=1> Acesso em 25/07/2017

LACERDA, H. Fundamentos de harmonia. Apostila para Disciplina Fundamentos de Harmonia I da Escola de Música da Universidade Federal de Minas Gerais. Minas Gerais: 2003.

LIMA, M. R. R. Harmonia- uma abordagem prática. São Paulo: Marisa Ramires Rosa de Lima, 2008.

MACHADO, E. L.; WILDT, F.K. Harmonia na Bossa Nova - Um mapeamento da produção científica. Anais VI - Forum de Pesquisa Cientifica em Arte da Escola de Musica e Belas Artes do Parana. Curitiba, 2008-2009. p. 216-226. Disponível em: $<$ http://www.embap.pr.gov.br/arquivos/File/Forum/anais-vi/20EltonMachado.pdf> Acesso em $25 / 07 / 2017$

MED, B. Teoria da Música. Brasília, DF: Musimed: 1996.

MELLO, M. Harmonia Avançada. I Festival de Música de Ourinhos. Ourinhos, 2001.

OLIVEIRA, J. Z; OLIVEIRA, M. Noção de tonalidade. In MEDEIROS, B. R. (Org). Cognição Musical: aspectos multidisciplinares. São Paulo: Paulistana, 2008. pp 42-45. Disponível em: <http://www.abcogmus.org/documents/SIMCAM4.pdf> Acesso em $25 / 07 / 2017$

QUEIROZ, A.A. Uma notação musical para representação de progressões harmônicas utilizando grafos. Música Hodie, v.9, n. 1, 2009. Disponível em: <https://www.revistas.ufg.br/musica/article/view/10704/12407> Acesso em 25/07/2017

QUEIROZ, F. J. G. Canto gregoriano, modos eclesiásticos: o que aprendemos com os nossos livros de teoria musical. Ictus-Periódico do PPGMUS/UFBA, v.7, p. 113-136, 2006. Disponível em: <http://www.ictus.ufba.br/index.php/ictus/article/view/98> Acesso em $25 / 07 / 2017$

PASCOAL, M.L; PASCOAL, A. Estrutura Tonal: Harmonia. São Paulo: Instituto de Artes da UNICAMP, 2000.

PRIOLLI, M.L.M. Harmonia da Concepção Básica a Expressão Contemporânea. $10^{\mathrm{a}}$ ed. Rio de Janeiro: Casa Oliveira de Música, 2011

PY, B. M.A. A Harmonia na música popular brasileira: reflexões sobre a prática e a teoria da harmonia e seu desenvolvimento através da canção no século XX. Dissertação (Mestrado), Música,UNIRIO, Rio de Janeiro, 2006. Disponível em: $<$ http://www.unirio.br/ppgm/arquivos/dissertacoes/bruno-py> Acesso em 25/07/2017 
RAMIRES, M. A análise harmônica e suas questões recorrentes: o legado de Rameau. IV Encontro de Pequisa em Música da Universidade Estadual de Maringá, p. 1-8, Maringá, 2009. Disponível

$<$ http://www.dmu.uem.br/pesquisa/index.php?conference=epem\&schedConf=epem2009\&pag e=paper\&op=view\&path\%5B\%5D=50> Acesso em: 25/07/2017

REIS, J. T. A abordagem do conceito de harmonia tonal nos processos de ensino e aprendizagem de acordeon fomentados por dois professores atuantes na região metropolitana de Porto Alegre. ABEM, Londrina, v. 19, n. 26, p. 145- 157, 2011. Disponivel em: $<$ http://abemeducacaomusical.com.br/revista_abem/ed26/revista26_artigo12.pdf> Acesso em $25 / 07 / 2017$

SENNA, C. Curso de Harmonia. Rio de Janeiro: Caio Senna, 2002.

TADDEI, R. C. A teoria de Hugo Riemann - Além da Harmonia simplificada ou funções tonais dos acordes. Anais do SIMPOM, Rio de Janeiro, n. 2, p. 1313-1320, 2012. Disponivel em <http://www.seer.unirio.br/index.php/simpom/article/view/2558> Acesso em 25/07/2017

TINÉ, P.J.S. A harmonia no contexto da música popular: um paralelo com a harmonia tradicional. Videtur, Letras 6, São Paulo, $2002 . \quad$ Disponível em:<http://www.hottopos.com/vdletras6/tine.htm> Acesso em 25/07/2017

WILDT, F. K. Primeira Lei Tonal - Função Harmônica nas óticas funcional e tradicional um breve estudo comparativo. In Cantare, Curitiba, v. 5, n. 2,p. 29-48, julho-dezembro 2015. Disponível em: <http://periodicos.unespar.edu.br/index.php/incantare/article/view/354> Acesso em 25/07/2017. 